DOC.20041109.0007

QA: QA

ANL-EBS-MD-000037 REV 03

November 2004

BECHTEL

SAIC compary uc

NOTICE OF OPEN CHANGED DOCUMENTS - THIS DOCUMENT IS IMPACTED BY THE LISTED CHANGE DOCUMENT AND CANNOT BE USED WITHOUT IT.

1) ACN-001, DATED 03/16/2005

\title{
In-Package Chemistry Abstraction
}

Prepared for:

U.S. Department of Energy

Office of Civilian Radioactive Waste Management

Office of Repository Development

1551 Hillshire Drive

Las Vegas, Nevada 89134-6321

Prepared by:

Bechtel SAIC Company, LLC

1180 Town Center Drive

Las Vegas, Nevada 89144

Under Contract Number

DE-AC28-01RW12101 


\section{DISCLAIMER}

This report was prepared as an account of work sponsored by an agency of the United States Government. Neither the United States Government nor any agency thereof, nor any of their employees, nor any of their contractors, subcontractors or their employees, makes any warranty, express or implied, or assumes any legal liability or responsibility for the accuracy, completeness, or any third party's use or the results of such use of any information, apparatus, product, or process disclosed, or represents that its use would not infringe privately owned rights. Reference herein to any specific commercial product, process, or service by trade name, trademark, manufacturer, or otherwise, does not necessarily constitute or imply its endorsement, recommendation, or favoring by the United States Govemment or any agency thereof or its contractors or subcontractors. The views and opinions of authors expressed herein do not necessarily state or reflect those of the United States Government or any agency thereof. 
QA: QA

\section{In-Package Chemistry Abstraction} ANL-EBS-MD-000037 REV 03

November 2004 


\section{OCRWM}

\section{Type of Mathematical Model}

Process Model

凶 Abstraction Model

System Model

Describe Intended Use of Model

3. Title

In-Package Chemistry Abstraction

4. DI (including Rev. No., if applicable):

ANL-EBS-MD-000037 REV 03

5. Total Appendices

Seven (7)
6. No. of Pages in Each Appendix

A-14, B-8, C-4, D-10, E-4, F-CD, G-4

\begin{tabular}{|c|c|c|c|}
\hline & Printed Name & Signature & Date \\
\hline 7. Originator & Emma Thomas & 22 & $11 / 9 / 04$ \\
\hline $\begin{array}{l}\text { 8. Independent Technical } \\
\text { Reviewer }\end{array}$ & Laura Price & & $11 / 9 / 04$ \\
\hline 9. Checker & Patricia Bernot & & 418104 \\
\hline 10. QER & Judy Gebhart & & $11 / 9104$ \\
\hline 11. Responsible Manager/Lead & Dennis Thomas & & $11 / 9 / 04$ \\
\hline 12. Responsible Manager & Neil Brown & & $11 / 9 / 04$ \\
\hline
\end{tabular}

13. Remarks

\section{Change History}

14. Revision No.

00

01

02

03
15. Description of Change

Initial Issue.

The entire abstraction model was revised to reflect updated inputs/outputs from the feed process model AMR (ANL-EBS-MD-000050 REV 01).

Complete revision to incorporate new conceptual model.

Complete revision to support regulatory integration. Change bars were not used because the changes were too significant. This revision incorporates the suggestions identified in CR 2065. 


\section{ACKNOWLEDGEMENTS}

This model report was developed through the contributions of the following individuals, listed in alphabetical order:

- Sara Arthur, AREVA. Contributor to all prior revisions of this report (REV00 through REV03b), and to the final REV03. Responsible for various sensitivity analyses.

- Patrick Brady, Sandia National Laboratories. Co-authored all prior revisions of this report (REV00 through REV03b), and major contributor to the final REV03. Developed the surface complexation model, and co-developed the batch reactor conceptual model (with Paul Domski).

- Paul Domski, AREVA. Originator and lead author of all prior revisions of this report (REV00 through REV03b), and major contributor to the final REV03. Co-developed the batch reactor conceptual model (with Pat Brady) and developed the model abstraction.

- Susan LeStrange, BSC. Contributor to the final REV03. Responsible for various sensitivity analyses.

- Paul Mariner, AREVA. Co-authored previous revision of this report (REV03b). Responsible for the development of the surface complexation model demonstration.

- Emma Thomas, BSC. Originator and lead author for the final REV03 of this report. Responsible for incorporation of Regulatory Integration Team comments and items in the RIT Action Item Database. 


\section{CONTENTS}

Page

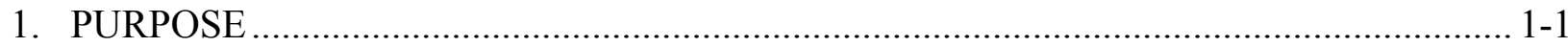

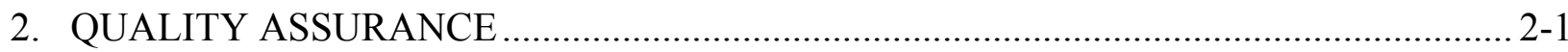

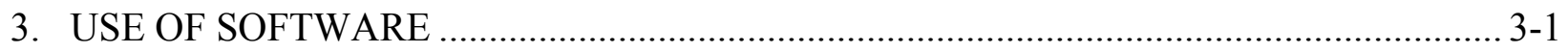

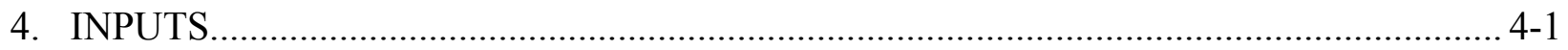

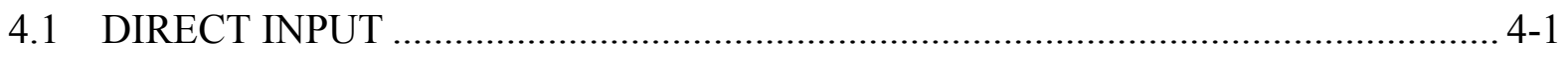

4.1.1 Thermodynamic Database ...................................................................... 4-2

4.1.2 Input Water Compositions and Rates .......................................................... 4-3

4.1.3 Waste Form Compositions and Rates ......................................................... 4-6

4.1.4 Waste Package Material Compositions and Rates........................................ 4-8

4.1.5 Atomic Weights ................................................................................... 4-10

4.1.6 Surface Complexation Inputs.................................................................... 4-10

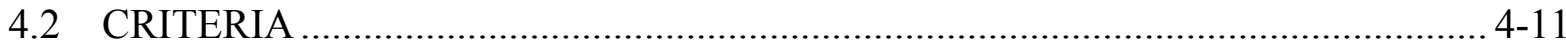

4.3 CODES, STANDARDS, AND REGULATIONS .............................................. 4-12

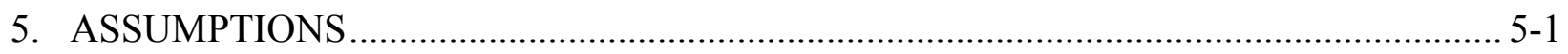

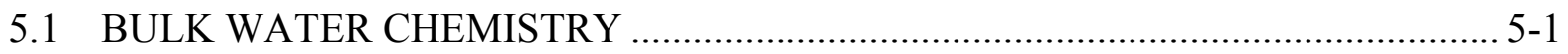

5.2 CONSTANT CORROSION OF ALLOYS ………........................................... 5-1

5.3 THERMODYNAMIC EQUILIBRIUM ………………………........................... 5-2

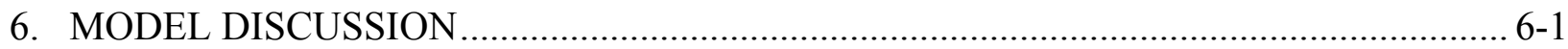

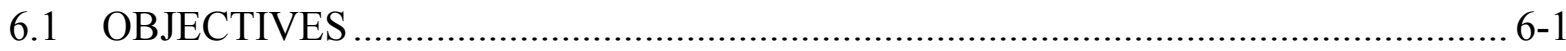

6.2 FEATURES, EVENTS, AND PROCESSES ……………..................................... 6-1

6.3 BASE-CASE CONCEPTUAL MODEL ......................................................... 6-1

6.3.1 Batch Reactor Model .......................................................................... 6-3

6.3.2 Surface Complexation Model ............................................................... 6-21

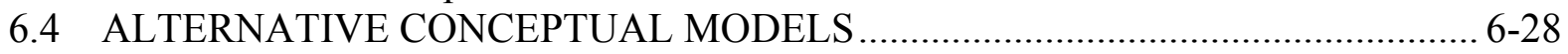

6.4.1 Alternative Conceptual Model I............................................................. 6-28

6.4.2 Alternative Conceptual Model II .............................................................. 6-28

6.5 BATCH REACTOR BASE CASE MODEL OUTPUT ……….............................. 6-29

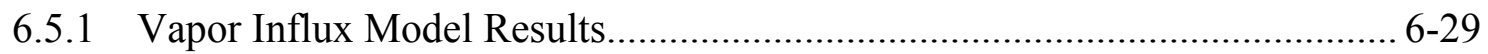

6.5.2 Water Influx Case Model Results ................................................................... 6-35

6.5.3 Conceptual Model Conclusions ………………......................................... 6-51

6.6 BATCH REACTOR SENSITIVITY ANALYSES ………………........................... 6-51

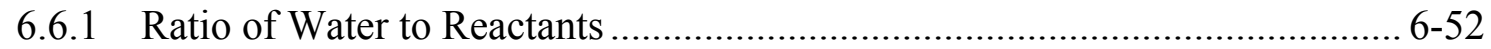

6.6.2 Thermally Perturbed Fluids ................................................................... 6-56

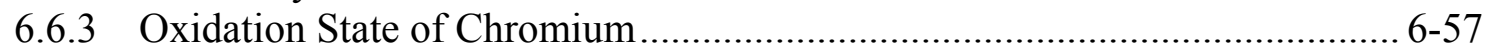

6.6.4 Carbon Dioxide and Oxygen Fugacity ........................................................ 6-61

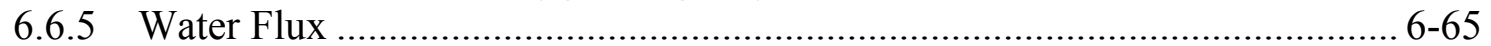

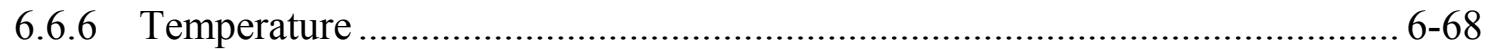

6.6.7 Design Change from Neutronit to NiGd Alloy ............................................. 6-70 


\section{CONTENTS (Continued)}

6.6.8 HLWG Composition Change... $6-73$

6.6.9 Quantity of Carbon Steel Type A516 in Waste Package Design..................... 6-75

6.6.10 Degradation Rates..................................................................................... 6-77

6.6.11 Hematite versus Goethite..................................................................... 6-81

6.6.12 Lower HLW Glass Exposure Factor.......................................................... 6-82

6.6.13 Codisposal Waste Package Containing 5 HLWG Canisters............................ 6-83

6.7 SURFACE COMPLEXATION MODEL OUTPUT ............................................. 6-86

6.7.1 pH Buffering During Dissolution of Carbon Steel ....................................... 6-87

6.7.2 pH Buffering During Dissolution of Stainless Steel, Fuel, and HLWG......... 6-91

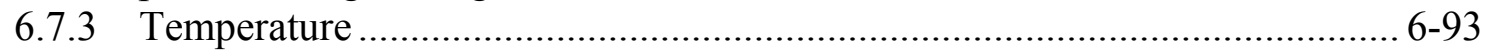

6.8 SURFACE COMPLEXATION DEMONSTRATION ........................................... 6-93

6.8.1 Surface Complexation Reaction Databases .................................................. 6-94

6.8.2 Surface Properties ………………………............................................ 6-95

6.8.3 Water and Gas Compositions............................................................... 6-96

6.8.4 Surface Complexation Calculations.......................................................... 6-96

6.9 APPLICATION OF SURFACE COMPLEXATION MODEL TO THE BATCH

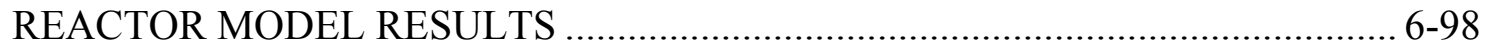

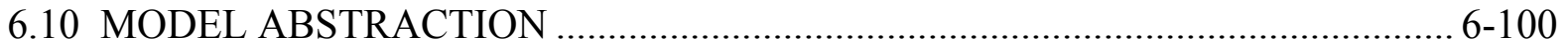

6.10.1 pH Abstractions ................................................................................... 6-101

6.10.2 Ionic Strength Abstractions................................................................... 6-102

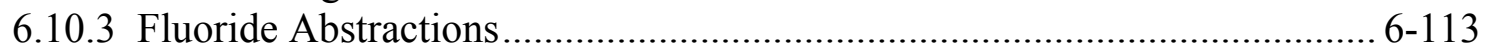

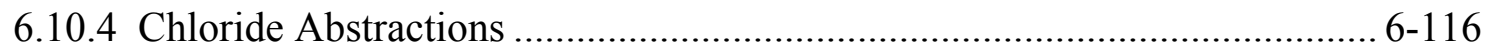

6.10.5 Total Carbonate Abstraction ............................................................... 6-118

6.10.6 Eh Abstraction ................................................................................. 6-120

6.10.7 Linking the Vapor Influx and Water Influx Model for TSPA-LA ............... 6-122

6.10.8 Output Uncertainty................................................................................ 6-124

6.10.9 Model Abstraction Conclusions.................................................................... 6-124

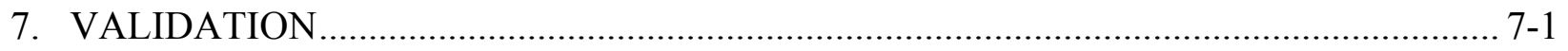

7.1 DOCUMENTED DECISIONS AND ACTIVITIES IMPLEMENTED DURING MODEL DEVELOPMENT PROCESS ………............................................................ 7-1

7.2 POST-MODEL DEVELOPMENT VALIDATION METHODS ................................ 7-3

7.2.1 Rationale for Selection of Validation Methods ................................................ 7-3

7.2.2 Fuel-Degradation Model Consistent with Results from Laboratory Experiments .........................................................................................

7.2.3 Types of Minerals Formed Consistent with Experimental Results .................. 7-4

7.2.4 Steel-Degradation Model Consistent with Results from Laboratory Experiment ............................................................................................... 7-4

7.2.5 $\mathrm{pH}$ and Ionic Strength Consistent with Natural Analogue Observation ........... 7-5

7.2.6 Relationship Between Ionic Strength and Flow Rate ..................................... 7-7

7.2.7 Surface Complexation Model ................................................................ 7-8

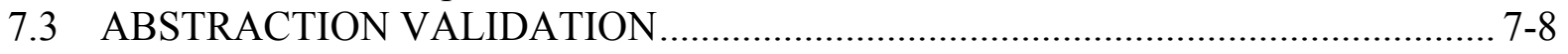

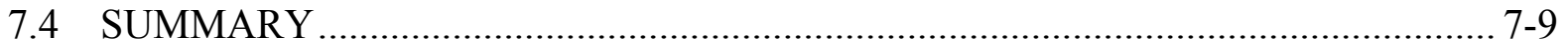




\section{CONTENTS (Continued)}

Page

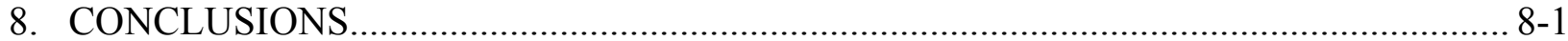

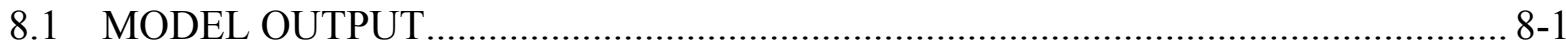

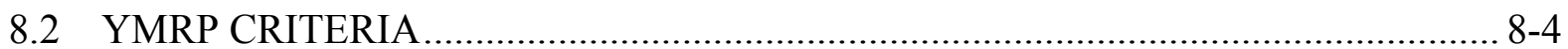

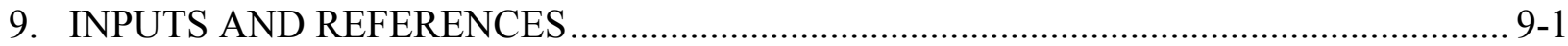

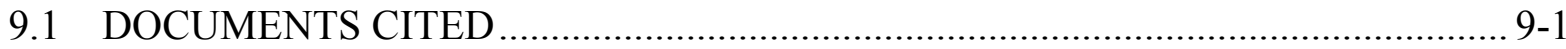

9.2 CODES, STANDARDS, REGULATIONS, AND PROCEDURES ......................... 9-10

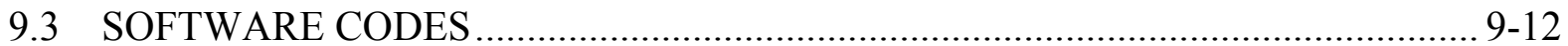

9.4 SOURCE DATA, LISTED BY DATA TRACKING NUMBER …………….......... 9-12

9.5 OUTPUT DATA, LISTED BY DATA TRACKING NUMBER …………….......... 9-12

APPENDIX A. ADDITIONAL IN-PACKAGE CHEMISTRY PLOTS …………………..... A-1

APPENDIX B. IN-PACKAGE RADIOLYSIS ANALYSES ………………………..............

APPENDIX C. DATA QUALIFICATION PLAN ................................................................

APPENDIX D. QUALIFICATION OF DATA THAT SUPPORTS IN-PACKAGE CHEMISTRY ABSTRACTION ….......................................................... D-1

APPENDIX E. EVALUATION OF IN-PACKAGE CHEMISTRY SURFACE COMPLEXATION MODEL ....................................................................

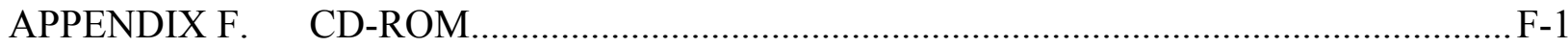

APPENDIX G. LISTING OF FILES ON COMPACT DISK …………………………….... G-1 


\section{INTENTIONALLY LEFT BLANK}




\section{FIGURES}

6-1. CSNF Single-Component Vapor Influx pH Outputs ................................................ 6-29

6-2. CSNF Multicomponent Ensemble pH Profiles............................................................. 6-31

6-3. CSNF Multicomponent Vapor Influx Ionic Strength .............................................. 6-31

6-4. CDSP Single-Component Vapor Influx Results......................................................... 6-32

6-5. CDSP Multicomponent Ensemble pH Profiles........................................................ 6-33

6-6. CDSP Multicomponent Vapor Influx Model Ionic Strength Profiles ............................ 6-34

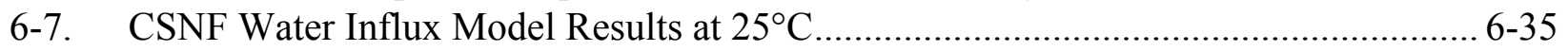

6-8. $\quad$ CSNF Water Influx Model Results for Three Seepage Compositions at $25^{\circ} \mathrm{C}$............. 6-36

6-9. CSNF Water Influx Model Mineral Phases for Three Seepage Compositions .............. 6-37

6-10. CSNF Water Influx Model Aqueous Species for Three Seepage Compositions............ 6-38

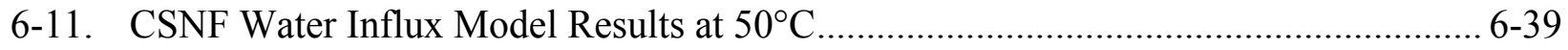

6-12. CSNF Water Influx Model Results for Three Seepage Compositions at $50^{\circ} \mathrm{C}$.............. 6-40

6-13. CSNF Water Influx Model $25^{\circ} \mathrm{C}$ Ionic Strength Profiles ........................................... 6-41

6-14. CSNF Water Influx Model $50^{\circ} \mathrm{C}$ Ionic Strength Profiles .............................................. 6-42

6-15. CSNF Water Influx Model: Eh, Reactant Summary, and Corrosion Products............... 6-43

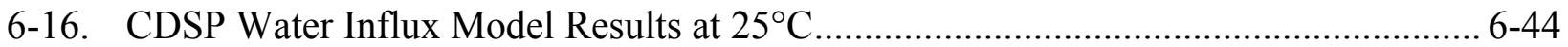

6-17. CDSP Water Influx Model Results for Three Seepage Compositions at $25^{\circ} \mathrm{C} \mathrm{.............} \mathrm{6-45}$

6-18. CDSP Water Influx Model Mineral Phases for Three Seepage Compositions .............. 6-46

6-19. CDSP Water Influx Model Aqueous Species for Three Seepage Compositions............ 6-47

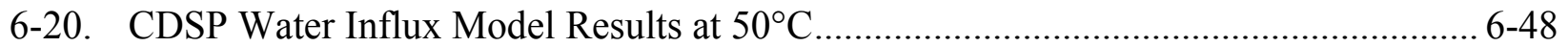

6-21. CDSP Water Influx Model Results for Three Seepage Compositions at $50^{\circ} \mathrm{C}$............. 6-48

6-22. CDSP Water Influx Model $25^{\circ} \mathrm{C}$ Ionic Strength Profiles ........................................... 6-50

6-23. CDSP Water Influx Model $50^{\circ} \mathrm{C}$ Ionic Strength Profiles ............................................ 6-50

6-24. Ratio of Water to Reactants for CSNF: Impact on $\mathrm{pH}$.............................................. 6-53

6-25. Ratio of Water to Reactants for CSNF: Impact on Ionic Strength ................................ 6-54

6-26. Ratio of Water to Reactants for CDSP: Impact on $\mathrm{pH}$............................................. 6-54

6-27. Ratio of Water to Reactants for CDSP: Impact on Ionic Strength ............................... 6-55

6-28. Thermally Perturbed Composition 51 (W6) for CSNF.................................................. 6-56

6-29. Thermally Perturbed Composition 20013 (W5) for CDSP............................................. 6-57

6-30. $\mathrm{Cr}(\mathrm{III})$ versus the $\mathrm{Cr}(\mathrm{VI})$ for CSNF: Impact on $\mathrm{pH}$................................................ 6-59

6-31. $\mathrm{Cr}(\mathrm{III})$ versus the $\mathrm{Cr}(\mathrm{VI})$ for CSNF: Impact on Ionic Strength .................................. 6-59

6-32. $\mathrm{Cr}(\mathrm{III})$ versus the $\mathrm{Cr}(\mathrm{VI})$ for CDSP: Impact on $\mathrm{pH}$................................................ 6-60

6-33. $\mathrm{Cr}(\mathrm{III})$ versus the $\mathrm{Cr}(\mathrm{VI})$ for CDSP: Impact on Ionic Strength ................................... 6-60

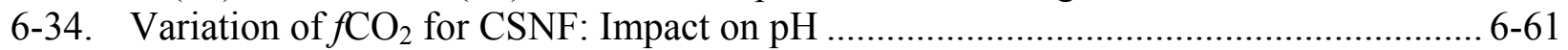

6-35. Variation of $f \mathrm{CO}_{2}$ for CSNF: Impact on Ionic Strength .......................................... 6-62

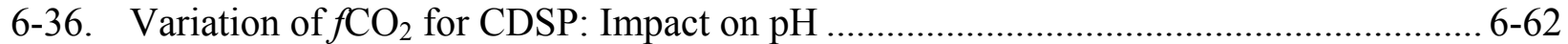

6-37. Variation of $f \mathrm{CO}_{2}$ for CDSP: Impact on Ionic Strength ............................................. 6-63

6-38. Variation of $f \mathrm{O}_{2}$ for CSNF: Impact on $\mathrm{pH}$ and Ionic Strength .................................... 6-64

6-39. Variation of $f \mathrm{O}_{2}$ for CDSP: Impact on $\mathrm{pH}$ and Ionic Strength .................................. 6-64

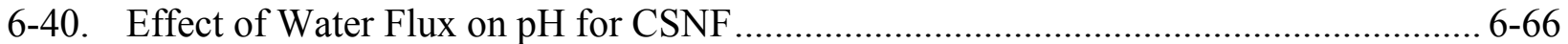

6-41. Effect of Water Flux on Ionic Strength for CSNF ................................................. 6-66

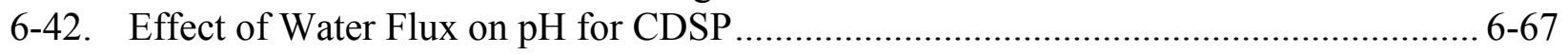




\section{FIGURES (Continued)}

Page

6-43. Effect of Water Flux on Ionic Strength for CDSP ……............................................ 6-67

6-44. Effect of Increasing Temperature on the $\mathrm{pH}$ for CSNF ............................................. 6-68

6-45. Effect of Increasing Temperature on Ionic Strength for CSNF ................................... 6-69

6-46. Effect of Increasing Temperature on the $\mathrm{pH}$ for CDSP ............................................... 6-69

6-47. Effect of Increasing Temperature on Ionic Strength for CDSP ................................. 6-70

6-48. NiGd Alloy Design Change for Water Influx Case: Impact on pH.............................. 6-71

6-49. NiGd Alloy Design Change for Water Influx Case: Impact on Ionic Strength .............. 6-72

6-50. NiGd Alloy Design Change for Vapor Influx Case: Impact on pH.............................. 6-72

6-51. NiGd Alloy Design Change for Vapor Influx Case: Impact on Ionic Strength.............. 6-73

6-52. Comparison of HLW Glass Compositions …………………................................ 6-75

6-53. Corrected Carbon Steel Type A516 Guide Information for CSNF ……….................. 6-76

6-54. Effect of Replacing Carbon Steel Type A516 with Stainless Steel Type 316 ................ 6-77

6-55. Corrosion Rate Comparison for CSNF ............................................................... 6-78

6-56. Corrosion Rate Comparison for CDSP .................................................................. 6-79

6-57. CSNF Rate Using Apex and Maximum Specific Surface Area Term........................... 6-80

6-58. HLWG Rate Using Maximum Uncertainty for $\mathrm{k}_{\mathrm{E}}$ Term ........................................ 6-81

6-59. HLW Glass Exposure Factor Impact on $\mathrm{pH}$ and Ionic Strength................................. 6-83

6-60. 2-MCO/2-DHLW Design versus 5 DHLW/DOE SNF: Impact on $\mathrm{pH}$......................... 6-85

6-61. 2-MCO/2-DHLW Design Versus 5 DHLW/DOE SNF: Impact on Ionic Strength....... 6-86

6-62. Mineral Assemblage for Base Case ..................................................................... 6-100

6-63. Mineral Assemblage for Moderated pH Case......................................................... 6-100

6-64. CSNF Vapor Influx Ionic Strength Abstraction ...................................................... 6-104

6-65. CSNF Water Influx Model $25^{\circ} \mathrm{C}$ Ionic Strength Abstraction...................................... 6-105

6-66. CDSP Vapor Influx Ionic Strength Profiles and Abstraction .................................... 6-108

6-67. CSNF Water Influx Case: Ionic Strength Profile with Error Bars................................ 6-111

6-68. CSNF Vapor Influx Case: Ionic Strength Profile with Uncertainty ........................... 6-111

6-69. CDSP Water Influx Case: Ionic Strength Profile with Error Bars................................. 6-112

6-70. CDSP Vapor Influx Case: Ionic Strength Profile with Uncertainty ............................. 6-112

6-71. CSNF Water Influx Model $25^{\circ} \mathrm{C}$ Fluoride Profiles and Abstraction.......................... 6-114

6-72. CDSP Vapor Influx Model $25^{\circ} \mathrm{C}$ Fluoride Profiles .................................................. 6-115

6-73. CDSP Water Influx Model $25^{\circ} \mathrm{C}$ Fluoride Profiles and Abstraction Limits ............... 6-116

6-74. CSNF Water influx Model $25^{\circ} \mathrm{C}$ Chloride Profiles and Abstraction Limits ................ 6-117

6-75. CDSP Water Influx Model $25^{\circ} \mathrm{C}$ Chloride Profiles and Abstraction Limits............... 6-117

6-76. Total Carbonate Function Compared to Model Output at Two Temperatures............ 6-120

6-77. Eh Function Compared to Model Output at Two Temperatures ................................ 6-122

6-78. CSNF Vapor Influx-Water Influx Model Comparison .............................................. 6-123

6-79. CDSP Vapor Influx-Water Influx Model Comparison .............................................. 6-123 


\section{TABLES}

Page

1-1. Upstream and Downstream Documents............................................................ 1-2

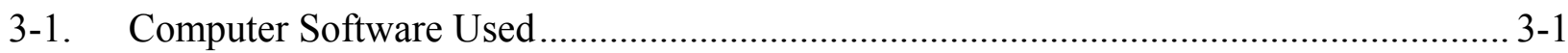

3-2. Computers and Operating Systems Used................................................................ 3-2

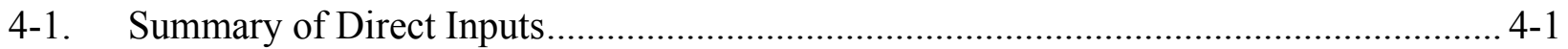

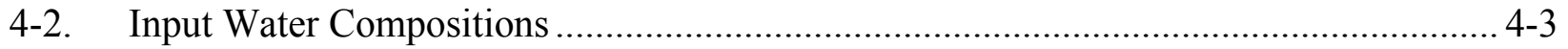

4-3. Thermally Perturbed Seepage Compositions ................................................................ 4-5

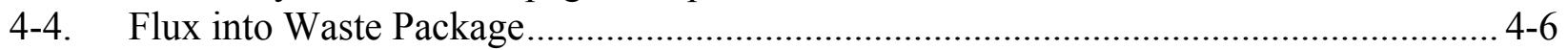

4-5. High-Level Waste Glass Composition................................................................... 4-7

4-6. Materials Nomenclature and Waste Package Breakdown .............................................. 4-8

4-7. Composition of Steel and Aluminum Alloys .......................................................... 4-9

4-8. Steel and Alloy Densities and Corrosion Rates .......................................................... 4-10

4-9. Surface Complexation Reactions ......................................................................... 4-11

4-10. Properties of Major Iron Minerals ...................................................................... 4-11

6-1. Included FEPs for the In-Package Chemistry Model Report........................................... 6-1

6-2. CSNF Vapor Influx Multicomponent Ensembles ...................................................... 6-8

6-3. CDSP Vapor Influx Multicomponent Ensembles ........................................................ 6-8

6-4. EQ6 Input Guide for the Water Influx Model Runs …………................................... 6-9

6-5. EQ6 Input Fluid Compositions ……………....................................................... 6-11

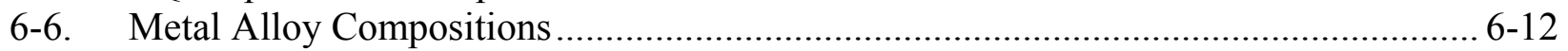

6-7. Metal Alloy Corrosion Rates .................................................................................... 6-13

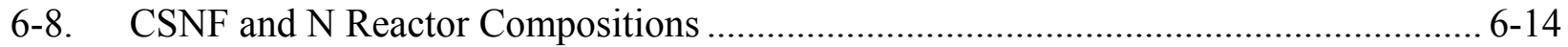

6-9. CSNF Transition State Theory Rate Law and Coefficients......................................... 6-15

6-10. HLWG Transition State Theory Rate Law and N Reactor Rate Constants ................... 6-15

6-11. Total Surface Areas and Moles for the CSNF and CDSP Waste Packages.................... 6-16

6-12. Minerals Suppressed in In-Package Chemistry Model EQ6 Runs ………..................... 6-19

6-13. Major Mineral Phases Formed in EQ6 Runs ......................................................... 6-20

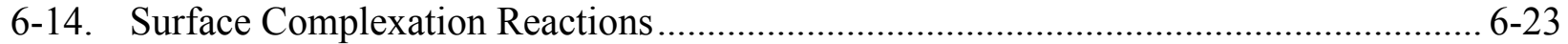

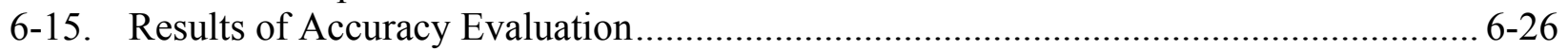

6-16. Alternative In-Package Chemistry Conceptual Models................................................... 6-28

6-17. HLWG Sensitivity: High-Level Waste Glass Composition …………………................ 6-74

6-18. Corrosion Rates for Sensitivity Analysis ................................................................ 6-78

6-19. Input to Calculations for 5 DHLW/TMI SNF-Long Waste Package ............................. 6-84

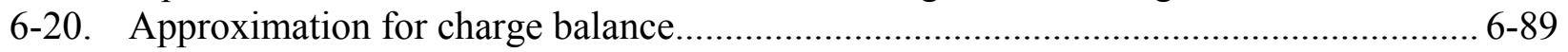

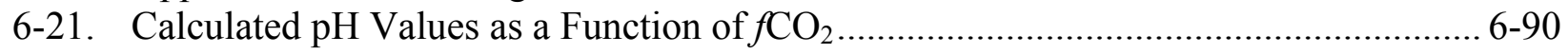

6-22. Initial $\mathrm{pH}$ of Waters Prior to Surface Complexation Calculations ............................... 6-96

6-23. Equilibrium $\mathrm{pH}$ Predicted in Surface Complexation Calculations ............................... 6-98

6-24. Mapping of Batch Reactor Cases to Abstractions ................................................... 6-101

6-25. CSNF Water Influx Model $25^{\circ} \mathrm{C}$ Ionic Strength Abstraction................................... 6-105

6-26. Flux Limits for CSNF Water Influx Model $25^{\circ} \mathrm{C}$ Ionic Strength Abstraction ............ 6-105

6-27. CSNF Water Influx Model 50 ${ }^{\circ} \mathrm{C}$ Ionic Strength Abstraction..................................... 6-106 


\section{TABLES (Continued)}

Page

6-28. Flux Limits for CSNF Water Influx Model $50^{\circ} \mathrm{C}$ Ionic Strength Abstraction ........... 6-106

6-29. CDSP Water Influx Model $25^{\circ} \mathrm{C}$ Ionic Strength Abstraction.

6-30. Flux Limits for CDSP Water Influx Model $25^{\circ} \mathrm{C}$ Ionic Strength Abstraction

6-31. CDSP Water Influx Model $50^{\circ} \mathrm{C}$ Ionic Strength Abstraction....

6-32. Flux Limits for CDSP Water Influx Model $50^{\circ} \mathrm{C}$ Ionic Strength Abstraction 6-110

6-33. Total Carbonate as a Function of $\mathrm{pH}$ 6-118

6-34. Log K Values for the Carbonate Species at Temperature. 6-118

6-35. Log K Temperature Interpolation Functions for Total Carbonate Abstraction 6-119

6-36. Eh as a Function of $\mathrm{pH}, \mathrm{O}_{2}$, and Absolute Temperature.....

7-1. Validation Criteria, Activities, and Metrics ........................................................... 7-3

8-1. $\quad$ Range of Applicability ..................................................................................... 8-2

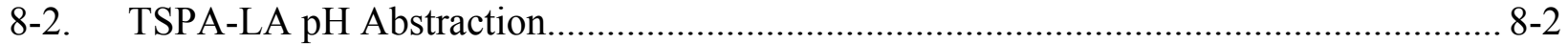

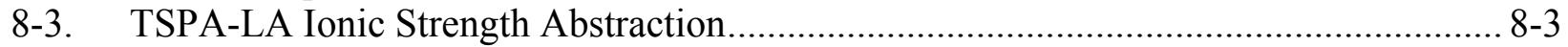

8-4. TSPA-LA Total Carbonate Abstraction................................................................... 8-3

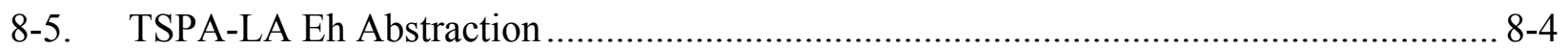

8-6. TSPA-LA Fluoride and Chloride Abstraction ......................................................... 8-4 


\section{ACRONYMS}

B\&W Babcock and Wilcox

CDSP codisposed

$\mathrm{CPU} \quad$ central processing unit

CSNF commercial spent nuclear fuel

DOE U.S. Department of Energy

DTN Data Tracking Number

EBS engineered barrier system

FEPs features, events, and processes

GPC glass pour canisters

HFO hydrous ferric oxide

HLWG high-level waste glass

IED information exchange drawing

IEP isoelectric point

MCO multi-canister overpack

PWR pressurized water reactor

Q water flux through the waste package

SNF spent nuclear fuel

TMI Three Mile Island

TSPA-LA Total Systems Performance Assessment-License Application

XRD $\quad$ X-ray diffraction

ZPC zero point of charge 


\section{ELEMENTAL SYMBOLS}

Ag Silver

Al Aluminium

Am Americium

$\mathrm{Ba}$ Barium

Be Beryllium

C Carbon

$\mathrm{Ca}$ Calcium

$\mathrm{Cl}$ Chlorine

$\mathrm{Cm}$ Curium

Co Cobalt

$\mathrm{Cr}$ Chromium

Cs Cesium

$\mathrm{Cu}$ Copper

$\mathrm{Eu}$ Europium

F Fluorine

$\mathrm{Fe} \quad$ Iron

Gd Gadolinium

$\mathrm{H}$ Hydrogen

Ho Holmium

In Indium

K Potassium

$\mathrm{Kr} \quad$ Krypton

La Lanthanum

$\mathrm{Li} \quad$ Lithium

$\mathrm{Mg}$ Magnesium

Mn Manganese

Mo Molybdenum

$\mathrm{N}$ Nitrogen
$\mathrm{Na}$ Sodium

$\mathrm{Nb}$ Niobium

$\mathrm{Nd}$ Neodymium

$\mathrm{Ni}$ Nickel

$\mathrm{Np}$ Neptunium

$\mathrm{P}$ Phosphorus

$\mathrm{Pa}$ Protactinium

$\mathrm{Pb} \quad$ Lead

Pd Palladium

$\mathrm{Pm}$ Promethium

Pr Praseodymium

$\mathrm{Rh} \quad$ Rhodium

$\mathrm{Rn}$ Radon

$\mathrm{Ru} \quad$ Ruthenium

$\mathrm{S} \quad$ Sulfur

Si Silicon

Sm Samarium

Tc Technetium

Th Thorium

Ti Titanium

U Uranium

V Vanadium

W Tungsten

Xe Xenon

Y Yttrium

Zn Zinc

$\mathrm{Zr}$ Zirconium 


\section{PURPOSE}

This report was developed in accordance with the requirements in Technical Work Plan for: Regulatory Integration Modeling and Analysis of the Waste Form and Waste Package (BSC 2004 [DIRS 171583]). The purpose of the in-package chemistry model is to predict the bulk chemistry inside of a breached waste package and to provide simplified expressions of that chemistry as function of time after breach to Total Systems Performance Assessment for the License Application (TSPA-LA).

The scope of this report is to describe the development and validation of the in-package chemistry model. The in-package model is a combination of two models, a batch reactor model that uses the EQ3/6 geochemistry-modeling tool, and a surface complexation model that is applied to the results of the batch reactor model. The batch reactor model considers chemical interactions of water with the waste package materials and the waste form for commercial spent nuclear fuel (CSNF) waste packages and codisposed waste packages that contain both high-level waste glass (HLWG) and DOE spent fuel. The surface complexation model includes the impact of fluid-surface interactions (i.e., surface complexation) on the resulting fluid composition.

The model examines two types of water influx: (1) the condensation of water vapor that diffuses into the waste package, and (2) seepage water that enters the waste package from the drift as a liquid.

1. Vapor Influx Case: The condensation of vapor onto the waste package internals is simulated as pure $\mathrm{H}_{2} \mathrm{O}$ and enters at a rate determined by the water vapor pressure for representative temperature and relative humidity conditions.

2. Water Influx Case: The water entering a waste package from the drift is simulated as typical groundwater and enters at a rate determined by the amount of seepage available to flow through openings in a breached waste package.

TSPA-LA uses the vapor influx case for the nominal scenario for simulations where the waste package has been breached but the drip shield remains intact, so all of the seepage flow is diverted from the waste package. The chemistry from the vapor influx case is used to determine the stability of colloids and the solubility of radionuclides available for transport by diffusion, and to determine the degradation rates for the waste forms. TSPA-LA uses the water influx case for the seismic scenario, where the waste package has been breached and the drip shield has been damaged such that seepage flow is actually directed into the waste package. The chemistry from the water influx case that is a function of the flow rate is used to determine the stability of colloids and the solubility of radionuclides available for transport by diffusion and advection, and to determine the degradation rates for the CSNF and HLW glass. TSPA-LA does not use this model for the igneous scenario.

Outputs from the in-package chemistry model implemented inside TSPA-LA include $\mathrm{pH}$, ionic strength, and total carbonate concentration. These inputs to TSPA-LA will be linked to the following principle factors: dissolution rates of the CSNF and HLWG, dissolved concentrations of radionuclides, and colloid generation. 
Other outputs from the in-package chemistry model used in other models supporting TSPA-LA include Eh (redox potential), chloride, and fluoride concentration. Specific information available in the output files from the batch reactor model includes time series concentrations of the elements and their aqueous complexes constituting the waste package, waste form, seepage, gas composition, and mineralogical phase abundance.

The in-package chemistry model is activated within TSPA-LA once the waste package has been breached and the interior temperature of the waste package is below the boiling temperature of water. All references to time within this report refer to the time after waste package breach and after the waste package cools to $100^{\circ} \mathrm{C}$. Liquid water may only persist in appreciable quantities once the drift environment has cooled to below approximately $100^{\circ} \mathrm{C}$. While the boiling point of pure water at the repository elevation is approximately $96^{\circ} \mathrm{C}$, the value of $100^{\circ} \mathrm{C}$ is used to reflect possible higher boiling points of liquids containing dissolved solids. The in-package chemistry model is applicable over the water volumetric flux (hereafter referred to as "flux") range from $0.15 \mathrm{~L} / \mathrm{yr}$ to $300 \mathrm{~L} / \mathrm{yr}$ per waste package, a temperature range from $25^{\circ} \mathrm{C}$ to $100^{\circ} \mathrm{C}$, a carbon dioxide partial pressure range of $10^{-5}$ to $10^{-1.5}$ atmospheres, and an oxygen partial pressure up to 0.2 atmospheres. Spatially, the applicability of the in-package chemistry model is limited to the waste package interior.

Limitations to this model include:

- Limited availability of long-term metal alloy corrosion information such as the evolution of the surface area of the metal waste package components as a function of time. This limitation is discussed in Section 5, Assumption 5.3.

- Limited availability of data on thin film chemistry. This limitation is discussed in Section 5, Assumption 5.1.

- Limited availability of thermodynamic data for certain elements that constitute the waste package and waste forms (transition metals and radionuclides) that prohibited the use of high-ionic strength solutions as initial starting compositions for the in-package chemistry model (concentrated brines). This data limitation also influenced the boundary conditions used in the model where the ratio of water to reactants was selected for the base case. This limitation is discussed in Section 6.3.1.1.

- The batch reactor model and the surface complexation model are implemented in series, so the feedback between the models is not accounted for during the modeling. This limitation is addressed in Section 6.9.

Table 1-1 provides a list of upstream and downstream documents associated with this model.

Table 1-1. Upstream and Downstream Documents

\begin{tabular}{|c|l|}
\hline $\begin{array}{c}\text { Upstream } \\
\text { Documents (Directly } \\
\text { Used Inputs Only) }\end{array}$ & $\begin{array}{l}\text { CSNF Waste Form Degradation: Summary Abstraction (BSC 2004 [DIRS 169987]), } \\
\text { Defense HLW Glass Degradation Model (BSC 2004 [DIRS 169988]), EBS Radionuclide } \\
\text { Transport Abstraction (BSC 2004 [DIRS 169868]) }\end{array}$ \\
\hline $\begin{array}{c}\text { Downstream } \\
\begin{array}{c}\text { Documents (Direct } \\
\text { Uses Only) }\end{array}\end{array}$ & $\begin{array}{l}\text { Clad Degradation Features, Events, and Processes (ANL-WIS-MD-000008), Waste-Form } \\
\text { Features, Events, and Processes (ANL-WIS-MD-000009), Total System Performance } \\
\text { Assessment (TSPA) Model/Analysis for the License Application (MDL-WIS-PA-000004) }\end{array}$ \\
\hline
\end{tabular}




\section{QUALITY ASSURANCE}

QA Program Applicability: Development of this report has been determined to be subject to the Yucca Mountain Project's quality assurance program (BSC 2004 [DIRS 171583], Section 8) because it will be used to support performance assessments. Approved QA procedures identified in the technical work plan (BSC 2004 [DIRS 171583], Section 4) have been used to conduct and document the activities described in this model report. This model report describes bulk chemistry inside of a breached waste package that does not affect any items in Q-List (BSC 2004 [DIRS 168361]).

Electronic Management of Data: The technical work plan contains the process control evaluation used to evaluate the control of electronic management of data (BSC 2004 [DIRS 171583], Appendix A) during the modeling and documentation activities, and this evaluation determined that the methods in the implementing procedures are adequate. No deviations from these methods were performed. 


\section{INTENTIONALLY LEFT BLANK}




\section{USE OF SOFTWARE}

A list of controlled and baselined software used in this report is provided in Table 3-1, and the operating environments are provided in Table 3-2. The range of use for each piece of software is within that for which it was qualified. Each of the software codes was selected because it is appropriate for use in geochemical modeling and uses the project qualified thermodynamic database, and there are no limitations on the outputs due to the selected software. The use of the software was consistent with the intended use and within the documented validation range of the software. No software was used prior to qualification to develop any preliminary output.

Microsoft Excel, a commercial off-the-shelf software program, is used in this report; however, the results are not dependent on the software program used, so this software is exempt from requirements in LP-SI.11Q-BSC, Software Management.

For all software, the formulas and inputs used in this model are discussed in Section 4. The outputs are discussed in Section 6. No other information is required for an independent person to reproduce the work.

Table 3-1. Computer Software Used

\begin{tabular}{|c|c|c|c|c|}
\hline $\begin{array}{l}\text { Software } \\
\text { Name }\end{array}$ & Version & $\begin{array}{c}\text { Software Tracking Number } \\
\text { (Qualification Status) }\end{array}$ & $\begin{array}{l}\text { Description and } \\
\text { Components Used }\end{array}$ & $\begin{array}{l}\text { Input and Output Files } \\
\text { (Included in Appendix F) } \\
\text { (Ind }\end{array}$ \\
\hline \multirow{2}{*}{ EQ3/6 } & \multirow{2}{*}{$7.2 b$} & \multirow{2}{*}{$\begin{array}{l}\text { LLNL: UCRL-MA-110662 } \\
\text { (LSCR198) } \\
\text { [DIRS 149359] } \\
\text { (Qualified on Windows } 95 \\
\text { and HP-UX 10.20 B) }\end{array}$} & $\begin{array}{l}\text { EQ3NR: a FORTRAN } \\
\text { speciation-solubility code }\end{array}$ & $\begin{array}{ll}\text { input: } & * \\
\text { output: } & * 3 \mathrm{i}, 6 \mathrm{i} \\
& * 30,60\end{array}$ \\
\hline & & & $\begin{array}{l}\text { EQPT: a data file } \\
\text { preprocessor in FORTRAN }\end{array}$ & $\begin{array}{l}\text { input: data0.* } \\
\text { output: data1.* }\end{array}$ \\
\hline EQ6 & 7.2bLV & $\begin{array}{l}\text { 10075-7.2bLV-02 } \\
\text { [DIRS 159731] } \\
\text { (Qualified on Windows } 2000 \\
\text { and NT) }\end{array}$ & $\begin{array}{l}\text { EQ6: a reaction path code } \\
\text { which models water-rock } \\
\text { interaction or fluid mixing in } \\
\text { either a pure reaction } \\
\text { progress mode or a time } \\
\text { mode }\end{array}$ & $\begin{array}{ll}\text { input: } & { }^{*} .6 \mathrm{i} \\
\text { pickup: } & { }^{*} .6 \mathrm{p} \\
\text { output: } & { }^{*} .60 \\
& { }^{*} . \text { elem_aqu.txt } \\
& { }^{*} . \text {.elem_min.txt } \\
& { }^{*} . \text {.elem_tot.txt } \\
& { }^{*} . \text { min_info.txt } \\
& \text { *.bin } \\
\end{array}$ \\
\hline GetEQData & 1.0 .1 & $\begin{array}{l}\text { 10809-1.0.1-0 } \\
\text { [DIRS 161900] } \\
\text { (Qualified on Windows NT } \\
4.0 \text { and Windows 2000) } \\
\end{array}$ & $\begin{array}{l}\text { A Microsoft Excel macro. It is } \\
\text { used to postprocess EQ3/6 } \\
\text { output information. }\end{array}$ & $\begin{array}{ll}\text { input: } & * \\
\text { * } .30,60 \\
\text { output: } & * \\
* & \text {.xls }\end{array}$ \\
\hline PHREEQC & 2.3 & $\begin{array}{l}\text { 10068-UM-2.3-01 } \\
\text { [DIRS 157837] } \\
\text { (Qualified on Windows 2000) }\end{array}$ & $\begin{array}{l}\text { A code for geochemical } \\
\text { speciation, reaction path } \\
\text { modeling, reactive transport, } \\
\text { and surface complexation } \\
\text { modeling. }\end{array}$ & $\begin{array}{ll}\text { input: } & * \\
\text { output: } & *\end{array}$ \\
\hline transl & 2.0 & $\begin{array}{l}10251-2.0-00 \\
\text { [DIRS 155029] } \\
\text { (Qualified on Windows 98) }\end{array}$ & $\begin{array}{l}\text { A code for translating a } \\
\text { nonPitzer EQ3/6 database } \\
\text { into PHREEQC format }\end{array}$ & $\begin{array}{l}\text { input: data0.* } \\
\text { output: data1.* }\end{array}$ \\
\hline $\begin{array}{l}\text { Microsoft } \\
\text { Excel }\end{array}$ & 97 SR-2 & $\begin{array}{l}\text { Commercial off-the-shelf } \\
\text { software: Exempt }\end{array}$ & $\begin{array}{l}\text { Used in this document for } \\
\text { graphical representation and } \\
\text { arithmetical manipulations }\end{array}$ & $\begin{array}{ll}\text { input: } & * \\
\text { output: } & { }^{*} . \text {.xls }\end{array}$ \\
\hline
\end{tabular}


Table 3-2. Computers and Operating Systems Used

\begin{tabular}{|l|l|l|l|}
\hline \multicolumn{1}{|c|}{ Computer Make } & \multicolumn{1}{|c|}{ CPU \# } & \multicolumn{1}{c|}{$\begin{array}{c}\text { Operating } \\
\text { System }\end{array}$} & \multicolumn{1}{c|}{ Software Used } \\
\hline Dell Optiplex GX300 & 117728 & Windows 95 & EQ3/6 V7.2b \\
\hline Dell Latitude C610 & $632 \mathrm{MT11}$ & Windows 2000 & EQ6 V7.2bLV, GetEQData, \\
\hline Dell Optiplex GX260 & 4BPQW11 & Windows 2000 & PHREEQC \\
\hline Dell Optiplex GX110 & 3YS420B & Windows 98 & transl \\
\hline Dell Optiplex GX260 & 152381 & Windows 2000 & EQ3/6 V7.2bLV \\
\hline Dell Optiplex GX400 & 151295 & Windows NT 4.0 & EQ6 V7.2bLV, GetEQData \\
\hline
\end{tabular}

NOTE: $\quad \mathrm{CPU}=$ central processing unit. 


\section{INPUTS}

This section lists the inputs used to develop this report. The information used to develop the model was not used to validate the model.

\subsection{DIRECT INPUT}

The information in the following sections is used as direct input to the in-package chemistry model. Table 4-1 lists the data used in the in-package chemistry model.

Table 4-1. Summary of Direct Inputs

\begin{tabular}{|c|c|c|c|}
\hline Identifier & Input & Reference & Used in: \\
\hline data0.ymp.R2 & Thermodynamic Data & DTN: MO0302SPATHDYN.000 [DIRS 161756] & $\begin{array}{l}\text { For EQ6 runs } \\
\text { and Section } \\
6.3 .2 .1\end{array}$ \\
\hline J-13 Well Water & Water Composition & DTN: MO0006J13WTRCM.000 [DIRS 151029] & \multirow{19}{*}{$\begin{array}{l}\text { Section 6.3.1.3, } \\
\text { Appendix F } \\
\text { CDSP.xls and } \\
\text { CSNF.xls and in } \\
\text { all EQ6 input } \\
\text { files }\end{array}$} \\
\hline Ca-porewater & \multirow[b]{2}{*}{ Water Composition } & \multirow[b]{2}{*}{ DTN: GS020408312272.003 [DIRS 160899] } & \\
\hline Na-porewater & & & \\
\hline $51.3 \mathrm{i}$ & Water Composition & $\begin{array}{l}\text { DTN: MO0303MWDSCMAB.000 [DIRS 162551], } \\
\text { file: W6_THCabstraction3i3o3pfiles, path: } \\
\text { ESPIJolleylEQ36 for P\&CEITHC } \\
\text { AbstractionIW6Itf4 }\end{array}$ & \\
\hline $10006.3 \mathrm{i}$ & Water Composition & $\begin{array}{l}\text { DTN: MO0303MWDSCMAB.000 [DIRS 162551], } \\
\text { file: W4_THCabstraction3i3o3pfiles, path: } \\
\text { ESPIJolleylEQ36 for PCEITHC } \\
\text { AbstractionIW4ltf4 }\end{array}$ & \\
\hline $20013.3 i$ & Water Composition & $\begin{array}{l}\text { DTN: MO0303MWDSCMAB.000 [DIRS 162551] } \\
\text { file: W5_THCabstraction3i3o3pfiles, path: } \\
\text { ESPIJolleylEQ36 for P\&CEITHC } \\
\text { AbstractionIW5Itf4 }\end{array}$ & \\
\hline Water Entry Rate & \multirow{2}{*}{ Flow Rates } & BSC 2004 [DIRS 169131], Table 6.8-1 and 6.8-2 & \\
\hline Vapor Entry Rate & & BSC 2004 [DIRS 169868], Table 6.5-14 & \\
\hline \multirow{4}{*}{ HLWG } & Reaction Rate & $\begin{array}{l}\text { BSC } 2004 \text { [DIRS 169988], Section 8.1, Equation } \\
50 \text { and 51, Table 8-1 }\end{array}$ & \\
\hline & Density & Baxter 1988 [DIRS 106164], Table 10 & \\
\hline & Composition & CRWMS M\&O 2001 [DIRS 153263], Table 3 & \\
\hline & $f_{\text {exposure }}$ & BSC 2004 [DIRS 169988], Table 8-1 & \\
\hline \multirow{2}{*}{ N Reactor Fuel } & Reaction Rate & DOE 2000 [DIRS 152658], Equation 2-39 & \\
\hline & Composition & DOE 2000 [DIRS 150095], Table 3-1 & \\
\hline \multirow[t]{2}{*}{ CSNF } & Isotopic Inventory & $\begin{array}{l}\text { BSC } 2003 \text { [DIRS 169110], Attachment III Disk } 1 \\
\text { of 9, ATT III/ LPM1/ uniform_profile/ 3.5/ } \\
\mathrm{ft71-case10.N04}\end{array}$ & \\
\hline & Reaction Rate & $\begin{array}{l}\text { BSC } 2004 \text { [DIRS 169987], Section 8.1, } \\
\text { Tables 8-2 and 8-3 }\end{array}$ & \\
\hline $\begin{array}{l}\text { 21-PWR CSNF } \\
\text { Waste Package }\end{array}$ & $\begin{array}{l}\text { Waste Package } \\
\text { Component } \\
\text { Dimensions }^{\text {a }}\end{array}$ & $\begin{array}{l}\text { Punatar } 2001 \text { [DIRS 155635], p. 2-5; } \\
\text { BSC } 2004 \text { [DIRS 167207], Table 1a }\end{array}$ & \\
\hline $\begin{array}{l}2 \mathrm{MCO} / 2 \text { DHLW } \\
\text { Waste Package }\end{array}$ & $\begin{array}{l}\text { Waste Package } \\
\text { Component } \\
\text { Dimensions }\end{array}$ & DOE 2000 [DIRS 150095], Section 4 & \\
\hline Periodic Table & $\begin{array}{l}\text { Atomic Weights of } \\
\text { Elements and } \\
\text { Isotopes }\end{array}$ & $\begin{array}{l}\text { Audi and Wapstra } 1995 \text { [DIRS 149625]; } \\
\text { Parrington et al. } 1996 \text { [DIRS 103896] }\end{array}$ & \\
\hline
\end{tabular}


Table 4-1. Summary of Direct Inputs (Continued)

\begin{tabular}{|c|c|c|c|}
\hline Identifier & Input & Reference & Used in: \\
\hline \multirow[b]{3}{*}{$\begin{array}{l}\text { Stainless Steel } \\
\text { Type } 316\end{array}$} & Corrosion rate & DTN: MO0409SPAACRWP.000 [DIRS 172059] & \\
\hline & Density & ASTM G 1-90 1999 [DIRS 103515], Table XI, p. 7 & \\
\hline & Composition & $\begin{array}{l}\text { ASTM A 240/A 240M-03b } 2003 \text { [DIRS 165003], } \\
\text { Table 1, p. } 4\end{array}$ & \\
\hline \multirow[b]{3}{*}{$\begin{array}{l}\text { Stainless Steel } \\
\text { Type } 304 \mathrm{~L}\end{array}$} & Corrosion rate & DTN: MO0409SPAACRWP.000 [DIRS 172059] & \\
\hline & Density & ASTM G 1-90 1999 [DIRS 103515], Table XI, p. 7 & \\
\hline & Composition & $\begin{array}{l}\text { ASTM A 240/A 240M-03b } 2003 \text { [DIRS 165003], } \\
\text { Table 1, p. } 3\end{array}$ & \\
\hline \multirow[b]{3}{*}{$\begin{array}{l}\text { Carbon Steel } \\
\text { Type A516 }\end{array}$} & Corrosion rate & DTN: MO0409SPAACRWP.000 [DIRS 172059] & \\
\hline & Density & $\begin{array}{l}\text { ASTM A 20/A 20M-95a } 1995 \text { [DIRS 104189], p. } \\
21\end{array}$ & \\
\hline & Composition & $\begin{array}{l}\text { ASTM A 516/A 516M-01 } 2001 \text { [DIRS } 162723 \text {, } \\
\text { Table 1, grade } 70,1 / 2 " \text { to } 2 " \text { thickness, product } \\
\text { analysis. }\end{array}$ & \\
\hline \multirow[b]{3}{*}{$\begin{array}{l}\text { Aluminum Alloy } \\
6061\end{array}$} & Corrosion rate & DTN: MO0409SPAACRWP.000 [DIRS 172059] & \\
\hline & Density & ASTM G 1-90 1999 [DIRS 103515], Table X1.1 & \\
\hline & Composition & $\begin{array}{l}\text { ASTM B 209-96 } 1996 \text { [DIRS 144744], Table 1, } \\
\text { p. } 7\end{array}$ & \\
\hline \multirow[b]{3}{*}{$\begin{array}{l}\text { Aluminum Alloy } \\
1100\end{array}$} & Corrosion rate & DTN: MO0409SPAACRWP.000 [DIRS 172059] & \\
\hline & Density & ASTM G 1-90 1999 [DIRS 103515], Table XI, p. 7 & \\
\hline & Composition & $\begin{array}{l}\text { ASTM B 209-96 } 1996 \text { [DIRS 144744], Table 1, } \\
\text { p. } 7\end{array}$ & \\
\hline \multirow[b]{3}{*}{ Neutronit ${ }^{\mathrm{b}}$} & Corrosion rate & DTN: MO0409SPAACRWP.000 [DIRS 172059] & \\
\hline & Density & Kügler, A. 1996 [DIRS 107760]; & \\
\hline & Composition & $\begin{array}{l}\text { For B content ASTM A 887-89 } 2000 \text { [DIRS } \\
\text { 154062], Table 1, S30463, S30464, and S } 30466\end{array}$ & \\
\hline \multirow[b]{2}{*}{ NiGd Alloy } & Corrosion rate & DTN: MO0409SPAACRWP.000 [DIRS 172059] & \\
\hline & $\begin{array}{l}\text { Composition and } \\
\text { density }\end{array}$ & ASTM B 932-04. 2004 [DIRS 168403] & \\
\hline Goethite & Surface properties & $\begin{array}{l}\text { Langmuir } 1997 \text { [DIRS 100051], p. } 345, \\
\text { Table } 10.2\end{array}$ & \\
\hline \multirow{2}{*}{$\begin{array}{l}\text { Surface } \\
\text { Complexation }\end{array}$} & \multirow{2}{*}{$\begin{array}{l}\text { Surface Complexation } \\
\text { Reactions }\end{array}$} & Dzombak and Morel 1990 [DIRS 105483] & \multirow{2}{*}{$\begin{array}{l}\text { Sections } 6.3 .2 \text {, } \\
6.7 \text {, and } 6.8\end{array}$} \\
\hline & & Appelo et al. 2002 [DIRS 168168] & \\
\hline $\mathrm{Cr}(I I I)$ solids & $\begin{array}{l}\text { LogK for } \mathrm{Cr}(\mathrm{OH})_{3} \text { and } \\
\text { eskolaite }\end{array}$ & Ball and Nordstrom 1998 [DIRS 163015] & \multirow[t]{4}{*}{ Section 6.6 .3} \\
\hline $\begin{array}{l}\text { Nitric Acid } \\
\text { Production Rate }\end{array}$ & Reaction Rate & BSC 2004 [DIRS 172017], Table 21, p. 33 & \\
\hline $\begin{array}{l}\text { G value of Nitric } \\
\text { Acid Production }\end{array}$ & \multirow[b]{2}{*}{$\begin{array}{l}\text { Used to Calculate } \\
\text { hydrogen peroxide } \\
\text { production }\end{array}$} & BSC 2004 [DIRS 172017], p. 27 & \\
\hline $\begin{array}{l}\text { G value of } \\
\text { Hydrogen } \\
\text { Peroxide } \\
\text { Production }\end{array}$ & & IAEA 1998 [DIRS 150560], Table 8.2, p. 214 & \\
\hline
\end{tabular}

NOTE: $\quad{ }^{a}$ Detailed waste package dimensions used in CSNF.x/s are tabulated in Table A-1 in Appendix A.

${ }^{\mathrm{b}}$ Recent design changes have replaced Neutronit with NiGd Alloy, as described in Section 4.1.4.

\subsubsection{Thermodynamic Database}

The in-package chemistry model used a version of the thermodynamic database data0.ymp.R2 (DTN: MO0302SPATHDYN.000 [DIRS 161756]) as a necessary component in the execution of the EQ3/6 software. This database used in the in-package chemistry model contains data for temperatures up to $200^{\circ} \mathrm{C}$. The database is appropriate for the in-package chemistry model 
because it includes the elements that constitute the waste package, waste form, seepage, and gas compositions in the temperature range needed for the model.

The data0.ymp.R2 (DTN: MO0302SPATHDYN.000 [DIRS 161756]) file has an error in the log $\mathrm{K}$ value and formula of solid $\mathrm{PuO}_{2}(\mathrm{OH})_{2} \mathrm{H}_{2} \mathrm{O}$, which was documented in MO0312SPATDMIF.000 [DIRS 167800]. As this solid was not used in any calculations of this report, this correction has no impact on its output.

The CSNF and HLWG (compositions given in Table 6-8 and Table 4-5, respectively) were added to the database in order to take advantage of EQ3/6's ability to use a pH- and carbonatedependent rate law, using the EQ6 transition state theory formalism to describe the degradation. A range of degradation rates based on $\mathrm{pH}$ can be specified only for reactants entered as "minerals" (solids contained in the database). "Special reactants" (reactants not contained in the database) must have a constant or fixed degradation rate.

\subsubsection{Input Water Compositions and Rates}

Table 4-2 summarizes the input water compositions used in the in-package chemistry model as direct input.

Table 4-2. Input Water Compositions

\begin{tabular}{|c|c|c|c|c|}
\hline Parameter & Units & Ca-porewater $^{\text {a }}$ & Na-porewater ${ }^{b}$ & J-13 Well Water ${ }^{c}$ \\
\hline $\mathrm{Ca}^{2+}$ & $\mathrm{mg} / \mathrm{L}$ & 94 & 81 & 13.0 \\
\hline $\mathrm{Mg}^{2+}$ & $\mathrm{mg} / \mathrm{L}$ & 18.1 & 3.3 & 2.01 \\
\hline $\mathrm{Na}^{+}$ & $\mathrm{mg} / \mathrm{L}$ & 39 & 120 & 45.8 \\
\hline $\mathrm{K}^{+}$ & $\mathrm{mg} / \mathrm{L}$ & 7.6 & 6.1 & 5.04 \\
\hline $\mathrm{SiO}_{2}$ & $\mathrm{mg} / \mathrm{L}$ & 42 & 42 & 61.0 \\
\hline $\mathrm{NO}_{3}^{-}$ & $\mathrm{mg} / \mathrm{L}$ & 2.6 & 0.41 & 8.78 \\
\hline $\mathrm{HCO}_{3}{ }^{-}$ & $\mathrm{mg} / \mathrm{L}$ & 397 & 362 & See Section 6.3.1.3.1 \\
\hline $\mathrm{Cl}-$ & $\mathrm{mg} / \mathrm{L}$ & 21 & 24 & 7.14 \\
\hline F- & $\mathrm{mg} / \mathrm{L}$ & 3.4 & 6 & 2.18 \\
\hline $\mathrm{SO}_{4}{ }^{2-}$ & $\mathrm{mg} / \mathrm{L}$ & 36 & 31 & 18.4 \\
\hline $\mathrm{pH}$ & $\mathrm{pH}$ & 7.6 & 7.4 & 7.41 \\
\hline \multicolumn{2}{|c|}{ Sources } & \multicolumn{2}{|c|}{ GS020408312272.003 [DIRS 160899] } & MO0006J13WTRCM.000 [DIRS 151029] \\
\hline
\end{tabular}

For simplicity, and based on their calcium and sodium concentrations, samples ECRB-SYS-CS1000/7.3-7.7/UC and ECRB-SYS-CS2000/16.3-16.5/UC were termed "Ca-porewater" and "Na-porewater," respectively.

Three water compositions were used as the initial condition(s) in the water influx model of the in-package chemistry model for water entering a breached waste package. The decision to use these water compositions was based on several lines of reasoning. Although it is not expected to enter the repository, the J-13 well water composition was used for comparison purposes (i.e., to maintain continuity between the current work and past in-package chemistry analyses). The Caand Na-porewater compositions were used because they were obtained from core samples proximal to the repository. These waters are intended to represent seepage compositions that 
would enter a breached waste package, especially over the long term. The U.S. Geological Survey identified the location of boreholes from which the cores were removed by noting the following in its data spreadsheet (DTN: GS020408312272.003 [DIRS 160899]):

Chemical composition of pore water extracted from cores of 15 ECRB-SYS-CS Series boreholes, USW SD-9, and USW NRG-7/7a, 04/26/2001 to 02/12/2002.

High trace element values created due to reflux due to boiling events were not considered in the incoming water compositions, because these effects would be transitory compared to the regulatory timeframe, and the chemistry would quickly revert to compositions similar to that listed in Table 4-2.

Section 6.2.2.1 of Drift-Scale Coupled Processes (DST and THC Seepage) Models (BSC 2004 [DIRS 168848]) uses the Ca-porewater (labeled "W5" in BSC 2004 [DIRS 168848]) and another composition (labeled "W4" [ECRB-SYS-CS2000/16.5-21/UC]) also from the U.S. Geological Survey data (DTN: GS020408312272.003 [DIRS 160899]) that originates from the next interval in the same core as that from which the Na-porewater was extracted. The composition of the Na-porewater used in the in-package chemistry model differs only slightly from the "W4" composition used in Drift-Scale Coupled Processes (DST and THC Seepage) Models (BSC 2004 [DIRS 168848]). Thus, continuity has been established for key inputs for the in-package chemistry model and the drift scale processes models.

Compared to the J-13 well water composition, the porewater compositions are significantly more concentrated (Table 4-2). Two anions that may be important with regard to steel corrosion (chloride and fluoride) are concentrated in the porewaters by factors of approximately 2 to 3 compared to J-13 well water. Drift-Scale Coupled Processes (DST and THC Seepage) Models (BSC 2004 [DIRS 168848]) states "W5" (Ca-porewater) has the highest $(\mathrm{Ca}+\mathrm{Mg}) /(\mathrm{Na}+\mathrm{K})$ ratio of the ECRB samples, and "W4" (Na-porewater) has the lowest $(\mathrm{Ca}+\mathrm{Mg}) /(\mathrm{Na}+\mathrm{K})$ ratio of the ECRB samples and higher fluoride than other samples. Thus, the two porewaters represent compositional end members and capture the spread of the porewater compositions. A Piper diagram (BSC 2004 [DIRS 168848], Figure 6.2-4) shows that these two samples represent compositional end members.

Since these samples cover the spectrum of observed porewater compositions sampled and there is a possibility that waters of similar composition may enter a drift and contact a breached waste package, the use of these compositions is well justified. Furthermore, use of these data in the in-package chemistry model ensures the feeds to the TSPA-LA model will reflect the compositional variation of the initial water composition.

Additional water compositions were also used as inputs for sensitivity analyses purposes. The waters from Section 6.6 of Engineered Barrier System: Physical and Chemical Environment Model (BSC 2004 [DIRS 169054]) represent seepage compositions modeled to enter the drift during the postclosure period and that have been thermally perturbed and in equilibrium with higher carbon dioxide fugacities. These include compositions that correspond to thermally perturbed equivalents of the Ca-porewater (W5) and the Na-porewater (W4). A third water composition (W6) from Engineered Barrier System: Physical and Chemical Environment Model (BSC 2004 [DIRS 169054], Section 6.6) was also used to represent a high-temperature composition that could enter a breached waste package. These compositions, along with the 
temperature and carbon dioxide fugacity, were taken from EQ3 files obtained from DTN: MO0303MWDSCMAB.000 [DIRS 162551] and are listed in Table 4-3.

Table 4-3. Thermally Perturbed Seepage Compositions

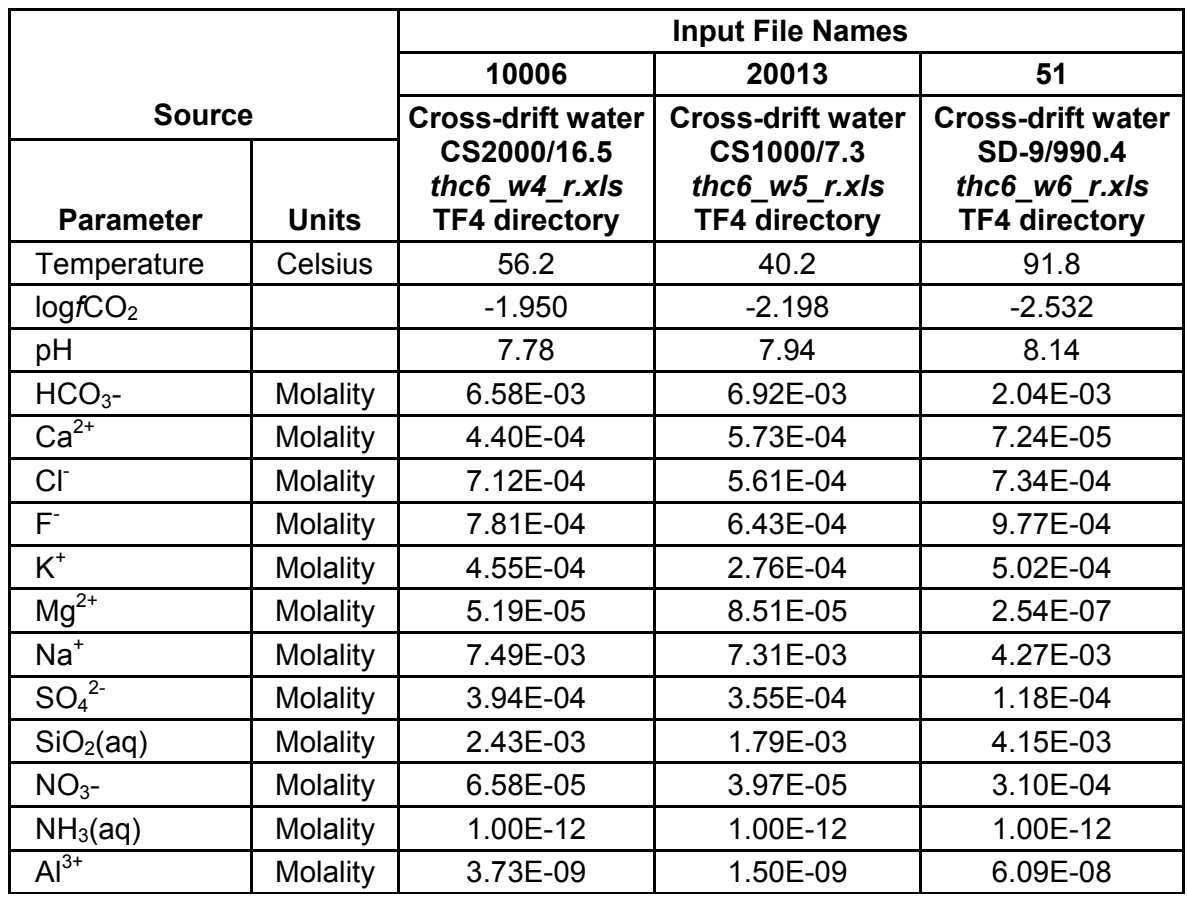

Source: DTN: MO0303MWDSCMAB.000 [DIRS 162551].

NOTE: $\quad \mathrm{fCO}_{2}$ is carbon dioxide fugacity.

The potential flow rate for water flux into the waste package is a function of seepage rate, condition of the drip shield, and number and types of openings in a breached waste package. The potential flow rate for water vapor flux into the waste package is a function of relative humidity, temperature, and number and types of openings in a breached waste package. To cover the possible range of water fluxes, values from Abstraction of Drift Seepage (BSC 2004 [DIRS 169131]) and EBS Radionuclide Transport Abstraction (BSC 2004 [DIRS 169868]) used as bounding cases are presented in Table 4-4. The seepage values are used to ensure that the water flow rates considered in this model are sufficient to cover the potential seepage rates that will be used by TSPA-LA. TSPA-LA starts with the seepage rates from Abstraction of Drift Seepage (BSC 2004 [DIRS 169131]) and adjusts the rate depending on the condition of the drip shield and the number and types of openings in the breached waste package. The maximum seepage flow rate for the purposes of this calculation is the mean seepage rate for the upperbound scenario with the glacial transition climate in the Tptpmn. The true maximum seepage flow is on the order of $10,000 \mathrm{~kg} / \mathrm{yr} / \mathrm{WP}$, but the drip shield and the remaining waste package divert much of the seepage flow, so it would not be reasonable to model this flow entering a waste package. Therefore, these rates represent the maximum range of rates that could enter a waste package, and are justified. The water vapor rates from EBS Radionuclide Transport Abstraction (BSC 2004 [DIRS 169868]) were calculated to provide a range of vapor diffusion rates through stress corrosion cracks for representative temperature and relative humidity conditions. 
Table 4-4. Flux into Waste Package

\begin{tabular}{|l|l|l|l|}
\hline & Minimum Flow Rate & Maximum Flow Rate & \multicolumn{1}{c|}{ Source } \\
\hline Seepage & $0.0 \mathrm{~kg} / \mathrm{yr} / \mathrm{WP}$ & $294.6 \mathrm{~kg} / \mathrm{yr} / \mathrm{WP}$ & BSC 2004 [DIRS 169131], Table 6.8-1 and 6.8-2 \\
\hline Water Vapor & $22.1 \mathrm{~mol} \mathrm{H} \mathrm{H}_{2} \mathrm{O} / \mathrm{yr} / \mathrm{WP}$ & $239 \mathrm{~mol} \mathrm{H} \mathrm{H}_{2} \mathrm{O} / \mathrm{yr} / \mathrm{WP}$ & BSC 2004 [DIRS 169868], Table 6.5-14 \\
\hline
\end{tabular}

NOTE: Minimum and Maximum Water Vapor Flow Rates were calculated in BSC 2004 [DIRS 169868] for $30^{\circ} \mathrm{C}$ and $70^{\circ} \mathrm{C}$, respectively.

\subsubsection{Waste Form Compositions and Rates}

\subsubsection{CSNF}

The source for the composition of the PWR fuel used for the CSNF in the in-package chemistry model is PWR Assembly End-Effect Reactivity Evaluation (BSC 2003 [DIRS 169110]), which starts with fresh fuel $\left(\mathrm{UO}_{2}\right)$ and calculates the composition of the irradiated fuel when it is discharged from the reactor (specified by burnup) and at specified times after discharge. The calculations were performed in that report using the SAS2H sequence and the ORIGEN sequence of the SCALE computer code system. The calculation covers initial enrichment of 2 to $5 \mathrm{wt} \%$ (fuels less than $2 \%$ enriched are bounded by this calculation) ${ }^{235} \mathrm{U}$, and burnup of 0 to $50 \mathrm{GWd} / \mathrm{MTU}$. The quantity of fuel in one assembly is based on the Babcock and Wilcox $(\mathrm{B} \& W) 15 \times 15$-assembly design with the mass of type MK-B2. The MK-B2 design contains the greatest mass of uranium per assembly (CRWMS M\&O 1998 [DIRS 104440], p. 26). The B\&W $15 \times 15$ fuel assembly is one of the most reactive 21-PWR designs (B\&W Fuel Company 1991 [DIRS 104439], p. II 6-6).

The recommended CSNF rate law (BSC 2004 [DIRS 169987], Tables 8-2 and 8-3) is $\mathrm{pH}, \mathrm{O}_{2}$ partial pressure, total carbonate, and temperature dependent. This rate is appropriate for temperatures less than $100^{\circ} \mathrm{C}$, and total carbonate concentrations greater than $2 \times 10^{-4}$ molar (BSC 2004 [DIRS 169987], Section 8.2).

For $\mathrm{pH}>6.8$ (BSC 2004 [DIRS 169987], Section 8.1, using Table 8-2):

$$
\log (\mathrm{F})=\log (\mathrm{A})+4.705+(-1,093.826) \times \mathrm{IT}+(-0.102) \times p \mathrm{CO}_{3}+(-0.338) \times p \mathrm{O}_{2} \quad \text { (Eq. 4-1) }
$$

For $\mathrm{pH} \leq 6.8$ (BSC 2004 [DIRS 169987], Section 8.1, using Table 8-3)

$$
\log (\mathrm{F})=\log (\mathrm{A})+6.60+(-1,093.826) \times \mathrm{IT}+(-0.338) \times p \mathrm{O}_{2}+(-0.340) \times p H \quad \text { (Eq. 4-2) }
$$

where

$\log (\mathrm{F})$ is $\log _{10}$ rate (per day)

$\log (\mathrm{A})$ is $\log _{10}$ of the fuel effective specific surface area $(\mathrm{m} 2 / \mathrm{mg})$

IT is inverse temperature (Kelvin)

$p \mathrm{CO}_{3}=-\log _{10}$ (total molar carbonate species concentration)

$p \mathrm{O}_{2}=-\log _{10}$ (oxygen partial pressure in atmospheres)

$\log (\mathrm{F} / \mathrm{A})$ is the rate is in units of $\mathrm{mg} / \mathrm{m}^{2} /$ day. For low $f \mathrm{CO}_{2}$ conditions, the rate described in Equation 4-1 should be used with a $p \mathrm{CO}_{3}$ equal to $2 \times 10^{-4}$ molar (BSC 2004 [DIRS 169987], Section 8.2). 


\subsubsection{N Reactor}

The source for the $\mathrm{N}$ Reactor fuel composition used in the in-package chemistry model is Table 3-1 of $N$ Reactor (U-Metal) Fuel Characteristics for Disposal Criticality Analysis (DOE 2000 [DIRS 150095]).

A linear rate (i.e., constant reaction rate) of $1.4 \times 10^{4} \mathrm{mg} /\left(\mathrm{m}^{2} \cdot \mathrm{d}\right)$ is used to describe the dissolution of the $\mathrm{N}$ Reactor fuel. This is the best estimate dissolution rate that is five times the constant U-metal rate contained in Review of Oxidation Rates of DOE Spent Nuclear Fuel, Part 1: Metallic Fuel (DOE 2000 [DIRS 152658], Equation 2-39). While the TSPA-LA models the dissolution of DSNF as instantaneous (i.e., occuring within one time step), the time steps in TSPA-LA are considerably larger than the time steps within EQ6. To compensate for this, the EQ6 model uses the aqueous rate because it is faster than the vapor rate. The typical TSPA-LA timestep is 100 years or more, and the minimum is 10 years. Therefore, using the rate described within EQ6 results in complete dissolution of the DSNF within 15 years, is essentially the same as TSPA-LA instantaneously degrading the fuel.

\subsubsection{HLW Glass}

The simplified HLW glass composition in Table 4-5 is from Table 3 of EQ6 Calculations for Chemical Degradation of $N$ Reactor (U-metal) Spent Nuclear Fuel Waste Packages (CRWMS M\&O 2001 [DIRS 153263]), which cites Defense Waste Processing Facility Wasteform and Canister Description (Baxter 1988 [DIRS 106164], Table 6-8). The Savannah River glass composition was used in the model to maintain continuity with other analyses (CRWMS M\&O 2001 [DIRS 153263]). Furthermore, the Savannah River glass has a higher concentration of potassium (about 23 times more than the Hanford glass) (CRWMS M\&O 2000 [DIRS 151947], p. 8, Table 5-1). Since potassium contributes to high $\mathrm{pH}$ conditions, use of the Savannah River glass is justified in this model.

Table 4-5. High-Level Waste Glass Composition

\begin{tabular}{|c|c|}
\hline Element & Mol/100g* $\mathbf{H L W}$ \\
\hline $\mathrm{O}$ & $2.70 \mathrm{E}+00$ \\
\hline $\mathrm{U}$ & $7.82 \mathrm{E}-03$ \\
\hline $\mathrm{Ba}$ & $1.08 \mathrm{E}-03$ \\
\hline $\mathrm{Al}$ & $8.63 \mathrm{E}-02$ \\
\hline $\mathrm{S}$ & $4.01 \mathrm{E}-03$ \\
\hline $\mathrm{Ca}$ & $1.62 \mathrm{E}-02$ \\
\hline $\mathrm{P}$ & $4.89 \mathrm{E}-04$ \\
\hline $\mathrm{Si}$ & $7.76 \mathrm{E}-01$ \\
\hline $\mathrm{B}$ & $2.91 \mathrm{E}-01$ \\
\hline $\mathrm{F}$ & $1.66 \mathrm{E}-03$ \\
\hline $\mathrm{Fe}$ & $1.72 \mathrm{E}-01$ \\
\hline $\mathrm{K}$ & $7.51 \mathrm{E}-02$ \\
\hline $\mathrm{Mg}$ & $3.33 \mathrm{E}-02$ \\
\hline $\mathrm{Na}$ & $5.77 \mathrm{E}-01$ \\
\hline
\end{tabular}

Source: CRWMS M\&O 2001 [DIRS 153263], Table 3.

NOTE: * Elemental mole \% of the glass are calculated based on 100 grams of reactant. 
The HLWG rate expression (BSC 2004 [DIRS 169988]) follows the transition-state rate law and is dependent on the $\mathrm{pH}$ of the solution. The rate law coefficients provided were deemed the "most probable" in Defense HLW Glass Degradation Model (BSC 2004 [DIRS 169988]).

For acidic conditions (BSC 2004 [DIRS 169988], Section 8.1, Equation 50):

$$
\text { rate }_{G}=k_{E_{-} \text {acidic }} \times 10^{-0.49 \cdot \mathrm{pH}} \times \exp (-31 \mathrm{~kJ} / \mathrm{mol} / \mathrm{RT})
$$

The minimum and most probable value of $k_{E_{-} \text {acidic }}$ is $8.41 \times 10^{3} \mathrm{~g} /\left(\mathrm{m}^{2} \cdot \mathrm{d}\right)$

For alkaline conditions $\quad$ (BSC 2004 [DIRS 169988], Section 8.1, Equation 51):

$$
\text { rate }_{G}=k_{E_{-} \text {alkaline }} \times 10^{0.49 \cdot \mathrm{pH}} \times \exp (-69 \mathrm{~kJ} / \mathrm{mol} / \mathrm{RT})
$$

The minimum and most probable value of $k_{E_{-} \text {alkaline }}$ is $2.82 \times 10^{1} \mathrm{~g} /\left(\mathrm{m}^{2} \cdot \mathrm{d}\right)$.

where

rate $_{G}$ is the glass rate law in units of $\mathrm{g} / \mathrm{m}^{2} /$ day

$k_{E_{-} \text {acidic }}$ is the glass degradation rate coefficient for acidic solutions in units of $\mathrm{g} /\left(\mathrm{m}^{2} \cdot \mathrm{d}\right)$

$k_{E_{-}}$alkaline is the glass degradation rate coefficient for alkaline solutions in units of $\mathrm{g} /\left(\mathrm{m}^{2} \cdot \mathrm{d}\right)$

This rate is appropriate for temperatures less than $100^{\circ} \mathrm{C}$. The exposure factor, $\mathrm{f}_{\text {exposure, }}$ is applied to the HLWG rate to take into account increased reactive surface area due to glass fracturing. The most likely value for $f_{\text {exposure }}$ is 4 , and the maximum is 17 .

\subsubsection{Waste Package Material Compositions and Rates}

Table 4-6 contains the names and shorthand names used in this model and waste package type for the metal alloys used throughout this document.

Table 4-6. Materials Nomenclature and Waste Package Breakdown

\begin{tabular}{|l|c|c|c|}
\hline \multicolumn{1}{|c|}{ Material Nomenclature } & Shorthand & \multicolumn{2}{c|}{ Waste Package Type } \\
\cline { 2 - 4 } & Alloy 22 & CSNF & CDSP \\
\hline Alloy 22, UNS N06022 & Stainless Steel Type 316 & X & X \\
\hline SA-240 S31600 Stainless Steel & Stainless Steel Type 304L & & X \\
\hline SA-240 S30403 UNS N06625 Stainless Steel & Carbon Steel Type A516 & $X$ & $X$ \\
\hline SA-516 Grade 70 Carbon Steel & Aluminum Alloy Type 6061 & $X$ & \\
\hline SB-209 6061 T4 & Aluminum Alloy Type 1100 & & X \\
\hline Aluminum Alloy-1100 & Neutronit & $X$ & \\
\hline Neutronit A978 & NiGd Alloy & $X$ & \\
\hline Alloy N06464 & X \\
\hline
\end{tabular}

Table 4-7 summarizes the composition of the steel and aluminum alloys present in the CSNF and CDSP waste packages. While there may be some variability in the composition of the alloys used in the construction of the waste packages, the values in Table 4-7 are vendor data and very little variation is expected. However, a sensitivity analysis is conducted in Section 6.6.9 that varies the composition of the Carbon Steel Type A516 to show the effect on the model response. 
The alloy compositions represent the best available information on the materials that will be used in the construction of the waste package.

Table 4-7. Composition of Steel and Aluminum Alloys

\begin{tabular}{|c|c|c|c|c|c|c|c|}
\hline Element & $\begin{array}{c}\text { Carbon } \\
\text { Steel Type } \\
\text { A516 } \\
\text { (wt \%) } \\
\end{array}$ & $\begin{array}{c}\text { Neutronit } \\
\text { (wt \%) }\end{array}$ & $\begin{array}{c}\text { Aluminum } \\
\text { Alloy } 6061 \\
\text { (wt \%) }\end{array}$ & \begin{tabular}{|c|} 
Stainless \\
Steel Type \\
316 \\
$(w t \%)$ \\
\end{tabular} & $\begin{array}{c}\text { Aluminum } \\
\text { Alloy } 1100 \\
\text { (wt \%) }\end{array}$ & \begin{tabular}{|c|} 
Stainless \\
Steel Type \\
$304 \mathrm{~L}$ \\
$(w t \%)$ \\
\end{tabular} & $\begin{array}{c}\text { NiGd Alloy } \\
\text { (wt \%) }\end{array}$ \\
\hline$C$ & $0.28^{a}$ & 0.04 & - & 0.08 & - & 0.03 & 0.01 \\
\hline Mn & $\begin{array}{c}0.85-1.2 \\
1.045^{b}\end{array}$ & - & 0.15 & 2.00 & 0.05 & 2.00 & 0.5 \\
\hline $\mathrm{P}$ & 0.035 & - & - & 0.045 & - & 0.045 & 0.005 \\
\hline$S$ & 0.035 & - & - & 0.03 & - & 0.03 & 0.005 \\
\hline $\mathrm{Si}$ & $\begin{array}{c}0.13-0.45 \\
0.29^{\mathrm{b}}\end{array}$ & - & $\begin{array}{c}0.40-0.8 \\
0.60^{\mathrm{b}}\end{array}$ & 0.75 & $\begin{array}{c}0.95(\mathrm{Si}+\mathrm{Fe}) \\
0.45\end{array}$ & 0.75 & 0.08 \\
\hline $\mathrm{Cr}$ & - & 18.5 & $\begin{array}{c}0.04-0.35 \\
0.195^{\mathrm{b}}\end{array}$ & $\begin{array}{c}16.0-18.0 \\
17.00^{\mathrm{b}}\end{array}$ & - & $\begin{array}{c}18.0-20.0 \\
19.00^{\mathrm{b}}\end{array}$ & $\begin{array}{c}14.5-17.1 \\
15.8^{\mathrm{b}}\end{array}$ \\
\hline $\mathrm{Ni}$ & - & 13 & - & $\begin{array}{c}10.0-14.0 \\
12.00^{\mathrm{b}} \\
\end{array}$ & - & $\begin{array}{c}8.0-12.0 \\
10.00^{b}\end{array}$ & 64.035 \\
\hline Co & - & 0.2 & - & - & - & - & 2 \\
\hline Mo & - & 2.2 & - & $\begin{array}{c}2.00-3.00 \\
2.50^{\mathrm{b}} \\
\end{array}$ & - & - & $\begin{array}{c}13.1-16.0 \\
14.55^{\mathrm{b}} \\
\end{array}$ \\
\hline $\mathrm{N}$ & - & - & - & 0.1 & - & 0.10 & 0.01 \\
\hline $\mathrm{Fe}$ & 98.3 & 64.815 & 0.7 & 65.495 & $\begin{array}{c}0.95(\mathrm{Si}+\mathrm{Fe}) \\
0.50\end{array}$ & 68.045 & 1 \\
\hline$B$ & - & $\begin{array}{c}0.75-1.74^{c} \\
1.245^{b}\end{array}$ & - & - & - & - & - \\
\hline $\mathrm{Zn}$ & - & - & 0.25 & - & 0.10 & - & - \\
\hline $\mathrm{Cu}$ & - & - & $\begin{array}{c}0.15-0.40 \\
0.275^{\mathrm{b}}\end{array}$ & - & $0.05-0.20$ & - & - \\
\hline Mg & - & - & $\begin{array}{c}0.8-1.2 \\
1.0^{\mathrm{b}} \\
\end{array}$ & - & - & - & - \\
\hline $\mathrm{Ti}$ & - & - & 0.15 & - & - & - & - \\
\hline $\mathrm{Al}$ & - & - & 96.68 & - & 99.85 & - & - \\
\hline Gd & - & - & - & - & - & - & $\begin{array}{c}1.9-2.1 \\
2.0^{\mathrm{b}} \\
\end{array}$ \\
\hline 0 & - & - & - & - & - & - & 0.005 \\
\hline Total & 100.0 & 100.0 & 100.0 & 100.0 & 100.0 & 100.0 & 100.0 \\
\hline
\end{tabular}

Source: Table 4-1.

NOTE: $\quad{ }^{a}$ Value is for thicknesses between $1 / 2$ inch to 2 inches.

${ }^{\mathrm{b}}$ Represents the average of the range specified in source.

${ }^{\mathrm{C}}$ Ranges for types B3, B4, and B6.

Table 4-8 provides the densities and corrosion rates for the waste package metal alloys described in Table 4-7. 
Table 4-8. Steel and Alloy Densities and Corrosion Rates

\begin{tabular}{|c|c|c|c|c|c|c|c|}
\hline & $\begin{array}{c}\text { Carbon } \\
\text { Steel Type } \\
\text { A516 }\end{array}$ & Neutronit & $\begin{array}{c}\text { Aluminum } \\
\text { Alloy 6061 }\end{array}$ & $\begin{array}{c}\text { Stainless } \\
\text { Steel } \\
\text { Type 316 }\end{array}$ & $\begin{array}{c}\text { Aluminum } \\
\text { Alloy 1100 }\end{array}$ & $\begin{array}{c}\text { Stainless } \\
\text { Steel } \\
\text { Type 304L }\end{array}$ & NiGd Alloy \\
\hline Density (g/cm $\left.{ }^{3}\right)$ & 7.85 & 7.76 & 2.70 & 8.00 & 2.71 & 7.94 & 8.76 \\
\hline $\begin{array}{c}\text { Minimum } \\
\text { Corrosion Rate } \\
(\boldsymbol{\mu m} / \mathbf{y r})\end{array}$ & 3.69 & 0.001 & 0.4 & 0.0014 & 0.4 & 0.001 & $0.0528^{\mathrm{a}}$ \\
\hline $\begin{array}{c}\text { Maximum } \\
\text { Corrosion Rate } \\
(\boldsymbol{\mu m} / \mathbf{y r})\end{array}$ & 130.7 & 29.2 & 110.9 & 14.8 & 110.9 & 39.1 & $0.09-1^{\mathrm{b}}$ \\
\hline
\end{tabular}

Source: Table 4-1.

NOTE: ${ }^{a}$ Average Rate from DTN: MO0409SPAACRWP.000 [DIRS 172059].

${ }^{b}$ ASTM B 932-04. 2004 [DIRS 168403]. $1 \mu \mathrm{m} / \mathrm{yr}$ rate is appropriate for the first 10 years until the passive layer forms, after which the $0.09 \mu \mathrm{m} / \mathrm{yr}$ rate is appropriate.

The corrosion rates used in this model cover the ranges provided in DTN: MO0409SPAACRWP.000 [DIRS 172059] for temperatures from $25^{\circ} \mathrm{C}$ to $90^{\circ} \mathrm{C}$. The corrosion rates used are justified because they consider the full range intended to encompass the possible range of degradation rates for the materials that make up the waste package as documented by Probability Analysis of Corrosion Rates for Waste Package Materials (BSC 2004 [DIRS 169356]).

The base case reflects the use of Neutronit as a neutron absorber within the CSNF waste package. At a late point in the design process, a decision was made to replace the Neutronit with a NiGd alloy (BSC 2004 [DIRS 170710]). Section 6.6.7 contains a sensitivity analysis comparing the base-case CSNF (containing Neutronit) with the new design. This analysis demonstrates that, although the change in design results in a minor change in overall chemistry, the resulting $\mathrm{pH}$ and ionic strength of the solutions are still within the abstracted range provided to TSPA-LA by the base analysis.

\subsubsection{Atomic Weights}

Atomic weights of the elements and radionuclide isotopes used were taken from Atomic Mass Adjustment, Mass List for Analysis (Audi and Wapstra 1995 [DIRS 149625]) and Nuclides and Isotopes, Chart of the Nuclides (Parrington et al. 1996 [DIRS 103896], p. 50). These documents have been used as a source for this information throughout the Yucca Mountain Project and are appropriate as a source for atomic weights in this analysis. As explained in Section 6.3.1.3, the atomic weights of the elements are used to convert the weight percent of the elements in the metal alloys to moles of elements in the metal alloys that are used as input in the EQ6 files.

\subsubsection{Surface Complexation Inputs}

The surface complexation reactions presented in Table 4-9 are used to develop the pH-buffering effects in the surface complexation model in Section 6.3.2 and Section 6.7. 
Table 4-9. Surface Complexation Reactions

\begin{tabular}{|c|c|}
\hline Reaction & $\log K$ \\
\hline $\mathrm{HFO} \_\mathrm{sOH}+\mathrm{H}^{+}=\mathrm{HFO} \_\mathrm{sOH}_{2}{ }^{+}$ & $7.29^{\mathrm{a}}$ \\
\hline $\mathrm{HFO} \_\mathrm{wOH}+\mathrm{H}^{+}=\mathrm{HFO} \_\mathrm{wOH}_{2}{ }^{+}$ & $7.29^{a}$ \\
\hline $\mathrm{HFO} \_\mathrm{sOH}=\mathrm{HFO} \mathrm{sO}^{-}+\mathrm{H}^{+}$ & $-8.93^{b}$ \\
\hline $\mathrm{HFO} \_\mathrm{wOH}=\mathrm{HFO} \_\mathrm{wO}^{-}+\mathrm{H}^{+}$ & $-8.93^{b}$ \\
\hline $\mathrm{HFO} \_\mathrm{wOH}+\mathrm{CO}_{3}^{2-}+2 \mathrm{H}^{+}=\mathrm{HFO}{ }_{2} \mathrm{HCO}_{3}+\mathrm{H}_{2} \mathrm{O}$ & $20.37^{\mathrm{C}}$ \\
\hline $\mathrm{HFO} \_\mathrm{wOH}+\mathrm{CO}_{3}{ }^{2-}+\mathrm{H}^{+}=\mathrm{HFO}{ }_{-} \mathrm{wCO}_{3}{ }^{-}+\mathrm{H}_{2} \mathrm{O}$ & $12.78^{\mathrm{c}}$ \\
\hline
\end{tabular}

Sources: ${ }^{a}$ Dzombak and Morel 1990 [DIRS 105483], Table 5.7, Equation 5.2.

${ }^{b}$ Dzombak and Morel 1990 [DIRS 105483], Table 5.7, Equation 5.3.

c Appelo et al. 2002 [DIRS 168168], p. 3,097.

NOTE: HFO_s and HFO_w represent adsorption sites, strong (s) and weak (w), respectively.

Surface properties of iron corrosion products are presented in Table 4-10. The isoelectric point $\left(\mathrm{pH}_{\mathrm{IEP}}\right)$ is the $\mathrm{pH}$ at which the surface has a net neutral charge. It is also called the pristine point of zero charge (pHPZC) (Langmuir 1997 [DIRS 100051], p. 350).

Table 4-10. Properties of Major Iron Minerals

\begin{tabular}{|c|c|c|c|c|}
\hline Mineral & $\begin{array}{c}\text { Surface Area } \\
\left(\mathrm{m}^{2} / \mathrm{gm}\right)\end{array}$ & $\begin{array}{c}\text { Site Density } \\
\text { (sites/area or wt) }\end{array}$ & $\begin{array}{c}\text { Sites } \\
(\mathrm{mol} / \mathrm{mol} \mathrm{Fe})\end{array}$ & $\begin{array}{c}\text { Isoelectric Point } \\
\left(\mathrm{pH}_{\mathrm{IEP}}\right)\end{array}$ \\
\hline Goethite $(\mathrm{FeOOH})$ & 45 to 169 & $\begin{array}{l}2.6 \text { to } 18 \text { sites } / \mathrm{nm}^{2} \\
(1.35 \mathrm{mmol} / \mathrm{g})\end{array}$ & $\begin{array}{l}0.017-0.45^{\mathrm{e}} \\
0.12^{\mathrm{e}}\end{array}$ & $\begin{array}{l}5.9 \text { to } 6.7 \\
7.28^{\mathrm{a}, \mathrm{f}}\end{array}$ \\
\hline Hematite $\left(\mathrm{Fe}_{2} \mathrm{O}_{3}\right)$ & $\begin{array}{l}1.8 \text { (natural) } \\
3.1 \text { (synthetic) }\end{array}$ & $\begin{array}{l}5 \text { to } 22 \mathrm{sites} / \mathrm{nm}^{2} \\
(0.114-0.015 \mathrm{mmol} / \mathrm{g})\end{array}$ & $0.0024-0.018^{\mathrm{e}}$ & $\begin{array}{l}4.2 \text { to } 6.9 \\
8.67^{\mathrm{a}, \mathrm{f}}\end{array}$ \\
\hline $\begin{array}{l}\text { Ferrihydrite (poorly crystalline } \\
\text { hydrous ferric oxide, HFO) }\end{array}$ & $250,306,600$ & $\begin{array}{l}20 \text { sites } / \mathrm{nm}^{2} \\
(2.2 \mathrm{mmol} / \mathrm{g})^{d}\end{array}$ & $\begin{array}{l}0.1 \text { to } 0.9 \\
(0.2)^{\mathrm{c}, \mathrm{f}}\end{array}$ & $\begin{array}{l}8.5 \text { to } 8.8 \\
7.9 \text { to } 8.2^{b}\end{array}$ \\
\hline $\begin{array}{l}\text { Bulk composite geological } \\
\text { material }\end{array}$ & 600 & $\begin{array}{l}2.31 \mathrm{sites} / \mathrm{nm}^{2} \\
\left(3.84 \mathrm{E}-06 \mathrm{~mol} / \mathrm{m}^{2}=\right. \\
2.3 \mathrm{mmol} / \mathrm{g})\end{array}$ & not applicable & not applicable \\
\hline
\end{tabular}

Sources: Langmuir 1997 [DIRS 100051], pp. 345 and 351, Tables 10.2 and 10.3 (unless otherwise noted).

a Stumm (1992 [DIRS 141778], p. 54).

${ }^{\mathrm{b}}$ HFO (Dzombak and Morel 1990 [DIRS 105483], p. 95).

${ }^{c}$ Approximate median value chosen by Dzombak and Morel (1990 [DIRS 105483], p. 94).

NOTES: ${ }^{d}$ Calculated from 0.2 moles sites/mole Fe and a formula weight of $89 \mathrm{~g}$ ferrihydrite/mol Fe.

${ }^{e}$ Calculated using the formula given in Langmuir 1997 [DIRS 100051], p. 346: Sites (mol/mol Fe) = Site Density * Surface Area * $10^{18} \mathrm{~nm}^{2} / \mathrm{m}^{2 *} 89 \mathrm{~g}$ ferrihydrite/mol Fe/Avogado's number $(6.022 \mathrm{E} 23 \mathrm{sites} / \mathrm{mol}$ of sites).

${ }^{f}$ These numbers are presented for comparison purposes only and are not direct inputs to this report.

The surface complexation inputs are justified for use because they are representative of the best available data on surface complexation.

\subsection{CRITERIA}

Work described in this document will support the following criteria from Yucca Mountain Review Plan, Final Report (NRC 2003 [DIRS 163274]) as described in Technical Work Plan for: Regulatory Integration Modeling and Analysis of the Waste Form and Waste Package (BSC 2004 [DIRS 171583]). The full text of these criteria is quoted in Section 8.2 along with a 
detailed explanation of how this document addresses those criteria and the location where the appropriate information can be found.

- Quantity and Chemistry of Water Contacting Waste Packages and Waste Forms, Acceptance Criteria (NRC 2003 [DIRS 163274], Section 2.2.1.3.3)

- AC1-System Description and Model Integration are Adequate

- AC2-Data are Sufficient for Model Justification

- AC3-Data Uncertainty is Characterized and Propagated Through the Model Abstraction

- AC4-Model Uncertainty is Characterized and Propagated Through the Model Abstraction

- AC5-Model Abstraction Output is Supported by Objective Comparisons

\subsection{CODES, STANDARDS, AND REGULATIONS}

ASTM C 1174-97 [DIRS 105725], Standard Practice for Prediction of the Long-Term Behavior of Materials, Including Waste Forms, Used in Engineered Barrier Systems (EBS) for Geological Disposal of High-Level Radioactive Waste, is used to support the model development methodology, categorize the models developed with respect to their usage for long-term total system performance assessment, and relate the information or data used to develop the model to the requirements of the standard. 


\section{ASSUMPTIONS}

\subsection{BULK WATER CHEMISTRY}

Assumption: In the absence of a thin film model, it is assumed the bulk water chemistry calculated by this batch reactor model is applicable to thin films of water.

Rationale: For films thicker than 8 to 20 monolayers, the behavior is similar to bulk water (Sposito 1984 [DIRS 127253]).

1. The $\mathrm{OH}$ bond distance in a water molecule is $\sim 0.1 \mathrm{~nm}$; the length of a hydrogen bond between water molecules is $\sim 0.3 \mathrm{~nm}$ (Stumm and Morgan 1996 [DIRS 125332], p. 7).

2. The effect of a cation on the structure of bulk water is localized to a suite of no more than 6 to 20 water solvation molecules (p. 57). About 10 molecular layers of water on clay minerals exist at humidities of $98 \%$ (p. 61). The spatial extent of adsorbed water on a phyllosilicate surface is, conservatively, whatever is included in the region bounded by a plane about $1.0 \mathrm{~nm}$ from the basal plane of the clay mineral. The bounding plane at $1.0 \mathrm{~nm}$ is expected to include all but a few percent of the siloxane surface effects on water structure (pp. 69 to 70). A 1-nm layer of water is roughly 4 to 10 water molecules, depending on how they are arranged, so an 8- to 20-water molecule layer is, therefore, around $2 \mathrm{~nm}$. In addition, cation hydration is similar to hydration of surface complexation sites (p. 64). The above clay observations and the magnitude of cation hydration shell radii both suggest that 1 to $2 \mathrm{~nm}$ of surface associated water is not structurally different than bulk water (Sposito 1984 [DIRS 127253], pp. 57, 61, 64, 69, and 70).

Confirmation Status: This modeling assumption, when combined with the diffusion implementation of the EBS radionuclide transport model (BSC 2004 [DIRS 169868]) within TSPA-LA, is conservative in its estimation of radionuclide release and is, therefore, justified, and does not require confirmation.

Use in the Model: This assumption is used throughout Section 6 in the development of the conceptual model.

\subsection{CONSTANT CORROSION OF ALLOYS}

Assumption: In the absence of a surface area function within a geochemistry-modeling tool, the surface areas of the reactants are fixed and assumed not to vary with time.

Rationale: As a material degrades, its surface area will certainly change, but how it varies with time and degree of degradation is extremely complex. The constant surface area simplification can only result in faster degradation that is conservative with respect to the impact of the degradation on the solution chemistry. Also, the EQ6 code does not have the ability to implement a surface area function. 
Confirmation Status: The impact of this simplification is that reactants may not degrade as quickly as modeled, but this difference is accounted for by varying the range of degradation rates used and is, therefore, justified and requires no further confirmation.

Use in the Model: This assumption is used in Sections 6.3.

\subsection{THERMODYNAMIC EQUILIBRIUM}

Assumption: In the absence of data on the long-term behavior of man-made materials in the waste package for the 10,000-year regulatory period, it is assumed that all homogeneous solution and gas reactions and all heterogeneous gas-solution reactions are reversible and at equilibrium. Heterogeneous reactions between solutions and precipitating solids are also assumed to be at equilibrium except for those by which waste and waste-package components degrade and dissolve in the in-package fluids. These reactions are irreversible and described by various expressions for reaction kinetics. These assumptions are implicit in the EQ3/EQ6 reaction and reaction path codes used to model the evolution of the in-package chemistry.

Rationale: The justification for equilibrium between solution and precipitating solids is because solids that might require longer times to reach equilibrium than are considered in the modeling, are explicitly excluded from consideration as described in Section 6.3.1.1. In this model, kinetic factors do not control the reactions, even though it is unlikely that all reactions will actually reach equilibrium, even over the 10,000-year regulatory period.

Confirmation Status: This assumption is justified because it is conservative in several ways (generates a lower $\mathrm{pH}$ due to the oxidation of the sulfur and generates a high ionic strength due to the oxidation of chromium). This assumption does not lead to nonconservatisms (such as moderate $\mathrm{pH}$ values that would lead to lower solubilities or moderate ionic strengths $(>0.05)$ that would destabilize colloids (BSC 2003 [DIRS 166845]). The impact of kinetic control for several species is examined in sensitivity studies in Section 6.6 and is shown to result in chemistries within the predicted ranges provided to TSPA-LA; therefore, no further confirmation is required.

Use in the Model: This assumption is used in Sections 6.3. 


\section{MODEL DISCUSSION}

\subsection{OBJECTIVES}

The objective of the in-package chemistry model is to predict the bulk water chemistry that could exist inside a breached waste package. This chemistry is simplified in the form of abstractions for $\mathrm{pH}\left(\mathrm{pH}=-\log \left[\mathrm{H}^{+}\right]\right)$, ionic strength, Eh (redox potential), total carbonate (i.e., sum of aqueous carbonate species), chloride, and fluoride concentration. Ionic strength is defined as a measure of interionic effect resulting primarily from electrical attraction and repulsions between the various ions; $I=1 / 2 \sum_{\mathrm{i}} \mathrm{c}_{\mathrm{i}} \mathrm{Z}_{\mathrm{i}}^{2}$, where $\mathrm{c}_{\mathrm{i}}$ is the ion concentration, and $\mathrm{Z}_{\mathrm{i}}$ is the ion charge. The summation is carried out for all cations and anions in solution (Stumm and Morgan 1996 [DIRS 125332], p. 101).

The $\mathrm{pH}$, ionic strength, and total carbonate abstractions are used by TSPA-LA in conjunction with the other models to determine the stability of colloids, the solubility of radionuclides, and the degradation rates of the waste forms. The fluoride abstraction is not directly used by TSPA-LA, but is used by Dissolved Concentration Limits of Radioactive Elements (BSC 2004 [DIRS 169425]) to ensure that the predicted solubilities are valid over the range of fluoride concentrations possible in the waste package.

\subsection{FEATURES, EVENTS, AND PROCESSES}

Table 6-1 provides a list of "included" FEPs determined to be related to the in-package chemistry model (MO0407SEPFEPLA.000 [DIRS 170760]). The table also indicates where within this report the indicated FEP is addressed. The discussion of these FEPs, in the indicated sections, provides a summary of how the respective FEP is treated within TSPA-LA.

Table 6-1. Included FEPs for the In-Package Chemistry Model Report

\begin{tabular}{|l|l|l|}
\hline FEP Number & \multicolumn{1}{|c|}{ FEP Name } & \multicolumn{1}{|c|}{ Addressed In } \\
\hline 2.1.01.02.0B & Interactions between co-disposed waste & Sections 6.5.1.2, 6.5.3, 6.6.13, 6.10.9 \\
\hline 2.1.02.09.0A & Chemical effects of void space in waste package & Sections 6.5.3, 6.6.1, 6.6.4,6.10.9 \\
\hline 2.1.09.01.0B & Chemical characteristics of water in waste package & Sections 6.5.3, 6.7.1, 6.10.9 \\
\hline $2.1 .09 .06 .0 \mathrm{~A}$ & Reduction-oxidation potential in waste package & Sections 6.5.2.1.3, 6.5.3, 6.6.4, 6.10.9 \\
\hline 2.1.09.07.0A & Reaction kinetics in waste package & $\begin{array}{l}\text { Sections 6.5.2.1, 6.5.2.2, 6.5.3, 6.6.3, } \\
6.6 .4,6.6 .10,6.10 .9\end{array}$ \\
\hline 2.1.09.02.0A & Chemical interaction with corrosion products & $\begin{array}{l}\text { Sections 6.3.2, 6.5.1.2, 6.5.2.1, 6.5.3, } \\
6.7 .1,6.10 .9\end{array}$ \\
\hline 2.1.11.08.0A & $\begin{array}{l}\text { Thermal effects on chemistry and microbial activity in } \\
\text { the EBS }\end{array}$ & $\begin{array}{l}\text { Sections 6.5.2.1, 6.5.2.2, 6.5.3, 6.6.6, } \\
6.7 .3,6.10 .9\end{array}$ \\
\hline 2.2.08.12.0B & Chemistry of water flowing into the waste package & $\begin{array}{l}\text { Sections 6.5.2.1, 6.5.2.2, 6.5.3, 6.6.2, } \\
6.10 .9\end{array}$ \\
\hline
\end{tabular}

\subsection{BASE-CASE CONCEPTUAL MODEL}

The base-case conceptual model is a combination of a batch reactor model with a surface complexation model. The batch reactor portion of the model combines water, oxygen, carbon dioxide, waste forms, and metal alloys. The system is in equilibrium with atmospheric conditions, and the reactants degrade in the presence of water according to a rate determined by 
the physical properties and the exposed surface area of each reactant. For each reactant, a mass per time rate is selected based on experimental measurements, and the surface area available to react is calculated based on the dimensions of the waste package internals. During reaction progress, metal (hydr)oxide corrosion products and secondary mineral phases precipitate from solution, waste forms, and metal alloys are consumed, and water changes in its initial composition and mass due to these reactions. The corrosion products are generally less dense than the starting metals and waste forms, so as the reactions progress, the volume of the system increases. The surface complexation portion of the model examines the effects of the contact of the solution with corrosion product surfaces. An overall model limitation is that these two portions of the model are implemented in series by applying the surface complexation effects to the output of the batch reactor model; when in fact, surface complexation occurs as the reactants are degrading. However, the impact of this simplification is considered in the uncertainty of the output abstractions and is discussed in Section 6.9.

The base case is divided into two water cases: (1) water enters the waste package as a vapor and condenses, and (2) water enters the waste package as a liquid.

1. Vapor Influx Case: The condensation of vapor onto the waste package internals is simulated as pure $\mathrm{H}_{2} \mathrm{O}$ and enters at a rate determined by the water vapor pressure for representative temperature and relative humidity conditions.

2. Water Influx Case: The water entering a waste package from the drift is simulated as typical groundwater and enters at a rate determined by the amount of seepage available to flow through openings in a breached waste package.

TSPA-LA uses the vapor influx case for simulations where the waste package has been breached and the drip shield remains intact, so all seepage flow is diverted from the waste package. The chemistry from the vapor influx case is used to determine the stability of colloids and the solubility of radionuclides available for transport by diffusion, and to determine the degradation rates for the waste forms. TSPA-LA uses the water influx case when simulating a seismic event in which the waste package has been breached and the drip shield has been damaged such that seepage flow is actually directed into the waste package. The chemistry from the water influx case, which is a function of the flow rate, is used to determine the stability of colloids, the solubility of radionuclides available for transport by diffusion and advection, and degradation rates for the waste forms.

The chemical processes considered in the model include:

- Reaction-path tracing of the in-package chemical system

- Conservation of mass

- Kinetic dissolution of the waste package components and spent nuclear fuel (N Reactor fuel) using linear rate laws

- Kinetic dissolution of waste forms (CSNF and HLWG) using transition-state theory rate laws (i.e., nonlinear rate laws which are dependant on the fluid chemistry)

- Equilibrium precipitation and dissolution of metal corrosion products and complex mineral phases 
- Thermal (i.e., temperature) effects on fluid chemistry

- Equilibrium oxidation and reduction reactions

- Chemical interaction of input solution with codisposed waste (DSNF with HLWG)

- Effect of variable input water compositions on the resulting fluid composition

- Chemical effects of void space (proximity of waste package components with atmospheric conditions)

- Influence of surface complexation on the fluid $\mathrm{pH}$.

The physical processes considered in the model include:

- Water ingress and egress (egress for the water influx only) through the waste package

- Mixing of water in contact with waste package components.

\subsubsection{Batch Reactor Model}

\subsubsection{Batch Reactor Modeling Concepts and Assumptions}

Thermodynamic Equilibrium-A thermodynamic chemical equilibrium approach is used for the aqueous species in this report. The main justification for the use of the thermodynamic chemical equilibrium approach is the extended period of concern mandated by the regulations. Although the use of kinetic factors would be appropriate, such an approach cannot be used with the limited available data. The effects of kinetically controlled reactions would be a moreneutral $\mathrm{pH}$ and lower ionic strengths. The $\mathrm{pH}$ and ionic strength ranges projected by the thermodynamic equilibrium approach is wide enough to encompass the $\mathrm{pH}$ and ionic strength ranges that would be projected by a kinetic approach, as shown in the sensitivity analyses in Section 6.6.3. The uncertainty ranges for the ionic strength model passed to TSPA-LA favor lower ionic strengths that account for the effect of the surface complexation model on ionic strength, as well as the effect of kinetics.

A good example of the thermodynamic-versus-kinetic approach is the treatment of sulfur. The complete oxidation of sulfur to $\mathrm{SO}_{4}{ }^{2-}$ is a conservative way to examine the effects of corrosion on $\mathrm{pH}$. At thermodynamic equilibrium, the $\mathrm{S}, \mathrm{N}$, and $\mathrm{P}$ in the steels will be oxidized to the acid anions $\mathrm{SO}_{4}{ }^{2-}, \mathrm{NO}_{3}{ }^{-}$and $\mathrm{PO}_{4}{ }^{3-}$. Even if there are kinetic barriers to the completion of these oxidation reactions, it is conservative to model their equilibria. To balance this treatment, the surface complexation model adds more realism to the model by buffering $\mathrm{pH}$ (Section 6.3.2). Likewise, allowing $\mathrm{Cr}$ to oxidize to $\mathrm{Cr}(\mathrm{VI})$ is extremely conservative and leads to very high ionic strengths. To balance this treatment, a sensitivity analysis in Section 6.6.3 compares the effect of using $\mathrm{Cr}(\mathrm{III})$ rather than $\mathrm{Cr}(\mathrm{VI})$. The results are significant and are discussed in more detail in Section 6.6.3. Other examples include N, C, and B, but the amount of these elements in the composition of the waste package components is not significant enough to warrant a sensitivity analysis.

$\mathrm{CO}_{2}$ and $\mathrm{O}_{2}$ Partial Pressure-Oxygen and carbon dioxide maintain equilibrium with the waste package solution and the ambient atmosphere outside of the waste package. The partial pressure of $\mathrm{CO}_{2}$ and $\mathrm{O}_{2}$ of the ambient repository atmosphere are set to $10^{-3.0}$ and $0.2 \mathrm{~atm}$, respectively $\left(\log f \mathrm{CO}_{2}=-3\right.$ and $\left.\log \mathrm{fO}_{2}=-0.7\right)$. The oxygen partial pressure is set to equal atmospheric 
pressure (Weast 1977 [DIRS 106266], p. F-210). The carbon dioxide pressure is set higher than the atmospheric value because ambient fluids drawn from boreholes near the repository horizon appear to be in equilibrium with above-atmospheric carbon dioxide levels (Yang et al. 1996 [DIRS 100194], Table 8). Sensitivity analyses of the model response to the $\mathrm{CO}_{2}$ and $\mathrm{O}_{2}$ partial pressure are discussed in Section 6.6.4. Nitrogen and minor and trace gases in the atmosphere were not included in the model as gasses because they are either inert or of such low concentration to be of no consequence on the model results.

Evaporation-For the water influx case, the effects of evaporation inside of the waste package are not modeled because they will have a negligible influence on the in-package chemistry. There will be a period immediately after waste package breach (when water first enters and the relative humidity increases) where evaporation inside a waste package will be high, but this phenomenon was not included in the in-package chemistry model. At high flux values, the effect of early-time evaporative processes is likely to have a negligible impact on the model results because the humidity inside of the breached waste package would increase quickly and the high water flux would diminish any evaporative effects on the fluid composition. At low water flux values, the opposite would be true. Humidity would increase slowly, and low water flux would have less of a dilution effect. However, the uncertainty associated with evaporation is captured in the broad uncertainty applied to the model results.

For the vapor influx case, the consumption of water by corrosion reactions combined with the effects of evaporation will lower the relative humidity and, thus, increase the driving force for diffusion of vapor through the openings in a breached waste package.

Well-Mixed Batch Reactor-The reactants in the batch reactor are well mixed. Because the waste package components are evenly distributed and in close proximity to one another inside of the waste package, and an important aspect of the model is to investigate the effects of the interactions of the various components, the well-mixed concept is justified. In addition, the waste package will be cooling slowly over time, so the temperature gradients within the waste package will contribute to convective flow that will further mix the contents of the waste package. Localized effects (small areas with reducing conditions and more extreme $\mathrm{pH}$ values and ionic strengths) will occur, but these will be transient and not significant enough to alter model results.

Approximately half of the waste package (CSNF or CDSP) volume is taken up with the waste form and structural components and the rest of the waste package is empty. This empty space is referred to as the void space and can fill with water. The waste package is tightly packed (there are no large gaps of space), but individual components are relatively thin sheets of metal or small pellets of fuel packed tightly together, so available space for water is spread throughout the waste package. This spatial configuration is further justification for a well-mixed model.

Scaling to One Liter-The waste package is represented in the EQ6 input file as amounts, compositions, and surface areas of the major materials, such as carbon and stainless steel, aluminum or other alloys, and different fuel types. Each material is also assigned a reaction rate that EQ6 combines with the surface area to determine the actual rate at which the material degrades. The water flux rate is calculated to provide a representative quantity of water to interact with the waste package components at a rate corresponding to the rate at which seepage 
water could enter a waste package, or the rate at which vapor could enter a waste package and condense.

EQ6 works on a per liter basis; therefore, all of the reactants and the water flow rate are scaled accordingly. To maintain the proper ratio of each of the materials to each other, the reactants are scaled based on the total surface area of all of the waste package materials. The ratio of the waste package components to the amount of water that they come in contact with is treated as a variable in this model. For one case, the ratio is such that the materials of the waste package are in contact with a volume of water equal to that of the void space. This case is referred to as the "bathtub" model and has the highest ratio of water to waste package materials. Other ratios are examined in which less water is considered. By lowering the ratio of water to reactants, more reactants are available to react that approximates the effects of capillary forces distributing the water to the tight spaces in the waste package, even if the waste package is not completely filled. The base case uses a ratio of water to reactants that is half of the "bathtub" model to examine a lower ratio. The impact of varying this ratio is examined in a sensitivity analysis in Section 6.6.1.

As the ratio of water to reactants is decreased, the ionic strength of the solution increases. As described in the B-dot discussion below, this model is appropriate for use up to about 4 molal. The lowest ratio of water to reactants used in this model approaches this limit, so that a lower ratio could not be examined without exceeding the 4 molal limit. Because ionic strength is an output of this model and this high ionic strength boundary condition effects radionuclide solubility, this 4 molal boundary condition is discussed in greater detail below. The base case uses a ratio of water to reactants that is half of the "bathtub" model to examine a lowest possible ratio.

The highest ionic strengths predicted by the in-package chemistry models are 3 to 4 molal. This upper limit captures the maximum concentrations that would be expected in the aqueous solution because as ionic strength gets above about 1 molal, a "salting out" effect starts to occur, in which cations get less soluble as the ionic strength increases. As an explanation, reactions that control solubility are written in terms of activity, where activity $(a)$ is the molal concentration of the species $(m)$ times the activity coefficient $(\gamma), a=m \times \gamma$ (Langmuir 1997 [DIRS 100051], Equation 4.1). Figure 4.2 of Langmuir (1997 [DIRS 100051]) shows that for cations, as the ionic strength increases above about 1 to 2 molal, the activity coefficient increases. For a set activity value, when the activity coefficient increases, the concentration of dissolved cations decreases.

Dissolved Concentration Limits of Radioactive Elements (BSC 2004 [DIRS 169425]) also notes that at high ionic strengths activity coefficients calculated using the algorithm in EQ3/6 v. 7.2b diverge from those calculated from experimental data. In that report the influence of this divergence on solubilities is not expressed by decreasing the solubilities to reflect the salting out effect because the species dominating the solubilities in some cases are anions, which do not exhibit the salting out effect. Instead, the uncertainties of solubilities modeled at ionic strengths above 1 molal are increased by an amount corresponding to the maximum divergence in the ionic strengths.

The surface area of the CSNF and N Reactor are treated as the geometric surface area because the rates reported in Section 4.1.3 are given in terms of geometric surface area. A sensitivity study in Section 6.6.10 examines the use of specific surface area for the CSNF. Similarly, the 
measured rates of the steels are based on a geometric surface area. The surface area of the highlevel waste glass (HLWG) is the geometric surface area multiplied by the exposure factor (BSC 2004 [DIRS 169988]).

Waste Package Materials not Included in the EQ6 Input File-The waste package outer barrier is constructed of Alloy 22, and the fuel cladding is made of Zircaloy, both of which degrade very slowly compared to the other materials in the waste package. These two materials are not included in the EQ6 input file because they would react so slowly that the effect on the results would be negligible. The corrosion rate for Zircaloy is very low (BSC 2004 [DIRS 169356], Section 6.3.5) and the probability of Alloy 22 corroding quickly is low as shown in Figure 51 of General Corrosion and Localized Corrosion of Waste Package Outer Barrier (CRWMS M\&O 2000 [DIRS 144229], p. 109).

In the EQ6 input file, only the inside surface area of the Stainless Steel Type 316 inner vessel is modeled because only the inside of the vessel is in contact with the solution. The gap between the inner vessel and the outer barrier is very small and, even if water did manage to enter this gap, it would be a very small quantity and would not contact the solution inside the inner vessel. Only the outside surface area of the glass pour canisters was used because they are filled with glass, so the majority of the surface area exposed to water will be the outside of the canister.

Codisposal Waste Packages - The N Reactor spent nuclear fuel was chosen to represent all DOE spent nuclear fuel because it accounts for about $85 \%$ of the total metric tons of heavy metal of DOE spent nuclear fuel (DOE 2002 [DIRS 158405]). This selection was deemed appropriate by a sensitivity in Section 6.6.13 that examines the behavior of a waste package containing five HLWG canisters and one DOE canister containing one assembly of Three Mile Island (TMI) SNF (waste package type: 5-DHLW long), and the results are very similar.

Corrosion-Long-term corrosion of the internal waste package components may proceed in a nonlinear fashion, where corrosion of fresh surfaces would be rapid and then decrease as corrosion product buildup limits corrosion by impeding oxygen and water diffusion. At some future time, if a mechanism to expose fresh metal surfaces were in action, such as a "sloughing off" mechanism, corrosion could again proceed unimpeded until a new layer of corrosion products formed. Under static conditions, with only gravity acting, the frequency of "sloughing off" could be envisioned to be partially a function of the orientation of a particular component (i.e., angle to vertical and the mass of corrosion product present on a surface). In a dynamic system, an outside force, such as a seismic event, acting on the waste package could also expose fresh metal surfaces. In essence, this speculative model combines two random events together, sloughing off under gravity and sloughing off under a randomly occurring outside force; the timing of neither is predictable. It is a conservatism that the surface is continually reacting until all of the steels are fully corroded (Section 5.2). However, the range of corrosion rates examined account for this slowing down of corrosion.

The corrosion rates considered for this report are aqueous corrosion rates. Atmospheric rates can be higher or lower than aqueous rates (DTNs: MO0312SPAPCEML.003 [DIRS 167409] and MO0409SPAACRWP.000 [DIRS 172059]). The use of aqueous rates for this model is justified because the intent of this model is to examine the chemistry generated by water interacting inside a waste package. Additionally, sensitivity studies were performed (Section 6.6.10) to examine the effect of increasing and decreasing the corrosion rates. 
Code Implementation-The EQ6 code simulates a titration in which reactants are added to the system according to their kinetic rate and surface area exposed. For the vapor influx case, the water is simply entered as one of the reactants with a rate corresponding to the maximum diffusion rate of vapor through openings in a breached waste package. For the water influx case, the water is entered as a "displacer" reactant type that takes advantage of the solid center flow through capability of EQ6, at a rate corresponding to seepage water entering a waste package.

The physical system modeled in the batch reactor model differs slightly from the implementation in TSPA-LA. For the vapor influx case, the rate at which the water enters is greater than the rate at which the water is consumed in corrosion reactions, so water accumulates in the system. TSPA-LA applies the chemistry of the vapor influx case to a continuous water film that coats the waste package internals and transports radionuclides and colloids by diffusion across that film, so no water is accumulated. This discrepancy is studied in a sensitivity analysis that looks at the effects of accumulating water in the system in Section 6.6.1.

Once the waste package breaches, the quantity of water required by the EQ6 model (1 liter) is instantly present. In actuality, after the waste package breaches, water would enter the waste package and take a certain amount of time to accumulate. This amount of time for accumulation is difficult to quantify, and would only result in a delay in radionuclide transport, so for the purposes of this model, the water is instantly available. The impact of this modeling simplification is explored in a sensitivity analysis in Section 6.6.1 and discussed in Section 6.10.2.

Applicability of the B-dot Equation-The B-dot equation is defined and carefully examined in Dissolved Concentration Limits of Radioactive Elements (BSC 2004 [DIRS 169425], Section 6.3.3). For the purposes of the in-package chemistry model, EQ3/6 results generated using the B-dot activity coefficient equation for solutions with ionic strength greater than 1 molal and up to 4 molal are sufficiently accurate for the intent of this calculation (mainly to estimate $\mathrm{pH}$ ). Experimental data (in sulfate, nitrate, and chloride solutions) show that EQ3/6 results using the B-dot activity coefficient equation can be used qualitatively up to an ionic strength of about 4 molal to indicate the general nature of the reactions that would actually occur (CRWMS M\&O 1997 [DIRS 100222], Appendix D). Dissolved Concentration Limits of Radioactive Elements (BSC 2004 [DIRS 169425]) adds an uncertainty term to the solubilities if the ionic strength of the solution is between 1 and 3 molal, and does not provide solubilities if the ionic strength is greater than 3 molal, because of the applicability of the B-dot equation. The in-package chemistry model extends the range of applicability of the B-dot equation because the purpose of this model is to predict bulk chemistry properties such as $\mathrm{pH}$ and ionic strength, as opposed to Dissolved Concentration Limits of Radioactive Elements (BSC 2004 [DIRS 169425]), which predicts more precise solubility values.

\subsubsection{Batch Reactor Base Case Runs}

For the vapor influx case, several runs include just a single reactant and some examine specific components together, in addition to the complete runs that contain all of the components. These runs examine the chemistry and the contribution of each of the reactants and reactant combinations to the in-package chemistry. A significant source of uncertainty in the vapor influx case is that water may react with any one of a number of combinations of reactants. When selecting which components to examine, the spatial proximity of a waste package component to 
the waste forms or HLWG and reactant reactivity or surface area were considered. For example, Carbon Steel Type A516 is highly reactive (high corrosion rate), has a high surface area in CSNF packages, and is in close proximity to the waste. For these reasons, Carbon Steel Type A516 appears in nearly every combination run. In addition, the impact on $\mathrm{pH}$ of the reactants was considered; for example, comp8 contains Aluminum Alloy 1100 and HLWG and, although these components are not necessarily in close proximity to each other, Aluminum Alloy 1100 and HLWG raise $\mathrm{pH}$ values as they degrade. Therefore, this case examines the combined effect of $\mathrm{pH}$-raising reactants degrading together.

Table 6-2 and Table 6-3 summarize the vapor influx cases and the EQ6 input file (*.6i) name conventions, where CS stands for CSNF and CD stands for CDSP. For example, CS_comp7.6i is a CSNF waste package case and has Aluminum Alloy 6061 and Carbon Steel Type A516 as reactants.

Table 6-2. CSNF Vapor Influx Multicomponent Ensembles

\begin{tabular}{|c|c|c|c|c|c|c|c|c|c|c|c|}
\hline $\begin{array}{l}\text { CSNF Waste Package } \\
\text { Component / EQ6 File }\end{array}$ & $\begin{array}{l}\bar{o} \\
\bar{g} \\
0 \\
\mathcal{O}^{\prime} \\
\mathcal{J}^{\prime}\end{array}$ & 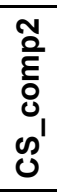 & 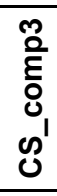 & 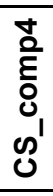 & 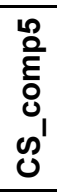 & $\begin{array}{l}0 \\
\stackrel{0}{E} \\
\text { है } \\
\mathcal{U}_{1} \\
\mathcal{U}^{\prime}\end{array}$ & 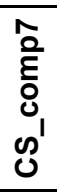 & $\begin{array}{l}\infty \\
\stackrel{\infty}{z} \\
\delta \\
0 \\
0 \\
0 \\
0\end{array}$ & 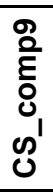 & $\begin{array}{l}\text { 웅 } \\
\text { हे } \\
0 \\
0 \\
\text { y }\end{array}$ & $\begin{array}{l}\bar{\sigma} \\
\bar{o} \\
\bar{g} \\
0 \\
\mathcal{O} \\
\mathcal{U}\end{array}$ \\
\hline $\begin{array}{l}\text { Stainless Steel Type } 316 \\
\text { Inner Vessel }\end{array}$ & $x$ & & & & & $x$ & & & $x$ & $x$ & \\
\hline Neutronit / NiGd Alloy* & $\mathrm{x}$ & $\mathrm{x}$ & & & $\mathrm{x}$ & $\mathrm{x}$ & & $\mathrm{x}$ & & & \\
\hline Aluminum Alloy 6061 & $\mathrm{x}$ & $\mathrm{x}$ & $\mathrm{x}$ & & $\mathrm{x}$ & $\mathrm{x}$ & $\mathrm{x}$ & & & & $\mathrm{X}$ \\
\hline Carbon Steel Type A516 & $\mathrm{x}$ & $x$ & $x$ & $\mathrm{x}$ & $\mathrm{x}$ & $\mathrm{x}$ & $\mathrm{x}$ & $\mathrm{x}$ & $\mathrm{x}$ & $\mathrm{x}$ & $\mathrm{X}$ \\
\hline CSNF & $x$ & $x$ & $x$ & $x$ & & & & & & $x$ & $x$ \\
\hline
\end{tabular}

NOTE: A recent design has replaced the Neutronit with a NiGd alloy. This change is examined in a sensitivity analysis in Section 6.6.7. The results of this analysis show the change has minimal impact, so the vapor influx cases that were run using Neutronit were not rerun using the NiGd alloy.

Table 6-3. CDSP Vapor Influx Multicomponent Ensembles

\begin{tabular}{|c|c|c|c|c|c|c|c|c|}
\hline $\begin{array}{l}\text { CDSP Waste Package Component / } \\
\text { EQ6 File }\end{array}$ & 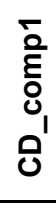 & 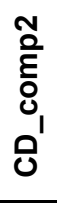 & 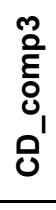 & 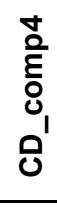 & 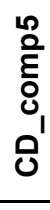 & 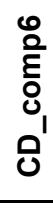 & 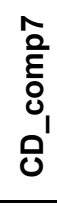 & $\begin{array}{l}\infty \\
\text { है } \\
\text { ¿े } \\
0\end{array}$ \\
\hline Stainless Steel Type 316 Inner Vessel & $x$ & & & & & & & \\
\hline Aluminum Alloy 1100 & $\mathrm{x}$ & $x$ & & $x$ & & & & $x$ \\
\hline Stainless Steel Type 304L MCO & $x$ & $x$ & $x$ & $x$ & & & & \\
\hline Stainless Steel Type 304L MCO Top & $\mathrm{x}$ & $x$ & $x$ & $x$ & & & & \\
\hline Stainless Steel Type 304L GPC & $x$ & $x$ & $x$ & $x$ & $x$ & $x$ & & \\
\hline Carbon Steel Type A516 Plates & $x$ & $x$ & $x$ & $x$ & $x$ & & $x$ & \\
\hline U-Metal & $\mathrm{x}$ & $x$ & $x$ & & & & & \\
\hline HLWG & $x$ & $x$ & $x$ & $x$ & $x$ & $x$ & $x$ & $x$ \\
\hline
\end{tabular}

NOTE: MCO = Multicanister overpack; GPC = glass-pour canister . 
For the water influx case, a series of model runs was conducted in which four key inputs were varied across their expected input range to generate a broad range of model response. The key parameters include water flux, fuel exposure (clad failure), initial water composition, and temperature. The water flux and fuel exposure (for CSNF cases) input parameters are also input variables in the total system performance assessment to the in-package chemistry model. The temperature was varied to increase the range of applicability of the in-package chemistry model. The input water composition was varied to determine if the in-package chemistry model response is sensitive to water flowing into the engineered barrier system.

Other model inputs were varied in sensitivity analyses (Sections 6.6) to expand the applicability of the model abstraction for TSPA-LA implementation and to quantify model uncertainty.

The matrix of the base-case EQ6 runs and input file naming convention is given in Table 6-4. The sensitivity studies were run in separate directories named for the parameter for which the sensitivity analysis was conducted.

Table 6-4. EQ6 Input Guide for the Water Influx Model Runs

\begin{tabular}{|c|c|c|c|c|c|c|c|c|c|}
\hline \multicolumn{2}{|c|}{$\begin{array}{c}\text { Waste Package } \\
\text { Type }\end{array}$} & \multicolumn{2}{|c|}{ Flux (L/yr) } & \multicolumn{2}{|c|}{ Cladding Failure } & \multicolumn{2}{|c|}{ Water Type } & \multicolumn{2}{|c|}{ Temperature $\left({ }^{\circ} \mathrm{C}\right)$} \\
\hline & & 1 & 0.15 & 1 & $1 \%$ & C & Ca-Porewater & 25 & 25 \\
\hline & & 2 & 1.5 & 2 & $10 \%$ & $\mathrm{~N}$ & Na-Porewater & 50 & 50 \\
\hline C & CSNF & 3 & 15 & 3 & $100 \%$ & $\mathrm{~J}$ & $\begin{array}{l}\text { J-13 Well } \\
\text { Water }\end{array}$ & 90 & 90 \\
\hline & & 1 & 0.15 & \multirow{2}{*}{\multicolumn{2}{|c|}{$N / A^{a}$}} & C & Ca-Porewater & 25 & 25 \\
\hline & & 2 & 1.5 & & & $\mathrm{~N}$ & Na-Porewater & 50 & 50 \\
\hline $\mathrm{D}$ & CDSP & 3 & 15 & 3 & $100 \%$ & $\mathrm{~J}$ & $\begin{array}{l}\text { J-13 Well } \\
\text { Water }\end{array}$ & 90 & 90 \\
\hline
\end{tabular}

NOTE: For the base case, for each waste package type, the three flux cases were each run with the three different types of waters at $25^{\circ} \mathrm{C}$ and $50^{\circ} \mathrm{C}$. Sensitivity studies were performed at $90^{\circ} \mathrm{C}$ for a representative case for each waste package type (Section 6.6.6).

a For $\mathrm{N}$ Reactor, the fuel is always $100 \%$ exposed, due to the condition of the cladding.

For example, for EQ6 input file, C22C25.6i corresponds to the following run:

$$
\begin{aligned}
& \mathrm{C}=\mathrm{CSNF} \\
& 2=1.5 \mathrm{~L} / \mathrm{yr} \\
& 2=10 \% \text { clad failure } \\
& \mathrm{C}=\mathrm{Ca} \text { porewater } \\
& 25=25^{\circ} \mathrm{C} \\
& .6 \mathrm{i}=\mathrm{EQ} 6 \text { input file extension. }
\end{aligned}
$$

\subsubsection{Batch Reactor Model Inputs}

All of the inputs to the EQ3/6 input files are in terms of moles, centimeters, and seconds. The amounts and compositions of reactants are all converted to moles, the surface areas are converted to $\mathrm{cm}^{2}$, and the degradation and flow rates are all converted to moles per second. During the checking process, some minor inconsistencies were identified in the input files, and these inconsistencies are documented in Table A-2. 


\subsection{Water Compositions and Rates}

The water compositions listed in Table 4-2 and Table 4-3 were used as input into EQ3NR. The output from EQ3NR, the "pickup" (*.3p) file, is used as an integral part of each EQ6 input file. EQ3NR recasts the reported concentrations from Table 4-2 into molal units that are the working units of EQ6.

For the J-13 well water composition, the measured $\mathrm{pH}$ of 7.41 from Table 4-2 was changed to 7.0 based on work reported by Harrar et al. (1990 ([DIRS 100814], p. 4-9) that contains measured values of $\mathrm{pH}: 6.9$ to 7.1. The $\mathrm{HCO}_{3}{ }^{-}$was used to charge balance the solution in the EQ3 input file.

Table 6-5 provides the EQ3NR output molal concentrations of the elements used in the EQ6 input files. For code stability, each of the elements contained in the composition of any of the reactants must also be modeled as present in the fluid composition; therefore, certain elements are present in concentrations of $1.00 \mathrm{E}-16$ molal. The $\mathrm{pH}$ of the $\mathrm{J}-13$ well water is set at approximately the mean field measurement of 7 (Harrar et al. 1990 [DIRS 100814], p. 4-9). Many of the $\mathrm{pH}$ values included in that report are lab measurements typically higher than field measurements, likely due to loss of dissolved $\mathrm{CO}_{2}$ (Harrar et al. 1990 [DIRS 100814], p. 4-9).

The diffusion flux of water vapor into a breached waste package used for the base case in this model report was 44 moles per year per waste package (corresponds to $\sim 0.8$ liters). The diffusion flux of water vapor into a waste package was calculated (BSC 2004 [DIRS 169868], Table 6.5-14) for ingress of water vapor through stress corrosion cracks ranged from 22 to 239 moles per year per waste package. Sensitivity studies were performed (Section 6.6.5) to assess the impact of considering the full range of potential vapor diffusion rates.

The seepage rates into a breached waste package used for the base case in this report are 0.15 , 1.5 , and $15 \mathrm{~L} / \mathrm{yr}$. These rates are based on the total potential seepage presented in Table 4-4, but only a fraction of the rates from Table 4-4 will actually enter a breached waste package, a fraction that is varied inside the TSPA-LA. A sensitivity analysis (Section 6.6.5) assesses the impact of considering a wide range of potential seepage rates up to $1,000 \mathrm{~L} / \mathrm{yr}$. 
Table 6-5. EQ6 Input Fluid Compositions

\begin{tabular}{|c|c|c|c|c|c|c|c|}
\hline $\begin{array}{c}\text { Constituent } \\
{\text { (molal) })^{\mathrm{a}}}\end{array}$ & Ca-Porewater & Na-Porewater & $\begin{array}{c}\mathrm{J}-13 \text { Well } \\
\text { Water }^{\mathrm{b}}\end{array}$ & Pure Water $^{c}$ & $51^{d}$ & $10006^{d}$ & $20013^{d}$ \\
\hline Ionic strength & 0.011 & 0.012 & 0.0035 & $\mathrm{~N} / \mathrm{A}$ & $5.00 \mathrm{E}-03$ & $1.00 \mathrm{E}-02$ & $1.00 \mathrm{E}-02$ \\
\hline $\mathrm{pH}$ & 7.6 & 7.4 & 7.0 & 5.4 & 8.14 & 7.78 & 7.94 \\
\hline $\mathrm{O}$ & $5.55 \mathrm{E}+01$ & $5.55 \mathrm{E}+01$ & $5.55 \mathrm{E}+01$ & $5.55 E+01$ & $5.55 \mathrm{E}+01$ & $5.55 \mathrm{E}+01$ & $5.55 E+01$ \\
\hline $\mathrm{Al}$ & $1.00 \mathrm{E}-16$ & $1.00 \mathrm{E}-16$ & $1.00 \mathrm{E}-16$ & $1.00 \mathrm{E}-16$ & $6.09 \mathrm{E}-08$ & 3.73E-09 & 1.50E-09 \\
\hline B & $1.00 \mathrm{E}-16$ & $1.00 \mathrm{E}-16$ & $1.00 \mathrm{E}-16$ & $1.00 \mathrm{E}-16$ & $1.00 \mathrm{E}-16$ & $1.00 \mathrm{E}-16$ & $1.00 \mathrm{E}-16$ \\
\hline $\mathrm{Ba}$ & $1.00 \mathrm{E}-16$ & $1.00 \mathrm{E}-16$ & $1.00 \mathrm{E}-16$ & $1.00 \mathrm{E}-16$ & $1.00 \mathrm{E}-16$ & $1.00 \mathrm{E}-16$ & $1.00 \mathrm{E}-16$ \\
\hline $\mathrm{Ca}$ & $2.35 \mathrm{E}-03$ & $2.02 \mathrm{E}-03$ & $3.24 \mathrm{E}-04$ & $1.00 \mathrm{E}-16$ & 7.24E-05 & $4.40 \mathrm{E}-04$ & 5.73E-04 \\
\hline $\mathrm{Cl}$ & 5.92E-04 & 6.77E-04 & $2.01 \mathrm{E}-04$ & $1.00 \mathrm{E}-16$ & 7.34E-04 & $7.12 \mathrm{E}-04$ & $5.61 \mathrm{E}-04$ \\
\hline Co & $1.00 \mathrm{E}-16$ & $1.00 \mathrm{E}-16$ & $1.00 \mathrm{E}-16$ & $1.00 \mathrm{E}-16$ & $1.00 \mathrm{E}-16$ & $1.00 \mathrm{E}-16$ & $1.00 \mathrm{E}-16$ \\
\hline $\mathrm{Cr}$ & $1.00 \mathrm{E}-16$ & $1.00 \mathrm{E}-16$ & $1.00 \mathrm{E}-16$ & $1.00 \mathrm{E}-16$ & $1.00 \mathrm{E}-16$ & $1.00 \mathrm{E}-16$ & $1.00 \mathrm{E}-16$ \\
\hline $\mathrm{Cs}$ & $1.00 \mathrm{E}-16$ & $1.00 \mathrm{E}-16$ & $1.00 \mathrm{E}-16$ & $1.00 \mathrm{E}-16$ & $1.00 \mathrm{E}-16$ & $1.00 \mathrm{E}-16$ & $1.00 \mathrm{E}-16$ \\
\hline $\mathrm{Cu}$ & $1.00 \mathrm{E}-16$ & $1.00 \mathrm{E}-16$ & $1.00 \mathrm{E}-16$ & $1.00 \mathrm{E}-16$ & $1.00 \mathrm{E}-16$ & $1.00 \mathrm{E}-16$ & $1.00 \mathrm{E}-16$ \\
\hline $\mathrm{F}$ & 1.79E-04 & 3.16E-04 & 1.15E-04 & $1.00 \mathrm{E}-16$ & 9.77E-04 & 7.81E-04 & $6.43 \mathrm{E}-04$ \\
\hline $\mathrm{Fe}$ & $1.00 \mathrm{E}-16$ & $1.00 \mathrm{E}-16$ & $1.00 \mathrm{E}-16$ & $1.00 \mathrm{E}-16$ & $1.00 \mathrm{E}-16$ & $1.00 \mathrm{E}-16$ & $1.00 \mathrm{E}-16$ \\
\hline $\mathrm{Gd}$ & $1.00 \mathrm{E}-16$ & $1.00 \mathrm{E}-16$ & $1.00 \mathrm{E}-16$ & $1.00 \mathrm{E}-16$ & $1.00 \mathrm{E}-16$ & $1.00 \mathrm{E}-16$ & $1.00 \mathrm{E}-16$ \\
\hline $\mathrm{H}$ & $1.11 \mathrm{E}+02$ & $1.11 \mathrm{E}+02$ & $1.11 \mathrm{E}+02$ & $1.11 \mathrm{E}+02$ & $1.11 \mathrm{E}+02$ & $1.11 \mathrm{E}+02$ & $1.11 \mathrm{E}+02$ \\
\hline$C$ & $6.76 \mathrm{E}-03$ & $8.62 \mathrm{E}-03$ & $2.49 \mathrm{E}-03$ & $3.79 \mathrm{E}-05$ & $2.04 \mathrm{E}-03$ & $6.58 \mathrm{E}-03$ & $6.92 \mathrm{E}-03$ \\
\hline $\mathrm{P}$ & $1.00 \mathrm{E}-16$ & $1.00 \mathrm{E}-16$ & $1.00 \mathrm{E}-16$ & $1.00 \mathrm{E}-16$ & $1.00 \mathrm{E}-16$ & $1.00 \mathrm{E}-16$ & $1.00 \mathrm{E}-16$ \\
\hline I & $1.00 \mathrm{E}-16$ & $1.00 \mathrm{E}-16$ & $1.00 \mathrm{E}-16$ & $1.00 \mathrm{E}-16$ & $1.00 \mathrm{E}-16$ & $1.00 \mathrm{E}-16$ & $1.00 \mathrm{E}-16$ \\
\hline $\mathrm{K}$ & 1.94E-04 & 1.56E-04 & $1.29 \mathrm{E}-04$ & $1.00 \mathrm{E}-16$ & $5.02 \mathrm{E}-04$ & $4.55 \mathrm{E}-04$ & $2.76 \mathrm{E}-04$ \\
\hline $\mathrm{Li}$ & $1.00 \mathrm{E}-16$ & $1.00 \mathrm{E}-16$ & $1.00 \mathrm{E}-16$ & $1.00 \mathrm{E}-16$ & $1.00 \mathrm{E}-16$ & $1.00 \mathrm{E}-16$ & $1.00 \mathrm{E}-16$ \\
\hline $\mathrm{Mg}$ & $7.45 \mathrm{E}-04$ & 1.36E-04 & 8.27E-05 & $1.00 \mathrm{E}-16$ & $2.54 \mathrm{E}-07$ & $5.19 \mathrm{E}-05$ & $8.51 \mathrm{E}-05$ \\
\hline $\mathrm{Mn}$ & $1.00 \mathrm{E}-16$ & $1.00 \mathrm{E}-16$ & $1.00 \mathrm{E}-16$ & $1.00 \mathrm{E}-16$ & $1.00 \mathrm{E}-16$ & $1.00 \mathrm{E}-16$ & $1.00 \mathrm{E}-16$ \\
\hline Mo & $1.00 \mathrm{E}-16$ & $1.00 \mathrm{E}-16$ & $1.00 \mathrm{E}-16$ & $1.00 \mathrm{E}-16$ & $1.00 \mathrm{E}-16$ & $1.00 \mathrm{E}-16$ & $1.00 \mathrm{E}-16$ \\
\hline $\mathrm{N}$ & 4.19E-05 & 6.61E-06 & $1.42 \mathrm{E}-04$ & $1.00 \mathrm{E}-16$ & $3.10 \mathrm{E}-04$ & 6.58E-05 & 3.97E-05 \\
\hline $\mathrm{Na}$ & 1.70E-03 & $5.22 \mathrm{E}-03$ & 1.99E-03 & $1.00 \mathrm{E}-16$ & $4.29 \mathrm{E}-03$ & $7.48 \mathrm{E}-03$ & 7.31E-03 \\
\hline $\mathrm{Ni}$ & $1.00 \mathrm{E}-16$ & $1.00 \mathrm{E}-16$ & $1.00 \mathrm{E}-16$ & $1.00 \mathrm{E}-16$ & $1.00 \mathrm{E}-16$ & $1.00 \mathrm{E}-16$ & 1.00E-16 \\
\hline $\mathrm{Np}$ & $1.00 \mathrm{E}-16$ & $1.00 \mathrm{E}-16$ & $1.00 \mathrm{E}-16$ & $1.00 \mathrm{E}-16$ & $1.00 \mathrm{E}-16$ & $1.00 \mathrm{E}-16$ & $1.00 \mathrm{E}-16$ \\
\hline $\mathrm{Pb}$ & $1.00 \mathrm{E}-16$ & $1.00 \mathrm{E}-16$ & $1.00 \mathrm{E}-16$ & $1.00 \mathrm{E}-16$ & $1.00 \mathrm{E}-16$ & $1.00 \mathrm{E}-16$ & $1.00 \mathrm{E}-16$ \\
\hline $\mathrm{Pu}$ & $1.00 \mathrm{E}-16$ & $1.00 \mathrm{E}-16$ & $1.00 \mathrm{E}-16$ & $1.00 \mathrm{E}-16$ & $1.00 \mathrm{E}-16$ & $1.00 \mathrm{E}-16$ & $1.00 \mathrm{E}-16$ \\
\hline $\mathrm{Ru}$ & $1.00 \mathrm{E}-16$ & $1.00 \mathrm{E}-16$ & $1.00 \mathrm{E}-16$ & $1.00 \mathrm{E}-16$ & $1.00 \mathrm{E}-16$ & $1.00 \mathrm{E}-16$ & $1.00 \mathrm{E}-16$ \\
\hline$S$ & $3.75 \mathrm{E}-04$ & 3.23E-04 & $1.92 \mathrm{E}-04$ & $1.00 \mathrm{E}-16$ & $1.18 \mathrm{E}-04$ & 3.94E-04 & $3.55 \mathrm{E}-04$ \\
\hline $\mathrm{Si}$ & 6.99E-04 & 6.99E-04 & $1.02 \mathrm{E}-03$ & $1.00 \mathrm{E}-16$ & $4.15 \mathrm{E}-03$ & $2.43 \mathrm{E}-03$ & 1.79E-03 \\
\hline Tc & $1.00 \mathrm{E}-16$ & $1.00 \mathrm{E}-16$ & $1.00 \mathrm{E}-16$ & $1.00 \mathrm{E}-16$ & $1.00 \mathrm{E}-16$ & $1.00 \mathrm{E}-16$ & $1.00 \mathrm{E}-16$ \\
\hline $\mathrm{Ti}$ & $1.00 \mathrm{E}-16$ & $1.00 \mathrm{E}-16$ & $1.00 \mathrm{E}-16$ & $1.00 \mathrm{E}-16$ & $1.00 \mathrm{E}-16$ & $1.00 \mathrm{E}-16$ & $1.00 \mathrm{E}-16$ \\
\hline U & $1.00 \mathrm{E}-16$ & $1.00 \mathrm{E}-16$ & $1.00 \mathrm{E}-16$ & $1.00 \mathrm{E}-16$ & $1.00 \mathrm{E}-16$ & $1.00 \mathrm{E}-16$ & $1.00 \mathrm{E}-16$ \\
\hline $\mathrm{Zn}$ & $1.00 \mathrm{E}-16$ & $1.00 \mathrm{E}-16$ & $1.00 \mathrm{E}-16$ & $1.00 \mathrm{E}-16$ & $1.00 \mathrm{E}-16$ & $1.00 \mathrm{E}-16$ & $1.00 \mathrm{E}-16$ \\
\hline $\mathrm{Zr}$ & $1.00 \mathrm{E}-16$ & $1.00 \mathrm{E}-16$ & $1.00 \mathrm{E}-16$ & $1.00 \mathrm{E}-16$ & $1.00 \mathrm{E}-16$ & $1.00 \mathrm{E}-16$ & $1.00 \mathrm{E}-16$ \\
\hline
\end{tabular}

Sources: ${ }^{a}$ EQ3NR pickup file "Ca_trc.3p", "Na_trc.3p", "J13_trc.3p", "pure_trc.3p" (Appendix F).

${ }^{\mathrm{b}}$ Note that $\mathrm{C}$ levels calculated from charge balance are in agreement with measured alkalinity.

${ }^{c}$ EQ3NR pickup file (Appendix F). Recall that pure water in contact with atmospheric carbon dioxide is mildly acidic.

d DTN: MO0303MWDSCMAB.000 [DIRS 162551], 51.3p: Cross-drift water CS1000/7.3 thc6_w5_r.x/s, 10006.3p: Cross-drift water CS1000/7.3 thc6_w5_r.xls, and 20013.3p: Cross-drift water SD-9/990.4 thc6_w6_r.xls (TF4 directory). 


\subsection{Metal Alloy Composition and Corrosion Rates}

The in-package chemistry model represents the metal alloys as "special reactants," in the EQ6 input files, with the compositions given in Table 6-6 (converted to units appropriate for EQ6 in CSNF.xls and CDSP.xls in Appendix F). The steel corrosion rates given in Table 6-7 (from Table 4-8, converted to units appropriate to EQ6) represent values for the temperature range from $25^{\circ} \mathrm{C}$ to $90^{\circ} \mathrm{C}$. The values are supported by the data in DTN: MO0409SPAACRWP.000 [DIRS 172059] that cover a range of temperatures and corroding water compositions.

Table 6-6. Metal Alloy Compositions

\begin{tabular}{|c|c|c|c|c|c|c|c|}
\hline & \begin{tabular}{|c} 
Carbon \\
Steel Type \\
A516 \\
\end{tabular} & Neutronit & $\begin{array}{l}\text { Aluminum } \\
\text { Alloy } 6061\end{array}$ & $\begin{array}{c}\text { Stainless } \\
\text { Steel Type } \\
316\end{array}$ & $\begin{array}{l}\text { Aluminum } \\
\text { Alloy } 1100\end{array}$ & \begin{tabular}{|c} 
Stainless \\
Steel Type \\
304L \\
\end{tabular} & $\begin{array}{l}\text { NiGd } \\
\text { Alloy }\end{array}$ \\
\hline Element & moles & moles & moles & moles & moles & moles & moles \\
\hline C & 2.33E-02 & 3.33E-03 & & 1.67E-03 & & 2.50E-03 & 8.33E-04 \\
\hline $\mathrm{Mn}$ & 1.90E-02 & & 2.73E-03 & 3.64E-02 & & 3.64E-02 & $9.10 \mathrm{E}-03$ \\
\hline$P$ & 1.13E-03 & & & 1.45E-03 & & 1.45E-03 & 1.61E-04 \\
\hline$S$ & 1.09E-03 & & & 9.36E-04 & & 9.36E-04 & 1.56E-04 \\
\hline $\mathrm{Si}$ & 1.03E-02 & & 2.14E-02 & 2.67E-02 & 1.60E-02 & 2.67E-02 & 2.85E-03 \\
\hline $\mathrm{Cr}$ & & 3.56E-01 & 3.75E-03 & 3.27E-01 & & 3.65E-01 & 3.04E-01 \\
\hline $\mathrm{Ni}$ & & 2.21E-01 & & 2.04E-01 & & 1.70E-01 & $1.09 \mathrm{E}+00$ \\
\hline Co & & 3.39E-03 & & & & & 3.39E-02 \\
\hline Mo & & 2.29E-02 & & 2.61E-02 & & & 1.52E-01 \\
\hline $\mathrm{N}$ & & & & 5.71E-03 & & 7.14E-03 & 7.14E-04 \\
\hline $\mathrm{Fe}$ & 1.76E+00 & $1.16 \mathrm{E}+00$ & 1.25E-02 & $1.17 \mathrm{E}+00$ & 8.95E-03 & $1.22 \mathrm{E}+00$ & 1.79E-02 \\
\hline$B$ & & 1.15E-01 & & & & & \\
\hline $\mathrm{Zn}$ & & & 3.82E-03 & & & & \\
\hline $\mathrm{Cu}$ & & & 4.33E-03 & & 7.87E-04 & & \\
\hline $\mathrm{Mg}$ & & & 4.11E-02 & & & & \\
\hline $\mathrm{Ti}$ & & & 3.13E-03 & & & & \\
\hline $\mathrm{Al}$ & & & $3.58 \mathrm{E}+00$ & & $3.67 E+00$ & & \\
\hline $\mathrm{Gd}$ & & & & & & & 1.27E-02 \\
\hline $\mathrm{O}$ & & & & & & & 3.13E-04 \\
\hline
\end{tabular}

Source: Appendix F, CSNF.x/s and CDSP.x/s, "Materials" worksheet.

NOTE: Elemental mole \% of the reactant are calculated based on 100 grams of reactant. 
Table 6-7. Metal Alloy Corrosion Rates

\begin{tabular}{|c|c|c|c|c|c|c|c|c|}
\hline $\begin{array}{c}\text { Corrosion } \\
\text { Rate }\end{array}$ & Units & $\begin{array}{c}\text { Carbon } \\
\text { Steel Type } \\
\text { A516 }\end{array}$ & Neutronit & $\begin{array}{c}\text { Aluminum } \\
\text { Alloy 6061 }\end{array}$ & $\begin{array}{c}\text { Stainless } \\
\text { Steel } \\
\text { Type 316 }\end{array}$ & $\begin{array}{c}\text { Aluminum } \\
\text { Alloy 1100 }\end{array}$ & $\begin{array}{c}\text { Stainless } \\
\text { Steel Type } \\
\text { 304L }\end{array}$ & $\begin{array}{c}\text { NiGd } \\
\text { Alloy }\end{array}$ \\
\hline \multirow{2}{*}{ Minimum } & $\mu \mathrm{m} / \mathrm{yr}$ & 3.69 & 0.001 & 0.4 & 0.0014 & 0.4 & 0.001 & 0.0528 \\
\cline { 2 - 9 } & $\mathrm{moles} / \mathrm{s}-\mathrm{cm}^{2}$ & $9.18 \mathrm{E}-13$ & $2.46 \mathrm{E}-16$ & $3.42 \mathrm{E}-14$ & $3.55 \mathrm{E}-16$ & $3.42 \mathrm{E}-14$ & $2.52 \mathrm{E}-16$ & $1.30 \mathrm{E}-14$ \\
\hline \multirow{2}{*}{ Maximum } & $\mu \mathrm{m} / \mathrm{yr}$ & 130.7 & 29.2 & 110.9 & 14.8 & 110.9 & 39.1 & 1 \\
\cline { 2 - 9 } & $\mathrm{moles} / \mathrm{s}-\mathrm{cm}^{2}$ & $3.52 \mathrm{E}-11$ & $7.18 \mathrm{E}-12$ & $9.49 \mathrm{E}-12$ & $3.75 \mathrm{E}-12$ & $9.49 \mathrm{E}-12$ & $9.84 \mathrm{E}-12$ & $2.46 \mathrm{E}-13$ \\
\hline \multirow{2}{*}{ Base Case } & $\mu \mathrm{m} / \mathrm{yr}$ & 72 & 0.1 & 3.0 & 0.1 & 3.0 & 0.1 & 0.0528 \\
\cline { 2 - 9 } & $\mathrm{moles} / \mathrm{s}-\mathrm{cm}^{2}$ & $1.80 \mathrm{E}-11$ & $2.54 \mathrm{E}-14$ & $2.54 \mathrm{E}-13$ & $2.53 \mathrm{E}-14$ & $2.54 \mathrm{E}-13$ & $2.52 \mathrm{E}-14$ & $1.30 \mathrm{E}-14$ \\
\hline
\end{tabular}

Source: Appendix F, CSNF.x/s and CDSP.x/s, worksheet "Rates."

NOTES: ${ }^{a}$ The density and corrosion rates of Aluminum Alloy 6061 were also used for Aluminum Alloy 1100.

${ }^{\mathrm{b}}$ The density of Neutronit was used for NiGd alloy.

The corrosion rates used for the base case are rates that fall within the range provided in DTN: MO0409SPAACRWP.000 [DIRS 172059]. Sensitivity studies (Section 6.6.10.1) using $10 \times$ higher and $10 \times$ lower than the base case cover most of the maximum and minimum rates listed in Table 6-7. The results show that different rates do not affect the range of the model output (maximum or minimum $\mathrm{pH}$ or ionic strength). Changes in these rates only affect the timing of the $\mathrm{pH}$ or ionic strength responses that occur when a reactant is depleted. Since the output is not time-dependant, the timing of the shifts in $\mathrm{pH}$ or ionic strength does not impact the results. The rates in Table 6-7 were compared to the atmospheric rates given in DTN: MO0312SPAPCEML.003 [DIRS 167409], spreadsheet atmospheric.xls. For the Carbon Steel Type A516, some of the atmospheric rates were higher $(1,057.18 \mu \mathrm{m} / \mathrm{yr})$ than the $130.7 \mu \mathrm{m} / \mathrm{yr}$ value given in Table 6-7. For Aluminum Alloy Types 1100 and 6061 , all of the atmospheric rates are lower than the minimum rate given in Table 6-7. For Stainless Steel Type 316, some of the atmospheric rates were higher $(53 \mu \mathrm{m} / \mathrm{yr})$ than the $14.8 \mu \mathrm{m} / \mathrm{yr}$ value given in Table 6-7. The impact of atmospheric corrosion was examined in a sensitivity analysis (Section 6.6.10) by increasing and decreasing all of the base case rates by a factor of ten.

The amount of metal alloy that EQ6 "adds" to the reaction during a run (moles) is the product of the coefficients (moles/s- $\mathrm{cm}^{2}$ ) in Table 6-7, the duration of the EQ6 time step(s), and the surface area $\left(\mathrm{cm}^{2}\right)$ of the reactant. Therefore, the amount of reactant added per time step $=$ moles $/ \mathrm{s}-\mathrm{cm}^{2} \times \mathrm{s} \times \mathrm{cm}^{2}$. The duration of the EQ6 time step varies depending on how quickly the given reactions reach equilibrium.

\subsection{SNF and HLWG Composition and Reaction Rates}

For EQ6 runs, the CSNF was specified to have $3.5 \mathrm{wt} \%{ }^{235} \mathrm{U}$ enrichment, $40 \mathrm{GWd} / \mathrm{MTU}$ fuel burnup, and 10,000 years of decay time BSC 2003 [DIRS 169110]. The number of elements in the fuel composition was reduced to allow EQ6 to run more efficiently. EQ6 run time increases rapidly and nonlinearly as the number of elements is increased. Therefore, the moles of $\mathrm{Ru}$ in Table 6-8 includes the moles of $\mathrm{Ru}, \mathrm{Rh}, \mathrm{Pd}$, and $\mathrm{Ag}$, and the moles of $\mathrm{Gd}$ in Table 6-8 include the moles of Gd, Y, Pr, Nd, Pm, Sm, Eu, and Ho in the CSNF composition (BSC 2003 [DIRS 169110]). The combined elements are expected to behave in a similar manner due to their position in the periodic table. The elements not included in the fuel composition used in the 
model are $\mathrm{Th}, \mathrm{Pa}, \mathrm{Am}, \mathrm{Cm}, \mathrm{Li}, \mathrm{Be}, \mathrm{As}, \mathrm{Kr}, \mathrm{Nb}$, and $\mathrm{Xe}$. The concentration of the elements excluded from the CSNF composition are estimated to be below levels which have influence over the calculated in-package chemistry; thus, their exclusion does not impact the results of the in-package chemistry model.

Table 6-8 summarizes the composition of the CSNF and N Reactor fuels, respectively. The CSNF is an oxide fuel while the N Reactor fuel is a uranium metal type of fuel.

Table 6-8. CSNF and N Reactor Compositions

\begin{tabular}{|l|c|c|}
\hline \multicolumn{1}{|c|}{ Element } & $\begin{array}{c}\text { CSNF } \\
\text { Moles/100g }\end{array}$ & $\begin{array}{c}\text { N Reactor } \\
\text { Moles/100g }\end{array}$ \\
\hline $\mathrm{U}$ & 0.3617 & 0.420 \\
\hline $\mathrm{Np}$ & 0.0009 & $\mathrm{~N} / \mathrm{A}$ \\
\hline $\mathrm{Pu}$ & 0.0027 & $\mathrm{~N} / \mathrm{A}$ \\
\hline $\mathrm{Zr}$ & 0.0005 & $\mathrm{~N} / \mathrm{A}$ \\
\hline $\mathrm{Mo}$ & 0.0009 & $\mathrm{~N} / \mathrm{A}$ \\
\hline $\mathrm{Tc}$ & 0.0008 & $\mathrm{~N} / \mathrm{A}$ \\
\hline $\mathrm{Ru}$ & 0.0020 & $\mathrm{~N} / \mathrm{A}$ \\
\hline $\mathrm{Cs}$ & 0.0013 & $\mathrm{~N} / \mathrm{A}$ \\
\hline $\mathrm{Ba}$ & 0.0010 & $\mathrm{~N} / \mathrm{A}$ \\
\hline $\mathrm{Gd}$ & 0.0035 & $\mathrm{~N} / \mathrm{A}$ \\
\hline $\mathrm{O}$ & 0.7385 & $\mathrm{~N} / \mathrm{A}$ \\
\hline
\end{tabular}

Source: CSNF.xls, and for N Reactor, moles of $U=100 / 238 \mathrm{~g} / \mathrm{mol}$.

NOTE: Elemental mole \% of the reactant are calculated based on 100 grams of reactant.

For input into EQ6, the simplified HLWG formula is used based on $100 \mathrm{~g}$ from Table 4-5. As described in EQ6 Calculations for Chemical Degradation of N Reactor (U-metal) Spent Nuclear Fuel Waste Packages (CRWMS M\&O 2001 [DIRS 153263]), to arrive at this simplified composition, several elements in the glass composition from Defense Waste Processing Facility Wasteform and Canister Description (Baxter 1988 [DIRS 106164], Table 10), were:

- Decayed to other elements $\left({ }^{238} \mathrm{Pu}\right.$ to $\left.{ }^{234} \mathrm{U}\right)$

- Combined with other elements (Li added to $\mathrm{Na}$ ) or

- Excluded to reduce the number of elements for ease in running EQ6.

The elements not included in the model of the glass composition were $\mathrm{Ag}, \mathrm{Cs}, \mathrm{Cu}, \mathrm{Mn}, \mathrm{Cl}, \mathrm{Ni}$, $\mathrm{Pb}, \mathrm{Th}$, and Ti. These elements occur in such low quantities that their omission has no impact on the modeling results. These minor changes were made to the basic composition to increase the efficiency of the calculations, to decrease the EQ6 run time, and to allow the use of a $\mathrm{pH}$ dependent rate law. The simplified glass composition was included in the EQ6 database as a mineral named 'SRL_Bulk' (Stoichiometric fractions less than 0.0001 moles/100g are not read by EQ3/6).

Table 6-9 provides the CSNF reaction rate constants at various temperatures for the equations provided in CSNF Waste Form Degradation: Summary Abstraction (BSC 2004 [DIRS 169987]). 
The two equations in Section 4.1.3 for the dissolution of CSNF were combined into a single closed-form expression for use in EQ6. The CSNF reaction rate is a transition state theory rate law that is dependent on temperature, $\mathrm{pH}$, and bicarbonate concentration. The bicarbonate concentration is used rather than total carbonate because the CSNF rate law is insensitive to carbonate concentration in the output $\mathrm{pH}$ range (3 to 8 ) of the model. Figure A-1 of Appendix A shows the CSNF total degradation constant as a function of $\mathrm{pH}$ and derived in terms of total carbonate and $\mathrm{HCO}_{3}{ }^{-}$. This figure shows that from $\mathrm{pH} 2$ to about $\mathrm{pH} 10$, the total degradation constant is not sensitive to carbonate, but above $\mathrm{pH} 10$ the degradation constant is sensitive to carbonate. To simplify the base case, the surface area used with the two equations in Section 4.1.3 was the geometric surface area (the $\log (\mathrm{A})$ term was not used). The impact of this simplification is examined in a sensitivity analysis in Section 6.6.10.2.

Table 6-9. CSNF Transition State Theory Rate Law and Coefficients

\begin{tabular}{|c|c|c|}
\hline \multicolumn{3}{|c|}{ Total Degradation Rate Constant $=\mathbf{k}_{\mathbf{1}}[\mathbf{H +}]^{\mathbf{0 . 3 4}} ; \mathbf{k}_{\mathbf{2}}\left[\mathrm{HCO}_{\mathbf{3}}\right]^{\mathbf{0 . 1 0}}\left(\mathbf{m o l} / \mathbf{c m}^{\mathbf{2}} \cdot \mathbf{s}\right)$} \\
\hline Temperature (Celsius) & Rate Constant $\left(\mathbf{k}_{\mathbf{1}}\right)$ & Rate Constant $\left(\mathbf{k}_{\mathbf{2}}\right)$ \\
\hline 25.0 & $5.72 \mathrm{E}-12$ & $7.29 \mathrm{E}-14$ \\
\hline 40.2 & $8.62 \mathrm{E}-12$ & $1.10 \mathrm{E}-13$ \\
\hline 50.0 & $1.10 \mathrm{E}-11$ & $1.40 \mathrm{E}-13$ \\
\hline 56.2 & $1.27 \mathrm{E}-11$ & $1.62 \mathrm{E}-13$ \\
\hline 90.0 & $2.60 \mathrm{E}-11$ & $3.31 \mathrm{E}-13$ \\
\hline 91.8 & $2.69 \mathrm{E}-11$ & $3.42 \mathrm{E}-13$ \\
\hline
\end{tabular}

Source: CSNF_Rates.x/s.

The glass dissolution rate law is the $\mathrm{pH}$-dependent, transition state theory rate law provided in Defense HLW Glass Degradation Model (BSC 2004 [DIRS 169988], Section 8.1, Equations 40a and $40 \mathrm{~b}$ ). The first rate mechanism (described with $\mathrm{k}_{1}$ ) in Table 6-10 is dominant at $\mathrm{pH}$ values greater than or equal to 7.1, while the second rate mechanism (described with $\mathrm{k}_{2}$ ) is dominant at $\mathrm{pH}$ values below 7.1. The rate constants for various temperatures are given in Table 6-10.

Table 6-10. HLWG Transition State Theory Rate Law and N Reactor Rate Constants

\begin{tabular}{|c|c|c|}
\hline \multicolumn{3}{|c|}{ HLWG } \\
\hline \multicolumn{3}{|c|}{ Total Degradation Rate Constant $=\mathrm{k}_{1}[\mathrm{H}+]^{-0.49} ; \mathrm{k}_{2}[\mathrm{H}+]^{0.49}\left(\mathrm{~mol} / \mathrm{cm}^{2} \cdot \mathrm{s}\right)$} \\
\hline Temperature (Celsius) & Rate Constant $\left(\mathbf{k}_{1}\right)$ & Rate Constant $\left(\mathrm{k}_{2}\right)$ \\
\hline 25.0 & $2.66 \mathrm{E}-22$ & $3.61 \mathrm{E}-13$ \\
\hline 40.2 & 1.03E-21 & $6.61 \mathrm{E}-13$ \\
\hline 50.0 & $2.29 E-21$ & $9.49 \mathrm{E}-13$ \\
\hline 56.2 & $3.72 E-21$ & $1.18 \mathrm{E}-12$ \\
\hline 90.0 & $3.88 \mathrm{E}-20$ & $3.38 \mathrm{E}-12$ \\
\hline 91.8 & 4.34E-20 & $3.56 \mathrm{E}-12$ \\
\hline \multicolumn{3}{|c|}{ N Reactor ${ }^{a}$} \\
\hline Temperature (Celsius) & \multicolumn{2}{|c|}{ Total Degradation constant $\mathrm{K}\left(\mathrm{mol} / \mathrm{cm}^{2} \cdot \mathrm{s}\right)$} \\
\hline 25.0 & \multicolumn{2}{|c|}{$1.63 \mathrm{E}-10$} \\
\hline 50.0 & \multicolumn{2}{|c|}{ 1.29E-09 } \\
\hline 90.0 & \multicolumn{2}{|c|}{ 1.97E-08 } \\
\hline
\end{tabular}

Source: CDSP.xls, worksheet: "CDSP Rates."

NOTE: ${ }^{a}$ The $25^{\circ} \mathrm{C}$ rate for CDSP was used for all EQ6 runs (the high temperature rates were not used in any runs). 


\subsection{Waste Package Components Total Surface Areas and Moles}

The total surface areas and moles of reactants for the waste packages were calculated in CSNF.xls and CDSP.xls and are presented in Table 6-11. The dimensions and masses of components from the IED were used to calculate surface areas and amounts that were then converted into $\mathrm{cm}^{2}$ and moles for use by the EQ6 code. Minor changes in waste package design have occurred during the development of this model, and are described in New WP Designs.xls in Appendix F (Spreadsheets). Changes of this magnitude have little impact on the model output, as shown in Figures A-18 and A-19.

For the HLWG, the exposure factors given in Section 4.1.3.3 are: $f_{\text {exposure }}=4$ (most likely) and 17 (maximum), but an exposure factor of 21 was applied to this total surface area. This higher value is more conservative because it results in a higher degradation of the glass and, thus, has a stronger impact on the chemistry.

The latest waste package design replaces Neutronit with a NiGd alloy. A sensitivity analysis was performed in Section 6.6.7 examining the impact of this change.

Table 6-11. Total Surface Areas and Moles for the CSNF and CDSP Waste Packages

\begin{tabular}{|c|c|c|c|c|c|}
\hline \multicolumn{3}{|c|}{ CSNF } & \multicolumn{3}{|c|}{ CDSP } \\
\hline $\begin{array}{c}\text { Waste Package } \\
\text { Component }\end{array}$ & $\begin{array}{c}\text { Total Surface } \\
\text { Area }\left(\mathrm{cm}^{2}\right)\end{array}$ & Total Moles & $\begin{array}{c}\text { Waste Package } \\
\text { Component }\end{array}$ & $\begin{array}{l}\text { Total Surface } \\
\text { Area }\left(\mathrm{cm}^{2}\right)\end{array}$ & $\begin{array}{l}\text { Total } \\
\text { Moles }\end{array}$ \\
\hline $\begin{array}{l}\text { Stainless Steel Type } \\
316 \text { Inner vessel }\end{array}$ & 241,600 & 105,310 & $\begin{array}{l}\text { Stainless Steel Type } \\
316 \text { Inner vessel }\end{array}$ & 269,170 & 131,890 \\
\hline NEUTRONIT & 529,130 & 20,980 & Aluminum Alloy 1100 & 141,780 & 810 \\
\hline Aluminum Alloy 6061 & 258,960 & 3,420 & $\begin{array}{l}\text { Stainless Steel Type } \\
304 \mathrm{~L} \text { MCO }\end{array}$ & 487,050 & 27,000 \\
\hline $\begin{array}{c}\text { FBT (Carbon Steel } \\
\text { Type A516) } \\
\end{array}$ & $1,777,410$ & 34,840 & $\begin{array}{l}\text { Stainless Steel Type } \\
\text { 304L MCO top }\end{array}$ & 36,380 & 29,860 \\
\hline $\begin{array}{c}\text { Stiffeners (Carbon Steel } \\
\text { Type A516) }\end{array}$ & 27,650 & 2,010 & $\begin{array}{l}\text { Stainless Steel Type } \\
\text { 304L GPC }\end{array}$ & 179,200 & 14,830 \\
\hline CSNF (100\% Exposure) & $4,624,210$ & 108,430 & $\begin{array}{l}\text { Carbon Steel Type } \\
\text { A516 plates }\end{array}$ & 334,300 & 11,460 \\
\hline CSNF (10\% Exposure) & 462,420 & 10,840 & N Reactor $(100 \%)$ & $1,639,430$ & 127,460 \\
\hline CSNF (1\% Exposure) & 46,242 & 1,084 & N Reactor $(10 \%)$ & 819,720 & 63,730 \\
\hline & & & HLWG & $3,113,960^{a}$ & $57,660^{b}$ \\
\hline
\end{tabular}

Source: CSNF (No A516 Correction).xls, and CDSP.xls

NOTES: $M C O=$ Multicanister overpack; GPC = glass-pour canister

${ }^{a}$ An exposure factor of 21 was applied to the geometric surface area to obtain this surface area

b The density of the HLWG used to calculate the amount of glass was $2.85 \mathrm{~g} / \mathrm{cm}^{3}$. This value is from the upper end of the range provided by Baxter (1988 [DIRS 106164], Table 10).

\subsection{Vapor Influx Case: Model Inputs}

The vapor influx cases include single component runs that examine the interactions of water with a single waste package component, and multi component runs that examine the interactions of water with several waste package components. The vapor influx cases use a very low ratio of water to reactants to simulate vapor condensing over a large surface area. For simplicity and 
comparison purposes, each of the single component runs considers the liter of water to be in contact with $10,000 \mathrm{~cm}^{2}$ of available surface area. The single component and the water flow rate are scaled to the surface area of $10,000 \mathrm{~cm}^{2}$. For the multi component runs, the reactants are scaled to one liter and to the total surface area of the components being examined. The scaling calculations for the vapor influx cases are provided in CSNF.xls and CDSP.xls.

\subsection{Water Influx Case: Model Inputs}

The total moles and reactants for the water influx models are scaled to one liter of water. The ratio of water to reactants for the water influx cases is approximately half of what the ratio would be in a bathtub model. This ratio was selected to generate a model that is more realistic than the bathtub model and that is more closely aligned to the conceptual implementation of the model within TSPA-LA. TSPA-LA applies the output of this model to a continuous film over the waste package interior that is available to transport radionuclides. The reactants are scaled to one liter of water and the total surface area. Different exposures of fuel result in different total surface areas, so each fuel exposure case is scaled differently. The water flow rates are also scaled to the total surface area. The scaling calculations for the water influx cases are provided in CSNF (No A516 Correction).xls and CDSP.xls.

\subsection{Mineral Controls}

In the in-package chemistry model, the minerals that precipitate from solution during an EQ6 run are determined by the code in accordance with the thermodynamics of the chemical system. Based on the modeled conditions, certain minerals will precipitate from solution and others will not. In order to use EQ6 to choose "correct" precipitation phases, the analyst must assume that the database includes data for all possibly relevant phases. There is no test of completeness in the construction or qualification of the database. In using the EQ6 software the analyst must decide, on the basis of prior knowledge related to the phenomena, that mineral phases will not be allowed to form in a simulation; this is called mineral "suppression." Table 6-12 lists the mineral phases suppressed in the EQ6 runs. By deciding which minerals to suppress, the analyst is implicitly deciding which minerals will form. Trial runs are often performed so that the analyst can see first hand what minerals are forming and what minerals should be suppressed. By suppressing a phase, a decision is made based on knowledge of a phase's mode of occurrence and the relative kinetics of formation.

Table 6-13 provides a list of the major minerals that were not suppressed and were observed to precipitate in the EQ6 runs for the in-package chemistry model. Phases in abundance in greater than $10^{-4}$ moles over the 20,000-year model period are included in the list.

For certain simulations, the EQ6 code was not able to converge to a solution because of difficulties related to finding a stable mineral assemblage for the particular chemical conditions of the simulation. In these cases EQ6 gives an error statement indicating that convergence was not possible because a phase rule violation occurred, and EQ6 would list the mineral phases involved in the violation. Suppressing one of the suspect phases was used as a means of getting the EQ6 to converge. The specifics are provided in the following paragraph.

In three runs $(\mathrm{C} 13 \mathrm{~N} 50.6 \mathrm{i}, \mathrm{C} 23 \mathrm{~N} 50.6 \mathrm{i}$, and $\mathrm{C} 33 \mathrm{~N} 50.6 \mathrm{i})$, the uranium phosphate phase $\left(\mathrm{UO}_{2}\right)_{3}(\mathrm{PO} 4)_{2}: 6 \mathrm{H}_{2} \mathrm{O}$ was suppressed and $\left(\mathrm{UO}_{2}\right)_{3}(\mathrm{PO} 4)_{2}: 4 \mathrm{H}_{2} \mathrm{O}$ formed in its place; thus, the effect 
on the chemistry was negligible. In run $\mathrm{CD}_{-}$Comp6.6i the phase bunsenite (NiO) was suppressed because of a phase-rule violation and trevorite $\left(\mathrm{NiFe}_{2} \mathrm{O}_{4}\right)$ formed in its place, another phase that had an inconsequential impact on the chemistry. In all of the runs, the phase $\mathrm{PuO}_{2}$ (aged, hyd) was suppressed to aid code convergence. No other plutonium phase precipitated in its place. Although plutonium is important from a dose perspective, it has no impact on the $\mathrm{pH}$ of the system because of its relatively low concentration compared to the major elements $(\mathrm{Ca}, \mathrm{Mg}, \mathrm{Na}, \mathrm{K}, \mathrm{Cl}, \mathrm{S}$, and $\mathrm{C})$. Therefore, the $\mathrm{Pu}$ concentrations predicted by the model should not be used for the purposes of predicting dissolved plutonium concentrations.

The corrosion product assemblage is likely to be made up of some mixture of hematite, goethite, and ferrihydrite (Section 6.3). From a modeling point of view, hematite was the primary ferric iron phase allowed to form in the batch reactor simulations because it is the most thermodynamically stable mineral. Because EQ6 is a thermodynamic equilibrium code, the use of hematite over goethite leads to the lowest dissolved iron concentrations. However, goethite also requires consideration because it is kinetically favored, so goethite formation was also allowed in some cases and its impact on the in-package chemistry is examined in Section 6.6.11. Ferrihydrite is not modeled in the batch reactor simulations because it has limited thermodynamic data. The fact that the $\mathrm{pH}$ predicted by the goethite and hematite simulations are very similar to each other indicates ferrihydrite use would also be similar. 


\begin{tabular}{|c|c|c|}
\hline Mineral & Chemical Formula & Justification \\
\hline Quartz & $\mathrm{SiO}_{2}$ & $\begin{array}{l}\text { Quartz is formed at higher temperatures (around } 573^{\circ} \mathrm{C} \text { ), but its extremely simple elemental makeup makes it resistant to corrosion, } \\
\text { allowing it to exist widespread as a detrital fragment in many sedimentary rocks, which is why it has been noted in so many } \\
\text { sedimentary deposits. However, other forms of } \mathrm{SiO}_{2} \text { can form as primary sedimentary minerals at low temperatures (such as } \\
\text { chalcedony) (Klein and Hurlbut } 1985 \text { [DIRS } 105907] \text {, pp. } 441 \text { to 442). Therefore, the mineral quartz has been suppressed in the EQ6 } \\
\text { runs, allowing the lower temperature varieties of } \mathrm{SiO}_{2} \text { to form. }\end{array}$ \\
\hline Goethite & $\alpha-\mathrm{FeOOH}$ & $\begin{array}{l}\text { Goethite }(\alpha-\mathrm{FeOOH}) \text { and hematite }\left(\alpha-\mathrm{Fe}_{2} \mathrm{O}_{3}\right) \text { are the two most thermodynamically stable Fe minerals under oxidizing conditions } \\
\text { (Schwertmann and Taylor } 1995 \text { [DIRS } 105959]) \text {. Goethite was suppressed in the } \mathrm{EQ} 6 \text { runs, however, suppressing goethite had no } \\
\text { effect on the results of the model since hematite is more thermodynamically stable than goethite, and EQ6 would not allow goethite to } \\
\text { form unless hematite was suppressed. Sensitivity runs were performed where hematite was suppressed and goethite allowed to form, } \\
\text { the results are included in Section } 6.6 .11 \text { and the conclusion drawn, therein, was that the chemistry of the system was largely } \\
\text { independent of which phase was allowed to form, either goethite or hematite. }\end{array}$ \\
\hline Tridymite & $\mathrm{SiO}_{2}$ & $\begin{array}{l}\text { Tridymite exists as both } \alpha \text { and } \beta \text { types. The low temperature } \alpha \text {-tridymite forms only from preexisting } \beta \text {-tridymite that forms in the } \\
\text { temperature range of } 870^{\circ} \mathrm{C} \text { to } 1,470^{\circ} \mathrm{C} \text { (Roberts et al. } 1990 \text { [DIRS 107105], pp. } 881 \text { to 882). }\end{array}$ \\
\hline Muscovite & $\mathrm{KAl}_{2}\left(\mathrm{Si}_{3} \mathrm{Al}\right) \mathrm{O}_{10}(\mathrm{OH}, \mathrm{F})_{2}$ & $\begin{array}{l}\text { Occurs in high T and/or P mineral assemblages and as a detrital mineral in sedimentary rocks (Roberts et al. } 1990 \text { [DIRS 107105], } \\
\text { p. 586). }\end{array}$ \\
\hline Celadonite & $\begin{array}{l}\mathrm{K}\left(\mathrm{Mg}, \mathrm{Fe}^{2+}\right)\left(\mathrm{Fe}^{3+}, \mathrm{Al}\right) \mathrm{Si}_{4} \\
\mathrm{O}_{10}(\mathrm{OH})_{2}\end{array}$ & $\begin{array}{l}\text { Celadonite is found in altered volcanic rocks (Roberts et al. } 1990 \text { [DIRS 107105], p. 149. Celadonite can form at low temperatures, but } \\
\text { this is due to either diagenesis of preexisting material, low-grade metamorphic processes, or concentration of the liquid environment } \\
\text { through evaporation (Li et al. } 1997 \text { [DIRS 159034]). }\end{array}$ \\
\hline Annite & $\mathrm{KFe}_{3}{ }^{2+} \mathrm{AlSi}_{3} \mathrm{O}_{10}(\mathrm{OH}, \mathrm{F})_{2}$ & Synthesized, natural occurrence uncertain (Roberts et al. 1990 [DIRS 107105], p. 32) \\
\hline Dolomite & $\mathrm{CaMg}\left(\mathrm{CO}_{3}\right)_{2}$ & $\begin{array}{l}\text { Dolomite is usually derived by secondary mineralization, from the replacement of Ca for } \mathrm{Mg} \text { in the calcite crystal structure in Mg-rich } \\
\text { waters (Klein and Hurlbut } 1985 \text { [DIRS 105907], p. 340). Due to the fact that it rarely occurs as a primary mineral, it was also } \\
\text { suppressed. }\end{array}$ \\
\hline Andradite & $\mathrm{Ca}_{3} \mathrm{Fe}_{2}\left(\mathrm{SiO}_{4}\right)_{3}$ & Andradite is a high P/T mineral found in metamorphic and igneous rocks (Deer et al. 1966 [DIRS 102773], p. 30). \\
\hline Phlogopite & $\mathrm{KMg}_{3} \mathrm{AlSi}_{3} \mathrm{O}_{10}(\mathrm{OH}, \mathrm{F})_{2}$ & Occurs chiefly in metamorphic limestones and ultrabasic rocks (Roberts et al. 1990 [DIRS 107105], p. 671). \\
\hline Talc & $\mathrm{Mg}_{3} \mathrm{Si}_{4} \mathrm{O}_{10}(\mathrm{OH})_{2}$ & $\begin{array}{l}\text { Talc is characteristically associated with low-grade metamorphic rock and hydrothermal alteration of ultrabasic rocks (Kerr } 1977 \\
\text { [DIRS 161606], p. 450). }\end{array}$ \\
\hline $\begin{array}{l}\text { Ferrite-Ca } \\
\text { Ferrite-Mg }\end{array}$ & $\begin{array}{l}\mathrm{CaFe}_{2} \mathrm{O}_{4} \\
\mathrm{MgFe}_{2} \mathrm{O}_{4}\end{array}$ & $\begin{array}{l}\text { Magnesioferrite has been found in sintered magnesite of furnace linings and other refractories (Palache et al. } 1944 \text { [DIRS 163604], } \\
\text { p. 705), not expected to form at low T. }\end{array}$ \\
\hline Zircon & $\mathrm{ZrSiO}_{4}$ & High P/T mineral. Found in sedimentary deposits as a detrital mineral (Roberts et al. 1990 [DIRS 107105], p. 975). \\
\hline Soddyite & $\left(\mathrm{UO}_{2}\right)_{2} \mathrm{SiO}_{4}: 2 \mathrm{H}_{2} \mathrm{O}$ & $\begin{array}{l}\text { Suppression of soddyite had no effect on the results of this model report, since this mineral is fairly soluble under the conditions } \\
\text { simulated by the model, and it would not have precipitated in any of the EQ6 runs even if its formation had not been suppressed. }\end{array}$ \\
\hline $\mathrm{PuO}_{2}$ & $\mathrm{PuO}_{2}$ & $\begin{array}{l}\text { The measured solubilities of solid } \mathrm{Pu}(\mathrm{IV}) \text { oxide/hydroxide scatter within several orders of magnitude because of the difficulties of } \\
\text { establishing equilibrium of } \mathrm{Pu}(\mathrm{IV}) \text {, polymerization and disproportionation reactions and the strong sorption capacities of } \mathrm{Pu}^{4+} \\
\text { (Runde } 1999 \text { [DIRS } 144800]) \text {. Experimental } \mathrm{Pu} \text { solution concentrations during } \mathrm{PuO}_{2} \text { or } \mathrm{PWR} \text { SNF degradation have been shown to be } \\
\text { between the solubility of } \mathrm{PuO}_{2} \text { and that of a more soluble phase, } \mathrm{Pu}(\mathrm{OH})_{4}\left(\text { or } \mathrm{PuO}_{2} \cdot 2 \mathrm{H}_{2} \mathrm{O} \text { ) (Rai and Ryan } 1982 \text { [DIRS 112060]; Wilson }\right. \\
\text { and Bruton } 1989 \text { [DIRS 137607], Section } 3.1 \text { and Table 3). }\end{array}$ \\
\hline
\end{tabular}

NOTE: $P=$ Pressure; $T=$ Temperature. 


\begin{tabular}{|l|c|}
\hline \multicolumn{1}{|c|}{ Mineral } & Chemical Formula \\
\hline Hematite & $\alpha-\mathrm{Fe}_{2} \mathrm{O}_{3}$ \\
\hline Pyrolusite & $\mathrm{MnO}_{2}$ \\
\hline Trevorite & $\mathrm{NiFe}_{2} \mathrm{O}_{4}$ \\
\hline Powellite & $\mathrm{Ca}\left({\mathrm{Mo}, \mathrm{W})_{4}}\right.$ \\
\hline Tenorite & $\mathrm{CuO}$ \\
\hline Schoepite & $\mathrm{CO}_{3}: 2 \mathrm{H}_{2} \mathrm{O}$ \\
& \\
\hline Gibbsite & $\mathrm{Al}(\mathrm{OH})_{3}$ \\
\hline Kaolinite & $\mathrm{Al}_{2} \mathrm{Si}_{2} \mathrm{O}_{5}(\mathrm{OH})_{4}$ \\
\hline Nontronite & $\mathrm{Na}_{0.33} \mathrm{Fe}_{2}$ \\
\hline GdPO & $\left(\mathrm{Si}, \mathrm{Al}_{4} \mathrm{O}_{10}(\mathrm{OH})_{2}: \mathrm{nH}_{2} \mathrm{O}\right.$ \\
\hline $\mathrm{GdPO}_{4}: 10 \mathrm{H}_{2} \mathrm{O}$ \\
\end{tabular}

Goethite $(\alpha-\mathrm{FeOOH})$ and hematite $\left(\alpha-\mathrm{Fe}_{2} \mathrm{O}_{3}\right)$ are the two most thermodynamically stable and most widespread Fe minerals under oxidizing condition. Hematite is usually found in tropical and subtropical regions where higher temperatures and lower water activities aid in its

formation. Hematite needs a precursor such as ferrihydrite from which it forms through dehydration and rearrangement (Schwertmann and Taylor 1995 [DIRS 105959]).

Secondary mineral forming from alteration of manganite or other manganese-bearing minerals. (Roberts et al. 1990 [DIRS 107105], p. 704). Manganite forms as a low temperature hydrothermal vein mineral; in circulating meteoric water; or bog, lacustrine, or shallow marine deposits (Roberts et al. 1990 [DIRS 107105], p. 524). Found as a secondary mineral in the oxidation zone at the Morro de Ferro site in Brazil (Waber 1991 [DIRS 126924]). Formed in the system $\mathrm{Mn}_{-} \mathrm{O}_{2}-\mathrm{H}_{2} \mathrm{O}$ at $25^{\circ} \mathrm{C}$ and one atmosphere (Bricker 1965 [DIRS 157873], Table 1).

High P/T mineral (Roberts et al. 1990 [DIRS 107105], p. 881). Trevorite was allowed to form since Ni-substituted goethite, hematite and $\mathrm{NiFe}_{2} \mathrm{O}_{4}$ can be synthesized at low pressure and temperature (Cornell et al. 1992 [DIRS 164025]), and Ni-substituted iron oxides are not in the EQ6 database.

Occurs as a secondary mineral in the oxidation zones of ore deposits (Roberts et al. 1990 [DIRS 107105], p. 692). Secondary mineral, often by the alteration of molybdenite, in copper deposits, deposits encountering contact metamorphism (Palache et al. 1951 [DIRS 162280], p. $1,080)$.

Occurs chiefly in the oxidation zone of copper deposits, often associated with other secondary minerals. Also occurs as a sublimation product deposited on lavas in volcanic regions (Roberts et al. 1990 [DIRS 107105], p. 856; Palache et al. 1944 [DIRS 163604], p. 509). CuO is a component of patina formed in atmospheric and aqueous corrosion of copper alloys, though not specifically given the mineral name tenorite (Sequeira 2000 [DIRS 162970]).

Alteration product of uraninite $\left(\mathrm{UO}_{2}\right)$; associated with bequerelite, curite and other secondary minerals of $\mathrm{U}$ (Palache et al. 1944

[DIRS 163604], p. 628). The phase Na-boltwoodite was observed to form in some simulations where it was typically below $10^{-4}$ moles. It is a phase that is expected to be stable in the corroding waste package environment (BSC 2004 [DIRS 169425], Section 6.7.2.1).

Most common $\mathrm{Al}(\mathrm{OH})_{3}$ polymorph (Hsu 1995 [DIRS 105875]). $\mathrm{AlOOH}$ are rarer than hydroxides and are considered the product of weathering (Allen and Hajek 1995 [DIRS 159372]) so the $\mathrm{Al}(\mathrm{OH})_{3}$ polymorphs will be the primary ones expected to form in the waste package.

Most common kaolin, formation at $25^{\circ} \mathrm{C}$ is usually slow, however it can crystallize easily from the alteration of smectites (Dixon 1995 [DIRS 159374]).

One of the three most common smectite minerals found in soils. Smectites are common in temperate and cold climates, but may form or be preserved in tropical environments where leaching is limited or drainage is restricted (Allen and Hajek 1995 [DIRS 159372]).

Gadolinium phosphate hydrates are insoluble in near-neutral pH solutions (Firsching and Brune 1991 [DIRS 106357]). Monazite type minerals, of which $\mathrm{GdPO}_{4}$ is one, is usually formed under hydrothermal conditions, but studies have indicated the formation of monazites at low temperatures (Spahiu and Bruno 1995 [DIRS 103804]), and the formation of $\mathrm{GdPO}_{4}: 10 \mathrm{H}_{2} \mathrm{O}$ is consistent with the formation of $\left(\mathrm{UO}_{2}\right)_{3}\left(\mathrm{PO}_{4}\right)_{2}: \mathrm{xH}_{2} \mathrm{O}$.

$\mathrm{x}=4$ or $6 .\left(\mathrm{UO}_{2}\right)_{3}\left(\mathrm{PO}_{4}\right)_{2}: 4 \mathrm{H}_{2} \mathrm{O}$ is a stable phase under oxidizing conditions, low temperature, and $\mathrm{pH}$ values relevant for natural water systems (Sandino 1991 [DIRS 113307], pp. 16 to 17). $\left(\mathrm{UO}_{2}\right)_{3}\left(\mathrm{PO}_{4}\right)_{2}: 6 \mathrm{H}_{2} \mathrm{O}$ was also allowed to form since uranyl phosphates are associated with a wide range of weathered U deposits (Finch and Murakami 1999 [DIRS 145442]), but few uranyl phosphates are included in the EQ6 database.

Chalcedony readily precipitates from aqueous solutions and is frequently found lining or filling cavities in rocks (Klein and Hurlbut 1985 [DIRS 105907], pp. 441 to 442 ).

High P/T mineral, found in sedimentary deposits as a detrital mineral (Roberts et al. 1990 [DIRS 107105], p. 62), also formed in metamict zircon (Deer et al. 1966 [DIRS 102773], p. 15). Baddeleyite was allowed to form in the waste package since hydrolysis of Zr salts leads to precipitation of poorly crystalline oxides at low temperatures (Milnes and Fitzpatrick 1995 [DIRS 105911], pp. 1,189 to 1,190), and soluble Zr may be incorporated in or sorb on clay mineral surfaces (Milnes and Fitzpatrick 1995 [DIRS 105911], pp. 1,185 to 1,186). So, it is likely that some of the $\mathrm{Zr}$ released by degradation of waste package components will precipitate or be sorbed. 


\subsubsection{Surface Complexation Model}

The surface complexation model examines the effects of the contact of the solution predicted by the batch reactor model (Section 6.3.1) with corrosion product surfaces. Waste form and waste package degradation will involve oxidation and hydration of fuel elements and steels. Carbon Steel Type A516 corrosion will be particularly rapid relative to fuel oxidation and will result in large accumulations of ferric (hydr)oxide corrosion products inside the waste package, where (hydr)oxide means any oxide, hydroxide, or oxyhydroxide that has ferric iron in it. Because there is substantially more iron in the waste packages than $\mathrm{U}$ - the most abundant radionuclide it is reasonable to expect ferric (hydr)oxides to be the single most abundant phase in degraded waste packages.

Although the formation of large masses of ferric (hydr)oxide corrosion products is inevitable, it is difficult to predict which one will dominate the mineralogy of the whole. Goethite and hematite are expected to eventually be the most abundant iron oxides in corrosion products (Schwertmann and Cornell 1991 [DIRS 144629], Section 4.2.2). Poorly crystalline solids such as ferrihydrite $\left(\mathrm{Fe}_{5} \mathrm{HO}_{8} \cdot 4 \mathrm{H}_{2} \mathrm{O}\right)$ and $\mathrm{Fe}(\mathrm{OH})_{3}$ that form during rapid oxidation of $\mathrm{Fe}(\mathrm{II})$ and hydrolysis of $\mathrm{Fe}(\mathrm{III})$, will probably be present throughout the period of steel degradation in the waste package (Schwertmann and Cornell 1991 [DIRS 144629], Sections 1.3 and 8.1). These poorly crystalline iron oxides are unstable with respect to hematite and goethite, but their transformation is significantly inhibited or retarded by their adsorption or structural substitution, or both, of silicate, phosphate, and $\mathrm{Cr}(\mathrm{III})$, which are common components of the waste package solution. To summarize, the corrosion product assemblage is likely to be made up of some mixture of hematite, goethite, and ferrihydrite. However, the batch reactor model uses hematite and goethite, as described in Section 6.3.1.3.5, but the surface complexation uses ferric (hydr)oxides. Properties of these phases are presented in Table 4-10.

In natural systems, less crystalline ferric (hydr)oxides appear to control the surface chemistry of soils and aquifers by coating the surfaces of other more abundant minerals. The observation that "surface coatings on larger mineral grains in soils and sediments may exhibit site densities per unit mass similar to ferrihydrite even though present as fine-grained crystalline material" (Davis et al. 2002 [DIRS 168855]) is routinely observed for natural systems. Specifically, surface coatings of natural minerals appear to possess the site densities per unit mass of amorphous materials (Davis et al. 1998 [DIRS 154436]; Waite et al. 2000 [DIRS 168856]). Consequently, the surface chemistry of natural sediments is routinely modeled by assuming that the surface area of the sediments is composed entirely of ferrihydrite (Waite et al. 2000 [DIRS 168856]). Although modeling surface effects in natural systems remains the focus of continuing research, the present state of knowledge suggests that a reasonable approach to approximating the buffering of $\mathrm{pH}$ by ferric (hydr)oxide corrosion products inside of breached waste packages is to estimate quantitatively the properties and effects of the resulting ferric (hydr)oxide surfaces. Thus, similar to those described by Waite et al. (2000 [DIRS 168856]), surface complexation reactions in the waste packages are treated as if they are entirely due to ferrihydrite coatings.

Reported isoelectric points $\left(\mathrm{pH}_{\mathrm{IEP}}\right)$ of ferric (hydr)oxides are listed in Table 4-10. The $\mathrm{pH}_{\text {IEP }}$ values from Chemistry of the Solid-Water Interface, Processes at the Mineral-Water and Particle-Water Interface in Natural Systems (Stumm 1992 [DIRS 141778]) and Surface Complexation Modeling, Hydrous Ferric Oxidei (Dzombak and Morel 1990 [DIRS 105483]) are 
considered more reliable measurements than those tabulated by Langmuir (1997 [DIRS 100051]) because Stumm (1992 [DIRS 141778]) and Dzombak and Morel (1990 [DIRS 105483]) works are devoted solely to the topic of adsorption. These $\mathrm{pH}_{\mathrm{IEP}}$ values range from 7.3 to 8.7 (Table 4-10). Iron corrosion will result in a mixture of amorphous and crystalline iron phases (Schwertmann and Cornell 1991 [DIRS 144629], Sections 4.2.1 and 4.2.2). However, the amorphous iron phases will likely dominate the surface reactions in the waste package due to their higher surface-site concentrations per mass of water. Ferrihydrite, therefore, is a good choice as an iron corrosion product to represent the mixture of iron corrosion products. This choice is consistent with the findings of Schwertmann and Cornell (1991 [DIRS 144629]) and Waite et al. (2000 [DIRS 168856]). Another reasonable choice is goethite based on its relatively high specific surface area and comparable surface site density (Table 4-10).

For TSPA-LA, the most important effect of surface reactions is the capacity to buffer the $\mathrm{pH}$ in the near-neutral range. Based on work by Stumm (1992 [DIRS 141778]) and Dzombak and Morel (1990 [DIRS 105483]), the isoelectric points of ferrihydrite and goethite are between 7 to 8 (Table 4-10) that indicates that the predominant surfaces in the waste package will tend to buffer the $\mathrm{pH}$ in the near-neutral range, adsorbing protons as $\mathrm{pH}$ values decrease and releasing protons as $\mathrm{pH}$ values increase. Considerable departures from the near-neutral $\mathrm{pH}$ range (i.e., outside the 5 to $9 \mathrm{pH}$ range) have the potential of increasing dose calculations in TSPA-LA by increasing radionuclide solubilities. Thus, consideration of surface reactions tends to improve predictions of repository performance. Therefore, steps must be taken to prevent overstating the potential effects of surface reactions. This concern is addressed in Sections 6.7 and 6.8.

A quick calculation shows that between 10 and 40 moles of ferric (hydr)oxides (ferrihydrite, goethite, or hematite) will form per kilogram of water in almost all runs due to the degradation of Carbon Steel Type A516 and Stainless Steel Type 316 (Appendix F, CSNF.xls, "Moles Corrosion Products" tab). Roughly $30 \%$ of the ferric (hydr)oxides appears in the first 100 years due to the degradation of Carbon Steel Type A516. The batch reactor model calculates the formation of ferric (hydr)oxides and accounts for their presence in, for example, the calculation of dissolved Fe levels. Nevertheless, the batch reactor model does not consider the ability of iron(III) mineral surfaces to control in-package $\mathrm{pH}$ through the acquisition or loss of protons at low and high $\mathrm{pH}$ values, respectively. The latter effect is likely to be large given that there are from 0.02 to 0.9 moles of reactive sites per mole of Fe(III) precipitated as goethite or ferrihydrite (Table 4-10, 0.02 rounded up from 0.017). The total amount of reactive sites available for $\mathrm{pH}$ buffering is between 0.2 moles $(10$ moles $\times 0.02)$ and 36 moles $(40$ moles $\times 0.09)$ per liter of void space. Compare this to maximal estimated acid and base loads of the batch reactor model, respectively, $\sim 10^{-3}$ moles of protons per liter (corresponds to $\mathrm{pH} \sim 3$ ) and $10^{-4}$ hydroxyls per liter (corresponds to $\mathrm{pH} \sim 10$ ).

The approach is then to consider the chemical reactivity of the fuel and steel components in isolation and in combination in order to bound the fluid compositions produced by oxidation, as modeled in the batch reactor model (Section 6.3.1) and to then consider the degree to which ferric (hydr)oxide surface will affect their chemistry.

The above discussion addresses the subject matter of "Included" FEP 2.1.09.02.0A (Chemical interaction with corrosion products) and indicates how that subject matter has been included and addressed within TSPA-LA. Corrosion products are generated during the degradation of the 
metal alloys that make up the waste package components. Therefore, the effect of the corrosion products on the in-package chemistry is directly handled by the in-package surface complexation model that accounts for the effects of surface complexation of the in-package fluids with the corrosion products.

\subsubsection{Development of the Surface Complexation Demonstration Database}

The surface complexation demonstration database for hydrous ferric oxide (HFO) is developed in this section. This database is used in Section 6.8, in the surface complexation demonstration. The surface complexation demonstration is solely intended to build confidence in the surface complexation model discussed in the previous section, and is not an actual technical product of this model.

The data to be evaluated are the surface complexation reactions and log K values in Table 6-14 and includes data by Dzombak and Morel (1990 [DIRS 105483]). Surface Complexation Modeling, Hydrous Ferric Oxide (Dzombak and Morel 1990 [DIRS 105483]) is a widely acclaimed treatise on surface complexation modeling for HFO.

A diffuse-layer surface complexation model for hydrous ferric oxide (HFO) is used in this report to demonstrate the adsorption effects predicted by the in-package chemistry model. The model is developed and documented in detail in Surface Complexation Modeling, Hydrous Ferric Oxide (Dzombak and Morel 1990 [DIRS 105483]). It is one of several adsorption models available within PHREEQC. The diffuse layer surface model was selected because it has the largest thermodynamic database for support.

The thermodynamic database used for the surface complexation demonstration is provided in Table 6-14 for ferrihydrite (in addition to the data provided in Table 4-9). These data are used as input to develop a surface complexation database. They are also used to develop a PHREEQC database for the adsorption demonstrations. In addition, several of these reactions are used to explain $\mathrm{pH}$-buffering effects.

Table 6-14. Surface Complexation Reactions

\begin{tabular}{|c|c|c|}
\hline Reaction & $\log K$ & $\begin{array}{c}\text { Source: Dzombak and } \\
\text { Morel } 1990 \text { [DIRS 105483] }\end{array}$ \\
\hline $\mathrm{HFO} \_\mathrm{sOH}+\mathrm{Ca}^{2+}=\mathrm{HFO} \_\mathrm{sOHCa}{ }^{2+}$ & 4.97 & Table 10.1 \\
\hline $\mathrm{HFO} \_\mathrm{wOH}+\mathrm{Ca}^{2+}=\mathrm{HFO} \_\mathrm{wOCa}^{+}+\mathrm{H}^{+}$ & -5.85 & Table 10.1 \\
\hline $\mathrm{HFO} \_\mathrm{sOH}+\mathrm{Cd}^{2+}=\mathrm{HFO} \_\mathrm{sOCd}^{+}+\mathrm{H}^{+}$ & 0.47 & Table 10.2 \\
\hline $\mathrm{HFO} \_w O H+\mathrm{Cd}^{2+}=\mathrm{HFO} \_w O C d^{+}+\mathrm{H}^{+}$ & -2.9 & Table 10.2 \\
\hline $\mathrm{HFO} \_\mathrm{sOH}+\mathrm{Cr}^{3+}+\mathrm{H}_{2} \mathrm{O}=\mathrm{HFO} \_\mathrm{sOCrOH}{ }^{+}+2 \mathrm{H}^{+}$ & 2.06 & Tables 10.3 (and 6.43) $^{\mathrm{a}}$ \\
\hline $\mathrm{HFO} \_\mathrm{sOH}+\mathrm{Cu}^{2+}=\mathrm{HFO} \_\mathrm{sOCu}{ }^{+}+\mathrm{H}^{+}$ & 2.89 & Table 10.2 \\
\hline $\mathrm{HFO} \_w O H+\mathrm{Cu}^{2+}=\mathrm{HFO} \_w O C u^{+}+\mathrm{H}^{+}$ & 0.6 & Table 10.5 \\
\hline $\mathrm{HFO} \_\mathrm{sOH}+\mathrm{Ni}^{2+}=\mathrm{HFO} \_\mathrm{sONi}^{+}+\mathrm{H}^{+}$ & 0.37 & Table 10.2 \\
\hline $\mathrm{HFO}_{2} \mathrm{wOH}+\mathrm{Ni}^{2+}=\mathrm{HFO} \_\mathrm{wONi}^{+}+\mathrm{H}^{+}$ & -2.5 & Table 10.5 \\
\hline $\mathrm{HFO} \_\mathrm{sOH}+\mathrm{Pb}^{2+}=\mathrm{HFO} \_\mathrm{sOPb}^{+}+\mathrm{H}^{+}$ & 4.65 & Table 10.2 \\
\hline $\mathrm{HFO} \_\mathrm{wOH}+\mathrm{Pb}^{2+}=\mathrm{HFO} \_\mathrm{wOPb}^{+}+\mathrm{H}^{+}$ & 0.3 & Table 10.5 \\
\hline $\mathrm{HFO} \_\mathrm{sOH}+\mathrm{Sr}^{2+}=\mathrm{HFO} \_\mathrm{sOHSr}{ }^{2+}$ & 5.01 & Table 10.1 \\
\hline $\mathrm{HFO} \_\mathrm{wOH}+\mathrm{Sr}^{2+}=\mathrm{HFO} \_\mathrm{wOSr}^{+}+\mathrm{H}^{+}$ & -6.58 & Table 10.1 \\
\hline $\mathrm{HFO} \_\mathrm{wOH}+\mathrm{Sr}^{2+}+\mathrm{H}_{2} \mathrm{O}=\mathrm{HFO} \_w O S r O H+2 \mathrm{H}^{+}$ & -17.6 & Table 10.1 \\
\hline
\end{tabular}


Table 6-14. Surface Complexation Reactions (Continued)

\begin{tabular}{|l|c|l|}
\hline \multicolumn{1}{|c|}{ Reaction } & log K & \multicolumn{1}{c|}{ Source: Dzombak and } \\
Morel 1990 [DIRS 105483]
\end{tabular}

NOTE: ${ }^{a}$ There is a charge balance error in the reaction in Dzombak and Morel 1990 [DIRS 105483], Table 10.3. Reaction is taken from Table 6.43 instead.

\subsection{Evaluation of Experimental Data}

An entire chapter by Dzombak and Morel (1990 [DIRS 105483], Chapter 4) is dedicated to the careful and thorough compilation of experimental data. Dzombak and Morel (1990 
[DIRS 105483]) established a rigorous, systematic procedure to identify and collect all available adsorption data from refereed papers, books, technical reports, and dissertations. These data were then scrutinized for the critical information needed to determine whether to accept or reject the data for the purpose of deriving surface complexation model reactions. The decision to accept or reject a given data set was based on reliability and/or usefulness of the data. Critical information included (Dzombak and Morel (1990 [DIRS 105483], p. 66):

- Method of preparation of the HFO

- Composition of the electrolyte solution

- Temperature

- Type of reaction vessel

- Methods employed to avoid carbonate contamination

- Sorbate/sorbent ratio

- Equilibration time

- Method of solid-liquid separation

- Analytical methods

- Method for controlling $\mathrm{pH}$

- Other potentially important factors.

Experimental details for each data set, whether accepted or rejected, are included in Surface Complexation Modeling, Hydrous Ferric Oxide (Dzombak and Morel (1990 [DIRS 105483], Appendix A).

Dzombak and Morel (1990 [DIRS 105483]) did not include carbonate as one of the sorbates in its model. The carbonate adsorption reactions in Table 4-9 are obtained from Appelo et al. (2002 [DIRS 168168]). These reactions were derived from experimental data presented by Zachara et al. (1987 [DIRS 105963]), one of the papers Dzombak and Morel (1990 [DIRS 105483]) accepted for its experimental chromate adsorption data. Based on the critical information necessary to accept or reject the data set (as outlined above), carbonate adsorption data from the report by Zachara et al. (1987 [DIRS 105963]) was found to satisfy the data criterion.

Several of the sorbates and their adsorption reactions in Table 4-9 and Table 6-14 are estimated based on linear free energy relationships (Dzombak and Morel 1990 [DIRS 105483], Chapter 10). Their effects are reflected in this report's results (Section 6.8.4). 


\subsection{Evaluation of Accuracy of Derived Surface Complexation Reactions}

The accuracy of the surface complexation database is evaluated by comparing model predictions to the experimental data (i.e., to the experimental data presented by Dzombak and Morel (1990 [DIRS 105483]) and Appelo et al. (2002 [DIRS 168168])).

Surface complexation reactions were considered acceptable if:

- Predictions of percent adsorbed within 20\% (absolute) of experimental data for at least $90 \%$ of the experimental data for a given sorbate

- $\mathrm{pH}$ predicted within $0.5 \mathrm{pH}$ unit for at least $90 \%$ of the surface hydrolysis experimental data.

The percentage of experimental data that fall within these limits was determined for $\mathrm{pH}$ and each sorbate by examining the graphs presented in Dzombak and Morel (1990 [DIRS 105483]) and Appelo et al. (2002 [DIRS 168168]). On each of the graphs in Dzombak and Morel (1990 [DIRS 105483]), the differences between predictions and measurements were determined by comparing the data points to the dashed lines. The dashed lines represent predictions based on the derived surface complexation database. For carbonate adsorption, experimental data are compared to predictions represented by the solid lines in the graph presented by Appelo et al. (2002 [DIRS 168168], p. 3,097). The results are summarized in Table 6-15 for the sorbates with experimental adsorption data.

Table 6-15. Results of Accuracy Evaluation

\begin{tabular}{|l|l|l||l|l|l|}
\hline Sorbate & $\begin{array}{l}\text { Accuracy } \\
\text { Criterion }\end{array}$ & $\begin{array}{c}\text { Source: Dzombak } \\
\text { and Morel 1990 } \\
\text { [DIRS 105483] }\end{array}$ & Sorbate & $\begin{array}{l}\text { Accuracy } \\
\text { Criterion }\end{array}$ & $\begin{array}{c}\text { Source: Dzombak } \\
\text { and Morel 1990 } \\
\text { [DIRS 105483] }\end{array}$ \\
\hline $\mathrm{Pb}^{2+}$ & Met & pp. 108 to 109 & $\mathrm{H}^{+}$ & Met & pp. 96 to 100 \\
\hline $\mathrm{Zn}^{2+}$ & Met & pp. 113 to 123 & $\mathrm{PO}_{4}{ }^{3-}$ & Not Met & pp. 195 to 199 \\
\hline $\mathrm{Cd}^{2+}$ & Met & pp. 127 to 138 & $\mathrm{AsO}_{4}{ }^{2-}$ & Not Met & pp. 202 to 204 \\
\hline $\mathrm{Hg}^{2+}$ & Not Met & pp. 145 to 147 & $\mathrm{VO}_{4}{ }^{3-}$ & Met & pp. 207 to 212 \\
\hline $\mathrm{Cu}^{2+}$ & Met & pp. 150 to 154 & $\mathrm{AsO}_{3}{ }^{2-}$ & Not Met & pp. 214 to 216 \\
\hline $\mathrm{Ag}^{+}$ & Not Met & pp. 156 to 158 & ${\mathrm{~B}\left(\mathrm{OH}_{3}\right.}^{2}$ & Met & p. 218 \\
\hline $\mathrm{Ni}^{2+}$ & Met & p. 160 & $\mathrm{SO}_{4}{ }^{2-}$ & Met & p. 220 \\
\hline $\mathrm{Co}^{2+}$ & Not Met & pp. 166 to 169 & $\mathrm{SeO}_{4}{ }^{2-}$ & Met & pp. 222 to 225 \\
\hline $\mathrm{Cr}^{3+}$ & Met & pp. 171 to 172 & $\mathrm{SeO}_{3}{ }^{2-}$ & Met & p. 227 \\
\hline $\mathrm{Ca}^{2+}$ & Met & pp. 174 to 178 & $\mathrm{~S}_{2} \mathrm{O}_{3}{ }^{2-}$ & Met & p. 229 \\
\hline $\mathrm{Sr}^{2+}$ & Met & pp. 181 to 186 & $\mathrm{CrO}_{4}{ }^{2-}$ & Met & pp. 232 to 238 \\
\hline $\mathrm{Ba}^{2+}$ & Not Met & pp. 188 to 190 & $\mathrm{CO}_{3}{ }^{2-}$ & Met & p. $3,097{ }^{\text {a }}$ \\
\hline
\end{tabular}

NOTES: ${ }^{a}$ Appelo et al. 2002 [DIRS 168168].

${ }^{\mathrm{b}}$ No graphs provide percent adsorbed versus $\mathrm{pH}$ for $\mathrm{PO}_{4}{ }^{3-}$.

\subsubsection{Thermodynamic Database for PHREEQC}

YMP_R3.dat is the thermodynamic database developed for the PHREEQC calculations performed in Section 6.8. This database is developed in this section and documented in 
DTN: MO0403SPAYMPR3.000. It is nearly identical to the data0.ymp.R2 database for EQ3/6, except for the following:

- It is in PHREEQC database format

- It only has equilibrium constants for $25^{\circ} \mathrm{C}$ and, therefore, is only valid for calculations at $25^{\circ} \mathrm{C}$

- The error in the $\log \mathrm{K}$ value and formula of solid $\mathrm{PuO}_{2}(\mathrm{OH})_{2} \cdot \mathrm{H}_{2} \mathrm{O}$ was corrected

- Acetic acid, ethane, formate, formaldehyde, formic acid, methane, methanol, $\mathrm{H}_{2} \mathrm{O}_{2}$, and $\mathrm{HO}_{2}^{-}$have been removed

- Nine $\mathrm{CaO}-\mathrm{Al}_{2} \mathrm{O}_{3}$ minerals, $1.7 \mathrm{Ca}(\mathrm{OH})_{2} \mathrm{SiO}_{2} \cdot 0.917 \mathrm{H}_{2} \mathrm{O}, \mathrm{Be}_{13} \mathrm{U}$, friedl salt, hydrogarnet, and $\mathrm{U}_{3} \mathrm{P}_{4}$ have been removed

- USe, $\mathrm{USe}_{2}$ (alpha), USe ${ }_{2}$ (beta), and $\mathrm{USe}_{3}$ mineral phases have been renamed to $\mathrm{SeU}$, $\mathrm{Se}_{2} \mathrm{U}\left(\right.$ alpha), $\mathrm{Se}_{2} \mathrm{U}$ (beta), and $\mathrm{Se}_{3} \mathrm{U}$

- Surface complexation reactions documented in DTN: MO0403SPASURCR.000 are added to the database.

Other minor additions and modifications (due to differences in how the EQ3/6 and PHREEQC codes work) are documented in the comment lines of the YMP_R3.dat file.

This database was initially translated from the data0.ymp.R2 database in DTN: MO0210SPATHDYN.000 [DIRS 160229]. First, EQPT from EQ3/6, version 7.2b (STN: UCRL-MA-110662), was used on an IBM-compatible computer with a Windows 95 operating system to generate a datalf.ymp file from the data0.ymp.R2 database. Before this file could be translated to the PHREEQC format, the organic species and reactions listed above had to be removed. This was done and transl (transl V2.0, STN: 10251-2.0-00 [DIRS 155029]) was then used to perform the translation on an IBM-compatible computer with a Windows 98 operating system. The translation produced files named phreeqc.ymp (the database translation into PHREEQC) and fix_redox.out (a list of redox reactions requiring correction in the phreeqc.ymp file. As instructed in the Transl software management report (BSC 2001 [DIRS 154880]), the first file was corrected based on the redox comments in the second file. These files can be found in Appendix F.

Two additional steps were involved in the final production of the $Y M P_{-}$R3.dat database. First, the phreeqc.ymp file described above (YMP_R3.dat database in this step) was updated to match the changes made in the final data0.ymp.R2 EQ3/6 database (DTN: MO0302SPATHDYN.000 [DIRS 161756]) and to correct the error in the log $\mathrm{K}$ value and formula of solid $\mathrm{PuO}_{2}(\mathrm{OH})_{2} \mathrm{H}_{2} \mathrm{O}$. Second, the surface complexation reactions documented in DTN: MO0403SPASURCR.000 were added to the database.

The complete YMP_R3.dat database that includes the surface complexation database for HFO, is documented in DTN : MO0403SPAYMPR3.000. 


\subsection{ALTERNATIVE CONCEPTUAL MODELS}

\subsubsection{Alternative Conceptual Model I}

The interior of a waste package is spatially heterogeneous with respect to composition; therefore, a stream of water traveling vertically downward through the cross-sectional interior of a waste package would encounter different materials at different times. Along this flow path and at a given time, water molecules in the stream of water would react with the solid or solids to which they were immediately adjacent, resulting in a water stream with a variable composition along its flow path. This conceptual model could be viewed as a one-dimensional column composed of $n$ cells in which the reactants in each cell represent the waste package components in vertical cross section of the waste package - this model would eliminate the constraint of the EQ6 solidcentered flow-through mode, used in the in-package chemistry model, of a well-mixed batch reactor. This alternative conceptual model would also provide spatial information on the chemistry inside of a breached waste package, information that is not used by total system performance assessment.

The vapor influx model results showed (Section 6.5.1) the mixing model actually provides a good alternative to the more-complex Alternate Conceptual Model I since the waste package materials tend to have an overwhelming effect on the in-package chemistry regardless of mixing.

\subsubsection{Alternative Conceptual Model II}

Seepage entering a breached waste package is likely to vary in composition as a function of time (i.e., as the prevailing conditions in the drift and engineered barrier system (EBS) vary over time). Therefore, a conceptual model that implemented a continuously varying input fluid composition would be more realistic than the current in-package chemistry model, in which the input fluid compositions are constant over time. The water influx model showed that model response was largely insensitive to input water composition because the effect of the waste package materials on the in-package chemistry exerted much more control than the input water composition (Section 6.5.2). The alternative conceptual models are listed in Table 6-16.

Table 6-16. Alternative In-Package Chemistry Conceptual Models

\begin{tabular}{|l|l|l|}
\hline Alternative Conceptual Model & \multicolumn{1}{|c|}{ Key Features } & \multicolumn{1}{|c|}{ Screening Assessment and Basis } \\
\hline Alternative Conceptual Model I & $\begin{array}{l}\text { Waste package is compositionally } \\
\text { heterogeneous }\end{array}$ & $\begin{array}{l}\text { Vapor influx model showed resulting } \\
\text { chemical effects of individual waste } \\
\text { package components were comparable to } \\
\text { that of their ensembles (Section 6.5.1) }\end{array}$ \\
\hline Alternative Conceptual Model II & $\begin{array}{l}\text { Composition of seepage entering a } \\
\text { waste package is likely to vary as } \\
\text { a function of changing conditions } \\
\text { in the unsaturated zone and drift } \\
\text { environments }\end{array}$ & $\begin{array}{l}\text { The water influx model showed wide } \\
\text { compositional ranges in the seepage } \\
\text { composition had little influence on the } \\
\text { resulting in-package chemistry } \\
\text { (Section 6.5.2) }\end{array}$ \\
\hline
\end{tabular}

Although these alternative models have been considered, it has been demonstrated in this model report that the current base-case model is sufficient, robust, and adequate for its intended purpose. 


\subsection{BATCH REACTOR BASE CASE MODEL OUTPUT}

This section provides the output from the batch reactor model runs. The $\mathrm{pH}$ ranges from the surface complexation model are shown in some of these plots, but the implementation of the surface complexation model is actually discussed in Section 6.9.

The "time" on the x-axis for all plots refers to the time after both the breach of the waste package has occurred, and temperature in the repository has dropped below $100^{\circ} \mathrm{C}$.

\subsubsection{Vapor Influx Model Results}

\subsubsection{CSNF Output}

Figure 6-1 displays the EQ6 results of the CSNF single component runs. The pH profiles in Figure 6-1 are plotted as a function of reaction progress (the EQ6 zi $(\xi)$ variable is moles reacted) rather than time elapsed. Plotting the results in this manner allows reactants' different degradation rates to be compared with each other. This figure provides information on how each waste package component contributes to the in-package $\mathrm{pH}$ and shows the upper- and lower-pH bounds for the components in the CSNF package.

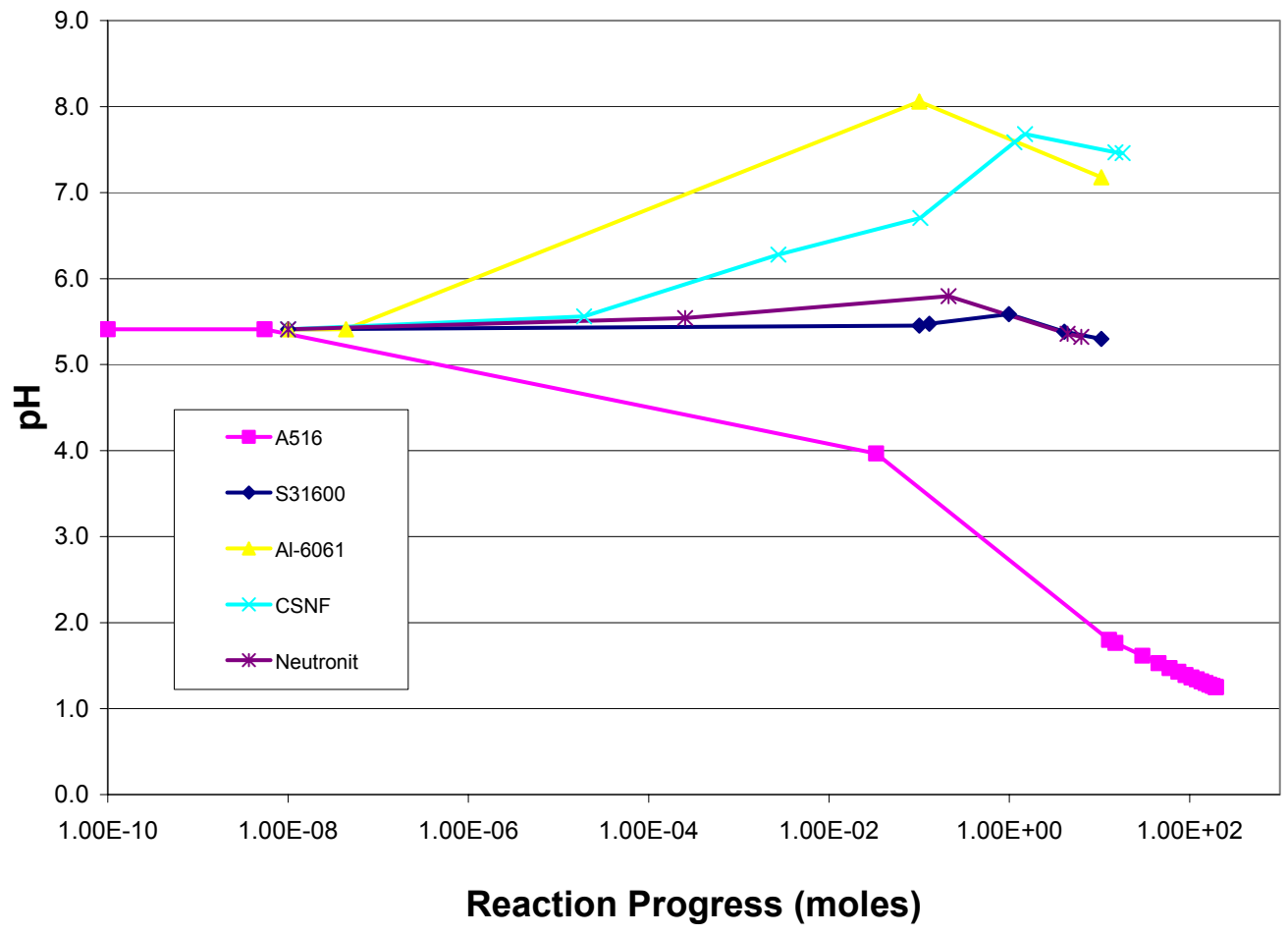

Source: $\quad$ CSNF_Vapor Influx_Singlereact.xls in Appendix F.

Figure 6-1. CSNF Single-Component Vapor Influx pH Outputs

The low $\mathrm{pH}$ resulting from Carbon Steel Type A516 corrosion is due to the combination of oxidation of sulfur, the large quantity of Carbon Steel Type A516, and its high corrosion rate relative to the other waste package components. When the surface complexation model is applied to the batch reactor results, the $\mathrm{pH}$ does not go below 4.5. In addition, the oxidation 
layer that would form on degrading steels would also slow degradation and further buffer the $\mathrm{pH}$, though this effect is not modeled (Section 5.2). Aluminum Alloy 6061 and CSNF have neutral to slightly basic $\mathrm{pH}$ profiles, while Stainless Steel Type 316 and Neutronit have slightly acidic $\mathrm{pH}$ profiles. The trends observed in the $\mathrm{pH}$ are a function of the mineral phases becoming saturated and then precipitating as more and more reactant is added to solution.

A comparison of Figure 6-1 and Figure 6-2 reveals that the $\mathrm{pH}$ range exhibited by the singlecomponent runs (Figure 6-1) is also bounded by the multicomponent runs. The multicomponent CSNF vapor influx cases are defined in Table 6-2. The similar $\mathrm{pH}$ range of the two groups of simulations illustrates $\mathrm{pH}$ is dominated by the reactants and not necessarily by the conceptual model. This builds confidence in the robustness of the model.

The most acid-producing profiles include those for Carbon Steel Type A516 (in Figure 6-1) and comp8 and comp9 (in Figure 6-2). The low $\mathrm{pH}$ observed in the comp8 and comp9 profiles is due to the lack of a buffering reactant in the ensemble. Comp8 is composed of Carbon Steel Type A516 and Neutronit, while comp9 is composed of Carbon Steel Type A516 and Stainless Steel Type 316, all of which are acid-producing reactants (Figure 6-1).

The comp3 and comp7 ensembles contain Aluminum Alloy 6061 and Carbon Steel Type A516, while comp3 also contains CSNF. For these two ensembles, the early-time $\mathrm{pH}(<100$ years) was controlled by Carbon Steel Type A516 dissolution, the middle period (100 to 1,000 years) by Aluminum Alloy 6061 dissolution, and greater than 1,000 years by equilibrium with the corrosion products. The CSNF in comp3 had a minimal effect on the system $\mathrm{pH}$.

Only reactant combinations that include CSNF will be used in the generation of $\mathrm{pH}$ abstractions because the fuel is a very important component in the waste package. The CSNF strongly influences the chemistry and it would be an error to not account for its effect on the chemistry. Therefore, simulations comp5 through comp9 that do not include CSNF as part of the ensemble, are not included in the in-package chemistry model abstraction.

Furthermore, Figure 6-2 shows $\mathrm{pH}$ trends are similar in shape and magnitude, with the exception of comp8 and 9 (because they do not contain CSNF). These two observations build confidence in the robustness of the conceptual model compared to Alternate Conceptual Model I (Section 6.4.1). Had the $\mathrm{pH}$ profiles shown a great degree of variability, it would indicate that the in-package chemistry is highly path dependent; thus, decreasing confidence in the robustness of the vapor influx model.

Figure 6-3 displays the ionic strength profiles for the CSNF vapor influx model runs. Under vapor influx conditions, the interior of the waste package is dry at the moment of waste package breach. With time the humidity of the interior of the waste package will equilibrate to the ambient drift conditions and water will begin to adsorb or condense to the interior waste package components. The ratio of water to reactants is initially small and increases with time, so the ionic strength will initially be high and decrease with time as more water enters the system. This is an effect that is not captured by the vapor influx EQ6 model, because the batch reactor model considers the water needed for the model is instantly available once the waste package breaches, rather than the water taking time to accumulate in the waste package (Section 6.3.1.1). However, this effect is accounted for in the ionic strength model abstraction (Section 6.10.2). 


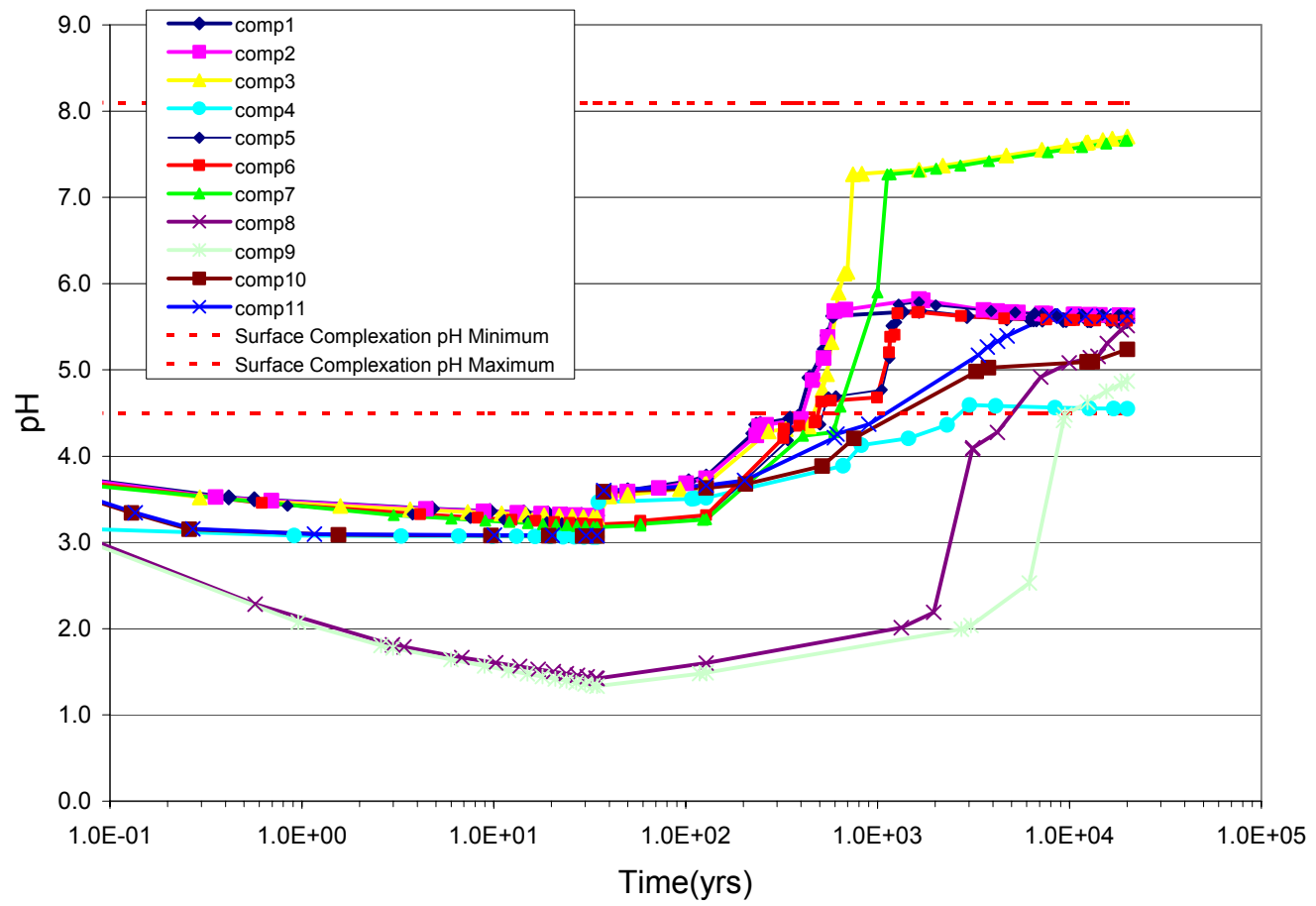

Source: CSNF_Vapor Influx_MultiComp.xls in Appendix F.

NOTE: Time refers to time after waste package breach.

Figure 6-2. CSNF Multicomponent Ensemble pH Profiles

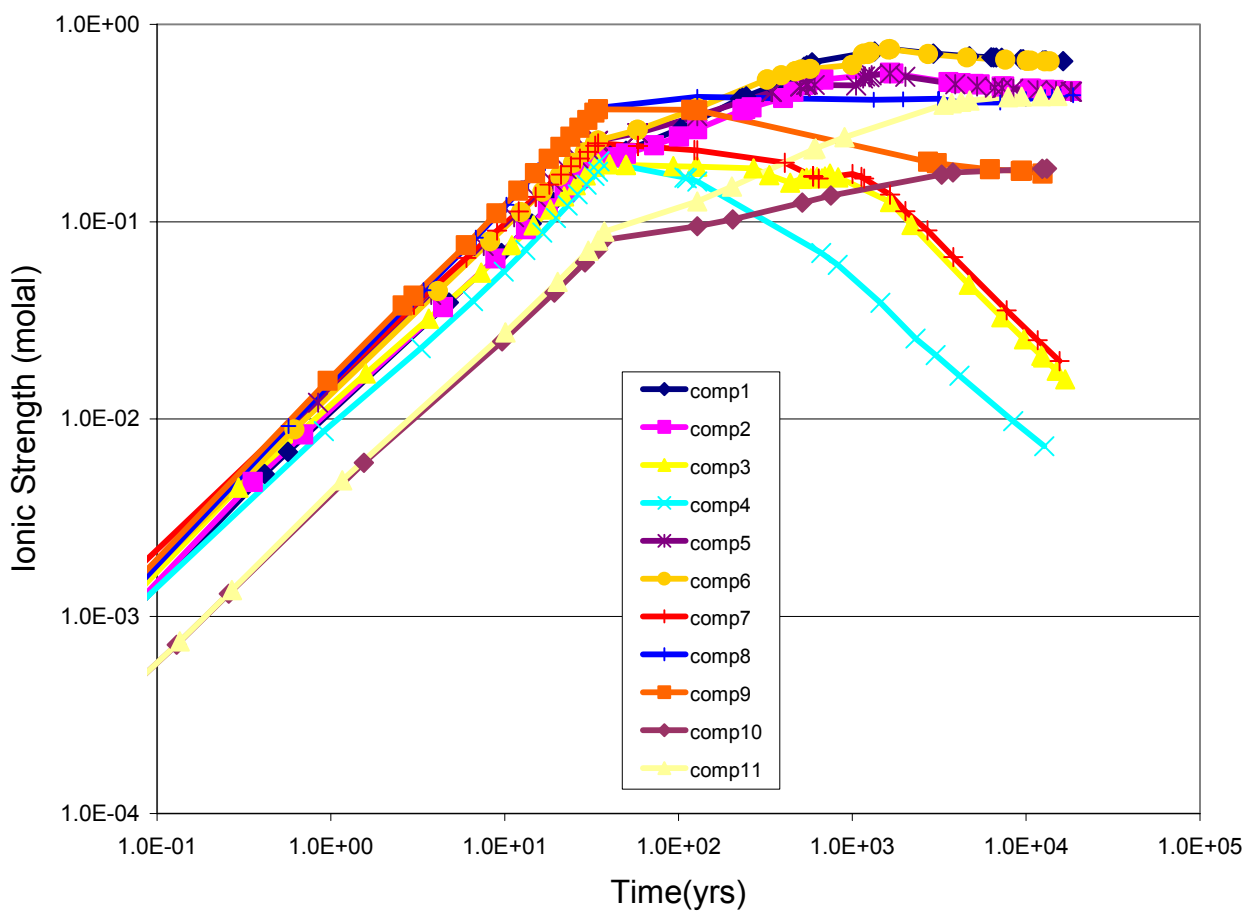

Source: CSNF_VaporInflux_MultiComp.xls (Appendix F ISpreadsheets).

NOTE: Time refers to time after waste package breach.

Figure 6-3. CSNF Multicomponent Vapor Influx lonic Strength 


\subsubsection{CDSP Output}

Figure 6-4 displays the EQ6 output-pH profiles for the CDSP waste package components. The CDSP package displays a much wider variation in $\mathrm{pH}$ compared to the CSNF package (Figure 6-1). HLWG generates high-pH conditions due the high concentrations of sodium and potassium. Aluminum Alloy 1100, Stainless Steel Type 316, and N Reactor fall in the middle of the $\mathrm{pH}$ range at approximately 5.7 to 6.2. Carbon Steel Type A516 and Stainless Steel Type 304L are strong acid generators at $\mathrm{pH}$ of 1.5 to 2 .

The differences between the $\mathrm{pH}$ produced by the two stainless steel types are due to the chromium to nickel ratio in the alloys, as shown in file CDSP_Stainless Steel $p H C r \_N i$ ratio.xls (Appendix F). For molar ratios of chromium to nickel greater than or equal to two, as in the case of Stainless Steel Type 304L, the pH of the solution after 15 moles have reacted is less than 2. For chromium to nickel ratios below two, as in the case of the Stainless Steel Type 316, the $\mathrm{pH}$ is above 5 .

The results of the CDSP multicomponent ensemble runs are displayed in Figure 6-5. The multicomponent CDSP vapor-influx cases are defined in Table 6-3. The low end of the $\mathrm{pH}$ range in Figure 6-4 is not reproduced in the multicomponent results (Figure 6-5). The ensembles include either HLWG or $\mathrm{N}$ Reactor fuel as a reactant because the TSPA-LA model for in-package chemistry does not take cladding credit for $\mathrm{N}$ Reactor fuel or the glass pour canisters. Therefore, the low pH generated by Stainless Steel Type 304L and Carbon Steel Type A516 (Figure 6-4) is not observed in the ensemble runs (Figure 6-5) because of the pH-buffering capacity that HLWG and N Reactor fuel provide.

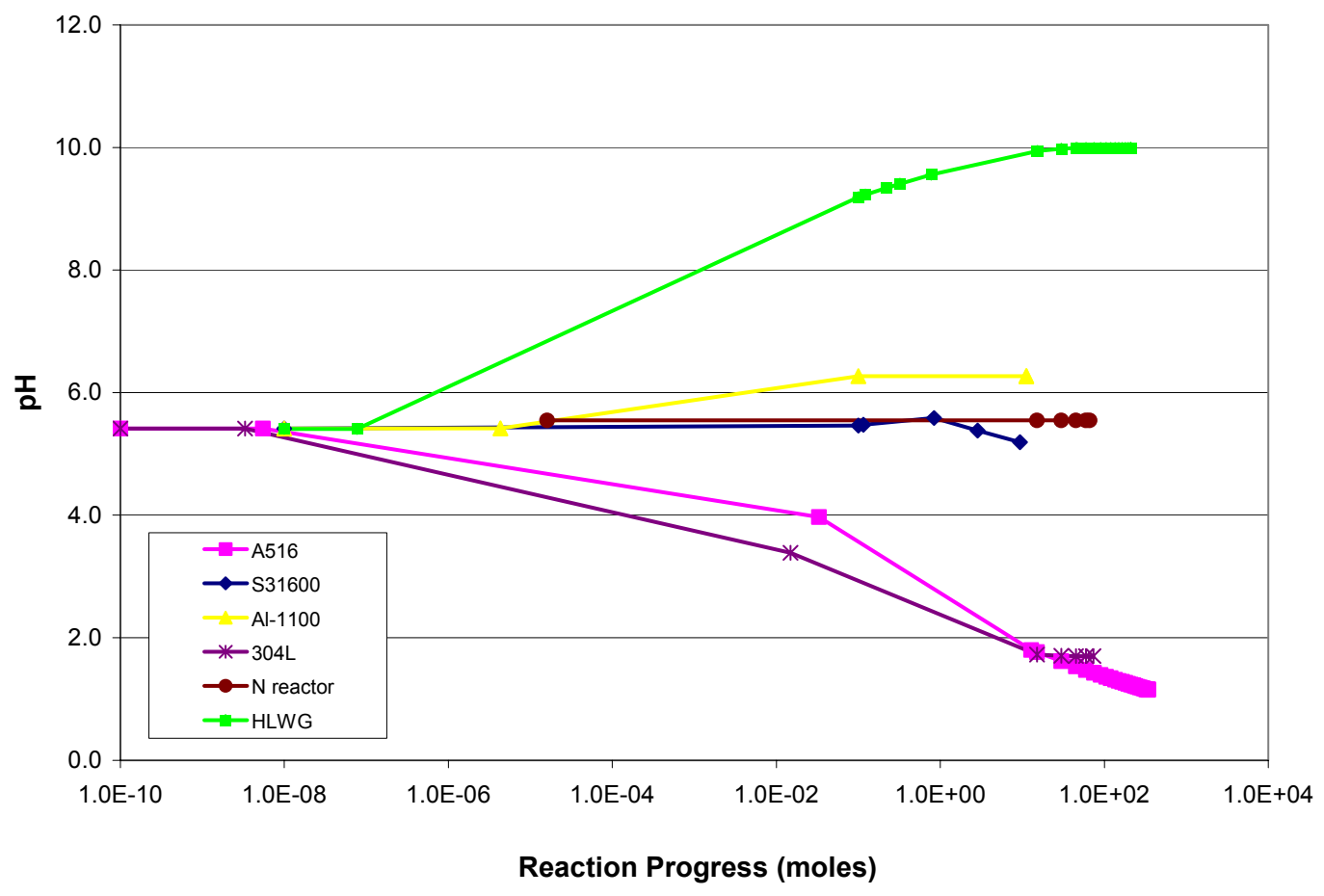

Source: CDSP_VaporInflux_SingleReact.xIs (Appendix F ISpreadsheets).

NOTE: Time refers to time after waste package breach.

Figure 6-4. CDSP Single-Component Vapor Influx Results 


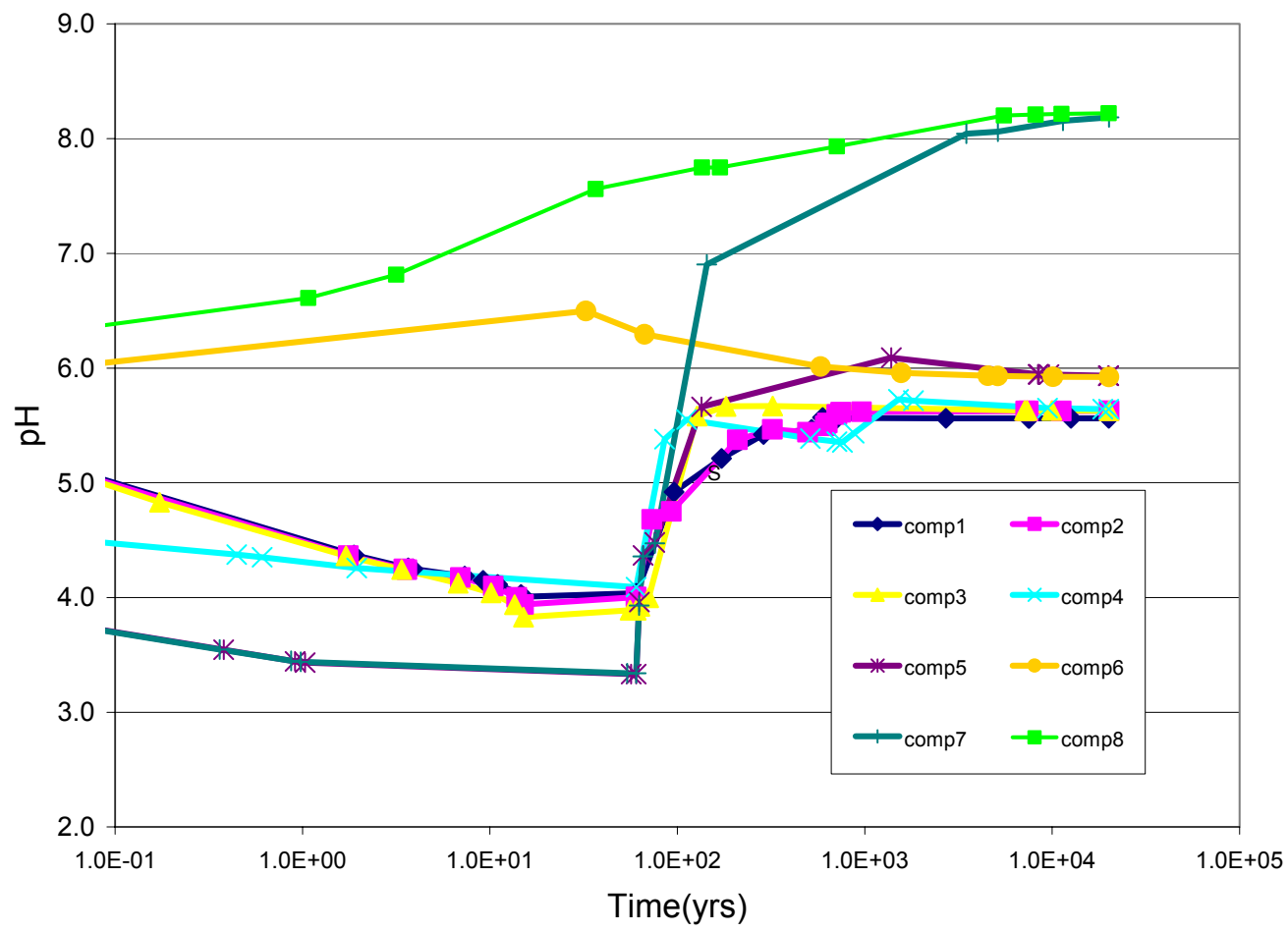

Source: CDSP_Vaporlnflux_MultiComp.xls (Appendix F).

NOTE: Time refers to time after waste package breach.

Figure 6-5. CDSP Multicomponent Ensemble pH Profiles

The ensemble simulations comp1, comp2, and comp3 include HLWG and N Reactor fuels as reactants; thus, the resulting chemistry of the reacted solutions $(\mathrm{pH} \cong 6$ ) reflects interactions between the codisposed waste, the nonspent nuclear fuel waste package components, the liquid phase water, and the atmosphere in the voids in the waste package and drift. The above discussion addresses the subject matter of "Included" FEP 2.1.01.02.0B (Interactions between co-disposed waste) and indicates how that subject matter has been included and addressed within TSPA-LA. The moderate $\mathrm{pH}$ observed in the comp1, comp2, and comp3 results reflects the buffering effect of schoepite on the $\mathrm{pH}$. In addition, the fuel and metal alloys are kinetic reactants that undergo oxidation and precipitate corrosion products that are in contact with the liquid phase water, thereby having a first order influence on the chemistry. The above discussion addresses the subject matter of "Included" FEP 2.1.09.02.0A (Chemical interaction with corrosion products) and indicates how that subject matter has been included and addressed within TSPA-LA.

High $\mathrm{pH}$ conditions are only realized in the comp7 and comp8 simulations in which HLWG is combined with Carbon Steel Type A516 and Aluminum Alloy 1100, respectively. In these two cases, the period of elevated $\mathrm{pH}$ only occurs after the metal alloys have been exhausted. Because neither Carbon Steel Type A516 nor Aluminum Alloy 1100 provide long-term pH buffering like the Stainless Steel Types 316 and 304L, the pH values increase when these metals are exhausted. In the Comp5 and Comp 6 simulations, where HLWG is paired with the various Stainless Steel Type 304L components, the resulting $\mathrm{pH}$ values are just slightly less than $\mathrm{pH}$. HLWG is contained in Stainless Steel Type 304L canisters in which the steels will moderate the basic 
conditions generated by HLWG dissolution and maintain neutral-pH conditions inside the waste package, well past 20,000 years. The presence of schoepite, resulting from $\mathrm{N}$ Reactor fuel degradation, and large quantity of steel in the waste package limits the potential of generating high-pH conditions in the CDSP waste package.

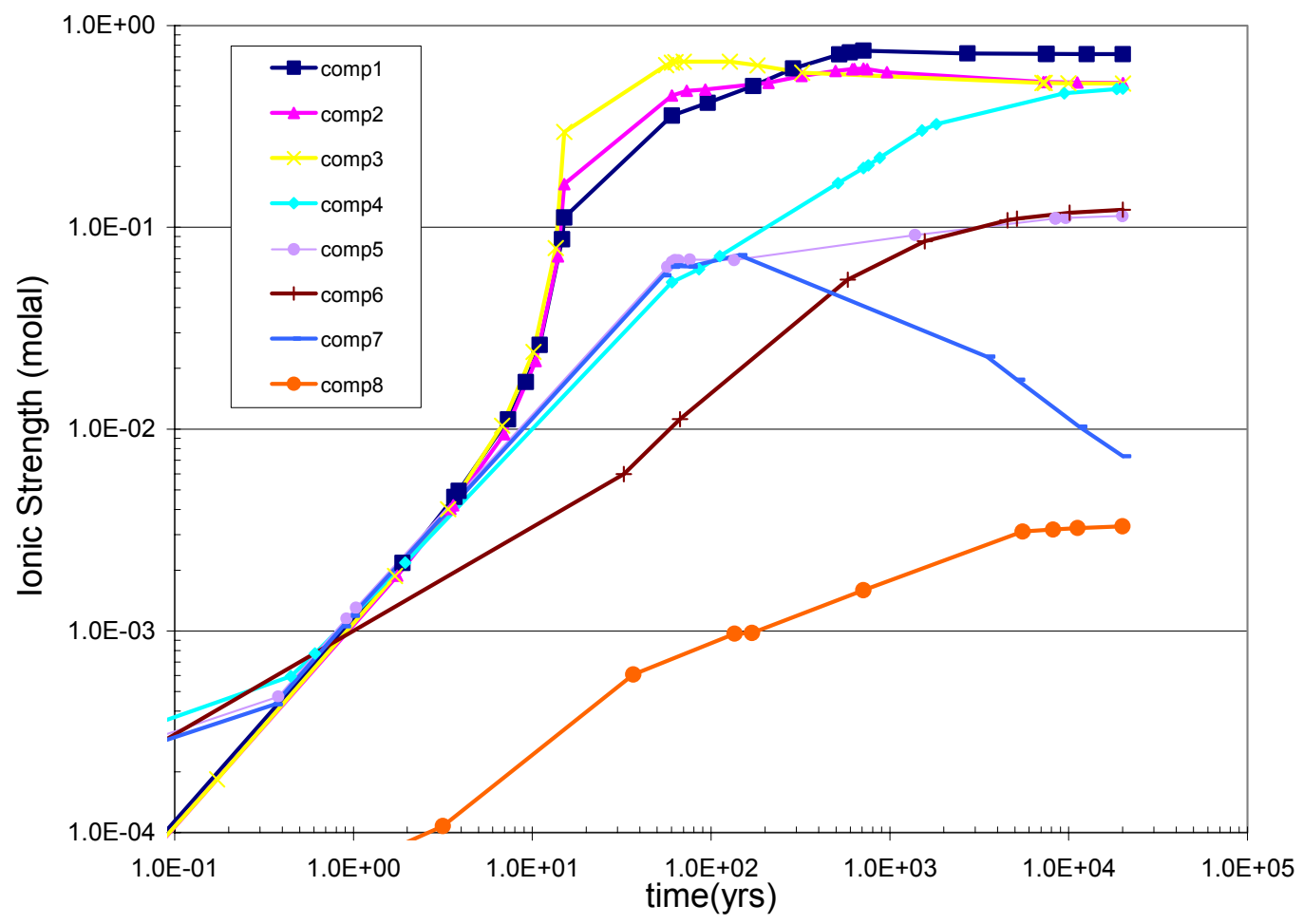

Source: CDSP_Vaporlnflux_MultiComp.xls (Appendix F).

NOTE: Time refers to time after waste package breach.

Figure 6-6. CDSP Multicomponent Vapor Influx Model lonic Strength Profiles

Figure 6-6 displays the ionic strength profiles for the CDSP vapor influx model runs. Under vapor influx conditions, the interior of the waste package is dry at the moment of waste package breach. With time the humidity of the interior of the waste package will equilibrate to the ambient drift conditions and water will begin to adsorb or condense to the interior waste package components. The ratio of water to reactants is initially small and increases with time, so the ionic strength will initially be high and decrease with time as more water enters the system. This is an effect that is not captured by the vapor influx EQ6 model, because the batch reactor model considers the water needed for the model is instantly available once the waste package breaches, rather than the water taking time to accumulate in the waste package (Section 6.3.1.1). However, this effect is accounted for in the ionic strength model abstraction (Section 6.10.2). 


\subsubsection{Water Influx Case Model Results}

\subsubsection{CSNF Output}

\subsubsection{1 pH}

The $\mathrm{pH}$ history for the full suite of water influx cases at $25^{\circ} \mathrm{C}$ is presented in Figure 6-7.

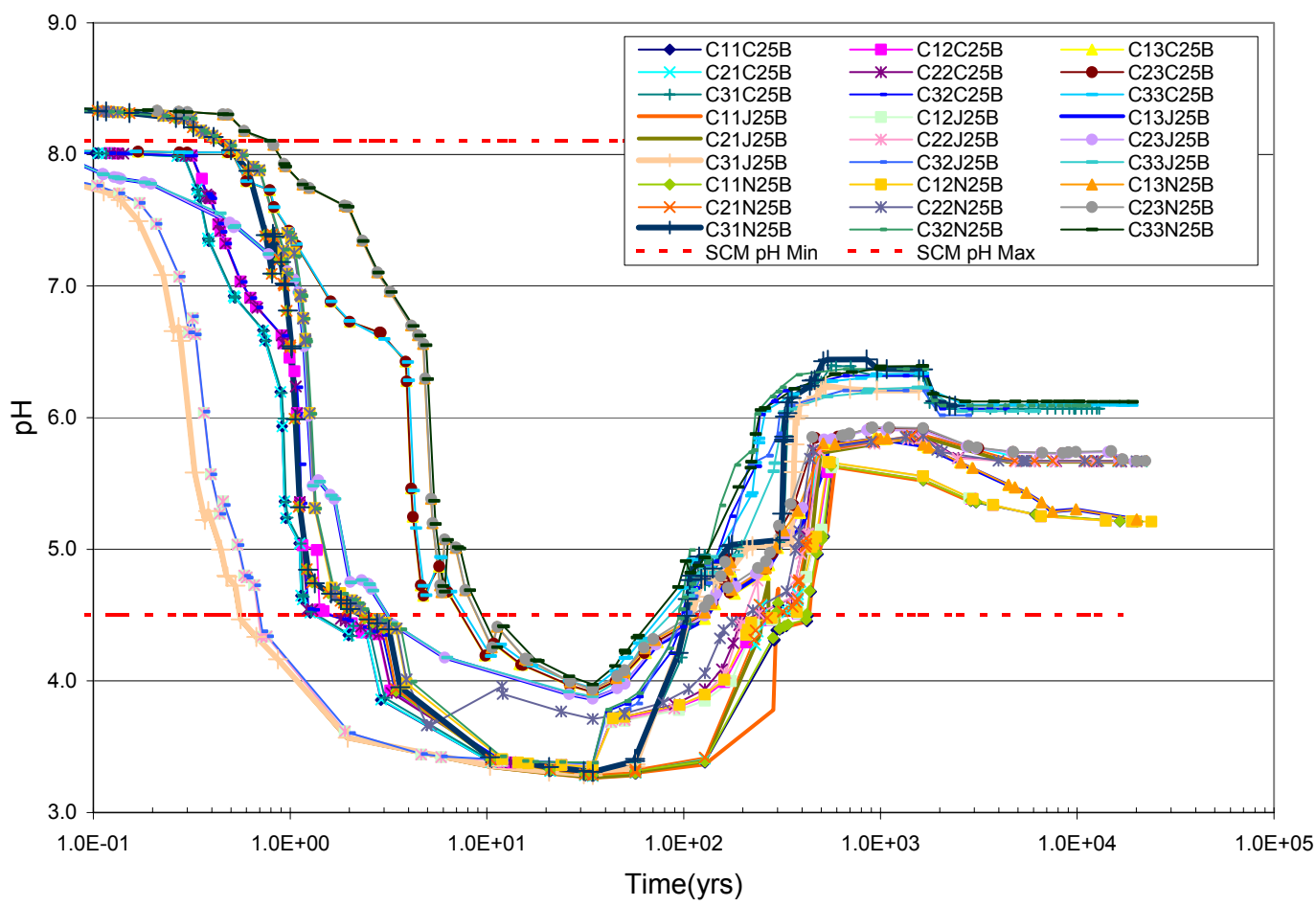

Source: CSNF_Water Influx_25.xIs (Appendix F ISpreadsheets).

NOTE: $\quad$ Time refers to time after waste package breach. SCM pH Min and SCM pH Max refers to the minimum and maximum $\mathrm{pH}$ values after the surface complexation model has been applied.

Figure 6-7. CSNF Water Influx Model Results at $25^{\circ} \mathrm{C}$

The $\mathrm{pH}$ history and reactant summary for the case showing the median flux and fuel exposure water influx model case $(\mathrm{Q}=1.5 \mathrm{~L} / \mathrm{yr}$ and fuel exposure $=10 \%)$ at $25^{\circ} \mathrm{C}$ using the three different seepage compositions are displayed in Figure 6-8. The EQ6 results plotted in Figure 6-8 only reflect the physical chemistry of the system; the surface complexation model is not represented in this plot. 


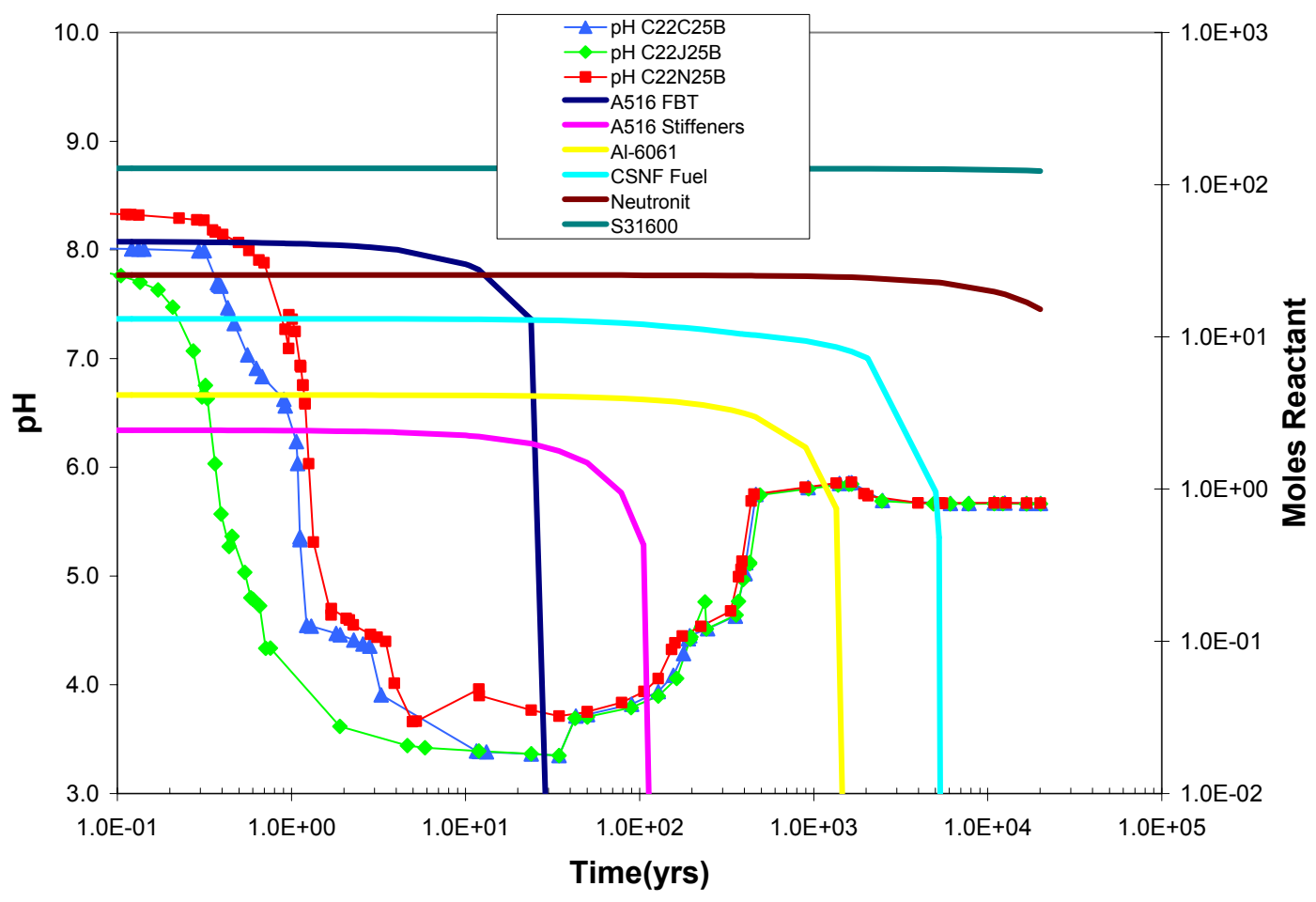

Source: CSNF_Water Influx_25.x/s (Appendix F ISpreadsheets).

NOTE: Time refers to time after waste package breach.

Figure 6-8. CSNF Water Influx Model Results for Three Seepage Compositions at $25^{\circ} \mathrm{C}$

An important feature of Figure 6-8 is the fact that the composition of the seepage (Table 4-2) has virtually no effect on the $\mathrm{pH}$ profile. The separation in the early-time (less than approximately 0.5 years after waste package breach) $\mathrm{pH}$ profiles is a function of the seepage chemistry. However, this difference dissipates in approximately 10 years, and the $\mathrm{pH}$ profiles become nearly identical. The above discussion addresses the subject matter of "Included" FEP 2.2.08.12.0B (Chemistry of water flowing into the waste package) and indicates how that subject matter has been included and addressed within TSPA-LA. Thus, the composition of the water flowing into the EBS has a negligible impact on the in-package chemistry $\mathrm{pH}$. The in-package chemistry model uses the results of cases examining the three seepage compositions, so the effect of the chemistry of the water flowing into the EBS is included in the feed to TSPA-LA. (Even though the abstractions passed to TSPA-LA from this model are not defined in terms of the incoming water composition). These results show that the model is robust with respect to Alternate Conceptual Model II. If the water influx model had been sensitive to the input water composition, then an alternate conceptual model with time-varying composition would be needed.

The model does not account for the possibility of seepage concentrated via evaporative processes entering the waste package. However, the waste package environment would tend to overwhelm the chemistry of concentrated solutions, and the concentrated solutions would only be a transient effect, which would be diminished once additional seepage water accumulated in the waste package. 
Further examination of Figure 6-8 shows that the reactants dissolve as a function of time (i.e., they are kinetic reactants) and their effect on the in-package chemistry is explicitly modeled in the in-package chemistry model and, thus, is carried over to TSPA-LA. The above discussion addresses the subject matter of "Included" FEP 2.1.09.07.0A (Reaction kinetics in waste package) and indicates how that subject matter has been included and addressed within TSPA-LA.

Figure 6-9 displays mineral phases that precipitated from solution for the $\mathrm{C} 22$ runs $(\mathrm{Q}=1.5 \mathrm{~L} / \mathrm{yr}$, fuel exposure $=10 \%$ ) at $25^{\circ} \mathrm{C}$ for the three seepage water compositions. Hematite, gibbsite, schoepite, pyrolusite, and trevorite constitute the five most abundant phases, all of which are expected to form in the oxidizing waste package environment (Table 6-13). The large amount of gibbsite $\left(\mathrm{Al}(\mathrm{OH})_{3}\right)$ that formed in these runs is due to the relatively low amount of available silica in the incoming waters and waste package components. Had more silica been available, greater quantities of aluminum-silicate phases would then have formed with proportionately less gibbsite formation. The silica phases that do form include kaolinite, nontronite- $\mathrm{Mg}$, and nontronite-Ca, all of which are clay minerals. The mineral assemblage plot (Figure 6-9) supports that the composition of the seepage has little influence over which minerals formed and their amounts. The J-13 well water minerals show some variability compared to the other two water compositions; however, the major phases are all present in nearly identical amounts.

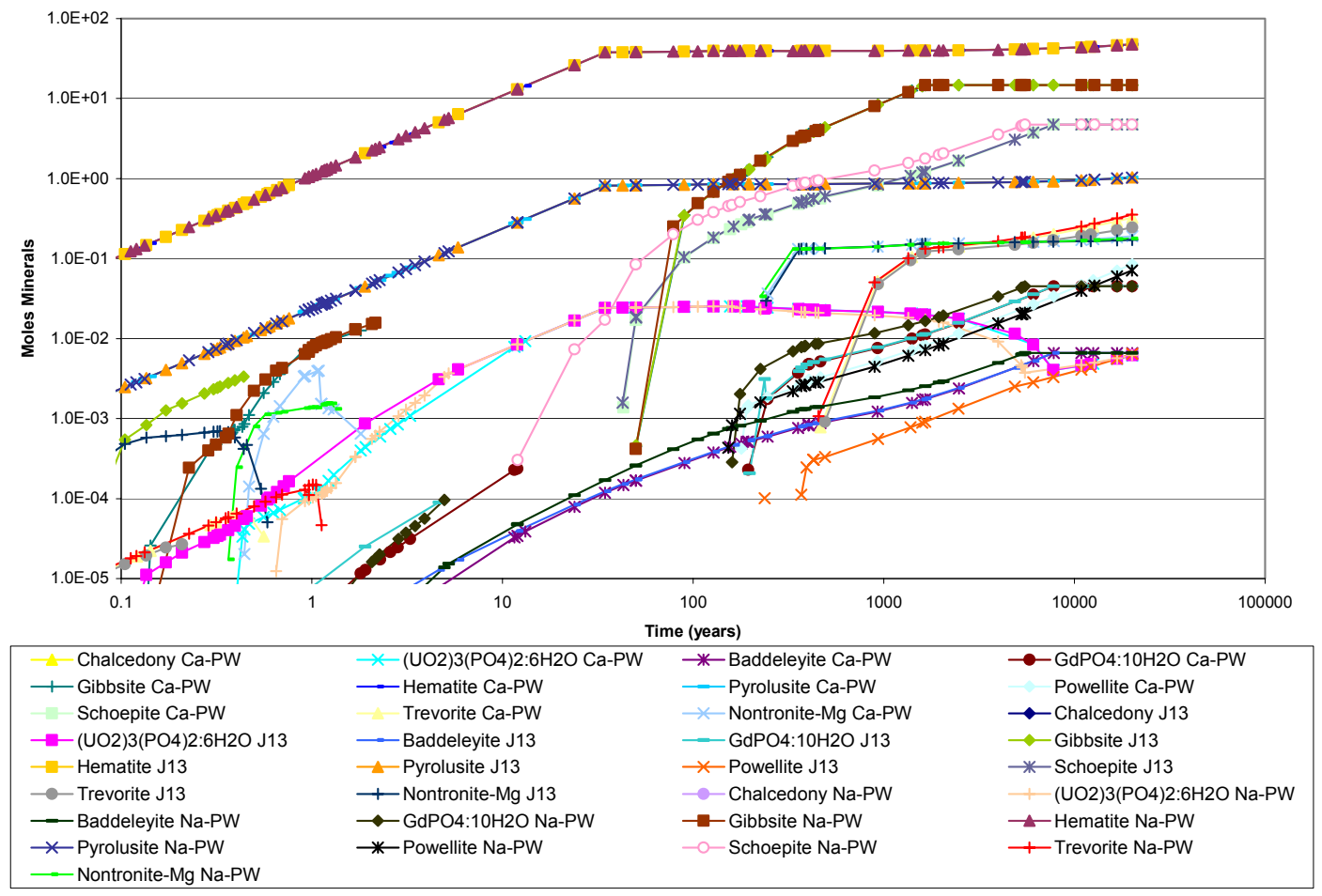

Source: CSNF_Water Influx_25.xIs (Appendix F ISpreadsheets).

NOTE: Time refers to time after waste package breach.

Figure 6-9. CSNF Water Influx Model Mineral Phases for Three Seepage Compositions 
Figure 6-10 displays aqueous species for the $\mathrm{C} 22$ runs at $25^{\circ} \mathrm{C}$ for the three input water compositions. This plot shows elements not present in the initial water compositions (Table 4-2) are controlled solely by the in-package chemical environment. In other words, those elements that originate from the waste package and waste forms have aqueous species concentrations that are nearly identical and independent of the initial water composition for the duration of the simulations. Examples of these elements include $\mathrm{Ni}, \mathrm{Cr}$, and $\mathrm{B}$, all of which originate from oxidation of the metal waste package components. Elements that were present in the initial water composition and were also involved in reactions in the waste package also have similar aqueous species concentrations. For example sulfur, which was present in all of the water compositions as sulfate $\left(\mathrm{SO}_{4}{ }^{2-}\right)$, shows similar concentration trends in the simulations, independent of the starting water composition, due to the sulfur contained in the Carbon Steel Type A516 that dominates the sulfate concentration trends observed in Figure 6-10. At times greater than about 5,000 years, the sulfur concentration trends for the three water compositions show some separation that is due to the sulfate concentration returning to the initial water composition values. Figure 6-9 and Figure 6-10 show that, depending on the initial fluid composition, there is a small degree of variability in the minerals and aqueous species of the reacted fluid chemistry that may exit a breached waste package. However, this variability is slight and is captured in the overall uncertainty treatment in the $\mathrm{pH}$ and ionic strength of the reacted solutions.

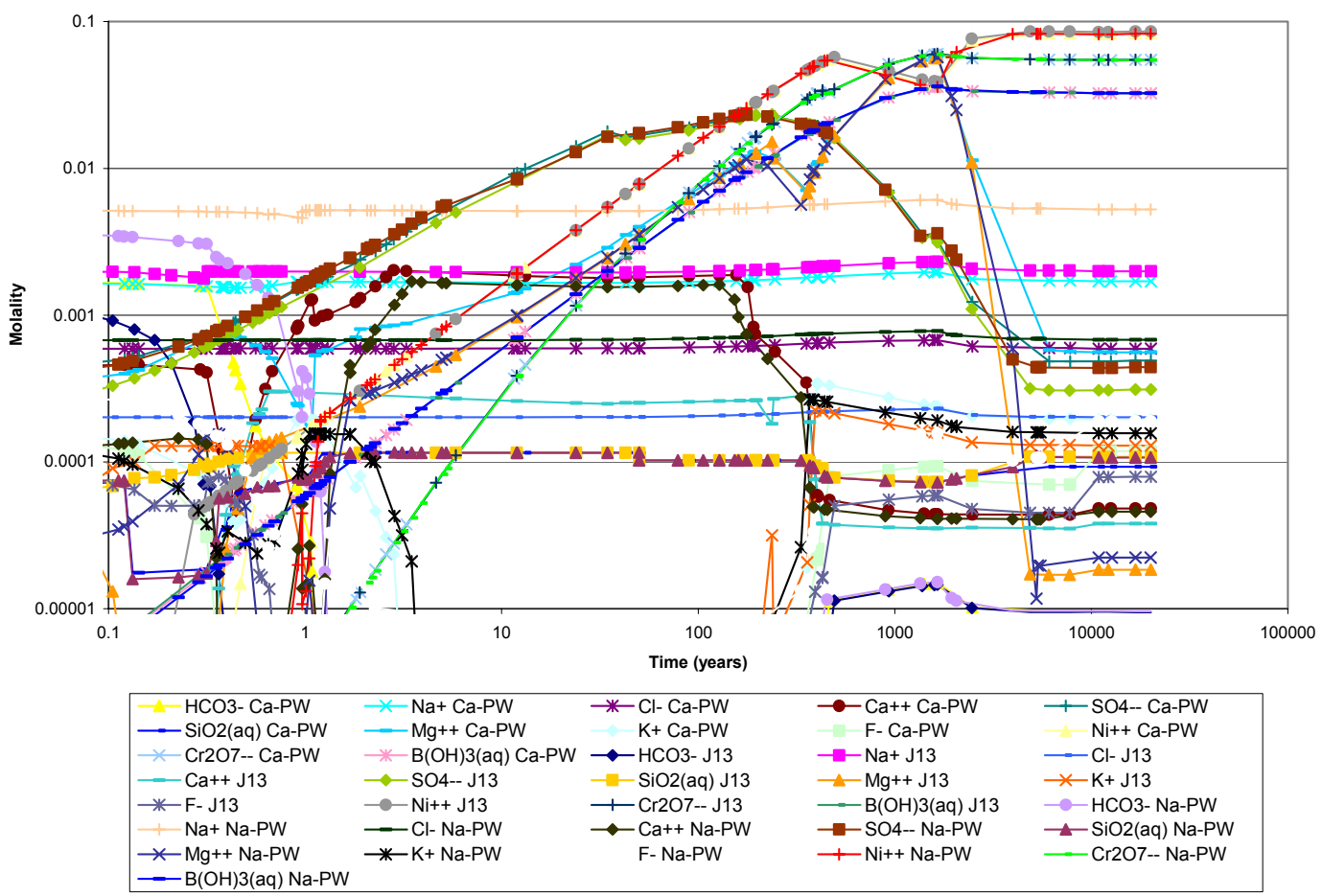

Source: $\quad$ CSNF_Water Influx_25.xls (Appendix F ISpreadsheets).

NOTE: Time refers to time after waste package breach.

Figure 6-10. CSNF Water Influx Model Aqueous Species for Three Seepage Compositions 
The $\mathrm{pH}$ history for the full suite of water influx cases at $25^{\circ} \mathrm{C}$ is presented in Figure 6-11.

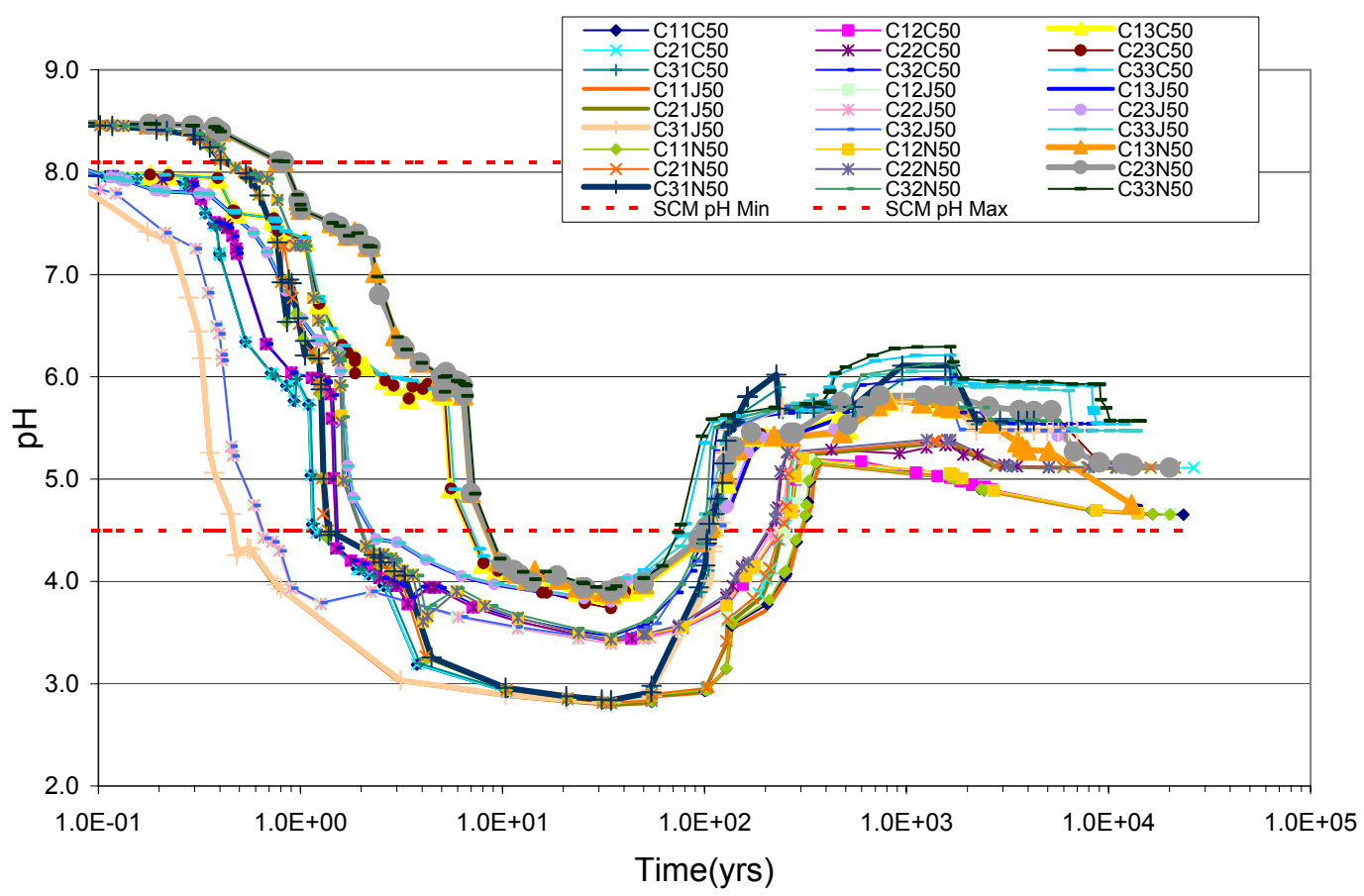

Source: CSNF_Water Influx_50.xls (Appendix F ISpreadsheets).

NOTE: Time refers to time after waste package breach. SCM pH Min and SCM pH Max refer to the minimum and maximum $\mathrm{pH}$ values after the surface complexation model has been applied.

Figure 6-11. CSNF Water Influx Model Results at $50^{\circ} \mathrm{C}$

Figure 6-12 shows a plot of $\mathrm{pH}$ and reactant summary for the median seepage flux and fuel exposure values $(\mathrm{Q}=1.5 \mathrm{~L} / \mathrm{yr}$, fuel exposure $=10 \%)$ at $50^{\circ} \mathrm{C}$ for the three input seepage compositions. Just as is shown in the $25^{\circ} \mathrm{C}$ runs in Figure 6-8, the initial composition of the seepage entering the waste package has little impact on the composition of the reacted fluid. The chemistry of the composition is dominated by the contents of the waste package. The batch reactor runs at $50^{\circ} \mathrm{C}$ use a temperature-appropriate CSNF degradation rate (Table 6-9). The metal alloy corrosion rates are the same as those used for the $25^{\circ} \mathrm{C}$ runs, because these rates are provided in DTN: MO0409SPAACRWP.000 [DIRS 172059] as appropriate for over this range of temperatures and because many of the experimental rates were measured at higher temperatures. The thermodynamic database includes high temperature data for most mineral and aqueous species; therefore, the reacted solution chemistry and precipitated mineral phases are temperature appropriate. 


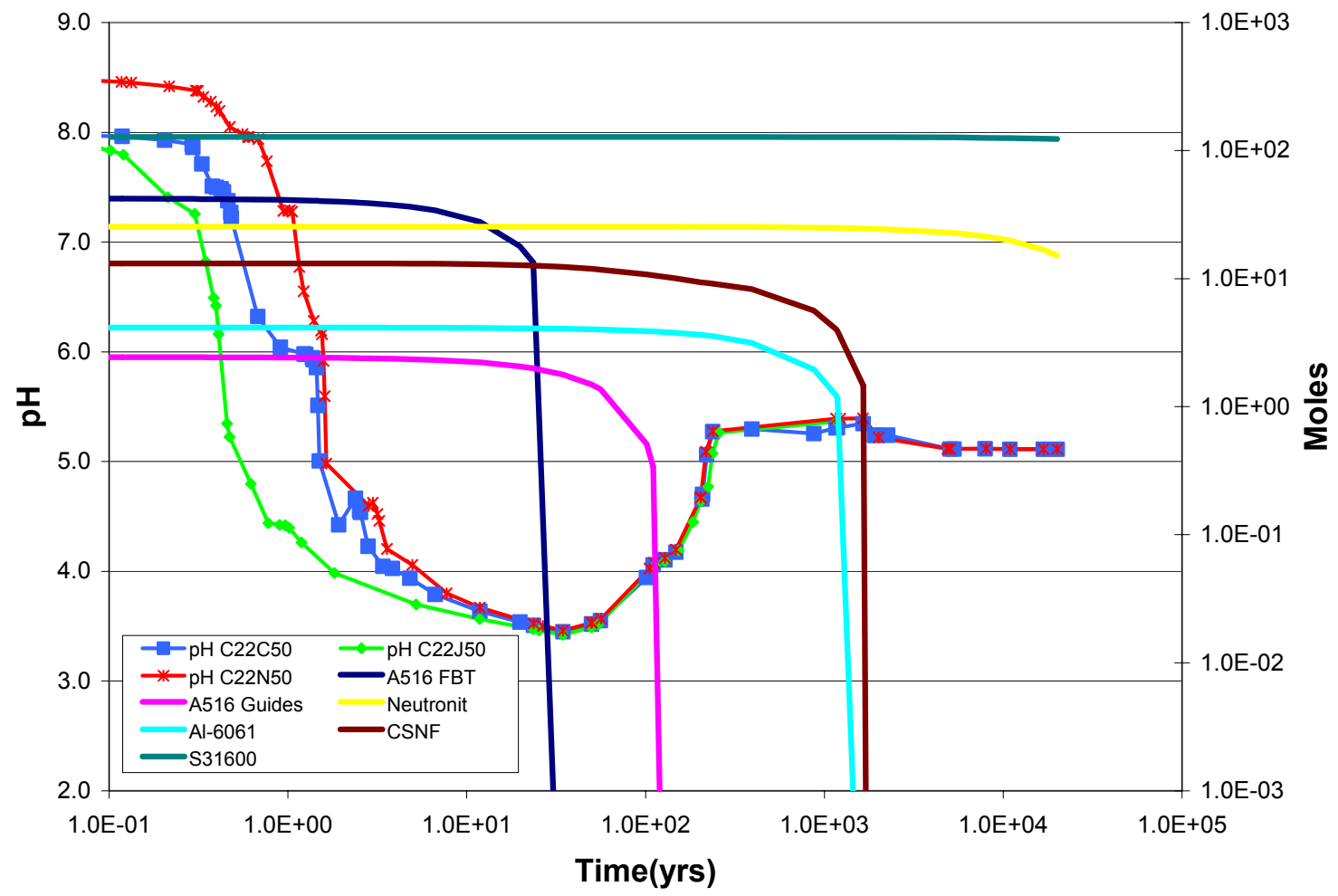

Source: CSNF_Water Influx_50.xIs (Appendix F ISpreadsheets).

NOTE: Time refers to time after waste package breach. When surface complexation is considered, the pH range is limited from 4.5 to 8.1 up to 600 years (Section 6.9).

Figure 6-12. CSNF Water Influx Model Results for Three Seepage Compositions at $50^{\circ} \mathrm{C}$

The $50^{\circ} \mathrm{C}$ runs achieve an overall lower $\mathrm{pH}$ profile at long time periods and slight variations in the stable mineral assemblages compared with the results at $25^{\circ} \mathrm{C}$. Since a suite of simulations was carried out at above ambient temperatures and the in-package chemistry model results reflect the increased thermal conditions, the TSPA-LA feed also reflects the increased thermal conditions. The above discussion addresses the thermal effects on chemistry portion of the subject matter of "Included" FEP 2.1.11.08.0A (Thermal effects on chemistry and microbial activity in the EBS) and indicates how that subject matter has been included and addressed within TSPA-LA. The microbial activity in the EBS subject matter is described in FEP 2.1.10.01.0A as documented in Engineered Barrier System Features, Events, and Processes (BSC 2004 [DIRS 169898]). The effect of temperature on the surface complexation model is discussed in Sections 6.7.3.

\subsection{Ionic Strength}

Figure 6-13 displays the ionic strength profiles for the CSNF water influx model runs at $25^{\circ} \mathrm{C}$. For the low-end seepage flux $(0.15 \mathrm{~L} / \mathrm{yr})$, the ionic strength exceeds 1 molal due to the accumulation of aqueous chromium species in the waste package effluent. These high chromium concentrations occur in the EQ6 simulations because there is no chromium-bearing mineral phase in the qualified thermodynamic database available to precipitate under the conditions of the simulation. Two chromium minerals were added to the database in a sensitivity analysis 
presented in Section 6.6.3. These results show that when the chromium is allowed to precipitate, the ionic strength is much lower. The ionic strength abstraction is used by the colloid and dissolved concentrations submodels in the TSPA-LA. The colloidal suspensions are unstable at ionic strength values above 0.05 molal (BSC 2003 [DIRS 166845]), so for the colloid submodel, the significance of exceeding the limits of the B-dot activity coefficient equation is diminished. For the dissolved concentrations model, TSPA-LA applies an additional uncertainty term to the concentrations if the ionic strengths is greater than one molal), so the significance of exceeding the limits of the B-dot activity coefficient equation is already captured. Figure 6-13 and Figure 6-14 display the ionic strength abstraction for the CSNF water influx model at $25^{\circ} \mathrm{C}$ and $50^{\circ} \mathrm{C}$, respectively, for the period 0 to 20,000 years.

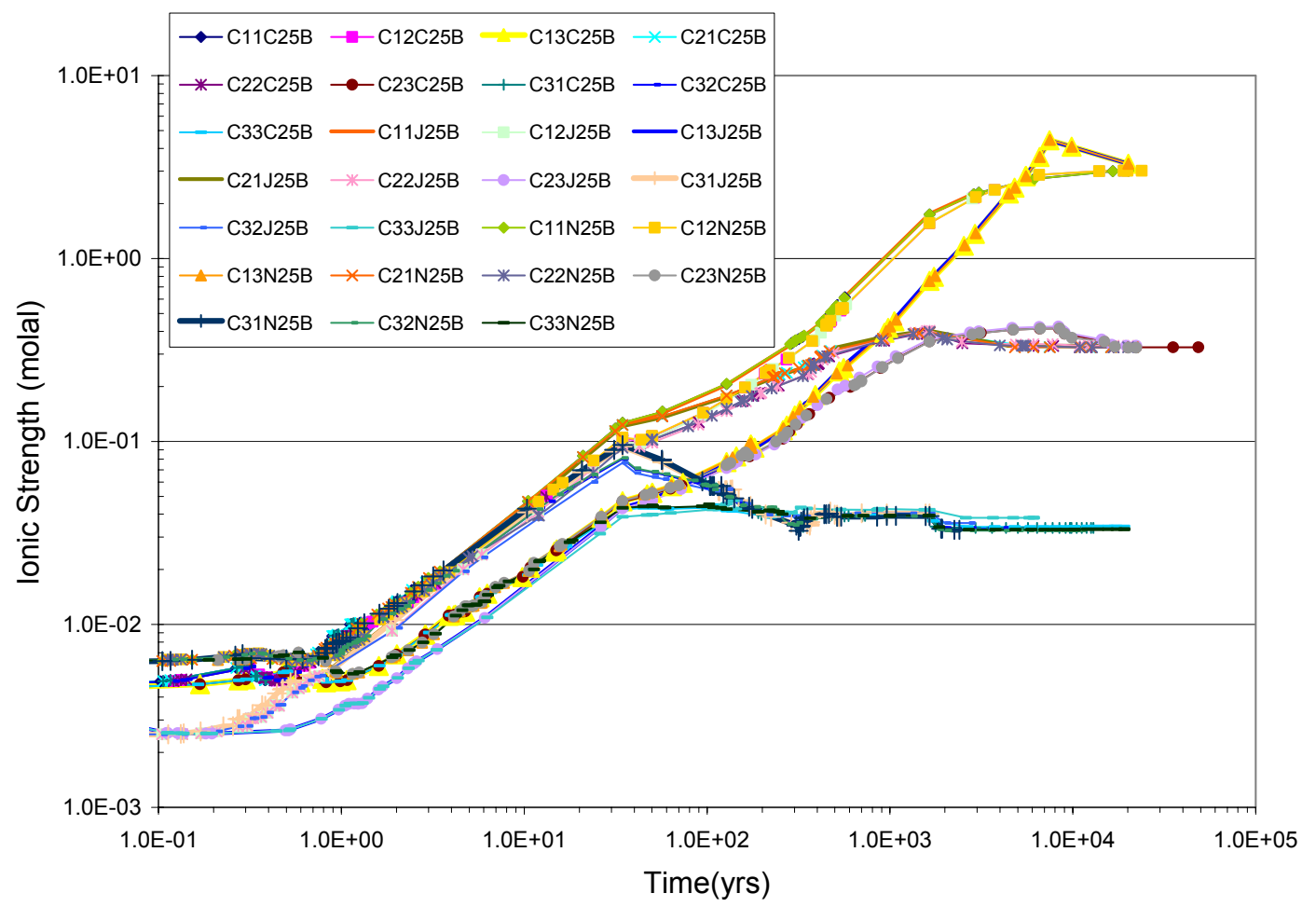

Source: CSNF_Water Influx_25.x/s (Appendix F).

NOTE: Time refers to time after waste package breach.

Figure 6-13. CSNF Water Influx Model $25^{\circ} \mathrm{C}$ lonic Strength Profiles 


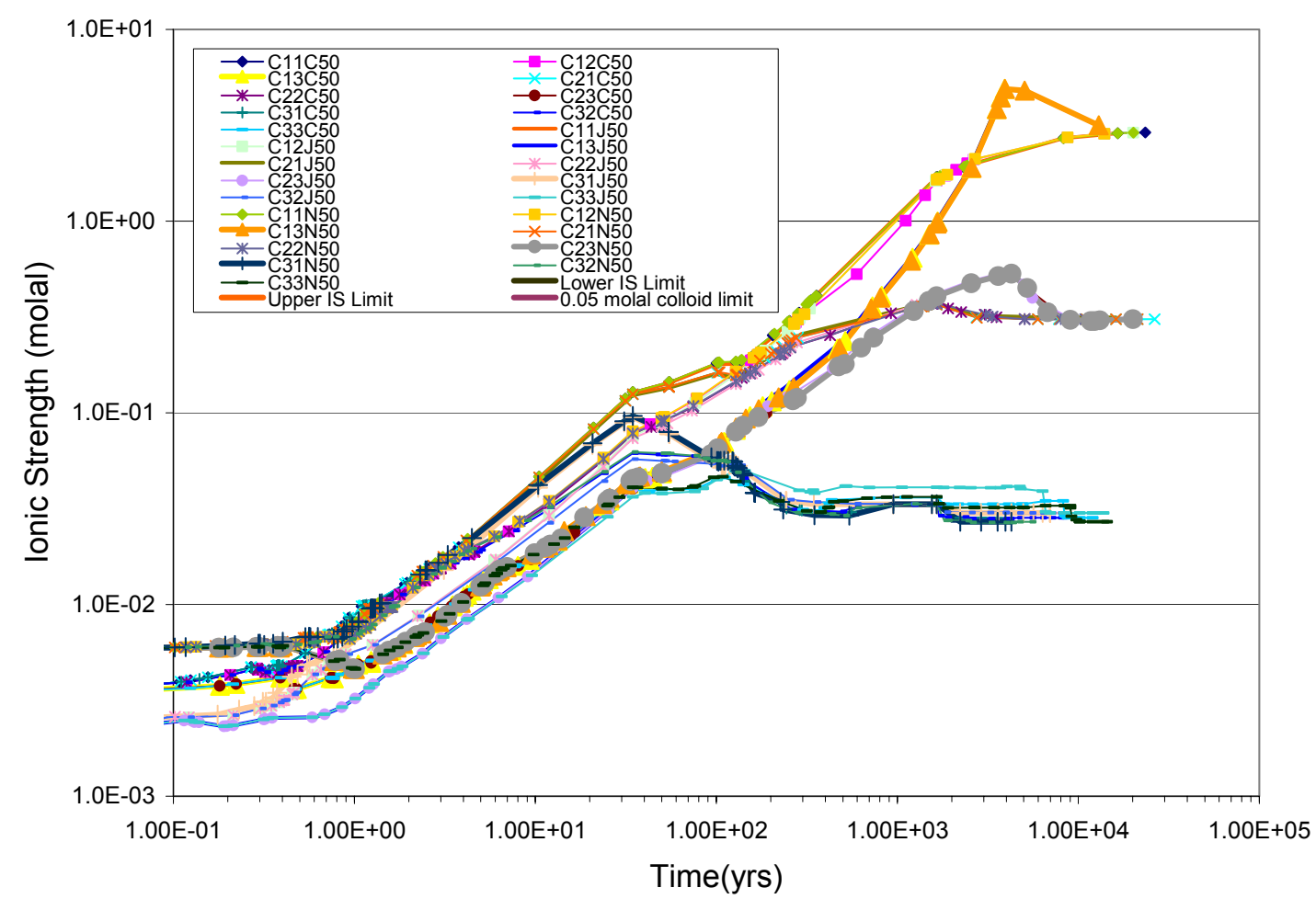

Source: CSNF_Water Influx_50.xls (Appendix F).

NOTE: Time refers to time after waste package breach.

Figure 6-14. CSNF Water Influx Model $50^{\circ} \mathrm{C}$ lonic Strength Profiles

\subsection{Eh}

Figure 6-15 displays the Eh (a measure of the redox potential), reactant summary, and oxidation products for run $\mathrm{C} 22 \mathrm{C} 25$ (the median flux and fuel exposure simulation for the Ca-porewater at $25^{\circ} \mathrm{C}$ ). The Eh varies between approximately 0.8 to 1.0 volts. The modeled conditions are uniformly oxidizing, so Eh changes only in response to $\mathrm{pH}$ changes. In reality, the presence of abundant reduced material and the ability of corrosion products to limit the access of water and oxygen are likely to cause substantial lowering of the in-package Eh. A lower Eh would lead toward more neutral $\mathrm{pH}$ values and more moderate ionic strengths, but because this effect cannot be quantified, the conservative, uniformly oxidizing Eh value was used for the model.

Since metal oxide corrosion products are precipitating from a solution that is in contact with the waste form and waste package components, the corrosion products have a first order influence on the in-package chemistry. The above discussion addresses the subject matter of "Included" FEPs 2.1.09.02.0A (Chemical interaction with corrosion products) and 2.1.09.06.0A (Reductionoxidation potential in waste package) and indicates how that subject matter has been included and addressed within TSPA-LA. 


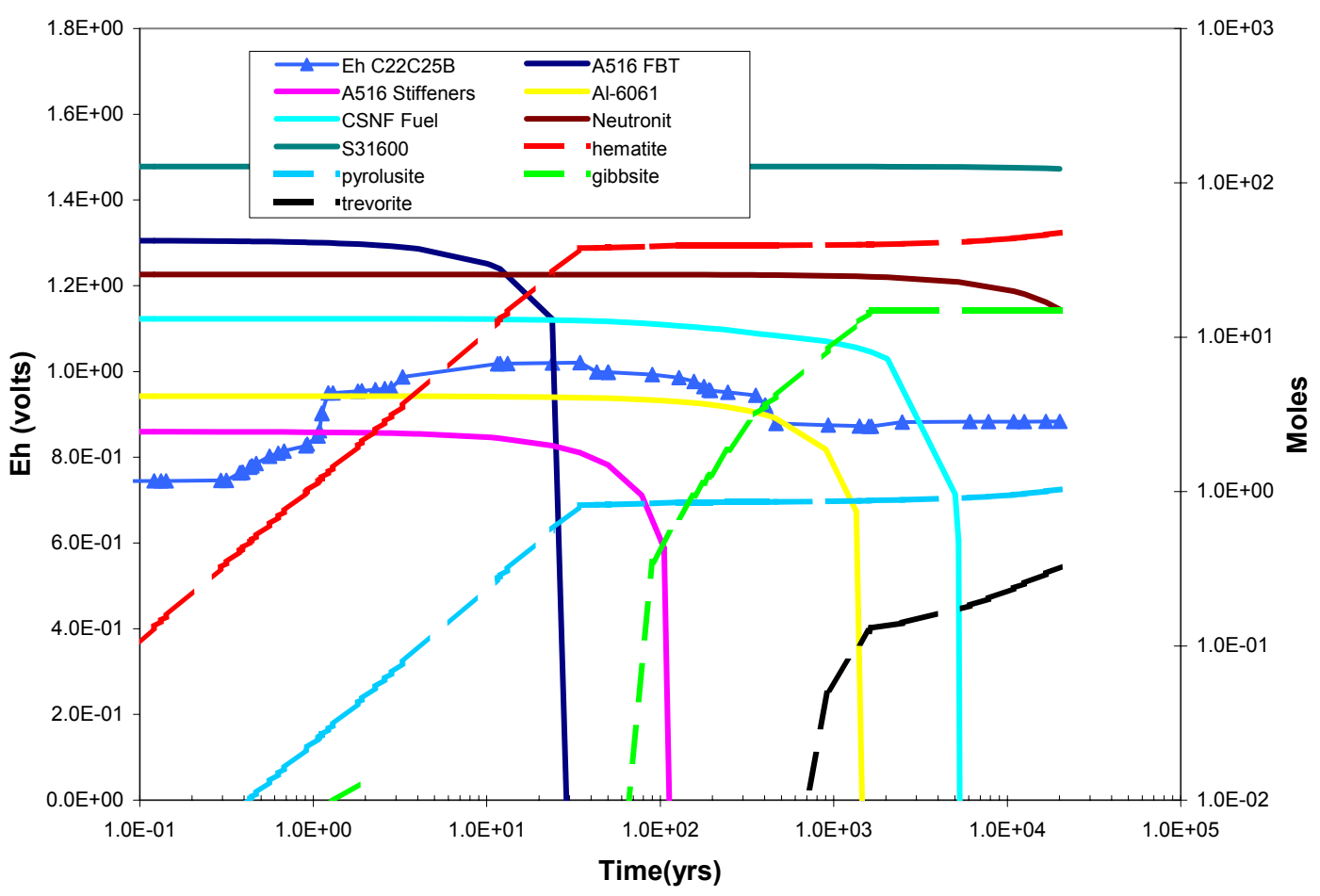

Source: CSNF_Water Influx_25.xIs (Appendix F ISpreadsheets).

NOTE: Time refers to time after waste package breach.

Figure 6-15. CSNF Water Influx Model: Eh, Reactant Summary, and Corrosion Products 


\subsubsection{CDSP Output}

\subsubsection{1 pH}

The $\mathrm{pH}$ history for the full suite of water influx cases at $25^{\circ} \mathrm{C}$ is presented in Figure 6-16.

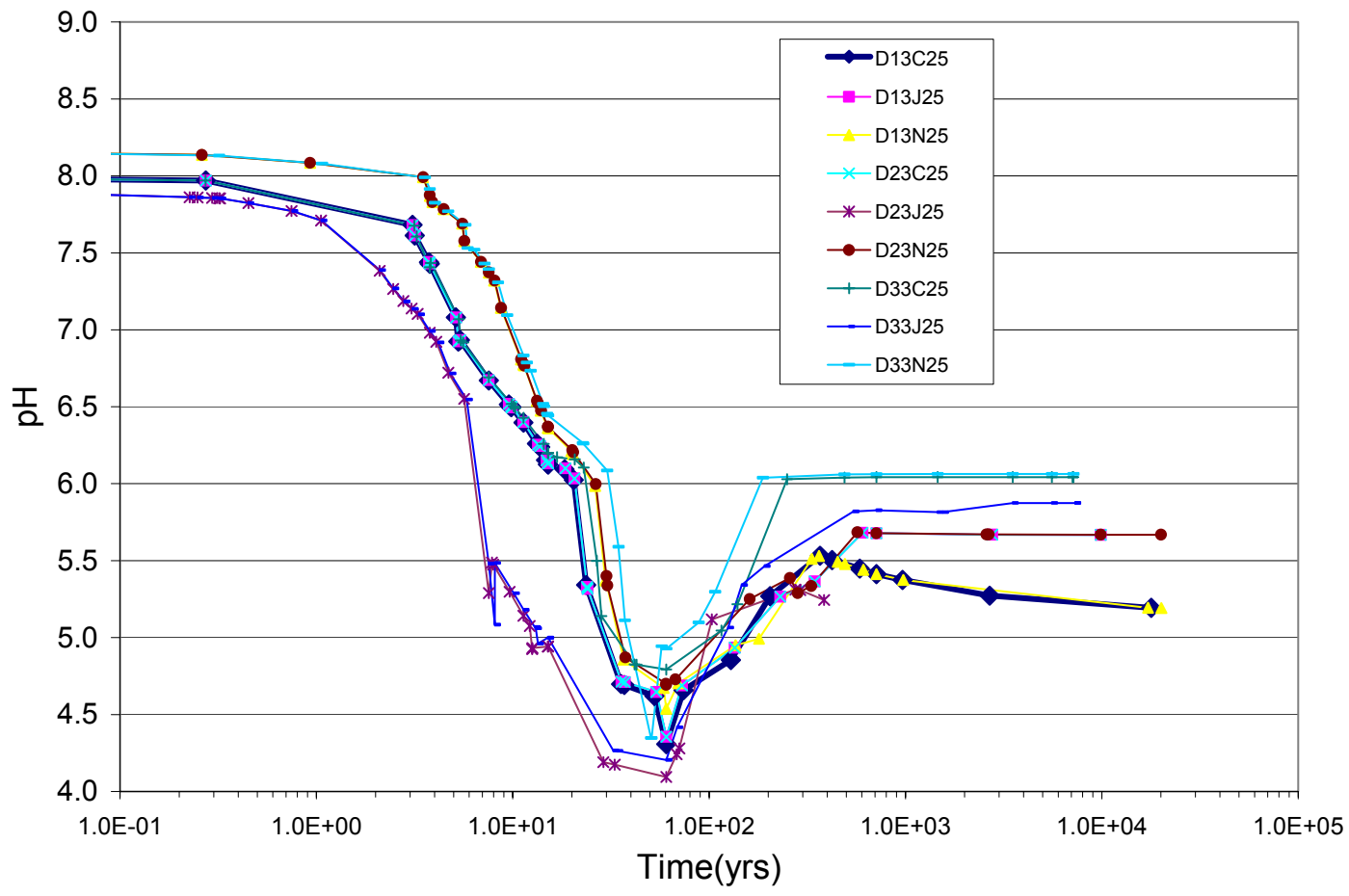

Source: CDSP_Water Influx_25.xIs (Appendix F ISpreadsheets).

NOTE: Time refers to time after waste package breach.

Figure 6-16. CDSP Water Influx Model Results at $25^{\circ} \mathrm{C}$

Figure 6-17 displays the CDSP water influx model $\mathrm{pH}$ profiles for the median flux $(\mathrm{Q}=1.5 \mathrm{~L} / \mathrm{yr})$ for the three seepage compositions at $25^{\circ} \mathrm{C}$. Also displayed is the reactant summary. pH profiles converge early in the simulations indicating that the model $\mathrm{pH}$ response is insensitive to starting water composition that is similar to the $\mathrm{pH}$ profile behavior of the CSNF water influx model (Figure 6-8).

The most outstanding feature in Figure 6-17 is the reactant summary for the N Reactor fuel. The figure shows that the $\mathrm{N}$ Reactor fuel dissolves over a short duration of just a few years. The rapid $\mathrm{N}$ Reactor fuel dissolution diminishes the importance of the $\mathrm{N}$ Reactor fuel to the overall in-package chemistry contribution. However, the large quantity of schoepite precipitated in the waste package influences the in-package chemistry for an extended duration by buffering $\mathrm{pH}$ in the near-neutral range. 


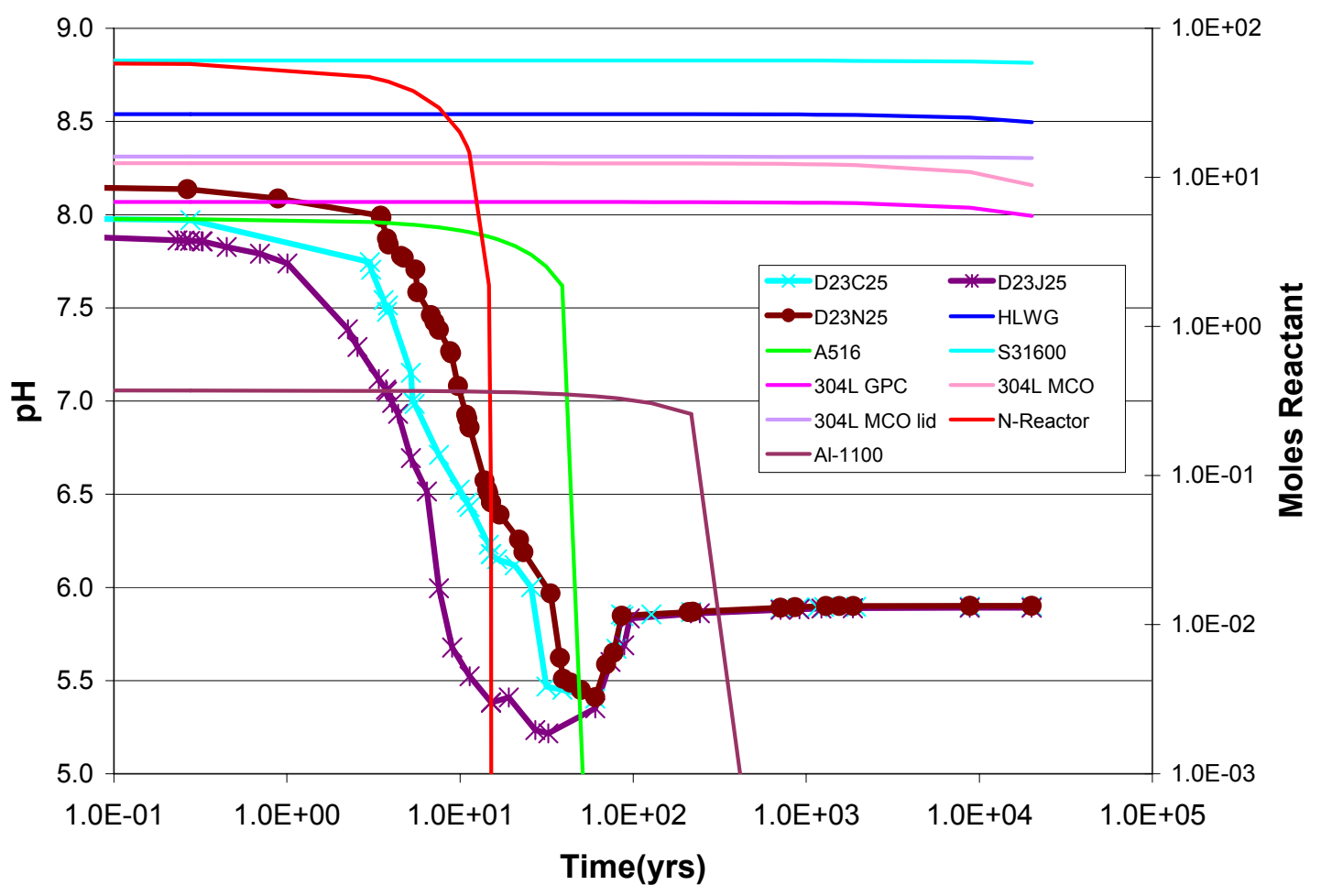

Source: $\quad$ CDSP_Water Influx_25.xIs (Appendix F ISpreadsheets).

NOTE: Time refers to time after waste package breach.

Figure 6-17. CDSP Water Influx Model Results for Three Seepage Compositions at $25^{\circ} \mathrm{C}$

Another important feature of the $\mathrm{pH}$ profiles in Figure 6-17 is the absence of a period of sustained high $\mathrm{pH}$ (greater than 9) that might be expected from the dissolution of the HLWG. Both of the CDSP vapor influx models, the single reactant and multicomponent, predicted that high $\mathrm{pH}$ conditions are possible in the absence of an acid producing reactant (i.e., steel alloy). However, in the water influx model, seepage is allowed to "stream" through the waste package reacting with waste package components. It is unlikely that seepage that has reacted with HLWG, could exit a waste package without contacting a steel component, or schoepite from $\mathrm{N}$ Reactor fuel degradation, along its flow path, both having the capacity to buffer the $\mathrm{pH}$ in the neutral range.

Figure 6-18 shows the minerals that formed for the CDSP water influx model for the three seepage compositions at $25^{\circ} \mathrm{C}$. This plot shows that schoepite, hematite, and gibbsite constitute the three most abundant mineral phases that form from the degradation of a CDSP waste package. The abundance of schoepite $\left(\mathrm{UO}_{3}: 2 \mathrm{H}_{2} \mathrm{O}\right)$ results from the complete reaction of the uranium metal $\mathrm{N}$ Reactor fuel, while the hematite and gibbsite are products of steel and aluminum alloys dissolution, respectively. Over the duration of the simulations, less gibbsite forms in CDSP runs compared to CSNF runs (Figure 6-9), while greater amounts of the nontronite clay minerals form in CDSP runs compared to CSNF runs. This occurs because silica is more available in CDSP compared to CSNF waste packages as a result of the presence and degradation of HLWG. This additional silica leads to greater amounts of nontronite formation in CDSP waste packages. 


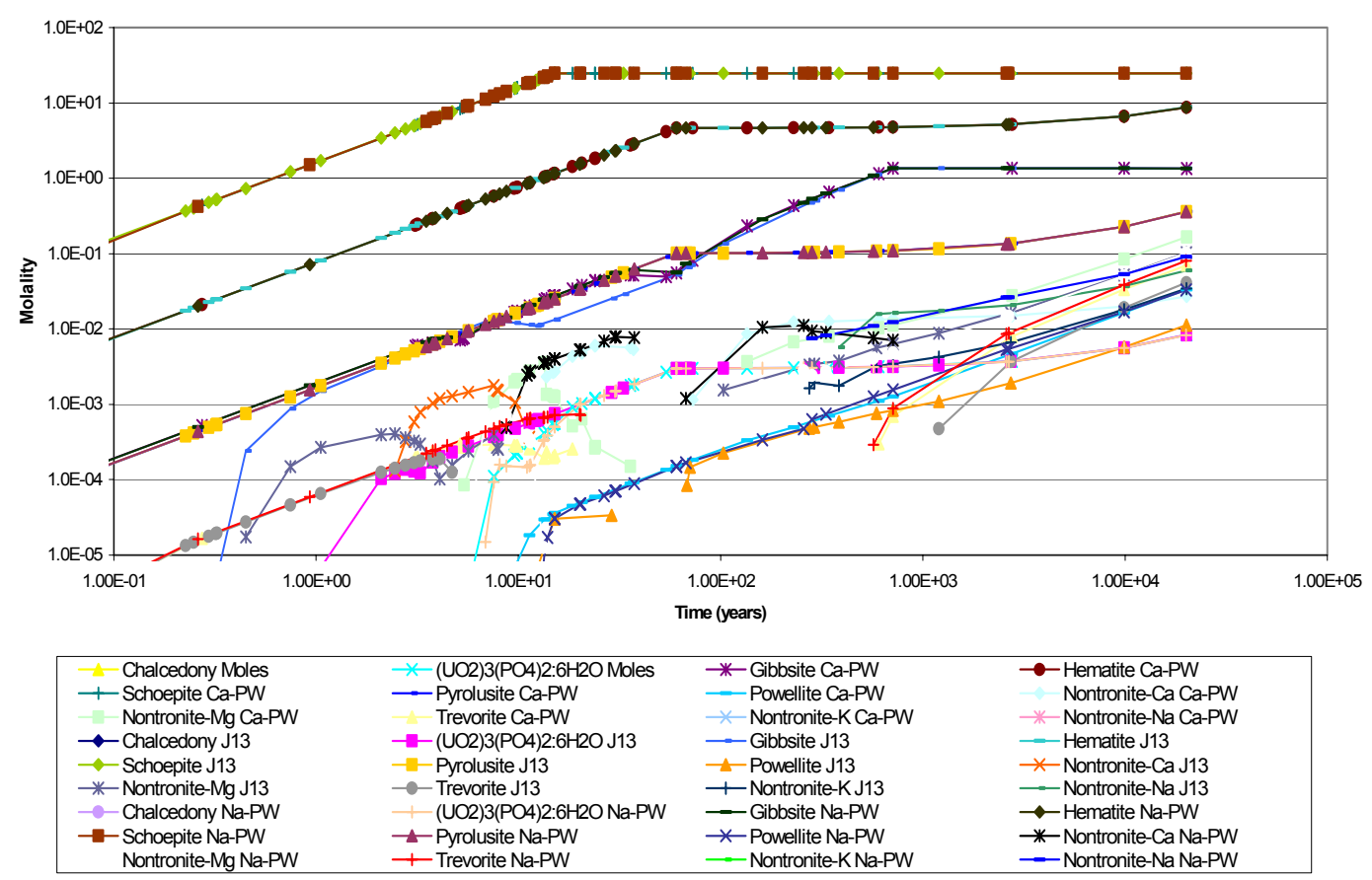

Source: CDSP_Water Influx_50.xIs (Appendix F ISpreadsheets).

NOTE: Time refers to time after waste package breach.

Figure 6-18. CDSP Water Influx Model Mineral Phases for Three Seepage Compositions

The CDSP mineral assemblages (Figure 6-18) for the three seepage compositions provide further support of the conclusion that the composition of the seepage has little influence over which minerals formed and their amounts.

Figure 6-19 displays the aqueous species for the CDSP runs at $25^{\circ} \mathrm{C}$ for the three input water compositions. Similar to CSNF, Figure 6-19 shows that elements which were not present in the initial water compositions (Table 4-2) (i.e., those elements that originate from the waste package and waste forms) have aqueous species concentrations that are nearly identical, and independent of the initial water composition, for the duration of the simulations. Sodium, chromium, and boron have the highest concentrations, and either originated from HLWG dissolution (in the case of the sodium) or from the oxidation of the metal waste package components (in the case of boron and chromium). Elements that do not originate from the waste form or package components, and that do not participate in the formation of minerals, will have aqueous species concentrations set by the incoming water composition (e.g., chloride). However, the concentrations of the majority of aqueous species are nearly identical and independent of the seepage composition. Therefore, it may be concluded that waste package components and waste forms set in-package chemistry, as opposed to composition of the water entering the breached waste package. The above discussion addresses the subject matter of "Included" FEP 2.2.08.12.0B (Chemistry of water flowing into the waste package) and indicates how that subject matter has been included and addressed within TSPA-LA. 
Further examination of Figure 6-17 shows that the reactants dissolve as a function of time (i.e., they are kinetic reactants) and their effect on the in-package chemistry is explicitly modeled in the in-package chemistry model and, thus, is carried over to TSPA-LA. The above discussion addresses the subject matter of "Included" FEP 2.1.09.07.0A (Reaction kinetics in waste package) and indicates how that subject matter has been included and addressed within TSPA-LA.

Figure 6-21 displays the CDSP water influx model $\mathrm{pH}$ profiles for the median flux $(\mathrm{Q}=1.5 \mathrm{~L} / \mathrm{yr})$ for the three seepage compositions at $25^{\circ} \mathrm{C}$.

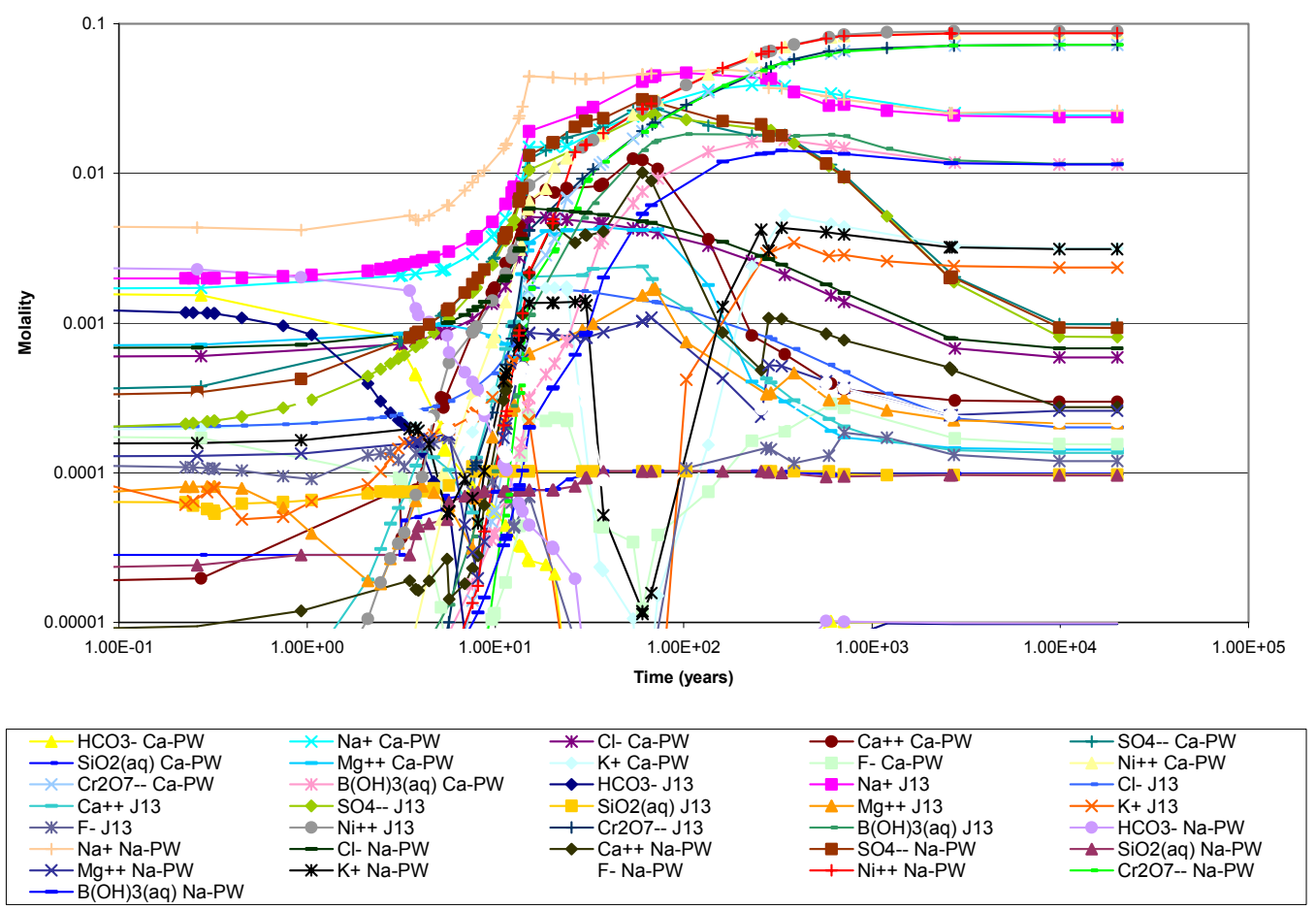

Source: CDSP_Water Influx_25.xIs (Appendix F ISpreadsheets).

NOTE: Time refers to time after waste package breach.

Figure 6-19. CDSP Water Influx Model Aqueous Species for Three Seepage Compositions

The $\mathrm{pH}$ history for the full suite of water influx cases at $50^{\circ} \mathrm{C}$ is presented in Figure 6-20. 


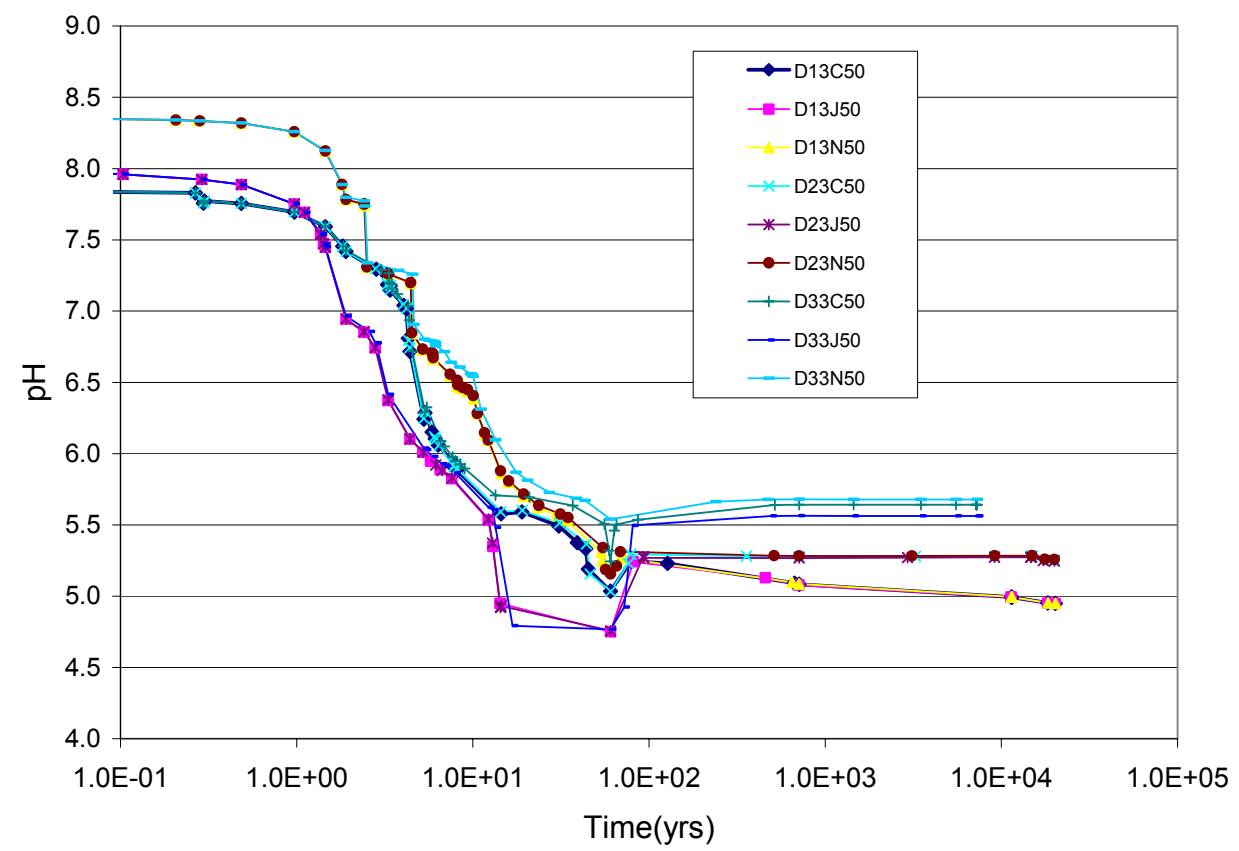

Source: CDSP_Water Influx_50.xIs (Appendix F ISpreadsheets).

NOTE: Time refers to time after waste package breach.

Figure 6-20. CDSP Water Influx Model Results at $50^{\circ} \mathrm{C}$

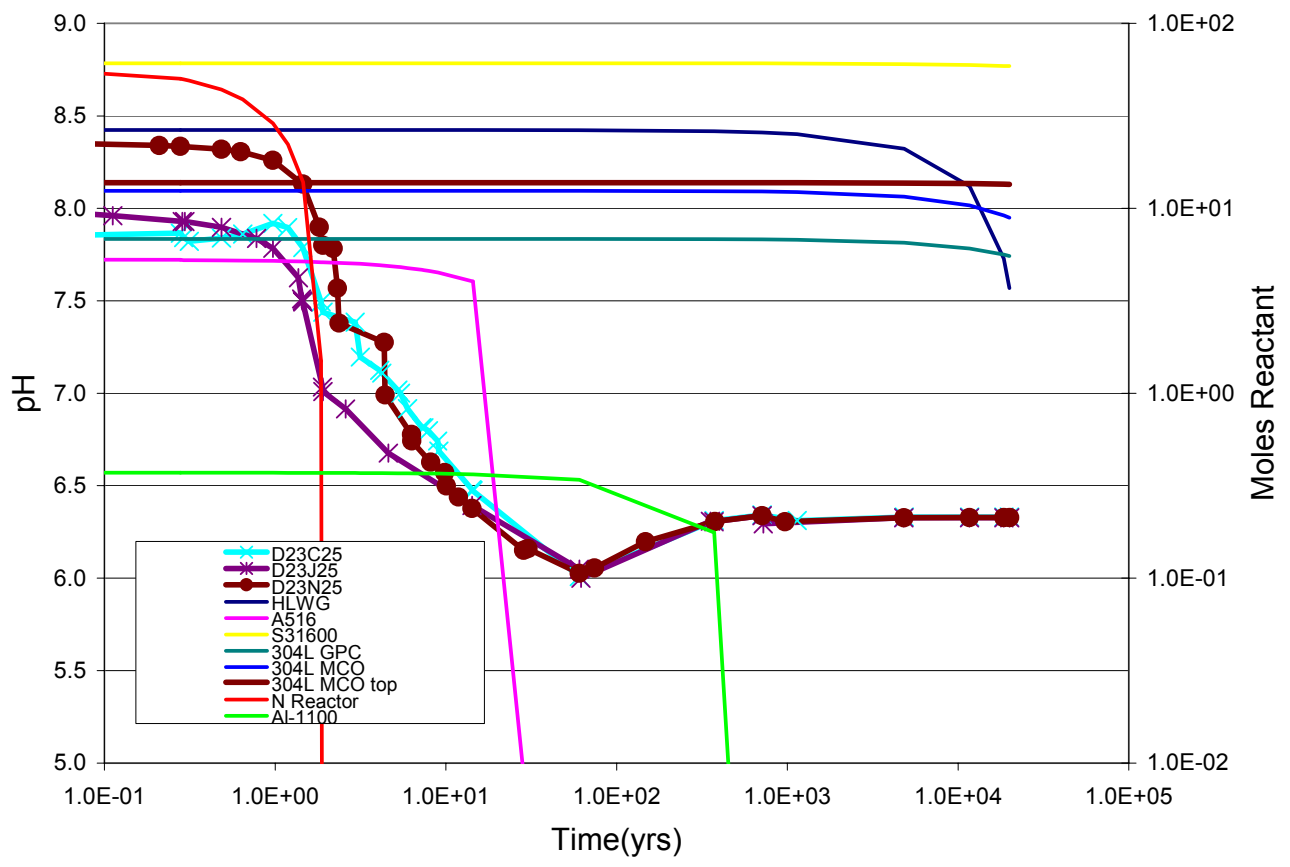

Source: CDSP_Water Influx_50.xIs (Appendix F ISpreadsheets).

NOTE: Time refers to time after waste package breach.

Figure 6-21. CDSP Water Influx Model Results for Three Seepage Compositions at $50^{\circ} \mathrm{C}$ 
The HLWG is more quickly depleted at $50^{\circ} \mathrm{C}$ than $25^{\circ} \mathrm{C}$ because of the higher rate constants (Table 6-10) at elevated temperature. Just as is shown in the $25^{\circ} \mathrm{C}$ runs in Figure 6-17, the initial composition of the seepage entering the waste package has little impact on the composition of the reacted fluid. The chemistry of the composition is dominated by the contents of the waste package. The batch reactor runs at $50^{\circ} \mathrm{C}$ use a HLWG-degradation rate that is temperature appropriate (Table 6-10). The metal alloy corrosion rates are the same as those used for the $25^{\circ} \mathrm{C}$ runs, however, these rates are also considered appropriate for $50^{\circ} \mathrm{C}$ because many of the experiments that generated the data for these rates were conducted at higher temperatures. The thermodynamic database includes high temperature data for most mineral and aqueous species; therefore, the reacted solution chemistry and precipitated mineral phases are temperature appropriate.

The $50^{\circ} \mathrm{C}$ runs achieve an overall higher $\mathrm{pH}$ profile at long time periods and slight variations in the stable mineral assemblages compared with the results at $25^{\circ} \mathrm{C}$. Since a suite of simulations was carried out at above ambient temperatures and the in-package chemistry model results reflect the increased thermal conditions, the TSPA-LA feed also reflects the increased thermal conditions. The above discussion addresses the thermal effects on chemistry portion of the subject matter of "Included" FEP 2.1.11.08.0A (Thermal effects on chemistry and microbial activity in the EBS) and indicates how that subject matter has been included and addressed within TSPA-LA. The microbial activity in the EBS subject matter is described in FEP 2.1.10.01.0A as documented in Engineered Barrier System Features, Events, and Processes (BSC 2004 [DIRS 169898]). The effect of temperature on the surface complexation model is discussed in Section 6.7.3.

\subsection{Ionic Strength}

Figure 6-22 displays the ionic strength profiles for the CDSP water influx model runs at $25^{\circ} \mathrm{C}$. For the low-end seepage flux $(0.15 \mathrm{~L} / \mathrm{yr})$, the ionic strength exceeds 1 molal due to the accumulation of aqueous chromium species in the waste package effluent. These high chromium concentrations occur in the EQ6 simulations because there is no chrome bearing mineral phase in the thermodynamic database available to precipitate under the conditions of the simulation. The ionic strength abstraction is used by the colloid and dissolved concentrations submodels in the TSPA-LA. The colloidal suspensions are unstable at ionic strength values above 0.05 molal (BSC 2003 [DIRS 166845]), so for the colloid submodel, the significance of exceeding the limits of the B-dot activity coefficient equation is diminished. For the dissolved concentrations model, TSPA-LA applies an additional uncertainty term to the concentrations if the ionic strengths is greater than one molal), so the significance of exceeding the limits of the B-dot activity coefficient equation is already captured. Figure 6-22 and Figure 6-23 display the ionic strength abstraction for the CDSP water influx model at $25^{\circ} \mathrm{C}$ and $50^{\circ} \mathrm{C}$, respectively, for the period 0 to 20,000 years. 


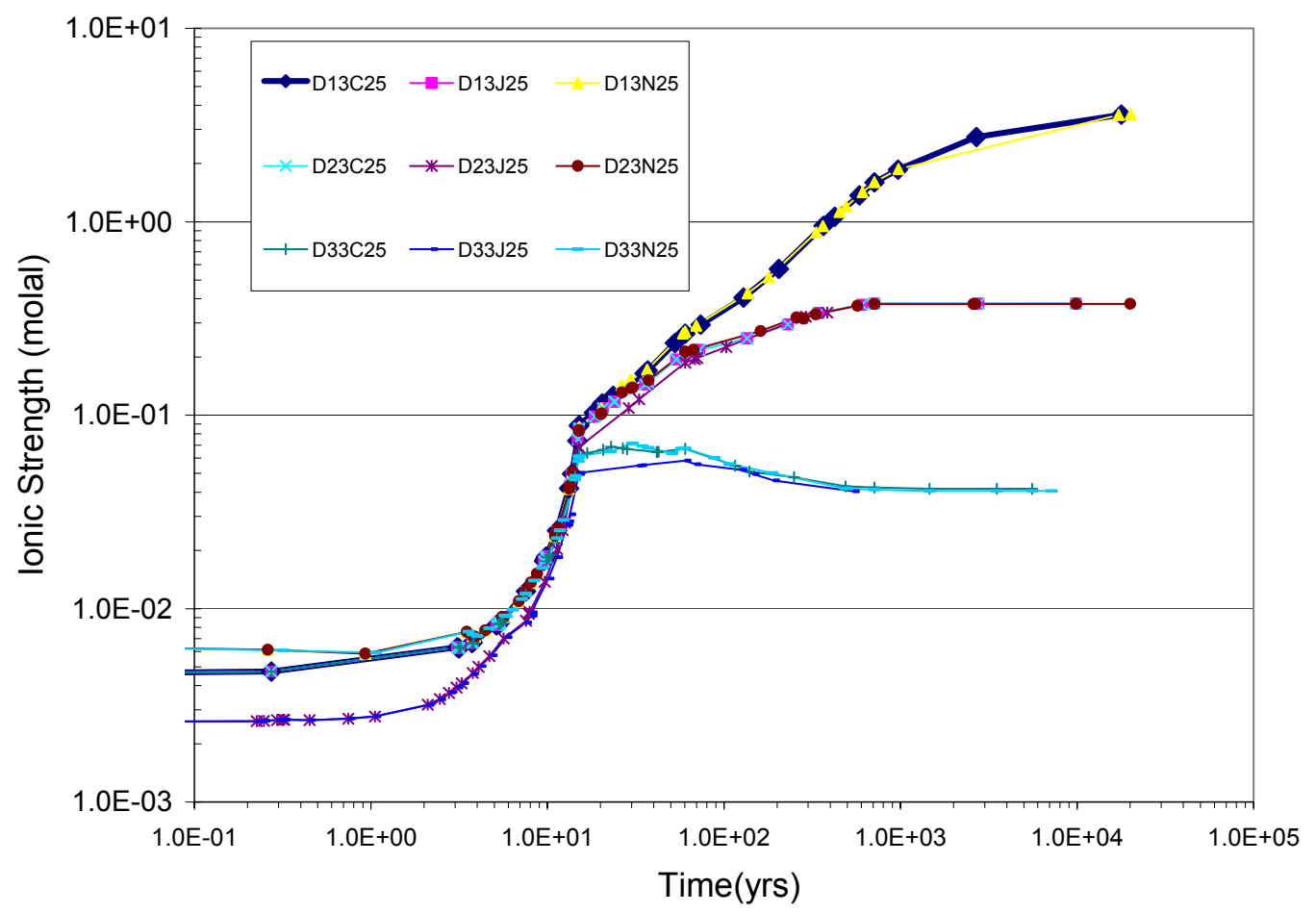

Source: CDSP_Water Influx_25.x/s (Appendix F).

NOTE: Time refers to time after waste package breach.

Figure 6-22. CDSP Water Influx Model $25^{\circ} \mathrm{C}$ lonic Strength Profiles

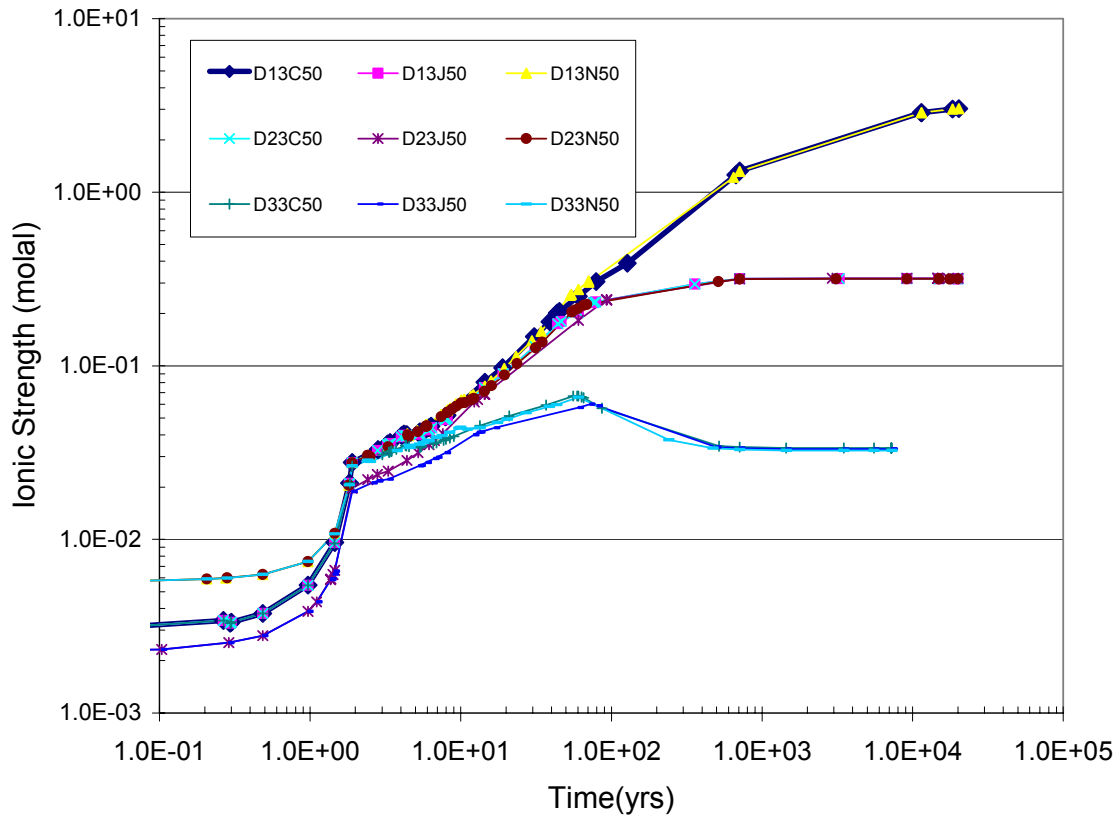

Source: CDSP_Water Influx_50.xls (Appendix F).

NOTE: Time refers to time after waste package breach.

Figure 6-23. CDSP Water Influx Model $50^{\circ} \mathrm{C}$ Ionic Strength Profiles 


\subsubsection{Conceptual Model Conclusions}

The CSNF vapor influx and water influx models results of the reacted solutions reflect interactions between CSNF, waste package components, liquid phase water, and the atmosphere in the voids in the waste package and drift. In addition, the reactants are kinetic reactants, the metal alloys undergo oxidation and precipitate corrosion products that are in contact with the liquid phase water thereby having a first order influence on the chemistry, and increased temperature was investigated. The above discussion addresses the subject matter of the following "Included FEPs," and indicates how that subject matter has been included and addressed within TSPA-LA:

- 2.1.02.09.0A, Chemical effects of void space in waste package

- 2.1.09.01.0B, Chemical characteristics of water in the waste package

- 2.1.09.02.0A, Chemical interaction with corrosion products

- 2.1.09.06.0A, Reduction - oxidation potential in waste package

- 2.1.09.07.0A, Reaction kinetics in waste package

- 2.1.11.08.0A, Thermal effects on chemistry and microbial activity in the EBS

- $2.2 .08 .12 .0 \mathrm{~B}$, Chemistry of water flowing into the waste package.

The CDSP vapor and water influx model runs include both high-level radioactive waste and $\mathrm{N}$ Reactor fuels as reactants; thus, the resulting chemistry of the reacted solutions reflects interactions between codisposed waste, the nonspent nuclear fuel waste package components, the liquid phase water, and the atmosphere in the voids in the waste package and drift. In addition, the reactants are kinetic, the fuel and metal alloys undergo oxidation and precipitate corrosion products that are in contact with the liquid phase water, thereby having a first order influence on the chemistry. The above discussion addresses the subject matter of the following "Included FEPs," and indicates how that subject matter has been included and addressed within TSPA-LA:

- 2.1.01.02.0B, Interactions between codisposed waste

- 2.1.02.09.0A, Chemical effects of void space in waste package

- 2.1.09.01.0B, Chemical characteristics of water in the waste package

- 2.1.09.02.0A, Chemical interaction with corrosion products.

- 2.1.09.07.0A, Reaction kinetics in waste package

- 2.2.08.12.0B, Chemistry of water flowing into the waste package.

\subsection{BATCH REACTOR SENSITIVITY ANALYSES}

Sensitivity analyses were performed to:

(1) Determine uncertainty ranges

(2) Expand the boundaries of temperature and $\mathrm{CO}_{2}$ fugacity ranges of the in-package chemistry model abstraction

(3) Demonstrate how various inputs (waste package design configuration, chromium oxidation, water to reactant ratio) impact the model output. 
The sensitivity analyses consider that variations in a model input will translate to the model output independent of the modeled scenario. For example, decreasing the corrosion rate of the steels used in the waste package for a specific fuel exposure-flux scenario has the effect of delaying the timing of a $\mathrm{pH}$ response. Therefore, it is expected that an equivalent model response will occur for a different fuel exposure-flux scenario.

In general, sensitivity runs were executed using the median seepage flux-fuel exposure case $\mathrm{C} 22 \mathrm{C} 25$ at $25^{\circ} \mathrm{C}$, with an equivalent set of runs executed for the codisposed case, D23C25. Key inputs were varied over a range of values, and the outputs were compared to the appropriate base case output. The spreadsheets associated with the plots in Section 6.6 are located in Appendix F\Spreadsheets $\backslash$ Sensitivities.

The results of applying the surface complexation model to the batch reactor model are discussed in Section 6.9, and these results are shown in the plots.

\subsubsection{Ratio of Water to Reactants}

The following runs were conducted to see the impact of varying the ratio of water to reactants. The highest ratio is that of the "bathtub," where all of the void space is filled with water. This ratio is decreased, and the impact on the $\mathrm{pH}$ and ionic strength are presented in Figure 6-24 and Figure 6-25. The ratio of water to reactants is varied based on the surface area. For the "bathtub" case, if the one liter of water were spread evenly over the scaled surface areas of the reactants, that layer of water would be approximately $0.58-\mathrm{cm}$ thick for the CSNF waste package and $0.69 \mathrm{~cm}$ for the CDSP waste package. In this sensitivity analysis, this ratio of water to reactants is examined based on the thickness of the layer of water that would result from one liter of water spread over the scaled surface areas for each case. For more details on the scaling used in this sensitivity, see CSNF.xls or CDSP.xls in Appendix F. 


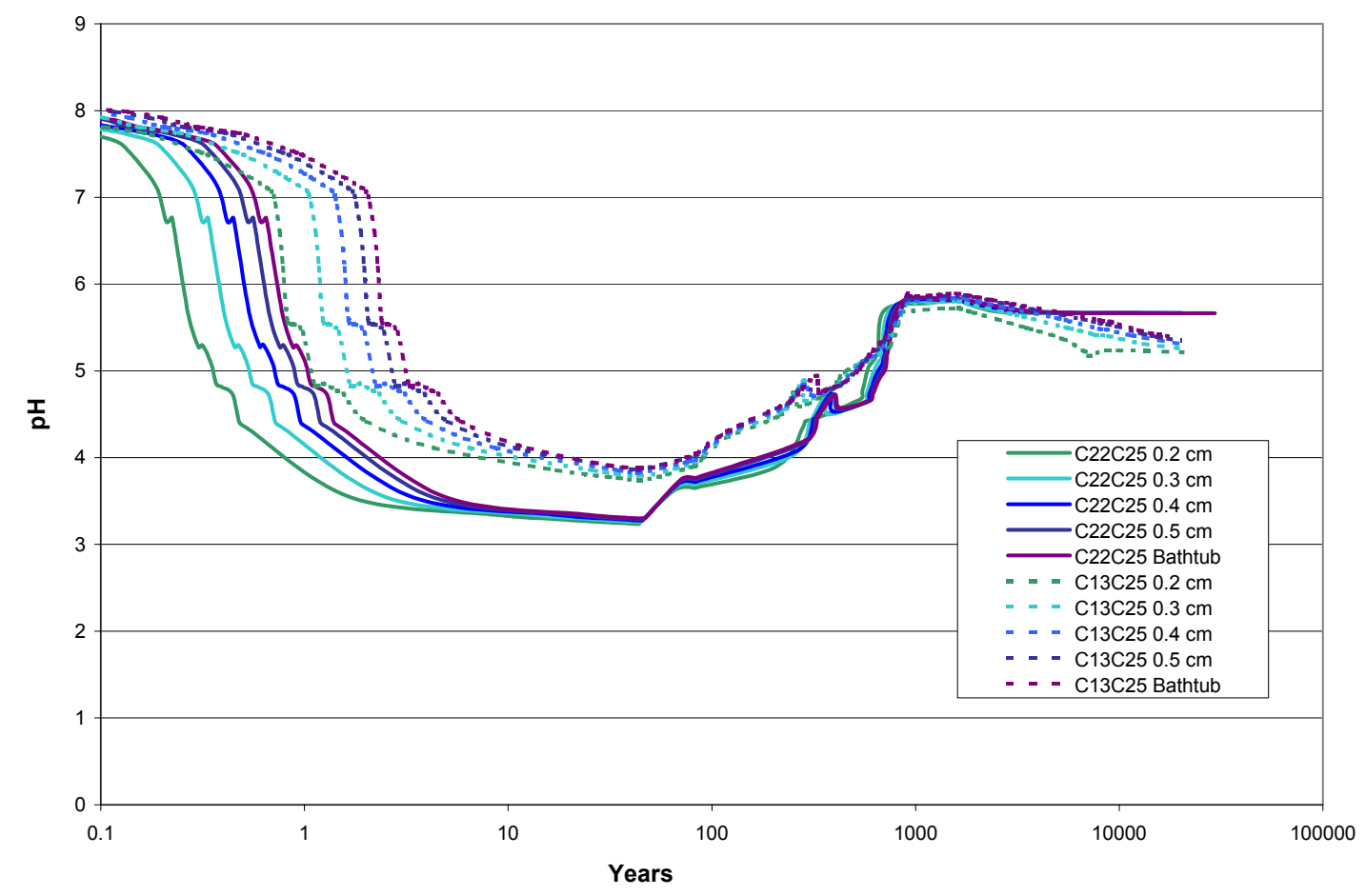

Source: $\quad$ CSNF_Water Ratio Sensitivity.xIs (Appendix F).

Figure 6-24. Ratio of Water to Reactants for CSNF: Impact on $\mathrm{pH}$

Figure 6-24 and Figure 6-26 show that the ratio of water to reactants has little effect on the overall $\mathrm{pH}$ of the system for both the CSNF and CDSP waste packages. The most notable effect is that lower ratios of water to reactants see the $\mathrm{pH}$ decrease earlier than the cases with a higher ratio, but the $\mathrm{pH}$ minimum and steady state $\mathrm{pHs}$ are very similar. For the CSNF case, the water ratio sensitivity analysis also examined a more conservative flux and fuel exposure case, C13C25 that uses the lowest water flux with the highest fuel exposure $(0.15 \mathrm{~L} / \mathrm{yr}$ and $100 \%$ CSNF exposure). In addition, sensitivity also uses a case with the median seepage flux-fuel exposure case $\mathrm{C} 22 \mathrm{C} 25$ at $25^{\circ} \mathrm{C}$ (the representative case used for most of the sensitivities). For all cases, the results also show the same trend in $\mathrm{pH}$; the lower ratios of water to reactants see the $\mathrm{pH}$ decrease earlier, but the $\mathrm{pH}$ minimum and steady state $\mathrm{pHs}$ are very similar. These results show that additional water in the system has minimal impact on $\mathrm{pH}$, which addresses two points dealing with the quantity of water, which were raised in the code implementation section of Section 6.3.1.1. In the vapor influx case, where water accumulates in the EQ6 model (as opposed to the implementation in TSPA-LA with no accumulation of water), the impacts of this accumulating water on $\mathrm{pH}$ are minimal. In addition, the immediate availability of water in the batch reactor model described also has minimal impact on the $\mathrm{pH}$ of the system. Therefore, the discrepancy between the batch reactor modeling, and the conceptualization of the vapor influx within TSPA-LA has minimal impact. 


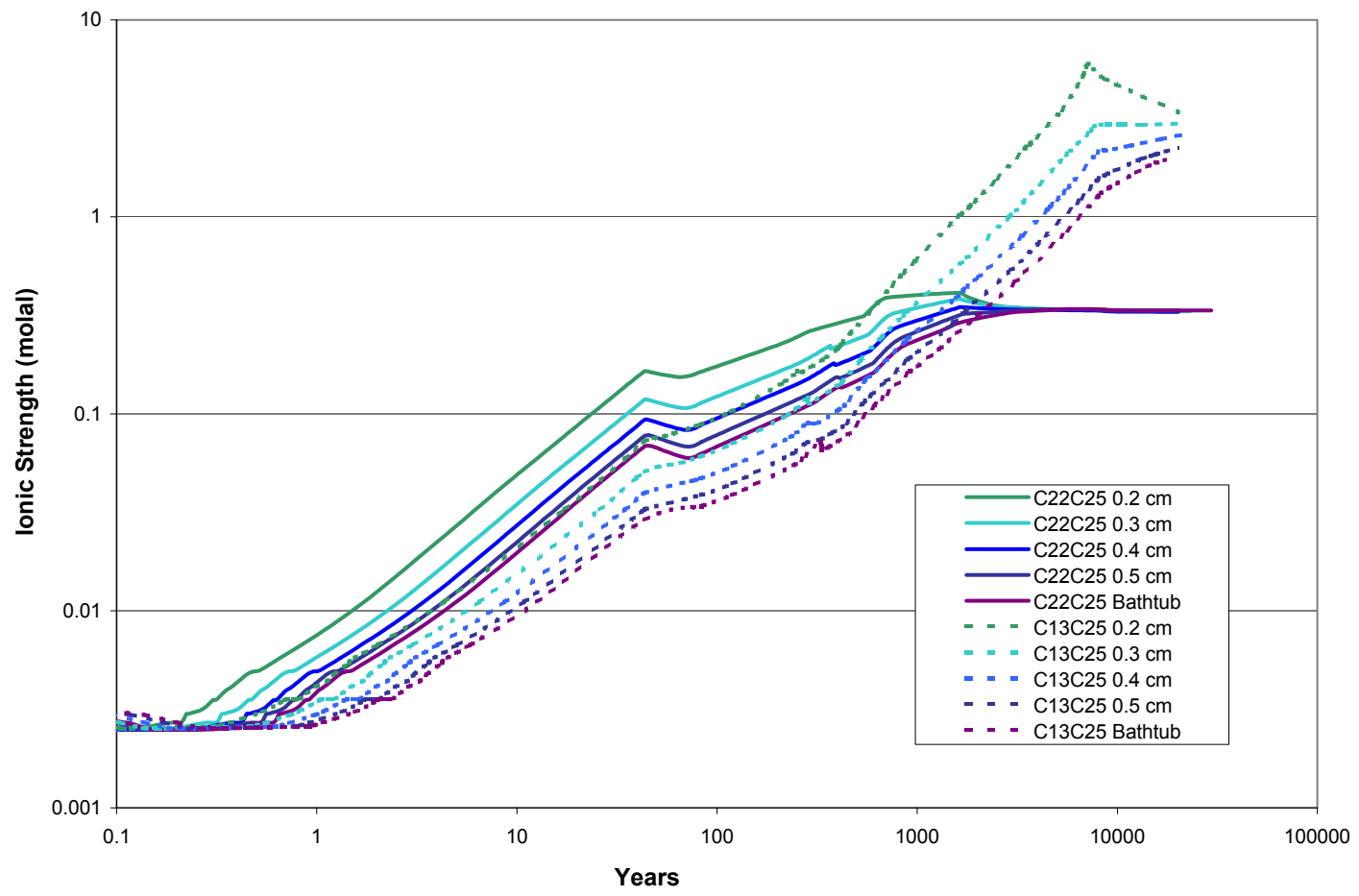

Source: $\quad$ CSNF_Water Ratio Sensitivity.xls (Appendix F).

Figure 6-25. Ratio of Water to Reactants for CSNF: Impact on lonic Strength

D23C25

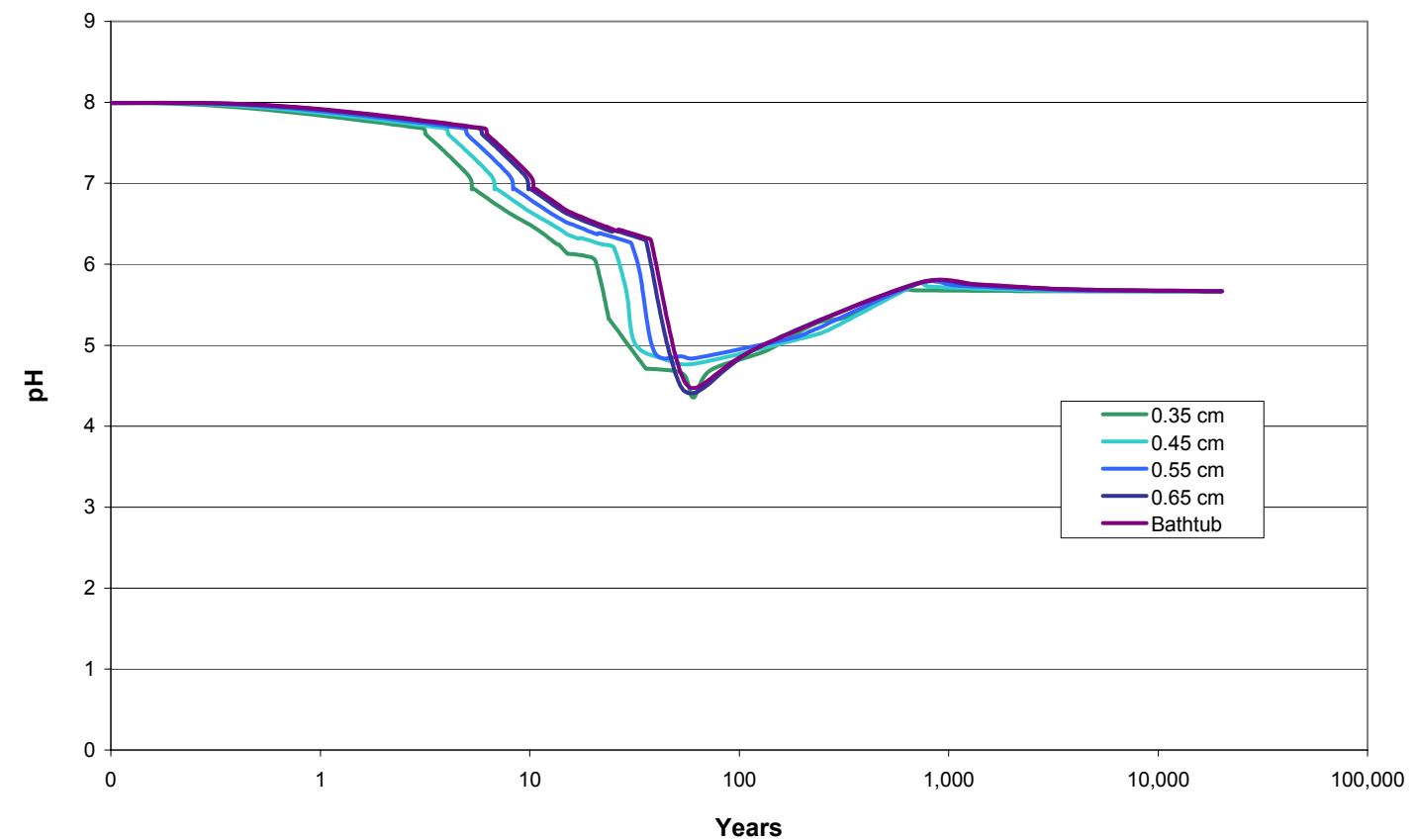

Source: $\quad$ CDSP_Water Ratio Sensitivity.xls (Appendix F).

Figure 6-26. Ratio of Water to Reactants for CDSP: Impact on $\mathrm{pH}$ 


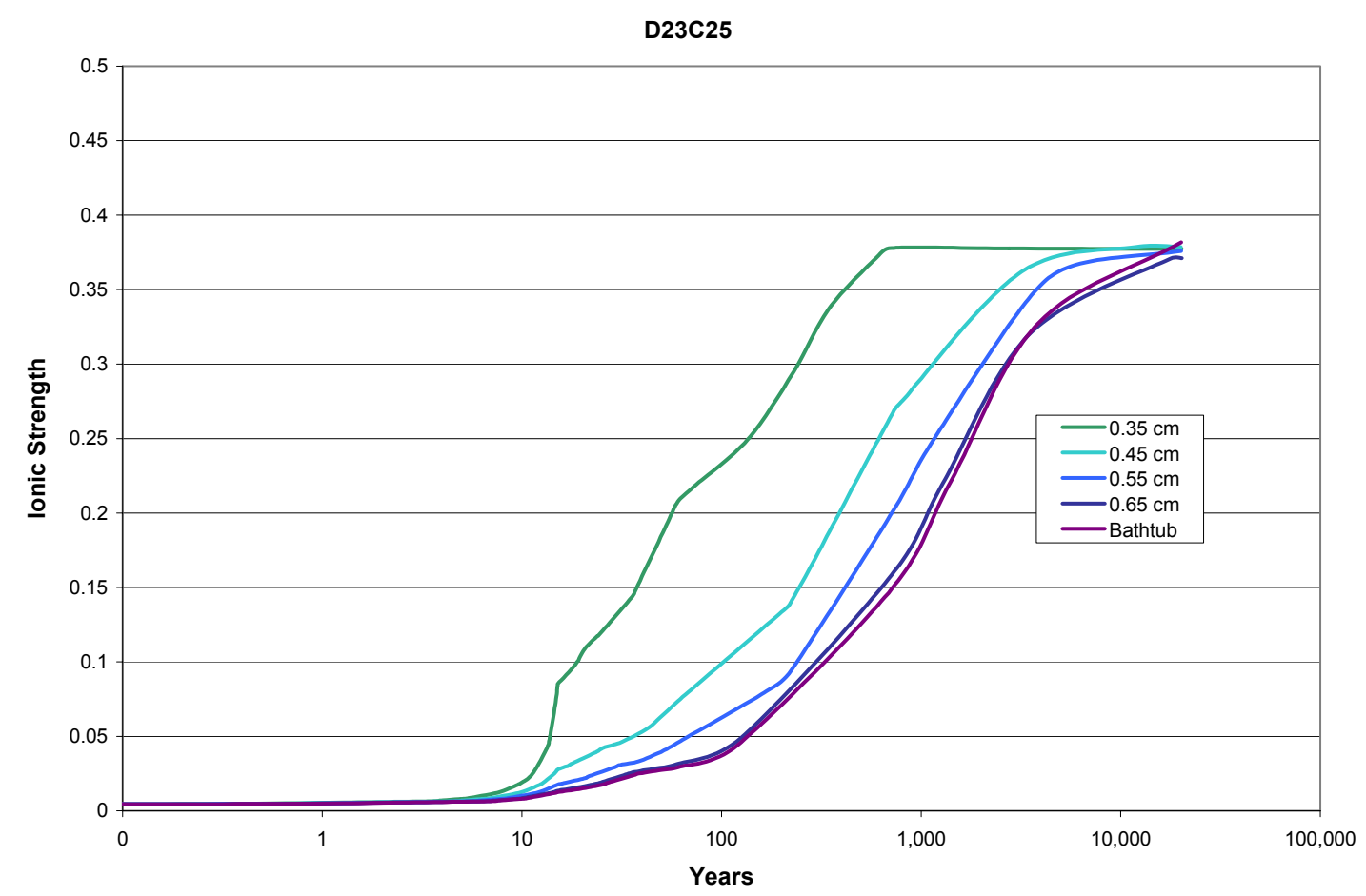

Source: $\quad C D S P \_$Water Ratio Sensitivity.xIs (Appendix F).

Figure 6-27. Ratio of Water to Reactants for CDSP: Impact on lonic Strength

Figure 6-25 and Figure 6-27 show that the ratio of water to reactants strongly affects the ionic strength. For this reason, the ionic strength model includes additional uncertainty to account for the potential variation in water to reactants ratio. For the two points dealing with the quantity of water, which were raised in the code implementation section of Section 6.3.1.1, the effects of water accumulation on ionic strength must be addressed. The discrepancy between the EQ6 batch reactor model and the conceptualization of the vapor influx case within TSPA-LA is more significant for the ionic strength. This discrepancy leads to lower modeled ionic strengths at later times (due to accumulating water). The immediate availability of water in the batch reactor model leads to lower modeled ionic strengths at early times.

Low ionic strengths $(<0.05$ molal $)$ are conservative for TSPA-LA under advective flow conditions for colloid stability because colloids are stable when ionic strength is less than 0.05 (BSC 2003 [DIRS 166845]). Low ionic strengths are not conservative in TSPA-LA under diffusive conditions, where colloids move much slower than dissolved species, and for the solubility of radionuclides (when the ionic strengths go above 1 molal, TSPA-LA adds additional uncertainty to the solubility of radionuclides (BSC 2004 [DIRS 169425]). However, the uncertainty term is also designed to bias higher ionic strengths when the ionic strength is high, by making the uncertainty term a percentage of the ionic strength value (Section 6.10.2.3) resulting in an overall output to TSPA-LA that is not nonconservative.

The above discussion addresses the subject matter of "Included" FEP 2.1.02.09.0A (Chemical effects of void space in waste package) and indicates how that subject matter has been included and addressed within TSPA-LA. 


\subsubsection{Thermally Perturbed Fluids}

This section uses three thermally perturbed fluid compositions that were abstracted in Engineered Barrier System: Physical and Chemical Environment Model (BSC 2004 [DIRS 169054], Section 6.6) as input for the in-package chemistry model.

The three waters have different carbon dioxide fugacity $\left(f \mathrm{CO}_{2}\right)$ and temperatures (Table 4-3). The EQ6 runs were set up to reflect increased temperature and $f \mathrm{CO}_{2}$, and CSNF (Table 6-9) and HLWG (Table 6-10) kinetic rate constants were recalculated at the new temperatures. EQ6 runs were executed at these conditions using the thermally perturbed seepage compositions, Na-porewater was used with the CDSP runs, and Ca-porewater was used with the CSNF runs for comparative purposes.

Figure 6-28 and Figure 6-29 are sample outputs and show the results for a CSNF run and a CDSP run where both $\mathrm{pH}$ and ionic strength are plotted on the same X-axis. The simulation results are in close agreement, even though their root compositions were different, which implies that incoming water composition has little influence over the in-package $\mathrm{pH}$ and ionic strength.

The remaining results are plotted in Appendix A, Figures A-2 through A-5.

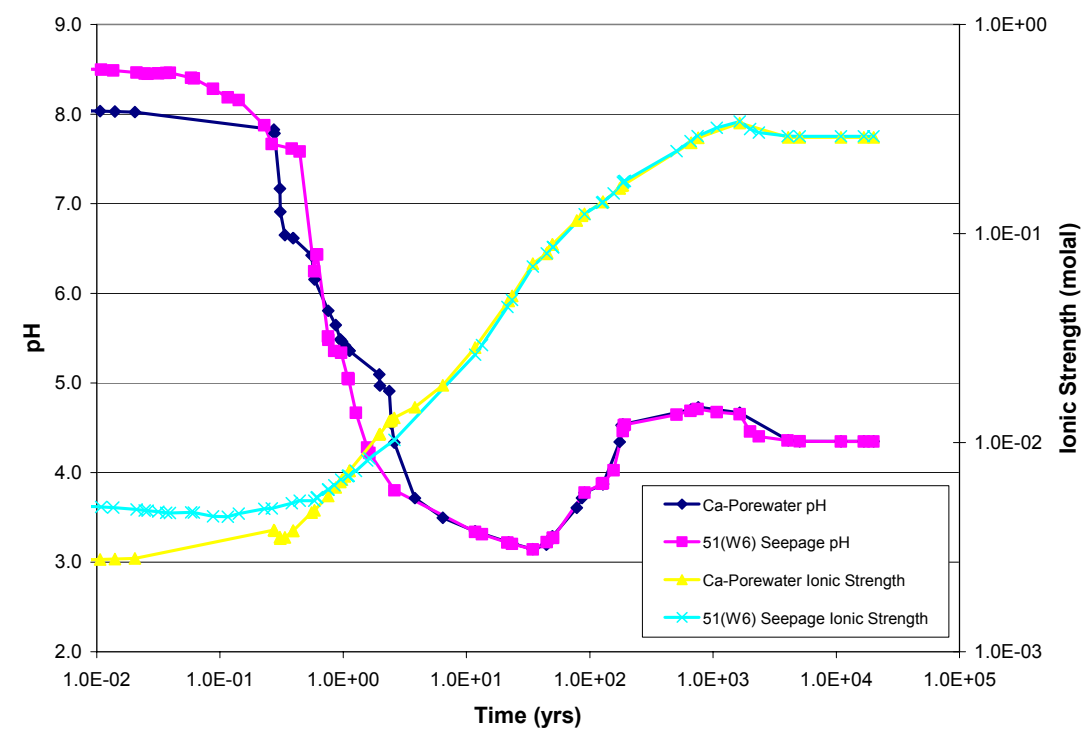

Source: $\quad$ CSNF_P\&CE_fluids.xls (Appendix F).

Figure 6-28. Thermally Perturbed Composition 51 (W6) for CSNF 


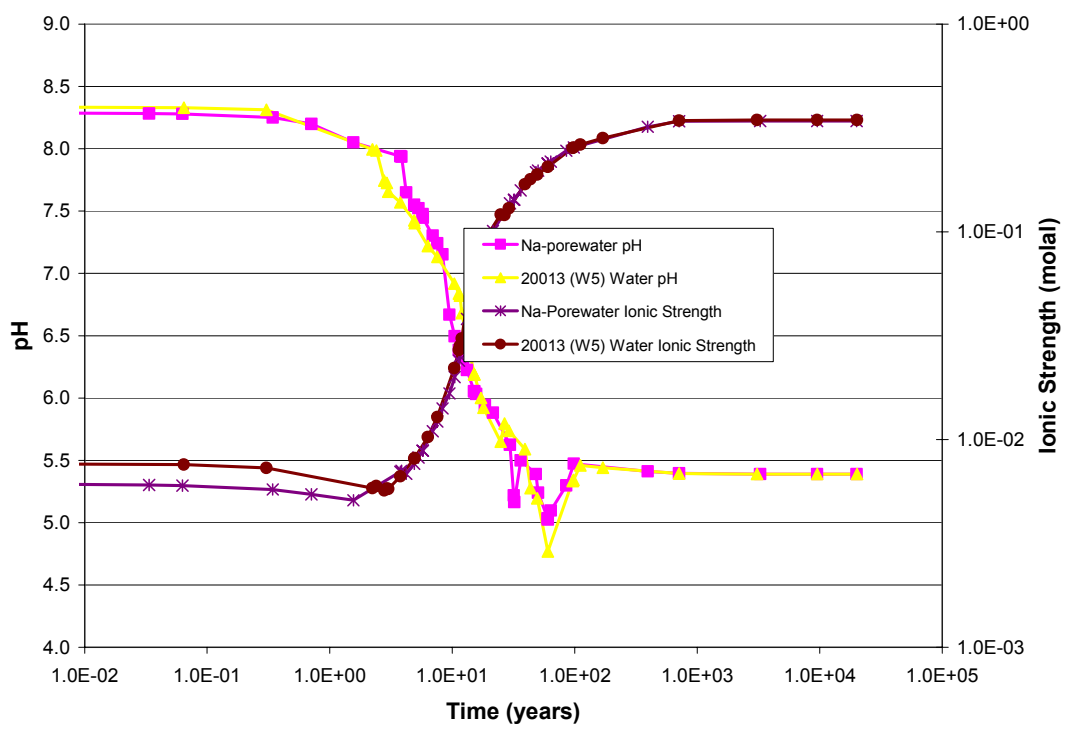

Source: $\quad C D S P \_P \& C E \_$fluids.xls (Appendix F).

Figure 6-29. Thermally Perturbed Composition 20013 (W5) for CDSP

It is expected that during the surface complexation period, the first 600 years (Section 6.9), there would be no impact on the conclusions drawn regarding the thermally perturbed waters. Variations in the bulk fluid composition would be negligible for elements originating in the waste package, and only slight variations are expected for elements peculiar to the water composition, with no impact on performance.

The above discussion addresses the subject matter of "Included" FEP 2.2.08.12.0B (Chemistry of water flowing into the waste package) and indicates how that subject matter has been included and addressed within TSPA-LA.

\subsubsection{Oxidation State of Chromium}

The element chromium (Cr) is a major constituent of several of the stainless steels and alloys used in the construction of the CSNF and CDSP waste packages (Table 4-7). A sensitivity analysis was performed to determine the influence of the Cr oxidation state (kinetic control), on the in-package $\mathrm{pH}$.

The in-package chemistry model allows complete oxidation of chromium to $\mathrm{Cr}(\mathrm{VI})$, while Engineered Barrier System: Physical and Chemical Environment Model (BSC 2004 [DIRS 169054], Section 6.8.2) limits the oxidation of chromium to $\mathrm{Cr}(\mathrm{III})$ :

Selection of $\mathrm{Cr}(\mathrm{III})$ over that of the more soluble $\mathrm{Cr}(\mathrm{VI})$ species is based on experimentally observed corrosion products, and on the kinetics and conditions required to obtain the fully oxidized Cr(VI) state (Smith and Purdy 1995 [DIRS 162976]). Smith and Purdy's examination of the actual chromium speciation as a result of corrosion of $316 \mathrm{~L}$ stainless steel demonstrated a predominance of the less soluble $\mathrm{Cr}(\mathrm{III})$ species, except under the conditions of hot concentrated nitric acid $\left(111^{\circ} \mathrm{C}\right.$ and $>7$ molar $\mathrm{HNO}_{3}$, see Smith and Purdy 1995, Figure 6). 
The two models differ on the oxidation state of chromium because even though both models contain stainless steel 316 that contains chromium, the in-package chemistry model includes neutronit or NiGd alloy which also have significant chromium. Therefore, chromium is a much greater factor in the in-package chemistry model, so a more conservative approach is taken.

The choice of $\mathrm{Cr}(\mathrm{VI})$ in the current model was based on thermodynamic equilibrium, as described in Section 6.3.1.1, for the purpose of being conservative relative to the release of radionuclides. The choice of $\mathrm{Cr}(\mathrm{VI})$ was also based on the predominance of manganese as a component of the steels (Table 4-7) which when oxidized to either $\mathrm{MnO}_{2}$ (pyrolusite), or to $\mathrm{MnOOH}$ (manganite) (Eary and Rai 1987 [DIRS 105780]; Johnson and Xyla 1991 [DIRS 105878]), tends to favor the $\mathrm{Cr}(\mathrm{VI})$ oxidation state.

To test what effect the $\mathrm{Cr}$ oxidation state had on the in-package $\mathrm{pH}$ and ionic strength, run $\mathrm{C} 22 \mathrm{C} 25$ was altered to favor $\mathrm{Cr}(\mathrm{III})$ predominance over $\mathrm{Cr}(\mathrm{VI})$ by adding two $\mathrm{Cr}$ (III) solids to the database and suppressing of all $\mathrm{Cr}(\mathrm{VI})$ aqueous species and mineral phases. The two $\mathrm{Cr}(\mathrm{III})$ solids added to the database were $\mathrm{Cr}(\mathrm{OH})_{3}$ and eskolaite $\left(\mathrm{Cr}_{2} \mathrm{O}_{3}\right)$, and their thermodynamic data are given by Ball and Nordstrom (1998 [DIRS 163015]).

Results are shown for $\mathrm{pH}$ and ionic strength for both $\mathrm{Cr}(\mathrm{III})$ and $\mathrm{Cr}(\mathrm{VI})$ for CSNF in Figure 6-30 and Figure 6-31. The $\mathrm{pH}$ and ionic strength results for CDSP are shown in Figure 6-32 and Figure 6-33. The plots showing $\mathrm{pH}$ indicate that the $\mathrm{Cr}$ oxidation state has minimal impact on $\mathrm{pH}$. The figures show that the $\mathrm{Cr}$ (III) system significantly reduces the ionic strength, however, the lower ionic strengths are still within the bounds provided to TSPA-LA by the ionic strength model abstraction. The possibility of a lower ionic strength if $\mathrm{Cr}(\mathrm{III})$ were to form is taken into account by biasing the abstracted ionic strength to lower values, via the uncertainty term, as discussed in Section 6.10.2.3.

The higher ionic strength predicted by the $\mathrm{Cr}(\mathrm{VI})$ system is conservative with respect to the calculation of radionuclide solubilities within TPSA-LA, so is, therefore, justified.

$\mathrm{Cr}(\mathrm{VI})$ can be favored in an oxidizing environment in the presence of manganese oxides, and the choice of the $\mathrm{Cr}(\mathrm{VI})$ system over the $\mathrm{Cr}(\mathrm{III})$ is conservative and well justified in the in-package environment.

The surface complexation model uses $\mathrm{Cr}(\mathrm{VI})$ as the predominant form of chromium, which is consistent with the batch reactor model.

The above discussion addresses the kinetics of the $\mathrm{Cr}$ species that is the subject matter of "Included" FEP 2.1.09.07.0A (Reaction kinetics in waste package) and indicates how that subject matter has been included and addressed within TSPA-LA. 


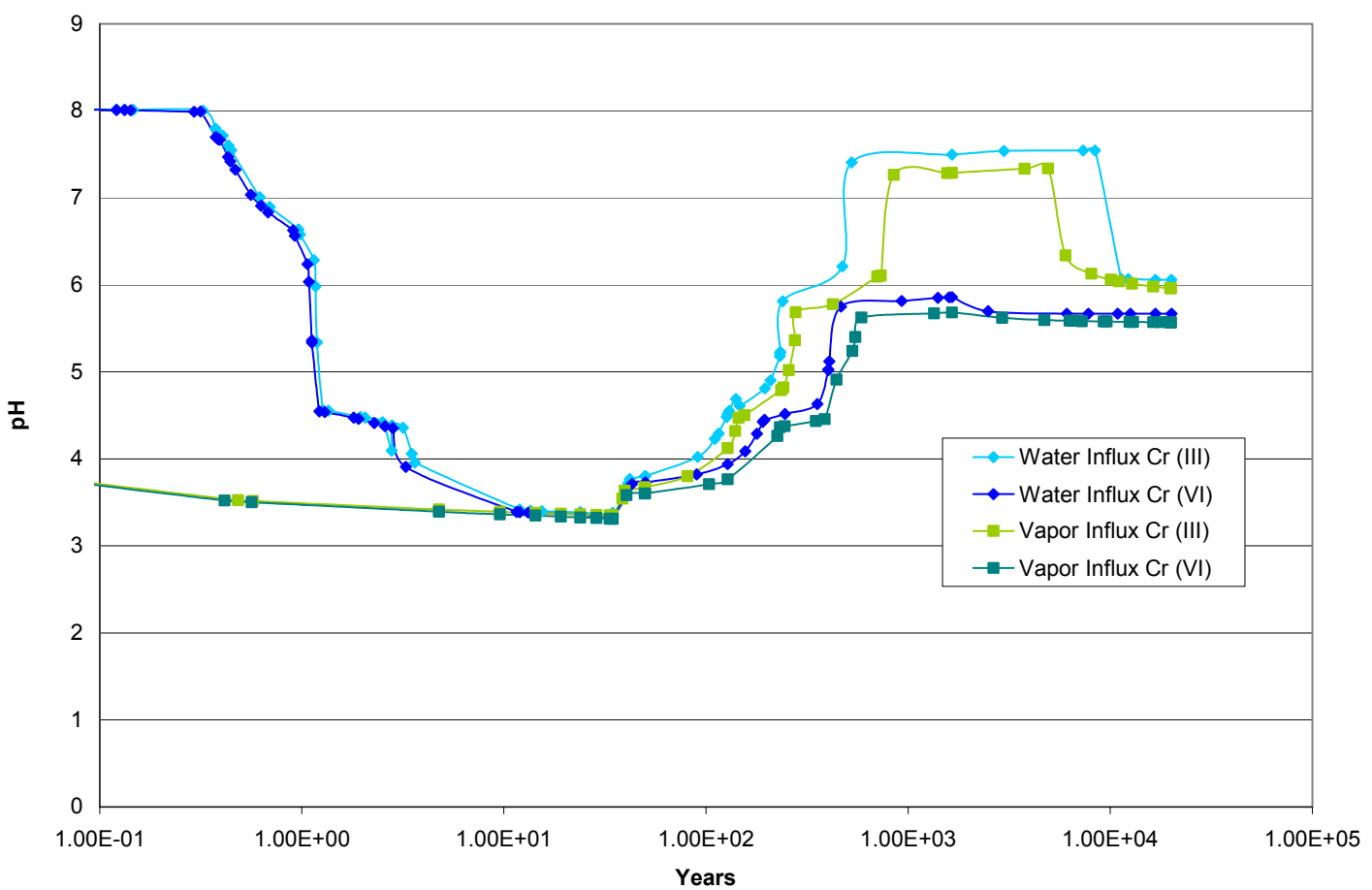

Source: $\quad$ Crlll Sensitivity.x/s (Appendix F).

Figure 6-30. $\mathrm{Cr}(\mathrm{III})$ versus the $\mathrm{Cr}(\mathrm{VI})$ for CSNF: Impact on $\mathrm{pH}$

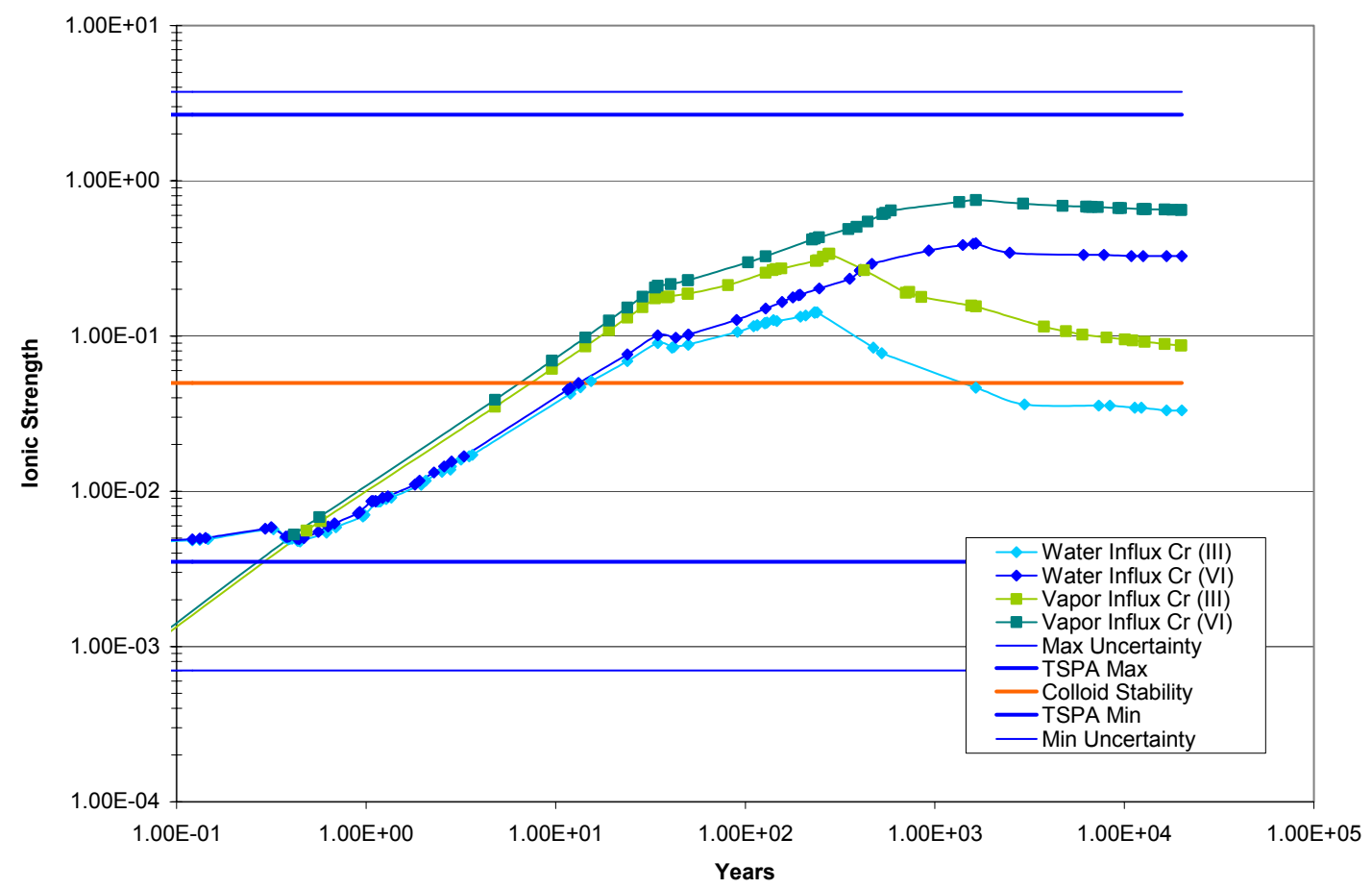

Source: Crlll Sensitivity.xls (Appendix F).

Figure 6-31. $\mathrm{Cr}(\mathrm{III})$ versus the $\mathrm{Cr}(\mathrm{VI})$ for CSNF: Impact on lonic Strength 


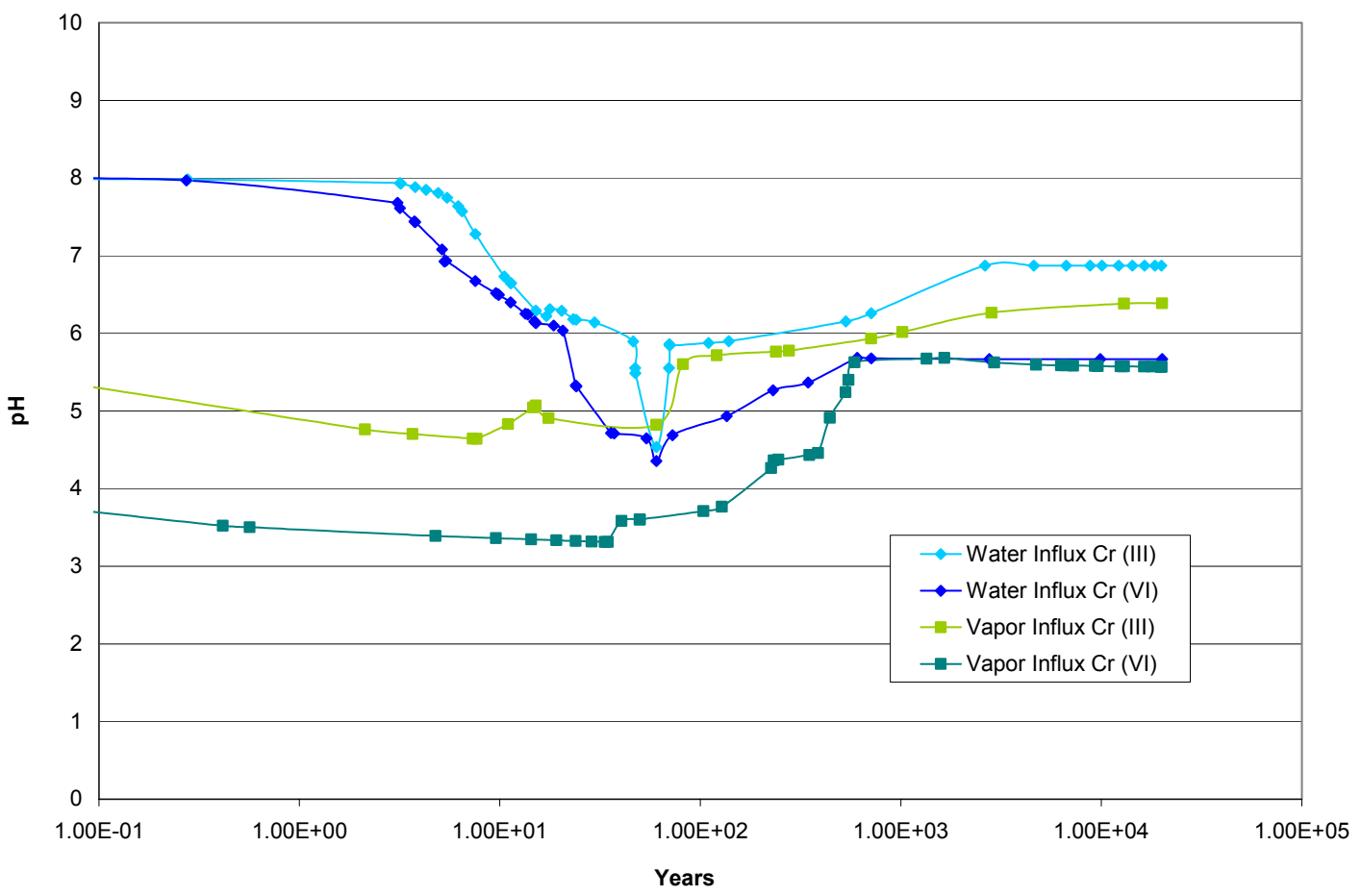

Source: Crlll Sensitivity.xls (Appendix F).

Figure 6-32. $\mathrm{Cr}(\mathrm{III})$ versus the $\mathrm{Cr}(\mathrm{VI})$ for $\mathrm{CDSP}$ : Impact on $\mathrm{pH}$

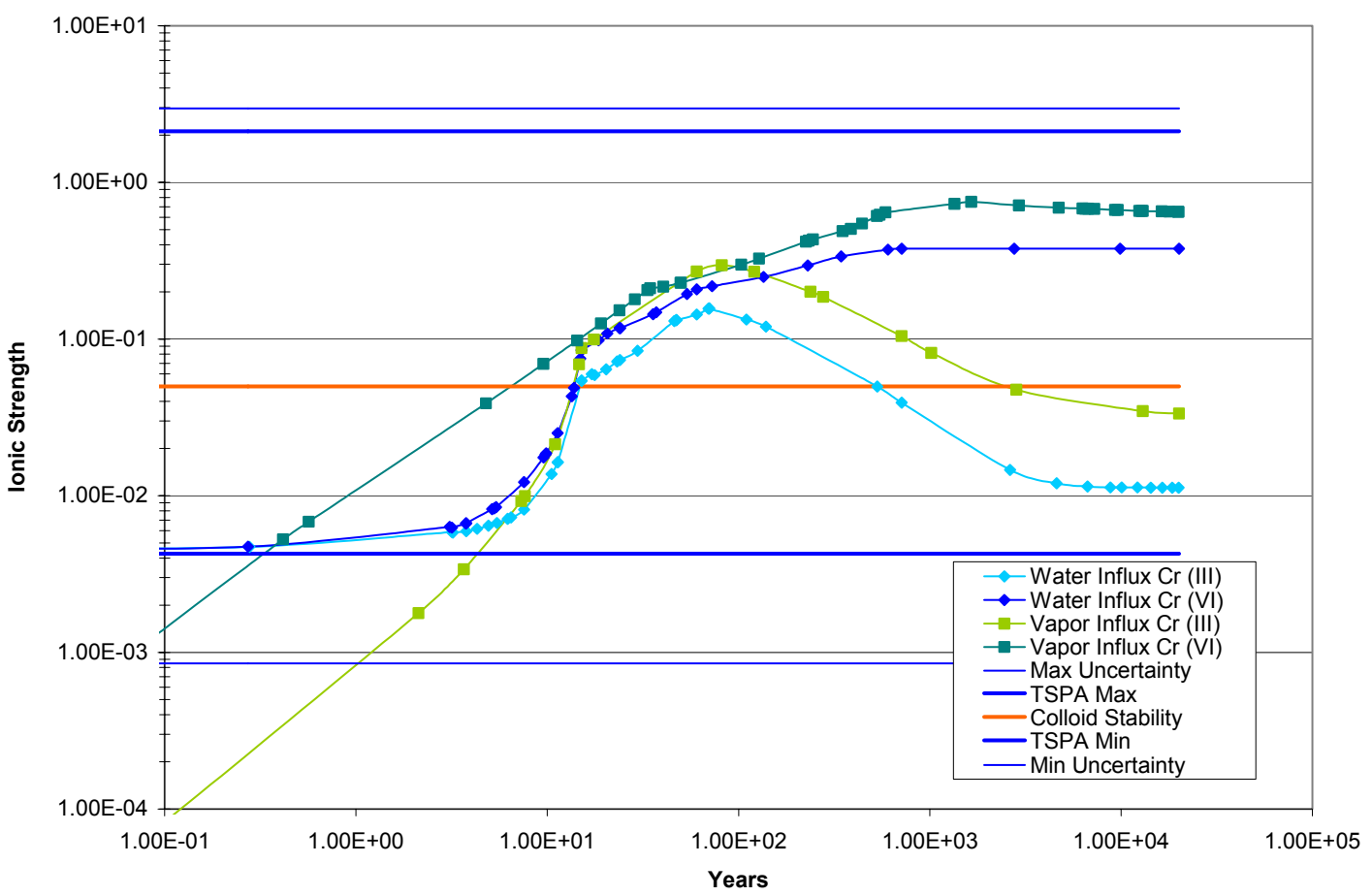

Source: Crlll Sensitivity.xls (Appendix F).

Figure 6-33. $\mathrm{Cr}(\mathrm{III})$ versus the $\mathrm{Cr}(\mathrm{VI})$ for CDSP: Impact on lonic Strength 


\subsubsection{Carbon Dioxide and Oxygen Fugacity}

The sensitivity studies in this section vary the $f \mathrm{CO}_{2}$ from $10^{-5.0}$ to $10^{-1.5}$ and the $f \mathrm{O}_{2}$ from $10^{-69}$ to $10^{-0.7}$. For total carbonate concentrations less than $2 \times 10^{-4}$ molar, the recommended CSNF degradation rate (BSC 2004 [DIRS 169987]) is to use Equation 4-1 with the total carbonate concentration set to $2 \times 10^{-4}$ molar. This rate was compared to the rate that would be calculated by EQ6 using Equation 4-1 with lower total carbonate concentrations, and the two rates were very similar, with the EQ6 rate slightly higher (as shown in CSNF_Eh_Carb.xls in Appendix F). The code calculates the rate of the CSNF based on the $\mathrm{pH}$ and total carbonate of the system for each time step. Since the total carbonate is above the $2 \times 10^{-4}$ molar limit for the majority of the run, this sensitivity uses the same transition state theory formalism (described in Section 4.1.1) as the base case (rather than trying to decouple the CSNF rate from the total carbonate for the brief period when the total carbonate drops below $2 \times 10^{-4}$ molar).

The following plots (Figure 6-34 through Figure 6-37) show the results of varying carbon dioxide fugacity on the $\mathrm{pH}$ and ionic strength.

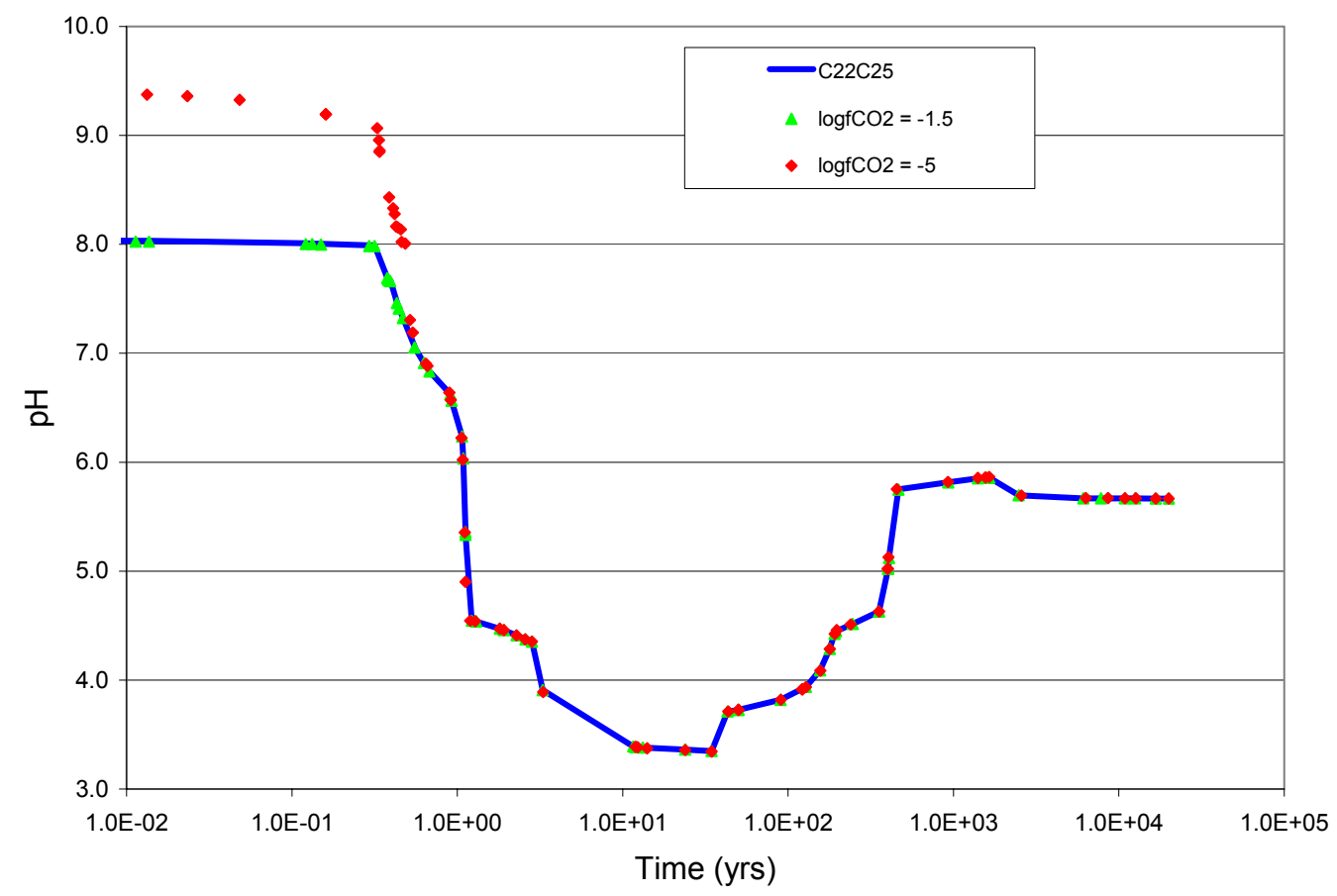

Source: CSNF_Sensitivity.xls (Appendix F).

Figure 6-34. Variation of $\mathrm{fCO}_{2}$ for CSNF: Impact on $\mathrm{pH}$ 


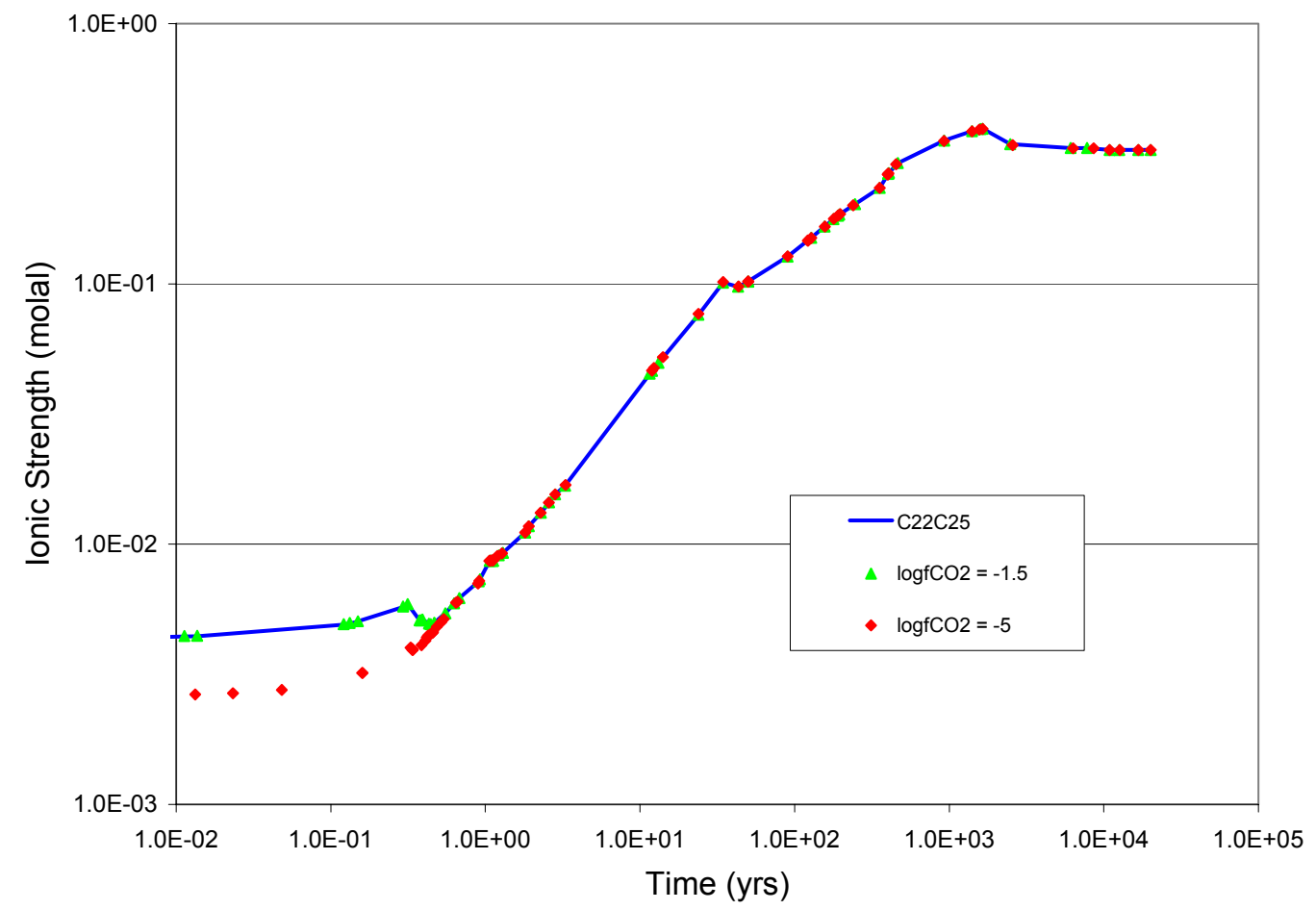

Source: CSNF_Sensitivity.xIs (Appendix F).

Figure 6-35. Variation of $\mathrm{fCO}_{2}$ for CSNF: Impact on lonic Strength

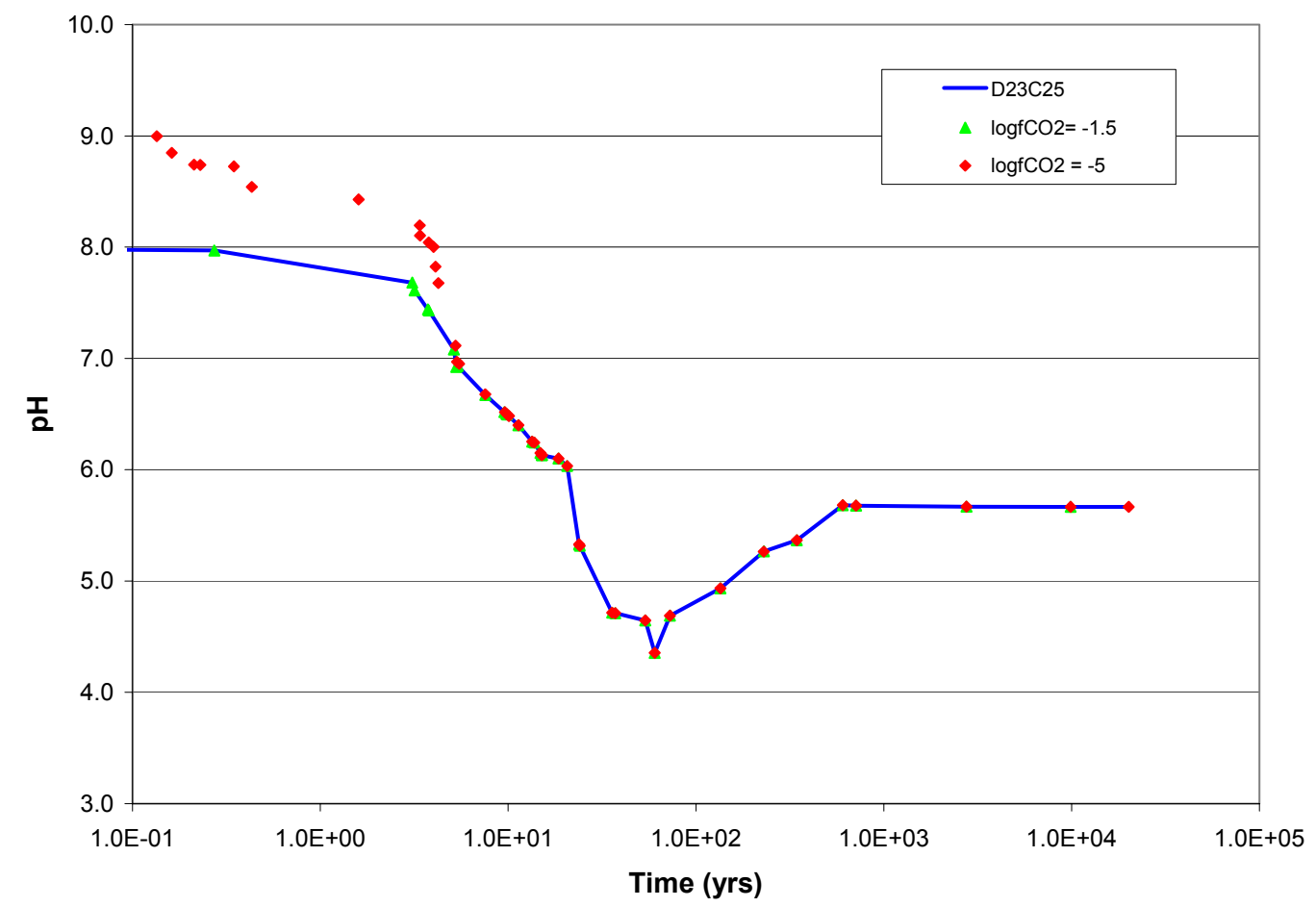

Source: CDSP_Sensitivity.xls (Appendix F).

Figure 6-36. Variation of $\mathrm{fCO}_{2}$ for CDSP: Impact on $\mathrm{pH}$ 


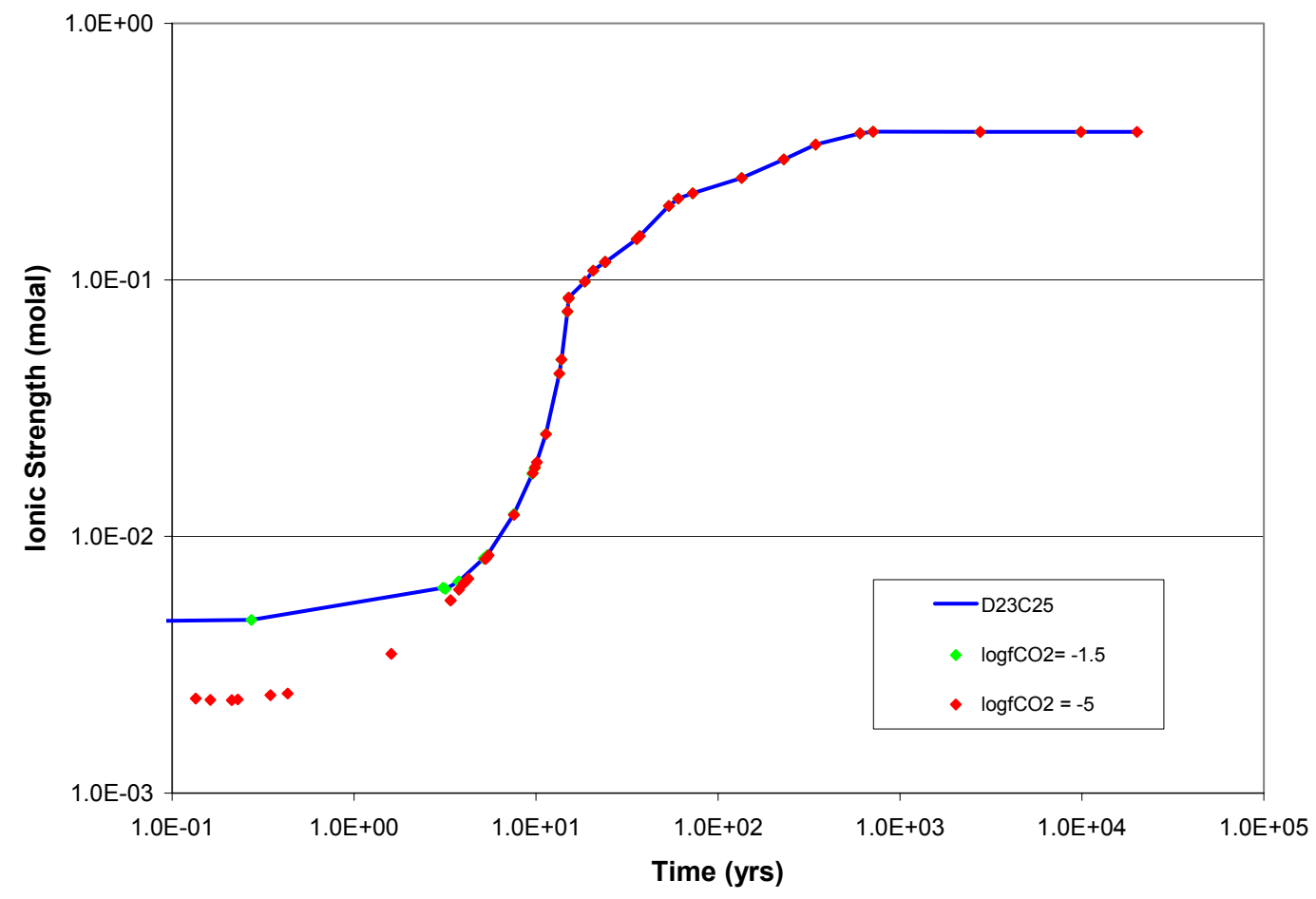

Source: CDSP_Sensitivity.xls (Appendix F).

Figure 6-37. Variation of $f \mathrm{CO}_{2}$ for CDSP: Impact on lonic Strength

The results show that for CSNF and CDSP, neither the $\mathrm{pH}$ nor the ionic strength is affected by increasing the log fugacity of carbon dioxide up to a value of -1.5 . However, decreasing the $\log$ $f \mathrm{CO}_{2}$ down to -5.0 does result in a high initial $\mathrm{pH}$, and a very low initial ionic strength. The higher $\mathrm{pH}$ at $\log f \mathrm{CO}_{2}=-5.0$ is significant, and these results are balanced by the surface complexation model that buffers the high $\mathrm{pH}$ (Section 6.7.2). The lower initial ionic strength results are relatively short lived, and occur well below the colloid stability limit of 0.05 molal (BSC 2003 [DIRS 166845]), so do not impact the results of this model.

The lack of variation in system $\mathrm{pH}$ as the carbon dioxide fugacity was increased (up to $\left.\log f \mathrm{CO}_{2}=-1.5\right)$ renders it possible to use $\mathrm{pH}$ as a means of calculating total carbonate (Section 6.10.5) over a wide range of $\mathrm{fCO}_{2}$ values. In the surface complexation model (Section 6.8), the CSNF pH distribution is cast as a function of $f \mathrm{CO}_{2}$, thus, allowing the formation of carbonate surface complexes. Since the carbon dioxide is fixed at a given value in the batch reactor modeling runs, the carbonate species in the bulk in-package fluid will reequilibrate in accordance with the relationships provided in Section 6.10.5. 


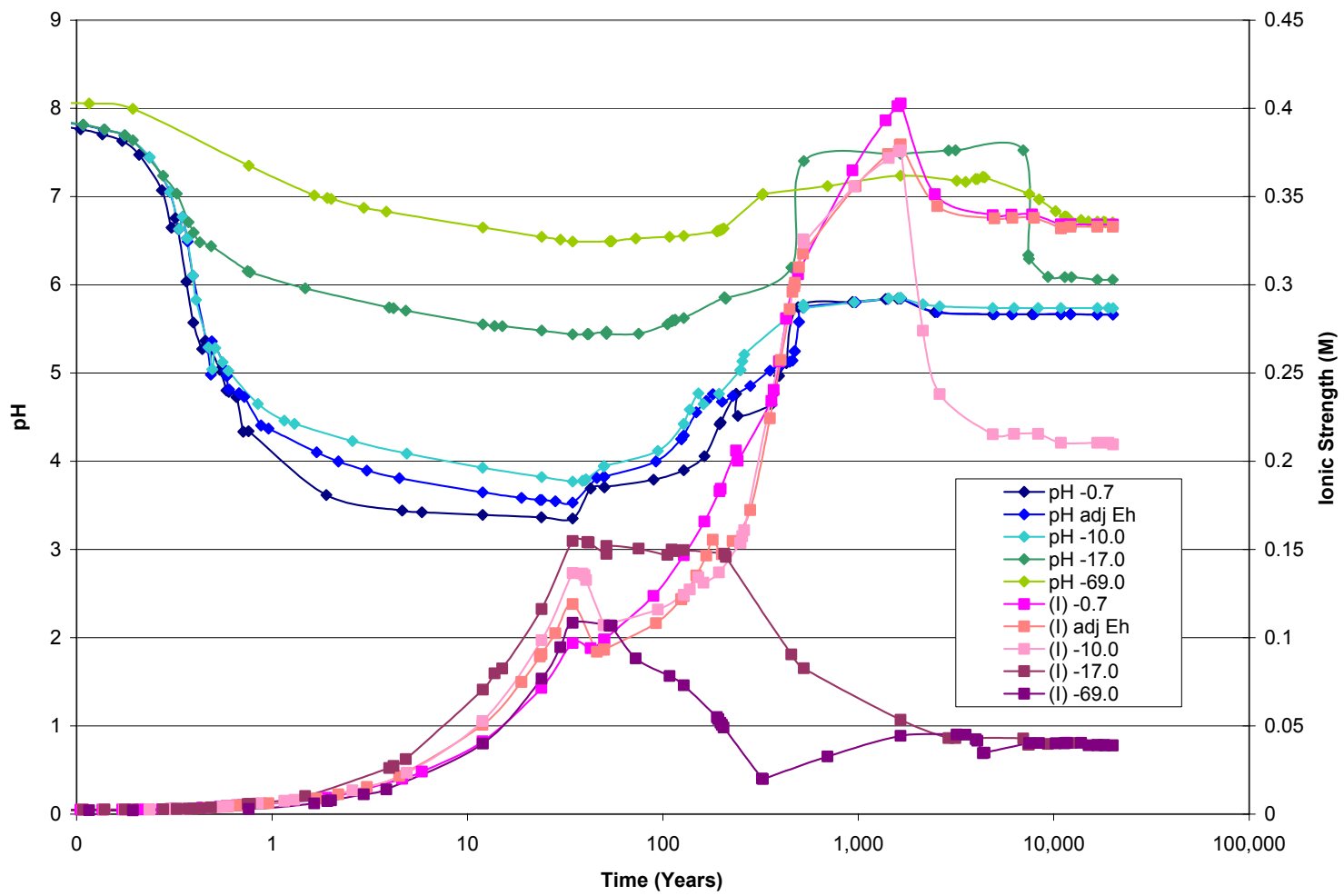

Source: CSNF_Oxidation State Sensitivity.xls (Appendix F).

Figure 6-38. Variation of $\mathrm{fO}_{2}$ for CSNF: Impact on $\mathrm{pH}$ and lonic Strength

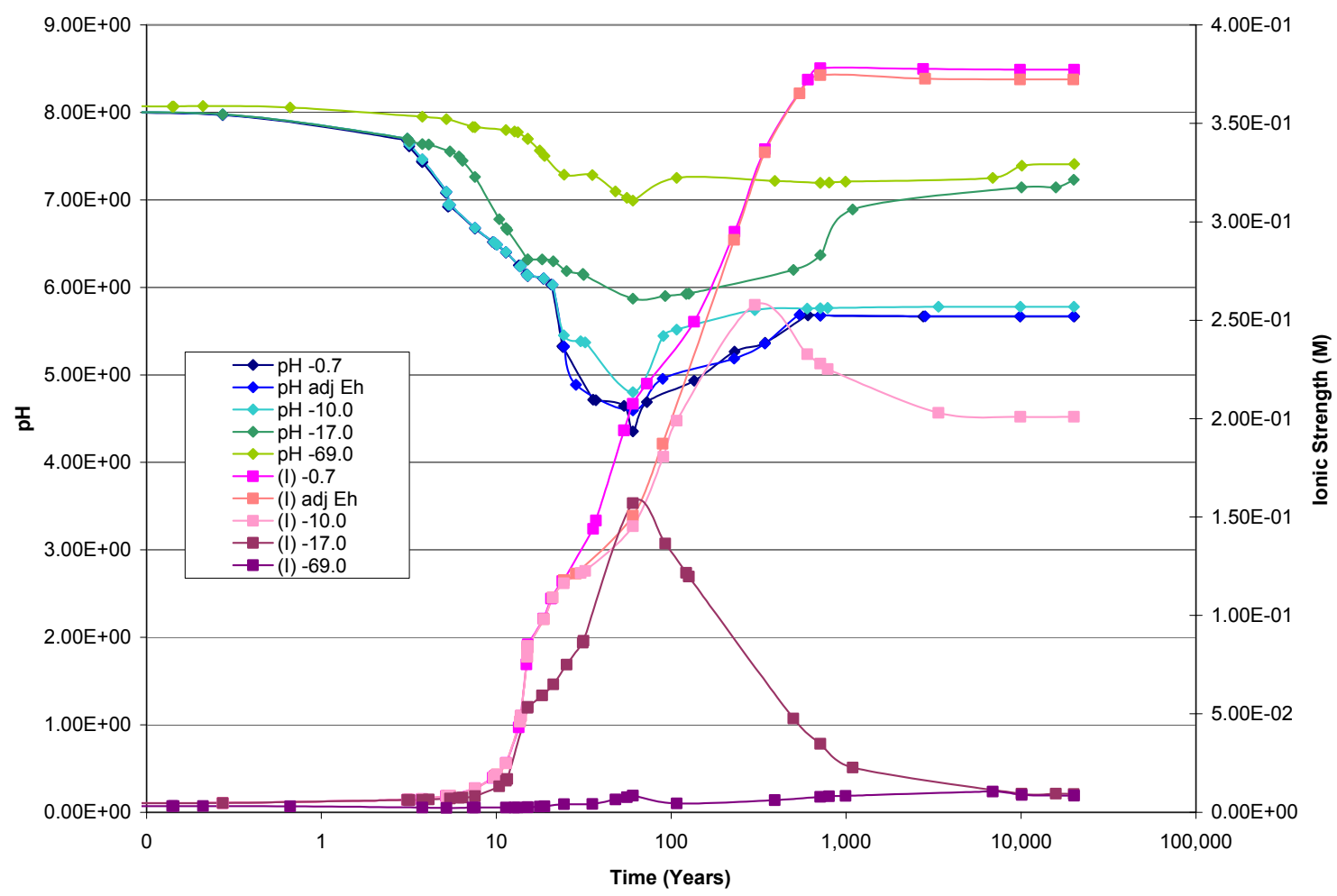

Source: CDSP_Oxidation State Sensitivity.xIs (Appendix F).

Figure 6-39. Variation of $\mathrm{fO}_{2}$ for CDSP: Impact on $\mathrm{pH}$ and lonic Strength 
The results shown in Figure 6-38 and Figure 6-39 show that using the adjusted Eh $(\mathrm{Eh}=1.1-0.0592 \times \mathrm{pH})$ from Dissolved Concentration Limits of Radioactive Elements (BSC 2004 [DIRS 169425]) gives results that are very similar to the base case. The Eh was calculated at the $\mathrm{pH}$ of the incoming water, and this Eh was applied to the entire run and did not vary with $\mathrm{pH}$. The results of this sensitivity show very similar $\mathrm{pH}$ and ionic strength results. More significant decreases in the $f \mathrm{O}_{2}$ (i.e., lower than the adjusted Eh value) tend to raise the $\mathrm{pH}$ and lower the ionic strength; however, all of the results shown in Figure 6-38 and Figure 6-39 fall within the range of values provided to TSPA-LA.

These sensitivities vary the composition of air in contact with the waste package internals. In addition, this sensitivity examines various states of kinetic equilibrium with the atmosphere by varying the $f \mathrm{CO}_{2}$ and $f \mathrm{O}_{2}$. The results of these sensitivities are used to broaden the range of applicability of this model and are also used in the model abstraction. The above discussion addresses the subject matter of "Included" FEPs 2.1.02.09.0A (Chemical effects of void space in waste package) 2.1.09.06.0A (Reduction-oxidation potential in waste package) and 2.1.09.07.0A (Reaction kinetics in waste package) and indicates how that subject matter has been included and addressed within TSPA-LA.

\subsubsection{Water Flux}

The flux of water through a waste package has direct impacts on the chemistry of the water exiting the package. The lower the flux rate the longer the residence time of the water in the package and greater the extent of the reaction between the water and the waste package components. There must exist an upper limit to flux at which there is virtually no reaction between the water and the waste package components.

This was confirmed as displayed in the following plots (Figure 6-40 through Figure 6-43) where the $\mathrm{pH}$ and ionic strength approach that of the incoming fluid as the flux was increased. As the flux increases, the chemistry stabilizes in a shorter time frame and the run terminates. 


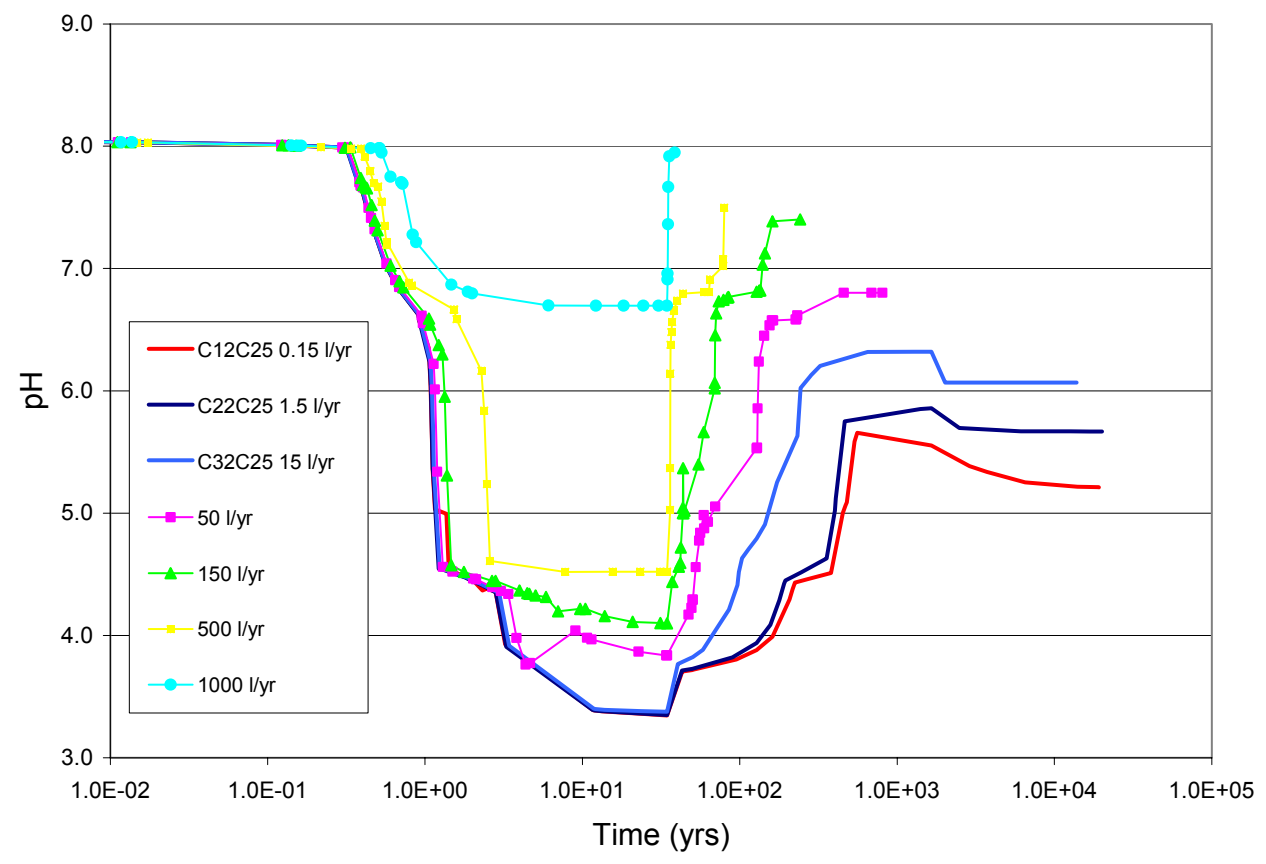

Source: CSNF_Sensitivity.xls (Appendix F).

Figure 6-40. Effect of Water Flux on pH for CSNF

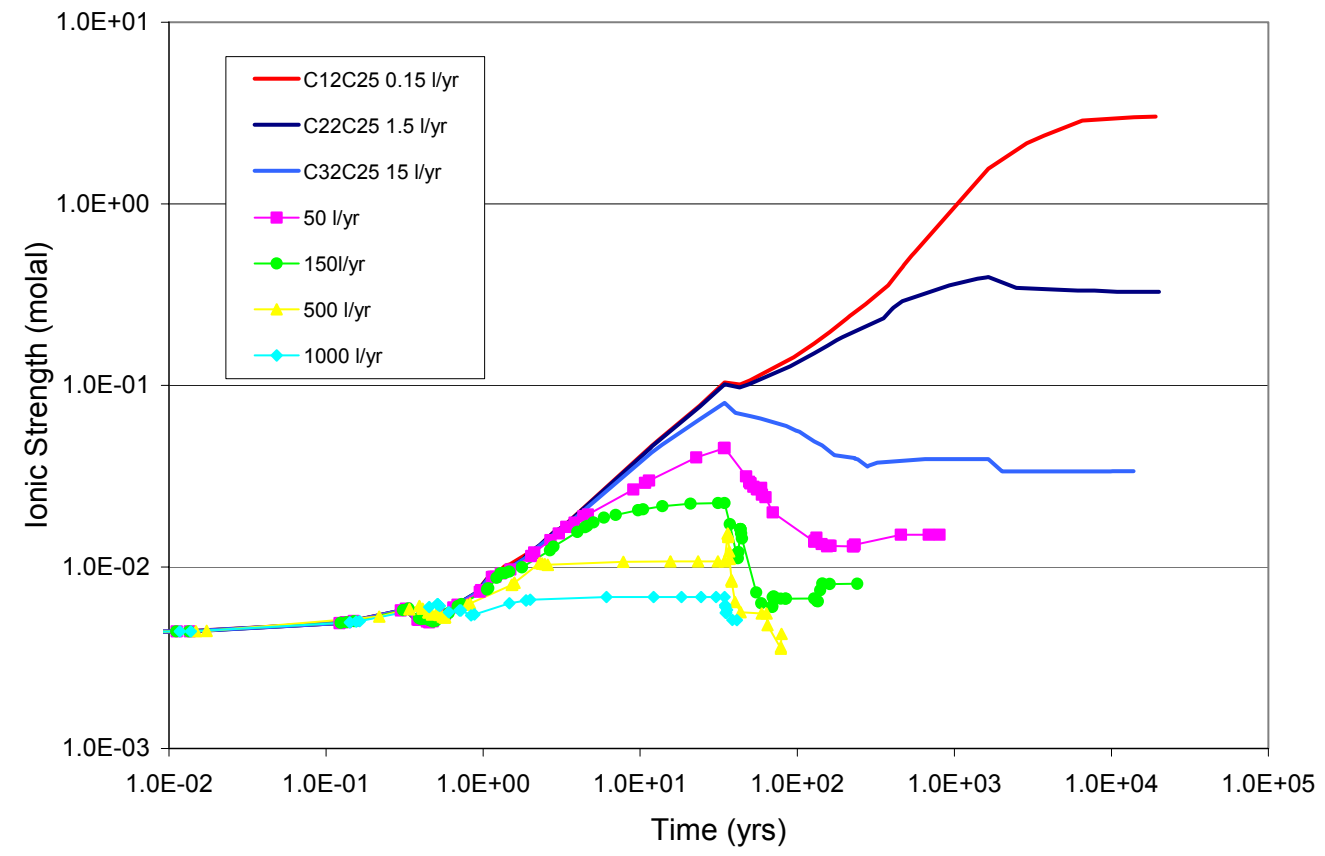

Source: CSNF_Sensitivity.xIs (Appendix F).

Figure 6-41. Effect of Water Flux on lonic Strength for CSNF 


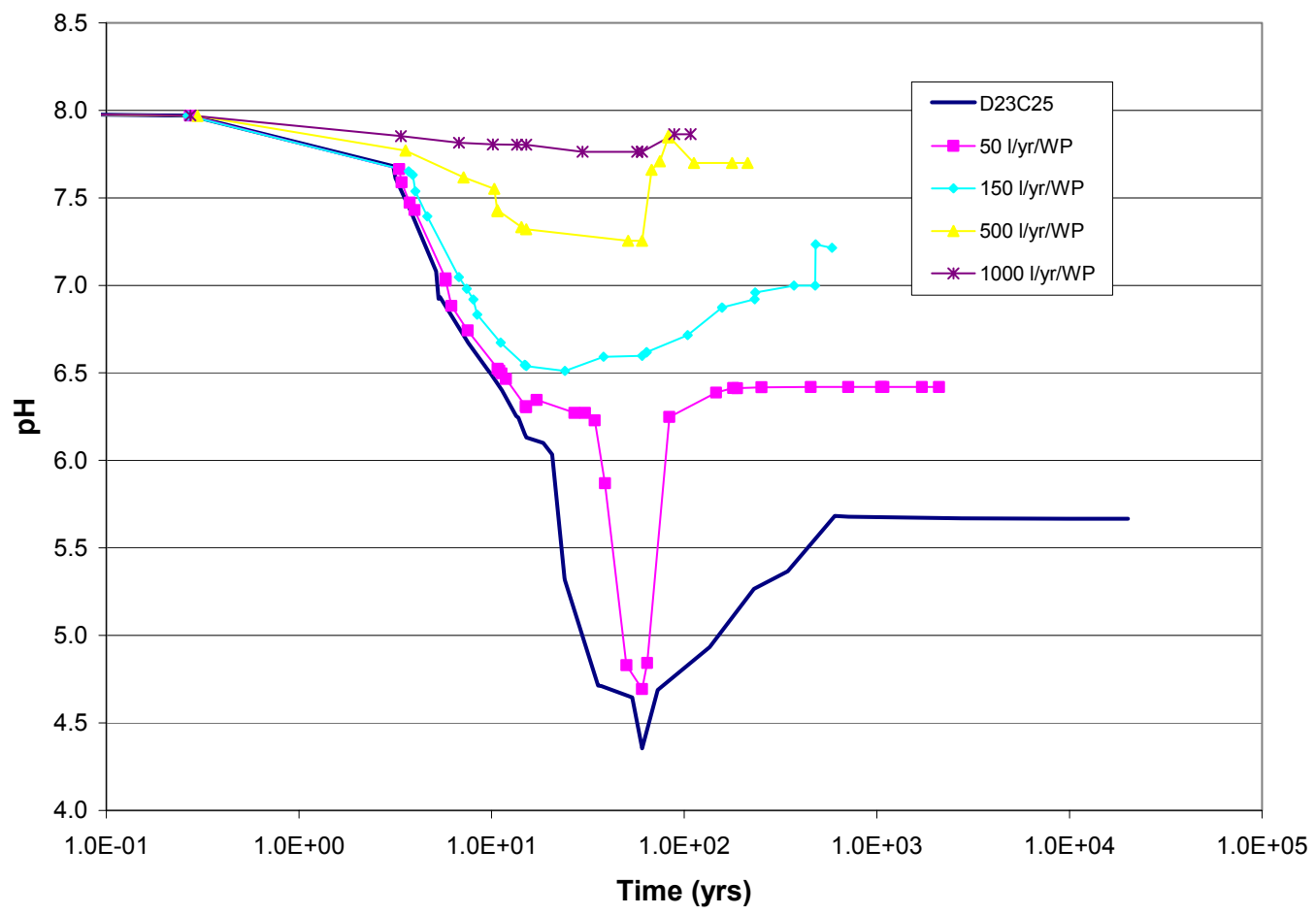

Source: CDSP_Sensitivity.xls (Appendix F).

Figure 6-42. Effect of Water Flux on $\mathrm{pH}$ for CDSP

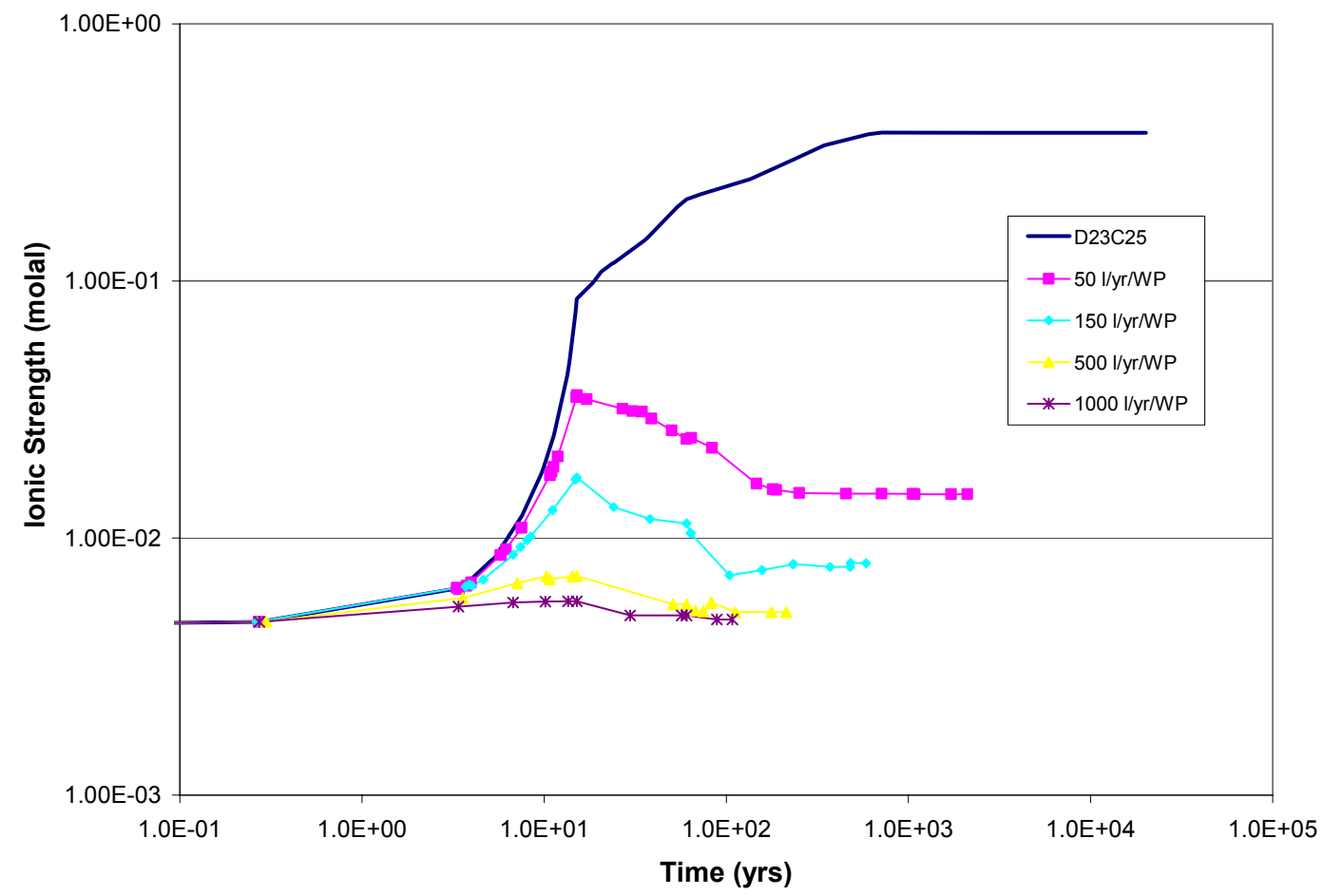

Source: CDSP_Sensitivity.xls (Appendix F).

Figure 6-43. Effect of Water Flux on lonic Strength for CDSP 


\subsubsection{Temperature}

The temperature of the waste package that receives seepage could vary significantly depending on the timing of waste package breach and seepage ingress. In addition to the sensitivity analysis that examines the type of fluids expected at high temperatures, the thermally perturbed fluid compositions, a set of simulations was performed at $50^{\circ} \mathrm{C}$ and $90^{\circ} \mathrm{C}$ with the base-case waters. The coefficients for the CSNF and HLWG rate expressions were recalculated at the temperature of the run (Table 6-9 and Table 6-10).

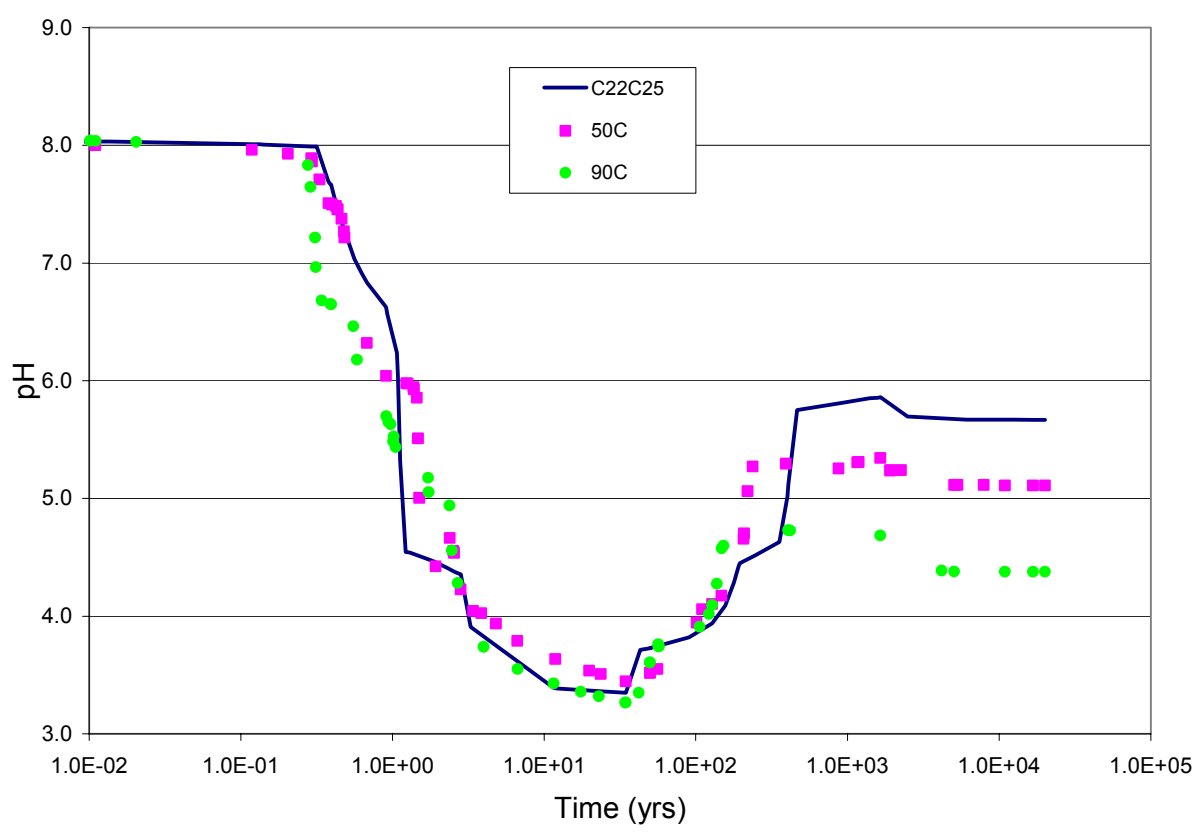

Source: CSNF_Sensitivity.xls (Appendix F).

Figure 6-44. Effect of Increasing Temperature on the $\mathrm{pH}$ for CSNF

Figure 6-44 shows that increasing the temperature has the effect of lowering the late-time $\mathrm{pH}$ for the CSNF runs. One reason for the $\mathrm{pH}$ lowering at high temperature is the decrease in the dissociation constant of water with increased temperature.

Figure 6-45 shows the ionic strength results of EQ6 simulations at higher temperatures for CSNF waste packages. The results plotted in Figure 6-45 show that temperature had a minor influence on ionic strength. Although evaporation from the interior of the waste package is not expected to be great, due to high humidity in the waste package interior, evaporation could still influence the ionic strength as the temperature increases. Fully decoupling the temperature and ionic strength could result in misleading ionic strength values; therefore, the ionic strength abstraction is temperature dependent (Section 6.10.2). 


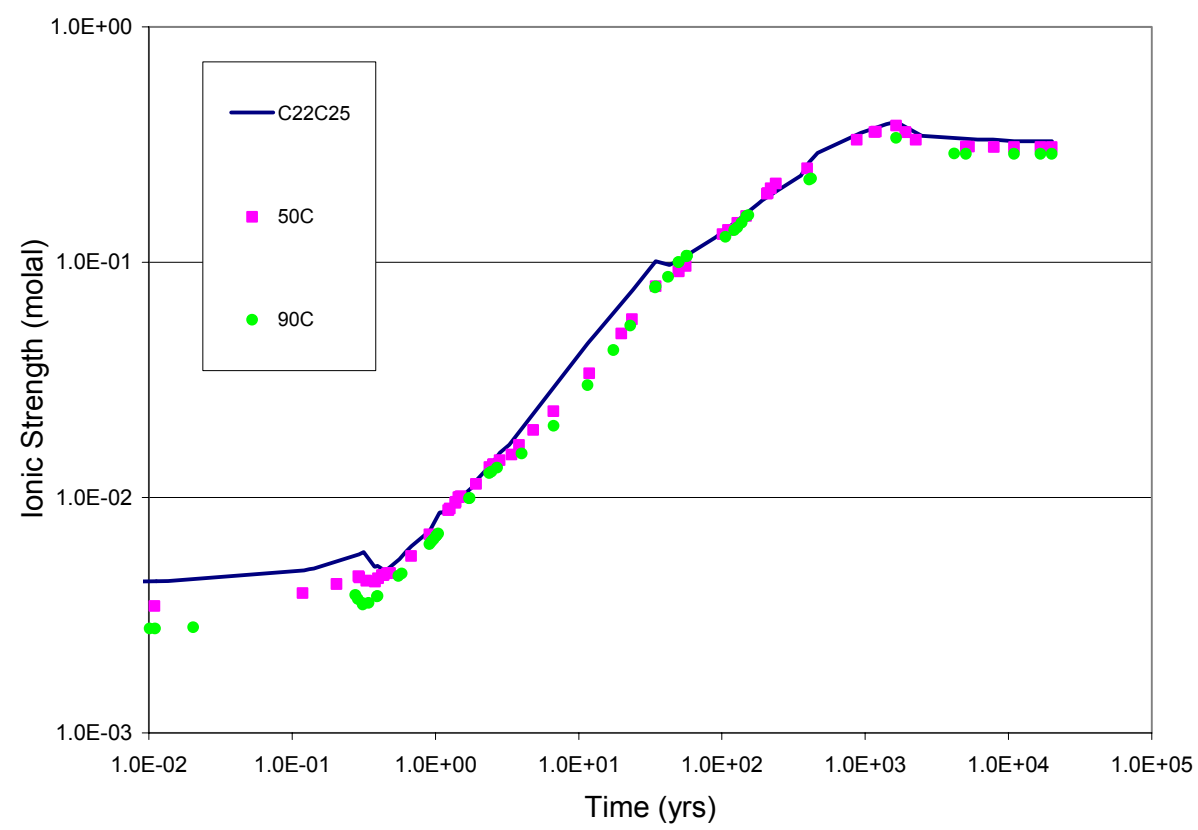

Source: CSNF_Sensitivity.xls (Appendix F).

Figure 6-45. Effect of Increasing Temperature on lonic Strength for CSNF

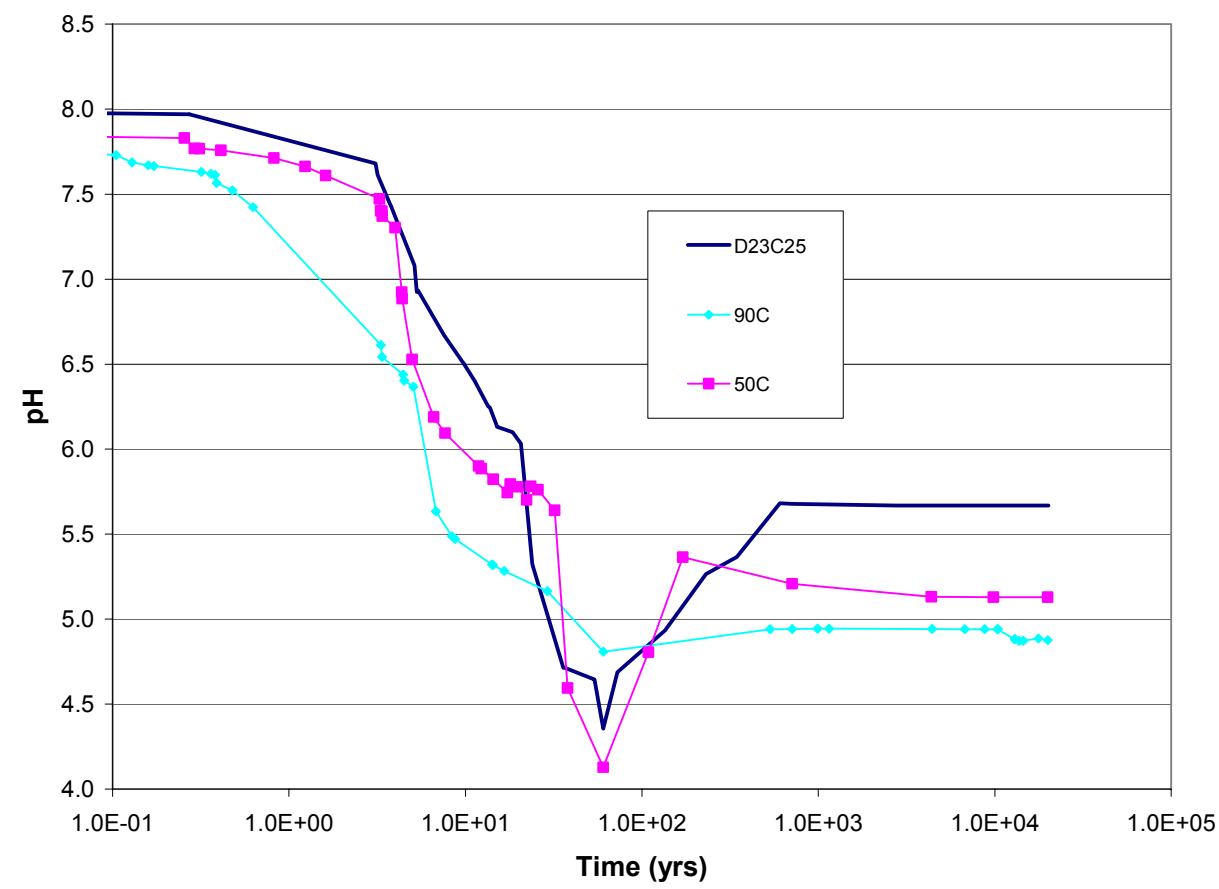

Source: $\quad C D S P_{-}$Sensitivity.xls (Appendix F).

Figure 6-46. Effect of Increasing Temperature on the $\mathrm{pH}$ for CDSP

Figure 6-46 shows that increasing the temperature has the effect of lowering the late-time $\mathrm{pH}$ for the CDSP runs. One reason for the $\mathrm{pH}$ lowering at high temperature is the decrease in the dissociation constant of water with increased temperature. 


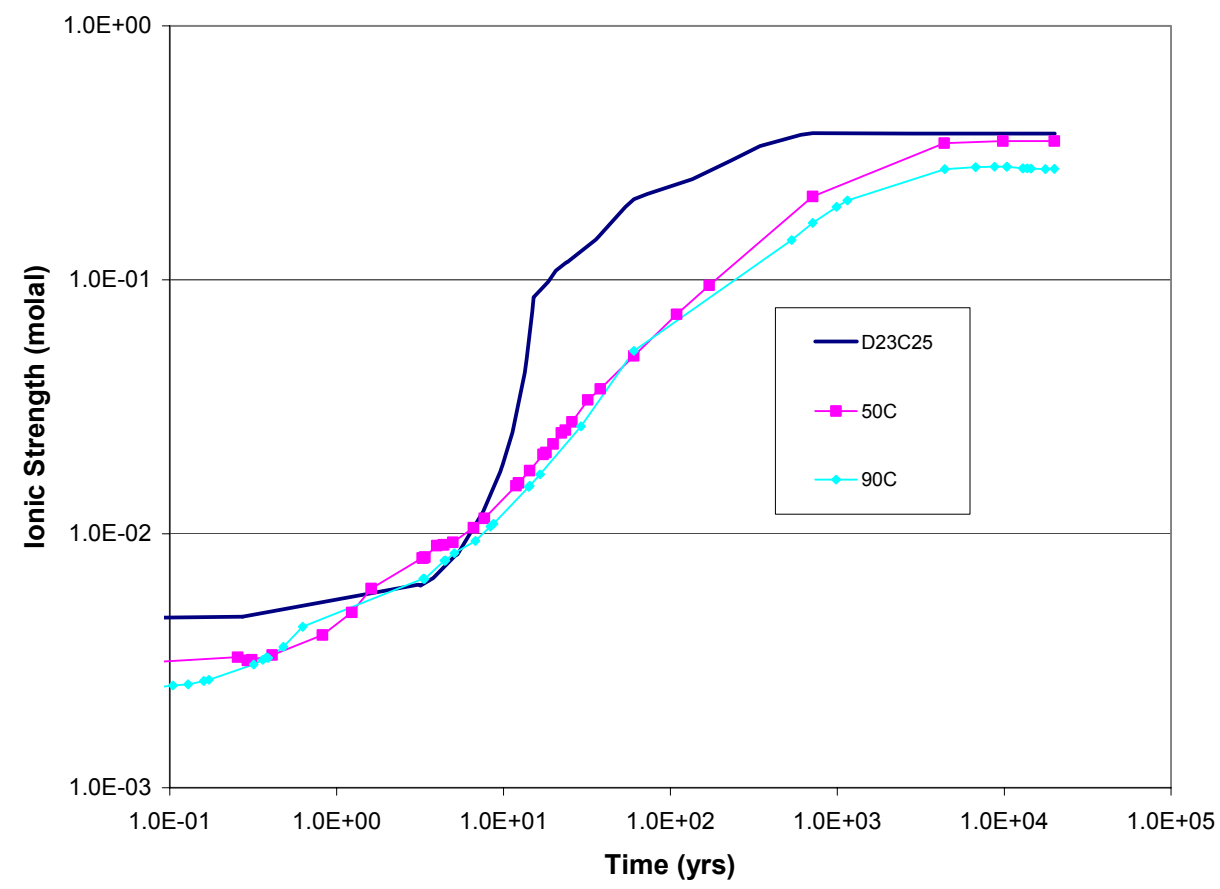

Source: $\quad C D S P \_S e n s i t i v i t y . x / s$ (Appendix F).

Figure 6-47. Effect of Increasing Temperature on lonic Strength for CDSP

The results plotted in Figure 6-47 show that temperature had a minor influence on the steady state ionic strength. Although evaporation from the interior of the waste package is not expected to be great, due to high humidity in the waste package interior, evaporation could still influence the ionic strength as the temperature increases. Fully decoupling the temperature and ionic strength could result in misleading ionic strength values; therefore, the ionic strength abstraction is temperature dependent (Section 6.10.2).

Although the simulations depicted in Figure 6-44 through Figure 6-47 were run at a maximum of $90^{\circ} \mathrm{C}$, the results of these high-temperature simulations have been used to extend the temperature limit of the $\mathrm{pH}$ and ionic strength abstractions (Sections 6.10.1 and 6.10.2) up to $100^{\circ} \mathrm{C}$. The temperature effect on $\mathrm{pH}$ from $50^{\circ} \mathrm{C}$ to $90^{\circ} \mathrm{C}$ is small enough to conclude that the additional ten degrees will have little impact on lowering the late-time $\mathrm{pH}$ for either CSNF or CDSP waste packages, because TSPA-LA, and this model consider that the transition from water to steam occurs at $100^{\circ} \mathrm{C}$.

The above discussion addresses the thermal effects on chemistry portion of the subject matter of "Included" FEP 2.1.11.08.0A (Thermal effects on chemistry and microbial activity in the EBS) and indicates how that subject matter has been included and addressed within TSPA-LA. The microbial activity in the EBS subject matter is described in FEP 2.1.10.01.0A and documented in Engineered Barrier System Features, Events, and Processes (BSC 2004 [DIRS 169898]).

\subsubsection{Design Change from Neutronit to NiGd Alloy}

The impact of replacing the neutronit with NiGd alloy in the CSNF waste package (Section 4.1.4) is examined in the following sensitivity. The quantity (moles) and surface area 
for the NiGd alloy are modeled as the same as the neutronit values. Two rates for the NiGd alloy are used: one run considers $0.052 \mu \mathrm{m} / \mathrm{yr}(52 \mathrm{~nm} / \mathrm{yr})$ from Table 4-8, and the second case uses $1 \mu \mathrm{m} / \mathrm{yr}$ for the first ten years, followed by $90 \mathrm{~nm} / \mathrm{yr}$ (BSC 2004 [DIRS 168434]) for the remainder of the run. The second rate case was examined to factor in the potential that the initial rate could be as high as $1 \mu \mathrm{m} / \mathrm{yr}$, but could slow down due to the passive layer that forms. A CSNF run with a mean flux value and mean fuel exposure $(\mathrm{Q}=1.5 \mathrm{~L} / \mathrm{yr}$ and $10 \%$ exposed) was used as the base case for this sensitivity. Because chromium is a major component of the NiGd alloy, and also has a great impact on the chemistry of the system, this sensitivity also examines the $\mathrm{Cr}(\mathrm{III})$ and $\mathrm{Cr}(\mathrm{VI})$ oxidation states for each run. The results are presented in Figure 6-48 through Figure 6-51.

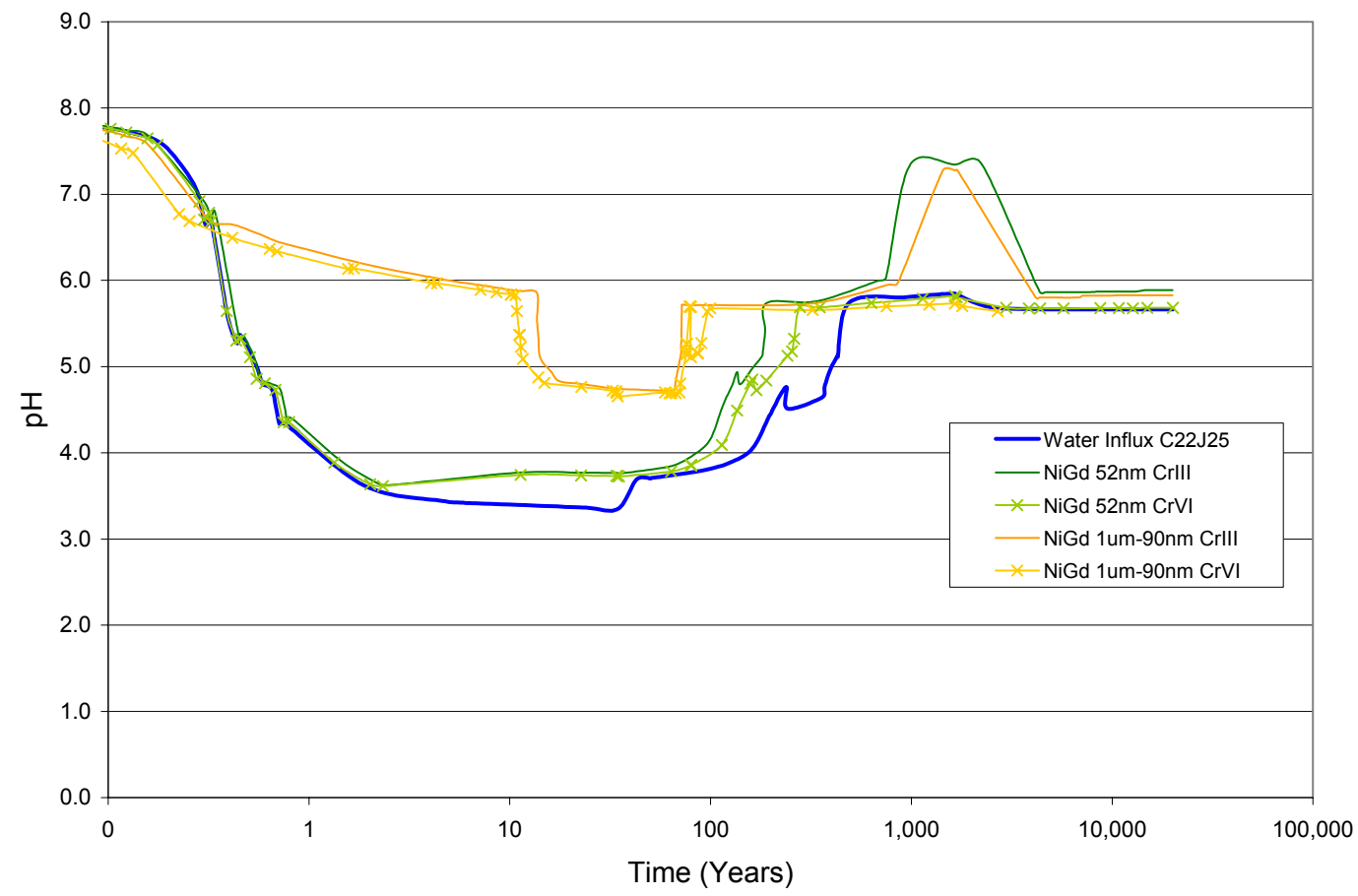

Source: $\quad$ CSNF_NiGd Sensitivity.xls (Appendix F).

Figure 6-48. NiGd Alloy Design Change for Water Influx Case: Impact on pH 


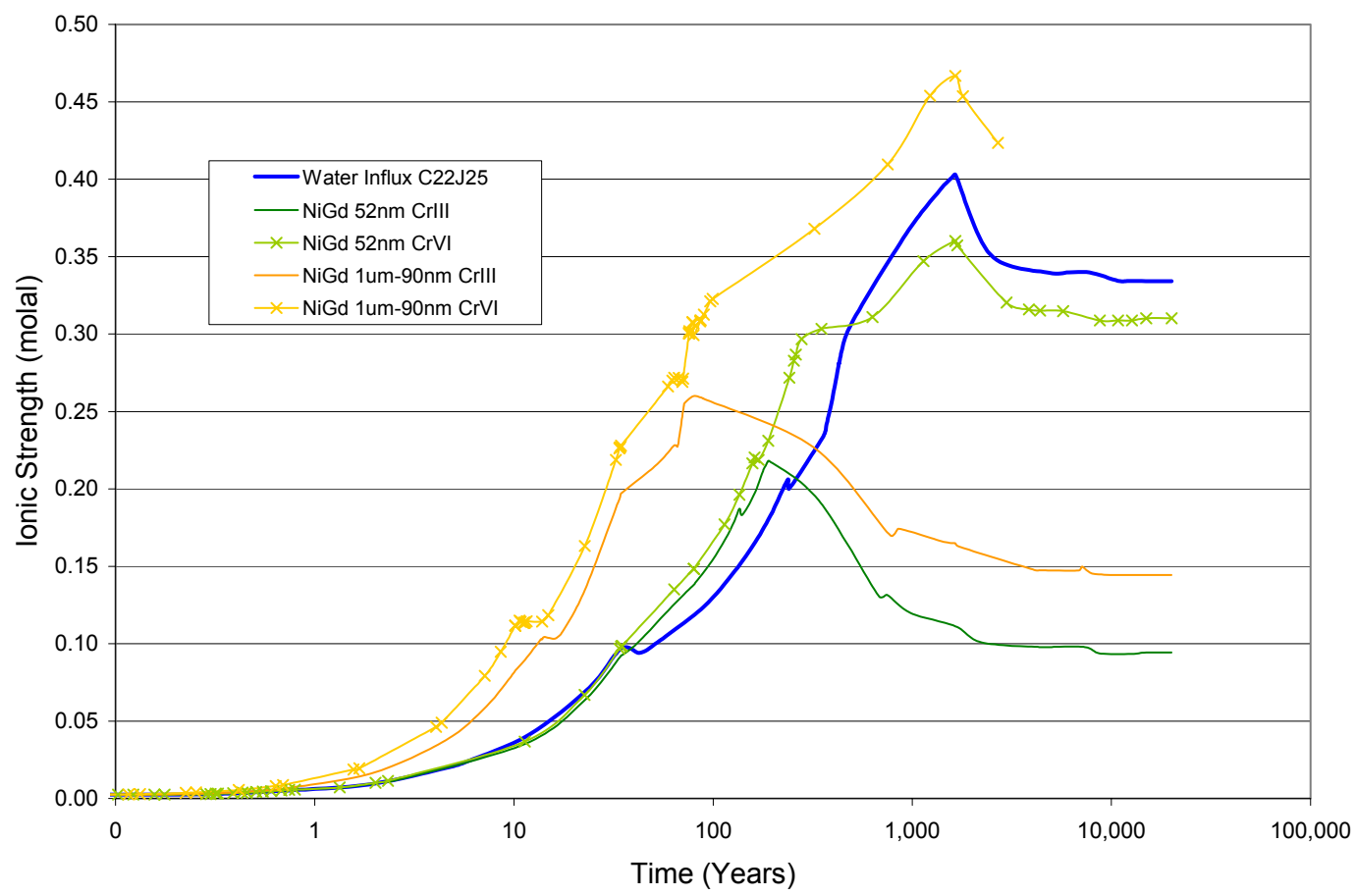

Source: CSNF_NiGd Sensitivity.xls (Appendix F).

Figure 6-49. NiGd Alloy Design Change for Water Influx Case: Impact on lonic Strength

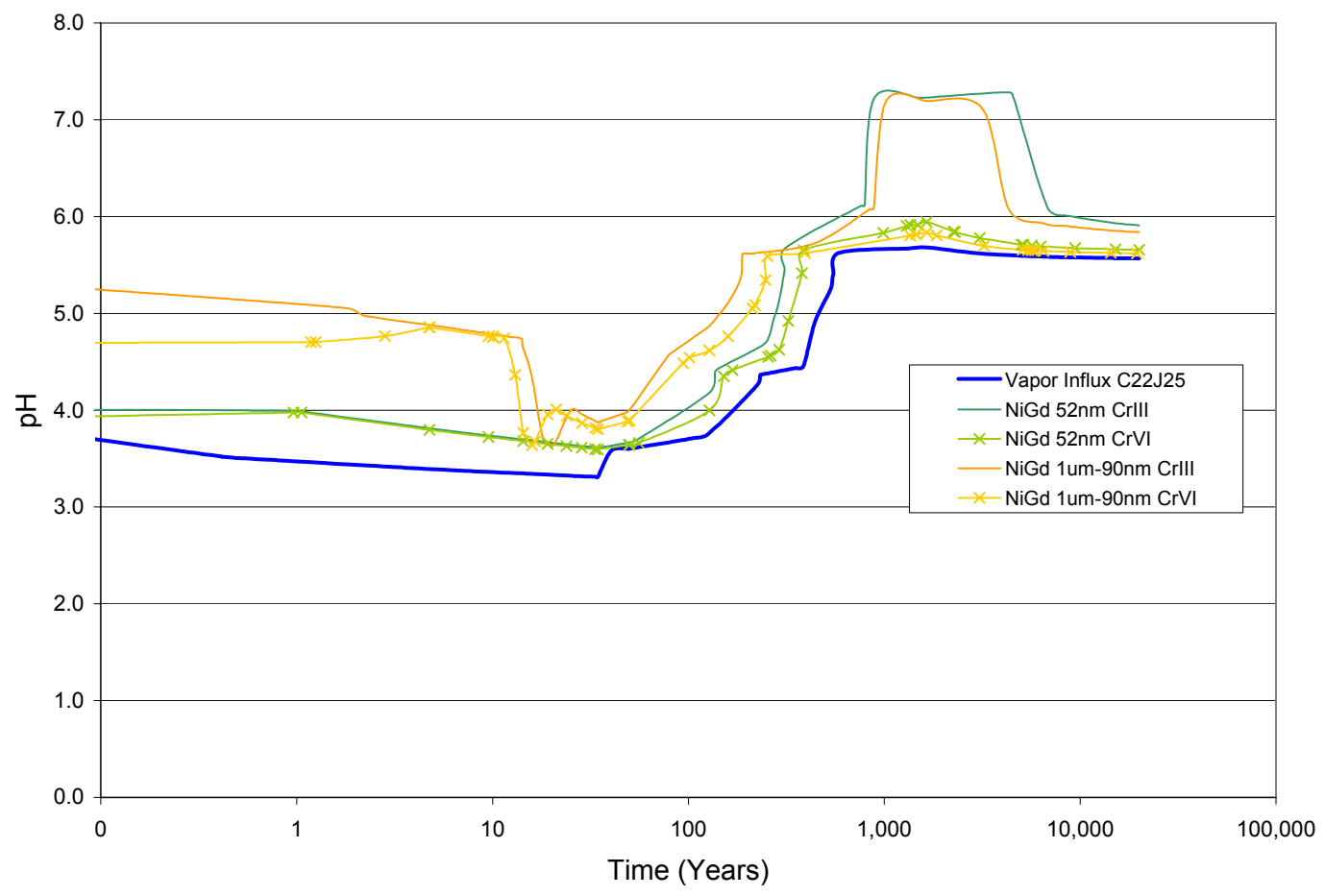

Source: CSNF_NiGd Sensitivity.xls (Appendix F).

Figure 6-50. NiGd Alloy Design Change for Vapor Influx Case: Impact on pH 


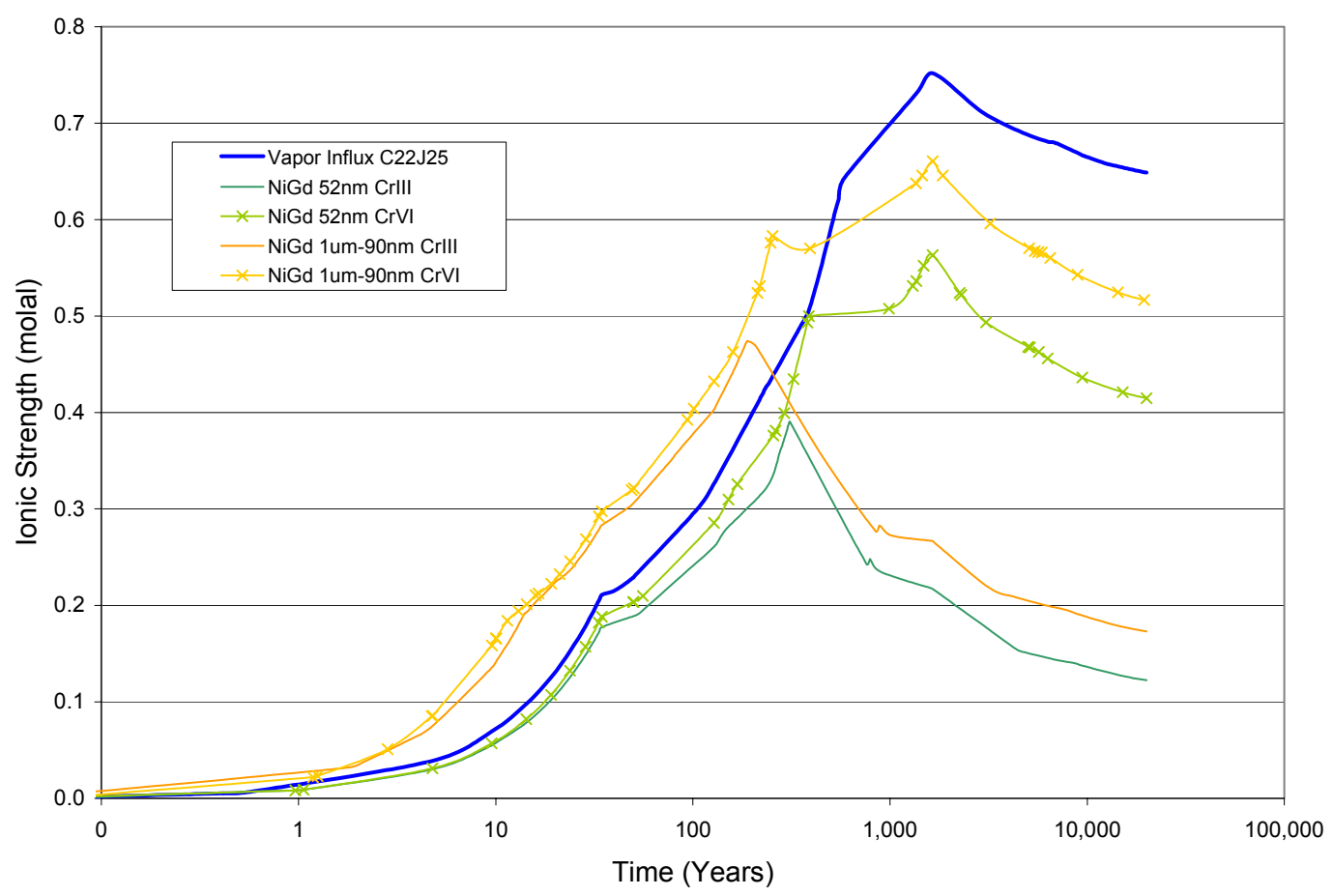

Source: $\quad$ CSNF_NiGd Sensitivity.xls (Appendix F).

Figure 6-51. NiGd Alloy Design Change for Vapor Influx Case: Impact on lonic Strength

The NiGd alloy runs have a slightly higher $\mathrm{pH}$ than the base case for early times that is more pronounced for the higher NiGd alloy rates, but the stabilized, long-term $\mathrm{pH}$ is very similar for all the cases. The $\mathrm{Cr}(\mathrm{VI})$ runs exhibit a high $\mathrm{pH}$ between 1,000 and 10,000 years as shown in the Cr sensitivity.

The ionic strength profiles for the NiGd alloy runs are similar to the base case, but are slightly higher than the base case for the water influx case, and slightly lower than the base case for the vapor influx case. The ionic strength effects are more impacted by the $\mathrm{Cr}$ oxidation state than the presence of NiGd alloy instead of neutronit.

The results of this sensitivity show that the change in design to NiGd alloy does impact the chemistry, but that the resulting $\mathrm{pH}$ and ionic strength are still within the abstracted range provided to TSPA-LA.

\subsubsection{HLWG Composition Change}

The impact of the HLWG composition on the in-package chemistry was evaluated by replacing the simplified glass composition described in Table 4-5 with two alternate glass compositions and running the CDSP water influx case. The D23C25 case was chosen because it has the highest glass exposure (100\%) and since this run was used to assess several other sensitivities.

The sources for the "raw" HLWG chemical composition used for these sensitivity runs are "Waste Treatment and Immobilization Plant (WTP) High-Level Waste (HLW) Canister Production Estimates to Support Analyses by the Yucca Mountain Project" (Hamel 2003 
[DIRS 164947], Table 1) and Projected Glass Composition and Curie Content of Canisters from the Savannah River Site (U) (Allison 2004 [DIRS 168734], Attachment I). The specific glass compositions chosen from these sources contain high concentrations of alkali metals (Na and $\mathrm{K}$ ), which increase solution $\mathrm{pH}$ during glass dissolution (which was the WAPS Low Viscosity Purex Only Glass Composition for the SRL_new glass composition, and the WTP Technology Case for the Hanford glass composition).

For input into EQ6, several elements in the glass composition from Hamel (2003 [DIRS 164947], Table 1) and Allison (2004 [DIRS 168734], Attachment I) were simplified in a manner similar to the base case glass presented in Table 4-5, and described in CRMWS M\&O 2001 [DIRS 153263]. The simplification is presented in detail in CDSP_HLWG_Sensitivity.xls in Appendix F. These minor changes were made to the basic composition to increase the efficiency of the calculations, to decrease the EQ6 run time, and to allow the use of a pHdependent rate law. These simplified glass compositions were calculated in CDSP_HLWG_Sensitivity.xls (Appendix F). These simplified glass compositions were also included in the EQ6 database as the minerals 'SRL_New' and 'HanfordTC' (Stoichiometric fractions less than 0.0001 moles/100 g are not read by EQ3/6). The resulting simplified HLWG formula based on $100 \mathrm{~g}$ is in Table 6-17. The base case composition is also presented for comparison purposes.

Table 6-17. HLWG Sensitivity: High-Level Waste Glass Composition

\begin{tabular}{|l|c|c|c|}
\hline Element & $\begin{array}{c}\text { Base Case } \\
\text { Moles/100g HLWG }\end{array}$ & $\begin{array}{c}\text { SRL_New } \\
\text { Moles/100g HLWG }\end{array}$ & $\begin{array}{c}\text { HanfordTC } \\
\text { Moles/100g HLWG }\end{array}$ \\
\hline $\mathrm{O}$ & 2.7038 & 2.6338 & 2.5781 \\
\hline $\mathrm{U}$ & 0.0078 & 0.0102 & 0.0107 \\
\hline $\mathrm{Ba}$ & 0.0011 & 0.0017 & 0.0018 \\
\hline $\mathrm{Al}$ & 0.0863 & 0.0578 & 0.2537 \\
\hline $\mathrm{S}$ & 0.0040 & 0.0028 & 0.0048 \\
\hline $\mathrm{Ca}$ & 0.0162 & 0.0182 & 0.0217 \\
\hline $\mathrm{P}$ & 0.0005 & 0.0003 & 0.0186 \\
\hline $\mathrm{Si}$ & 0.7765 & 0.7400 & 0.6068 \\
\hline $\mathrm{B}$ & 0.2912 & 0.2895 & 0.1845 \\
\hline $\mathrm{Fe}$ & 0.1722 & 0.2064 & 0.1364 \\
\hline $\mathrm{K}$ & 0.0752 & 0.0751 & 0.0059 \\
\hline $\mathrm{Mg}$ & 0.0333 & 0.0327 & 0.0060 \\
\hline $\mathrm{Na}$ & 0.5767 & 0.5931 & 0.8907 \\
\hline
\end{tabular}

Source: CDSP_HLWG_Sensitivity.xls (Appendix F).

NOTE: Elemental mole \% of the reactant are calculated based on 100 grams of reactant.

The results of the sensitivity runs with the alternate glass compositions, Figure 6-52, show only small differences in $\mathrm{pH}$ or ionic strength. 


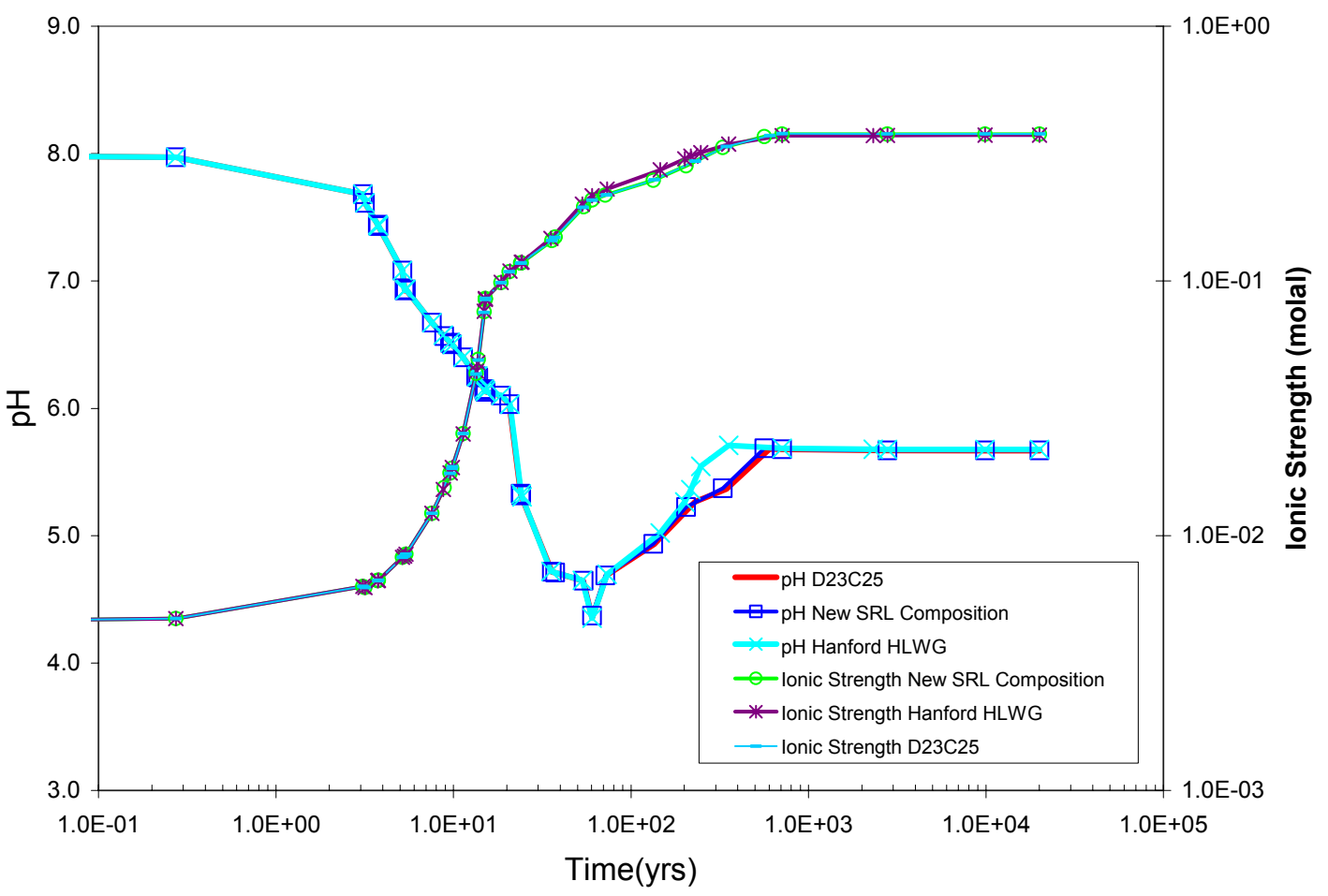

Source: CDSP_HLWG_Composition Sensitivity.xIs (Appendix F ISpreadsheets).

Figure 6-52. Comparison of HLW Glass Compositions

\subsubsection{Quantity of Carbon Steel Type A516 in Waste Package Design}

Variations in the waste package design configurations for the CSNF packages were examined to determine if the model response was sensitive. This sensitivity analysis was performed because not all of the Carbon Steel Type A516 that made up the "A516_Guides" was included in the EQ6 input files, so the additional Carbon Steel Type A516 was included and model runs were performed. This change affects the moles and surface area for all of the components because the additional volume of Carbon Steel Type A516 changed the calculated surface area that is used to normalize surface area of these components. The EQ6 input values are included in Appendix F, CSNF.xls, worksheet "Water Influx Corr A516 Guides." Run C11C25.6i was used as a comparison case because the effect of increased Carbon Steel Type A516 on the model response would be the greatest at low water flux and low fuel exposure. The results are presented in Figure 6-53 and show that the inclusion of this small quantity of Carbon Steel Type A516 has very little impact on the ionic strength. 


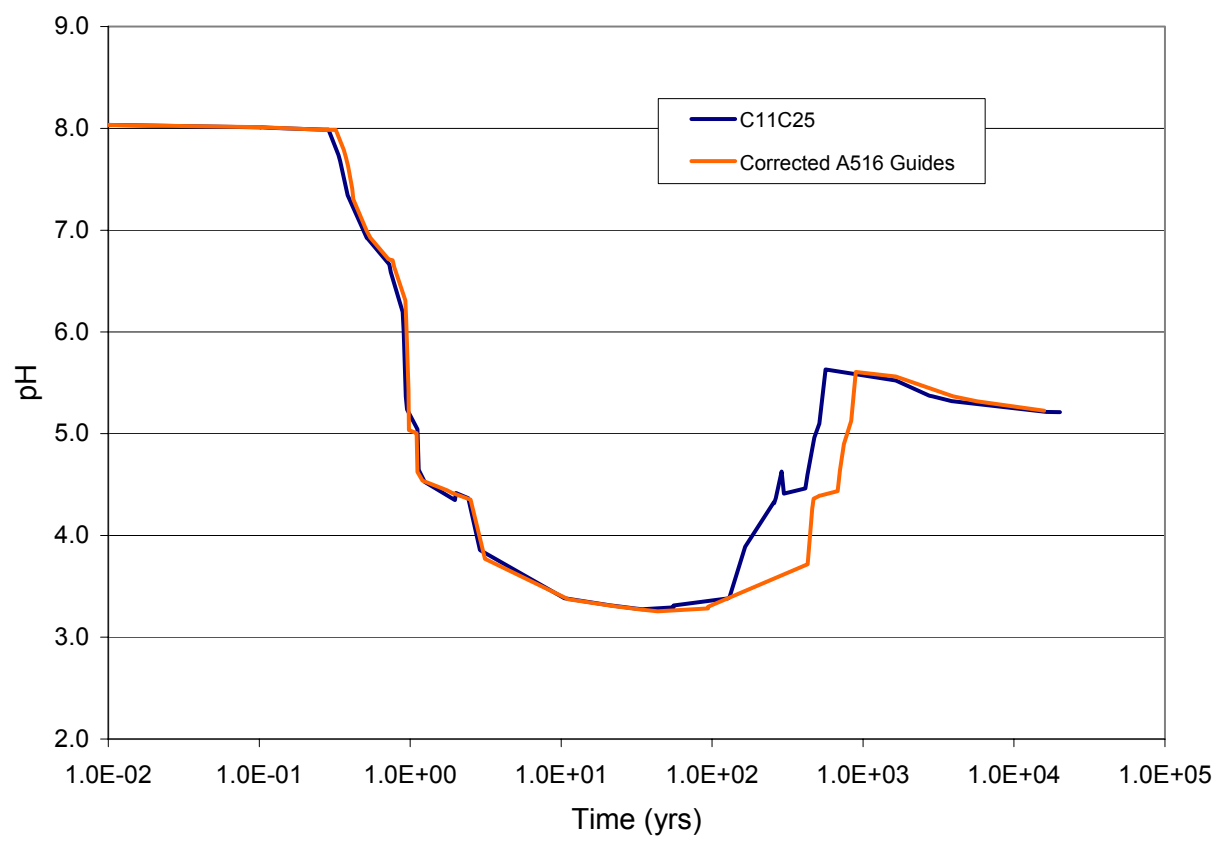

Source: CSNF_Sensitivity.xIs (Appendix F).

Figure 6-53. Corrected Carbon Steel Type A516 Guide Information for CSNF

The impact of the Carbon Steel Type A516 on the in-package chemistry was evaluated by replacing the Carbon Steel Type A516 with an equivalent amount of Stainless Steel Type 316 and running the CSNF water influx model. The $\mathrm{C} 11 \mathrm{C} 25$ case was chosen because the lowest $\mathrm{pH}$ conditions are generated at low water flux $(0.15 \mathrm{~L} / \mathrm{yr})$ and low fuel exposure $(1 \%)$.

The effect of the fuel exposure on the $\mathrm{pH}$ is direct, in that increasing the fuel exposure buffers the $\mathrm{pH}$ due the acid neutralizing capacity of the CSNF via the reaction:

$$
\mathrm{UO}_{2}+1 / 2 \mathrm{O}_{2}+2 \mathrm{H}^{+} \rightarrow \mathrm{UO}_{2}{ }^{2+}+\mathrm{H}_{2} \mathrm{O}
$$

where $\mathrm{UO}_{2}$ represents the CSNF. Thus, dissolution of $\mathrm{UO}_{2}$ consumes hydrogen ion $\left(\mathrm{H}^{+}\right)$and moderates the $\mathrm{pH}$ towards a more neutral value.

The results of the run in which Carbon Steel Type A516 was replaced by Stainless Steel Type 316 are displayed in Figure 6-54. As would be expected, the low-pH conditions observed in the C11C25 run in the first 100 years are not observed in the run in which Carbon Steel Type A516 is replaced with Stainless Steel Type 316. The reason for the moderation in the $\mathrm{pH}$ between the two runs is the lower corrosion rate, nearly three orders of magnitude, of Stainless Steel Type 316 compared to the Carbon Steel Type A516 steel. The slower corrosion of Stainless Steel Type 316 translates to a decrease in the amount of oxidized sulfur released into the aqueous phase as a function of time and, thus, the $\mathrm{pH}$ remains closer to neutral. At times greater than about 600 years (Figure 6-54) the $\mathrm{pH}$ is less for the Stainless Steel Type 316 case 
than for the $\mathrm{C} 11 \mathrm{C} 25$ case, due to the excess chromium in solution from the additional stainless steel.

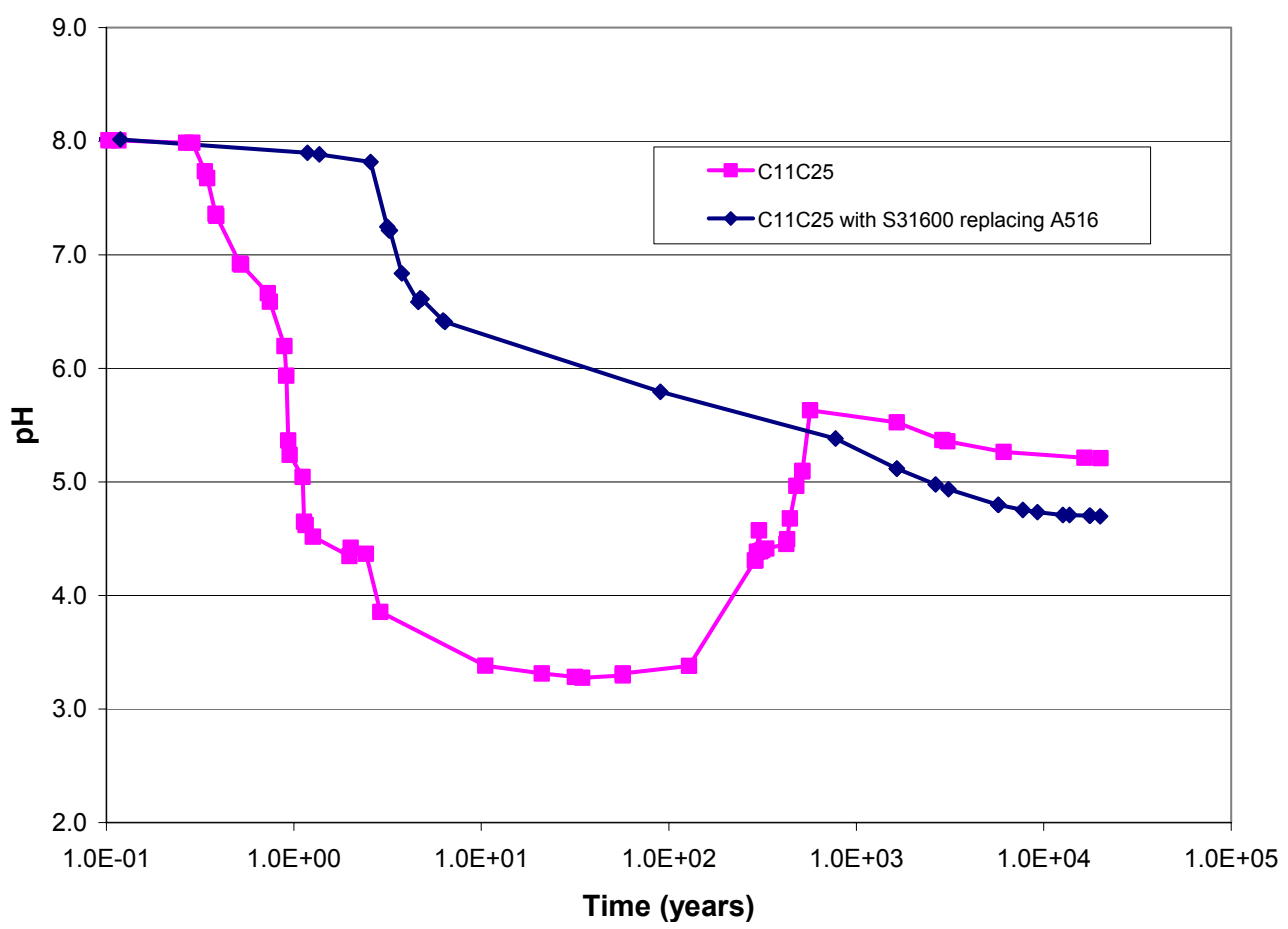

Source: CSNF_Sensitivity.xls (Appendix F).

Figure 6-54. Effect of Replacing Carbon Steel Type A516 with Stainless Steel Type 316

The implication of replacing the Carbon Steel Type A516 with stainless steel in the CSNF waste package is a more moderate $\mathrm{pH}$ condition during the period when Carbon Steel Type A516 would be corroding. Thus, with less extreme $\mathrm{pH}$ conditions the CSNF dissolution that increases at low $\mathrm{pH}$, would also be less. Additionally, it would be expected for waste packages that do not contain Carbon Steel Type A516, the low pH conditions would not be expected to develop. For example, the naval waste packages as stated in McKenzie (2002 [DIRS 165219], p. 9 of 47), for which:

Spacers are used for some basket designs to fill the internal length of the canister. Canister, basket, and spacer materials are stainless steels (including material dual certified as Type 316 and 316L stainless, Nitronic 50 and Nitronic 60) and Zircaloy. Hastelloy alloy C-22 may be used in future designs.

For these waste packages that do not contain Carbon Steel Type A516 in their design, the expected $\mathrm{pH}$ profiles would be near that displayed in Figure 6-54.

\subsubsection{Degradation Rates}

\subsubsection{Steel and Alloy Corrosion Rates}

To account for the full possible range of corrosion rates for all the materials in the waste package, a series of sensitivity runs was conducted that decreased and increased all the carbon 
steel and stainless steels by a factor of ten. The range of rates used in this sensitivity analysis is presented in Table 6-18, along with the minimum and maximum rates from Table 6-7 for comparison purposes.

Table 6-18. Corrosion Rates for Sensitivity Analysis

\begin{tabular}{|c|c|c|c|c|c|}
\hline Waste Package & $\begin{array}{l}\text { Base } \\
\text { Case } \\
\end{array}$ & $\begin{array}{l}10 \times \text { Lower } \\
\text { than Base }\end{array}$ & $\begin{array}{l}\text { 10x Higher } \\
\text { than Base }\end{array}$ & $\begin{array}{c}\begin{array}{c}\text { Minimum } \\
\text { from }\end{array} \\
\text { Table 6-7 }\end{array}$ & $\begin{array}{c}\text { Maximum } \\
\text { from } \\
\text { Table 6-7 }\end{array}$ \\
\hline Component & \multicolumn{5}{|c|}{$\mu \mathrm{m} / \mathrm{yr}$} \\
\hline $\begin{array}{l}\text { Carbon Steel } \\
\text { Type A516 }\end{array}$ & 72 & 7.2 & 720 & 3.69 & 130.7 \\
\hline Neutronit & 0.1 & 0.01 & 1 & 0.001 & 29.2 \\
\hline $\begin{array}{l}\text { Aluminum Alloy } \\
6061 \text { or } 1100\end{array}$ & 3.0 & 0.3 & 30 & 0.4 & 110.9 \\
\hline $\begin{array}{l}\text { Stainless Steel } \\
\text { Type } 316\end{array}$ & 0.1 & 0.01 & 1 & 0.0014 & 14.8 \\
\hline $\begin{array}{l}\text { Stainless Steel } \\
\text { Type 304L }\end{array}$ & 0.1 & 0.01 & 1 & 0.001 & 39.1 \\
\hline
\end{tabular}

The results of these runs are presented in Figure 6-55 and Figure 6-56.

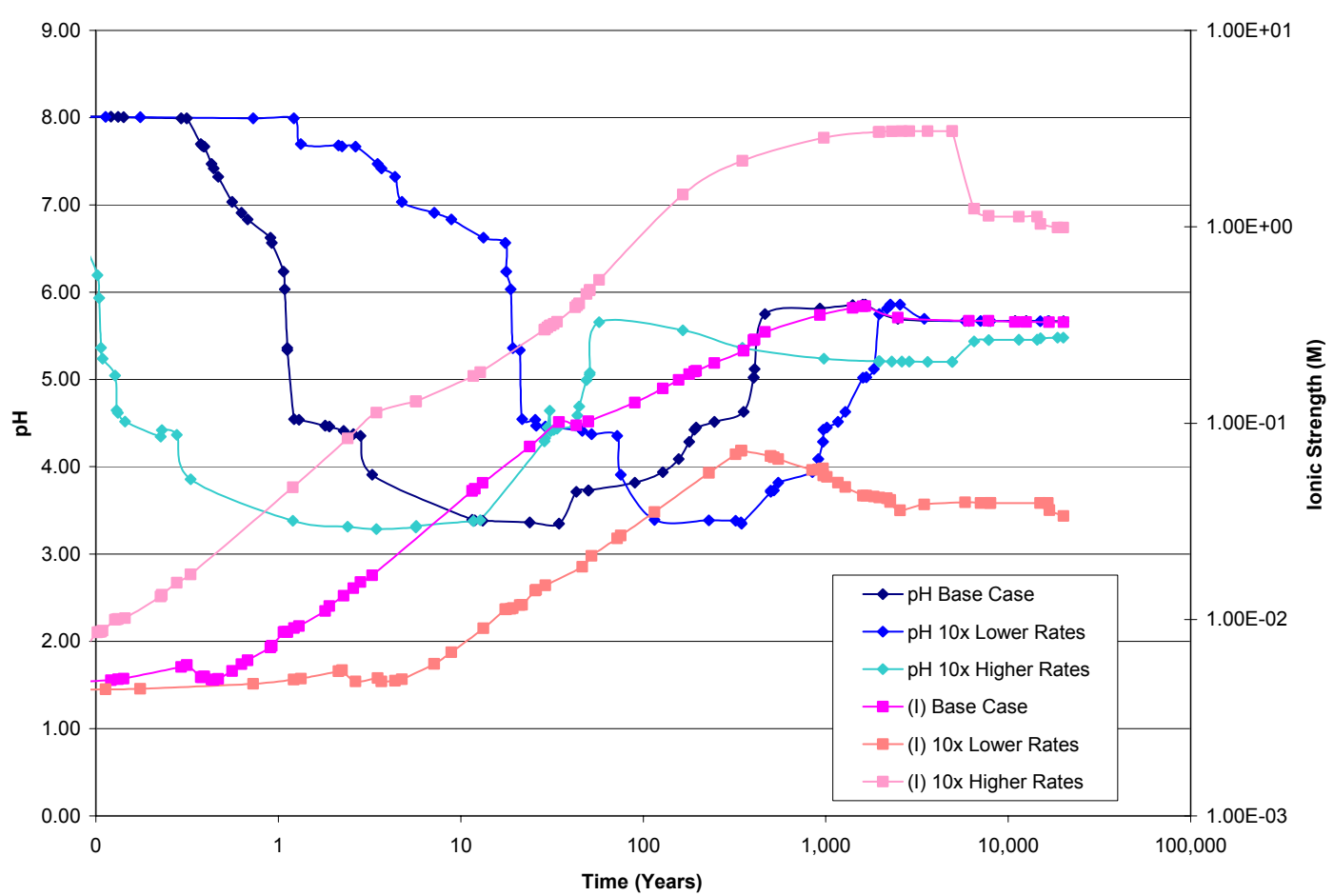

Source: CSNF_Corrosion Sensitivity.xls (Appendix F).

Figure 6-55. Corrosion Rate Comparison for CSNF 


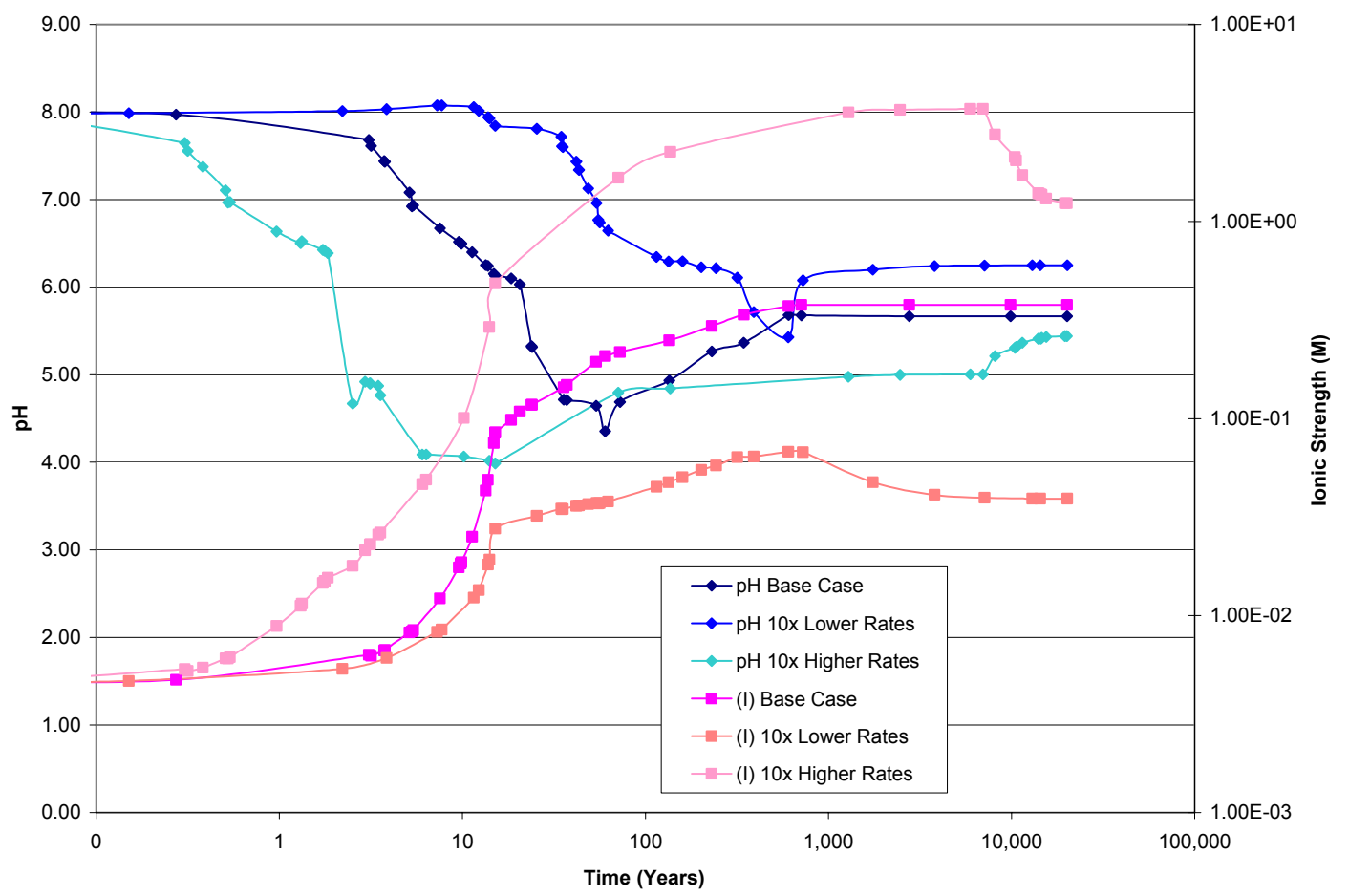

Source: $\quad C D S P \_C o r r o s i o n$ Sensitivity.xls (Appendix F).

Figure 6-56. Corrosion Rate Comparison for CDSP

The results in Figure 6-55 and Figure 6-56 show that both $\mathrm{pH}$ and ionic strength are sensitive to the corrosion rates used. The $\mathrm{pH}$ responses occur as a reactant is depleted and when that reactant no longer impacts the chemistry. The CSNF pH curves indicate that the different corrosion rates only affect the timing of the $\mathrm{pH}$ response, but do not actually change the $\mathrm{pH}$ minimum or maximum reached. The CDSP $\mathrm{pH}$ curves are slightly different, and the faster rates correspond to a lower $\mathrm{pH}$ minimum, however, over the two orders of magnitude change in rates, $\mathrm{pH}$ values only drop by one $\mathrm{pH}$ unit (from $10 \times$ lower than the base rate to $10 \times$ higher), the minimum $\mathrm{pH}$ only drops from $\sim 5.5$ (for the $10 \times$ lower rates) to $\sim 4.0$ (for the $10 \times$ higher rates). The CDSP case using the $10 \times$ higher rates results in a $\mathrm{pH}$ that is $0.5 \mathrm{pH}$ units less than the abstracted results presented in Section 6.10.1, however, these results were not incorporated into the abstraction because the difference is so minor, and likely to be overwhelmed by the $\mathrm{pH}$ elevating effect of the glass dissolution (shown in Figure 6-58). Comparing the two cases that use the lowest and the highest rates, shows that the $\mathrm{pH}$ values for the two cases can differ by up to $4 \mathrm{pH}$ units, and the timing of the $\mathrm{pH}$ response can vary by up to 1,000 years. However, these variations are accounted for in the $\mathrm{pH}$ abstraction that samples the $\mathrm{pH}$ between 4.5 and 7 or 8 , depending on the waste package and the $f \mathrm{CO}_{2}$ (Section 6.10.1).

The results in Figure 6-55 and Figure 6-56 indicate that the higher corrosion rates results in higher ionic strengths for both CSNF and CDSP waste packages. The high ionic strength is a result of the chromium from steel corrosion, so it follows that the faster the chromium is released, the higher the resulting ionic strength. The sensitivity cases with the highest rates result in ionic strengths approaching 4 for both the CSNF and CDSP cases. These results are mitigated by the sensitivity in Section 6.6.3 that shows how ionic strength values are affected because $\mathrm{Cr}(\mathrm{VI})$ is allowed to form. If the chromium in the high corrosion rate sensitivity were 
$\mathrm{Cr}(\mathrm{III})$, the ionic strength would be much lower. Therefore, it would be inappropriate to increase the abstracted ionic strength values to accommodate the highest corrosion rate sensitivity.

The above discussion addresses the subject matter of "Included" FEP 2.1.09.07.0A (Reaction kinetics in waste package) and indicates how that subject matter has been included and addressed within TSPA-LA.

\subsubsection{CSNF Degradation Rate}

The CSNF rate equation (BSC 2004 [DIRS 169987], Tables 8-2 and 8-3) includes a term, Log (A), that factors in both geometric surface area and the surface area of cracks in the fuel. For the base case of this report, the CSNF rate (Section 4.1.3) uses only the geometric surface area with no additional surface area for the fractures in the fuel (which corresponds to a $\log (\mathrm{A})$ value of -7.4). The inputs for this sensitivity analysis were calculated in CSNF_Rates.xls in Appendix F. The purpose of this sensitivity analysis is to examine the CSNF rate using the $100 \%$ exposure case, and include the specific surface area term, $\log (\mathrm{A})$, in the CSNF rate equation. The $\log (\mathrm{A})$ term was calculated using the mass of CSNF fuel for both the most likely or apex distribution $(\log (A)=-6.7)$, and the maximum distribution $(\log (A)=-5.4)$.

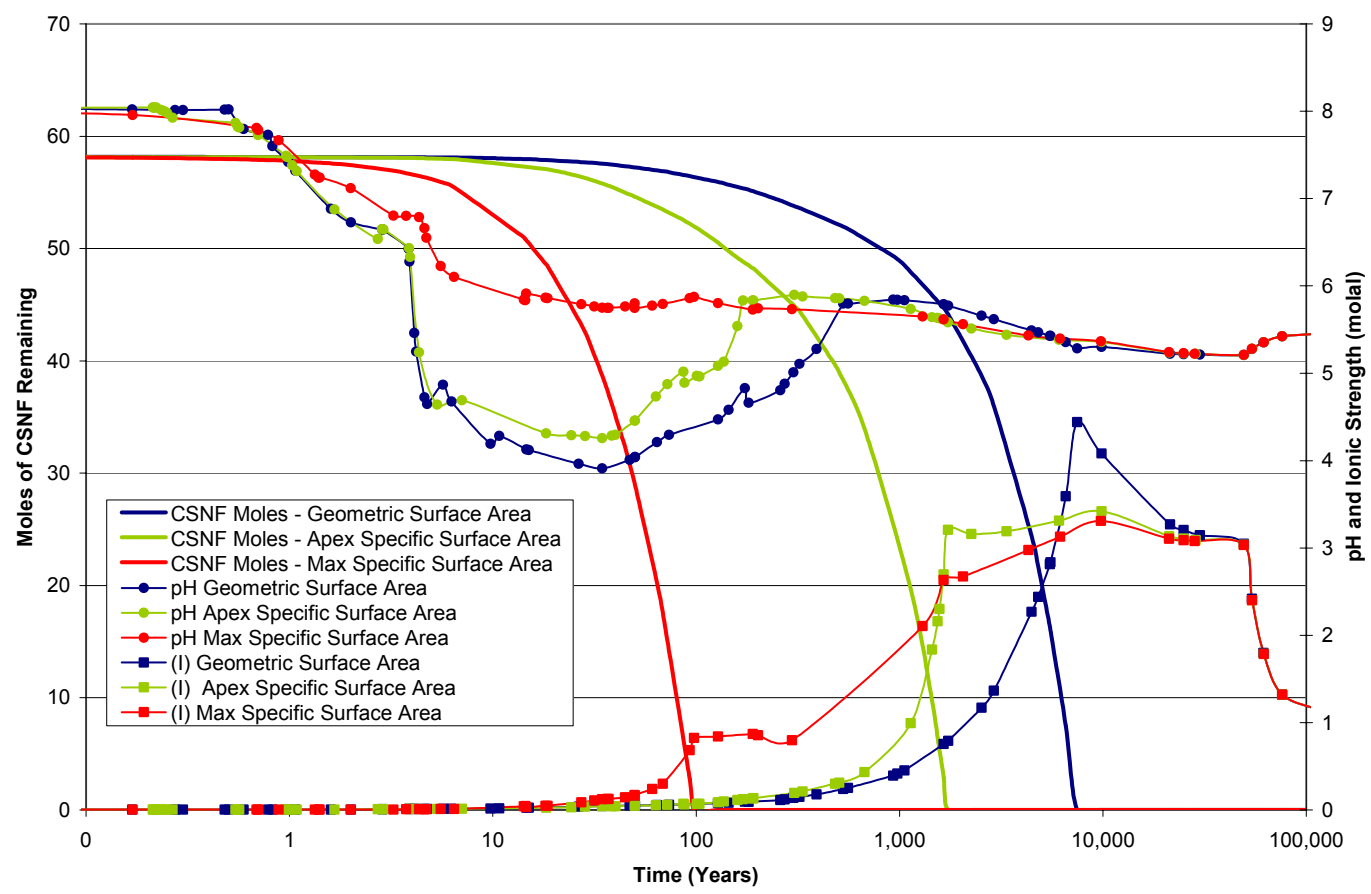

Source: $\quad$ CSNF_Rate Sensitivity.xIs (Appendix F).

Figure 6-57. CSNF Rate Using Apex and Maximum Specific Surface Area Term

The results show that for the case using the geometric surface area, the fuel completely degrades in $\sim 7,500$ years, using the apex distribution specific surface area results in degradation at $\sim 1,730$ years, and the maximum distribution results in degradation at $\sim 98$ years after waste package breach. The maximum rate results in a higher $\mathrm{pH}$ for the first hundred years, but shows the same steady state $\mathrm{pH}$ value. The maximum rate also results in a higher initial ionic strength, but the 
maximum ionic strength is less than the case using the geometric surface area. Because the results of this analysis are well within the abstracted range (Section 6.10) for both $\mathrm{pH}$ and ionic strength, and the fact that the surface area of the CSNF has a significant amount of uncertainty associated with it, the use of the geometric surface area for the base case is justified.

\subsubsection{HLWG Degradation Rate}

The HLWG rate has a very high uncertainty applied to the glass degradation rate coefficient $\left(\mathrm{k}_{\mathrm{E}}\right.$ term) of the rate equation (Section 4.1.3). The base case uses the most probable values for $\mathrm{k}_{\mathrm{E}}: k_{E \text { acidic }}$ is $8.41 \times 10^{3} \mathrm{~g} /\left(\mathrm{m}^{2} \cdot \mathrm{d}\right)$ and $k_{E \text { alkaline }}$ is $2.82 \times 10^{1} \mathrm{~g} /\left(\mathrm{m}^{2} \cdot \mathrm{d}\right)$. The maximum values for $\mathrm{k}_{\mathrm{E}}$ : are $k_{E_{-} \text {acidic }}$ is $1.15 \times 10^{7} \mathrm{~g} /\left(\mathrm{m}^{2} \cdot \mathrm{d}\right)$ and $k_{E_{-} \text {alkaline }}$ is $3.47 \times 10^{4} \mathrm{~g} /\left(\mathrm{m}^{2} \cdot \mathrm{d}\right)$. The inputs for this sensitivity analysis are calculated in CDSP.xls in Appendix F. This sensitivity analysis examines the impact of using these maximum $\mathrm{k}_{\mathrm{E}}$ values.

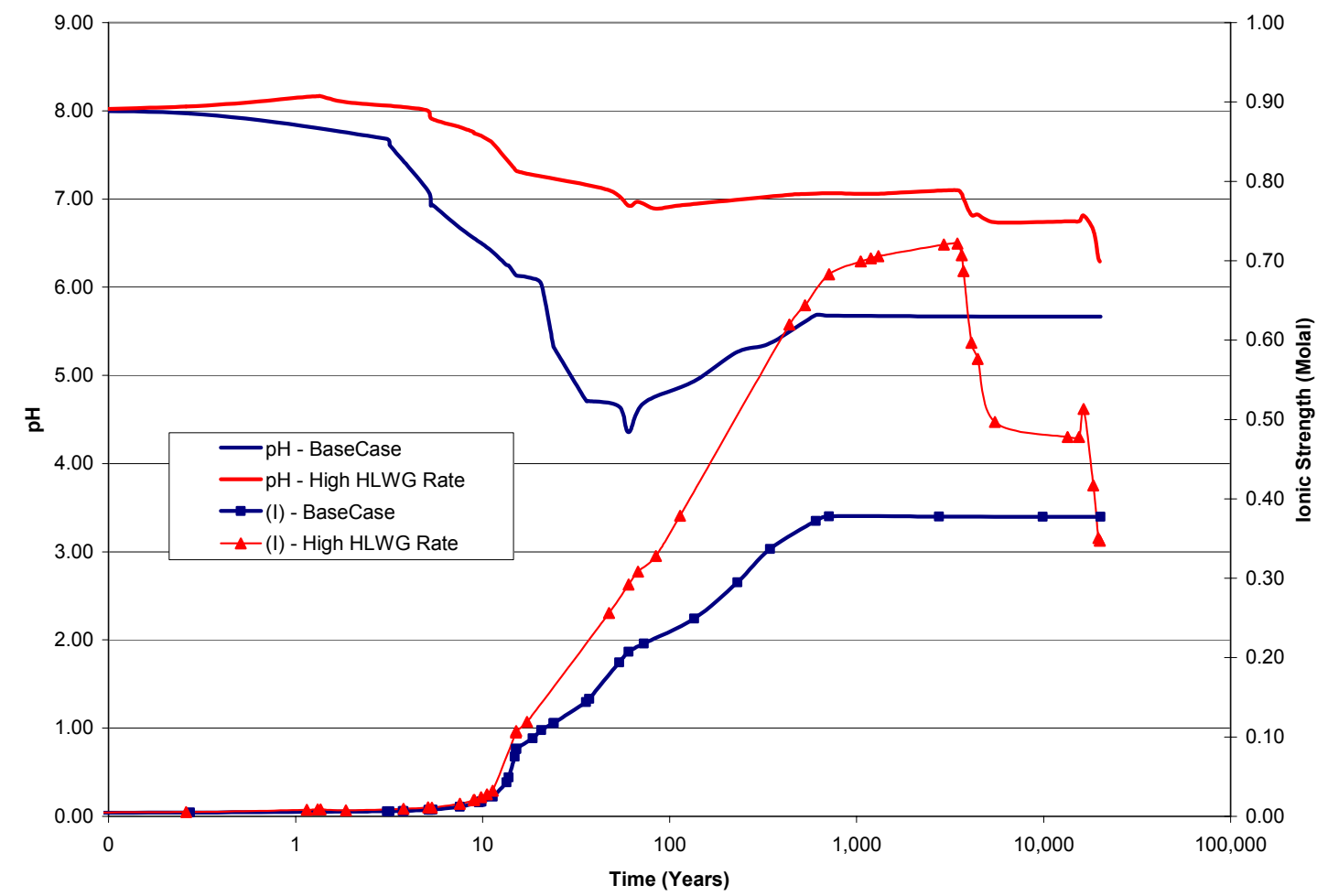

Source: CDSP_HLWG Rate Sensitivity.xIs (Appendix F).

Figure 6-58. HLWG Rate Using Maximum Uncertainty for $\mathrm{k}_{E}$ Term

These results show a considerably higher $\mathrm{pH}$ and ionic strength profile for the higher HLWG rate. The results are still within the abstracted output of this model (Section 6.10), so the exclusion of this very high rate is appropriate for this model.

\subsubsection{Hematite versus Goethite}

Which ferric (hydr)oxide phase will form in a degrading waste package is uncertain. Section 6.3.2 provides information that suggests that there is a time dependency where poorly crystalline ferrihydrite may initially dominate with a slow transformation, depending on the 
system chemistry, to goethite and hematite. The likely outcome is a mixture of these three phases in varying proportions. In the EQ6 modeling included in this report the runs were executed such that hematite was the ferric phase allowed to precipitate from solution, while the surface complexation model (Sections 6.7 and 6.8) uses goethite as the ferric phase active in the complexation of aqueous species.

To examine the influence of the ferric (hydr)oxide on the CSNF batch reactor model $\mathrm{pH}$ and ionic strength predictions, runs were completed where goethite was allowed to form in place of hematite. It was not possible to test the effect of ferrihydrite formation because it is not included in the thermodynamic database.

Runs were executed for the three test waters $(\mathrm{Ca}, \mathrm{Na}$, and $\mathrm{J} 13$ well water) and the results are plotted in Appendix A (Figure A-13 for $\mathrm{pH}$ profiles and Figure A-14 for ionic strength profiles). The $\mathrm{pH}$ results are virtually identical up to about 300 years when the $\mathrm{pH}$ values of the goethite runs are about $0.5 \mathrm{pH}$ units less, $\mathrm{pH}=5.2$, than the $\mathrm{pH}$ values of the hematite runs that are 5.7. This $0.5 \mathrm{pH}$ difference is insignificant and within the uncertainty of the model.

There is a difference in the ionic strength between ten and one thousand years where the goethite runs have higher ionic strength because the formation of goethite consumes more water than does hematite. This difference is insignificant in terms of performance because the ionic strength for both goethite and hematite are above the 0.05-molal colloid threshold (BSC 2003 [DIRS 166845]) for this entire period.

This sensitivity analysis has shown that the results of the batch reactor model are largely independent of which ferric (hydr)oxide mineral is allowed to form in the simulations. Therefore, the use of ferrihydrite, which is similar to goethite, in the surface complexation model is acceptable because it would not cause unusual excursions in the chemistry of the batch reactor model that used hematite as the primary phase.

\subsubsection{Lower HLW Glass Exposure Factor}

The exposure factor is the value that is multiplied by the geometric surface area of the HLW glass to achieve an effective surface area that includes an increase in surface area due to fractures in the glass. Defense HLW Glass Degradation Model (BSC 2004 [DIRS 169988, Table 8-1) gives a minimum and most-likely value of the exposure factor equal to 4 , but the base-case CDSP water influx case uses 21 . A sensitivity case was run to determine the impact on the $\mathrm{pH}$ and ionic strength of using a lower exposure factor. As with the base case, the water thickness was chosen such that the waste package was half full of water. The revised EQ6 inputs are provided in Appendix F (file CDSP.xls, tab "SDM EQ6 Inputs"). Figure 6-59 shows that the $\mathrm{pH}$ is about $1 / 2 \mathrm{pH}$ units lower for the lower exposure factor case. These results do not reflect the surface complexation effects that are expected to buffer the $\mathrm{pH}$ in the first few hundred years. As shown in Section 6.8.4, solutions with a $\mathrm{pH}$ of 3 to 4 are buffered to a $\mathrm{pH}$ of 7 to 8 when contacted with iron oxides. Therefore, due to the influence of the surface complexation, no significant $\mathrm{pH}$ change would be expected if the HLW glass exposure factor were at the lower value of 4 . 


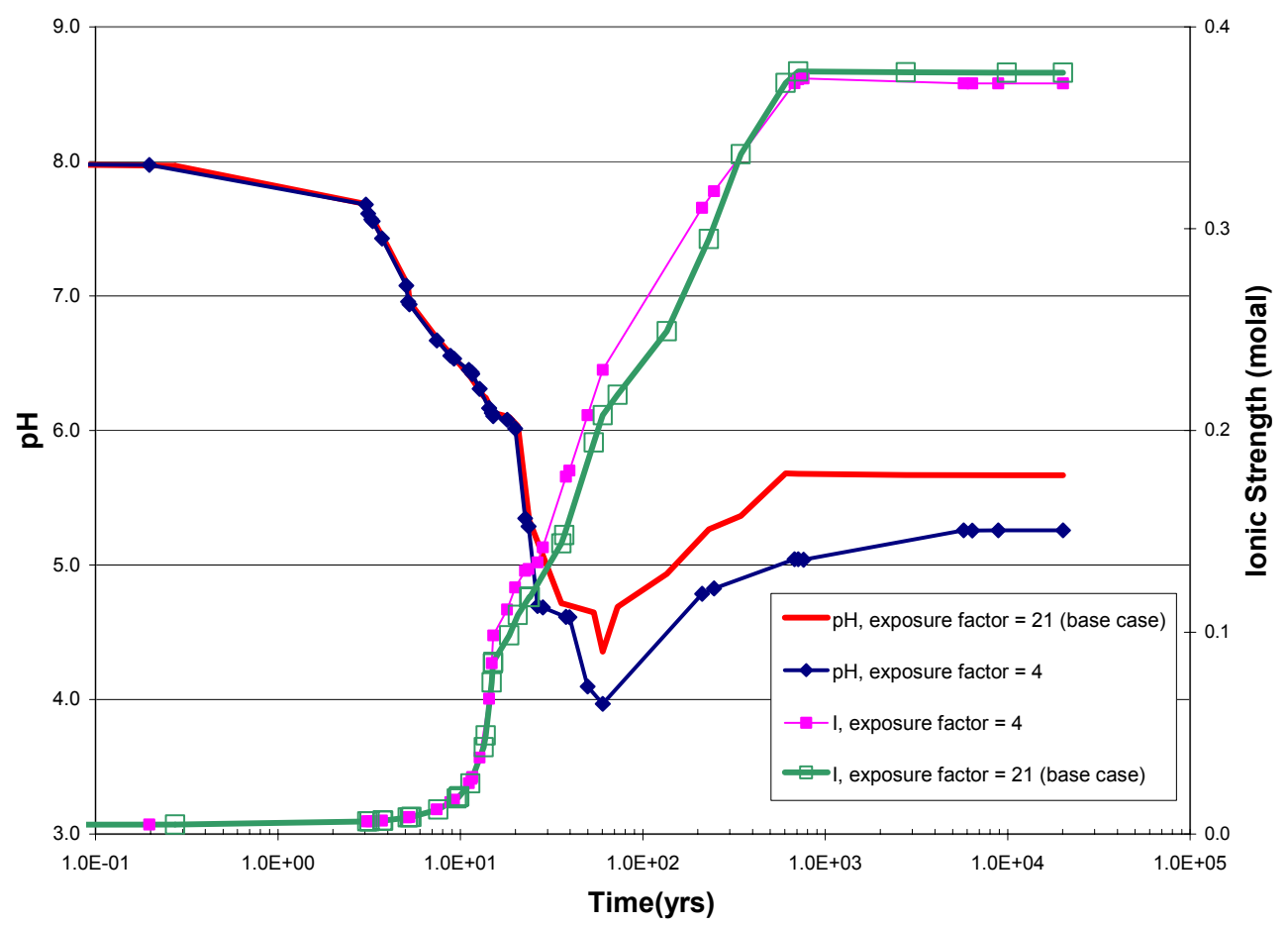

Source: $\quad C D S P_{-}$ff.xls (Appendix F ISpreadsheets).

NOTE: Base Case is D23C25

Figure 6-59. HLW Glass Exposure Factor Impact on $\mathrm{pH}$ and Ionic Strength

\subsubsection{Codisposal Waste Package Containing 5 HLWG Canisters}

The CDSP base case considers codisposal waste packages contain $\mathrm{N}$ Reactor fuel (2-MCO/2-DHLW). In addition to this type of waste package, the repository is expected to contain other waste packages containing the 5 DHLW/DOE SNF waste package design (BSC 2004 [DIRS 169472], Table 11). The 5 DHLW/DOE SNF waste package design contains five HLWG canisters (5-DHLW waste package) and 1 DOE canister containing DOE SNF. A sensitivity analysis was conducted to determine the impact on the in-package chemistry of the degradation of the $5 \mathrm{DHLW} / \mathrm{DOE}$ SNF waste package under the same conditions as the base case N Reactor D23C25 EQ6 run. The 5 DHLW/DOE SNF waste package design has a short waste package and a long waste package. This sensitivity examines the long waste package design because that is the design that will be used with the Three Mile Island (TMI) fuel. The EQ6 batch reactor model, water influx case, was run for a codisposal waste package containing five HLWG canisters (5-DHLW long waste package) and 1 DOE canister containing 1 assembly of TMI SNF. TMI SNF was chosen because it is chemically similar to the N Reactor fuel, and the purpose of this sensitivity is to examine the impact of the 5 DHLW/DOE SNF design, and using a drastically different fuel composition would have masked any differences due to the waste package design. The TMI SNF also represents a significant number of DOE canisters expected at the repository (DOE 2004 [DIRS 170071], Table A-2, "LEU oxide"). Two EQ6 calculations were run using the same drip rate, degradation rates (except fuel), temperature, and water composition as case D23C25. Two fuel degradation rates were used for these runs. Since the TMI fuel is a uranium oxide, the rates used in the EQ6 simulations were set equal to the CSNF rate and $100 \times$ the CSNF surface area, as recommended for DOE $\mathrm{UO}_{2}$-type SNF in 
(DOE 2002 [DIRS 158405], Section 6.8). In order to use the $\mathrm{pH}$ and carbonate-dependent degradation rate for CSNF as a basis for the TMI SNF rate, it was necessary to add the composition for the TMI SNF to the data0.ymp.R2 database (Appendix F, folder "databases", file data0.han, mineral name $=$ "TMI").

Table 6-19 contains all the input data needed for the calculations. The first step in the calculation was to calculate the void volume and the total surface area and moles (based on $100 \mathrm{~g} / \mathrm{mol}$ ) for all components of the waste package (Appendix F, file CDSP_Long WP.xls, tab "Void Volume" and tab "SDM EQ6 Inputs"). The next step was to calculate the water layer thickness such that the ratio of water to reactants was consistent with the base case (waste package was half-full of water). The layer thickness for the system was calculated to be $0.3 \mathrm{~cm}$. For input into EQ6 that is based on a 1-liter system, the total moles and surface area for all components were multiplied by the normalization factor that is defined as the modeled surface area $\left(1,000 \mathrm{~cm}^{3} \div 0.3 \mathrm{~cm}\right)$ divided by the total surface area. The resulting normalized moles and surface areas are provided in Appendix F, folder "spreadsheets," file CDSP_Long WP.xls, tab "SDM EQ6 Inputs." The EQ6 input and output files are provided in Appendix F, folder "CDSP/Sensitivities."

Table 6-19. Input to Calculations for 5 DHLW/TMI SNF-Long Waste Package

\begin{tabular}{|c|c|c|}
\hline Input & Source & Used In \\
\hline $\begin{array}{l}\text { Dimensions of the outer } \\
\text { barrier, inner vessel, and } \\
\text { divider plate assembly }\end{array}$ & $\begin{array}{l}\text { BSC } 2004 \text { [DIRS 166949] } \\
\text { BSC } 2004 \text { [DIRS 166950] } \\
\text { BSC } 2004 \text { [DIRS 168239] } \\
\text { BSC } 2004 \text { [DIRS 168240] } \\
\text { BSC } 2004 \text { [DIRS 168241] } \\
\text { BSC } 2004 \text { [DIRS 168237] } \\
\text { BSC } 2004 \text { [DIRS 168204] }\end{array}$ & $\begin{array}{l}\text { Appendix F: CDSP_Long WP.xls, tab "DOE } \\
\text { WP IED Info" }\end{array}$ \\
\hline $\begin{array}{l}\text { Mass of inner vessel and } \\
\text { divider plate assembly }\end{array}$ & $\begin{array}{l}\text { BSC } 2004 \text { [DIRS 169472], Table } \\
6\end{array}$ & $\begin{array}{l}\text { Appendix F: CDSP_Long WP.xIs, tab "Void } \\
\text { Volume" }\end{array}$ \\
\hline DOE canister dimensions & $\begin{array}{l}\text { DOE } 2002 \text { [DIRS 161752], } \\
\text { Figure } 10\end{array}$ & $\begin{array}{l}\text { Appendix F: CDSP_Long WP.x/s, tab "Void } \\
\text { Volume" }\end{array}$ \\
\hline $\begin{array}{l}\text { Normalization factor, } \\
\text { normalized moles and } \\
\text { surface area of waste } \\
\text { package components, based } \\
\text { on Shippingport PWR } \\
\end{array}$ & $\begin{array}{l}\text { BSC } 2001 \text { [DIRS 156873], Table } \\
1, \text { footnote I }\end{array}$ & $\begin{array}{l}\text { Appendix F: CDSP_Long WP.xIs, tab "DOE } \\
\text { SNF Normalized Values;" used to convert } \\
\text { normalized values from BSC } 2001 \\
\text { [DIRS 156873], Table 1, to total mass and } \\
\text { surface area for DOE long waste package }\end{array}$ \\
\hline $\begin{array}{l}\text { TMI assembly and canister } \\
\text { mass and surface area }\end{array}$ & $\begin{array}{l}\text { DTN: MO0405MWDGIFWP.000 } \\
\text { [DIRS 171239], file Rn Fix 07.xIs, } \\
\text { tab “DOE_SNF (Cat.8) (2), cell } \\
\text { block T87:Y147. }\end{array}$ & Appendix F: CDSP_Long WP.xls, tab "TMI" \\
\hline TMI fuel composition & $\begin{array}{l}\text { DTN: MO0405MWDGIFWP.000 } \\
\text { [DIRS 171239], file Rn Fix 07.xIs, } \\
\text { tab "DOE_SNF (Cat.8) (2), cells } \\
\text { AX56 to AX57. }\end{array}$ & Appendix F: folder "databases," file dataO.han \\
\hline $\begin{array}{l}\text { TMI fuel degradation rate }(1 \mathrm{x} \\
\text { and } 100 \mathrm{x} \text { CSNF rate) }\end{array}$ & $\begin{array}{l}\text { (DOE } 2002 \text { [DIRS 158405], } \\
\text { Section 6.8) }\end{array}$ & $\begin{array}{l}\text { Appendix F, folder "CDSP/Sensitivities," EQ6 } \\
\text { input files }\end{array}$ \\
\hline
\end{tabular}

NOTE: a The actual moles and surface areas of the components (HLW glass, HLW canisters, DOE canisters, and Carbon Steel Type A516 impact plates) that were calculated in the Shippingport PWR calculation are common to all DOE long codisposal waste packages, and have not changed since completion of BSC 2001 [DIRS 156873]. The normalized values from Table 1 of BSC 2001 [DIRS 156873] are multiplied by the normalization factor $(5,807)$ to calculate the true number of moles and surface area and are divided by the new normalization factor to obtain normalized values based on the current waste package design. 
The results of the sensitivity runs with the TMI codisposal waste package are shown in Figure 6-60. The $\mathrm{pH}$ is lower in the first approximately 200 years. However, these results do not reflect the surface complexation effects that are expected to buffer the $\mathrm{pH}$ in the first few hundred years. As shown in Section 6.8.4, solutions with a $\mathrm{pH}$ of 3 to 4 are buffered to a $\mathrm{pH}$ of 7 to 8 when contacted with iron oxides. Therefore, due to the influence of the surface complexation, no significant $\mathrm{pH}$ change would be expected with water contacting a breached TMI codisposal waste package as opposed to an N Reactor codisposal waste package.

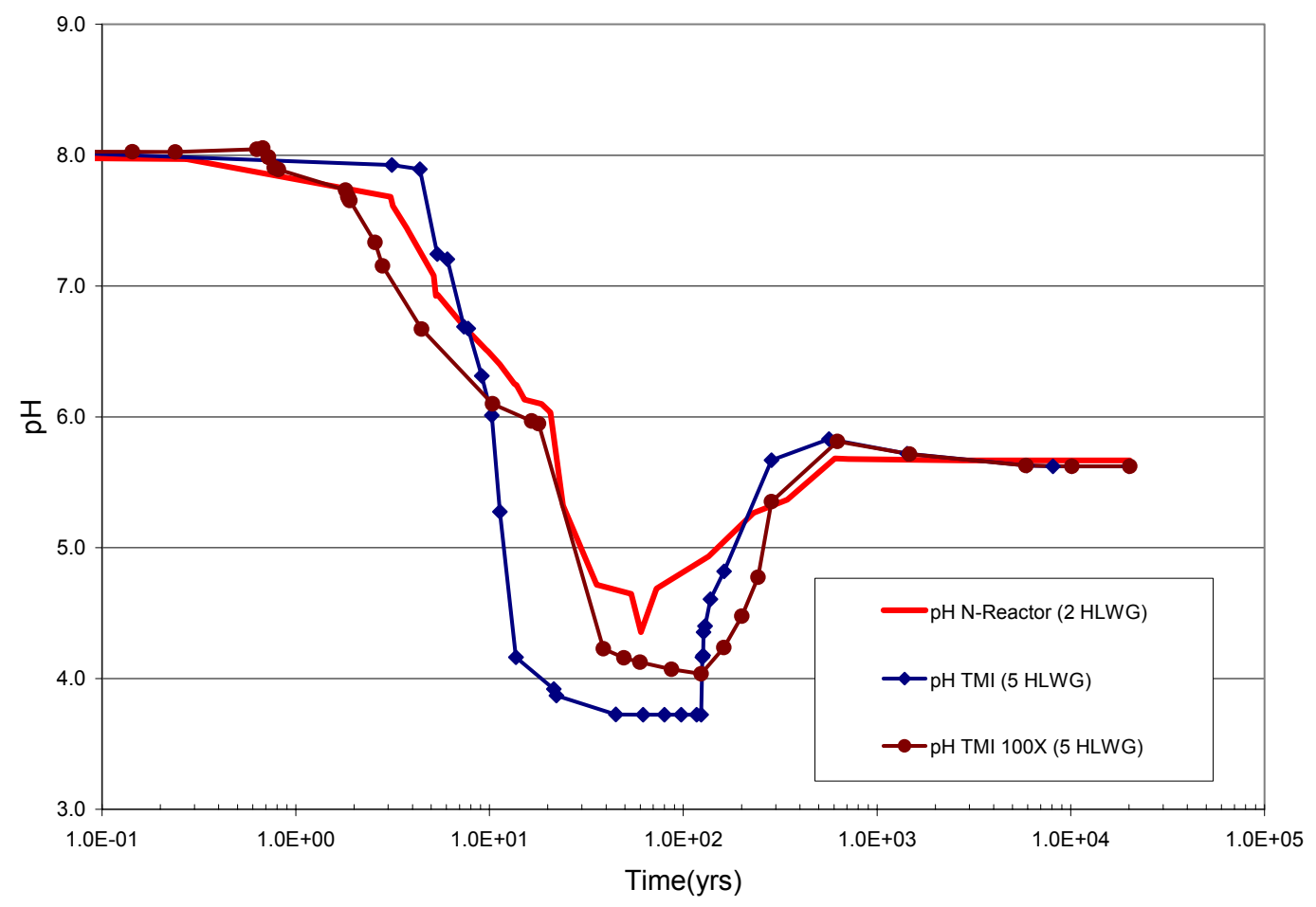

Source: CDSP_5_DHLWG WP Sensitivity.xls (Appendix F ISpreadsheets).

Figure 6-60. 2-MCO/2-DHLW Design versus 5 DHLW/DOE SNF: Impact on pH

Figure 6-61 shows that the range of ionic strength values for the TMI codisposal waste package is similar to the $\mathrm{N}$ Reactor codisposal waste package except for slightly higher values after 4,000 years. The maximum increase in ionic strength, from 0.38 to 0.57 molal at 20,000 years, is small compared to the variation in ionic strength due to the influence of other variables in the system, such as the drip rate (Section 6.5.2.2.2). Therefore, the degradation of the TMI codisposal waste package is not expected to have a significant impact on the ionic strength of the solution compared to the $\mathrm{N}$ Reactor codisposal waste package. 


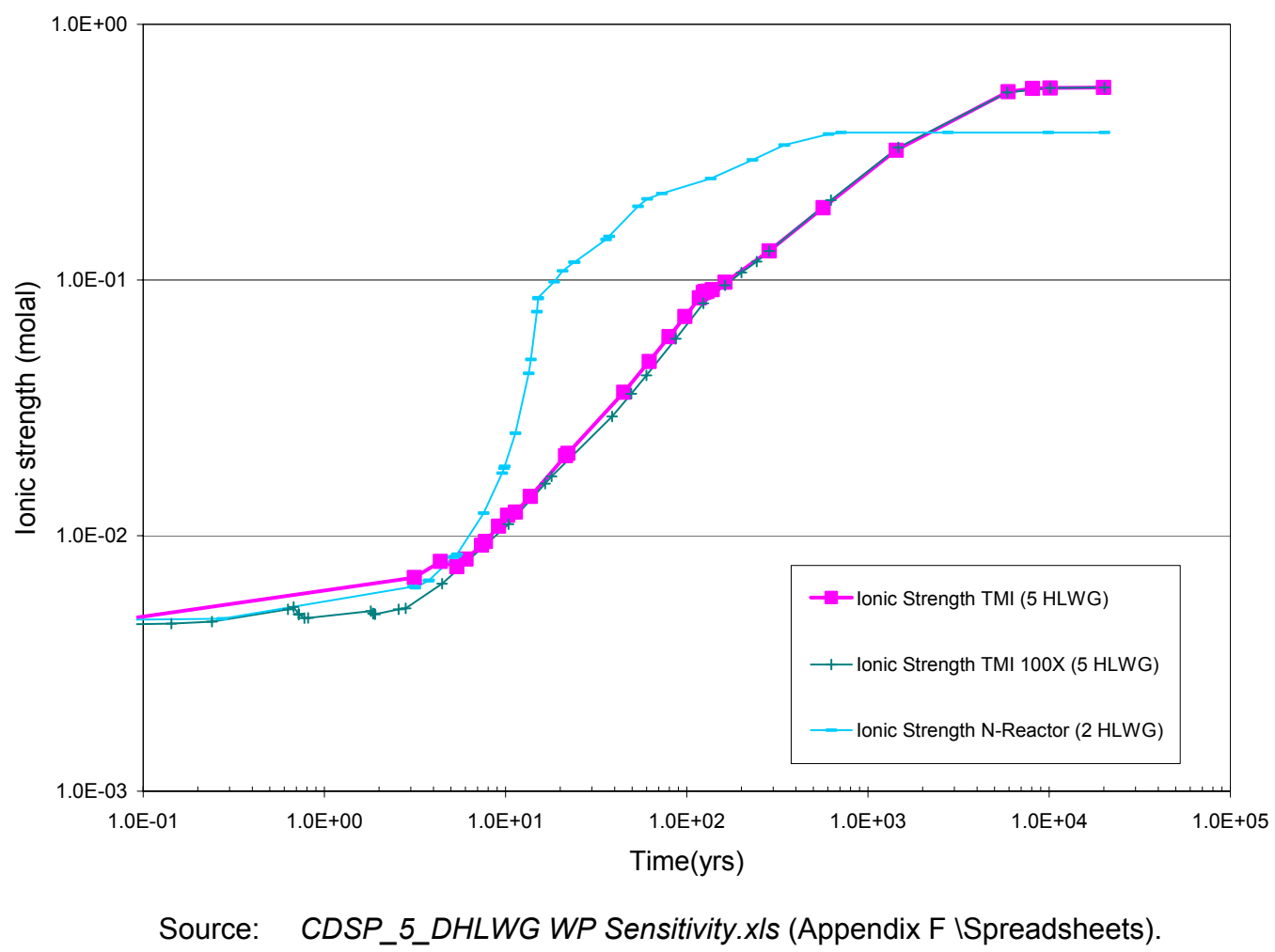

Figure 6-61. 2-MCO/2-DHLW Design Versus 5 DHLW/DOE SNF: Impact on Ionic Strength

The above discussion addresses the subject matter of "Included" FEP 2.1.01.02.0B (Interactions between co-disposed waste) and indicates how that subject matter has been included and addressed within TSPA-LA.

\subsection{SURFACE COMPLEXATION MODEL OUTPUT}

An analytical model is developed in this section to account for the $\mathrm{pH}$ buffering effects of iron corrosion product surfaces. The results of this analytical model are applied to the results of the batch reactor model in Section 6.9. As discussed in Section 6.3.2, ferric hydr(oxide) corrosion products such as ferrihydrite, goethite, and hematite will be present in abundance in the waste package in both the short and long term (Schwertmann and Cornell 1991 [DIRS 144629]). Justification is made in Section 6.3.2 for using either ferrihydrite or goethite as the representative iron corrosion product as long as the concentration of surface sites is not overestimated. Therefore, a compromise is made for the analytical model developed here. The compromise is to use a thermodynamic database for hydrous ferric oxide (HFO) while using the surface properties of goethite (i.e., specific surface area and specific site density). While there are differences in complexation reactions between HFO and goethite (Appelo et al. 2002 [DIRS 168168]), these differences are small compared to the differences in specific surface areas of HFO and goethite and especially between these minerals and hematite (Section 6.3.2). Choosing the lower surface site concentrations of goethite helps to ensure that the effects of complexation with iron corrosion product surfaces are not overestimated. 
Further justifying the use of the HFO thermodynamic database, studies have shown that the surface chemistry of natural sediments is routinely and successfully modeled by assuming that ferrihydrite is the dominant adsorbent in natural sediments or that the surface area of the sediments is composed entirely of ferrihydrite (Payne and Waite 1991 [DIRS 168860]; Waite et al. 2000 [DIRS 168856]). Ferrihydrite is equated with HFO in Dzombak and Morel (1990 [DIRS 105483]). The general formula for $\mathrm{HFO}$ is $\mathrm{Fe}_{2} \mathrm{O}_{3} \cdot \mathrm{nH}_{2} \mathrm{O}$ (Dzombak and Morel 1990 [DIRS 105483], p. 90); however, the bulk structure is uncertain and gradually changes from highly amorphous to more crystalline structures with age (Dzombak and Morel 1990 [DIRS 105483], p. 90). Because ferrihydrite is predicted to occur in abundance in the waste package at early times and persist over the long term (Schwertmann and Cornell 1991 [DIRS 144629]), the Dzombak and Morel (1990 [DIRS 105483]) database for HFO that is well documented and widely accepted (Section 6.3.2), is well suited for the analytical models developed below.

\subsection{1 pH Buffering During Dissolution of Carbon Steel}

In a multireactant system, such as the waste package interior, the evolution of the chemistry is most influenced by reactants that react rapidly, contain elements that have the potential to perturb the ambient chemical conditions, and are present in large enough quantities to exert a chemical change on the system. For these reasons, Carbon Steel Type A516 is considered to be of primary importance because of its high corrosion rate (Table 4-8) relative to the other reactants, the presence of reduced sulfur in its composition, which lowers system $\mathrm{pH}$ when oxidized, and its abundance in the waste package. During the period of rapid corrosion of Carbon Steel Type A516, a large quantity of ferric (hydr)oxides will accumulate in the waste packages in a relatively short period of about 200 years, and the oxidation of sulfur will tend to lower the system $\mathrm{pH}$. Occurring simultaneously with Carbon Steel Type A516 corrosion are corrosion and degradation of the other waste package metal alloys and waste forms, albeit at much slower rates than Carbon Steel Type A516. While the system chemistry would be dominated by Carbon Steel Type A516 corrosion the complexity of the system chemistry would be increased by the corrosion or degradation of the other waste package components. The steel alloys would form ferric (hydr)oxides and other metal corrosion products (e.g., pyrolusite), the aluminum alloys would form gibbsite and clay minerals, and while the spent nuclear fuel would form primarily schoepite, the HLWG would form clays - nearly all of the degradation products of the non-Carbon Steel Type A516 waste package components are phases with surface complexation properties. Considering only the reaction of Carbon Steel Type A516 would tend to underestimate the total number of surface sites available for the surface complexation reactions, as well as the nature of the sites (e.g., site density). In an actual degrading waste package the potential for surface complexation and $\mathrm{pH}$ buffering would be greater than in the simplified system which only considers Carbon Steel Type A516 corrosion products, and the $\mathrm{pH}$ would be even closer to neutral.

It is during the 0 - to 600 -year period that the analytic surface complexation model developed in this section was used to predict the in-package $\mathrm{pH}$. The reasons for limiting the application of the surface complexation model to this period are: 1) Increasing uncertainty in the ferric (hydr)oxide mineral assemblage as a function of time; and 2) this relatively brief period of low $\mathrm{pH}$, as predicted by the EQ6 batch reactor model, would be most influenced by the presence of surface complexation reactions. 
A mole of Carbon Steel Type A516 dissolves into neutral and subneutral solutions as (Table 6-6):

$$
\begin{gathered}
\mathrm{Fe}_{1.76} \mathrm{Mn}_{0.019} \mathrm{C}_{0.0233} \mathrm{Si}_{0.0103} \mathrm{P}_{0.00113} \mathrm{~S}_{0.00109}+m \mathrm{H}_{2} \mathrm{O}+q \mathrm{O}_{2} \rightarrow \\
0.00109 \mathrm{SO}_{4}{ }^{2-}+0.00113\left(\mathrm{H}_{3} \mathrm{PO}_{4}+\mathrm{H}_{2} \mathrm{PO}_{4}{ }^{-}+\mathrm{HPO}_{4}{ }^{2-}\right)+0.0103 \mathrm{H}_{4} \mathrm{SiO}_{4}+ \\
0.0233\left(\mathrm{H}_{2} \mathrm{CO}_{3}+\mathrm{HCO}_{3}{ }^{-}\right)+0.019 \mathrm{MnO}_{2}+1.76 \mathrm{FeOOH}+n \mathrm{H}^{+}
\end{gathered}
$$

where $m, n$, and $q$ are positive numbers that depend ultimately on the $\mathrm{pH}$ of the solution (at $25^{\circ} \mathrm{C}$, $\mathrm{HCO}_{3}{ }^{-}$is the predominant carbonate species above $\mathrm{pH} 6.3 ; \mathrm{H}_{2} \mathrm{PO}_{4}{ }^{-}$is the dominant $\mathrm{P}$ species between $\mathrm{pH} 2.4$ and 7; $\mathrm{H}_{3} \mathrm{PO}_{4}$ is the dominant species below $\mathrm{pH}$ 2.4). The choice of goethite $(\mathrm{FeOOH})$ as the iron corrosion product is irrelevant to the value of $n$. Goethite is used here and in Section 6.8.2 simply because the surface site concentrations of goethite are used. Charge balance requires that $n$, the amount of acid produced in the reaction, be equal to $2\left[\mathrm{SO}_{4}{ }^{2-}\right]+$ $\left[\mathrm{H}_{2} \mathrm{PO}_{4}{ }^{-}\right]+2\left[\mathrm{HPO}_{4}{ }^{2-}\right]+\left[\mathrm{HCO}_{3}{ }^{-}\right]$where the bracketed terms denote amounts added from Carbon Steel Type A516 dissolution (moles). The acid input and the resulting $\mathrm{pH}$ can be estimated for when a liter of water reacts with a mole of Carbon Steel Type A516 as:

$$
n=0.00218+0.00113+0+0=0.00331 \mathrm{~mol} / \mathrm{L} \mathrm{H}^{+}
$$

which when used in a solution charge balance equation corresponds to a $\mathrm{pH}$ of $\sim 2.5$ (assuming that all of the $\mathrm{C}$ reacts to carbonic acid). 0.1 moles of Carbon Steel Type A516 dissolution would result in $n=0.000331$ and a solution with a $\mathrm{pH}$ of $\sim 3.5$. The $\mathrm{pH}$ derived analytically for Carbon Steel Type A516 dissolution is close to the output $\mathrm{pH}$ calculated by EQ6. For example, Figure 6-8 shows the $\mathrm{pH}$ profiles for the three water compositions, and the stabilized $\mathrm{pH}$ when Carbon Steel Type A516 dominates the system chemistry at about ten years is $\sim 3.5$. The high initial $\mathrm{pH}$ values of around $\mathrm{pH}=8$ (Figure 6-8), 0.1 to 10 years, reflects the chemistry of the starting solutions and a finite amount of reaction needs to occur to overcome the buffer capacity of the water before the low pH (3.5) of the Carbon Steel Type A516 is realized.

The analytic equation and the EQ6 calculation both neglect the tendency for iron hydroxide corrosion product surfaces to buffer $\mathrm{pH}$ in the near-neutral range through the following surface reactions (Table 4-9):

$$
\begin{array}{ll}
>\mathrm{Fe}-\mathrm{OH}_{2}{ }^{+} \leftrightarrow>\mathrm{Fe}-\mathrm{O}-\mathrm{H}+\mathrm{H}^{+} & \mathrm{K}_{1}=[>\mathrm{Fe}-\mathrm{O}-\mathrm{H}]\left[\mathrm{H}^{+}\right] /\left[>\mathrm{Fe}-\mathrm{OH}_{2}^{+}\right]=10^{-7.29} \\
>\mathrm{Fe}-\mathrm{OH} \leftrightarrow>\mathrm{Fe}-\mathrm{O}^{-}+\mathrm{H}^{+} & \mathrm{K}_{2}=\left[>\mathrm{Fe}-\mathrm{O}^{-}\right]\left[\mathrm{H}^{+}\right] /[>\mathrm{Fe}-\mathrm{OH}]=10^{-8.93}
\end{array}
$$

$>\mathrm{Fe}^{-}$is a general representation of an adsorption site at the iron (hydr)oxide-solution interface. For the HFO reactions in Table 4-9, the adsorption sites are represented by HFO_s (strong site) and HFO_w (weak site). Sorbed bicarbonate also appears through (Table 4-9):

$$
>\mathrm{Fe}-\mathrm{O}-\mathrm{H}+\mathrm{H}^{+}+\mathrm{CO}_{3}{ }^{2-} \leftrightarrow>\mathrm{Fe}-\mathrm{CO}_{3}{ }^{-}+\mathrm{H}_{2} \mathrm{O}
$$

where

$$
\mathrm{K}_{\mathrm{CO} 3}=\left[\mathrm{Fe}-\mathrm{CO}_{3}{ }^{-}\right] \mathrm{a}_{\mathrm{H} 2 \mathrm{O}} /[>\mathrm{Fe}-\mathrm{OH}]\left[\mathrm{H}^{+}\right]\left[\mathrm{CO}_{3}{ }^{2-}\right]=10^{12.78}
$$


Constants are uncorrected for solution ionic strength.

To account for the surface effect, the Carbon Steel Type A516 dissolution reaction must be expanded to:

$$
\begin{gathered}
\mathrm{Fe}_{1.76} \mathrm{Mn}_{0.019} \mathrm{C}_{0.0233} \mathrm{Si}_{0.0103} \mathrm{P}_{0.00113} \mathrm{~S}_{0.00109}+m \mathrm{H}_{2} \mathrm{O}+q \mathrm{O}_{2} \rightarrow \\
0.00109 \mathrm{SO}_{4}{ }^{2-}+0.00113\left(\mathrm{H}_{3} \mathrm{PO}_{4}+\mathrm{H}_{2} \mathrm{PO}_{4}{ }^{-}+\mathrm{HPO}_{4}{ }^{2-}\right)+0.0103 \mathrm{H}_{4} \mathrm{SiO}_{4}+ \\
0.0233\left(\mathrm{H}_{2} \mathrm{CO}_{3}+\mathrm{HCO}_{3}{ }^{-}\right)+0.019 \mathrm{MnO}_{2}+(1.76-\mathrm{X}) \mathrm{FeOOH}+ \\
\mathrm{X}\left(>\mathrm{Fe}-\mathrm{O}-\mathrm{H}+>\mathrm{Fe}-\mathrm{O}-\mathrm{H}_{2}{ }^{+}+>\mathrm{Fe}-\mathrm{O}^{-}+>\mathrm{Fe}-\mathrm{CO}_{3}{ }^{-}\right)+n \mathrm{H}^{+} .
\end{gathered}
$$

where $\mathrm{X}$ is the amount of $\mathrm{Fe}$ in $\mathrm{FeOOH}$ (moles) that is exposed to solution.

The approximations applied to solving the charge balance equation for the expanded reaction above are listed and justified in Table 6-20 below. Specifically, since the output $\mathrm{pH}$ is calculated to be between $\mathrm{pH} 2.4$ (no surface effect) and $\sim \mathrm{pH} 8$ (surfaces considered), the magnitude of the charged species are calculated at these two end-members. The sulfate contribution to the charge balance is $\sim 0.002 \mathrm{~mol} / \mathrm{L}$; species whose concentrations are less than a factor of ten of this will tend to have a minor effect on the charge balance calculation.

Table 6-20. Approximation for charge balance

\begin{tabular}{|l|l|l|}
\hline \multicolumn{1}{|c|}{ Approximation } & \multicolumn{1}{c|}{ Justification } & \multicolumn{1}{c|}{ Notes } \\
\hline $\begin{array}{l}\text { Dissolved Mn can be } \\
\text { neglected }\end{array}$ & $\begin{array}{l}\mathrm{MnO}_{2} \text { growth limits } \\
\text { dissolved } \mathrm{Mn} \text { to low levels }\end{array}$ & $\begin{array}{l}\text { EQ3/6 runs show pyrolusite to limit } \\
\text { dissolved } \mathrm{Mn} \text { to very low levels over } \\
\text { the } \mathrm{pH} \text { range of interest }\end{array}$ \\
\hline $\begin{array}{l}\text { Deprotonated Si species do } \\
\text { not contribute to charge } \\
\text { balance }\end{array}$ & $\begin{array}{l}\text { Deprotonated Si species } \\
\text { only form at } \mathrm{pH}>9\end{array}$ & $\begin{array}{l}\text { At pH } 7\left[\mathrm{H}_{3} \mathrm{SiO}_{4}\right] \sim 10^{-4} \mathrm{~mol} / \mathrm{L} \mathrm{At} \mathrm{pH} \\
2.4\left[\mathrm{H}_{3} \mathrm{SiO}_{4}^{-}\right]=3.2 \times 10^{-10} \mathrm{~mol} / \mathrm{L}\end{array}$ \\
\hline $\begin{array}{l}\mathrm{OH}^{-} \text {can be neglected in the } \\
\text { charge balance }\end{array}$ & $\begin{array}{l}\mathrm{OH}^{-} \text {levels will always be } \\
\text { much less than sulfate levels } \\
\text { below pH 9 }\end{array}$ & $\begin{array}{l}\text { At pH } 8\left[\mathrm{OH}^{-}\right]=10^{-6} \mathrm{~mol} / \mathrm{L} \\
\text { At pH } 2.4\left[\mathrm{OH}^{-}\right]=2.5 \times 10^{-12} \mathrm{~mol} / \mathrm{L}\end{array}$ \\
\hline $\begin{array}{l}\mathrm{HSO}_{4}^{-} \text {can be neglected in } \\
\text { the charge balance }\end{array}$ & $\begin{array}{l}\mathrm{HSO}_{4}^{-} \text {only exceeds } \mathrm{SO}_{4}{ }^{2-} \\
\text { levels below pH } 2\end{array}$ & $\begin{array}{l}\text { At pH } 8\left[\mathrm{HSO}_{4}{ }^{-}\right]=10^{-9} \mathrm{~mol} / \mathrm{L} \\
\text { At pH } 2.4\left[\mathrm{HSO}_{4}^{-}\right]=4 \times 10^{-4} \mathrm{~mol} / \mathrm{L}\end{array}$ \\
\hline
\end{tabular}

Given a value of $\mathrm{X}=0.176(10 \%$ of reacted Fe become surface sites - a lower end value for goethite, Table 4-10) - for dissolution of 1 mole of Carbon Steel Type A516 into a near-neutral solution: $n=2\left[\mathrm{SO}_{4}{ }^{2-}\right]+\left[\mathrm{H}_{2} \mathrm{PO}_{4}{ }^{-}\right]+2\left[\mathrm{HPO}_{4}{ }^{-2}\right]+\left[\mathrm{HCO}_{3}{ }^{-}\right]+\left[>\mathrm{Fe}-\mathrm{O}^{-}\right]+\left[>\mathrm{Fe}-\mathrm{CO}_{3}{ }^{-}\right]-[>\mathrm{Fe}-\mathrm{O}-$ $\mathrm{H}_{2}^{+}$. Similarly, charge balance for a solution in contact with carbon dioxide gas at $0.001 \mathrm{~atm}$ and into which 1 mole of Carbon Steel Type A516 were dissolved would be:

$$
\begin{gathered}
{\left[\mathrm{H}^{+}\right]+\left[>\mathrm{Fe}-\mathrm{O}-\mathrm{H}_{2}^{+}\right]=2\left[\mathrm{SO}_{4}^{-2}\right]+\left[\mathrm{H}_{2} \mathrm{PO}_{4}^{-}\right]+2\left[\mathrm{HPO}_{4}^{-2}\right]} \\
+\left[\mathrm{HCO}_{3}^{-}\right]+\left[>\mathrm{Fe}-\mathrm{O}^{-}\right]+\left[>\mathrm{Fe}-\mathrm{CO}_{3}{ }^{-}\right]
\end{gathered}
$$

The two phosphate terms can be manipulated with the equilibrium constant for their conversion to give: $\left[\mathrm{H}_{2} \mathrm{PO}_{4}{ }^{-}\right]=0.00113 /\left(1+10^{-7.2} /\left[\mathrm{H}^{+}\right]\right)$and $\left[\mathrm{HPO}_{4}^{-2}\right]=0.00113\left(1-1 /\left(1+10^{-7.2} /\left[\mathrm{H}^{+}\right]\right)\right)$. 
Similarly, mass action expressions for $\left[\mathrm{OH}^{-}\right]+\left[\mathrm{HCO}_{3}^{-}\right]$can be manipulated to show that they are equal to $10^{-14} /\left[\mathrm{H}^{+}\right]$and $10^{-7.82} \mathrm{pCO}_{2} /\left[\mathrm{H}^{+}\right]$, respectively (DTN: MO0302SPATHDYN.000). Substituting these expressions, carbonate equilibrium constants, the surface equilibria above, and rearranging to solve for $\mathrm{pH}$ gives:

$$
\begin{gathered}
{\left[\mathrm{H}^{+}\right]=0.00218+0.00113 /\left(1+10^{-7.2} /\left[\mathrm{H}^{+}\right]\right)+0.00226\left(1-1 /\left(1+10^{-7.2} /\left[\mathrm{H}^{+}\right]\right)\right)+} \\
10^{-14} /\left[\mathrm{H}^{+}\right]+10^{-7.82} p \mathrm{CO}_{2} /\left[\mathrm{H}^{+}\right]+[>\mathrm{Fe}-\mathrm{O}-\mathrm{H}]\left(10^{-8.93} /\left[\mathrm{H}^{+}\right]+\right. \\
\left.p \mathrm{CO}_{2} 10^{-5.36} /\left[\mathrm{H}^{+}\right]-10^{7.29}\left[\mathrm{H}^{+}\right]\right)
\end{gathered}
$$

where, because of surface site mole balance, the site master species concentration $[>\mathrm{Fe}-\mathrm{O}-\mathrm{H}]$ can be approximated by:

$$
[>\mathrm{Fe}-\mathrm{O}-\mathrm{H}]=0.176 /\left(1+10^{-8.93} /\left[\mathrm{H}^{+}\right]+p \mathrm{CO}_{2} 10^{-5.36} /\left[\mathrm{H}^{+}\right]+10^{7.29}\left[\mathrm{H}^{+}\right]\right)
$$

The equations above can be solved for $\mathrm{pH}$ as a function of fixed partial pressure of $\mathrm{CO}_{2}$ (Table 6-21). These $\mathrm{pH}$ calculations are insensitive to the number of moles of Carbon Steel Type A516 that corrodes per $\mathrm{kg}$ of water as long as corrosion exceeds 0.1 moles per $\mathrm{kg}$ of water. This is the case for each Carbon Steel Type A516 corrosion calculation in this report.

Table 6-21. Calculated pH Values as a Function of $\mathrm{fCO}_{2}$

\begin{tabular}{|c|c|}
\hline $\begin{array}{c}\mathrm{Log}_{(\mathbf{f t m})} \\
\mathbf{f} \mathrm{CO}_{2}\end{array}$ & $\mathbf{p H}$ \\
\hline-5.0 & 8.1 \\
\hline-4.5 & 8.1 \\
\hline-4.0 & 8.0 \\
\hline-3.5 & 7.9 \\
\hline-3.0 & 7.7 \\
\hline-2.5 & 7.5 \\
\hline-2.0 & 7.3 \\
\hline-1.5 & 7.0 \\
\hline
\end{tabular}

To simplify the calculation, adsorption of phosphate, uranium, nickel, chromate, sulfate, and other sorbates was neglected. Under favorable conditions, these sorbates, if abundant, could have a noticeable impact on the final $\mathrm{pH}$ values calculated. As a check on the potential effects of these sorbates, surface complexation reactions involving the entire database in Table 4-9 are performed in Section 6.8.

The greater the number of surface sites the greater is the tendency for surface reactions to resist acid production from the steel and instead to maintain the $\mathrm{pH}$ near 7.6 (for dissolution of 1 mole of Carbon Steel Type A516 to produce a $\mathrm{pH}$ below 7 at $p \mathrm{CO}_{2}=0.001$ atm requires fewer than $1.5 \%$ of the Fe sites to be exposed). The calculations above were done without activity corrections for aqueous or surface species - so they are somewhat approximate. Nevertheless, they suggest that degradation of Carbon Steel Type A516 will result in solution $\mathrm{pH}$ values close to 7 to 8 because of corrosion product surface chemistry. The output $\mathrm{pH}$ values shown in 
Table 6-21 depend simply on interaction of produced acidity with near-neighbor Fe sites and not transport and mixing of fluids.

The effect of corrosion products on the $\mathrm{pH}$ of the in-package environment is a first order process that the surface complexation model provides as input to TSPA-LA. The above discussion addresses the subject matter of "Included" FEPs 2.1.09.02.0A (Chemical interaction with corrosion products) and 2.1.09.01.0B (Chemical characteristics of water in waste package) and indicates how that subject matter has been included and addressed within TSPA-LA.

\subsection{2 pH Buffering During Dissolution of Stainless Steel, Fuel, and HLWG}

Over time periods greater than a thousand years, the primary reactions affecting $\mathrm{pH}$ are dissolution of Stainless Steel Types 316 and 304L, in CDSP packages, stainless steel, spent fuel and alteration products (schoepite) and, in codisposal packages, HLWG. Simplified dissolution reactions for each are written below. Minor components have been left out of the respective compositions. The approximated compositions provide a sufficiently clear picture of the degree to which each reaction affects proton balances in solution. $\mathrm{SiO}_{2}$ refers either to aqueous silica or silica solid (e.g., chalcedony).

\section{Schoepite}

$p H \leq 5.5$

$$
\begin{array}{cc}
\boldsymbol{p H} \leq \mathbf{5 . 5} & \mathrm{UO}_{3} \cdot 2 \mathrm{H}_{2} \mathrm{O}+2 \mathrm{H}^{+} \leftrightarrow \mathrm{UO}_{2}{ }^{2+}+3 \mathrm{H}_{2} \mathrm{O} \\
\boldsymbol{p H}>\text { 7-7.5 } & \mathrm{UO}_{3} \cdot 2 \mathrm{H}_{2} \mathrm{O}+3 \mathrm{HCO}_{3}{ }^{-} \leftrightarrow \mathrm{UO}_{2}\left(\mathrm{CO}_{3}\right)_{3}{ }^{4-}+\mathrm{H}^{+}+3 \mathrm{H}_{2} \mathrm{O}
\end{array}
$$

NOTE: Schoepite stability for $5.5 \leq \mathrm{pH} \leq 7-7.5$ is dependent on $\mathrm{fCO}_{2}$.

\section{Stainless Steel Type 304L}

$$
\boldsymbol{p H} \leq \mathbf{6 . 5} \begin{gathered}
\mathrm{Fe}_{1.22} \mathrm{Cr}_{0.365} \mathrm{Ni}_{0.17} \mathrm{Si}_{0.0267} \mathrm{Mn}_{0.0364}+1.6106 \mathrm{O}_{2}+0.805 \mathrm{H}_{2} \mathrm{O} \rightarrow \\
1.22 \mathrm{FeOOH}+0.365 \mathrm{HCrO}_{4}{ }^{-}+0.17 \mathrm{Ni}^{2+}+ \\
0.0267 \mathrm{SiO}_{2}+0.0364 \mathrm{MnO}_{2}+0.025 \mathrm{H}^{+}
\end{gathered}
$$

$\boldsymbol{p H}>\mathbf{6 . 5} \quad \mathrm{Fe}_{1.22} \mathrm{Cr}_{0.365} \mathrm{Ni}_{0.17} \mathrm{Si}_{0.0267} \mathrm{Mn}_{0.0364}+1.6106 \mathrm{O}_{2}+0.805 \mathrm{H}_{2} \mathrm{O} \rightarrow$

$$
\begin{gathered}
1.22 \mathrm{FeOOH}+0.365 \mathrm{CrO}_{4}{ }^{2-}+0.17 \mathrm{Ni}^{2+}+ \\
0.0267 \mathrm{SiO}_{2}+0.0364 \mathrm{MnO}_{2}+0.39 \mathrm{H}^{+}
\end{gathered}
$$

\section{Stainless Steel Type 316}

$$
\begin{array}{r}
\boldsymbol{p H} \leq \mathbf{6 . 5} \mathrm{Fe}_{1.17} \mathrm{Ni}_{0.2} \mathrm{Cr}_{0.33} \mathrm{Mo}_{0.03} \mathrm{Si}_{0.03}+1.5475 \mathrm{O}_{2}+0.745 \mathrm{H}_{2} \mathrm{O}+0.01 \mathrm{H}^{+} \rightarrow \\
1.17 \mathrm{FeOOH}+0.03 \mathrm{SiO}_{2}+0.2 \mathrm{Ni}^{2+}+0.33 \mathrm{HCrO}_{4}^{-}+0.03 \mathrm{MoO}_{4}^{2-}
\end{array}
$$

$$
p H>6.5
$$

$\mathrm{Fe}_{1.17} \mathrm{Ni}_{0.2} \mathrm{Cr}_{0.33} \mathrm{Mo}_{0.03} \mathrm{Si}_{0.03}+1.5475 \mathrm{O}_{2}+0.745 \mathrm{H}_{2} \mathrm{O} \rightarrow$

$$
1.17 \mathrm{FeOOH}+0.03 \mathrm{SiO}_{2}+0.2 \mathrm{Ni}^{2+}+0.33 \mathrm{CrO}_{4}{ }^{2-}+0.03 \mathrm{MoO}_{4}{ }^{2-}+0.32 \mathrm{H}^{+}
$$




\section{HLWG}

$$
\begin{gathered}
\mathrm{Na}_{0.577} \mathrm{Si}_{0.776} \mathrm{~B}_{0.291} \mathrm{O}_{2.277}+0.577 \mathrm{H}^{+}+0.148 \mathrm{H}_{2} \mathrm{O} \rightarrow \\
0.577 \mathrm{Na}^{+}+0.776 \mathrm{SiO}_{2}+0.291 \mathrm{~B}(\mathrm{OH})_{3}
\end{gathered}
$$

Schoepite and iron corrosion products dominate the composition of the alteration products from time periods of 500 years and beyond, and the schoepite dissolves at acid $\mathrm{pH}$ to consume protons and at above neutral $\mathrm{pH}$ to produce protons. These two reactions, thus, constitute a negative feedback that resists $\mathrm{pH}$ excursions to high or low $\mathrm{pH}$, and ultimately anchors $\mathrm{pH}$ values near the schoepite solubility minimum - $\mathrm{pH} 6.5$ to 7, depending on the ambient carbon dioxide pressure. The EQ6 output supports the buffering of the $\mathrm{pH}$ near-neutral by schoepite, see for example comp1, comp2, and comp3 in Figure 6-5.

Considering the steels and glass in isolation from the schoepite points to another mechanism by which alkalinity increases from HLWG dissolution are resisted - namely that above $\mathrm{pH} 6.5 \mathrm{Cr}$ oxidizes to $\mathrm{CrO}_{4}{ }^{2-}$, whereas below it forms $\mathrm{HCrO}_{4}{ }^{-}$. This means that the ambient $\mathrm{pH}$ has an important effect on proton production by steel degradation. Specifically, at $\mathrm{pH} \leq 6.5$, steel degradation either consumes protons or produces relatively small amounts of them, whereas, at $\mathrm{pH}>6.5$, degradation of Stainless Steel Types 304L and 316 produces relatively large amounts of protons. This has the effect of anchoring $\mathrm{pH}$ values close to 6.5 and consuming proton consumption by glass degradation. Equilibrium surface reactions will also buffer $\mathrm{pH}$ (e.g., $>\mathrm{Fe}-\mathrm{OH}=>\mathrm{Fe}-\mathrm{O}^{-}+\mathrm{H}^{+}$and $>\mathrm{Fe}-\mathrm{HCO}_{3}=>\mathrm{Fe}-\mathrm{CO}_{3}{ }^{-}+\mathrm{H}^{+}$).

The fact that proton consumption prevails at $\mathrm{pH} \leq 6.5$, but proton production amplifies above $\mathrm{pH}$ 6.5, indicates long-term $\mathrm{pH}$ values will converge towards 6.5 as long as sufficient steel and HLWG exists in the package. There is over twice as much Stainless Steel Type 316 as HLWG and roughly 20\% more Stainless Steel Type 304L than HLWG. Roughly an order of magnitude increase in the HLWG/ Stainless Steel Type 304L + Stainless Steel Type 316 ratio (or a similar increase in the HLWG dissolution rate from the most probable value) would have to occur for HLWG dissolution to result in $\mathrm{pH}$ values greater than neutral. And this doubtful scenario would then have to somehow prevent the resulting water from coming into contact with schoepite in the package-which would also drive $\mathrm{pH}$ values back towards neutral. This makes a "HLWG only, no steel, no fuel" scenario able to produce high $\mathrm{pH}$ values highly unlikely. The most reasonable high-end $\mathrm{pH}$ for packages containing HLWG is, therefore, 6.5 to 7 . FeOOH corrosion products will also be abundant in codisposal packages, both from steel degradation and from the earlier dissolution of the Carbon Steel Type A516.

To summarize, over the first hundred years when the degraded waste form consists primarily of Carbon Steel Type A516 corrosion products and intact fuel, $\mathrm{pH}$ values will be held to near neutral by the surface properties of the corrosion products (the most abundant proton donor or acceptor in the package). Over longer time periods, when the degraded waste form will consist of schoepite, dissolving steels, and possibly HLWG, the $\mathrm{pH}$ will be anchored near neutral by dissolution reactions of schoepite and steel which consume protons at acidic $\mathrm{pH}$ and release them at alkaline $\mathrm{pH}$ values. Extremely unlikely scenarios involving degradation of individual components are required to overcome the intrinsic capacity of the degraded waste form to control its ambient $\mathrm{pH}$ to near neutral. 


\subsubsection{Temperature}

Temperature affects surface equilibria, aqueous speciation, and dissolution rates and for this reason might be expected to affect $\mathrm{pH}$ excursion limits (maximum and minimum $\mathrm{pH}$ ). In the absence of a schoepite solubility model, it is unreasonable to speculate about the location of the high temperature schoepite solubility minimum. The $\mathrm{pH}_{\mathrm{zpc}}$ of hematite changes from roughly 9.1 to 7.7 (with a temperature shift of $5^{\circ} \mathrm{C}$ to $75^{\circ} \mathrm{C}$ ) (Stumm 1992 [DIRS 141778], p. 76), which suggests a downward $\mathrm{pH}$ shift of possibly 1.5 units in goethite surface equilibria with an increase in temperature from $25^{\circ} \mathrm{C}$ to $90^{\circ} \mathrm{C}$. Site densities might decrease if higher temperatures favor formation of lower surface area materials. There are not enough high temperature surface chemistry data to advance more than a qualitative model for corrosion product surface behavior at higher temperatures.

The $\mathrm{pH}$ below which steel dissolves to $\mathrm{HCrO}_{4}{ }^{-}$, and above which it dissolves to $\mathrm{CrO}_{4}{ }^{2-}$, is 6.5 at $25^{\circ} \mathrm{C}, 6.7$ at $50^{\circ} \mathrm{C}$, and 6.9 at $100^{\circ} \mathrm{C}$. Higher temperatures might, therefore, be expected to raise the upper-limit basic-pH range due to HLWG dissolution to $\sim 7$.

The above discussion addresses the thermal effects on chemistry portion of the subject matter of "Included" FEP 2.1.11.08.0A (Thermal effects on chemistry and microbial activity in the EBS) and indicates how that subject matter has been included and addressed within TSPA-LA. The microbial activity in the EBS subject matter is described in FEP 2.1.10.01.0A and documented in Engineered Barrier System Features, Events, and Processes (BSC 2004 [DIRS 169898]).

\subsection{SURFACE COMPLEXATION DEMONSTRATION}

The effects of ferric (hydr)oxide surfaces on $\mathrm{pH}$, as defined in Section 6.7, are demonstrated in this section using PHREEQC version 2.3. PHREEQC is a USGS geochemical code that has the capability of performing surface complexation reactions in aqueous systems.

The purpose of the PHREEQC surface complexation calculations in this section is to build confidence in the analytical model developed in Section 6.7. Additional complexity in surface complexation calculations is afforded by PHREEQC due to its ability to include effects of surface charge, ionic strength, and a much larger assortment of surface complexation reactions. However, as the calculations demonstrate, this increased complexity does not result in $\mathrm{pH}$ predictions that are largely different from those made by the simplified analytical model in Section 6.7. Unlike the results of the analytical model, the PHREEQC calculations are not passed on to TSPA-LA.

Surface complexation calculations are calculations of equilibrium adsorption reactions. Similar to aqueous reactions, each adsorption reaction is represented by a specific chemical reaction and an associated equilibrium constant. The primary difference between aqueous reactions in bulk water and adsorption reactions is that surface sites have fixed locations and densities relative to one another. As a result, adsorption and desorption of protons and other ions from these sites cause the surface to take on an electrostatic charge, which in turn, affects the behavior of nonadsorbed ions in the vicinity of the surface. Therefore, equilibrium surface complexation calculations incorporate equations that simulate the effects of surface charge. 
The particular surface complexation model chosen for these calculations is Dzombak and Morel's (1990 [DIRS 105483], Chapter 2) generalized two-layer model, which is based on the Gouy-Chapman theory of the electrical double layer. In this model there is one layer associated with the surface charge (affected by site-specific adsorption) and a diffuse layer between the surface layer and the bulk solution that contains counter-charged ions. Details of the mathematical representation of surface effects are provided by Dzombak and Morel (1990 [DIRS 105483], Chapter 2) and the PHREEQC 2.3 user manual (BSC 2001 [DIRS 154877]).

The surface complexation calculations presented below require several inputs. These inputs include a thermodynamic database (Section 6.8.1), surface properties (Section 6.8.2), and initial water and gas compositions (Section 6.8.3). Results of this demonstration are presented in Section 6.8.4.

\subsubsection{Surface Complexation Reaction Databases}

The surface complexation database was taken primarily from Dzombak and Morel (1990 [DIRS 105483]) that develops and documents a broad, self-consistent database of surface complexation reactions for hydrous ferric oxide (HFO) based on the generalized two-layer model. Two additional reactions for carbonate adsorption are included in work by Appelo et al. (2002 [DIRS 168168]). These reactions were derived by Appelo et al. (2002 [DIRS 168168]) to be consistent with the Dzombak and Morel (1990 [DIRS 105483]) database.

In this report, two variations of this database are used for the surface complexation calculations. One database is YMP_R3.dat developed in Section 6.3.2.1 and documented in DTN: MO0403SPAYMPR3.000. The other database, YMP_R3mr.dat, is identical to the first, but it includes all reactions in Table 6-14, which are estimated using linear free-energy relationships. These estimated reactions are of sufficient accuracy for the intended use of the surface complexation calculations in this report.

For YMP_R3mr.dat, all reactions from Table 6-14 were entered exactly as displayed, with the exception of arsenite and silica. To conform to the PHREEQC representation of the uncharged aqueous arsenite species $\left(\mathrm{HAsO}_{2}\right)$, the arsenite adsorption reaction was changed to:

$$
\mathrm{HFO} \_w O H+\mathrm{HAsO}_{2}=\mathrm{HFO} \_\mathrm{wH}_{2} \mathrm{AsO}_{3}
$$

The $\log \mathrm{K}$ for this reaction was not changed because addition of $\mathrm{H}_{2} \mathrm{O}$ to both sides of the equation has a negligible effect on the $\log \mathrm{K}$ at ionic strengths below 1 molal. In addition, because the PHREEQC database does not include $\mathrm{a} \mathrm{SiO}_{3}{ }^{2-}$ aqueous species, the silica adsorption reactions were changed to:

$$
\mathrm{HFO} \_\mathrm{wOH}+\mathrm{SiO}_{2}=\mathrm{HFO}_{-} \mathrm{wSiO}_{3^{-}}+\mathrm{H}+
$$

and

$$
\mathrm{HFO} \_\mathrm{wOH}+\mathrm{SiO}_{2}+\mathrm{H}_{2} \mathrm{O}=\mathrm{HFO}_{-} \mathrm{wOHSiO}_{3}{ }^{2-}+2 \mathrm{H}+
$$

with $\log \mathrm{K}$ values of -7.06 and -14.66 , respectively. These reactions and $\log \mathrm{K}$ values were calculated by combining the silica reactions from Table 6-14. 


\subsubsection{Surface Properties}

As presented in Section 6.7, goethite is the representative iron product of each steel corrosion reaction. Because goethite is a major product of these reactions and it has a relatively large surface area and adsorption site density, goethite is the surface used in the surface complexation calculations. The rationale for using goethite surface areas in combination with the HFO thermodynamic database is discussed in detail in Sections 6.3.2, 6.6.11, and 6.7.

The surface properties of goethite are provided in Table 4-10. Multiplying the site concentration of $0.00135 \mathrm{~mol} / \mathrm{g}$ by the molecular weight of goethite $(88.85 \mathrm{~g} / \mathrm{mol})$ gives a site concentration of $0.120 \mathrm{~mol} / \mathrm{mol}$ of goethite. This site concentration is equivalent to a specific surface area of $49 \mathrm{~m}^{2} / \mathrm{g}$ with a specific site density of $16.6 \mathrm{sites} / \mathrm{nm}^{2}$ as well as equivalent to a specific surface area of $160 \mathrm{~m}^{2} / \mathrm{g}$ with a specific site density of $5 \mathrm{sites} / \mathrm{nm}^{2}$. These values largely span the general ranges listed in Table 4-10 for these parameters. For the calculations below, the lower value of $49 \mathrm{~m}^{2} / \mathrm{g}$ specific surface area is used to be conservative.

Between 10 and 40 moles of ferric (hydr)oxides are calculated to form per kilogram of water (Section 6.3.2). For the calculations presented below, the molality of goethite is set at 10 moles per $\mathrm{kg}$ water, though thin film conditions could lead to much higher molalities. Multiplying this molality by the molecular weight of goethite implies approximately 900 grams of goethite per $\mathrm{kg}$ water, a value used in the PHREEQC input files to quantify the abundance of the adsorbent. Multiplying this value by the site concentration from Table 4-10 in Section 6.3.2 $(0.00135 \mathrm{~mol} / \mathrm{g})$ gives a surface site molality of 1.2 . Because the database (Dzombak and Morel 1990 [DIRS 105483]) divides the total number of sites into strong and weak sites, whereby the concentration of strong sites is $2.5 \%$ of the weak site concentration, the molalities of weak and strong sites were set at 1.2 and 0.03 , respectively.

The only other surface parameter needed for the PHREEQC runs is the electric double layer thickness. This was estimated by solving Equation 2.4 in Surface Complexation Modeling, Hydrous Ferric Oxide (Dzombak and Morel 1990 [DIRS 105483], p. 12) for 1/ $\kappa$, the double-layer thickness (in meters):

$$
1 / \kappa=\sqrt{\frac{\varepsilon \varepsilon_{o} R T}{2 F^{2} I \cdot 10^{3}}}
$$

where, $\varepsilon$ is the dielectric constant of water $(78.5$, p. 12$), \varepsilon_{0}$ is the permittivity of free space (8.853E-12 C/V-m, p.12), $\mathrm{R}$ is the universal gas constant $(8.314 \mathrm{~J} / \mathrm{mol}-\mathrm{K}$; Dzombak and Morel 1990 [DIRS 105483], p.12), T is the temperature $(298.13 \mathrm{~K}), \mathrm{F}$ is the Faraday constant (96,485 C/mol, p.11), and I is the ionic strength in molarity. Ionic strength in these calculations is on the order of $0.01 \mathrm{~mol} / \mathrm{L}$. Thus, the double layer thickness is on the order of $3 \times 10^{-9} \mathrm{~m}$. This value was held constant for all runs because its effect on the calculated final $\mathrm{pH}$ is very small compared to uncertainties in other parameters, such as the total site concentration. 


\subsubsection{Water and Gas Compositions}

A total of four water compositions were equilibrated with the goethite surface, each at three different fugacities of carbon dioxide: $10^{-1.5}, 10^{-3.0}$, and $10^{-5.0}$ bar. The four water compositions came from DTN: MO0403SPAIPCHM.004 and include:

- Seepage water reacted with CSNF at 35 years (C31J25)

- Distilled water reacted with CSNF at 35 years (CS_comp3)

- Seepage water reacted with codisposal package at 60 years (D23N25)

- Distilled water reacted with codisposal package at 54 years (CD_comp7).

These compositions are summarized in SCM modeling summary.xls, Appendix F. The initial $\mathrm{pH}$ values of these waters are listed in Table 6-22. These values are low because they represent the effects of corrosion of Carbon Steel Type A516 and ignore the effects of surface complexation. Only those components whose concentrations exceeded 1.00E-08 molal were included in the simulations, with the exception of Fe that was always included regardless of its concentration. Components with total concentrations below 1.00E-08 molal have negligible effects on $\mathrm{pH}$ in these waters.

Table 6-22. Initial pH of Waters Prior to Surface Complexation Calculations

\begin{tabular}{|l|c|c|c|}
\hline \multicolumn{1}{|c|}{ Water } & Model & Year & pH \\
\hline C31J25 & Water Influx & 35 & 3.29 \\
\hline CS_comp3 & Vapor Influx & 35 & 3.29 \\
\hline D23N25 & Water Influx & 60 & 4.70 \\
\hline CD_comp7 & Vapor Influx & 54 & 3.34 \\
\hline
\end{tabular}

Source: Appendix $\mathrm{F}$

(Surface_Complexation_initial_water_ comps3.xls).

\subsubsection{Surface Complexation Calculations}

The surface complexation calculations were performed using the inputs in Sections 6.8.1 through 6.8.3 and several mineral constraints. Consistent with Table 6-13, gibbsite, hematite, and pyrolusite were allowed to precipitate to saturation. The surface complexation model uses the site concentrations for HFO, which is justified in Section 6.7, but the model demonstration precipitates hematite in order to be consistent with the EQ6 model. Section 6.6.11 examines the impact of forming hematite versus goethite. In addition, calcite and $\mathrm{PuO}_{2}$ (hydr,aged) were allowed to precipitate to saturation. Calcite only precipitated in the D23N25 seepage run at 60 years and at $f \mathrm{CO}_{2}$ of $10^{-1.5}$. The only mineral allowed to dissolve was schoepite that was allowed to dissolve to saturation due to its abundance in the waste packages. Because the molalities of the various phases forced to saturation were low compared to the surface site molalities, the predicted $\mathrm{pH}$ values were insensitive to the minerals allowed to precipitate (e.g., $\mathrm{PuO}_{2}, \mathrm{PuO}_{2}$ (hydr, aged), boltwoodite-Na).

The $\mathrm{pH}$ values resulting from the surface complexation calculations are presented in Table 6-23. The $\mathrm{pH}$ values not in parentheses were calculated using the YMP_R3mr.dat database, which contains all surface complexation reactions in Table 4-9 and Table $\overline{6}-14$. Those in parentheses 
were calculated using the YMP_R3.dat database developed in Section 6.3.2 and documented in DTN: MO0403SPAYMPR3.000. These runs and the YMP_R3mr.dat database are documented in Appendix F (PHREEQC files).

The $\mathrm{pH}$ values of the initial waters in Table 6-22 are for waters in equilibrium with a fugacity of carbon dioxide of $10^{-3}$ bars. As a result, the effects of surface complexation are best evaluated by comparing these $\mathrm{pH}$ values with the $\mathrm{pH}$ values in the " $10^{-3.0}$ bars $\mathrm{CO}_{2}$ " column in Table 6-23. The 3.3 to 4.7 range of initial $\mathrm{pH}$ values (Table 6-22) is buffered by surface complexation reactions to a $\mathrm{pH}$ range of approximately 7.1 to 8.3 (Table 6-23). There are two reasons for this effect. First, the surface acts as a pH buffer (Section 6.7), and second, the surface sites have a very high concentration per mass of water (Section 6.8.2). The low $\mathrm{pH}$ values of the initial waters in Table 6-20 should never exist because corrosion of the steel is accompanied by the generation of iron (hydr)oxide corrosion products that counteract the acidity generated by corrosion.

$\mathrm{pH}$ values increase with decreasing $\mathrm{CO}_{2}$ fugacity and decrease with increasing $\mathrm{CO}_{2}$ fugacity, as predicted in Table 6-21. Based on the results using the expanded YMP_R3mr.dat database, at $10^{-1.5}$ bars the $\mathrm{pH}$ is calculated to fall as low as about 6.5 , while at $10^{-5.0}$ bars, it increases to a maximum around 9.0, depending on the waste package type and initial water composition. The abridged YMP R3.dat database calculations give a slightly different $\mathrm{pH}$ range of 6.4 to 8.2 . The similarity in the $\mathrm{pH}$ values predicted by each database suggests that the abridged database contains the generally dominant surface complexation reactions.

The differences between the YMP_R3.dat and YMP_R3mr.dat $\mathrm{pH}$ calculations are due to the expanded surface complexation database in $Y M P \bar{R} 3 m r$.dat. The additional adsorbates in YMP R3mr.dat are $\mathrm{Ba}^{2+}, \mathrm{Co}^{2+}, \mathrm{Hg}^{2+}, \mathrm{Mg}^{2+}, \mathrm{Mn}^{2+}, \mathrm{NpO}_{2}{ }^{2+}, \mathrm{PuO}_{2}{ }^{2+}, \mathrm{UO}_{2}{ }^{2+}, \mathrm{AsO}_{4}{ }^{3-}, \mathrm{AsO}_{3}{ }^{3-}, \mathrm{F}^{-}$, $\mathrm{PO}_{4}{ }^{3-}$, and $\mathrm{SiO}_{3}{ }^{2-}$. While the expanded database allows consideration of additional surface complexation reactions, the representations of these reactions in the database are not verified for accuracy, as are the surface complexation reactions in the abridged database $\left(Y M P \_\right.$R3.dat $)$.

The $\mathrm{pH}$ ranges predicted in these calculations and presented in Table 6-23 are slightly larger than the range predicted by the analytical model in Table 6-21. There are good reasons for this. First, the range in Table 6-23 covers four different corrosion fluids. Table 6-21 covers corrosion of Carbon Steel Type A516 only. Second, the analytic model neglected ionic strength corrections for the primary surface equilibria and ignored exchange of other sorbing ions for protons or hydroxyls, except for carbonate. However, the first-order agreement between the analytic and the full surface complexation model suggests that the primary mechanisms controlling $\mathrm{pH}$ are adequately captured in Table 6-21.

According to the results of the YMP_R3mr.dat calculations, the following adsorbates account for $1 \%$ or more of all surface species in at least one of the simulations: $\mathrm{H}^{+}, \mathrm{CO}_{3}{ }^{2-}, \mathrm{UO}_{2}{ }^{2+}, \mathrm{Ni}^{2+}$, $\mathrm{CrO}_{4}{ }^{2-}, \mathrm{Ca}^{2+}, \mathrm{PO}_{4}{ }^{3-}$, and $\mathrm{SO}_{4}{ }^{2-}$. Concentrations of adsorbed $\mathrm{UO}_{2}{ }^{2+}$ are always around $15 \%$ to $25 \%$ of the concentration of all surface species. Percentages of surface sites adsorbing $\mathrm{CO}_{3}{ }^{2-}$ are a strong function of $\mathrm{CO}_{2}$ fugacity. At $10^{-1.5}$ bars, around $50 \%$ to $60 \%$ of all surface sites involve $\mathrm{CO}_{3}{ }^{-2}$ adsorption. This percentage range drops to approximately $15 \%$ to $25 \%$ at $10^{-3.0}$ bars and to less than $1 \%$ at $10^{-5.0}$ bars. 
$\mathrm{UO}_{2}{ }^{2+}$ is the only adsorbate not included in YMP_R3.dat that is calculated to occupy at least $5 \%$ or more of the surface sites in the YMP R $3 m r$.dat calculations. Thus, $\mathrm{UO}_{2}{ }^{2+}$ adsorption may be largely responsible for the differences between the $\mathrm{pH}$ calculations within each cell in Table 6-23. This relationship can be assessed by suppressing only the $\mathrm{UO}_{2}{ }^{2+}$ adsorption reactions from the YMP_R3mr.dat database and rerunning the simulations. Suppression of $\mathrm{UO}_{2}{ }^{2+}$ adsorption has the important repercussion of reducing schoepite dissolution, which also affects $\mathrm{pH}$ (Section 6.7).

Table 6-23. Equilibrium pH Predicted in Surface Complexation Calculations

\begin{tabular}{|c|c|c|c|c|c|c|c|}
\hline Water & Model & Year & $\begin{array}{c}\log f \mathrm{fOO}_{2} \\
=10^{-1.5}\end{array}$ & $\begin{array}{l}\log f_{C} \mathrm{O}_{2} \\
=10^{-3.0}\end{array}$ & $\begin{array}{c}\log f \mathrm{fCO}_{2} \\
=10^{-5.0}\end{array}$ & $\begin{array}{c}\text { Input } \\
\text { Filenames }\end{array}$ & $\begin{array}{c}\text { Output } \\
\text { Filenames }\end{array}$ \\
\hline $\mathrm{C} 31 \mathrm{~J} 25$ & $\begin{array}{l}\text { Water } \\
\text { Influx }\end{array}$ & 35 & $\begin{array}{l}6.60 \\
(6.59)^{1}\end{array}$ & $\begin{array}{l}7.54 \\
(7.56)\end{array}$ & $\begin{array}{l}7.98 \\
(7.93)\end{array}$ & $\begin{array}{l}\operatorname{cs} 35-15 \\
\operatorname{cs} 35-30 \\
\operatorname{cs} 35-50\end{array}$ & $\begin{array}{l}\text { cs35-15.out } \\
\text { cs35-30.out } \\
\text { cs35-50.out }\end{array}$ \\
\hline CS_comp3 & $\begin{array}{l}\text { Vapor } \\
\text { Influx }\end{array}$ & 35 & $\begin{array}{l}6.49 \\
(6.45)\end{array}$ & $\begin{array}{l}7.16 \\
(7.37)\end{array}$ & $\begin{array}{l}7.53 \\
(7.69)\end{array}$ & $\begin{array}{l}\text { cd35-15 } \\
\text { cd35-30 } \\
\text { cd35-50 }\end{array}$ & $\begin{array}{l}\text { cd35-15.out } \\
\text { cd35-30.out } \\
\text { cd35-50.out }\end{array}$ \\
\hline D23N25 & $\begin{array}{l}\text { Water } \\
\text { Influx }\end{array}$ & 60 & $\begin{array}{l}7.05 \\
(6.96)\end{array}$ & $\begin{array}{l}8.06 \\
(7.95)\end{array}$ & $\begin{array}{l}8.31 \\
(8.17)\end{array}$ & $\begin{array}{l}\text { co60-15 } \\
\text { co60-30 } \\
\text { co60-50 }\end{array}$ & $\begin{array}{l}\text { co60-15.out } \\
\text { co60-30.out } \\
\text { co60-50.out }\end{array}$ \\
\hline CD_comp7 & $\begin{array}{l}\text { Vapor } \\
\text { Influx }\end{array}$ & 54 & $\begin{array}{l}7.11 \\
(6.96)\end{array}$ & $\begin{array}{l}8.24 \\
(7.85)\end{array}$ & $\begin{array}{l}9.05 \\
(8.16)\end{array}$ & $\begin{array}{l}\text { cod54-15 } \\
\text { cod54-30 } \\
\text { cod54-50 }\end{array}$ & $\begin{array}{l}\text { cod54-15.out } \\
\text { cod54-30.out } \\
\text { cod54-50.out }\end{array}$ \\
\hline
\end{tabular}

NOTE: ${ }^{1}$ Values in parentheses are calculated using the abridged YMP_R3.dat database. Preceding values are calculated using the expanded YMP_R3mr.dat database.

\subsection{APPLICATION OF SURFACE COMPLEXATION MODEL TO THE BATCH REACTOR MODEL RESULTS}

The surface complexation model is applied only to the CSNF model. Corrosion product surfaces represent an important $\mathrm{pH}$ buffer that tends to anchor $\mathrm{pHs}$ near neutral. Its effect is most important to consider when $\mathrm{pHs}$ are otherwise predicted to depart substantially from neutral. For this reason it was applied for CSNF calculations. The pHs of CDSP effluents are not predicted to be as extreme as those for the CSNF waste packages, so the explicit surface complexation calculation was not included in the model, although buffering of $\mathrm{pH}$ will certainly occur.

The low $\mathrm{pH}$ trend observed during the initial 600 years was caused by the dissolution of Carbon Steel Type A516 where sulfur contained in the steel was oxidized and formed sulfuric acid. This period is also characterized by the formation of ferric (hydr)oxide corrosion products, hematite was allowed to form in the simulations because of its long term stability. Runs where goethite was allowed to form are documented in Section 6.7 and show much the same behavior in the $\mathrm{pH}$ profile. It is during this period that the surface complexation model (Section 6.7) is applied in the $\mathrm{pH}$ abstraction.

Because the surface complexation effects are accounted for by modifying the $\mathrm{pH}$ after the batch reactor results are presented, there is no feedback from the surface complexation model to the batch reactor model. Therefore, the impact of the modified $\mathrm{pH}$ on the batch reactor runs must be examined. All of the metal alloys use linear corrosion rates which are unaffected by $\mathrm{pH}$. The $\mathrm{CSNF}$ rate law is a function of $\mathrm{pH}$ and tends toward lower values in the neutral $\mathrm{pH}$ range. 
During the first six hundred years, the period when the surface complexation model is employed, the CSNF total degradation rate, from Figure A-1, decreases from approximately $2 \mathrm{E}-13 \mathrm{~mol} / \mathrm{sec}-\mathrm{cm}^{2}$ at $\mathrm{pH} 4$ to $7 \mathrm{E}-14 \mathrm{~mol} / \mathrm{sec}-\mathrm{cm}^{2}$ at $\mathrm{pH} 7$, a decrease of less than a factor of three. Thus, a factor of three less CSNF would dissolve during the first six hundred years, and the total duration that CSNF would be present in the waste package would be extended. The influence on the chemistry of the system would be minimal because schoepite, the primary CSNF degradation product, would still form just in smaller quantities.

During the period when the surface complexation is implemented, the redox potential of the system will vary in accordance with the $\mathrm{pH}$ predicted by the surface complexation model. Section 6.10.6 derives Eh as a function of temperature, oxygen partial pressure, and $\mathrm{pH}$; thus, the $\mathrm{pH}$ predicted from the surface complexation model will be used to calculate the redox potential for the initial 600 years, and will likely be different from that displayed in the 0- to 600-year period in Figure 6-15. This raises the question whether the $\mathrm{pH}$ and Eh for the first six hundred years are different than displayed in Figure 6-15 will result in the same mineral assemblage under the new conditions. This question was investigated by using EQ6 and reducing the sulfur of the Carbon Steel Type A516 composition. Sulfur was identified as the cause of the observed $\mathrm{pH}$ low in the model output, and its removal, or use of more realistic sulfur oxidation states, would create a $\mathrm{pH}$ similar to that predicted by the surface complexation model.

The results of this exercise showed that during the 0 - to 200-year period when the Carbon Steel Type A516 was corroding, the system $\mathrm{pH}$ values varied between 5 and 8 . This is the same $\mathrm{pH}$ as was predicted by the surface complexation model (Section 6.7), and the same set of minerals form as did when the $\mathrm{pH}$ was controlled by the sulfur contained in the Carbon Steel Type A516. A plot of the minerals and the $\mathrm{pH}$ is provided in Appendix A, Figure A-10. This exercise lends confidence to the argument that although the batch reactor model and the surface complexation model are decoupled, the surface complexation model's effect on $\mathrm{pH}$ would not influence the corrosion product mineral assemblage. Furthermore, since the Eh is a function of $\mathrm{pH}$, and the $\mathrm{pH}$ shown in Figure A-10 is in the same range as that for the surface complexation model (Section 6.7), it follows that there is no impact on the Eh from the decoupling of the models.

These same concepts apply to the period when the surface complexation model is active. During this time, dissolved ions will complex with the surfaces of the ferric (hydr)oxides minerals and deviations in ionic concentrations in the bulk fluid for various input water compositions will be slight for elements that do not originate from in-package materials. Therefore, it is expected that the input water composition will have the same effect on the in-package chemistry with surface complexation as it does when surface complexation is not active.

The mineral assemblages for the base case and for the same base case with a $\mathrm{pH}$ moderated to a minimum of 4.5 (by using 10× less sulfur in the Carbon Steel Type A516) are shown in Figure 6-62 and Figure 6-63. All of the major minerals are the same. The only differences are the formation of small amounts of baddeleyite, $\mathrm{NpO}_{2}$, Barite, $\mathrm{Fe}_{2}\left(\mathrm{MoO}_{4}\right)_{3}$, and antlerite in the base case, which do not form in the $\mathrm{pH}$-moderated case. This comparison shows that the lack of feedback from the surface complexation model to the batch reactor model has minimal affect on the minerals that form. 


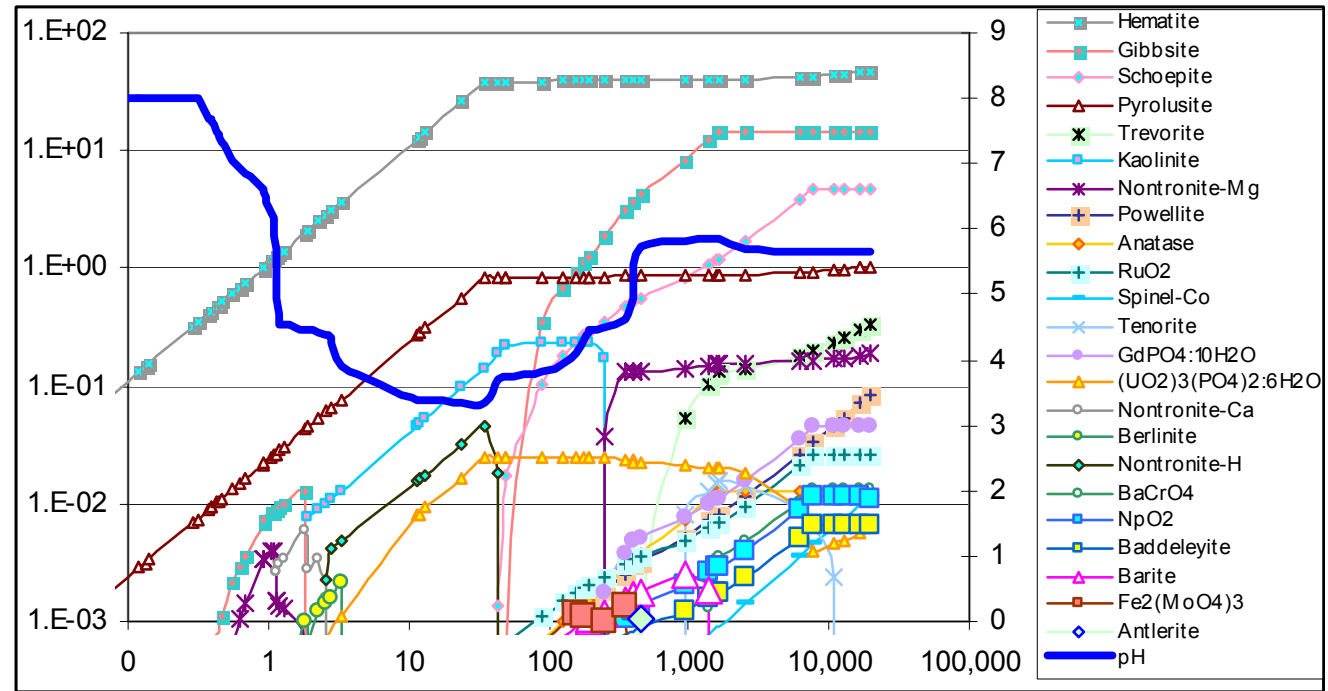

Source: Appendix F, CSNF_Low S in A516.x/s.

Figure 6-62. Mineral Assemblage for Base Case

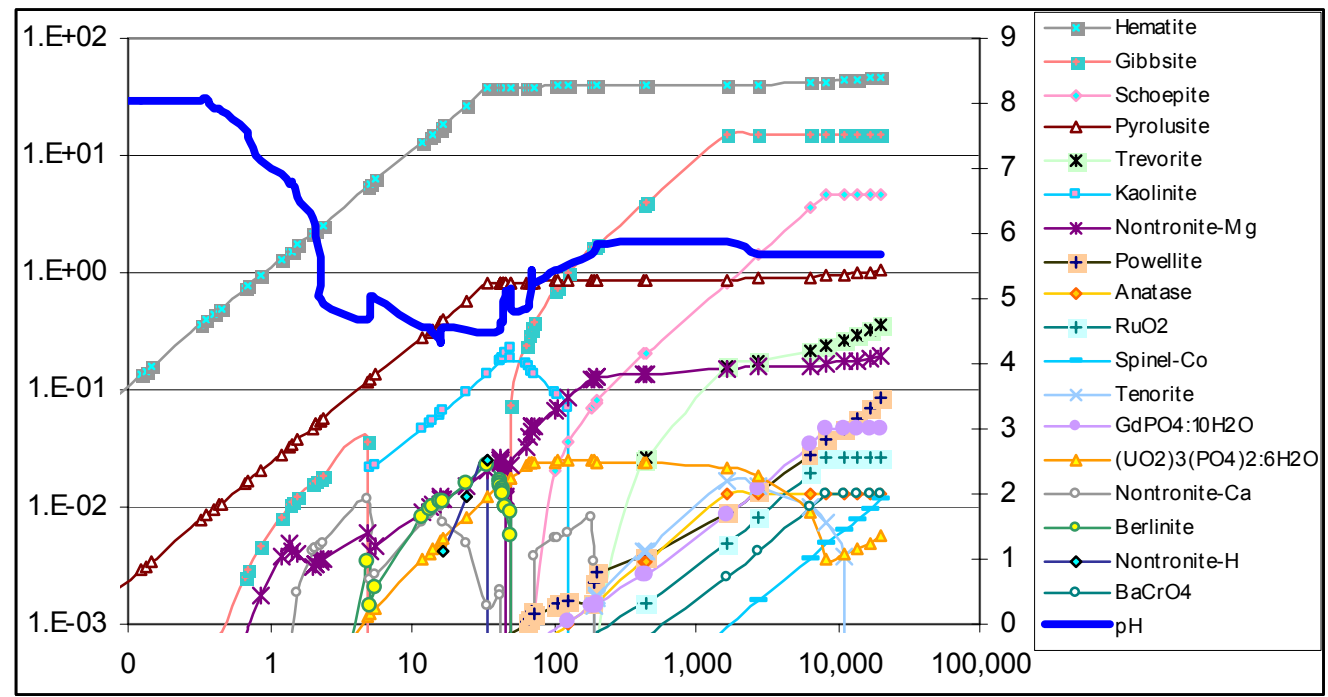

Source: Appendix F, CSNF_Low S in A516.x/s

Figure 6-63. Mineral Assemblage for Moderated pH Case

\subsection{MODEL ABSTRACTION}

The in-package chemistry model is activated within TSPA-LA once the waste package has been breached and the interior temperature of the waste package is below the boiling temperature of water. All references to time within this report refer to the time after waste package breach and after the waste package cools to $100^{\circ} \mathrm{C}$. The in-package chemistry model is applicable over the water volumetric flux (hereafter referred to as "flux") range from $0.15 \mathrm{~L} / \mathrm{yr}$ to $300 \mathrm{~L} / \mathrm{yr}$ per waste package, a temperature range from $25^{\circ} \mathrm{C}$ to $100^{\circ} \mathrm{C}$, a carbon dioxide partial pressure range of $10^{-5}$ to $10^{-1.5}$ atmospheres, and an oxygen partial pressure of 0.2 atmospheres. Spatially, the applicability of the in-package chemistry model is limited to the waste package interior. 
In the CSNF vapor influx model, there are no fluoride or chloride abstractions because these elements are not a constituent of the water vapor or in any of the waste package components. Therefore, only the $\mathrm{pH}$ and ionic strength are abstracted from the CSNF vapor influx model; the total carbonate and $\mathrm{Eh}$ are calculated as functions of $\mathrm{pH}$ and $f \mathrm{CO}_{2}$. The mapping of batch reactor cases to the abstractions is presented in Table 6-24.

Table 6-24. Mapping of Batch Reactor Cases to Abstractions

\begin{tabular}{|l|l|}
\hline \multicolumn{1}{|c|}{ Batch Reactor Cases } & \multicolumn{1}{c|}{ Developed Abstractions } \\
\hline CSNF Vapor Influx Case & $\mathrm{pH}$ and ionic strength \\
\hline CSNF Water Influx Case & $\mathrm{pH}$, ionic strength, fluoride and chloride concentrations \\
\hline CDSP Vapor Influx Case & $\mathrm{pH}$, ionic strength, and fluoride concentrations \\
\hline CDSP Water Influx Case & $\mathrm{pH}$, ionic strength, fluoride and chloride concentrations \\
\hline
\end{tabular}

NOTE: The CSNF waste package does not contain any $\mathrm{F}^{-}$or $\mathrm{Cl}^{-}$, so for the vapor influx case that condenses pure water onto the waste package materials, there are no $\mathrm{F}^{-}$or $\mathrm{Cl}^{-}$ abstractions. The CDSP waste package contains $\mathrm{F}^{-}$, but no $\mathrm{Cl}^{-}$.

\subsection{1 pH Abstractions}

As described in Sections 5.2, 6.3.2, and 6.7.1, the long-term condition of the surfaces of the waste package components is uncertain enough that the most realistic approach to anticipating in-package $\mathrm{pH}$ values is to simply allow it to vary between the limits set by the surface complexation model and batch reactor model, independent of time. However, Section 6.7.1 states that it is only appropriate to apply the surface complexation model for the first 600 years, thus making the model dependent on time, but this time dependence is only a function of when the surface complexation model is applied, and is not a function the time series $\mathrm{pH}$ values calculated by EQ3/6.

For the CSNF waste package, during the period when the surface complexation model is implemented ( 0 to 600 years), the $\mathrm{pH}$ ranges are defined by the surface complexation model as a function of the fugacity of carbon dioxide gas in Table 6-21. The maximum $\mathrm{pH}$ values for the 0- to 600-year period are the same as the values calculated in Section 6.7.1 (Table 6-21), no additional uncertainty was added because of schoepite buffering the upper end of the $\mathrm{pH}$ range (Section 6.8.2). Likewise, the minimum $\mathrm{pH}$ value should also correspond to the values in Table 6-21, however, to account for any uncertainty in when the surface complexation model might really be in effect, the $\mathrm{pH}$ minimum was set by the long-term $\mathrm{pH}$ minimum of 4.5. Applying a $\mathrm{pH}$ minimum of 4.5 for both the 0 -to-600-year time frame and the long term also accounts for the uncertainty associated with the steel and alloy corrosion rates. As shown in Figure 6-55, depending on the corrosion rates used, the $\mathrm{pH}$ minimum can occur anywhere between 10 and 1,000 years. This $\mathrm{pH}$ is also based on the $90^{\circ} \mathrm{C}$ simulation displayed in Figure 6-44, where for times greater than 600 years, $\mathrm{pH}$ stabilizes around 4.5. Allowing the $\mathrm{pH}$ to be sampled down to the long-term $\mathrm{pH}$ minimum is conservative, since it is lower than the $\mathrm{pH}$ minimum predicted by the surface complexation model. In addition, sampling the long-term $\mathrm{pH}$ minimum also removes any time dependence on the EQ6 results. As was discussed in Section 6.7.3, there is little surface chemistry data at high temperatures; however, the data that are available support the trend of decreasing $\mathrm{pH}$ with increased temperature observed in Figure 6-44. Each distribution should be uniformly sampled, $\mathrm{pH}$ values for intermediate values of $\log f \mathrm{CO}_{2}$ 
may be linearly interpolated between nearest neighbor values, and no uncertainty term should be added to the sampled value.

For the CSNF waste packages for the period from 600 to 20,000 years, the pH should be uniformly sampled between $\mathrm{pH} 4.5$ and 7. The $\mathrm{pH}$ minimum is based on the steel and alloy corrosion sensitivity (Section 6.6.10.1) which shows that the $\mathrm{pH}$ minimum can occur anywhere between 10 and 1,000 years (Figure 6-55). This $\mathrm{pH}$ minimum is supported by the long-term $\mathrm{pH}$ observed in Figure 6-44). The $\mathrm{pH}$ maximum of 7 is based on long-term $\mathrm{pH}$ observed for the higher water influx cases in Figure 6-40 and the low- $f \mathrm{O}_{2}$ case in Figure 6-38) with no additional uncertainty term added. Figure 6-40 shows that at very high water influx rates, the $\mathrm{pH}$ starts to increase to that of the incoming water at later times. However, the CSNF waste package contains enough schoepite to buffer the $\mathrm{pH}$ to 7 , even out to 20,000 years. Therefore, the CSNF $\mathrm{pH}$ is not dependent on the water influx rate.

For the CDSP waste package, the surface complexation model is not implemented, and the $\mathrm{pH}$ ranges for the entire regulatory timeframe should be uniformly sampled between a minimum and maximum $\mathrm{pH}$. The minimum $\mathrm{pH}$ is 4.5 (based on the long-term $\mathrm{pH}$ observed in Figure 6-46). The maximum $\mathrm{pH}$ is dependent on the water influx rate. As shown in Figure 6-42, at flow rates higher than $150 \mathrm{~L} / \mathrm{yr}$, the $\mathrm{pH}$ increases back towards that of the incoming water. Therefore, for low flow rates $(\mathrm{Q} \leq 150 \mathrm{~L} / \mathrm{yr})$, the maximum $\mathrm{pH}$ is 7.0 (Figure 6-39 for the low $f \mathrm{O}_{2}$ case), and for high flow rates $(\mathrm{Q}>150 \mathrm{~L} / \mathrm{yr}$ ), the $\mathrm{pH}$ maximum is that of the incoming water, 8.0 (based on Figure 6-42). The reason for the flux dependence is that at high flux values there is less opportunity for reactions to occur and the $\mathrm{pH}$ of the water more closely reflects the $\mathrm{pH}$ of the incoming water. There is no additional uncertainty term added.

The in-package chemistry is highly dependent on the waste package type; therefore, there is no correlation between CSNF and CDSP $\mathrm{pH}$ abstractions. Unlike the CSNF $\mathrm{pH}$ abstraction, the CDSP $\mathrm{pH}$ abstraction is dependent on water influx rate. The reason for this difference is that the surface complexation model is not applied to CDSP, and CDSP waste packages may not contain as much schoepite to buffer the $\mathrm{pH}$ as the CSNF waste packages do, especially the waste packages containing 5 HLWG canisters and no DOE SNF. Therefore, the CDSP $\mathrm{pH}$ abstraction extends up to that of the incoming water.

For naval waste packages that do not contain Carbon Steel Type A516 in their design, the expected $\mathrm{pH}$ profiles ( $\mathrm{pH}$ between 5 and 8) would be near those displayed in Figure 6-54.

\subsubsection{Ionic Strength Abstractions}

The ionic strength results predicted using the EQ6 model were based on water ratios that were adjusted to avoid exceeding the ionic strength limit of the aqueous model; thus, the ionic strength boundary condition was set by the model itself. Compounding this issue is the fact that at early times, the ratio of water to reactants is initially small and increases with time, so the ionic strength will initially be high and decrease with time as more water enters the system. Neither of these effects was captured in the EQ6 model, but is accounted for in the uncertainty treatment in Section 6.10.2.3. In contrast to the factors above, the ionic strengths predicted by EQ6 are likely to be high as the underlying calculations do not account for removal of dissolved salts from solution by corrosion product sorption or the lower oxidation state of chromium and other 
important materials in the waste package. However, the inability to predict the identities and abundances (hence site densities) of the corrosion products over long periods of time prevents estimation of the magnitude of the effect. For example, complete conversion of corrosion products to low site density hematite over time would lead to ionic strengths closer to the EQ6 prediction. Similarly, the oxidation state of chromium is difficult to quantify, so this model considers the most oxidized state to be consistent with the thermodynamic approach, discussed in Section 6.3.1.1, which is conservative relative to the chemistry predicted by the model.

The possibility of ionic strength being higher than was possible to model with the batch reactor model, or being lower due to sorption reactions or lower oxidation states, is dealt with by setting the uncertainty range to favor more extreme ionic strengths (Section 6.10.2.3).

\subsubsection{CSNF}

Unlike the batch reactor conceptual model (Section 6.3.1.1), under vapor influx conditions, the interior of the waste package is dry at the moment of waste package breach. With time, the humidity of the interior of the waste package will equilibrate to the ambient drift conditions and water will begin to adsorb or condense to the interior waste package components. The ratio of water to reactants is initially small and increases with time, so the ionic strength will initially be high and decrease with time as more water enters the system. This is an effect that is not captured by the vapor influx EQ6 model. Therefore, the ionic strength data that show a linear increase as a function of time, $<30$ years (Figure 6-64), was not included in the abstractions; only the stabilized ionic strength data were abstracted. The potentially high-ionic strength solutions that could occur based on the low ratio of water to reactants at early times, but not captured in the EQ6 model, are captured by the uncertainty treatment that is biased towards high ionic strengths.

Further complicating the effect of increasing water content is the role of corrosion products and surface complexation on ionic strength. Increasing water content and surface complexation have the same potential impact of decreasing the ionic strength. The applied uncertainty range accounts for this effect (Section 6.10.2.3). Figure 6-64 displays the ionic strength for the CSNF vapor influx ensembles. The abstraction of ionic strength only considers the stabilized ionic strength values (i.e., for times greater than about 30 years). By only using the stabilized ionic strength data, and applying an uncertainty range, which is biased towards lower ionic strength (Section 6.10.2.3), the abstraction should provide a realistic interpretation of the "true" ionic strength. The late-time falling ionic strength of comp3 and comp4 (Figure 6-64) also were not included because this trend represents the depletion of reactants in the EQ6 simulation. It was demonstrated that the waste package becomes filled with water and mineral phases by about 5,000 to 7,000 years ( $W P$ _volume.xls, Appendix F). This has no impact on the ionic strength abstraction because the colloid threshold ionic strength, 0.05 molal (BSC 2003 [DIRS 166845]), occurs well before this time around 10 to 30 years.

The CSNF water influx model ionic strength abstractions are regression curves of ionic strength as functions of water flux. The $25^{\circ} \mathrm{C} \mathrm{CSNF}$ water influx model ionic strength abstraction will be presented as an example. 
Figure 6-13 displays the ionic strength profiles for the CSNF water influx model runs at $25^{\circ} \mathrm{C}$. The period from 0 to 40 years is characterized by increasing ionic strength and will not be considered in the abstraction. Rather, in an actual system where the ratio of water would be low early on, the ionic strength would be high, and not until the water ratio increased would the ionic strength stabilize at values near those calculated by the batch reactor model.

The period from 40 to 20,000 years can be represented as a function where ionic strength is a function of seepage flux. For the low-end seepage flux $(0.15 \mathrm{~L} / \mathrm{yr})$, the ionic strength exceeds 1 molal due to the accumulation of aqueous chromium species in the waste package effluent. These high chromium concentrations occur in the EQ6 simulations because there is no chrome-bearing mineral phase in the thermodynamic database available to precipitate under the conditions of the simulation. The ionic strength abstraction is used by the colloid and dissolved concentrations submodels in the TSPA-LA. The colloidal suspensions are unstable at ionic strength values above 0.05 molal (BSC 2003 [DIRS 166845]), so for the colloid submodel, the significance of exceeding the limits of the B-dot activity coefficient equation is diminished. For the dissolved concentrations model, TSPA-LA applies an additional uncertainty term to the concentrations if the ionic strengths is greater than one molal), so the significance of exceeding the limits of the B-dot activity coefficient equation is already captured.

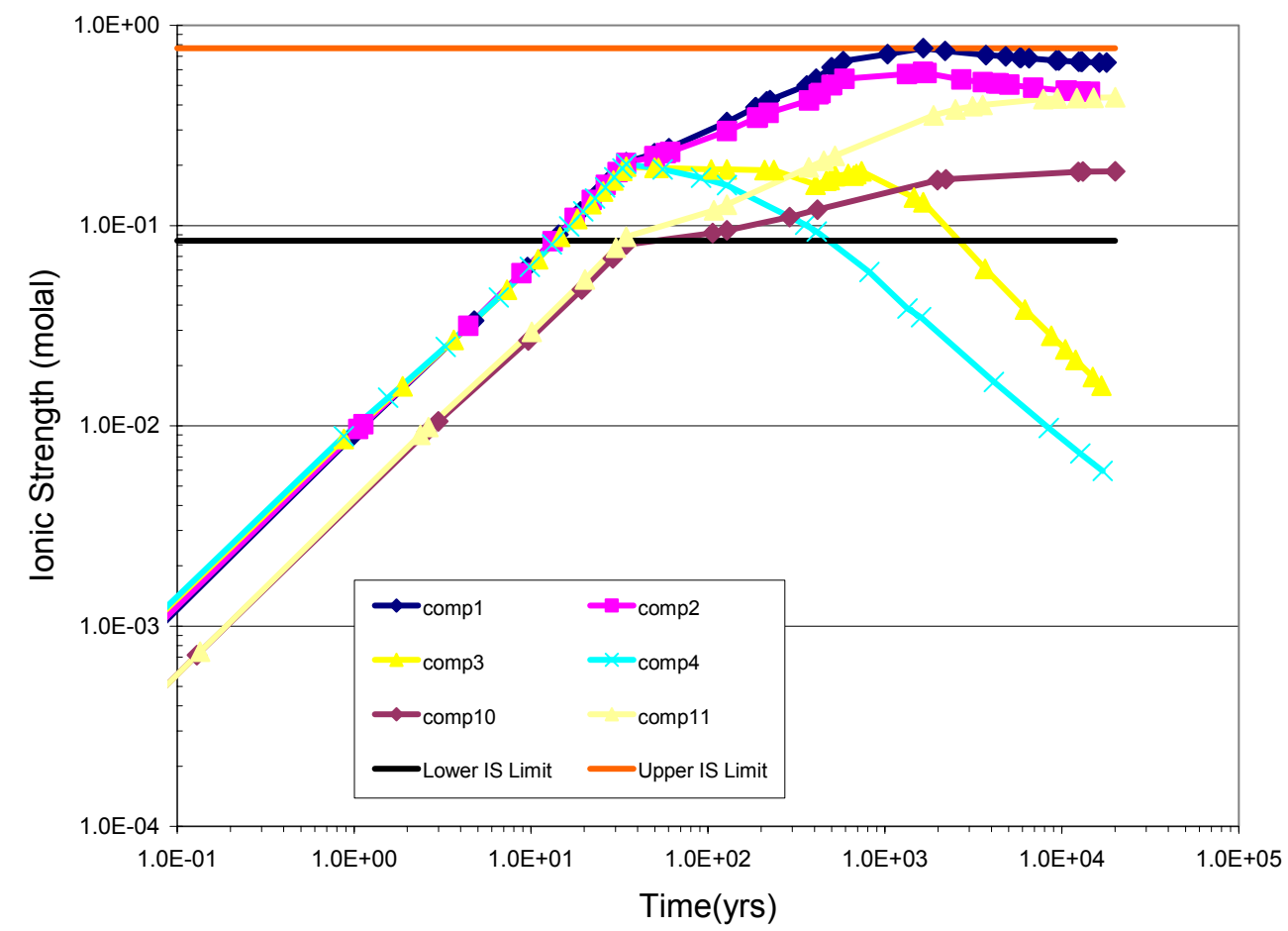

Source: $\quad$ CSNF_Vapor Influx.xIs (Appendix F ISpreadsheets).

Figure 6-64. CSNF Vapor Influx Ionic Strength Abstraction

The CSNF water influx model $25^{\circ} \mathrm{C}$ ionic strength is shown in Figure 6-13. Figure 6-65 displays the ionic strength abstraction for the CSNF water influx model at $25^{\circ} \mathrm{C}$, for the period from 40 to 20,000 years. This abstraction, and the ionic strength abstractions to follow, were all generated by plotting in Microsoft Excel the time weighted average ionic strength for the specified period versus the base ten logarithm of seepage flux and then using "Add Trendline" from the "Chart" submenu to fit the exponential function to the data. 


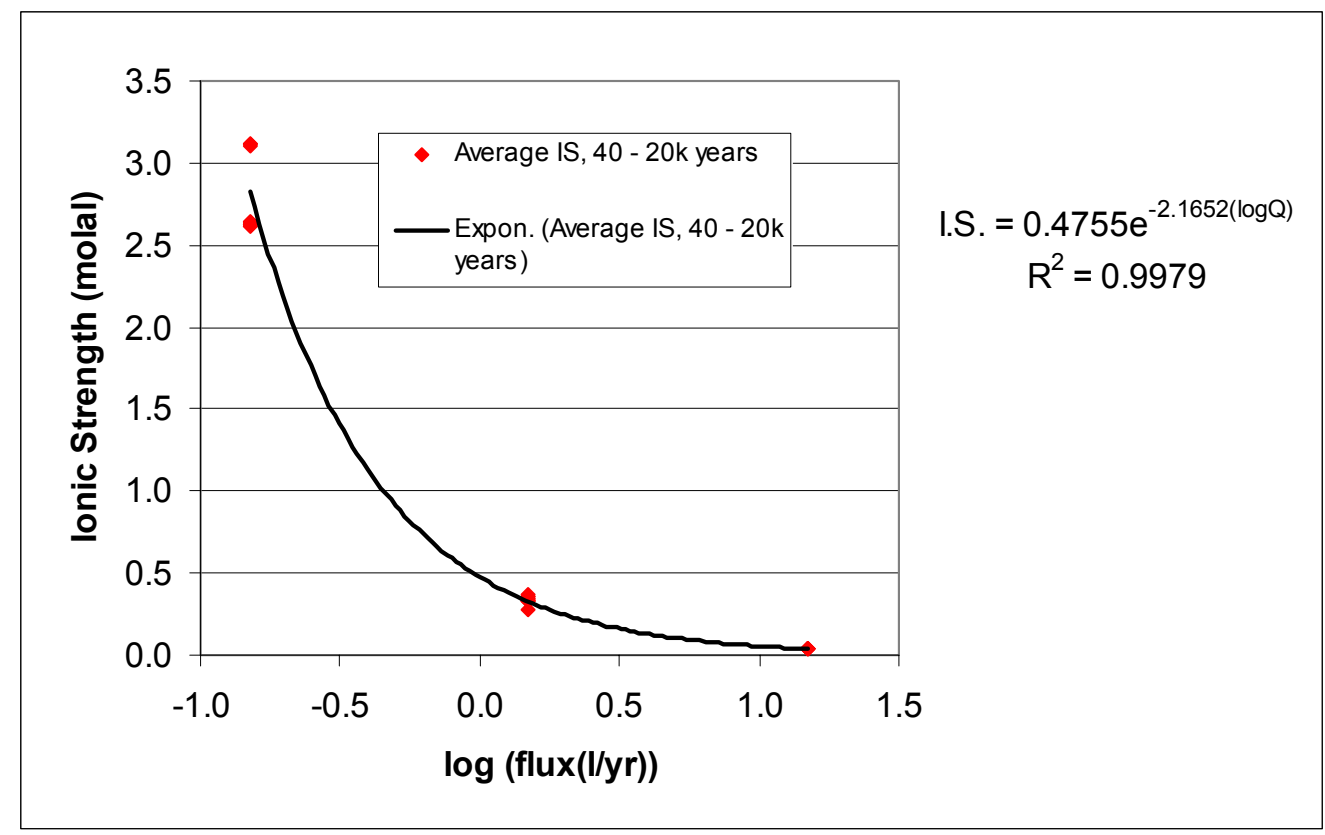

Source: CSNF_Water Influx_25.x/s (Appendix F ISpreadsheets).

Figure 6-65. CSNF Water Influx Model $25^{\circ} \mathrm{C}$ lonic Strength Abstraction

The ionic strength abstraction for the CSNF water influx model at $25^{\circ} \mathrm{C}$ is given in Table $6-25$.

Table 6-25. CSNF Water Influx Model $25^{\circ} \mathrm{C}$ lonic Strength Abstraction

\begin{tabular}{|c|c|}
\hline \multicolumn{2}{|c|}{$y=a E X P(b x)$} \\
\hline$a$ & $b$ \\
\hline 0.4755 & -2.1652 \\
\hline$R^{2}$ & 0.9979 \\
\hline
\end{tabular}

Source: CSNF_Water Influx_25.xIs (Appendix F ISpreadsheets).

NOTE: $\quad y=$ ionic strength, $X=\log _{10}(f \operatorname{lux}(L / y r))$.

The limits of flux for the abstraction are given in Table 6-26. The upper flux limit was calculated using the ionic strength calculated from that of the J-13 well water (Table 4-2) (i.e., at flux values greater than $185 \mathrm{~L} / \mathrm{yr}$ the abstracted ionic strength would be less than that of the J-13 well water). Even at the limits of the abstraction the uncertainty should still be applied.

Table 6-26. Flux Limits for CSNF Water Influx Model $25^{\circ} \mathrm{C}$ Ionic Strength Abstraction

\begin{tabular}{|c|c|}
\hline \multicolumn{2}{|c|}{ Flux Limits (L/yr/WP) } \\
\hline Lower & Upper $^{\mathbf{a}}$ \\
\hline 0.20 & 185 \\
\hline
\end{tabular}

Source: CSNF_Water Influx_25.xIs (Appendix F ISpreadsheets).

NOTE: $\quad{ }^{a} U p p e r$ Limit set by $\mathrm{J}-13$ well water ionic strength of 0.0035 molal (from j13.3o in Appendix F IEQ3). 
If the flux is less than the minimum, then the ionic strength should be evaluated using the lower flux limit from Table 6-26. Likewise, if the flux is greater than the upper limit, then the ionic strength should be evaluated using the upper limit value from Table 6-26.

The CSNF water influx model $50^{\circ} \mathrm{C}$ ionic strength is shown in Figure 6-14, and the abstraction takes the same form as the $25^{\circ} \mathrm{C}$ abstraction. The coefficients for the ionic strength function are provided in Table 6-27.

Table 6-27. CSNF Water Influx Model $50^{\circ} \mathrm{C}$ lonic Strength Abstraction

\begin{tabular}{|c|c|}
\hline \multicolumn{2}{|c|}{$\mathbf{y}=\mathbf{a E X P}(\mathbf{b x})$} \\
\hline $\mathbf{a}$ & $\mathbf{b}$ \\
\hline 0.4472 & -2.2424 \\
\hline $\mathrm{R}^{2}$ & 0.9971 \\
\hline
\end{tabular}

Source: CSNF_Water Influx_50.xls (Appendix F ISpreadsheets).

NOTE: $\quad y=$ ionic strength, $x=\log _{10}(f \operatorname{lux}(\mathrm{L} / \mathrm{yr}))$.

The flux limits for the CSNF water influx model $50^{\circ} \mathrm{C}$ ionic strength abstraction are listed in Table 6-28.

Table 6-28. Flux Limits for CSNF Water Influx Model $50^{\circ} \mathrm{C}$ lonic Strength Abstraction

\begin{tabular}{|c|c|}
\hline \multicolumn{2}{|c|}{ Flux Limits (L/yr/WP) } \\
\hline Lower & Upper $^{\mathrm{a}}$ \\
\hline 0.16 & 145 \\
\hline NOTE: & $\begin{array}{l}\text { a Upper Limit set by J-13 well water, } 0.0035 \text { molal } \\
\text { (from j13.3o in Appendix FlEQ3). }\end{array}$
\end{tabular}

If the flux is less than the minimum, then the ionic strength should be evaluated using the lower flux limit from Table 6-28. Likewise, if flux is greater than the upper limit, then ionic strength should be evaluated using the upper limit value from Table 6-28.

Figure 6-45 shows the ionic strength results of EQ6 simulations at progressively higher temperatures. The results plotted in Figure 6-45 show that temperature had a minor influence on ionic strength. Although evaporation from the interior of the waste package is not expected to be great, due to high humidity in the waste package interior, evaporation could still influence the ionic strength as the temperature increases. Therefore, the ionic strength abstraction is temperature dependent.

For TSPA-LA at temperatures from $25^{\circ} \mathrm{C}$ to $50^{\circ} \mathrm{C}$, and $50^{\circ} \mathrm{C}$ to $100^{\circ} \mathrm{C}$, a linear relationship should be established between the values calculated using the relationships provided in Table 6-25 and Table 6-27, to interpolate between the $25^{\circ} \mathrm{C}$ and $50^{\circ} \mathrm{C}$ abstractions, and to extrapolate beyond $50^{\circ} \mathrm{C}$ and up to $100^{\circ} \mathrm{C}$ honoring the limits of these relationships as defined in Table 6-25 and Table 6-27. 


\subsubsection{CDSP}

Unlike the batch reactor conceptual model (Section 6.3.1.1), under vapor influx conditions, the interior of the waste package is dry at the moment of waste package breach. With time, the humidity of the interior of the waste package will equilibrate to the ambient drift conditions and water will begin to adsorb or condense to the interior waste package components. The ratio of water to reactants is initially small and increases with time, so the ionic strength will initially be high and decrease with time as more water enters the system. This is an effect that is not captured by the vapor influx EQ6 model. Therefore, the ionic strength data that show a linear increase as function of time (Figure 6-66) was not included in the abstractions, only the stabilized ionic strength data was abstracted. The potentially high ionic strength solutions that could occur based on the low ratio of water to reactants at early times, but that are not captured in the EQ6 model, are captured by the uncertainty treatment that is biased towards high ionic strengths.

Further complicating the effect of increasing water content is the role of corrosion products and surface complexation on ionic strength. Both increasing water content and surface complexation have the same potential impact of decreasing the ionic strength. The applied uncertainty range accounts for this effect (Section 6.10.2.3).

Figure 6-66 displays the ionic strength for the CDSP vapor influx ensembles. The abstraction of ionic strength only considers the stabilized ionic strength values (i.e., for times greater than about 10 to 30 years). By only using the stabilized ionic strength data, and applying an uncertainty range, which is biased towards lower ionic strength (Section 6.10.2.3), the abstraction should provide a realistic interpretation of the "true" ionic strength. The late-time falling ionic strength of comp7 (Figure 6-66) was also not included because this trend represents the depletion of reactants in the EQ6 simulation.

Thus, a cumulative distribution was been generated where the lower ionic strength limit is set by the comp8 stabilized ionic strength value (3.2E-3), and since comp8 is the only simulation where the ionic strength is less than the 0.05 colloid stability value (BSC 2003 [DIRS 166845]), there is a 1 in 8 chance of the ionic strength being less than the threshold. Therefore, there is a $13 \%$ probability $(1 / 8=0.13)$ that the ionic strength will be between the minimum value $(3.2 \mathrm{E}-3 \mathrm{~m})$ and $0.05 \mathrm{~m}$. The upper ionic strength limit is set by compl that has the maximum ionic strength value of $7.5 \mathrm{E}-01$. There is a $100 \%$ probability that the ionic strength will be below $7.5 \mathrm{E}-01$.

It was demonstrated that the waste package becomes filled with water and mineral phases by about 5,000 to 7,000 years ( WP_volume.xls, Appendix F), this has no impact on the ionic strength abstraction because the colloid threshold ionic strength, 0.05 molal (BSC 2003 [DIRS 166845]), is exceeded well before this time for all of the simulations except for the comp8 simulation which reaches its maximum around 4,000 years.

For application in TSPA-LA, the ionic strength distribution should be sampled, and the uncertainty described in Section 6.10.2.3 should be applied. 


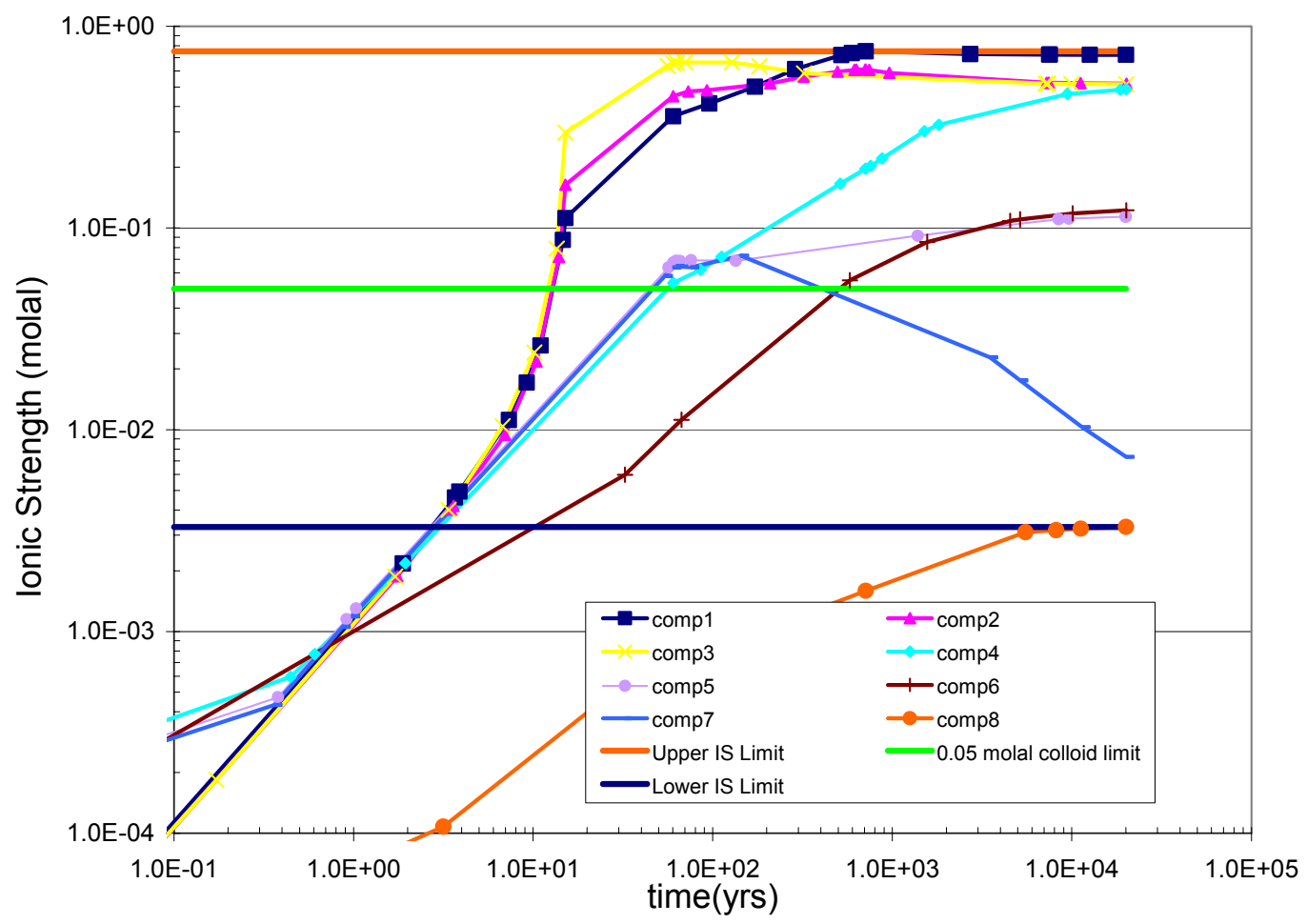

Source: $\quad C D S P_{-}$Vapor Influx.xls (Appendix F ISpreadsheets).

Figure 6-66. CDSP Vapor Influx Ionic Strength Profiles and Abstraction

Figure 6-22 displays the ionic strength profiles for the CDSP water influx model runs at $25^{\circ} \mathrm{C}$. The period from 0 to 80 years is characterized by increasing ionic strength and will not be considered in the abstraction. Rather, in an actual system where the water ratio would be low early on, the ionic strength would be high, and not until the water ratio increased would the ionic strength stabilize at values near those calculated by the batch reactor model.

The period from 80 to 20,000 years can be represented as a function, where ionic strength is a function of seepage flux. For the low-end seepage flux $(0.15 \mathrm{~L} / \mathrm{yr})$, the ionic strength exceeds 1 molal due to the accumulation of aqueous chromium species in the waste package effluent. These high chromium concentrations occur in the EQ6 simulations because there is no chrome bearing mineral phase in the thermodynamic database available to precipitate under the conditions of the simulation. The ionic strength abstraction is used by the colloid and dissolved concentrations submodels in the TSPA-LA. The colloidal suspensions are unstable at ionic strength values above 0.05 molal (BSC 2003 [DIRS 166845]), so for the colloid submodel, the significance of exceeding the limits of the B-dot activity coefficient equation is diminished. For the dissolved concentrations model, TSPA-LA applies an additional uncertainty term to the concentrations if the ionic strengths is greater than one molal), so the significance of exceeding the limits of the B-dot activity coefficient equation is already captured.

The ionic strength abstractions for CDSP were calculated in the same manner as those for CSNF, where the time weighted average ionic strength from 80 to 20,000 years was plotted versus the $\log$ of the seepage flux and the exponential function coefficients were estimated as described in 
Section 6.10.2.1. The ionic strength abstraction function for the CDSP water influx model at $25^{\circ} \mathrm{C}$ from 0 to 20,000 years is given in Table $6-29$.

Table 6-29. CDSP Water Influx Model $25^{\circ} \mathrm{C}$ lonic Strength Abstraction

\begin{tabular}{|c|c|c|}
\hline \multicolumn{3}{|c|}{$\mathbf{y}=\mathbf{a E X P}(\mathbf{b x})$} \\
\hline $\mathbf{a}$ & $\mathbf{b}$ \\
\hline 0.5201 & & -2.1306 \\
\hline \multicolumn{2}{|c|}{$\mathrm{R}^{2}=0.9993$} \\
\hline
\end{tabular}

Source: CDSP_Water Influx_25.xls (Appendix F ISpreadsheets).

NOTE: $y=$ ionic strength, $X=\log _{10}(f l u x(L / y r))$.

The limits of flux for the abstraction are given in Table 6-30. The upper flux limit was set using the ionic strength of $\mathrm{J}-13$ well water (from $j 13.3 o$ in Appendix $\mathrm{F} \backslash \mathrm{EQ} 3$ ) as the lower ionic strength limit (i.e., at flux values greater than $180 \mathrm{~L} / \mathrm{yr}$ the abstracted ionic strength would be less than that of the most dilute input solution, in this case, J-13 well water).

Table 6-30. Flux Limits for CDSP Water Influx Model $25^{\circ} \mathrm{C}$ Ionic Strength Abstraction

\begin{tabular}{|c|c|}
\hline \multicolumn{2}{|c|}{ Flux Limits (L/yr/WP) } \\
\hline Lower & Upper $^{\mathbf{a}}$ \\
\hline 0.25 & 180 \\
\hline
\end{tabular}

NOTE: ${ }^{a}$ Upper Limit set by $\mathrm{J}-13$ ionic strength of 0.0035 molal (from $j 13.30$ in Appendix F \EQ3).

If the flux is less than the minimum, then the ionic strength should be evaluated using the lower flux limit from Table 6-30. Likewise, if flux is greater than the upper limit, then ionic strength should be evaluated using the upper limit value from Table 6-30.

Figure 6-23 displays the ionic strength profiles for the CDSP water influx model runs at $50^{\circ} \mathrm{C}$. The CDSP water influx model $50^{\circ} \mathrm{C}$ ionic strength abstraction takes the same form as the $25^{\circ} \mathrm{C}$ abstraction. The coefficients for the ionic strength function are provided in Table 6-31.

The ionic strength abstraction for the CDSP water influx model at $50^{\circ} \mathrm{C}$ from 0 to 20,000 years is given in Table 6-31.

Table 6-31. CDSP Water Influx Model $50^{\circ} \mathrm{C}$ lonic Strength Abstraction

\begin{tabular}{|cc|cc|}
\hline \multicolumn{3}{|c|}{$\mathbf{y}=\mathbf{a E X P}(\mathbf{b x})$} \\
\hline $\mathbf{a}$ & & $\mathbf{b}$ \\
\hline 0.4324 & & -2.1369 \\
\hline \multicolumn{3}{|c|}{$\mathbf{R}^{2}=\mathbf{0 . 9 9 9 3}$} \\
\hline
\end{tabular}

Source: CDSP_Water Influx_50.xls (Appendix F ISpreadsheets).

NOTE: $\quad y=$ ionic strength, $X=\log _{10}(f \mid u x(L / y r))$. 
The limits of flux for the abstraction are given in Table 6-32. The upper flux limit was set using the ionic strength of $\mathrm{J}-13$ well water (from $j 13.3 o$ in Appendix $\mathrm{F} \backslash \mathrm{EQ} 3$ ) as the lower ionic strength limit (i.e., at flux values greater than $180 \mathrm{~L} / \mathrm{yr}$ the abstracted ionic strength would be less than that of the most dilute input solution, in this case, J-13 well water).

Table 6-32. Flux Limits for CDSP Water Influx Model $50^{\circ} \mathrm{C}$ Ionic Strength Abstraction

\begin{tabular}{|c|c|c|}
\hline \multicolumn{3}{|c|}{ Flux Limits (L/yr) } \\
\hline & Lower & Upper $^{a}$ \\
\hline & 0.18 & 180 \\
\hline Source: & \multicolumn{2}{|c|}{$\begin{array}{l}\text { CDSP_Water Influx_50.xIs (Appendix F } \\
\text { ISpreadsheets). }\end{array}$} \\
\hline NOTE: ${ }^{a}$ & \multicolumn{2}{|c|}{$\begin{array}{l}\text { a Upper Limit set by } \mathrm{J}-13 \text { well water at } 0.0035 \\
\text { molal (from j13.3o in Appendix } \mathrm{F} \backslash \mathrm{EQ} 3 \text { ). }\end{array}$} \\
\hline
\end{tabular}

If the flux is less than the minimum, then the ionic strength should be evaluated using the lower flux limit from Table 6-32. Likewise, if flux is greater than the upper limit, then ionic strength should be evaluated using the upper limit value from Table 6-32.

Figure 6-47 shows the ionic strength results of EQ6 simulations at progressively higher temperatures. The results plotted in Figure 6-47 show that temperature has an influence on ionic strength. Although evaporation from the interior of the waste package is not expected to be great, due to high humidity in the waste package interior, evaporation could still influence the ionic strength as the temperature increases. Therefore, the ionic strength abstraction is temperature dependent.

For TSPA-LA at temperatures other than $25^{\circ} \mathrm{C}$ or $50^{\circ} \mathrm{C}$, first calculate the ionic strengths at $25^{\circ} \mathrm{C}$ and at $50^{\circ} \mathrm{C}$, and then use a linear relationship between the two values (interpolating between $25^{\circ} \mathrm{C}$ and $50^{\circ} \mathrm{C}$, or extrapolating from $50^{\circ} \mathrm{C}$ to $100^{\circ} \mathrm{C}$ ).

\subsubsection{Uncertainty in Ionic Strength}

To assess the uncertainty in ionic strength to variability in model inputs, sensitivity analyses were performed (Section 6.6). Figure 6-67 and Figure 6-69 show how CSNF and CDSP ionic strength responses vary.

The ionic strength error bars are percentage values. Thus, the uncertainty range of $\pm 60 \%$ is shown in Figure 6-67 and Figure 6-69 by the black error bars. The final uncertainty values of $(-80 \%$ to $+40 \%)$ are also shown.

The uncertainty for water influx and vapor influx cases should be applied as follows:

$$
\text { Ionic strength }=\mathrm{IS}_{\text {sampled }}+\left(\text { Uncertainty }_{\text {sampled }} \times \mathrm{IS}_{\text {sampled }}\right)
$$

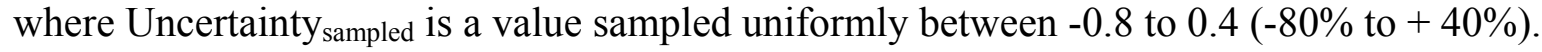




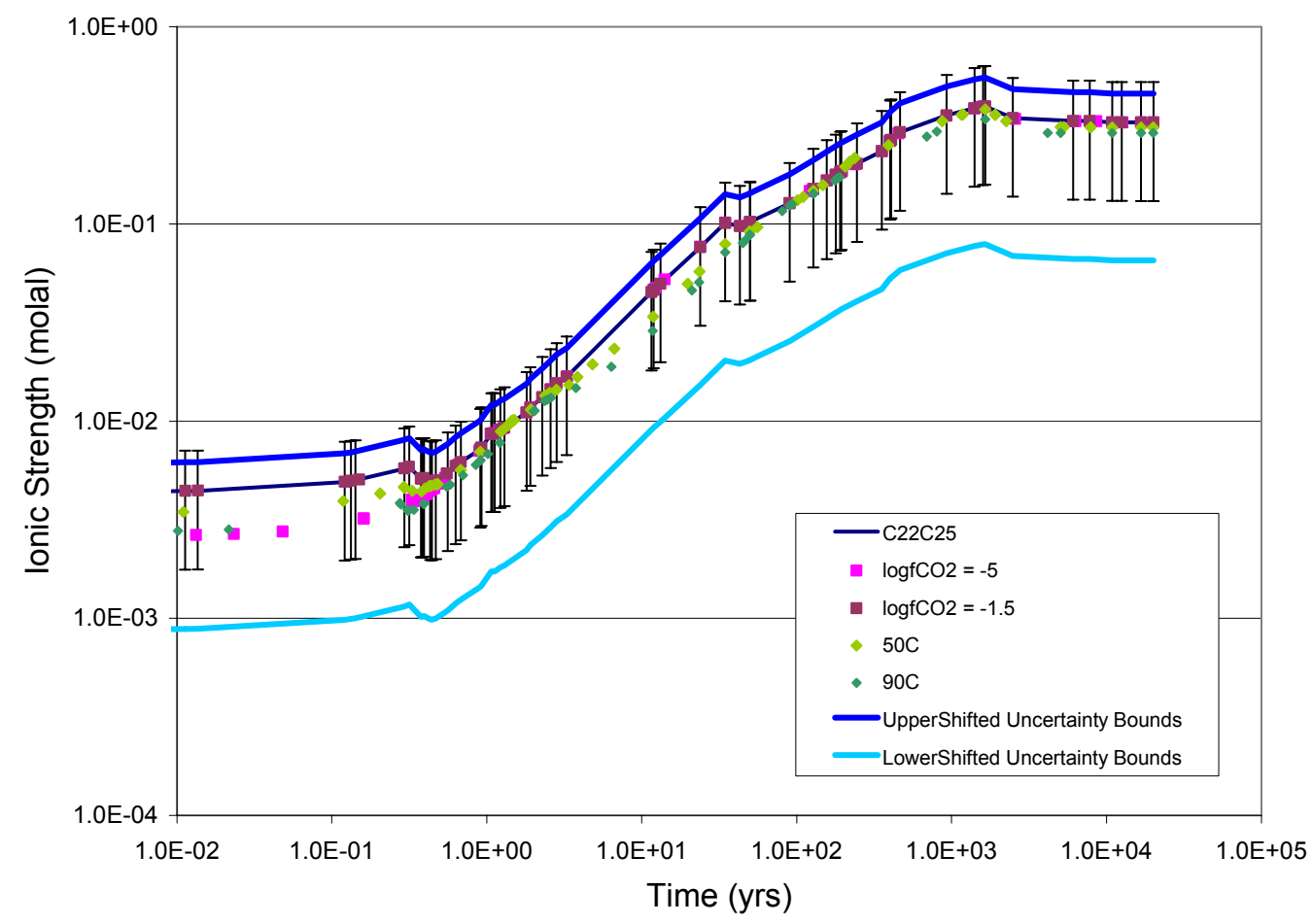

Source: CSNF_Sensitivity.xIs (Appendix F ISpreadsheets).

Figure 6-67. CSNF Water Influx Case: Ionic Strength Profile with Error Bars

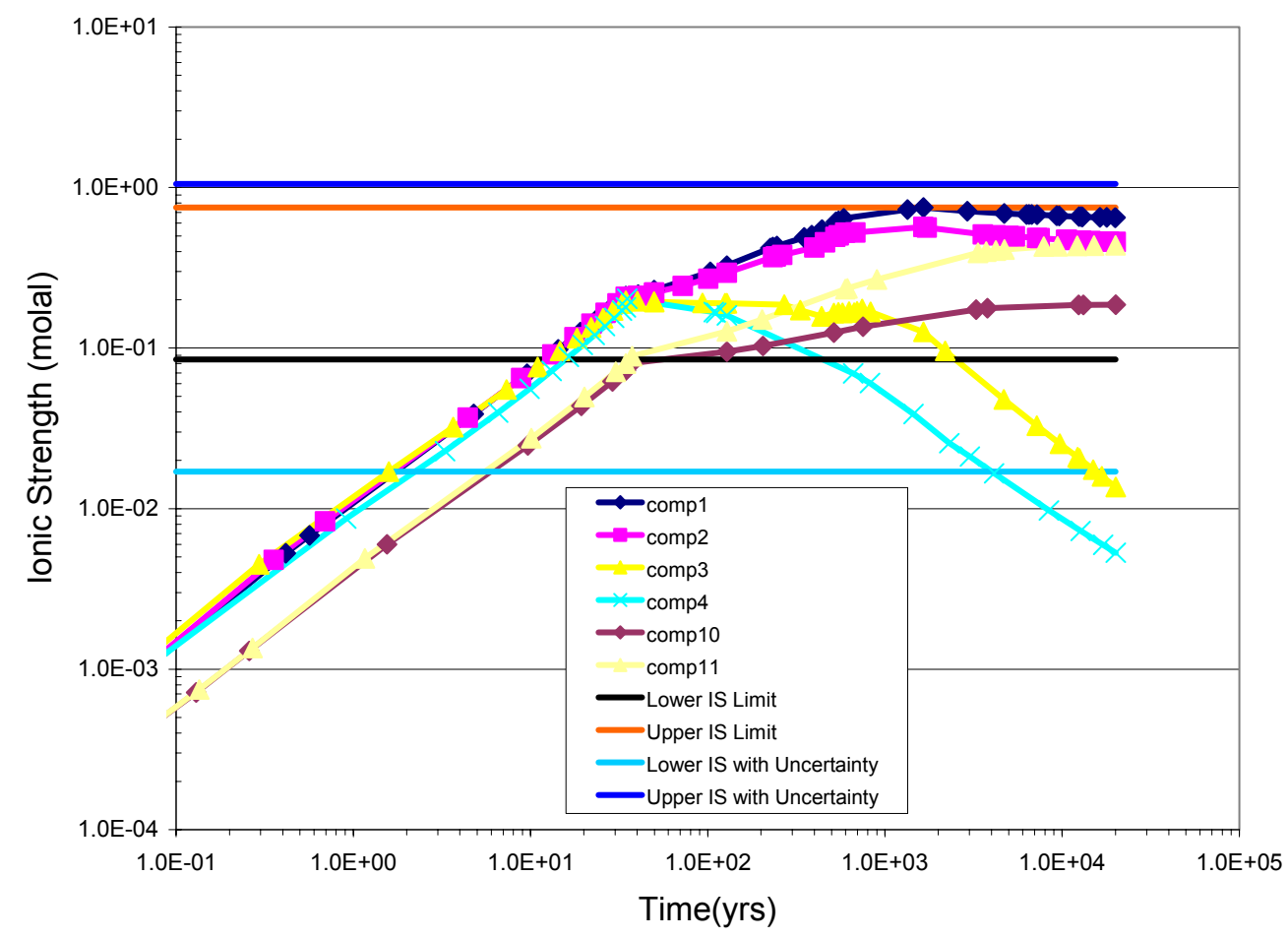

Source: CSNF_Vapor Influx_MultiComp.xIs (Appendix F ISpreadsheets).

Figure 6-68. CSNF Vapor Influx Case: Ionic Strength Profile with Uncertainty 


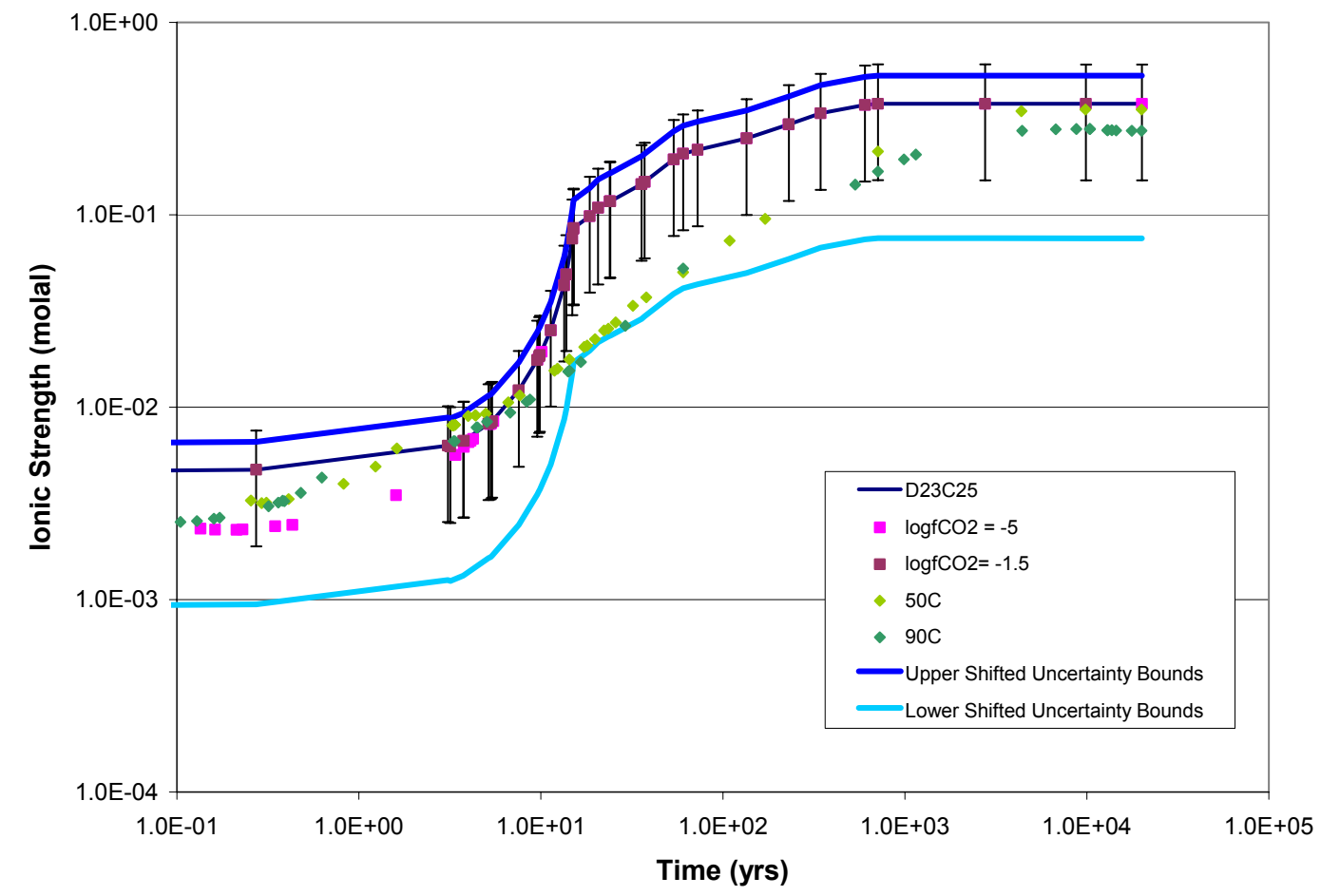

Source: CDSP_Sensitivity.xIs (Appendix F ISpreadsheets).

Figure 6-69. CDSP Water Influx Case: Ionic Strength Profile with Error Bars

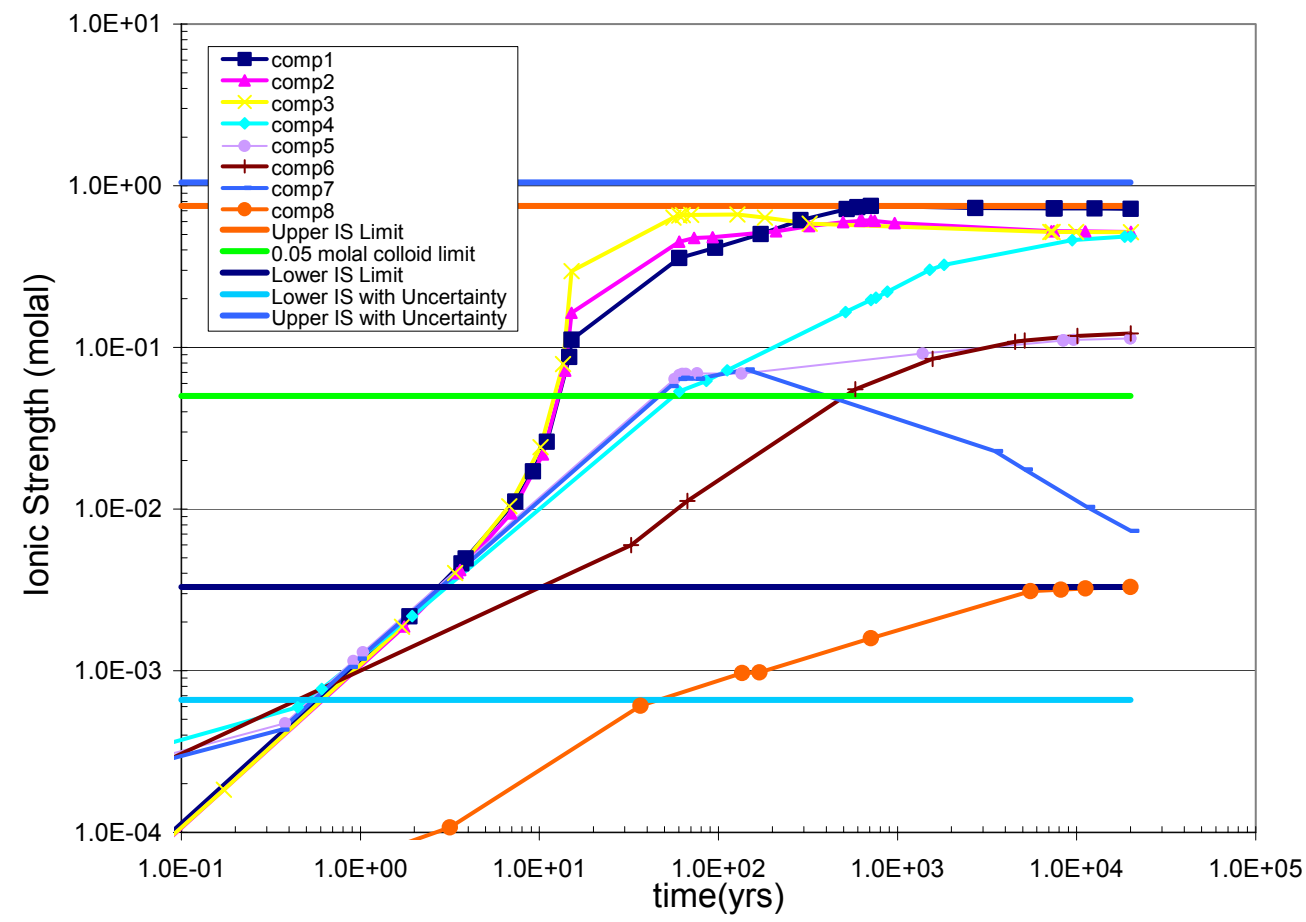

Source: CDSP_Vapor Influx_MultiComp.xls (Appendix F ISpreadsheets).

Figure 6-70. CDSP Vapor Influx Case: Ionic Strength Profile with Uncertainty 
For example, if the sampled ionic strength (IS) value is 0.72 , and the sampled uncertainty is -0.04 , then the total ionic strength should be:

$$
\begin{aligned}
\text { IS } & =0.72+(-0.04 \times 0.72) \\
& =0.69
\end{aligned}
$$

The uncertainty treatment of the ionic strength abstraction is based on the two intended uses of the ionic strength abstractions within TSPA-LA, determining colloids stability and solubility of radionuclides. A lower ionic strength is more conservative with respect to colloid stability under advective flow, but an ionic strength greater than one molal is conservative for radionuclide solubility and diffusion of radionuclides (colloids diffuse much more slowly than dissolved species). The uncertainty treatment above favors both low and high ionic strengths.

The colloid model report (BSC 2003 [DIRS 166845], Section 6.3.2.4) defines the upper limit of ionic strength for colloid stability, the value above which colloids are no longer stable as dispersed particles in solution, as 0.05 molal (BSC 2003 [DIRS 166845]). Therefore, below this 0.05 molal ionic strength threshold value, colloids are stable in solution and available for adsorption of radionuclides. The uncertainty treatment is designed to be conservative for colloid stability by applying an uncertainty range that decreases the ionic strength more often than increases it, so the uncertainty term is sampled between -0.8 to $0.4(-80 \%$ to $+40 \%)$. This bias to lower ionic strength values is also intended to account for several factors that were not explicitly modeled in the EQ6 simulations. These factors include the potential for $\mathrm{Cr}$ (III) formation, as described in Section 6.6.3, and the potential effects of lower $f \mathrm{O}_{2}$ values as described in Section 6.6.4.

The second intended use of the ionic strength abstraction is for Dissolved Concentration Limits of Radioactive Elements (BSC 2004 [DIRS 169425]) that adds an additional uncertainty term to the concentrations if the ionic strength exceeds 1 molal. The ionic strength uncertainty term is a function of the ionic strength itself, so the uncertainty term for a high sampled ionic strength is greater than for a lower sampled ionic strength. Having the uncertainty treatment as a function of the ionic strength increases a high ionic strength to an even higher value. Assigning more uncertainty to high ionic strengths is intended to account for the early times where the ratio of water to reactants is low.

This uncertainty range should be applied to both the vapor influx and water influx models for the entire temperature range $\left(25^{\circ} \mathrm{C}\right.$ to $\left.100^{\circ} \mathrm{C}\right)$.

\subsubsection{Fluoride Abstractions}

The fluoride profiles for the $25^{\circ} \mathrm{C}$ CSNF water influx model simulations are plotted in Figure 6-71 with the limits of the abstraction. Other than the input seepage compositions, there are no other sources of fluorine in the CSNF waste package. The dip in fluoride concentration at about one year (Figure 6-71) is the result of fluorapatite precipitation with subsequent dissolution as the concentration recovers to approximately 1E-04 molal. This early fluoride minimum was not considered for the abstraction because it occurs so early, and the minimum of the average fluoride concentrations was set as the lower bound of the abstraction instead. It is possible that 
surface complexation reactions could decrease the effective fluoride concentration of the waste package solutions; however, the surface complexation model was not used to generate the fluoride abstraction.

Given that the abstraction covers a wider range than what Figure 6-71 suggests, it is not necessary to apply an uncertainty value to the sampled fluoride value.

Although there is no dissolved fluoride in the water vapor, the HLWG contains fluorine (Table 4-5); therefore, a fluoride abstraction is provided for the CDSP vapor influx model. Figure 6-72 displays the fluoride profiles for the CDSP ensembles. The variation in the fluoride concentration (Figure 6-72) is due to precipitation/dissolution reactions of minor fluoride bearing phases (fluorite and fluorapatite). It is possible that surface complexation reactions could decrease the effective fluoride concentration of the waste package solutions; therefore, the values provided should be considered maximums. Since the range to be sampled encompasses 12 orders of magnitude, it is unnecessary to include any further uncertainty on the estimated fluoride concentration.

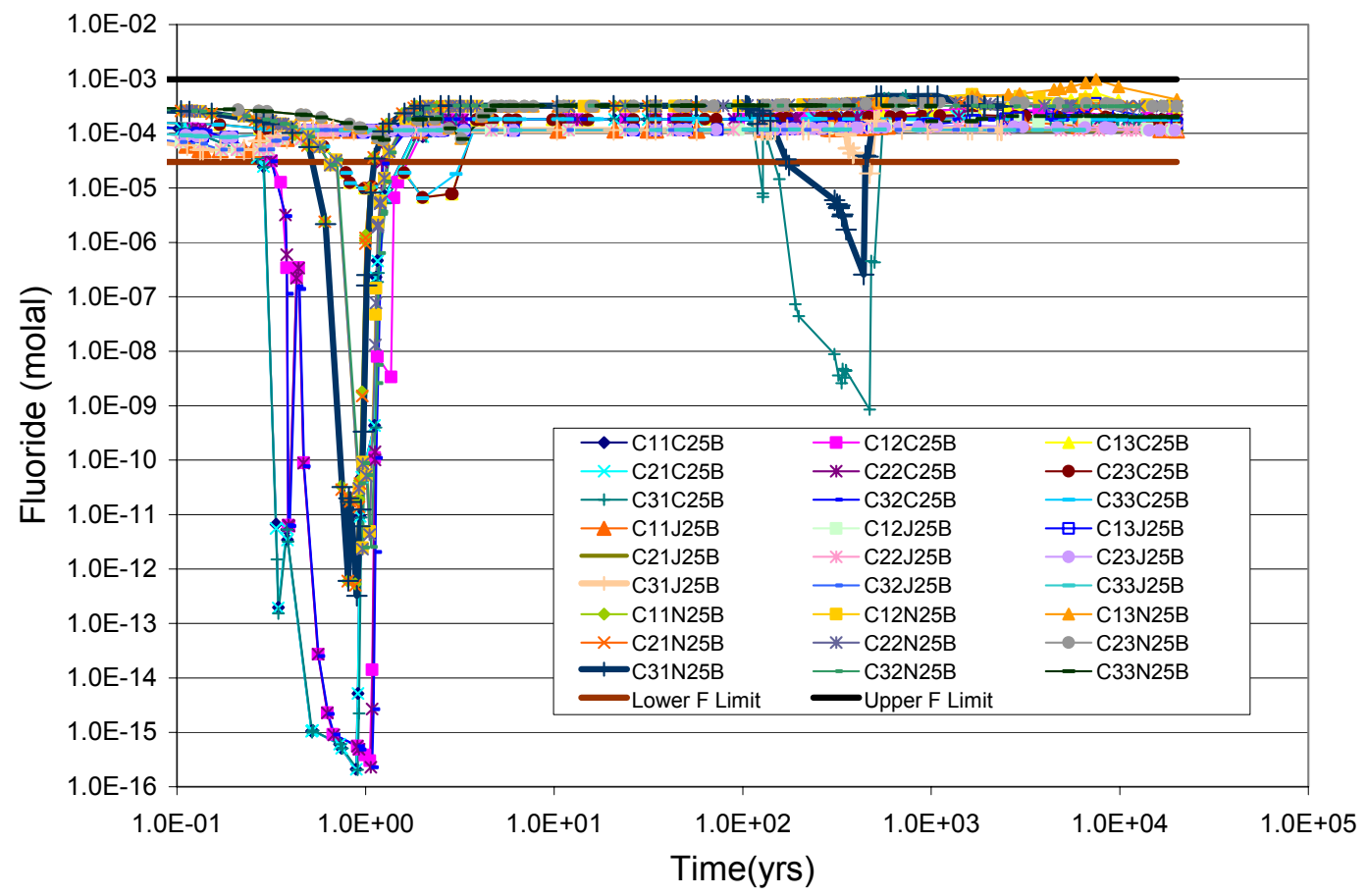

Source: $\quad$ CSNF_Water Influx_25.xIs (Appendix F ISpreadsheets).

Figure 6-71. CSNF Water Influx Model $25^{\circ} \mathrm{C}$ Fluoride Profiles and Abstraction 


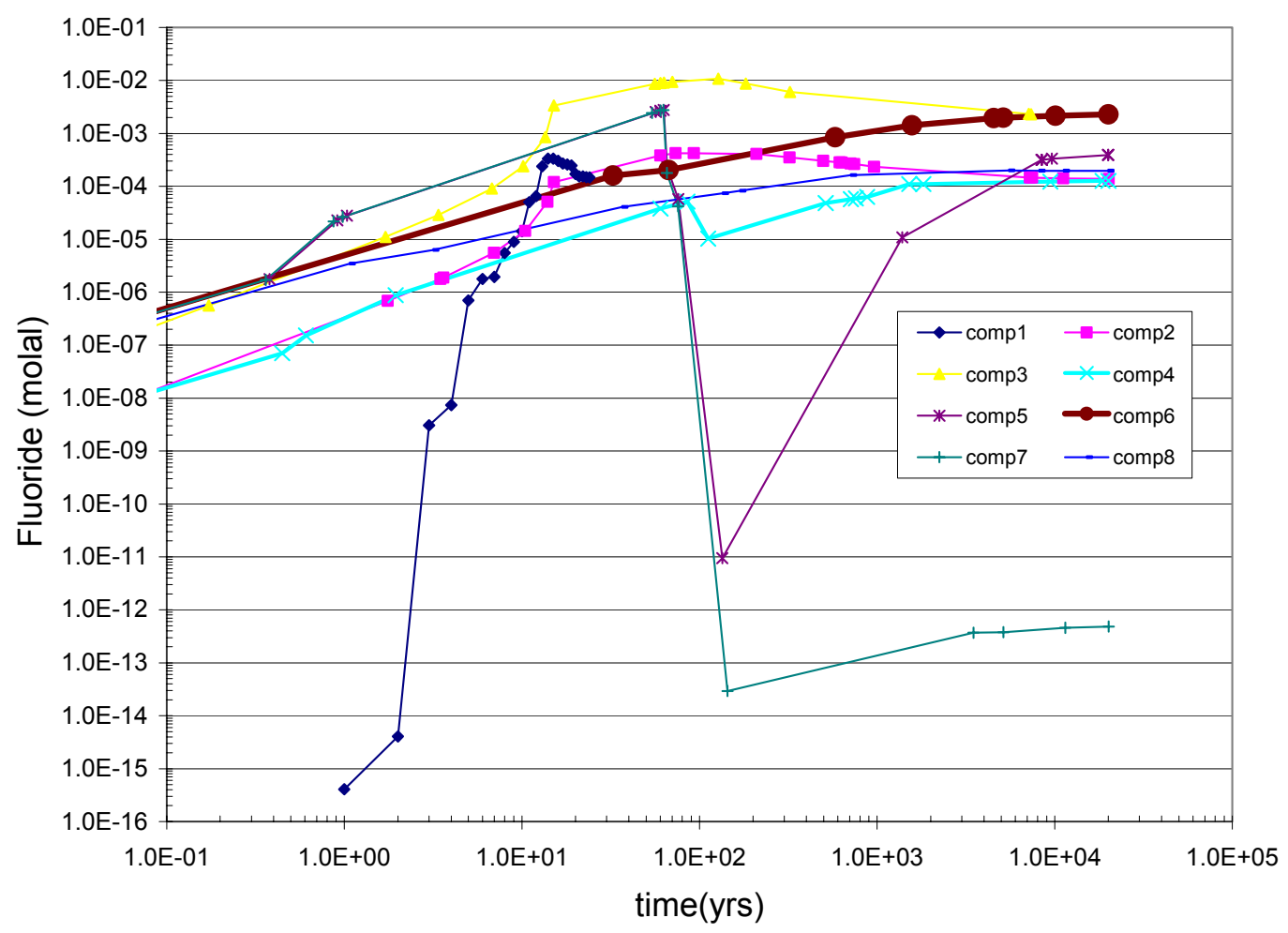

Source: $\quad C D S P \_V a p o r$ Influx_SingleReact.xls (Appendix F ISpreadsheets).

Figure 6-72. CDSP Vapor Influx Model $25^{\circ} \mathrm{C}$ Fluoride Profiles

The fluoride profiles for the CDSP vapor influx model $25^{\circ} \mathrm{C}$ simulations are plotted in Figure 6-72, and CDSP water influx model $25^{\circ} \mathrm{C}$ simulations are plotted in Figure 6-73. The minimum fluoride spike at about 5 years was not included in the abstraction because of its short duration. Compared to the CSNF fluoride profiles (Figure 6-71), the CDSP fluoride profiles are much more complex. The reason for the increased complexity is that fluorine is a component of the HLWG so that the aqueous fluoride concentration is controlled by the HLWG dissolution rate that is $\mathrm{pH}$ dependent (Table 6-10). It is possible that surface complexation reactions could decrease the effective fluoride concentration of the waste package solutions; therefore, the values provided should be considered maximums. 


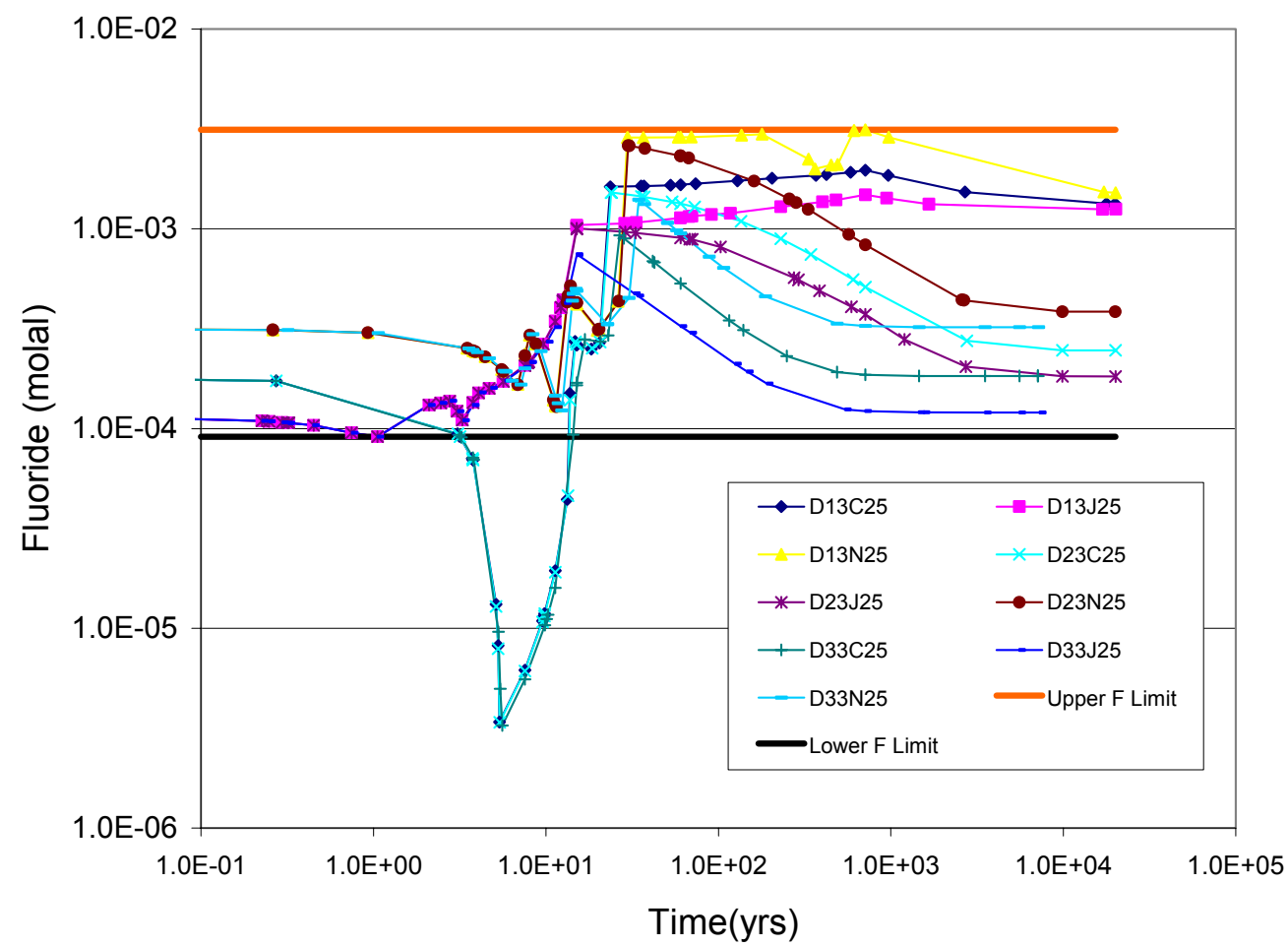

Source: CDSP_Water Influx_25.xIs (Appendix F ISpreadsheets).

Figure 6-73. CDSP Water Influx Model $25^{\circ} \mathrm{C}$ Fluoride Profiles and Abstraction Limits

\subsubsection{Chloride Abstractions}

Figure 6-74 shows the CSNF water influx model $25^{\circ} \mathrm{C}$ chloride profiles and abstraction limits. The CSNF water influx model $50^{\circ} \mathrm{C}$ chloride profiles are not plotted because they show the same trends as the $25^{\circ} \mathrm{C}$ profiles. It is possible that surface complexation reactions could decrease the effective chloride concentration of the waste package solutions; therefore, the values provided should be considered maximums.

CDSP water influx model chloride profiles are plotted in Figure 6-75 together with the abstraction limits. It is possible that surface complexation reactions could decrease the effective chloride concentration of the waste package solutions; therefore, the values provided should be considered maximums. 


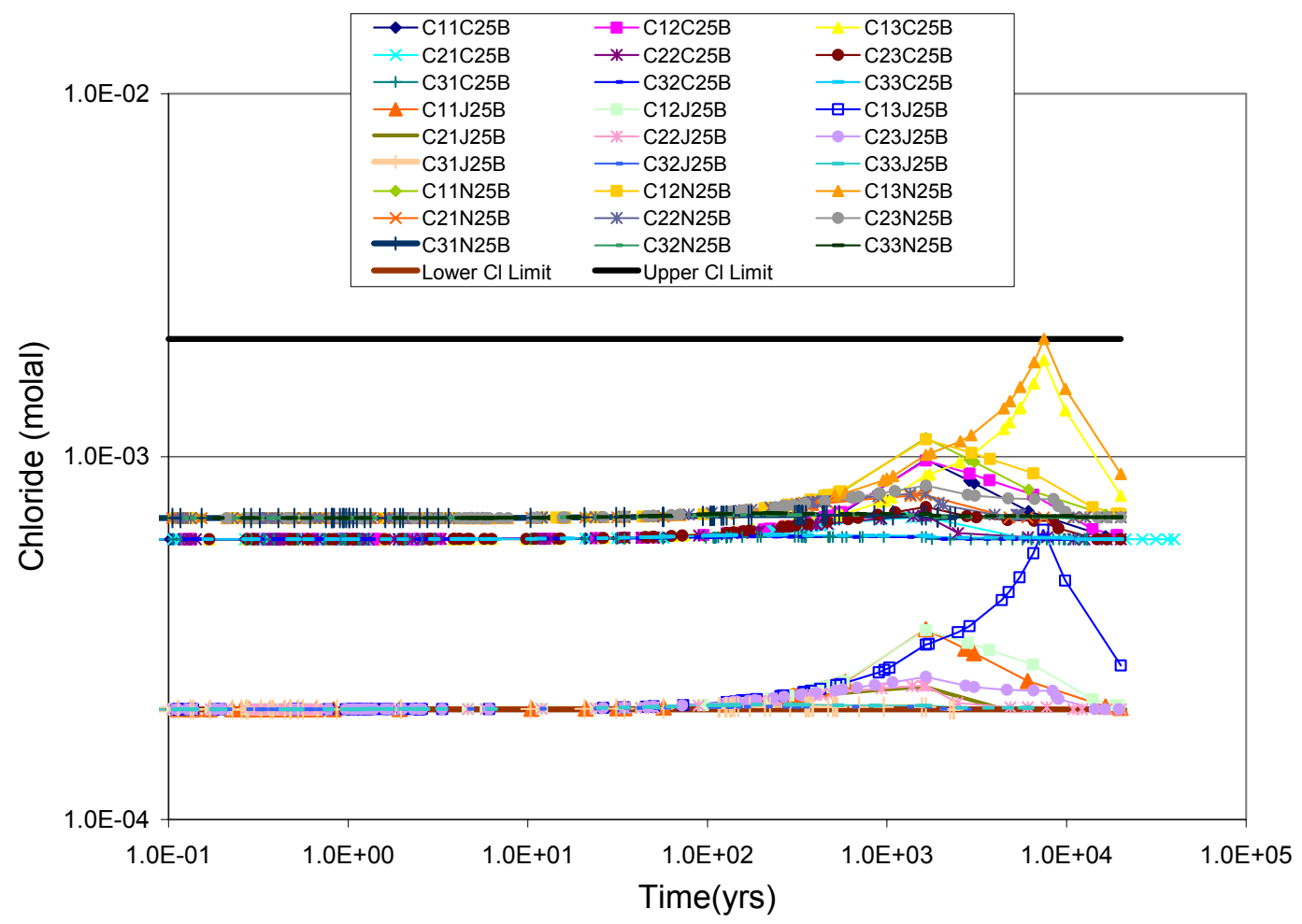

Source: CSNF_Water Influx_25.xIs (Appendix F ISpreadsheets).

Figure 6-74. CSNF Water influx Model $25^{\circ} \mathrm{C}$ Chloride Profiles and Abstraction Limits

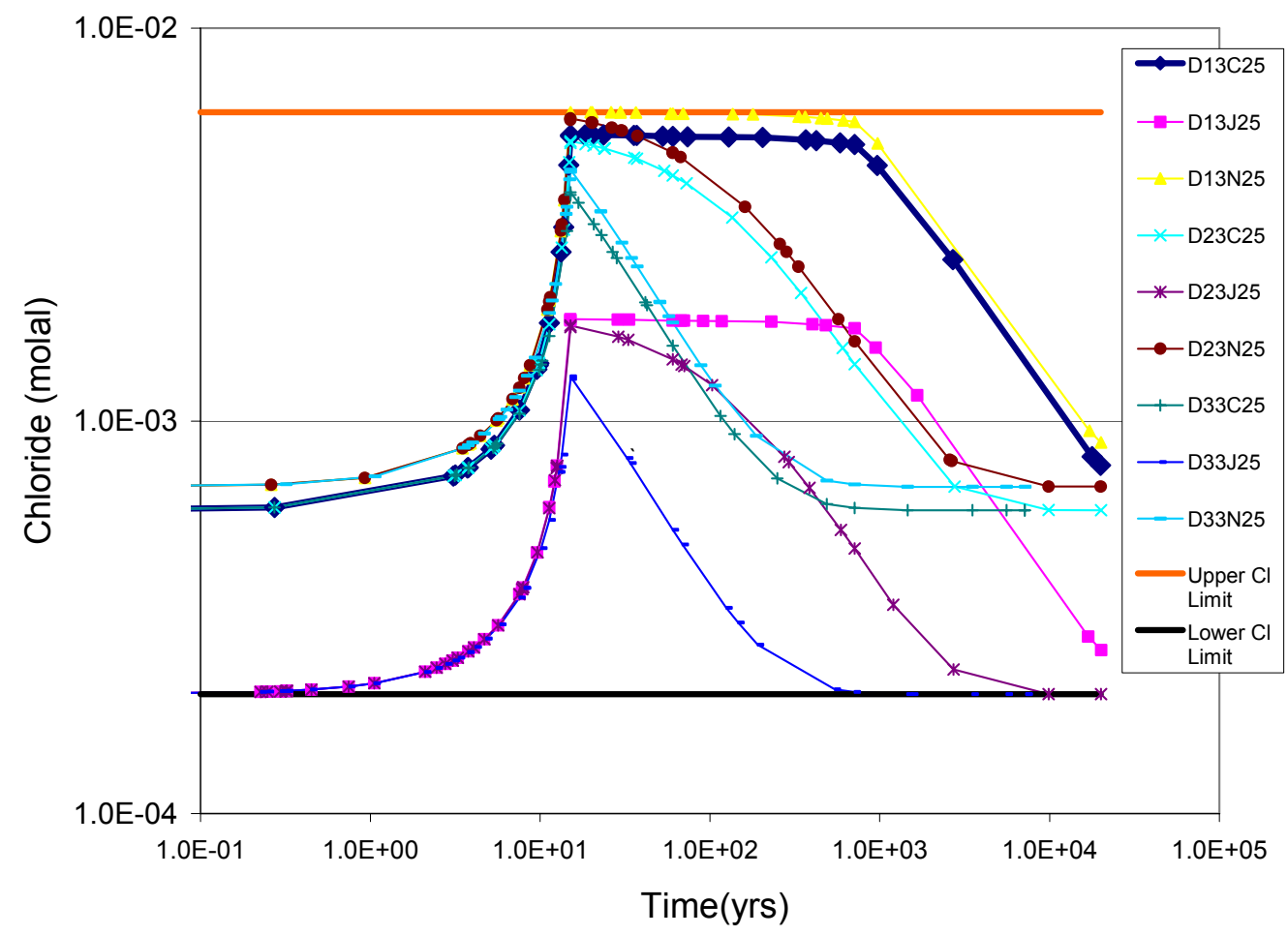

Source: CDSP_Water Influx_25.xls (Appendix F ISpreadsheets).

Figure 6-75. CDSP Water Influx Model $25^{\circ} \mathrm{C}$ Chloride Profiles and Abstraction Limits 


\subsubsection{Total Carbonate Abstraction}

Total carbonate is used in the kinetic rate expression for the dissolution of CSNF; therefore, abstracted values are needed for the TSPA-LA. The bulk solution total carbonate concentration should not be effected by carbonate surface complex reactions because of the large reservoir of atmospheric carbon dioxide available will maintain equilibrium with the bulk solution. In a system where the partial pressure of carbon dioxide $\left(\mathrm{CO}_{2}\right)$ is constant over the modeled period and the $\mathrm{pH}$ and temperature known, the total carbonate can be calculated using the equilibrium mass action expressions.

Where the total carbonate $(0<\mathrm{pH}<14)$ is equal to:

$$
\begin{array}{cc}
\multicolumn{1}{c}{\Sigma \mathrm{C}=\left[\mathrm{CO}_{2}(\mathrm{aq})\right]+\left[\mathrm{HCO}_{3}{ }^{-}\right]+\left[\mathrm{CO}_{3}{ }^{2-}\right]} \\
\mathrm{CO}_{2}(\mathrm{~g}) \Leftrightarrow \mathrm{CO}_{2}(\mathrm{aq}) \quad \operatorname{logK}=\mathrm{K}_{1} \quad\left[\mathrm{CO}_{2}(\mathrm{aq})\right]=p \mathrm{CO}_{2}(\mathrm{~g}) 10 \mathrm{~K}_{1} \\
\mathrm{CO}_{2}(\mathrm{aq}) \Leftrightarrow \mathrm{H}^{+}+\mathrm{HCO}_{3}^{-} \quad \operatorname{logK}=\mathrm{K}_{2} \quad\left[\mathrm{HCO}_{3}^{-}\right]=\left(p \mathrm{CO}_{2}(\mathrm{~g}) 10 \mathrm{~K}_{1} 10 \mathrm{~K}_{2}\right) / 10-\mathrm{pH} \\
\mathrm{HCO}_{3}{ }^{-} \Leftrightarrow \mathrm{H}^{+}+\mathrm{CO}_{3}{ }^{2-} & \operatorname{logK}=\mathrm{K}_{3} \quad\left[\mathrm{CO}_{3}{ }^{2-}\right]=\left[\left(p \mathrm{CO}_{2}(\mathrm{~g}) 10 \mathrm{~K}_{1} 10 \mathrm{~K}_{2}\right) / 10-\mathrm{pH}\right] 10 \mathrm{~K}_{3} / 10-\mathrm{pH}
\end{array}
$$

\begin{tabular}{|c|}
\hline $\begin{array}{l}\text { Equation of Total Carbonate } \\
(\mathrm{mol} / \mathrm{kg})\end{array}$ \\
\hline Total $\mathrm{C}=p \mathrm{CO}_{2}\left(10^{\mathrm{K}_{1}}+10^{\left(\mathrm{pH}+\mathrm{K}_{1}+\mathrm{K}_{2}\right)}+10^{\left(2 \mathrm{pH}+\mathrm{K}_{1}+\mathrm{K}_{2}+\mathrm{K}_{3}\right)}\right)$ \\
\hline Source: CSNF_Eh_Carb.xIs (Appendix F ISpreadsheets). \\
\hline $\begin{array}{l}\text { NOTE: } \mathrm{mol} / \mathrm{L} \sim \mathrm{mol} / \mathrm{kg} \text { except for concentrated brines or at high temperatures, or } \\
\text { both. }\end{array}$ \\
\hline
\end{tabular}

Combining terms and substituting back into expression (Eq. 6-25), the total carbonate for the system is equal to the expression in Table 6-33.

Table 6-33. Total Carbonate as a Function of $\mathrm{pH}$

Since the equilibrium constants for the carbonate species vary as a function of temperature, it is possible to derive expressions for $\mathrm{K}_{1}, \mathrm{~K}_{2}$, and $\mathrm{K}_{3}$ that include this functionality. The thermodynamic data from $0^{\circ} \mathrm{C}$ to $100^{\circ} \mathrm{C}$ for the carbonate species was extracted from

\begin{tabular}{|c|c|c|c|c|c|}
\hline \multirow[b]{2}{*}{$\log K$} & \multirow[b]{2}{*}{ Reaction } & \multicolumn{4}{|c|}{ Log $\mathrm{K}$ at Temperature } \\
\hline & & $0^{\circ} \mathrm{C}$ & $25^{\circ} \mathrm{C}$ & $60^{\circ} \mathrm{C}$ & $100^{\circ} \mathrm{C}$ \\
\hline $\mathrm{K}_{1}$ & $\begin{array}{l}\mathrm{CO}_{2}(\mathrm{~g})+\mathrm{H}_{2} \mathrm{O}=\mathrm{H}^{+}+\mathrm{HCO}_{3}^{-} \\
\underline{\mathrm{HCO}}_{3}^{-}+\mathrm{H}^{+}=\mathrm{CO}_{2}(\mathrm{aq})+\mathrm{H}_{2} \underline{\mathrm{O}} \\
\mathrm{CO}_{2}(\mathrm{~g})=\mathrm{CO}_{2}(\mathrm{aq})\end{array}$ & $\begin{array}{r}-7.6765 \\
+6.5804 \\
-1.0961 \\
\end{array}$ & $\begin{array}{r}-7.8136 \\
+6.3447 \\
-1.4689 \\
\end{array}$ & $\begin{array}{r}-8.0527 \\
+6.2684 \\
-1.7843 \\
\end{array}$ & $\begin{array}{r}-8.3574 \\
+6.3882 \\
-1.9692\end{array}$ \\
\hline $\mathrm{K}_{2}$ & $\mathrm{CO}_{2}(\mathrm{aq})+\mathrm{H}_{2} \mathrm{O}=\mathrm{HCO}_{3}^{-}+\mathrm{H}^{+}$ & -6.5804 & -6.3447 & -6.2684 & -6.3882 \\
\hline $\mathrm{K}_{3}$ & $\mathrm{HCO}_{3}^{-}=\mathrm{CO}_{3}^{2-}+\mathrm{H}^{+}$ & -10.6241 & -10.3288 & -10.1304 & -10.0836 \\
\hline
\end{tabular}
data0.ymp.R2 (DTN: MO0302SPATHDYN.000 [DIRS 161756]) and is compiled in Table 6-34. $\log \mathrm{K}_{1}$ (Table 6-34) is the result of combined expressions.

Table 6-34. Log K Values for the Carbonate Species at Temperature

Source: DTN: MO0302SPATHDYN.000 [DIRS 161756]. 
Log $\mathrm{K}$ temperature expressions were derived by plotting the $\log \mathrm{K}$ values from $0^{\circ}$ to $100^{\circ} \mathrm{C}$ (Table 6-35) versus their respective temperatures and fitting a polynomial to the data in Microsoft Excel. This is the same method used by the EQPT code when it compiles the log K grid of an EQ3/6 data0 file (Daveler and Wolery 1992 [DIRS 103803], p. 12). Therefore, consistency is maintained between the approach used in the model report and that used in EQ3/6.

Plots of the $\log \mathrm{K}$ temperature interpolations are included in CSNF_Eh_Carb.xls (Appendix $\mathrm{F}$ $\backslash$ Spreadsheets). The expressions in Table 6-34 are valid for temperatures in the range of $0^{\circ} \mathrm{C}$ to $100^{\circ} \mathrm{C}$. This range is larger than that for the $\mathrm{pH}$ abstractions $\left(25^{\circ} \mathrm{C}\right.$ to $\left.100^{\circ} \mathrm{C}\right)$ in Section 6.10 .1 .

Table 6-35. Log K Temperature Interpolation Functions for Total Carbonate Abstraction

\begin{tabular}{|c|l|c|}
\hline Log K & \multicolumn{1}{|c|}{ Log K expression $^{\mathbf{a}}$} & $\mathbf{R}^{\mathbf{2}}$ \\
\hline $\mathbf{K}_{\mathbf{1}}$ & ${\text { Log } \mathrm{K}_{1}=7 \mathrm{E}-05 \mathrm{~T}^{2}-0.0159 \mathrm{~T}-1.1023}_{0.9992}$ \\
\hline $\mathbf{K}_{\mathbf{2}}$ & $\operatorname{Log~K}_{2}=5 \mathrm{E}-07 \mathrm{~T}^{3}-0.0002 \mathrm{~T}^{2}+0.0132 \mathrm{~T}-6.5804$ & 1.0 \\
\hline $\mathbf{K}_{\mathbf{3}}$ & Log K $_{3}=-8 \mathrm{E}-05 \mathrm{~T}^{2}+0.0128 \mathrm{~T}-10.618$ & 0.9977 \\
\hline
\end{tabular}

Source: CSNF_Eh_Carb.xls (Appendix F ISpreadsheets).

NOTE: ${ }^{\mathrm{a}} \mathrm{T}=$ temperature in degrees Celsius.

Three feeds are required for the total carbonate abstraction, as it should be implemented in TSPA-LA. The first feed is the temperature that is required to calculate the appropriate $\log \mathrm{K}$ values. The second feed is the in-package $\mathrm{pH}$ that is estimated using the relationships and conditions specified in Sections 6.10.1. The third input is the $p \mathrm{CO}_{2}$. Once the $\log \mathrm{K}$ values and in-package $\mathrm{pH}$ are calculated they can be used to calculate the total carbonate via the expression in Table 6-33.

Since the $\mathrm{pH}$ abstractions account for propagated uncertainty, there is no need to introduce further uncertainty at the level of the total carbonate abstraction. Therefore, the carbonate abstraction can be used as is with no uncertainty term added to it.

Figure 6-76 shows the carbonate abstraction calculated at two temperatures compared to output from the model. The close agreement of the abstraction and the model output illustrates that the abstraction adequately reproduces the model output. 


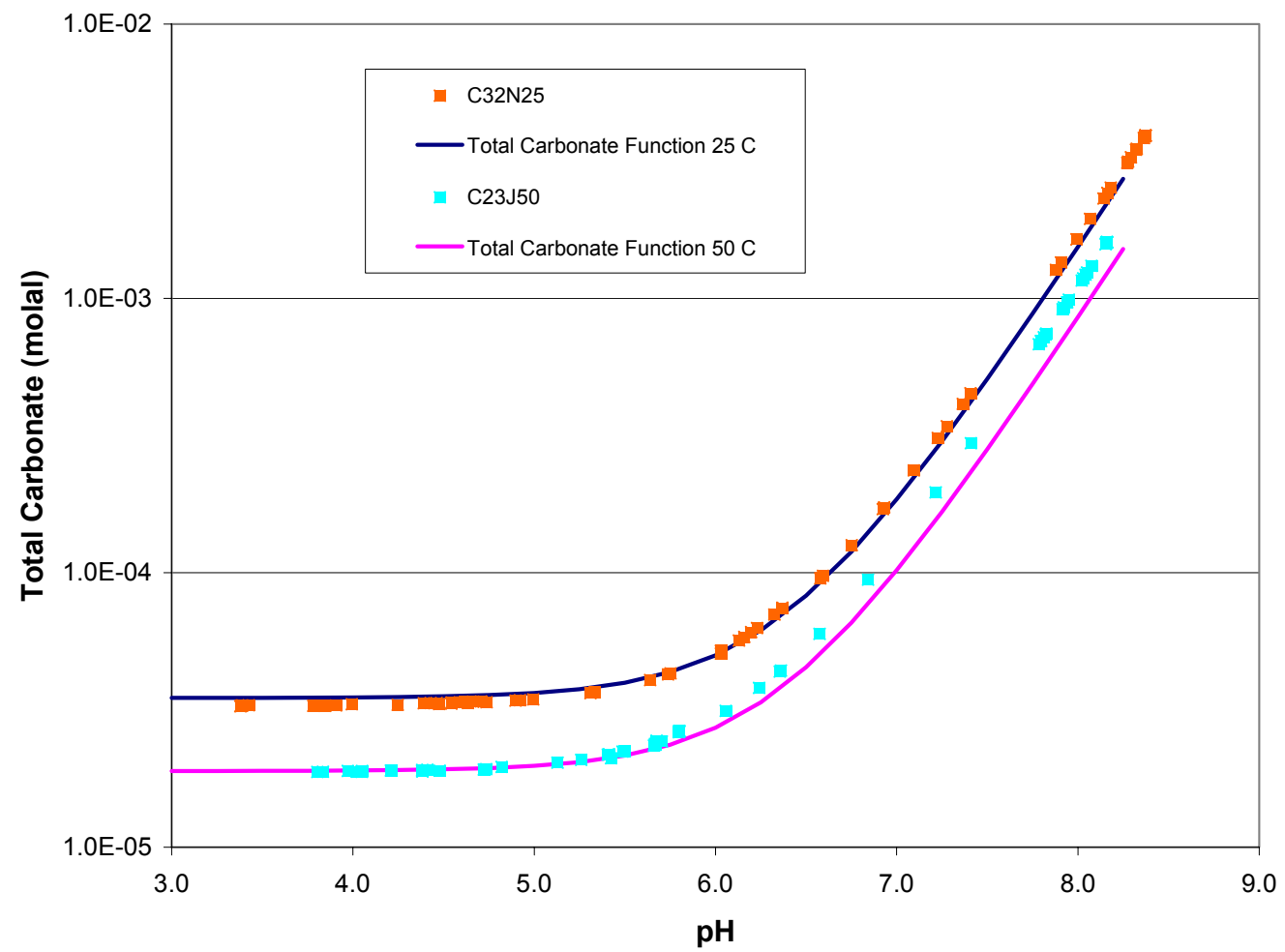

Source: CSNF_Eh_Carb.xls (Appendix F ISpreadsheets).

Figure 6-76. Total Carbonate Function Compared to Model Output at Two Temperatures

\subsubsection{Eh Abstraction}

In aqueous systems in equilibrium with a constant partial pressure of oxygen, the Eh may be calculated directly from the $\mathrm{pH}$. For the formation of water, the $\mathrm{pE}^{\circ}$ may be calculated from the following expression, where $\Delta \mathrm{G}^{\circ}$ is the Gibb's free energy of formation, $\mathrm{F}$ is the Faraday constant (23.06 kcal/volt-gram equivalent), Eh is the electron activity expressed in units of volts, and $\mathrm{pE}$ is the negative log base 10 of electron activity.

$$
1 / 2 \mathrm{O}_{2}+2 \mathrm{H}^{+}+2 \mathrm{e}^{-}=\mathrm{H}_{2} \mathrm{O}
$$

$\Delta \mathrm{G}^{\circ}=-56.688 \mathrm{kcal} / \mathrm{mol}$ (DTN: MO0302SPATHDYN.000 [DIRS 161756])

$$
\Delta \mathrm{G}^{\circ}=-\mathrm{nFEh}^{\circ}
$$

(Drever 1982 [DIRS 100725], p. 254, Equation 11-6)

$$
\mathrm{pE}=\mathrm{F} /(2.303 \mathrm{RT}) \mathrm{Eh}
$$

(Drever 1982 [DIRS 100725], p. 254) 
Solving Equation 6-28 for Eh and substituting into Equation 6-27 results in Equation 6-29, establishing a relationship between $\Delta \mathrm{G}^{\circ}$ and $\mathrm{pE}^{\circ}$ :

$$
\Delta \mathrm{G}^{\circ}=-2.303 n R T\left(\mathrm{pE}^{\circ}\right)
$$

Where, $\mathrm{n}=$ number of electrons [2], $\mathrm{R}=$ Gas Constant $(1.987 \mathrm{E}-03 \mathrm{kcal} / \mathrm{mol} \cdot \mathrm{K}), p \mathrm{O}_{2}$ is the partial pressure of oxygen, and $\mathrm{T}=$ absolute temperature (Kelvin).

Solving for $\mathrm{pE}^{\circ}$ with temperature dependency results in:

$$
\mathrm{pE}^{\circ}=6193.973 / \mathrm{T}
$$

Thus, for the formation of water in terms of one electron mole:

$$
\begin{gathered}
1 / 4 \mathrm{O}_{2}+\mathrm{H}^{+}+\mathrm{e}^{-}=1 / 2 \mathrm{H}_{2} \mathrm{O} \\
\mathrm{pE}=\mathrm{pE}^{\circ}+\log \left(p \mathrm{O}_{2}{ }^{1 / 4}\left[\mathrm{H}^{+}\right]\right) \\
\mathrm{pE}=6,193.973 / \mathrm{T}-\mathrm{pH}+0.25 \log \left(p \mathrm{O}_{2}\right)
\end{gathered}
$$

Converting to Eh gives the expression in Table 6-36. The expression for Eh as a function of $\mathrm{pH}$, oxygen partial pressure, and temperature (Table 6-36) is applicable for both CSNF and CDSP waste packages. The temperature should be input in degrees Kelvin, and the output is in volts.

Table 6-36. Eh as a Function of $\mathrm{pH}, \mathrm{pO}_{2}$, and Absolute Temperature

\begin{tabular}{|c|}
\hline $\begin{array}{c}\text { Equation of Eh } \\
\text { (volts) }\end{array}$ \\
\hline $\mathrm{Eh}=2.303 \mathrm{RT} / \mathrm{F}\left(6193.973 / \mathrm{T}-\mathrm{pH}+0.25 \log \mathrm{pO}_{2}\right)$ \\
\hline
\end{tabular}

Source: CSNF_Eh_Carb.xls (Appendix F ISpreadsheets).

Figure 6-77 shows the Eh abstraction function plotted with the model output from the $25^{\circ} \mathrm{C}$ and $50^{\circ} \mathrm{C}$ runs for the median case. Again, fluids are expected to be uniformly oxidizing. Variations in Eh come from $\mathrm{pH}$ shifts. Like the carbonate abstraction, uncertainty is built into the Eh abstraction by virtue of the input $\mathrm{pH}$, which already has associated uncertainty. 


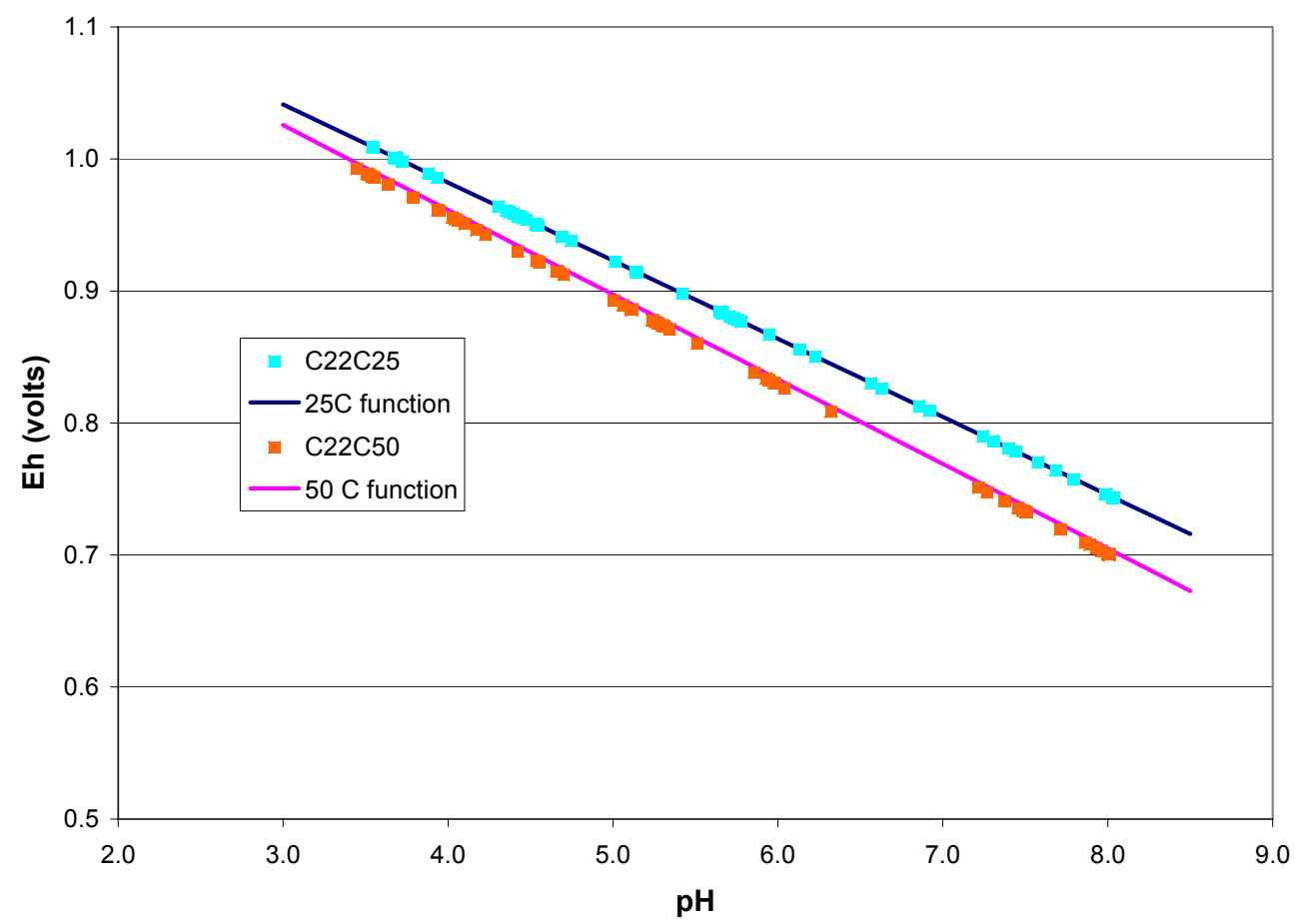

Source: CSNF_Eh_Carb.xls (Appendix F ISpreadsheets).

Figure 6-77. Eh Function Compared to Model Output at Two Temperatures

\subsubsection{Linking the Vapor Influx and Water Influx Model for TSPA-LA}

In a potential repository situation, one could imagine a scenario where a waste package could be breached under vapor influx conditions, and then at some future time, it is possible that seepage might also enter this same waste package and react with the remaining materials. The opposite sequence might also occur, where seepage enters a waste package and at some future time the seepage might cease and vapor influx conditions would prevail. This would be a scenario where the vapor influx model and the water influx model would need to be linked. In Section 6.5.2 it was demonstrated that the initial composition of the seepage entering a breached waste package did not exert a significant influence on the resulting in-package chemistry. As Figures 6-78 to 6-79 demonstrate, the results of the water influx model follow similar behavior as the ensemble outputs from the vapor influx model.

Based on the comparison of the results in Figure 6-78 and Figure 6-79, it is recommended that for the purposes of TSPA-LA, should it be necessary to link the vapor influx model and the water influx model, the change from one model to the other should occur synchronously. If a package is initially receiving water vapor and at some later time seepage begins to enter the package, then the vapor influx abstraction should cease and the seepage abstraction should begin at that in point. 


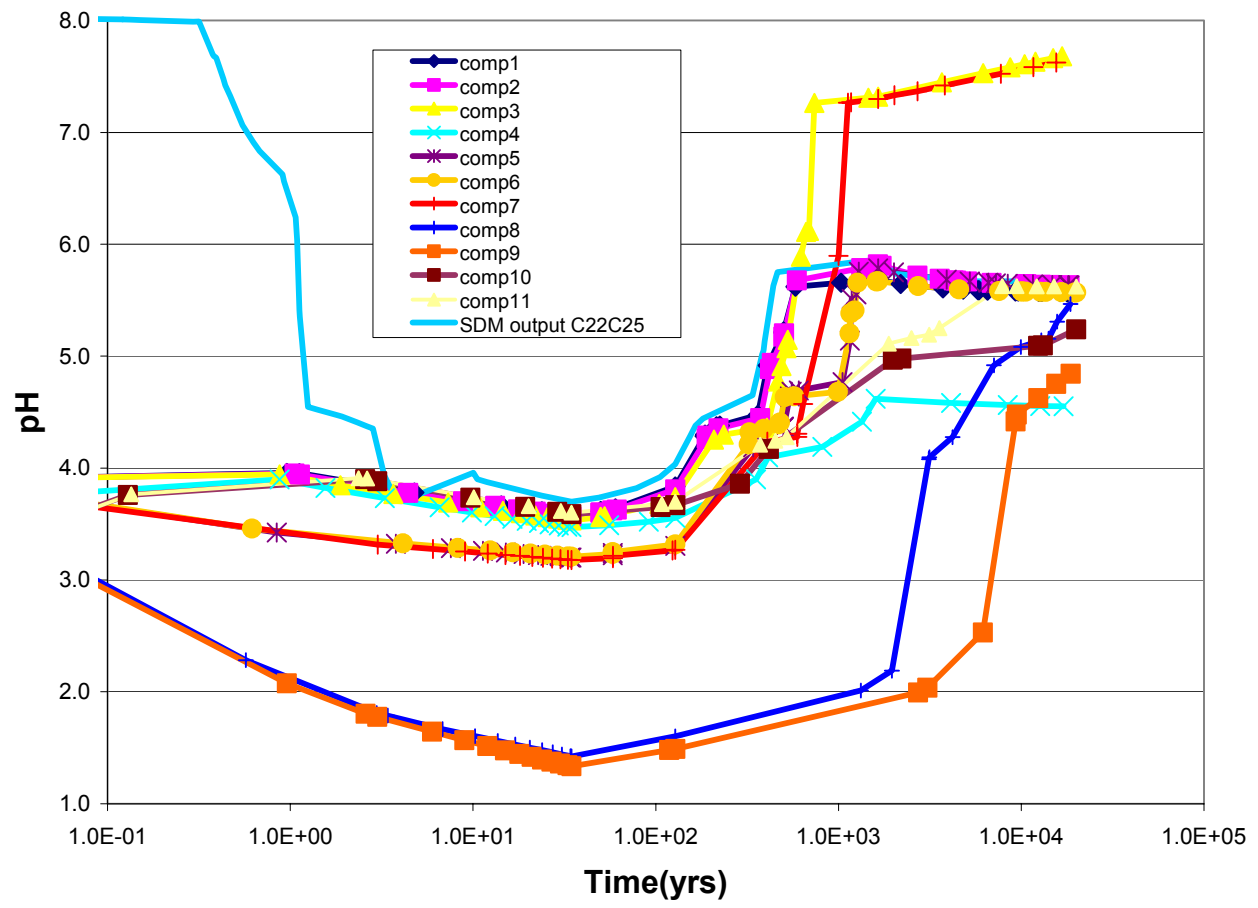

Source: CSNF_Sensitivity.xIs (Appendix F ISpreadsheets).

Figure 6-78. CSNF Vapor Influx-Water Influx Model Comparison

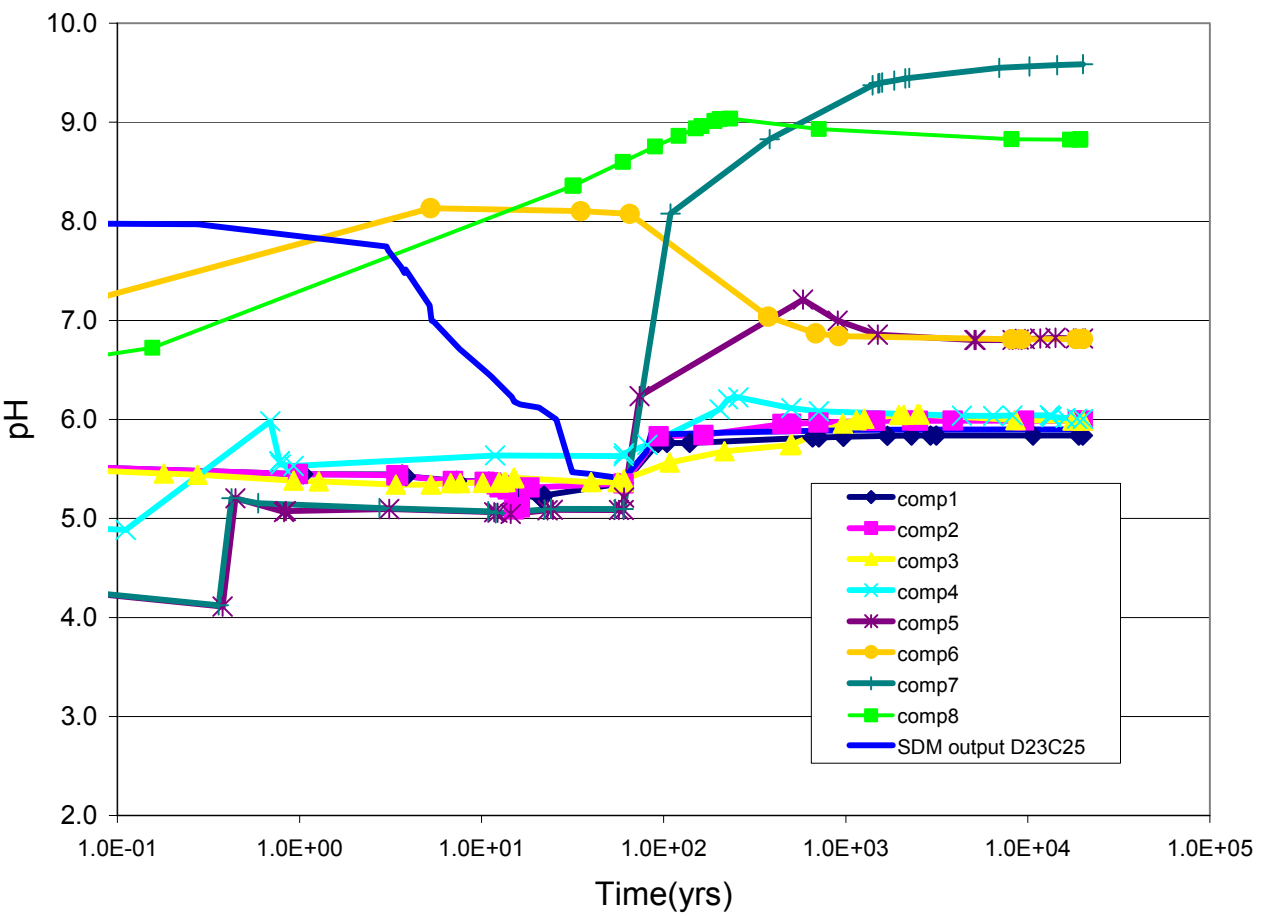

Source: $\quad C D S P \_S e n s i t i v i t y . x / s$ (Appendix F ISpreadsheets).

Figure 6-79. CDSP Vapor Influx-Water Influx Model Comparison 


\subsubsection{Output Uncertainty}

The in-package chemistry model combines two approaches to model uncertainty: (1) application of a factorial design approach to account for known large potential variations in model input (reactant combinations, water flux, fuel exposure, temperature, and seepage composition; and (2) sensitivity analysis of lesser known, not as well-defined input variations (carbon dioxide partial pressure, Carbon Steel Type A516 sulfur content, corrosion rates, and extreme temperatures and flux values). Where (1) provided the functional basis of the in-package chemistry model abstraction, (2) provided the uncertainty ranges of the abstracted parameters. Thus, the information to be used in TSPA-LA directly incorporates uncertainty exterior to the in-package environment (1) and interior to the in-package environment in a form that can be readily implemented in TSPA-LA (i.e., model uncertainty is propagated through the abstractions). Thus, the only restrictions on the subsequent use of the in-package chemistry model abstraction in TSPA-LA are that all of the abstractions presented in Section 6.10 must be applied within the stated limits (flux, temperature, $f \mathrm{CO}_{2}$, and fuel exposure) as specified in this report.

\subsubsection{Model Abstraction Conclusions}

The inputs to the batch reactor model are scaled according to their surface area, and the base case considers the waste package void space to be approximately half filled with water. The other half of the void space is filled with air in equilibrium with the drift atmosphere (Section 6.3.1). Sensitivity studies were conducted that varied the ratio of water to air (Section 6.6.1) and the composition of the air in contact with the water (Section 6.6.4). Therefore, the chemical effects of the void space (composition and quantity) have been investigated and incorporated into the model.

The batch reactor model generally considers the redox potential to be fully oxidizing, and this modeling assumption is discussed in Section 6.3.1.1. The redox potential is varied in a sensitivity analysis in Section 6.6 .4 by using lower fixed $f_{2}$ values, including the adjusted Eh model used in the dissolved concentration model, all the way down to $\log f \mathrm{O}_{2}=-69$. The sensitivity shows that the $\mathrm{pH}$ and ionic strength results are sensitive to the $\mathrm{fO}_{2}$ values, so the results of this sensitivity were used to develop the $\mathrm{pH}$ limits and the uncertainty to be applied to the ionic strength abstraction (Section 6.10.2.3).

The batch reactor model generally allows reactions to reach thermodynamic equilibrium, and this modeling assumption is discussed in Section 6.3.1.1 and the most important species, chromium species, are examined in more detail in Section 6.6.3. This sensitivity examines the impact of allowing kinetics to control the oxidation state, allowing only $\mathrm{Cr}$ (III) species to form. The sensitivity shows that the ionic strength results are sensitive to the oxidation state, so the results of this sensitivity were used to develop the uncertainty to be applied to the ionic strength abstraction (Section 6.10.2.3).

The sensitivity studies involving changes in design (Sections 6.6.7, 6.6.8, 6.6.9, and Appendix A) show that minor changes to the waste package or waste form design will not impact the results of this model. This conclusion applies to the design changes that call for the replacement of Neutronit with a NiGd alloy, or the addition of a purge port. 
The above discussion addresses the subject matter of "Included" FEPs 2.1.01.02.0B (Interactions between co-disposed waste), 2.1.02.09.0A (Chemical effects of void space in waste package), 2.1.09.01.0B (Chemical characteristics of water in waste package), 2.1.09.06.0A (Reductionoxidation potential in waste package), 2.1.09.07.0A (Reaction kinetics in waste package), 2.1.09.02.0A (Chemical interaction with corrosion products), 2.1.11.08.0A (Thermal effects on chemistry and microbial activity in the EBS), and 2.2.08.12.0B (Chemistry of water flowing into the waste package) and indicates how that subject matter has been included and addressed within TSPA-LA. 


\section{INTENTIONALLY LEFT BLANK}




\section{VALIDATION}

The purpose of the in-package chemistry model and the in-package chemistry model abstraction is to predict the bulk chemistry inside of a breached waste package and to provide simplified expressions of that chemistry for use in TSPA-LA. The technical work plan (BSC 2004 [DIRS 171583], Table 2-1) states that the postdevelopment validation of the model will focus on the three submodels. The fuel-degradation submodel will be validated by comparison with results from laboratory experiments published in refereed journals or literature. The types of minerals formed and the aqueous concentrations predicted by the model will be compared to experimental results to quantify the uncertainty range of the model. The steel-degradation submodel will be validated based on results published from laboratory experiments on man-made analog materials. The surface-complexation model will be validated by technical review.

Typical validation efforts outlined in the technical work plan and cited above were subsequently considered to provide insufficient confidence for predicting in-package chemistry over the much longer time spans to which the model is to be applied. Consequently, in addition to the validation methods outlined in the technical work plan, model validation efforts focused on natural analogue observation that might provide confidence in model predictions over near geologic time spans.

The primary output of the in-package chemistry model abstraction to total system performance assessment are ranges of $\mathrm{pH}$ and ionic strength. Adequate validation of the in-package chemistry model, therefore, entails showing on the basis of natural analogue evidence that the $\mathrm{pH}$ and ionic strength ranges are comparable.

The salient critical features of the in-package chemistry model are:

1. Alkaline waters $(\mathrm{pH}>7$, from comp_7 and comp_8 in Figure 6-5) formed by interaction of dilute solutions with waste form glass dissolution

2. Acidic waters $(\mathrm{pH}<7$, from comp_1 through comp_5 in Figure 6-5 and Figure 6-17) formed by interaction of incoming solutions with certain waste package components

3. Production of high ionic strength solutions (greater than $1 \mathrm{M}$ ) and low ionic strength solutions (less than $0.05 \mathrm{M}$ ) by reaction with waste form and waste package components (Section 6.10.2)

4. Buffering to intermediate $\mathrm{pH}$ values via interaction of fluids with corrosion products, (i.e., surface complexation) (Table 6-21).

\subsection{DOCUMENTED DECISIONS AND ACTIVITIES IMPLEMENTED DURING MODEL DEVELOPMENT PROCESS}

The technical work plan (BSC 2004 [DIRS 171583], Table 2-1) indicates that the in-package chemistry model requires a medium level of confidence (Level II) because of the in-package chemistry output impact, $\mathrm{pH}$, on plutonium and neptunium solubility. 
Achieving Level I criteria requires a single postdevelopment model validation method. Achieving Level II criteria requires satisfying Level I criteria and providing rationale for the selection of that postdevelopment model validation method.

Satisfying Level I criteria entails demonstrating that the model development efforts include:

(a) Evaluating and selecting input parameters and data: Section 4.1 provides the inputs used in the in-package chemistry model, which include waste package design information, material compositions, atomic weights, densities, water compositions, waste forms compositions, corrosion or reaction rates, and thermodynamic data. These inputs were chosen to best represent all of the components of the in-package chemistry model. Therefore, this criterion has been met for all of the salient features.

(b) Formulating defensible assumptions and simplifications: Sections 5, 6.3.1, and 6.3.2 provide the assumptions (Section 5) and simplifications (Sections 6.3.1 and 6.3.2) used in the in-package chemistry model. All model assumptions and simplifications have been shown to be either conservative or captured within the uncertainty of the model. Therefore, this criterion has been met for all of the salient features of the model.

(c) Ensuring consistency with physical principles, such as conservation of mass, energy, and momentum: Sections 6.3, 6.3.1, and 6.3.2 provide brief discussions of the EQ6 geochemical modeling software used for the in-package chemistry model simulations. EQ6 conserves mass, both of solids and water; therefore, the in-package chemistry model also conserves these properties. This criterion has been met for all of the salient features.

(d) Representing important future state (aleatoric), parameter, and alternative model uncertainties: Unexpected random (aleatoric) events are outside of the realm of the in-package chemistry model. However, the in-package chemistry model was designed to be robust enough to handle large changes in temperature, flux, and seepage composition. Alternate conceptual models were discussed in Section 6.4 and the current in-package chemistry model robustness eliminates the need for these alternate conceptual models. Therefore, this criterion has been met for all of the salient features.

(e) Ensuring simulation conditions have been set up to span the range of intended use and the avoidance of inconsistent outputs: Sections 6.3.1 and 6.3.2 outline the wide range of inputs (flux, fuel exposure, temperature, reactant combinations) that were used in the in-package chemistry model. These conditions span the range of intended use in TSPA-LA for which the in-package chemistry model will be used. Therefore, this criterion has been met for all of the salient features.

(f) Ensuring that model predictions (performance parameters) adequately represent the range of possible outcomes, consistent with important uncertainties: Sections 6.3.1 and 6.3.2 provide the input conditions that span the range of the intended use of the model; thus, logic dictates that the range of outputs (performance parameters) also represents the range of possible outcomes. Additionally, sensitivity analyses have been performed to expand the performance parameters to values consistent with important 
conditional uncertainties. Therefore, this criterion has been met for all of the salient features.

\subsection{POST-MODEL DEVELOPMENT VALIDATION METHODS}

Level II validation includes one method of postmodel development validation consistent with a model of moderate importance to mean annual dose and documentation of the rationale for selection of postmodel development activities.

\subsubsection{Rationale for Selection of Validation Methods}

The technical work package (BSC 2004 [DIRS 171583], Table 2-1) names three methods for validation, different methods for different aspects of the model report, and these methods are listed in Table $7-1$.

Table 7-1. Validation Criteria, Activities, and Metrics

\begin{tabular}{|l|l|}
\hline \multicolumn{1}{|c|}{ Validation Criteria / Activities } & \multicolumn{1}{|c|}{ Metric / Criteria } \\
\hline $\begin{array}{l}\text { Is the fuel-degradation model consistent with results from } \\
\text { laboratory experiments published in refereed journals or } \\
\text { literature? (VA 1, 3) }\end{array}$ & \\
\cline { 1 - 2 } $\begin{array}{l}\text { Are the types of minerals formed and the aqueous } \\
\text { concentrations predicted by the model consistent with } \\
\text { experimental results? (VA 1) }\end{array}$ & The criteria for meeting all of the \\
corroborating validation activities \\
$\begin{array}{l}\text { Is the steel-degradation model consistent with results from } \\
\text { laboratory experiments on man-made analog materials? } \\
\text { (VA 1) }\end{array}$
\end{tabular}

NOTE: VA is validation activity as defined in AP-SIII.10Q, Section 5.3.2c.

For the fuel-degradation and the steel-degradation portion of the model, the results were compared to experimental data from laboratories because the laboratory experiments were conducted in various environments intended to capture the possible range of conditions anticipated to exist in the repository.

Comparison of the existing data with information about either natural or man-made analogs was determined to be the most appropriate method to validate the model results regarding the types of minerals that are anticipated to form in the waste package prior to and following any postulated breaches. This selection was based on the conclusion that data regarding the long-term 
environmental performance (i.e., 10,000 or more years) addressed by the model would be difficult to duplicate in the laboratory and the use of analogs presented the best opportunity to provide a meaningful comparison with the model outputs of interest (i.e., pH, ionic strength data) that are developed and discussed in Section 6.10.

The validation of the surface complexation model introduces additional challenges due to the relatively new analytical approach to buffering $\mathrm{pH}$ that is used in the model. The surface complexation model is based in large part on the most readily available experimental data regarding this subject, and the limited, if any, availability of information regarding the surface complexation of natural or man-made analogs. As a result, the use of an independent technical review by an individual with appropriate expertise was deemed to be the most appropriate method of validation for the surface complexation model. Dr. Yifeng Wang, Principal Member of Technical Staff, Sandia National Laboratories, a recognized expert in the field of geochemistry, with a Ph.D. from the Dept. of Geological Sciences, Indiana University, was selected to review and report on the model developed herein. Dr. Wang's independent review was conducted in accordance with the requirements of Technical Work Plan for: Regulatory Integration Modeling and Analysis of the Waste Form and Waste Package (BSC 2004 [DIRS 171583]) and the results are reported in Appendix E.

\subsubsection{Fuel-Degradation Model Consistent with Results from Laboratory Experiments}

The fuel degradation model was derived from laboratory experiments done by DOE contractors, which are themselves consistent with results published in refereed journals and literature (BSC 2004 [DIRS 169987]). In particular, the CSNF degradation rate law is broadly consistent with that proposed by Grambow (1989 [DIRS 113233]). The HLW glass degradation model is consistent with experimental and literature data (BSC 2004 [DIRS 169988], Table 7-1). The DSNF degradation model is consistent with experimental data (BSC 2004 [DIRS 167618], Section 6.1.7).

\subsubsection{Types of Minerals Formed Consistent with Experimental Results}

The primary phases predicted to form in the model are ferric (hydr)oxides (hematite, goethite, etc.) from steel corrosion, and schoepite from the degradation of spent fuel. Steel is observed in nature and in experiments to corrode to metal oxides whose specific identities depend upon the particular conditions of corrosion and the composition of the steel. Hematite and goethite are routinely observed as the final corrosion end products (Schwertmann and Taylor 1995 [DIRS 105959]). Schoepite is observed as an alteration product in experiments (BSC 2004 [DIRS 169987]) and at the Pena Blanca natural analogue (Langmuir 1997 [DIRS 100051], p. 512). The aqueous concentrations of, respectively, Fe and $U$ in fluids in contact with ferric hydroxides and schoepite tend to be fixed by the presence of these solids (Langmuir 1997 [DIRS 100051]; Stumm and Morgan 1996 [DIRS 125332]).

\subsubsection{Steel-Degradation Model Consistent with Results from Laboratory Experiment}

The steel degradation rates were derived from a compilation of laboratory experiments and are therefore implicitly consistent. Moreover, this range of rates, 4 to $131 \mu \mathrm{m} / \mathrm{yr}$ for low carbon steel, is somewhat higher but otherwise broadly consistent with the rates determined from iron 
archeological artifacts, 0.1 to $10 \mu \mathrm{m} / \mathrm{yr}$ (Miller et al. 2000 [DIRS 156684], p. 101). The latter probably saw lower temperatures than the data from which the rate model was derived. The stainless steel degradation rates cover a broad range of rates and are consistent with many experimental results documented in Aqueous Corrosion Rates for Waste Package Materials (BSC 2004 [DIRS 169982]).

Recent experimental work was conducted on "corrosion of miniature waste packages" (Zarrabi et al. 2003 [DIRS 171238]) in bathtub and flow-through configurations. The x-ray diffraction (XRD) analysis of the corrosion products revealed a variety of ironoxyhydroxide minerals formed, regardless of the chemical conditions of inflow water to the miniature waste packages. The corrosion products were mainly goethite $(\mathrm{FeO}(\mathrm{OH}))$, lepidiocrocite $(\mathrm{FeO}(\mathrm{OH}))$, magnetite $\left(\mathrm{FeFe}_{2} \mathrm{O}_{4}\right)$, and maghemite- $\mathrm{C}\left(\mathrm{Fe}_{2} \mathrm{O}_{3}\right)$. Hematite was not observed, likely due to the short duration of the experiment. But, these minerals are consistent with other experimental work that did see the formation of hematite (Pednekar 1987 [DIRS 159329]).

In the XRD analysis, the most noticeable factor in the formation of minerals is the availability of oxygen to iron. The ratio of oxygen to iron in hematite $\left(\alpha-\mathrm{Fe}_{2} \mathrm{O}_{3}\right)$, goethite $(\alpha-\mathrm{FeOOH})$, and lepidocrocite $(\gamma-\mathrm{FeOOH})$ is 1.50 , whereas for magnetite $\left(\mathrm{Fe}_{3} \mathrm{O}_{4}\right)$, it is 1.33 . In dynamic systems (bathtub and flow-through configurations), formation of goethite is favored over hematite. However, the thermodynamic stability of these two minerals, in the presence of water, is very similar. The mineral that actually begins to form typically depends on the nature of the substrates upon which the mineral begins to grow. Once started, that mineral will generally persist, even though it may not be the most stable. These results are consistent with many available "natural analogs" that point in the same direction. For example, piles of buried Roman nails found in England revealed corrosion products corresponding to $\mathrm{Fe}_{2} \mathrm{O}_{3}$ that is similar to composition of goethite and hematite (Angus et al. 1962 [DIRS 167071]).

In the same study (Zarrabi et al. 2003 [DIRS 171238]), changes in $\mathrm{pH}$ and conductivity of several inflow solutions with different compositions were monitored. In one case, the $\mathrm{pH}$ of the inflow was adjusted to 2.1, and the outflow $\mathrm{pH}$ increased for the first week to 4.9 and then stabilized to a $\mathrm{pH}$ of 4.2. In the same experiment, conductivity of the effluent decreased from its original values of about 4,030 $(\mu \mathrm{S})$ to about 1,950 $(\mu \mathrm{S})$ and remained low for the duration of the experiment. This indicates the buffering capacity of carbon steel corrosion products.

In summary, this experiment validates the types of corrosion products that form from steel corrosion and also supports the $\mathrm{pH}$ trends used in the surface complexation model.

\subsection{5 pH and Ionic Strength Consistent with Natural Analogue Observation}

Because the output will be applied over geologic time spans, the specific outputs of this model ( $\mathrm{pH}$, ionic strength) are compared to natural analogue observation (rather than experimental data). 


\subsubsection{Production of Alkaline Waters by Glass Dissolution}

Glass dissolution causes $\mathrm{pH}$ values greater than 7 when protons from solution exchange with alkalis, typically $\mathrm{Na}^{+}, \mathrm{K}^{+}$, or $\mathrm{Ca}^{2+}$, present at the dissolving glass-solution interface, e.g.:

$$
\text { Glass- } \mathrm{Na}^{+}+\mathrm{H}^{+} \leftrightarrow \mathrm{Na}^{+}+\text {Glass- } \mathrm{H}^{+}
$$

The general link between dissolution of alkali-bearing silicate minerals and glasses with acidity destruction (alkalinity production) is amply documented in the peer-reviewed scientific literature. Typically, large-scale weathering of alkali-bearing silicates ultimately leads to high pH values in alkali lakes (Berner and Berner 1987 [DIRS 161746], pp. 280 to 281). Experiments seeking to mimic interaction of seawater with basaltic glass on the ocean floor occasionally observe alkaline $\mathrm{pH}$ values (note that basaltic glass is generally considered to be an appropriate natural analogue for nuclear waste glass (Ewing and Haaker 1979 [DIRS 161749]).

Because basaltic glass is an appropriate analog for waste glass, the alkaline, long-term $\mathrm{pH}$ values calculated for glass-bearing packages should be similar to those of ground waters from basalt formation and other rock types of basaltic composition. In his authoritative review of the chemistry of natural waters, Hem (1995 [DIRS 115670]) gives the analyses of two basalt ground waters and one water from a tuff containing the basaltic mineral olivine. The basalt waters have pH values of 7.8 and 7.9 (Hem 1995 [DIRS 115670], Table 12, Analyses 4 and 5) and water from an olivine tuff has a pH of 8.2 (Hem 1995 [DIRS 115670], Table 16, Analysis 3).

Besides saturated environments, such as lakes and deep groundwater mentioned above, increases in $\mathrm{pH}$ due to degradation of glass have also been observed in unsaturated environments that are more analogous to repository conditions. A study of the natural alteration of ancient vitreous slags (the glassy refuse that remains after the smelting of metallic ore) found that all samples (100 to 4,000 years old) had a first stage of weathering in which the solution $\mathrm{pH}$ increased due to the reaction of the protons of the solution in the acid environment with the vitreous slags. This was found for different chemical compositions of glass and for different weathering environments, from open-air stacks to underground conditions. If sufficient oxygen exists, such as in the case of the open-air samples, the second stage involves further increases in $\mathrm{pH}$ toward a neutral to moderately basic environment, as the dissolution of the glass skeleton proceeds (MahéLe Carlier et al. 2000 [DIRS 171509]).

In short, the high-end $\mathrm{pH}$ values predicted by the single component HLWG runs in the in-package chemistry model are corroborated by natural observations documented in the peer-reviewed literature. This, in tandem with the satisfaction of Level I criteria (a) through (f), therefore, provides sufficient justification for a Level II validation for this particular feature of the in-package chemistry model. On the basis of meeting the criteria for this feature, the level of confidence has been met.

\subsubsection{Lower Limits to $\mathrm{pH}$ Inside the Package}

$\mathrm{pH}$ values inside the degrading waste form are predicted to be between 4.5 and 8.5. The chemical makeup of the waste form corrosion products will be dominated by metal oxides and hydroxides similar to natural soils. The $\mathrm{pH}$ values in natural waters typically only become more 
acidic than 4.5 when high levels of organic acids are present, or when reduced sulfur is oxidized. Hem (1995 [DIRS 115670], Table 13, Analyses 1 and 4; Table 14, Sample 7) gives analyses of natural waters with $\mathrm{pH}$ values of 4.0,3.8, and 3.0, respectively. These waters all contain relatively high proportions of dissolved sulfate, indicating that the source of their acidity is the oxidation of reduced sulfur. Oxidation of reduced sulfur is also a major source of acidity in waters corroding waste package materials, particularly the low carbon steel. The levels of reduced sulfur in the waste package are too low to exceed the pH-buffering capacity of the corrosion products themselves (Section 6.7.1). Given a relative absence of high organic acids and reduced sulfur, the in-package chemistry model predicts low-end $\mathrm{pH}$ values of 4.5 . This low-end $\mathrm{pH}$ value is similar to the $\mathrm{pH}$ values of natural waters that contain little dissolved organic acids, and which are not influenced by sulfide oxidation, such as those described in Hem (1995 [DIRS 115670]), validating the model predictions of low-end $\mathrm{pH}$ values.

\subsubsection{Neutralization of Alkaline and Acidic Waters}

This section describes the neutralization of the alkaline waters produced by the dissolution of the HLWG (Section 7.2.5.1) and the acidic waters produced by the oxidation of the sulfur in the low carbon steels (Section 7.2.5.2). This neutralization is shown by comparing the $\mathrm{pHs}$ generated by the single components of the CDSP waste package in Figure 6-4 with the combined reactants shown in Figure 6-5. The concept of acids and bases neutralizing one another is a generally accepted fact and does not require validation.

\subsubsection{Production of Extreme Ionic Strength Solutions}

High ionic strength solutions ( $>1$ molal) are predicted to form when low volumes of fluid remain in contact with soluble waste form and waste package components for long periods of time. This observation is validated by the observation that older geologic fluids tend to be saltier than younger ones that have had less time to react with solids (Drever 1982 [DIRS 100725]).

Low ionic strength solutions $(<0.05$ molal $)$ are predicted to form when high volumes of water flow past the waste form and waste package components or when water only contacts the HLWG and aluminum alloy without contacting any other waste package materials. These low ionic strengths are conservative for colloid stability and thus result in the greatest radionuclide release in advective flow conditions, and therefore do not require validation.

\subsubsection{Relationship Between Ionic Strength and Flow Rate}

Freeze and Cherry (1979 [DIRS 101173], Figure 7.17(b)) show the relationship between groundwater flow rate and concentration of solution for a constant reaction rate. The plot shows that water flowing at a higher flow rate, but same degradation rate and same flow distance will have a lower concentration than water flowing at a lower flow rate. For the in-package system, this is equivalent to saying that if water is flowing through the waste package, the water with the highest flow rate will exit the waste paste with the lowest ionic strength. This behavior is exhibited in this model as shown in Figure 6-13 and Figure 6-14 for CSNF, and Figure 6-22 and Figure 6-23 for CDSP. 


\subsubsection{Surface Complexation Model}

A technical review of the surface complex model was conducted and is documented in Appendix E. The reviewer, Yifeng Wang, who was independent of the development and checking of the document, concluded:

A simplified version of surface complexation model, described by an analytic equation, is used in the package chemistry. I have checked the derivation of the equation, and no error has been found. The prediction of the equation has been confirmed by PHREEQC calculations.

In general, the surface complexation model developed for in-package chemistry is adequate for its intended use, i.e., to provide a more realistic prediction of in-package $\mathrm{pH}$.

Therefore, the surface complexation model has been validated by means of a technical review.

\subsection{ABSTRACTION VALIDATION}

This abstraction model uses mathematical relationships and statistical distributions to fit product output (i.e., product output is used as input for the abstraction). Thus, product output was used to generate the abstraction model (i.e., to generate the mathematical relationships and statistical distributions that will be used in TSPA-LA). Therefore, the acceptance criterion, for the abstraction relationships, is that they reflect the product output used in their generation. In other words, validation of the abstraction model requires comparison of abstracted parameter values to their corollary product output parameter values. It must be emphasized that this does not constitute validation of the product output, but only that the abstraction can reproduce a subset of the process model output through the use of mathematical relationships.

Validation of the CSNF and codisposal ionic strength abstractions is implicit in the method by which they were developed. The validation process used for the $\mathrm{pH}$ abstractions was a comparison of the abstracted $\mathrm{pH}$ for each time period to the product output value for a given set of input parameters. The response surfaces are mathematical constructs whose limits were set by the process models inputs and outputs. The ionic strength abstractions represent a best fit to the process model data, and are, therefore, able to reproduce the process model output for given set of input conditions within a range of uncertainty; thus, rendering them self validating. The ionic strength abstraction validation plots for the response surfaces, linear, and nonlinear relationships are contained in Appendix A. The distributions do not require any further validation because their limits are extracted directly from the product output and as such are self validated.

The total carbonate and Eh relationships use process model input data and an abstracted $\mathrm{pH}$ value to calculate a total carbonate concentration and Eh values in solution at a given time. The ability for these relationships to reproduce process model output was demonstrated in Sections 6.10.5 and 6.10.6. In other words the total carbonate and ionic strength abstractions were validated by comparison to product output (Figure 6-76 and Figure 6-77, respectively). 
The remaining parameters, fluoride and chloride concentrations were set to distributions where the values were taken directly from the product output for both CSNF and codisposal and are, thus, self-validated.

\subsection{SUMMARY}

To summarize, the in-package chemistry model is a numerical titration of water with acidproducing solids (steel components), alkali-producing solids (glass), and $\mathrm{pH}$ buffering via iron (hydr)oxide surface complexation. The outputs are ionic strength trajectories and $\mathrm{pH}$ distributions. Documenting that these are within the bounds of $\mathrm{pH}$ values and ionic strengths observed in natural situations, as done in the peer-reviewed literature, where similar processes prevail is critical to model validation of the in-package chemistry model. Additionally, the surface complexation model was validated via a technical review to determine if the approach and application were technically sound. Yifeng Wang (Appendix E) agrees that the surface complexation conceptual model and its formulation are adequate for intended use.

Achieving a sufficient level of confidence required documenting:

1. Fuel and steel degradation models

2. Formation of corrosion products

3. Production of low-pH waters by steel degradation

4. Production of high-pH waters by glass degradation

5. Production of ionic strengths extremes

6. $\mathrm{pH}$ buffering via surface complexation.

In addition to satisfying Level I criteria (a) through (f), the evidences provided above collectively provide broad justification for assignment of a Level II validation for the in-package chemistry model. The validation of in-package chemistry model meets the requirements for implementation in TSPA-LA and does not require any further validation. 


\section{INTENTIONALLY LEFT BLANK}




\section{CONCLUSIONS}

The in-package chemistry process models are developed and documented in Section 6 and Appendix B. Based on the results of the in-package chemistry process models, it may be concluded that the following inputs or processes have only minor impact on the model response such that they were not carried forward into the abstractions.

- Initial water composition

- Partial pressure of carbon dioxide and oxygen

- Radiolysis (Appendix B)

- Modifications to waste package design configuration (including the replacement of Neutronit with NiGd alloy, or the addition of a purge port)

- Sulfur content of Carbon Steel Type A516 waste package components

- Composition and fracturing of the HLW glass log

- Oxidation state of chromium

- Waste package component degradation rates

- Controlling iron mineral (hematite versus goethite)

- CDSP waste package configuration (2-MCO/2-DHLW versus 5 DHLW/DOE SNF).

The effect of the above factors on the model response is finite and accounted for in the abstractions via applied uncertainty terms. The following variables have a large influence on the in-package chemistry:

- Waste package type (CSNF versus codisposed)

- Water flux

- Temperature.

These variables are used as input to the in-package chemistry abstractions (i.e., the abstractions are functions of these variables). Therefore, in TSPA-LA the in-package chemistry is implemented as a function of external variables that directly links the in-package chemistry to the repository environment.

\subsection{MODEL OUTPUT}

The output of this model includes abstracted values for $\mathrm{pH}$, ionic strength, total carbonate, Eh, fluoride, and chloride concentrations. The uncertainties for these abstracted values are also presented. 
The output of this model starts once the waste package has been breached and once the temperature of the waste package has dropped to $100^{\circ} \mathrm{C}$. The range of applicability (restrictions for subsequent use) for the output of this model is provided in Table 8-1. The output of the model is provided in Table 8-2 through Table 8-6.

Table 8-1. Range of Applicability

\begin{tabular}{|l|l|l|}
\hline & \multicolumn{1}{|c|}{ Value } & \multicolumn{1}{c|}{ Units } \\
\hline Oxygen Fugacity & up to $10^{-0.7}$ & atmospheres \\
\hline Carbon Dioxide Fugacity & $10^{-5.0}$ to $10^{-1.5}$ & atmospheres \\
\hline Temperature & $25^{\circ} \mathrm{C}$ to $100^{\circ} \mathrm{C}$ & Celsius \\
\hline Water Flux & 0.15 to 300 & L/yr \\
\hline
\end{tabular}

Table 8-2. TSPA-LA pH Abstraction

\begin{tabular}{|c|c|c|c|c|c|c|c|c|c|}
\hline $\begin{array}{c}\text { Water Entry } \\
\text { Case }\end{array}$ & $\begin{array}{l}\text { WP } \\
\text { Type }\end{array}$ & $\begin{array}{l}\text { Period } \\
\text { (years) }\end{array}$ & $\begin{array}{l}\text { Temp } \\
\left({ }^{\circ} \mathrm{C}\right)\end{array}$ & $\begin{array}{l}\log \\
\mathrm{fCO}_{2}\end{array}$ & $\begin{array}{c}\text { Flux } \\
\text { (L/yr/WP) }\end{array}$ & $\begin{array}{c}\text { Min } \\
\mathrm{pH}\end{array}$ & $\begin{array}{c}\text { Max } \\
\text { pH }\end{array}$ & Distribution & Uncertainty \\
\hline \multirow{11}{*}{$\begin{array}{l}\text { Water Influx } \\
\text { and } \\
\text { Vapor Influx }\end{array}$} & \multirow{9}{*}{ CSNF } & \multirow{8}{*}{0 to 600} & \multirow{8}{*}{25 to 100} & -5.0 & $\mathrm{~N} / \mathrm{A}$ & 4.5 & 8.1 & \multirow{11}{*}{ Uniform } & \multirow{11}{*}{$\begin{array}{c}\text { No } \\
\text { Uncertainty }\end{array}$} \\
\hline & & & & -4.5 & $\mathrm{~N} / \mathrm{A}$ & 4.5 & 8.1 & & \\
\hline & & & & -4.0 & $\mathrm{~N} / \mathrm{A}$ & 4.5 & 8.0 & & \\
\hline & & & & -3.5 & $\mathrm{~N} / \mathrm{A}$ & 4.5 & 7.9 & & \\
\hline & & & & -3.0 & $\mathrm{~N} / \mathrm{A}$ & 4.5 & 7.7 & & \\
\hline & & & & -2.5 & $\mathrm{~N} / \mathrm{A}$ & 4.5 & 7.5 & & \\
\hline & & & & -2.0 & $\mathrm{~N} / \mathrm{A}$ & 4.5 & 7.3 & & \\
\hline & & & & -1.5 & N/A & 4.5 & 7.0 & & \\
\hline & & $\begin{array}{l}600 \text { to } \\
20,000\end{array}$ & 25 to 100 & $\mathrm{~N} / \mathrm{A}$ & $\mathrm{N} / \mathrm{A}$ & 4.5 & 7.0 & & \\
\hline & \multirow[t]{2}{*}{ CDSP } & \multirow[t]{2}{*}{$\begin{array}{c}0 \text { to } \\
20,000\end{array}$} & \multirow[t]{2}{*}{25 to 100} & $\mathrm{~N} / \mathrm{A}$ & $Q<=150$ & 4.5 & 7.0 & & \\
\hline & & & & $\mathrm{N} / \mathrm{A}$ & $Q>150$ & 4.5 & 8.0 & & \\
\hline
\end{tabular}

NOTE: The CSNF pH abstraction is not dependent on flow rate. The CDSP $\mathrm{pH}$ abstraction is not dependent on log $\mathrm{fCO}_{2}$. 
Table 8-3. TSPA-LA lonic Strength Abstraction

\begin{tabular}{|c|c|c|c|c|c|c|c|c|c|}
\hline $\begin{array}{l}\text { Water Entry } \\
\text { Case }\end{array}$ & $\begin{array}{l}\text { WP } \\
\text { Type }\end{array}$ & $\begin{array}{l}\text { Period } \\
\text { (years) }\end{array}$ & $\begin{array}{c}\text { Temp } \\
\left({ }^{\circ} \mathrm{C}\right)\end{array}$ & Min (I) (molal) & $\operatorname{Max}(\mathrm{I})$ (molal) & \multicolumn{2}{|c|}{ Distribution } & \multicolumn{2}{|c|}{ Uncertainty } \\
\hline \multirow{5}{*}{ Vapor influx } & CSNF & $\begin{array}{c}0 \text { to } \\
20,000\end{array}$ & $\begin{array}{c}25 \text { to } \\
100\end{array}$ & 0.085 & 0.75 & \multicolumn{2}{|c|}{ Log Uniform } & \multirow{15}{*}{ 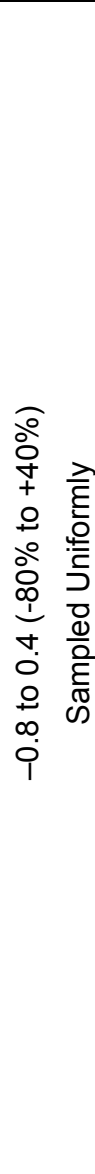 } & \multirow{15}{*}{ 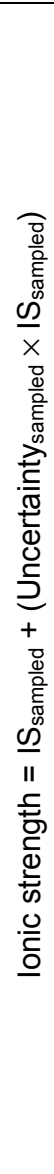 } \\
\hline & \multirow{4}{*}{ CDSP } & \multirow{4}{*}{$\begin{array}{c}0 \text { to } \\
20,000\end{array}$} & \multirow{4}{*}{$\begin{array}{c}25 \text { to } \\
100\end{array}$} & \multicolumn{2}{|c|}{ (I) (molal) } & \multicolumn{2}{|c|}{ Probability } & & \\
\hline & & & & \multicolumn{2}{|c|}{$3.2 \mathrm{E}-3$} & \multicolumn{2}{|c|}{0.0} & & \\
\hline & & & & \multicolumn{2}{|c|}{0.05} & \multicolumn{2}{|c|}{0.13} & & \\
\hline & & & & \multicolumn{2}{|c|}{0.75} & \multicolumn{2}{|c|}{1.0} & & \\
\hline \multirow{10}{*}{ Water Influx } & \multirow{2}{*}{\multicolumn{3}{|c|}{$\begin{array}{l}y=a E X P(b x) \\
y=\text { ionic strength } \\
x=\log _{10}(\text { flux }(L / y r))\end{array}$}} & & & & & & \\
\hline & & & & $\begin{array}{c}\text { Lower Flux } \\
\text { Limit } \\
\text { (L/yr/WP) }\end{array}$ & $\begin{array}{l}\text { Upper Flux } \\
\text { Limit } \\
\text { (L/yr/WP) }\end{array}$ & a & b & & \\
\hline & & & 25 & 0.20 & 185 & 0.4755 & -2.1652 & & \\
\hline & CSNF & $\begin{array}{c}0 \text { to } \\
20,000\end{array}$ & 50 & 0.16 & 145 & 0.4472 & -2.2424 & & \\
\hline & & & $\begin{array}{c}25 \text { to } \\
50\end{array}$ & & interpolate & & & & \\
\hline & & & $\begin{array}{c}50 \\
\text { to } 100\end{array}$ & & extrapolate & & & & \\
\hline & & & 25 & 0.25 & 180 & 0.5201 & -2.1306 & & \\
\hline & CDSP & $\begin{array}{c}0 \text { to } \\
20,000\end{array}$ & 50 & 0.18 & 180 & 0.4324 & -2.1369 & & \\
\hline & & & $\begin{array}{c}25 \text { to } \\
50\end{array}$ & & interpolate & & & & \\
\hline & & & $\begin{array}{c}50 \\
\text { to } 100\end{array}$ & & extrapolate & & & & \\
\hline
\end{tabular}

NOTE: The interpolations and extrapolations should be performed by first calculating an ionic strength value for $25^{\circ} \mathrm{C}$ and for $50^{\circ} \mathrm{C}$, interpolate or extrapolate the results from those values, and then add the uncertainty.

Table 8-4. TSPA-LA Total Carbonate Abstraction

\begin{tabular}{|c|l|c|}
\hline \multicolumn{3}{|c|}{ Equation of Total Carbonate $(\mathrm{mol} / \mathbf{k g})$} \\
\hline \multicolumn{3}{|c|}{ Total C $=\mathrm{PCO}_{2}\left(10^{\mathrm{K}_{1}}+10^{\left(\mathrm{pH}+\mathrm{K}_{1}+\mathrm{K}_{2}\right)}+10^{\left(2 \mathrm{pH}+\mathrm{K}_{1}+\mathrm{K}_{2}+\mathrm{K}_{3}\right)}\right)$} \\
\hline Log K & \multicolumn{1}{|c|}{ Log K expression } & $\mathbf{R}^{2}$ \\
\hline $\mathrm{K}_{1}$ & Log K $_{1}=7 \mathrm{E}-05 \mathrm{~T}^{2}-0.0159 \mathrm{~T}-1.1023$ & 0.9992 \\
\hline $\mathrm{K}_{2}$ & Log K $_{2}=5 \mathrm{E}-07 \mathrm{~T}^{3}-0.0002 T^{2}+0.0132 \mathrm{~T}-6.5804$ & 1.0 \\
\hline $\mathrm{K}_{3}$ & Log K $_{3}=-8 \mathrm{E}-05 T^{2}+0.0128 \mathrm{~T}-10.618$ & 0.9977 \\
\hline
\end{tabular}

NOTE: Temperature is in ${ }^{\circ} \mathrm{C}$. 
Table 8-5. TSPA-LA Eh Abstraction

\begin{tabular}{|c|}
\hline Equation of Eh (volts) \\
\hline $\mathrm{Eh}=2.303 \mathrm{R} \mathrm{T} / \mathrm{F}\left(6193.973 / \mathrm{T}-\mathrm{pH}+0.25 \log p \mathrm{O}_{2}\right)$ \\
\hline
\end{tabular}

NOTE: Temperature is in $\mathrm{K}$.

Table 8-6. TSPA-LA Fluoride and Chloride Abstraction

\begin{tabular}{|c|c|c|c|c|c|}
\hline $\begin{array}{c}\text { Water Entry } \\
\text { Case }\end{array}$ & $\begin{array}{l}\text { WP } \\
\text { Type }\end{array}$ & $\begin{array}{l}\text { Period } \\
\text { (years) }\end{array}$ & Temp ${ }^{\circ} \mathrm{C}$ & $\begin{array}{c}\text { Max F' } \\
(\text { Mol/kg) }\end{array}$ & $\begin{array}{c}\text { Max } \mathrm{Cl}^{-} \\
\text {(Mol/kg) }\end{array}$ \\
\hline \multirow[t]{2}{*}{ Vapor Influx } & CSNF & 0 to 20,000 & $25^{\circ} \mathrm{C}$ & $\mathrm{N} / \mathrm{A}$ & $\mathrm{N} / \mathrm{A}$ \\
\hline & CDSP & 0 to 20,000 & $25^{\circ} \mathrm{C}$ & 1.1E-02 & $\mathrm{N} / \mathrm{A}$ \\
\hline \multirow[t]{4}{*}{ Water Influx } & \multirow[t]{2}{*}{ CSNF } & \multirow[t]{2}{*}{0 to 20,000} & $25^{\circ} \mathrm{C}$ & 9.8E-04 & 2.1E-03 \\
\hline & & & $50^{\circ} \mathrm{C}$ & $1.5 \mathrm{E}-03$ & 3.2E-03 \\
\hline & \multirow[t]{2}{*}{ CDSP } & \multirow[b]{2}{*}{0 to 20,000} & $25^{\circ} \mathrm{C}$ & 3.1E-03 & 6.1E-03 \\
\hline & & & $50^{\circ} \mathrm{C}$ & 1.9E-03 & 6.1E-03 \\
\hline
\end{tabular}

NOTE: The CSNF waste package does not contain any $\mathrm{F}^{-}$or $\mathrm{Cl}^{-}$, so for the vapor influx case that condenses pure water onto the waste package materials, there are no $\mathrm{F}^{-}$or $\mathrm{Cl}^{-}$abstractions. The CDSP waste package contains $\mathrm{F}^{-}$, but no $\mathrm{Cl}^{-}$.

The mapping of batch reactor cases to the abstractions is presented in Table 6-24.

\subsection{YMRP CRITERIA}

The following acceptance criteria are from Section 2.2.1.3.3 of Yucca Mountain Review Plan, Final Report (NRC 2003 [DIRS 163274]) and are based on the requirements of 10 CFR 63.114 (a)-(c) and (e)-(g) [DIRS 156605].

\section{Acceptance Criterion 1 - System Description and Model Integration Are Adequate}

(1) TSPA adequately incorporates important design features, physical phenomena and couplings and uses consistent and appropriate assumptions throughout the quantity and chemistry of water contacting waste packages and waste forms abstraction process;

This model accurately reflects the design features of the repository, including the design of the waste package and waste form, as discussed in Sections 4.1.3 and 4.1.4, and the design of the drift as it impacts the incoming quantity and chemistry of water, as discussed in Section 4.1.2. The physical phenomena and couplings important to the process of possible degradation of the waste package and waste form, as discussed in Section 5 and in the conceptual models in Sections 6.3.1 and 6.3.2. The use of assumptions in this document is consistent throughout this document and with assumptions used in other reports, as discussed in Sections 5, 6.3.1, and 6.3.2.

(2) The abstraction of the quantity and chemistry of water contacting the waste packages and waste forms uses assumptions, technical bases, data and models that are appropriate and consistent with other related DOE abstractions. 
The abstraction of the in-package water is described in Section 6.10, and uses assumptions, technical bases, data and models listed in Sections 5, 6.3.1, 6.3.2, and 4.1, respectively, which are consistent with other model abstractions, such as Abstraction of Drift Seepage (BSC 2004 [DIRS 169131]), CSNF Waste Form Degradation (BSC 2004 [DIRS 169987]), Defense HLW Glass Degradation (BSC 2004 [DIRS 169988]), EBS Radionuclide Transport (BSC 2004 [DIRS 169868]), Physical and Chemical Environment (BSC 2004 [DIRS 169054]), Dissolved Concentration Limits of Radioactive Elements (BSC 2003 [DIRS 169425]), Drift-Scale Coupled Processes (BSC 2004 [DIRS 168848]), and Waste Form and In-Drift Colloids (BSC 2003 [DIRS 166845]).

(3) Important design features, such as waste package design and material selection, backfill, drip shield, ground support, thermal loading strategy, and degradation processes are adequate to determine the initial and boundary conditions for calculations of the quantity and chemistry of water contacting waste packages and waste forms.

Throughout this model, information is presented related to the design of the waste package (Section 4.1.4) and waste form (Section 4.1.3), degradation processes (Sections 4.1.4 and 6.3.1.1), physical phenomena (Section 6.3.1.1), and couplings that may affect the degradation of the engineered barriers (Section 6.3.1.1). These descriptions are consistent with the information delineated elsewhere in other reports and are adequate for their intended purposes (i.e., to enable the modelers to develop and implement appropriate models and to enable the reviewer to understand the bases for the analytical activities performed by the applicant and those results)

(4) Spatial and temporal abstractions appropriately address physical couplings (thermal-hydrologic-mechanical-chemical).

The spatial abstraction for the batch reactor model is described in Section 6.3.1.1 and appropriate addresses physical couplings. The temporal abstractions appropriately address physical couplings by using degradation rates that account for coupled processes for the waste package materials and the waste forms (Sections 4.1.3 and 4.1.4). Additionally, the incoming water compositions (Section 4.1.2) are consistent with Drift-Scale Coupled Processes (DST and THC Seepage) Models (BSC 2004 [DIRS 168848]), which accounts for coupled processes.

(5) Sufficient technical bases and justification are provided for TSPA assumptions and approximations for modeling coupled T-H-M-C effects on seepage and flow, the waste package chemical environment, and the chemical environment for radionuclide release. The effects of the distribution of flow on the amount of water contacting the waste package and waste form are consistently addressed in all relevant abstractions.

The incoming water compositions (Section 4.1.2) are consistent with Drift-Scale Coupled Processes (DST and THC Seepage) Models (BSC 2004 [DIRS 168848]), which accounts for coupled processes. The amount of water contacting the waste package and waste form is an input consistent with Abstraction of Drift Seepage (BSC 2004 [DIRS 169131]) and EBS 
Radionuclide Transport (BSC 2004 [DIRS 169868]), as described in Section 4.1.2, and these values are varied further in a sensitivity analysis in Section 6.6.5.

(6) The expected ranges of environmental conditions within the waste package emplacement drifts, inside of breached waste packages, and contacting the waste forms and their evolution with time are identified. These ranges may be developed to include: (i) the effects of drip shield and backfill on the quantity and chemistry of water; (ii) conditions that promote corrosion of engineered barriers and degradation of waste forms; (iii) irregular wet and dry cycles; (iv) gammaradiolysis; and (v) size and distribution of penetrations of waste packages.

This report uses the expected ranges of environmental conditions of the drift as inputs (Sections 4.1.2 and 6.3.1.1) and then determines the resulting ranges of environmental conditions inside the waste package (Section 6.10). The quantity of water entering the waste package is dependent upon the condition of the drip shield and waste package and the size and distribution of penetrations of waste packages, and this model varies the quantity to encompass a broad range of conditions, as described in Section 6.3.1.3. This model specifically studies the effects of gamma radiolysis on water composition, as presented in Appendix B.

(7) The model abstraction for quantity and chemistry of water contacting the waste packages and waste forms is consistent with the detailed design information on waste package design and other engineered features.

This model uses the design of the waste package and the waste package materials as input, as described in Section 4.1.4, and the input files for the model are based on this design information.

(8) Adequate technical bases are provided, including activities such as independent modeling, laboratory or field data, or sensitivity studies, for inclusion of any T-H-M-C couplings and features, events and processes;

This model is validated by laboratory data that studies coupled processes, as described in Section 7.2.2. The corrosion rates used by this model were determined by laboratory and field data, which include couplings, as described in Sections 4.1.3 and 4.1.4. This report addresses eight FEPs considered appropriate, as is discussed in Section 6.2. Table 6-1 includes a detailed listing of where within this report the specific FEPs are discussed and addressed. The technical information contained in Sections 4, 5, 6, and 7 is sufficient to provide the basis for the inclusion or exclusion decisions related to these FEPs.

(9) Performance affecting processes that have been observed in thermalhydrologic tests are included in the TSPA.

The effects observed in thermal-hydrologic tests and experiments (from the drift scale test) are used for validation purposes in Drift-Scale Coupled Processes (DST and THC Seepage) Models (BSC 2004 [DIRS 168848], Section 7.1), and the incoming water compositions (Section 4.1.2) are consistent with that model. 
(10) Likely modes for container corrosion are identified and considered in determining the quantity and chemistry of water entering the waste packages and contacting the waste forms.

The quantity of water entering the waste package is dependent upon the condition of the drip shield and waste package and the size and distribution of penetrations of waste packages, and this model varies the quantity to encompass a broad range of conditions, as described in Section 6.3.1.3. Section 6.10 determines the chemistry of the water within the waste package is a function of the degradation of the waste package materials and waste forms. These degradation processes are described in Sections 6.3.1 and 6.3.2.

(11) The abstraction of the in-package criticality or external-to-package criticality within the emplacement drifts provides an adequate technical basis for screening these events. If either event is included in the TSPA, then the DOE uses acceptable technical bases for selecting the design criteria that mitigate the potential impact of in-package criticality on the repository performance; identifies the FEPS that may increase the reactivity of the system inside the waste package, identifies the configuration classes and configurations that have the potential for nuclear criticality; and includes changes in thermal conditions and degradation of engineered barriers in the abstraction of the quantity and chemistry of water contacting waste packages and waste forms.

The subject of potential criticality is discussed in other reports. This criterion is considered not to be applicable to this report.

(12) Guidance in NUREG 1297 and NUREG 1298 (Altman et al., 1988 a, b) or other acceptable approaches is followed.

The information contained in this report is based on established physical models, justified assumptions and previously qualified input data. As a result, there was no need to use the guidance of NUREG 1297 and/or NUREG 1298 in the development of this report.

\section{Acceptance Criterion 2 - Data Are Sufficient For Model Justification}

(1) Geological, hydrological and geochemical values used in the License Application are adequately justified. Adequate description of how the data were used, interpreted and appropriately synthesized into the parameters is provided.

The sources for the geological, hydrological, and geochemical data are justified in Sections 4.1.1 through 4.1.6 and 6.3.1.3 describes how the data were used and converted into values appropriate for the model input files. The chemical thermodynamic database used in the modeling was developed specifically for the project and is consistent with the thermodynamic data being used by other reports.

(2) Sufficient data were collected on the characteristics of the natural system and engineered materials to establish initial and boundary conditions for conceptual models of T-H-M-C coupled processes that affect seepage and flow and the waste package environment; 
The sources for the geological, hydrological, and geochemical data (Sections 4.1.1 through 4.1.6) come from a broad body of data collected on the characteristics of the natural system and engineered materials. Section 6.3.1.3 describes how the data were used to establish initial and boundary conditions.

(3) Thermo-hydrologic tests were designed and conducted with the explicit objective of observing $T$-H processes for the temperature ranges anticipated in the repository and making measurements for mathematical models. Data are sufficient to verify that $T-H$ conceptual models address important $T-H$ phenomena;

Natural system data are used to develop Drift-Scale Coupled Processes (DST and THC Seepage) Models (BSC 2004 [DIRS 168848]), which is consistent with the water composition input to this model (Section 6.6). The natural system data are used to establish initial and boundary conditions that affect seepage and flow and are discussed in Section 6.3.1.1.

(4) Sufficient information to formulate the conceptual approaches for analyzing water contact with the drip shield, waste packages and waste forms is provided;

The conceptual model for water contacting the waste package materials and waste forms is provided in Section 6.3.1.1.

(5) Sufficient data are provided to complete a nutrient and energy inventory calculation, if it has been used to justify the inclusion of the potential for microbial activity affecting the waste package chemical environment and chemical environment for radionuclide release. As necessary, data are adequate to support determination of the probability for microbially induced corrosion and microbial effects, such as the production of organic by-products and microbially enhanced dissolution of the high-level radioactive waste glass form.

Microbially influenced corrosion is not addressed in this report.

\section{Acceptance Criterion 3 - Data Uncertainty is Characterized and Propagated Through the Model Abstraction}

Most of the input values were treated as variables and were varied over a wide range of possible values for the base case (Sections 6.3.1 and 6.3.2). In addition, many sensitivity analyses (Section 6.6) were run, which varied additional parameters, as well as expanded range of values that were used in the base case. The results of these analyses were used in the abstraction of the model to ensure that the model output captured the full possible range of variability (Section 6.10). In this way, the results of this model capture the expected behavior and the most extreme possibilities, so do not underrepresent the estimate of risk.

(1) Models use parameter values, assumed ranges, probability distributions and/or bounding assumptions that are technically defensible, reasonably account for uncertainties and variabilities, and do not result in under-representation of the risk estimate. 
Each of the models developed in this report use parameter values, assumed ranges, probability distributions or bounding assumptions, or both, that are technically defensible, reasonably account for uncertainties and variabilities, and do not result in underrepresentation of the risk estimate. In each situation, discussion and consideration of the uncertainties associated with specific data are addressed in detail. The treatment of uncertainty is explicitly addressed in Section 6.10.8 and specific sections throughout the document including Sections 6.6 and 6.10.2.3.

(2) Parameter values, assumed ranges, probability distributions and bounding assumptions used in the TSPA calculations of quantity and chemistry of water contacting waste packages and waste forms are technically defensible and reasonable based on data from the Yucca Mountain region (e.g., results from large block and drift-scale heater and niche tests) and a combination of techniques that may include laboratory experiments, field measurements, natural analog research and process modeling studies.

The models developed and discussed in this AMR use three different input water compositions for the base case, two of which are based on waters obtained from core samples proximal to the repository. The model uses three additional water compositions from Drift-Scale Coupled Processes (DST and THC Seepage) (BSC 2004 [DIRS 168848]) in a sensitivity analysis in Section 6.6.2. This subject is discussed in detail in Sections 4.1.2 and 6.3.1.3.1.

(3) Input values used in the TSPA calculations of quantity and chemistry of water contacting engineered barriers (e.g., drip shield and waste package) are consistent with the initial and boundary conditions and the assumptions of the conceptual models and design concepts for the Yucca Mountain site. Correlations between input values are appropriately established in the DOE TSPA. Parameters used to define initial conditions, boundary conditions and computational domain in sensitivity analyses involving coupled T-H-M-C effects on seepage and flow, the waste package chemical environment, and the chemical environment for radionuclide release, are consistent with available data. Reasonable or conservative ranges of parameters or functional relations are established.

The inputs to this model (Section 4.1.1 through 4.1.6) are consistent with initial boundary conditions and design concepts for the Yucca Mountain site because they come from various design documents and other related model reports. The results of this model (and others) are validated by comparison with laboratory data and natural analog, as described in Section 7.2. The model abstraction, developed in Section 6.10, uses reasonable and conservative abstractions to capture the range of output.

(4) Adequate representations of the uncertainties in the characteristics of the natural systems and engineered materials is provided in the parameter development for conceptual models, process level models, and alternative conceptual models. The DOE may constrain these uncertainties using sensitivity analyses or conservative limits. 
Most of the input values were treated as variables and were varied over a wide range of possible values for the base case (Section 6.3.1 and 6.3.2). In addition, many sensitivity analyses (Section 6.6) were run, which varied additional parameters, as well as expanded range of values that were used in the base case. The results of these analyses were used in the abstraction of the model to ensure that the model output captured the full possible range of variability (Section 6.10). In this way, the results of this model capture the expected behavior and the most extreme possibilities, so do not under-represent the estimate of risk.

(5) If criticality is included in the TSPA, then the DOE uses an appropriate range of input parameters is used for calculating the effective neutron multiplication factor;

The subject of possible criticality either in or external to the waste package is not discussed in this report. As such, this criterion is considered not to be applicable to this report.

(6) Where sufficient data do not exist, the definition of parameter values and conceptual models is based on appropriate use of other sources, such as expert elicitation conducted in accordance with NUREG-1563.

The information contained in this report is based on established physical models, justified assumptions and previously qualified input data. As a result, there was no need to use other sources, such as expert elicitation conducted in accordance with NUREG-1563, in the development of this report.

\section{Acceptance Criterion 4 - Model Uncertainty is Characterized and Propagated Through the Model Abstraction}

Uncertainties in inputs and the in methodology are considered in the development of the conceptual model (Sections 6.2.2 and 6.2.3) and output parameters (Section 6.10). Discussion of uncertainty in the conceptual model appears in various places throughout the report. The model uncertainty is consistent with available site data, laboratory experiments and natural analog as described in Section 7. The use of the output of the model by TSPA-LA was analyzed and the uncertainty treatment was altered so as lead to the most conservative results with respect to colloid stability and radionuclide solubility and thus resulted in over-representation of the risk estimate.

(1) Alternative modeling approaches of FEPs are considered and are consistent with available data and current scientific understanding; and the results and limitations are appropriately considered in the abstraction.

This report explicitly addresses alternative conceptual models related to the makeup of the water entering the waste package after postulated breach and the manner in which this water transits the waste package following entry in Section 6.4. Although due consideration was given to the use of these models, it was determined that the selected "base-case" model and selected input data is sufficient, robust and adequate for its intended purpose and that the use of the alternative conceptual models was not warranted. 
(2) Alternative modeling approaches are considered and the selected modeling approach is consistent with available data and current scientific understanding. A description that includes a discussion of alternative modeling approaches not considered in the final analysis and the limitations and uncertainties of the chosen model is provided

This report explicitly addresses alternative conceptual models related to the make-up of the water entering the waste package after postulated breach and the manner in which this water transits the waste package following entry in Section 6.4. Although due consideration was given to the use of these models, it was determined that the selected "base-case" model and selected input data is sufficient, robust and adequate for its intended purpose and that the use of the alternative conceptual models was not warranted.

(3) Consideration of conceptual model uncertainty is consistent with available site characterization data, laboratory experiments, field measurements, natural analog information, and process-level modeling studies; and the treatment of uncertainty does not result in under-representation of the risk estimate.

Each of the models developed in this report use parameter values, assumed ranges, probability distributions or bounding assumptions that are consistent with available site characterization data, technically defensible, reasonably account for uncertainties and variabilities, and do not result in underrepresentation of the risk estimate. In each situation, discussion and consideration of the uncertainties associated with specific data are addressed in detail. The treatment of uncertainty is explicitly addressed in Section 6.10.8 and specific sections throughout the document, including Sections 6.6 and 6.10.2.3.

(4) Adequate consideration is given to the effects of thermal-hydrologicmechanical-chemical coupled processes in the assessment of alternative conceptual models.

Alternative Conceptual Model I (Section 6.4.1) considers the effects of a nonhomogenous system as a result of coupled processes, such as the effects of gas and changes in boundary conditions. Alternative Conceptual Model II (Section 6.4.2) considers the composition of seepage entering a waste package is likely to vary as a function of changing conditions in the unsaturated zone and drift environments.

(5) If the DOE uses an equivalent continuum model for the TSPA abstraction, the models produce conservative estimates of the effects of coupled THMC processes on calculated compliance with post-closure public health and environmental standards.

The subject of an equivalent continuum model is not discussed in this report. As such, this criterion is considered not to be applicable to this report. 


\section{Acceptance Criterion 5 - Model Abstraction Output is Supported By Objective Comparisons}

The output of the model abstraction was compared with laboratory experiments and natural analog as described in Section 7.2. There are no confirmatory actions, such as compliance runs, additional sensitivity runs, and neutralization runs associated with this report.

(1) The models implemented in this TSPA abstraction provide results consistent with output from detailed process level models and/or empirical observations (laboratory and field testings and/or natural analogues);

The results of models implemented in this total system performance assessment abstraction were compared with results from detailed process-level models and or empirical observations (laboratory and field testing, or natural analogs) to ensure consistency. The results of such comparisons are addressed in Section 7 and Appendix E.

(2) Abstracted models for coupled THMC effects on seepage and flow and the waste package chemical environment, as well as on the chemical environment for radionuclide release, are based on the same assumptions and approximations demonstrated to be appropriate for process level models or closely analogous natural or experimental systems.

The model abstraction is validated in Section 7.3, and is based on the same assumptions and approximations used in other reports.

(3) Accepted and well-documented procedures are used to construct and test the numerical models that simulate coupled THMC effects on seepage and flow, waste package chemical environment, and the chemical environment for radionuclide release. Analytical and numerical models are appropriately supported. Abstracted model results are compared with different mathematical models to judge robustness of results.

Accepted and well-documented procedures contained in the quality assurance program (Section 2) governed the development of this report and the work it documents. This model was constructed, supported, and documented according to AP-SIII.10Q. Test and validation methods (Section 7), including comparison of abstracted output with that of other relevant models, also comply with AP-SIII.10Q, as well as with applicable written guidance. This report was generated according to the requirements of Technical Work Plan for: Regulatory Integration Modeling and Analysis of the Waste Form and Waste Package (BSC 2004 [DIRS 171583]) as directed by AP-2.27Q, Planning for Science Activities. 


\section{INPUTS AND REFERENCES}

\subsection{DOCUMENTS CITED}

159372 Allen, B.L. and Hajek, B.F. 1995. "Mineral Occurrence in Soil Environments." Chapter 5 of Minerals in Soil Environments. 2nd Edition. Dixon, J.B. and Weed, S.B., eds. SSSA Book Series, No. 1. Madison, Wisconsin: Soil Science Society of America. TIC: 237222.

171707 Allison, J.D.; Brown, D.S.; and Novo-Gradac, K.J. 1991. MINTEQA2/PRODEFA2, A Geochemical Assessment Model for Environmental Systems: Version 3.0 User's Manual. EPA/600/3-91/021. Athens, Georgia: U.S. Environmental Protection Agency, Office of Research and Development. TIC: 240804.

168734 Allison, J.M. 2004. "Request for Referenceable Information on High-Level Waste (HLW) Radionuclide Inventories in Support of Preparation of the Yucca Mountain Project License Application (Your Letter, JCP-0445, 1/28/04).” Memorandum from J.M. Allison (DOE/SR) to J. Arthur, III (OCRWM), February 26, 2004, 0303040661, with attachment. ACC: MOL.20040317.0265.

167071 Angus, N.S.; Brown, G.T.; and Cleere, H.F. 1962. "The Iron Nails from the Roman Legionary Fortress at Inchtuthil, Perthshire." Journal of The Iron and Steel Institute, 200, 956-957. London, England: Iron and Steel Institute. TIC: 255544.

172038 Appelo, C.A.J. and Postma, D. 1999. Geochemistry, Groundwater and Pollution. Brookfield, Vermont: A.A. Balkema. TIC: 250797.

168168 Appelo, C.A.J.; Van der Weiden, M.J.J.; Tournassat, C.; and Charlet, L. 2002. "Surface Complexation of Ferrous Iron and Carbonate on Ferrihydrite and the Mobilization of Arsenic.” Environmental Science \& Technology, 36, (14), 3096-3103. Washington, D.C.: American Chemical Society. TIC: 255581.

149625 Audi, G. and Wapstra, A.H. 1995. Atomic Mass Adjustment, Mass List for Analysis. Upton, New York: Brookhaven National Laboratory, National Nuclear Data Center. TIC: 242718.

104439 B\&W Fuel Company 1991. Final Design Package Babcock \& Wilcox BR-100 100 Ton Rail/Barge Spent Fuel Shipping Cask. Volume 2. 51-1203400-01. DBABE000000272-1000-00014 REV 00. Lynchburg, Virginia: B\&W Fuel Company. ACC: MOV.19960802.0083.

163015 Ball, J.W. and Nordstrom, D.K. 1998. "Critical Evaluation and Selection of Standard State Thermodynamic Properties for Chromium Metal and its Aqueous Ions, Hydrolysis Species, Oxides, and Hydroxides." Journal of Chemical \& Engineering Data, 43, (6), 895-918. Washington, D.C.: American Chemical Society. TIC: 254015. 
106164 Baxter, R.G. 1988. Defense Waste Processing Facility Wasteform and Canister Description. DP-1606, Rev. 2. Aiken, South Carolina: E.I. du Pont de Nemours \& Company, Savannah River Plant. TIC: 8704.

161746 Berner, E.K. and Berner, R.A. 1996. Global Environment: Water, Air, and Geochemical Cycles. Upper Saddle River, New Jersey: Prentice Hall. TIC: 253965.

157873 Bricker, O. 1965. "Some Stability Relations in the System $\mathrm{Mn}-\mathrm{O}_{2}-\mathrm{H}_{2} \mathrm{O}$ at $25^{\circ}$ and One Atmosphere Total Pressure." American Mineralogist, 50, 1296-1354. Washington, D.C.: Mineralogical Society of America. TIC: 238855.

156873 BSC (Bechtel SAIC Company) 2001. EQ6 Calculation for Chemical Degradation of Shippingport PWR Codisposal Waste Packages: Effects of Updated Design and Rates. CAL-EDC-MD-000016 REV 00. Las Vegas, Nevada: Bechtel SAIC Company. ACC: MOL.20011112.0069.

154880 BSC 2001. Software Management Report (SMR) for transl V.2.0. 10251-SMR-2.0-00. Las Vegas, Nevada: Bechtel SAIC Company. ACC: MOL.20010813.0419.

154877 BSC 2001. User Manual (UM) for PHREEQC Version 2.3. SDN: 10068-UM-2.3-00. Las Vegas, Nevada: Bechtel SAIC Company. ACC: MOL.20010525.0172.

169110 BSC 2003. PWR Assembly End-Effect Reactivity Evaluation. CAL-UDC-NU-000006 REV 00, with 01 errata. Las Vegas, Nevada: Bechtel SAIC Company.

ACC: MOL.20010412.0158; DOC.20031014.0007.

166845 BSC 2003. Waste Form and In-Drift Colloids-Associated Radionuclide Concentrations: Abstraction and Summary. MDL-EBS-PA-000004 REV 00 ICN 01. Las Vegas, Nevada: Bechtel SAIC Company. ACC: DOC.20031222.0012.

170710 BSC 2004. 21-PWR Waste Package Configuration. 000-MW0-DSU0-00403-00000D. Las Vegas, Nevada: Bechtel SAIC Company. ACC: ENG.20040708.0005.

169131 BSC 2004. Abstraction of Drift Seepage. MDL-NBS-HS-000019, Rev. 01. Las Vegas, Nevada: Bechtel SAIC Company.

169982 BSC 2004. Aqueous Corrosion Rates for Waste Package Materials. ANL-DSD-MD000001 REV 01. Las Vegas, Nevada: Bechtel SAIC Company. ACC: DOC.20041012.0003.

169987 BSC 2004. CSNF Waste Form Degradation: Summary Abstraction. ANL-EBS-MD000015 REV 02. Las Vegas, Nevada: Bechtel SAIC Company. ACC: DOC.20040908.0001.

167207 BSC 2004. D\&E/PA/C IED Typical Waste Package Components Assembly. 800-IEDWIS0-00202-000-00B. Las Vegas, Nevada: Bechtel SAIC Company. ACC: ENG.20040202.0010. 
169472 BSC 2004. D\&E/PA/C IED Typical Waste Package Components Assembly. 800-IEDWIS0-00202-000-00C. Las Vegas, Nevada: Bechtel SAIC Company. ACC: ENG.20040517.0008.

169988 BSC 2004. Defense HLW Glass Degradation Model. ANL-EBS-MD-000016 REV 02. Las Vegas, Nevada: Bechtel SAIC Company. ACC: DOC.20041020.0015.

166949 BSC 2004. Design \& Engineering, 5 DHLW/DOE SNF - Long Waste Package Configuration. 000-MW0-DS00-00202-000-00A. Las Vegas, Nevada: Bechtel SAIC Company. ACC: ENG.20040120.0023.

166950 BSC 2004. Design \& Engineering, 5 DHLW/DOE SNF - Long Waste Package Configuration. 000-MW0-DS00-00203-000-00A. Las Vegas, Nevada: Bechtel SAIC Company. ACC: ENG.20040120.0024.

168239 BSC 2004. Design and Engineering, 5 DHLW Short Divider Plate Inner Bracket. 000-MW0-DS00-00701-000-00A. Las Vegas, Nevada: Bechtel SAIC Company. ACC: ENG.20040305.0008.

168240 BSC 2004. Design and Engineering, 5 DHLW Short Divider Plate Middle Bracket. 000-MW0-DS00-00801-000-00A. Las Vegas, Nevada: Bechtel SAIC Company. ACC: ENG.20040305.0003.

168241 BSC 2004. Design and Engineering, 5 DHLW Short Divider Plate Outer Bracket. 000-MW0-DS00-00901-000-00A. Las Vegas, Nevada: Bechtel SAIC Company. ACC: ENG.20040304.0010.

168237 BSC 2004. Design and Engineering, 5 DHLW Short Divider Plate Tube. 000-MW0DS00-00601-000-00A. Las Vegas, Nevada: Bechtel SAIC Company. ACC: ENG.20040304.0022.

168204 BSC 2004. Design and Engineering, Outer Corrosion Barrier Support Ring. 000MW0-MGR0-00601-000-00A. Las Vegas, Nevada: Bechtel SAIC Company. ACC: ENG.20040305.0006.

169425 BSC 2004. Dissolved Concentration Limits of Radioactive Elements. ANL-WIS-MD000010, Rev. 03. Las Vegas, Nevada: Bechtel SAIC Company.

168848 BSC 2004. Drift-Scale Coupled Processes (DST and THC Seepage) Models. MDLNBS-HS-000001 REV 02 Errata 002. Las Vegas, Nevada: Bechtel SAIC Company. ACC: DOC.20030804.0004; DOC.20040219.0002; DOC.20040405.0005.

169868 BSC 2004. EBS Radionuclide Transport Abstraction. ANL-WIS-PA-000001, Rev. 01. Las Vegas, Nevada: Bechtel SAIC Company.

169898 BSC 2004. Engineered Barrier System Features, Events, and Processes. ANL-WISPA-000002, Rev. 03. Las Vegas, Nevada: Bechtel SAIC Company. 
169054 BSC 2004. Engineered Barrier System: Physical and Chemical Environment Model. ANL-EBS-MD-000033 REV 02 Errata 001. Las Vegas, Nevada: Bechtel SAIC Company. ACC: DOC.20040426.0003.

172017 BSC 2004. Gamma and Neutron Radiolysis in the 21-PWR Waste Package from Ten to One Million Years. 000-00C-DSU0-00700-000-00A. Las Vegas, Nevada: Bechtel SAIC Company. ACC: ENG.20041013.0008.

169356 BSC 2004. Probability Analysis of Corrosion Rates for Waste Package Materials. ANL-DSD-MD-000001 REV 00. Las Vegas, Nevada: Bechtel SAIC Company. ACC: DOC.20040506.0004.

168361 BSC 2004. Q-List. 000-30R-MGR0-00500-000-000 REV 00. Las Vegas, Nevada: Bechtel SAIC Company. ACC: ENG.20040721.0007.

171583 BSC 2004. Technical Work Plan For: Regulatory Integration Modeling and Analysis of the Waste Form and Waste Package. TWP-WIS-MD-000009 REV 00 ICN 01. Las Vegas, Nevada: Bechtel SAIC Company. ACC: DOC.20040910.0001.

167618 BSC 2004. DSNF and Other Waste Form Degradation Abstraction. ANL-WIS-MD000004 REV 03. Las Vegas, Nevada: Bechtel SAIC Company.

ACC: DOC.20040928.0003.

161921 Christensen, H. 1995. "Remodeling of the Oxidant Species During Radiolysis of High-Temperature Water in a Pressurized Water Reactor.” Nuclear Technology, 109, 373-382. La Grange Park, Illinois: American Nuclear Society. TIC: 253765.

161918 Christensen, H. and Bjergbakke, E. 1982. Radiolysis of Ground Water from Spent Fuel. SKB TR-82-18. Stockholm, Sweden: Svensk Kärnbränsleförsörjning A.B. TIC: 205896.

161919 Christensen, H.; Sunder, S.; and Shoesmith, D.W. 1994. Development of a Kinetic Model to Predict the Rate of Oxidation and Dissolution of Nuclear Fuel $\left(\mathrm{UO}_{2}\right)$ by the Radiolysis of Water. AECL-11102. Pinawa, Manitoba, Canada: Atomic Energy of Canada Limited. TIC: 242350.

164025 Cornell, R.M.; Giovanoli, R.; and Schneider, W. 1992. "The Effect of Nickel on the Conversion of Amorphous Iron(III) Hydroxide into More Crystalline Iron Oxides in Alkaline Media." Journal of Chemical Technology and Biotechnology, 53, (1), 73-79. Oxford, England: Blackwell Scientific Publishing. TIC: 254448.

100222 CRWMS M\&O 1997. Degraded Mode Criticality Analysis of Immobilized Plutonium Waste Forms in a Geologic Repository. Predecisional Document. A00000000-017175705-00014 REV 01. Las Vegas, Nevada: CRWMS M\&O.

ACC: MOL.19980422.0911. 
104440 CRWMS M\&O 1998. Summary Report of Commercial Reactor Criticality Data for Crystal River Unit 3. B00000000-01717-5705-00060 REV 01. Las Vegas, Nevada: CRWMS M\&O. ACC: MOL.19980728.0189.

144229 CRWMS M\&O 2000. General Corrosion and Localized Corrosion of Waste Package Outer Barrier. ANL-EBS-MD-000003 REV 00. Las Vegas, Nevada: CRWMS M\&O. ACC: MOL.20000202.0172.

151947 CRWMS M\&O 2000. Source Terms for HLW Glass Canisters. CAL-MGR-NU000002 REV 01. Las Vegas, Nevada: CRWMS M\&O. ACC: MOL.20000823.0004.

153263 CRWMS M\&O 2001. EQ6 Calculations for Chemical Degradation of N Reactor (Umetal) Spent Nuclear Fuel Waste Packages. CAL-EDC-MD-000010 REV 00. Las Vegas, Nevada: CRWMS M\&O. ACC: MOL.20010227.0017.

103803 Daveler, S.A. and Wolery, T.J. 1992. EQPT, A Data File Preprocessor for the EQ3/6 Software Package: User's Guide and Related Documentation (Version 7.0). UCRLMA-110662 PT II. Livermore, California: Lawrence Livermore National Laboratory. TIC: 205240.

154436 Davis, J.A.; Coston, J.A.; Kent, D.B.; and Fuller, C.C. 1998. "Application of the Surface Complexation Concept to Complex Mineral Assemblages.” Environmental Science \& Technology, 32, (19), 2820-2828. Washington, D.C.: American Chemical Society. TIC: 249656.

168855 Davis, J.A.; Payne, T.E.; and Waite, T.D. 2002. "Simulating the $\mathrm{pH}$ and $\mathrm{pCO}_{2}$ Dependence of Uranium(VI) Adsorption by a Weathered Schist with Surface Complexation Models." Chapter 4 of Geochemistry of Soil Radionuclides. SSSA Special Publication Number 59. Zhang, P-C. and Brady, P.V., eds. Madison, Wisconsin: Soil Science Society of America. TIC: 253952.

102773 Deer, W.A.; Howie, R.A.; and Zussman, J. 1966. An Introduction to the RockForming Minerals. New York, New York: John Wiley \& Sons. TIC: 245492.

159374 Dixon, J.B. 1995. "Kaolin and Serpentine Group Minerals." Chapter 10 of Minerals in Soil Environments. 2nd Edition. Dixon, J.B. and Weed, S.B., eds. SSSA Book Series, No. 1. Madison, Wisconsin: Soil Science Society of America. TIC: 237222.

150095 DOE (U.S. Department of Energy) 2000. N Reactor (U-Metal) Fuel Characteristics for Disposal Criticality Analysis. DOE/SNF/REP-056, Rev. 0. Washington, D.C.: U.S. Department of Energy, Office of Environmental Management. TIC: 247956.

152658 DOE 2000. Review of Oxidation Rates of DOE Spent Nuclear Fuel, Part 1: Metallic Fuel. DOE/SNF/REP-054, Rev. 0. Washington, D.C.: U.S. Department of Energy. TIC: 248978. 
158405 DOE 2002. DOE Spent Nuclear Fuel Information in Support of TSPA-SR.

DOE/SNF/REP-047, Rev. 2. Idaho Falls, Idaho: U.S. Department of Energy, Idaho Operations Office. TIC: 252089.

161752 DOE 2002. SNF Canister Characteristics for Criticality Analysis of a Dual Canister/Waste Package Disposal Strategy. DOE/SNF/REP-074, Rev. 0. Idaho Falls, Idaho: U.S. Department of Energy. TIC: 253869.

168434 DOE 2004. Interim Report on the Corrosion Performance of a Neutron Absorbing $\mathrm{Ni}$-Cr-Mo-Gd Alloy. DOE/SNF/REP-086, Rev. 0. Idaho Falls, Idaho: U.S. Department of Energy, Idaho Operations Office. ACC: DOC.20040412.0001.

170071 DOE 2004. Packaging Strategies for Criticality Safety for "Other” DOE Fuels in a Repository. DOE/SNF/REP-090, Rev. 0. Idaho Falls, Idaho: U.S. Department of Energy, Idaho Operations Office. ACC: MOL.20040708.0386.

100725 Drever, J.I. 1982. The Geochemistry of Natural Waters. Englewood Cliffs, New Jersey: Prentice Hall. TIC: 240706.

105483 Dzombak, D.A. and Morel, F.M.M. 1990. Surface Complexation Modeling, Hydrous Ferric Oxide. New York, New York: John Wiley \& Sons. TIC: 224089.

105780 Eary, L.E. and Rai, D. 1987. "Kinetics of Chromium(III) Oxidation to Chromium(VI) by Reaction with Manganese Dioxide." Environmental Science \& Technology, 21, (12), 1187-1193. Washington, D.C.: American Chemical Society. TIC: 243224.

161749 Ewing, R.C. and Haaker, R.F. 1979. Naturally Occurring Glasses: Analogues for Radioactive Waste Forms. PNL-2776. Richland, Washington: Pacific Northwest Laboratory. ACC: NNA.19900315.0277.

145442 Finch, R.J. and Murakami, T. 1999. "Systematics and Paragenesis of Uranium Minerals." Chapter 3 of Uranium: Mineralogy, Geochemistry and the Environment. Burns, P.C. and Finch, R.J., eds. Reviews in Mineralogy Volume 38. Washington, D.C.: Mineralogical Society of America. TIC: 247121.

106357 Firsching, F.H. and Brune, S.N. 1991. "Solubility Products of the Trivalent RareEarth Phosphates." Journal of Chemical Engineering Data, 36, 93-95. Washington, D.C.: American Chemical Society. TIC: 240863.

101173 Freeze, R.A. and Cherry, J.A. 1979. Groundwater. Englewood Cliffs, New Jersey: Prentice-Hall. TIC: 217571.

113233 Grambow, B. 1989. Spent Fuel Dissolution and Oxidation: An Evaluation of Literature Data. SKB TR-89-13. Stockholm, Sweden: Svensk Kärnbränsleförsörjning A.B. TIC: 208579.

164947 Hamel, W.F. 2003. "Waste Treatment and Immobilization Plant (WTP) High-Level Waste (HLW) Canister Production Estimates to Support Analyses by the Yucca 
Mountain Project." Memorandum from W.F. Hamel (DOE) to W.J. Taylor, June 26, 2003, with attachment. ACC: MOL.20030828.0080.

100814 Harrar, J.E.; Carley, J.F.; Isherwood, W.F.; and Raber, E. 1990. Report of the Committee to Review the Use of J-13 Well Water in Nevada Nuclear Waste Storage Investigations. UCID-21867. Livermore, California: Lawrence Livermore National Laboratory. ACC: NNA.19910131.0274.

115670 Hem, J.D. 1985. Study and Interpretation of the Chemical Characteristics of Natural Water. 3rd Edition. Geological Survey Water-Supply Paper 2254. Washington, D.C.: U.S. Government Printing Office. ACC: NNA.19940427.0181.

105875 Hsu, P.H. 1995. "Aluminum Hydroxides and Oxyhydroxides.” Chapter 7 of Minerals in Soil Environments. 2nd Edition. Dixon, J.B. and Weed, S.B., eds. SSSA Book Series, No. 1. Madison, Wisconsin: Soil Science Society of America. TIC: 237222.

158974 HydroGeoLogic and Allison Geoscience Consultants. 1999. MINTEQA2/PRODEFA2, A Geochemical Assessment Model for Environmental Systems: User Manual Supplement for Version 4.0. Athens, Georgia: U.S. Environmental Protection Agency, National Exposure Research Laboratory. TIC: 252456.

150560 IAEA (International Atomic Energy Agency) 1998. Waterside Corrosion of Zirconium Alloys in Nuclear Power Plants. IAEA-TECDOC-996. Vienna, Austria: International Atomic Energy Agency. TIC: 248234.

105878 Johnson, C.A. and Xyla, A.G. 1991. "The Oxidation of Chromium (III) to Chromium (VI) on the Surface of Manganite (MnOOH)." Geochimica et Cosmochimica Acta, 55, 2861-2866. New York, New York: Pergamon Press. TIC: 243616.

161606 Kerr, P.F. 1977. Optical Mineralogy. 4th Edition. New York, New York: McGrawHill. TIC: 252886.

105907 Klein, C. and Hurlbut, C.S., Jr. 1985. Manual of Mineralogy. 20th Edition. New York, New York: John Wiley \& Sons. TIC: 242818.

107760 Kügler, A. 1996. Böhler Neutronit A976 Sheet and Plate for Nuclear Engineering. Murzzuschlag, Austria: Böhler Bleche GmbH. TIC: 240558.

100051 Langmuir, D. 1997. Aqueous Environmental Geochemistry. Upper Saddle River, New Jersey: Prentice Hall. TIC: 237107.

159034 Li, G.; Peacor, D.R.; Coombs, D.S.; and Kawachi, Y. 1997. "Solid Solution in the Celadonite Family: The New Minerals Ferroceladonite, $\mathrm{K}_{2} \mathrm{Fe}_{2}{ }^{2}+\mathrm{Fe}_{3}{ }^{2}+\mathrm{Si}_{8} \mathrm{O}_{20}(\mathrm{OH})_{4}$, and Ferroaluminoceladonite, $\mathrm{K}_{2} \mathrm{Fe}_{2}{ }^{2}+\mathrm{Al}_{2} \mathrm{Si}_{8} \mathrm{O}_{20}(\mathrm{OH})_{4}$." American Mineralogist, 82, (5-6), 503-511. Washington, D.C.: Mineralogical Society of America. TIC: 252472. 
171509 Mahé-Le Carlier, C.; Le Carlier de Veslud, C.; Ploquin, A.; and Royer, J-J. 2000. "Natural Weathering of Archaeo-Methallurgical Slags: An Analog for Present Day Vitrified Wastes." Earth and Planetary Sciences, 330, 179-184. New York, New York: Elsevier. TIC: 256502.

165219 McKenzie, J.M. 2002. Naval Nuclear Propulsion Program Technical Baseline Compliance Document, Revision 1, October 2002. Letter from J.M. McKenzie (DOE) to J. Williams (DOE/OCRWM), November 19, 2002, NR:RA:RWIshihara U\#022852, with enclosure. ACC: HQO.20030502.0028; HQO.20030502.0029.

156684 Miller, W.; Alexander, R.; Chapman, N.; McKinley, I.; and Smellie, J. 2000. Geological Disposal of Radioactive Wastes \& Natural Analogues, Lessons from Nature and Archaeology. Waste Management Series, Volume 2. New York, New York: Pergamon. TIC: 251762.

105911 Milnes, A.R. and Fitzpatrick, R.W. 1995. "Titanium and Zirconium Minerals." Chapter 23 of Minerals in Soil Environments. 2nd Edition. Dixon, J.B. and Weed, S.B., eds. SSSA Book Series, No. 1. Madison, Wisconsin: Soil Science Society of America. TIC: 237222.

119707 Notz, K.J.; Welch, T.D.; Moore, R.S.; and Reich, W.J. 1990. Preliminary Waste Form Characteristics (Draft). ORNL TM-11081. Oak Ridge, Tennessee: Oak Ridge National Laboratory. ACC: HQX.19901003.0018.

163274 NRC (U.S. Nuclear Regulatory Commission) 2003. Yucca Mountain Review Plan, Final Report. NUREG-1804, Rev. 2. Washington, D.C.: U.S. Nuclear Regulatory Commission, Office of Nuclear Material Safety and Safeguards. TIC: 254568.

163604 Palache, C.; Berman, H.; and Frondel, C. 1944. Elements, Sulfides, Sulfosalts, Oxides. Volume I of The System of Mineralogy of James Dwight Dana and Edward Salisbury Dana, Yale University 1837-1892. 7th Edition. New York, New York: John Wiley \& Sons. TIC: 209331.

162280 Palache, C.; Berman, H.; and Frondel, C. 1951. Halides, Nitrates, Borates, Carbonates, Sulfates, Phosphates, Arsenates, Tungstates, Molybdates, Etc. Volume II of The System of Mineralogy of James Dwight Dana and Edward Salisbury Dana, Yale University 1837-1892. 7th Edition. New York, New York: John Wiley \& Sons. TIC: 209332.

159511 Parkhurst, D.L. and Appelo, C.A.J. 1999. User's Guide to PHREEQC (Version 2)—A Computer Program for Speciation, Batch-Reaction, One-Dimensional Transport, and Inverse Geochemical Calculations. Water-Resources Investigations Report 99-4259. Denver, Colorado: U.S. Geological Survey. TIC: 253046.

103896 Parrington, J.R.; Knox, H.D.; Breneman, S.L.; Baum, E.M.; and Feiner, F. 1996. Nuclides and Isotopes, Chart of the Nuclides. 15th Edition. San Jose, California: General Electric Company and KAPL, Inc. TIC: 233705. 
168860 Payne, T.E. and Waite, T.D. 1991. "Surface Complexation Modelling of Uranium Sorption Data Obtained by Isotope Exchange Techniques." Radiochimica Acta, 52/53, 487-493. München, Germany: R. Oldenbourg Verlag. TIC: 255999.

159329 Pednekar, S.P. 1987. Final Report on Corrosion of Carbon Steel in Aqueous Environments at Temperatures Below Boiling - A Literature Review to Electric Power Research Institute, February 24, 1987. Columbus, Ohio: Battelle, Columbus Division. TIC: 224492.

155635 Punatar, M.K. 2001. Summary Report of Commercial Reactor Criticality Data for Crystal River Unit 3. TDR-UDC-NU-000001 REV 02. Las Vegas, Nevada: Bechtel SAIC Company. ACC: MOL.20010702.0087.

112060 Rai, D. and Ryan, J.L. 1982. "Crystallinity and Solubility of Pu(IV) Oxide and Hydrous Oxide in Aged Aqueous Suspensions.” Radiochimica Acta, 30, 213-216. Munchen, Germany: R. Oldenbourg Verlag. TIC: 219107.

107105 Roberts, W.L.; Campbell, T.J.; and Rapp, G.R., Jr. 1990. Encyclopedia of Minerals. 2nd Edition. New York, New York: Van Nostrand Reinhold. TIC: 242976.

144800 Runde, W. 1999. "Letter Report on Plutonium Thermodynamic Database." Letter from W. Runde (LANL) to P. Dixon (LANL), August 1, 1999, with attachments. ACC: MOL.19991214.0624.

113307 Sandino, A. 1991. Processes Affecting the Mobility of Uranium in Natural Waters. Ph.D. thesis. Stockholm, Sweden: Royal Institute of Technology. TIC: 246941.

144629 Schwertmann, U. and Cornell, R.M. 1991. Iron Oxides in the Laboratory: Preparation and Characterization. New York, New York: VCH Publishers. TIC: 237942.

105959 Schwertmann, U. and Taylor, R.M. 1995. "Iron Oxides." Chapter 8 of Minerals in Soil Environments. 2nd Edition. Dixon, J.B. and Weed, S.B., eds. SSSA Book Series, No. 1. Madison, Wisconsin: Soil Science Society of America. TIC: 237222.

162970 Sequeira, C.A.C. 2000. "Corrosion of Copper and Copper Alloys.” Chapter 42 of Uhlig's Corrosion Handbook. 2nd Edition. Revie, R.W., ed. New York, New York: John Wiley \& Sons. TIC: 248360.

162976 Smith, W.H. and Purdy, G.M. 1995. "Chromium in Aqueous Nitrate Plutonium Process Streams: Corrosion of 316 Stainless Steel and Chromium Speciation." Waste Management, 15, (7), 477-484. New York, New York: Pergamon. TIC: 254034.

103804 Spahiu, K. and Bruno, J. 1995. A Selected Thermodynamic Database for REE to be Used in HLNW Performance Assessment Exercises. SKB TR-95-35. Stockholm, Sweden: Svensk Kärnbränsleförsörjning A.B. TIC: 225493. 
127253 Sposito, G. 1984. The Surface Chemistry of Soils. New York, New York: Oxford University Press. TIC: 217687.

141778 Stumm, W. 1992. Chemistry of the Solid-Water Interface, Processes at the MineralWater and Particle-Water Interface in Natural Systems. New York, New York: John Wiley \& Sons. TIC: 237213.

125332 Stumm, W. and Morgan, J.J. 1996. Aquatic Chemistry, Chemical Equilibria and Rates in Natural Waters. 3rd Edition. New York, New York: John Wiley \& Sons. TIC: 246296.

126924 Waber, N. 1991. Mineralogy, Petrology and Geochemistry of the Pocos de Caldas Analogue Study Sites, Minas Gerais, Brazil. II. Morro do Ferro. SKB TR-90-12. Stockholm, Sweden: Svensk Kärnbränsleförsörjning A.B. TIC: 206350.

168856 Waite, T.D.; Davis, J.A.; Fenton, B.R.; and Payne, T.E. 2000. “Approaches to Modelling Uranium(VI) Adsorption on Natural Mineral Assemblages." Radiochimica Acta, 88, (9-11), 687-693. München, Germany: Oldenbourg Wisenschaftsverlag. TIC: 255860 .

106266 Weast, R.C., ed. 1977. CRC Handbook of Chemistry and Physics. 58th Edition. Cleveland, Ohio: CRC Press. TIC: 242376.

137607 Wilson, C.N. and Bruton, C.J. 1989. Studies on Spent Fuel Dissolution Behavior Under Yucca Mountain Repository Conditions. PNL-SA-16832. Richland, Washington: Pacific Northwest Laboratory. ACC: HQX.19890918.0047.

100194 Yang, I.C.; Rattray, G.W.; and Yu, P. 1996. Interpretation of Chemical and Isotopic Data from Boreholes in the Unsaturated Zone at Yucca Mountain, Nevada. WaterResources Investigations Report 96-4058. Denver, Colorado: U.S. Geological Survey. ACC: MOL.19980528.0216.

105963 Zachara, J.M.; Girvin, D.C.; Schmidt, R.L.; and Resch, C.T. 1987. "Chromate Adsorption on Amorphous Iron Oxyhydroxide in the Presence of Major Groundwater Ions.” Environmental Science \& Technology, 21, (6), 589-594. Easton,

Pennsylvania: American Chemical Society. TIC: 243613.

171238 Zarrabi, K.; McMillan, S.; Elkonz, S.; and Cizdziel, J. 2003. Corrosion and Mass Transport Processes in Carbon Steel Miniature Waste Packages. Document TR-03003, Rev. 0. Task 34. Las Vegas, Nevada: University of Nevada, Las Vegas. ACC: MOL.20040202.0079.

\subsection{CODES, STANDARDS, REGULATIONS, AND PROCEDURES}

10047548 FR 28194. 10 CFR Part 60 Disposal of High-Level Radioactive Wastes in Geologic Repositories Technical Criteria. Readily available. 
15660510 CFR 63. Energy: Disposal of High-Level Radioactive Wastes in a Geologic Repository at Yucca Mountain, Nevada. Readily available.

AP-SIII.2Q, Rev. 1, ICN 2. Qualification of Unqualified Data. Washington, D.C.: U.S. Department of Energy, Office of Civilian Radioactive Waste Management. ACC: DOC.20040127.0008.

AP-SIII.10Q, Rev. 1, ICN 2. Models. Washington, D.C.: U.S. Department of Energy, Office of Civilian Radioactive Waste Management. ACC: DOC.20030627.0003.

104189 ASTM A 20/A 20M-95a. 1995. Standard Specification for General Requirements for Steel Plates for Pressure Vessels. West Conshohocken, Pennsylvania: American Society for Testing and Materials. TIC: 240026.

165003 ASTM A 240/A 240M-03b. 2003. Standard Specification for Chromium and Chromium-Nickel Stainless Steel Plate, Sheet, and Strip for Pressure Vessels and for General Applications. West Conshohocken, Pennsylvania: American Society for Testing and Materials. TIC: 254845.

162723 ASTM A 516/A 516M-01. 2001. Standard Specification for Pressure Vessel Plates, Carbon Steel, for Moderate- and Lower-Temperature Service. West Conshohocken, Pennsylvania: American Society for Testing and Materials. TIC: 253997.

154062 ASTM A 887-89 (Reapproved 2000). 2000. Standard Specification for Borated Stainless Steel Plate, Sheet, and Strip for Nuclear Application. West Conshohocken, Pennsylvania: American Society for Testing and Materials. TIC: 249544.

144744 ASTM B 209-96. 1996. Standard Specification for Aluminum and Aluminum-Alloy Sheet and Plate. West Conshohocken, Pennsylvania: American Society for Testing and Materials. TIC: 247078.

168403 ASTM B 932-04. 2004. Standard Specification for Low-Carbon Nickel-ChromiumMolybdenum-Gadolinium Alloy Plate, Sheet, and Strip. West Conshohocken, Pennsylvania: American Society for Testing and Materials. TIC: 255846.

105725 ASTM C 1174-97. 1998. Standard Practice for Prediction of the Long-Term Behavior of Materials, Including Waste Forms, Used in Engineered Barrier Systems (EBS) for Geological Disposal of High-Level Radioactive Waste. West Conshohocken, Pennsylvania: American Society for Testing and Materials. TIC: 246015.

103515 ASTM G 1-90 (Reapproved 1999). 1999. Standard Practice for Preparing, Cleaning, and Evaluating Corrosion Test Specimens. West Conshohocken, Pennsylvania: American Society for Testing and Materials. TIC: 238771. 
LP-SI.11Q-BSC, Rev. 0, ICN 0. Software Management. Washington, D.C.: U.S. Department of Energy, Office of Civilian Radioactive Waste Management. ACC: DOC.20040225.0007.

\subsection{SOFTWARE CODES}

149359 Software Code: EQ3/6. V7.2b. LLNL: UCRL-MA-110662.

159731 Software Code: EQ6. 7.2bLV. PC. 10075-7.2bLV-02. Windows NT, 2000.

161900 Software Code: GetEQData. V1.0.1. PC w/Windows 2000. 10809-1.0.1-0.

157837 Software Code: PHREEQC. V2.3. PC. 10068-2.3-01.

155029 Software Code: transl. V2.0. PC Windows98. 10251-2.0-00.

\subsection{SOURCE DATA, LISTED BY DATA TRACKING NUMBER}

160899 GS020408312272.003. Collection and Analysis of Pore Water Samples for the Period from April 2001 to February 2002. Submittal date: 04/24/2002.

151029 MO0006J13WTRCM.000. Recommended Mean Values of Major Constituents in J13 Well Water. Submittal date: 06/07/2000.

160229 MO0210SPATHDYN.000. Themodynamic Data Input Files - DATA0.YMP.R2. Submittal date: 10/02/2002.

161756 MO0302SPATHDYN.000. Thermodynamic Data Input Files - Data0.YMP.R2. Submittal date: 02/05/2003.

162551 MO0303MWDSCMAB.000. THC Seepage Chemistry Model Abstraction Binning EQ3 Input, Pickup and Output Files. Submittal date: 03/06/2003.

167409 MO0312SPAPCEML.003. EBS P\&CE Model Longevity of Materials Evaluation. Submittal date: 12/18/2003.

167800 MO0312SPATDMIF.000. Thermodynamic Data Input Files - Data0.YMP.R3. Submittal date: 12/22/2003.

171239 MO0405MWDGIFWP.000. Input and Output for Geochemical Interactions in Failed Co-Disposal Waste Packages for Shippingport PWR and TRIGA Spent Fuel and in Dual Canister Packages of Three Mile Island and Fort St. Vrain Spent Fuel. Submittal date: $05 / 13 / 2004$.

170760 MO0407SEPFEPLA.000. LA FEP List. Submittal date: 07/20/2004.

172059 MO0409SPAACRWP.000. Aqueous Corrosion Rates For Non-Waste Form Waste Package Materials. Submittal date: 09/16/2004. 


\subsection{OUTPUT DATA, LISTED BY DATA TRACKING NUMBER}

MO0404SPAIPCHM.005. Abstractions of In-Package Chemistry for TSPA-LA. Submittal date: 04/29/2004.

MO0403SPASURCR.000. Surface complexation reactions in PHREEQC format from the surface complexation demonstration (Section 6.8).

MO0403SPAYMPR3.000. Surface complexation demonstration (Section 6.8) thermodynamic database for PHREEQC (YMP_R3.dat) with abridged surface complexation reactions.

MO0403MWDSRFCC.000. Surface complexation demonstration (Section 6.8) input and output PHREEQC files, and the expanded PHREEQC database (YMP_R3mr.dat) which contains surface complexation reactions.

MO0312SPAICSCR.002. Developed in Appendix B, and documents the effect of radiolysis on the in-package chemistry.

MO0411MWDIPCAB.000. Model Warehouse Data for In-Package Chemistry Abstraction. Submittal date: 11/04/2004.

MO0411SPAMOICA.000. Model Output for In-Package Chemistry Abstraction. Submittal date: 11/04/2004. 


\section{INTENTIONALLY LEFT BLANK}


APPENDIX A

ADDITIONAL IN-PACKAGE CHEMISTRY PLOTS 


\section{INTENTIONALLY LEFT BLANK}




\section{A. ADDITIONAL IN-PACKAGE CHEMISTRY PLOTS}

Appendix A is comprised of additional plots. The computer files are included in Appendix F.

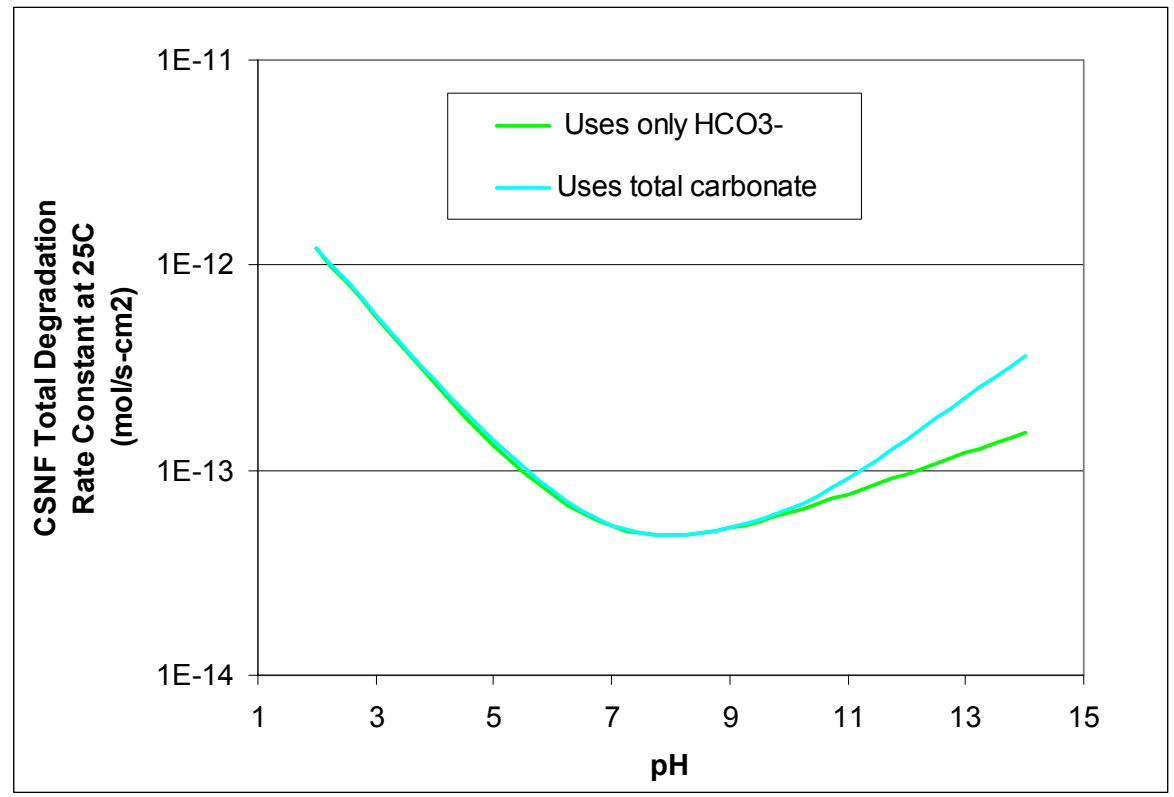

Source: Appendix F, CSNF_Eh_Carb.xls, worksheet "CSNF Rate Sensitivity."

Figure A-1. CSNF Total Degradation Rate Constant as a Function of $\mathrm{pH}$

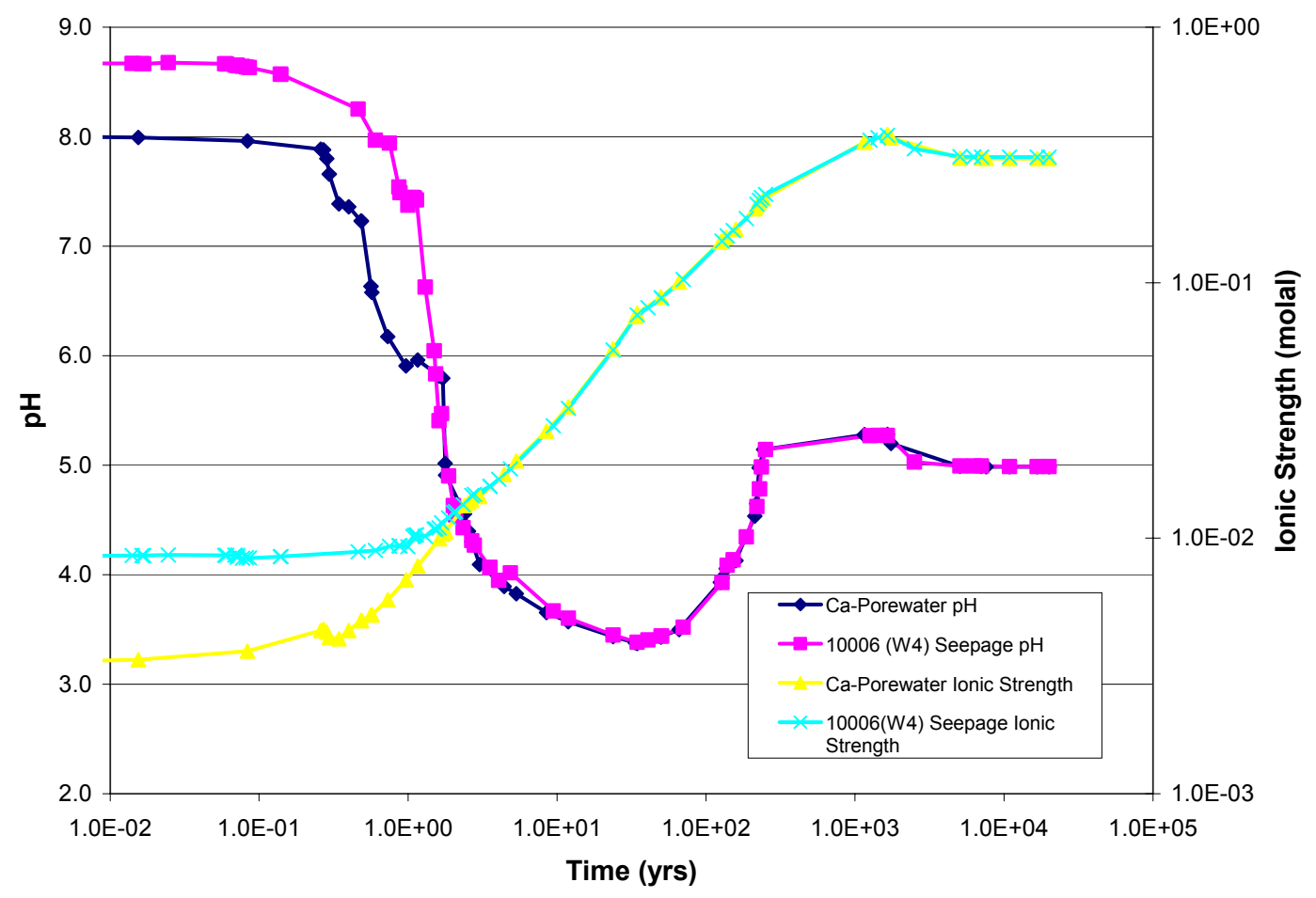

Source: $\quad$ CSNF_P\&CE_fluids.xls in Appendix F.

Figure A-2. Thermally Perturbed Composition 10006 (W4) with Ca-porewater (W5) for CSNF 


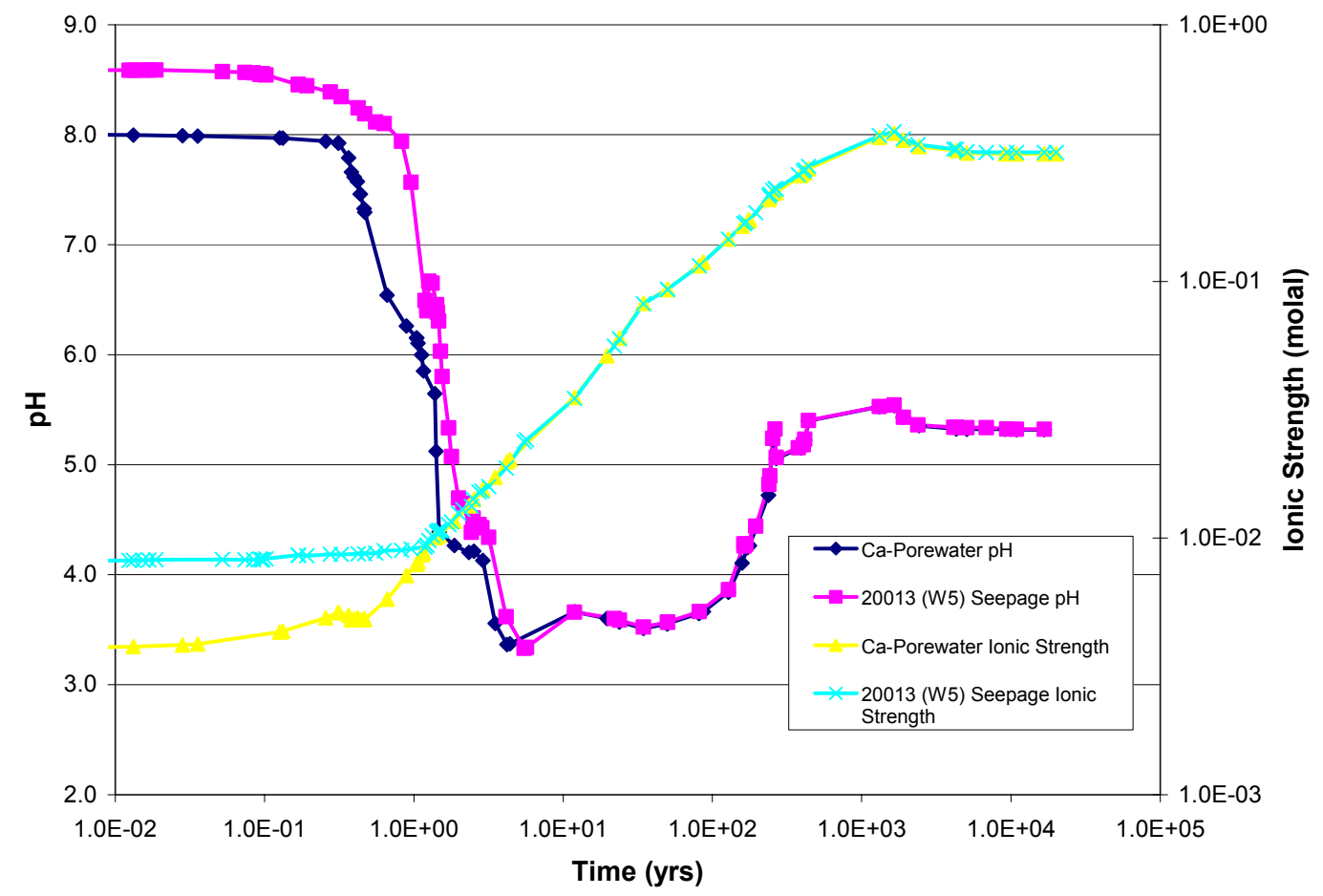

Source: CSNF_P\&CE_fluids.xls in Appendix F.

Figure A-3. Thermally Perturbed Composition 20013 (W5) with Ca-porewater (W5) for CSNF

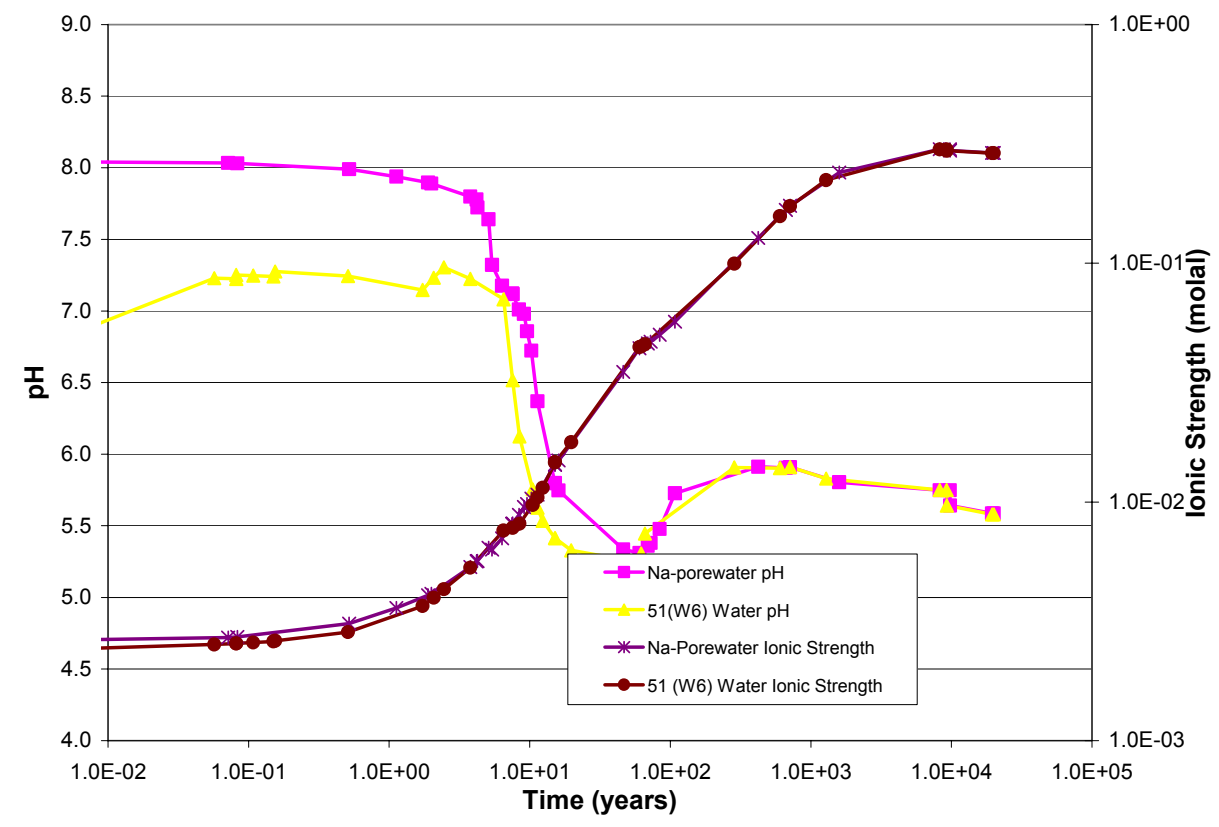

Source: CDSP_P\&CE_fluids.xls in Appendix F.

Figure A-4. Thermally Perturbed Composition 51 (W6) with Na-porewater (W5) for CDSP 


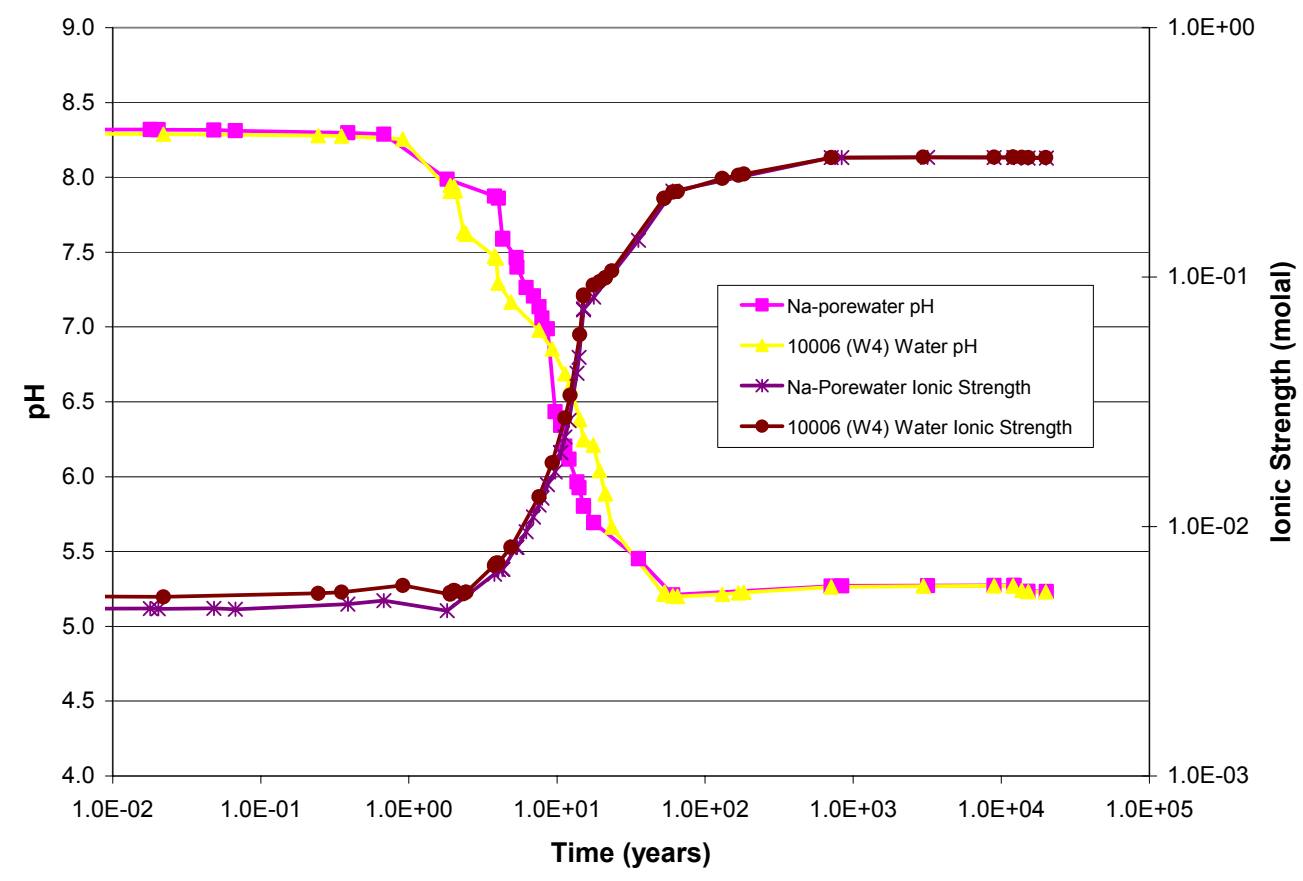

Source: $\quad C D S P \_P \& C E \_$fluids.x/s in Appendix F.

Figure A-5. Thermally Perturbed Composition 10006 (W4) with Na-porewater (W5) for CDSP

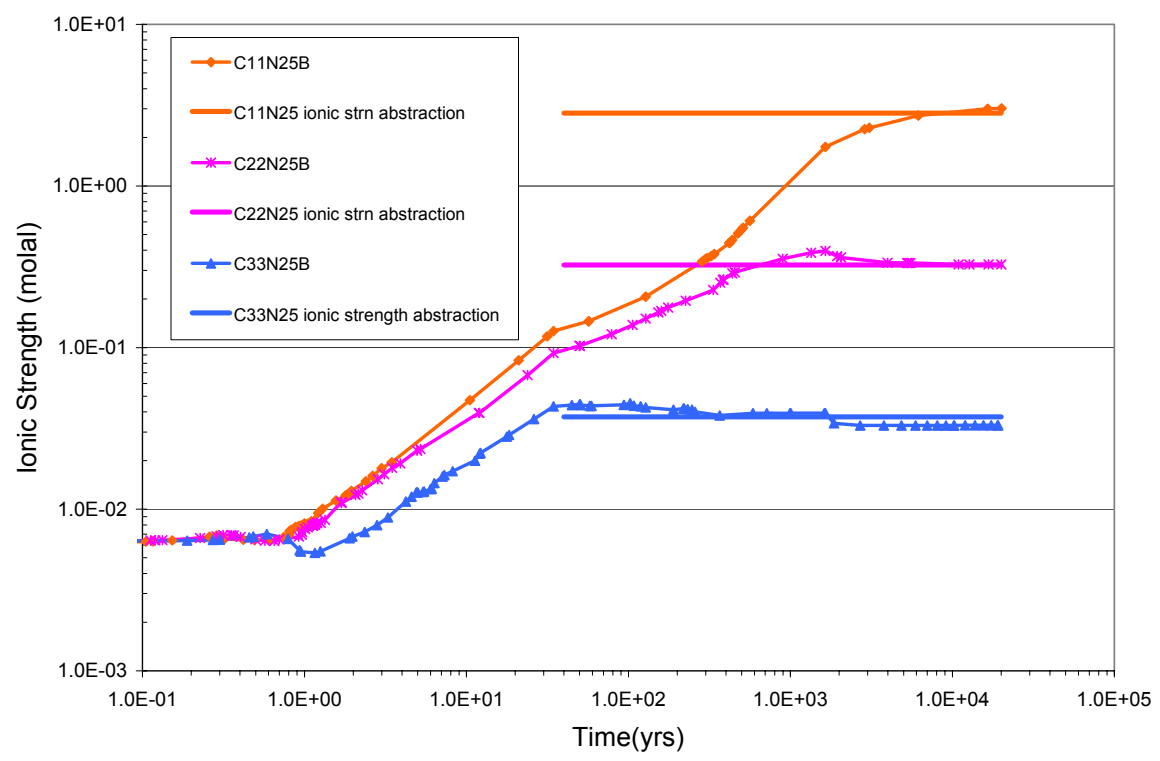

Source: CSNF_Water Influx_25.x/s in Appendix F.

Figure A-6. Validation of lonic Strength Abstraction to Model Output for $25^{\circ} \mathrm{C}$ CSNF 


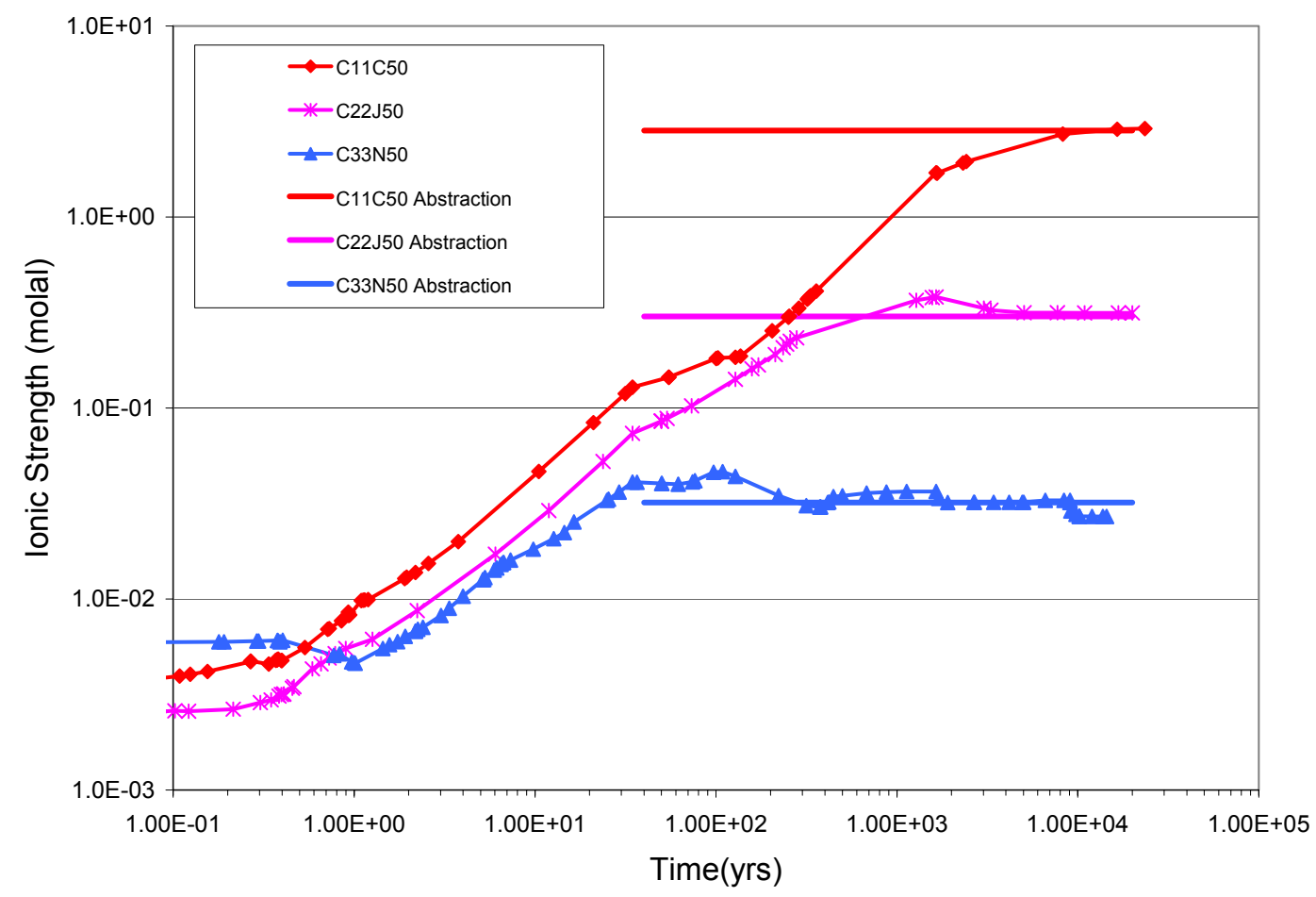

Source: CSNF_Water Influx_50.x/s in Appendix F.

Figure A-7. Validation of lonic Strength Abstraction to Model Output for $50^{\circ} \mathrm{C}$ CSNF

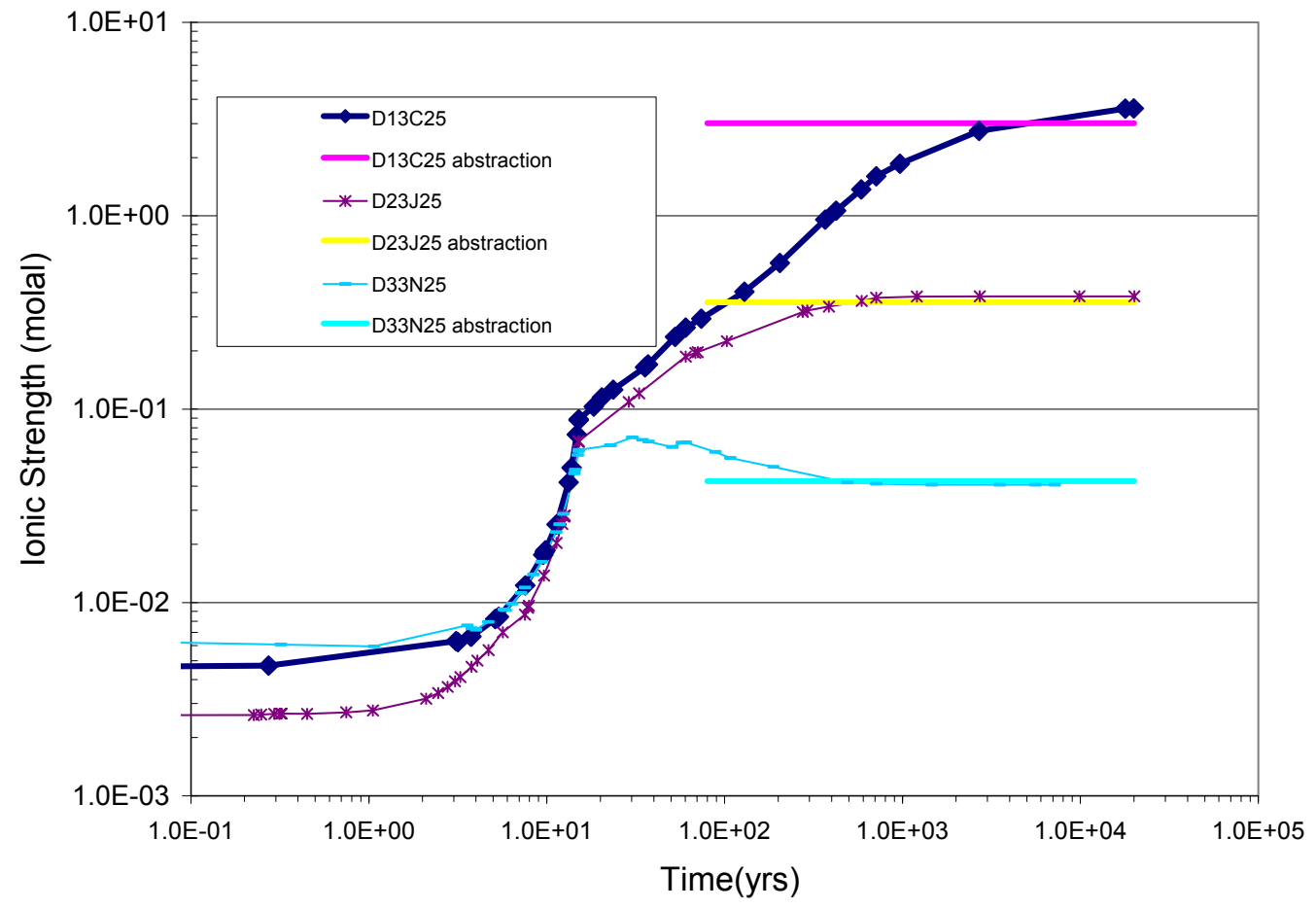

Source: $\quad C D S P \_$Water Influx_25.x/s in Appendix F.

Figure A-8. Validation of lonic Strength Abstraction to Model Output for $25^{\circ} \mathrm{C} \mathrm{CDSP}$ 


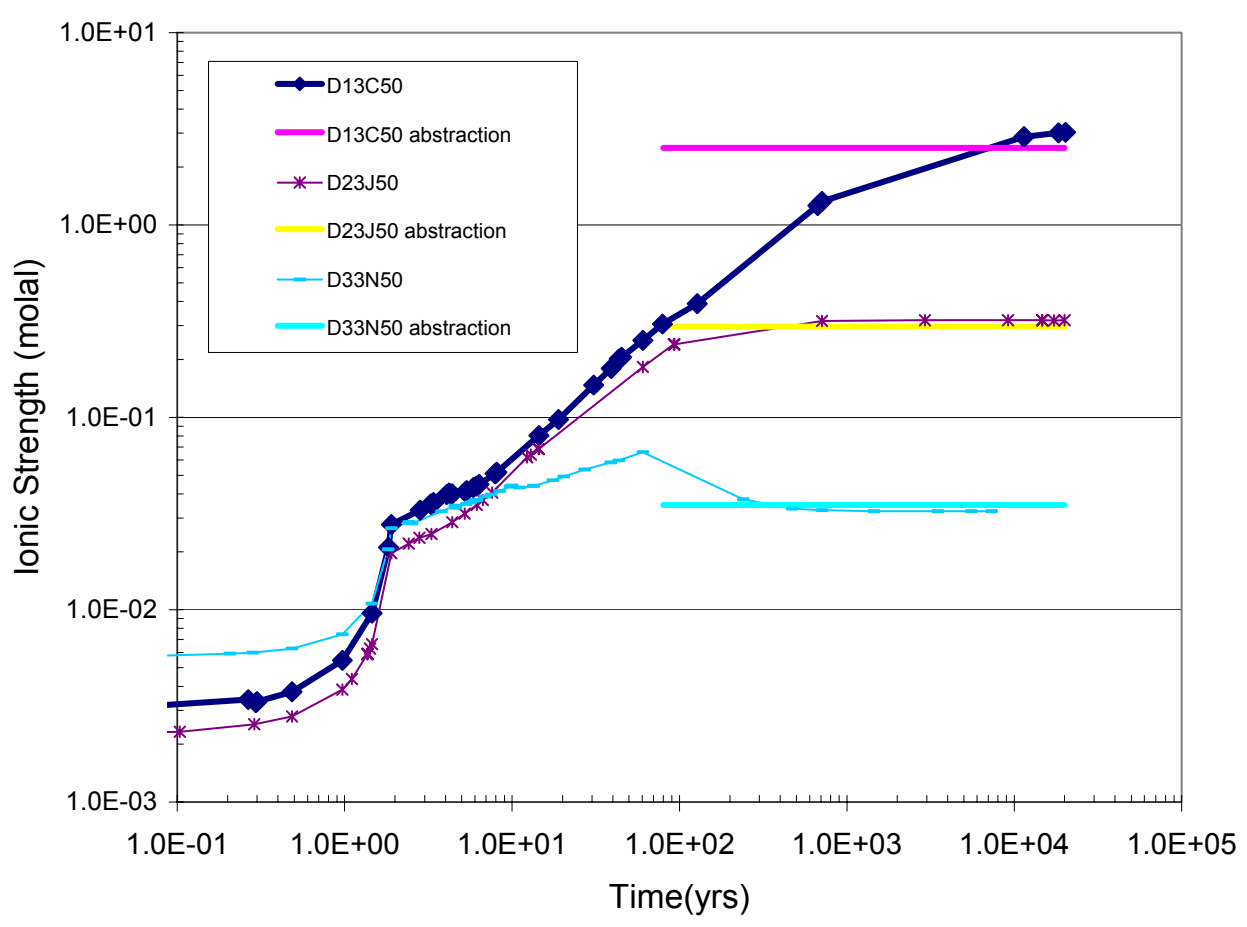

Source: $\quad C D S P \_$Water Influx_50.x/s in Appendix F.

Figure A-9. Validation of lonic Strength Abstraction to Model Output for $50^{\circ} \mathrm{C} \mathrm{CDSP}$

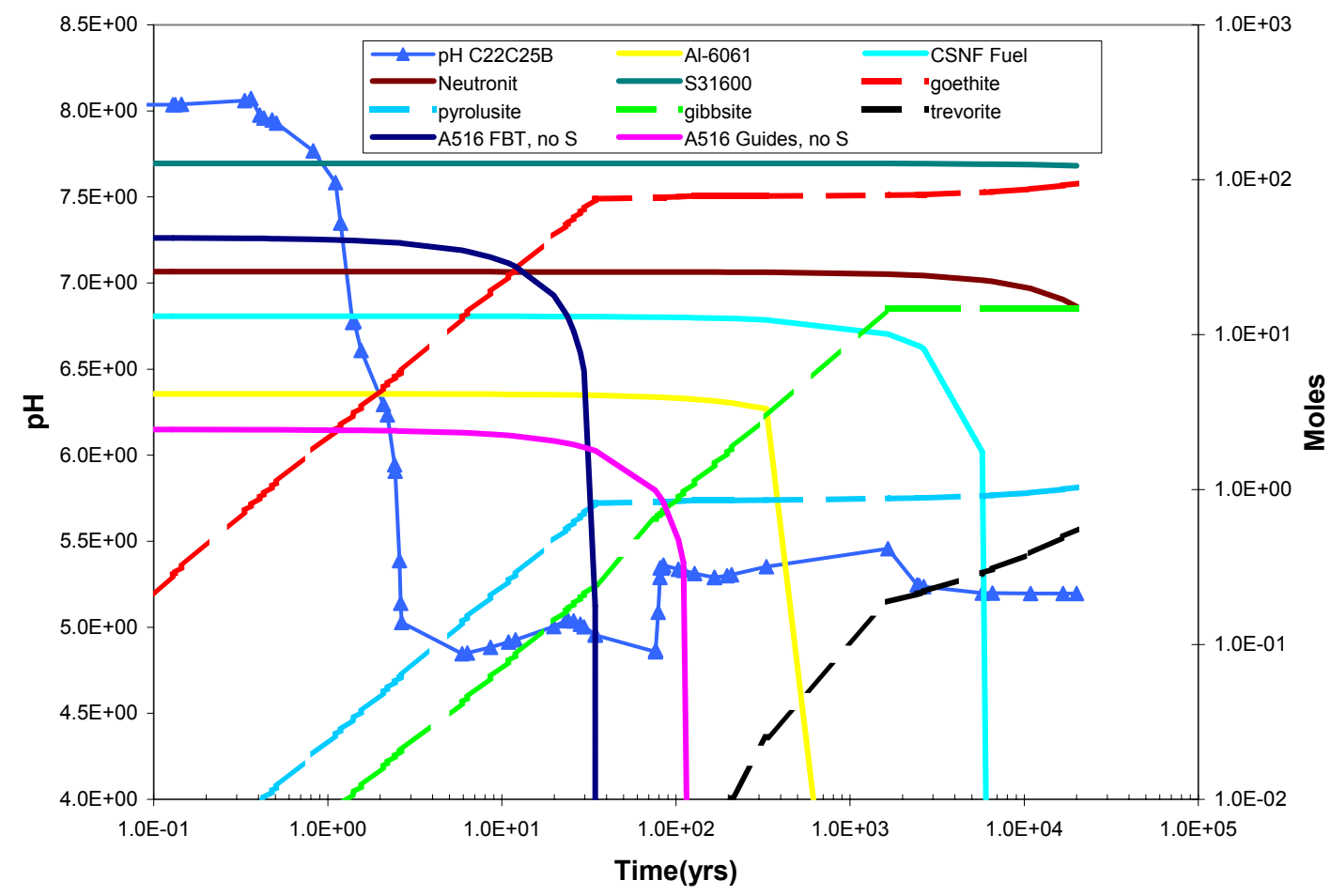

Source: CSNF_Water Influx_25.x/s in Appendix F.

Figure A-10. Corrosion Products and pH with no Sulfur in the Carbon Steel Type A516 Composition 


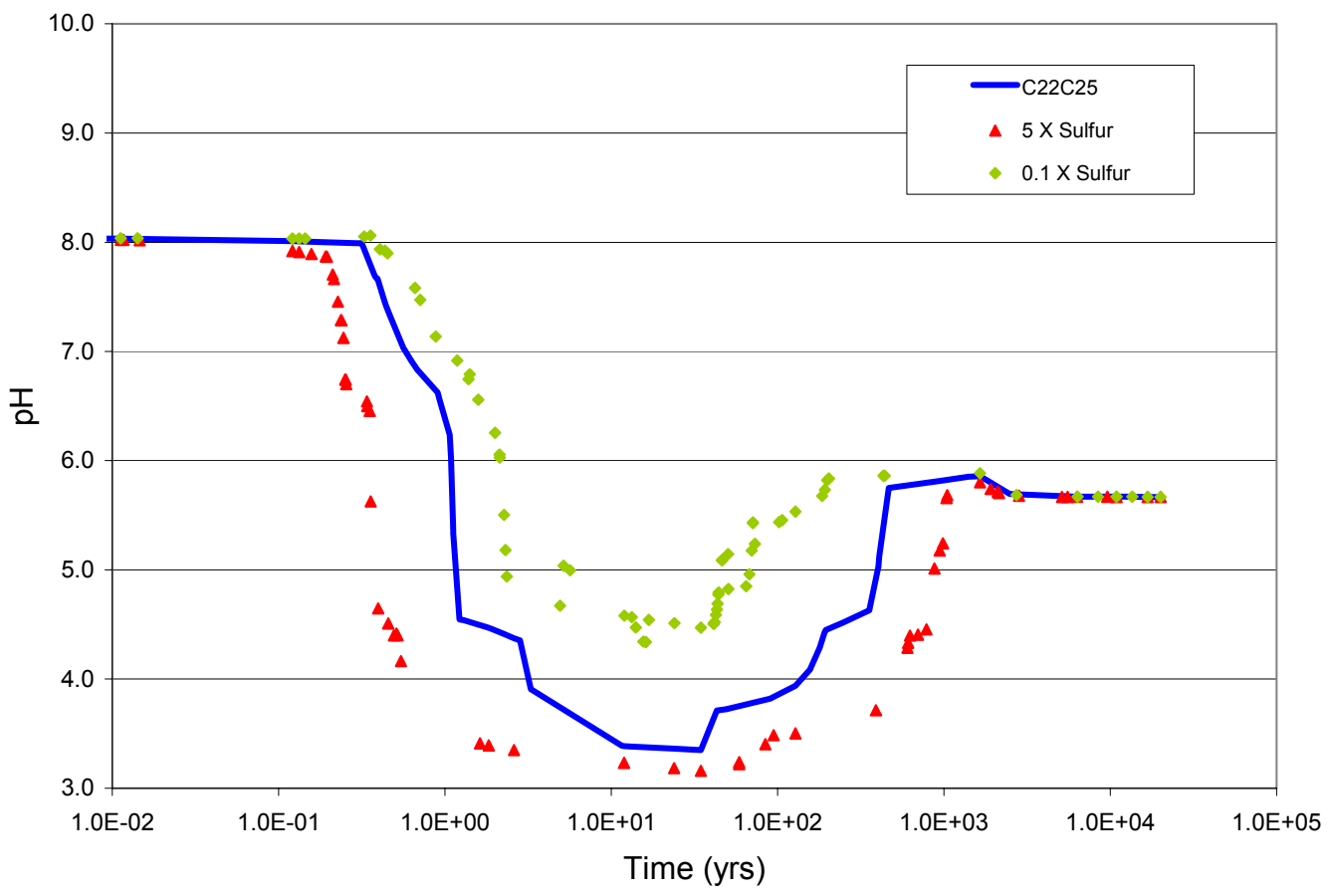

Source: Appendix F, CSNF_Sensitivity.xls.

Figure A-11. Effect of Varying Sulfur Content in Carbon Steel Type A516 on pH

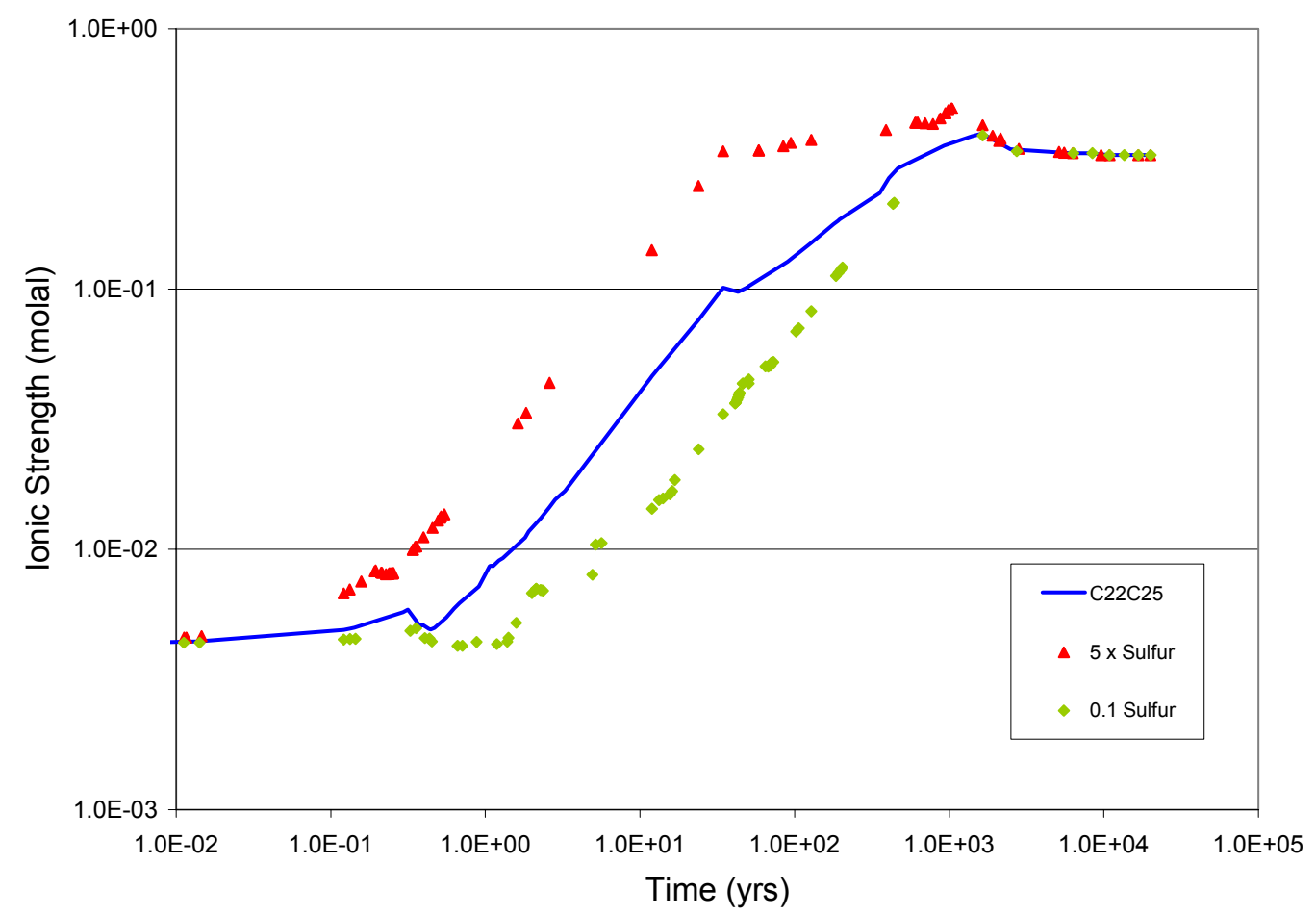

Source: Appendix F, CSNF_Sensitivity.xls.

Figure A-12. Effect of Varying Sulfur Content in Carbon Steel Type A516 on lonic Strength 


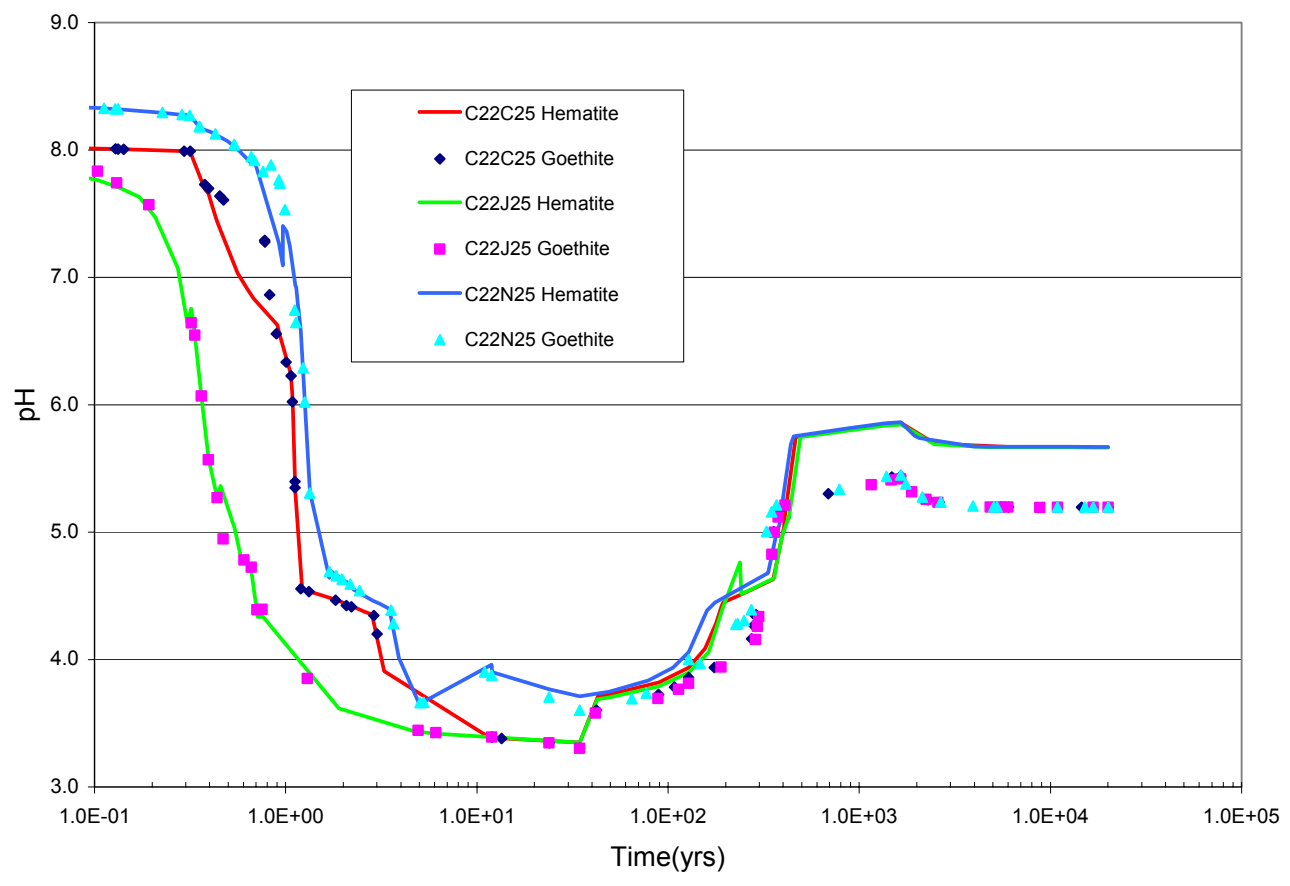

Source: Appendix F, CSNF_Water Influx_25.xIs.

Figure A-13. Effect of Goethite and Hematite on pH

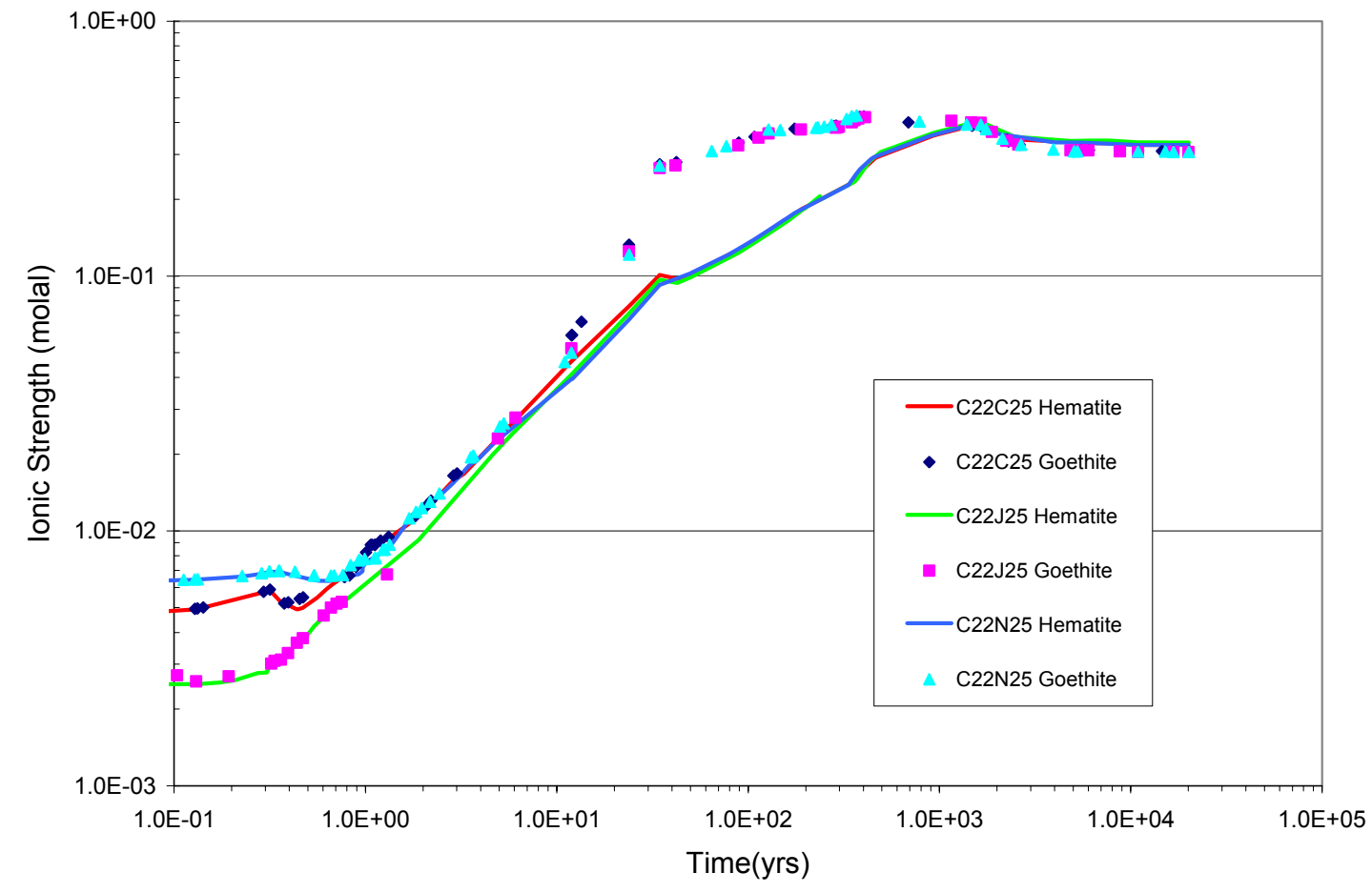

Source: Appendix F, CSNF_Water Influx_25.x/s.

Figure A-14. Effect of Goethite and Hematite on lonic Strength 
Table A-1. 21-PWR Waste Package Internal Component Dimensions

\begin{tabular}{|c|c|c|c|}
\hline Component & Subcomponent & Dimension & Value $(\mathrm{mm})$ \\
\hline \multirow{6}{*}{$\begin{array}{c}\text { Inner Shell } \\
\text { (1 Per Waste } \\
\text { Package) }\end{array}$} & & Inner Diameter & 1,424 \\
\hline & & Outer Diameter & 1,524 \\
\hline & & Inner Height & 4,585 \\
\hline & & Inner Shell Assembly Height & 4,762 \\
\hline & Bottom Lid & Thickness & 88.9 \\
\hline & Top Lid & Thickness & 50.8 \\
\hline \multirow{8}{*}{$\begin{array}{c}\text { Fuel Plate Assembly } \\
\text { (4 Per Waste } \\
\text { Package) }\end{array}$} & Fuel Basket A,B-Plate & Height & 1,396 \\
\hline & Fuel Basket A,B-Plate & Width & 1,134 \\
\hline & Fuel Basket C-Plate & Height & 733.2 \\
\hline & Fuel Basket C-Plate & Width & 1,134 \\
\hline & Fuel Basket D,E-Plate & Height & 1,394 \\
\hline & Fuel Basket D,E-Plate & Width & 1,132 \\
\hline & A,B,\& C Plates & Thickness & 7 \\
\hline & D \& E Plates & Thickness & 5 \\
\hline \multirow{3}{*}{$\begin{array}{c}\text { Fuel Basket Tube } \\
\text { (21 Per Waste } \\
\text { Package) }\end{array}$} & & Length & 4,575 \\
\hline & Exterior Dimension & Width, Height & 236.4 \\
\hline & Interior Dimension & Width, Height & 226.4 \\
\hline \multirow{9}{*}{$\begin{array}{c}\text { Side } \\
\text { Corner-Guide } \\
\text { Stiffeners } \\
\text { (4 Per Waste } \\
\text { Package) }\end{array}$} & \multirow{3}{*}{$\begin{array}{c}\text { Basket A Stiffener (64 } \\
\text { Per Waste Package) }\end{array}$} & Height & 77.8 \\
\hline & & Width & 209.2 \\
\hline & & Thickness & 10 \\
\hline & \multirow{3}{*}{$\begin{array}{c}\text { Basket B Stiffener (32 } \\
\text { Per Waste Package) }\end{array}$} & Height & 91.7 \\
\hline & & Width & 216.4 \\
\hline & & Thickness & 10 \\
\hline & \multirow{3}{*}{$\begin{array}{c}\text { Basket C Stiffener (32 } \\
\text { Per Waste Package) }\end{array}$} & Height & 227.3 \\
\hline & & Width & 227.3 \\
\hline & & Thickness & 10 \\
\hline \multirow{4}{*}{$\begin{array}{c}\text { Basket A-Sideguide } \\
\text { (32 Per Waste } \\
\text { Package) }\end{array}$} & & Width & 236.3 \\
\hline & & Height & 89.7 \\
\hline & & Length & 1,134 \\
\hline & & Thickness & 10 \\
\hline \multirow{4}{*}{$\begin{array}{c}\text { Basket B-Sideguide } \\
\text { (16 Per Waste } \\
\text { Package) }\end{array}$} & & Width & 236.4 \\
\hline & & Height & 93.4 \\
\hline & & Length & 1,134 \\
\hline & & Thickness & 10 \\
\hline \multirow{4}{*}{\begin{tabular}{|c|} 
Basket Cornerguide \\
(16 Per Waste \\
Package)
\end{tabular}} & & Width & 243.4 \\
\hline & & Height & 243.4 \\
\hline & & Length & 1,134 \\
\hline & & Thickness & 10 \\
\hline
\end{tabular}

Source: BSC 2004 [DIRS 167207], Table 1a. 
Table A-2. Minor Input Inconsistencies in the EQ3 and EQ6 Input Files

\begin{tabular}{|c|c|c|c|}
\hline Input & Base Value & Alternate Value & Justification \\
\hline $\begin{array}{l}\text { Stainless Steel } \\
\text { Type } 316 \\
\text { composition }\end{array}$ & $\begin{array}{l}\text { Stainless Steel Type } \\
316 \text { composition }\end{array}$ & $\begin{array}{l}\text { Use of Stainless Steel } \\
\text { Type } 316 N G \text { or } 316 \mathrm{~L} \\
\text { composition }\end{array}$ & $\begin{array}{l}\text { The difference is due to older materials } \\
\text { copied over from previous input files, } \\
\text { but is so minor that it will not impact the } \\
\text { results as shown for Case D } 23 C 25 \text { in } \\
\text { Figure A-13. }\end{array}$ \\
\hline $\begin{array}{l}\text { NiGd alloy } \\
\text { composition }\end{array}$ & $\begin{array}{l}\text { Co }=2 \text { wt } \% \\
O=0.005 \text { wt } \%\end{array}$ & No Co or O was used & $\begin{array}{l}\text { The difference is due to a transcription } \\
\text { error when copying the composition } \\
\text { from the source, but is so minor that it } \\
\text { will not impact the results as shown for } \\
\text { Case C22J } 25 \text { in Figure A- } 14 \text {. }\end{array}$ \\
\hline Al-1100 composition & $\begin{array}{l}\mathrm{Cu}=0.05-0.20 \mathrm{wt} \% \\
\mathrm{Mn}=0.05 \mathrm{wt} \% \\
\mathrm{Zn}=0.10 \mathrm{wt} \%\end{array}$ & $\begin{array}{l}\text { Min } \mathrm{Cu} \text { value was used } \\
\text { No } \mathrm{Mn} \text { or } \mathrm{Zn} \text { was used. }\end{array}$ & $\begin{array}{l}\text { The difference is due to a transcription } \\
\text { error when copying the composition } \\
\text { from the source, but is so minor that it } \\
\text { will not impact the results, based on a } \\
\text { similar error noted above shown in } \\
\text { Figure A-14. }\end{array}$ \\
\hline $\begin{array}{l}\text { Stainless Steel } \\
\text { Type } 304 \\
\text { composition }\end{array}$ & $\begin{array}{l}\text { Moles of } P=1.61 \mathrm{E}-03 \\
0.045\end{array}$ & $\begin{array}{l}\text { Moles of } P=1.45 E-03 \\
0.05\end{array}$ & $\begin{array}{l}\text { The difference is due to the number of } \\
\text { significant figures in the weight percent } \\
\text { but is so minor that it will not impact the } \\
\text { results. }\end{array}$ \\
\hline Temperature & $\begin{array}{l}\text { EQ3 input file for } 50 \\
\text { and } 90^{\circ} \mathrm{C} \text { runs }\end{array}$ & $\begin{array}{l}\text { EQ3 input file used } \\
25^{\circ} \mathrm{C}\end{array}$ & $\begin{array}{l}\text { The difference is due to not updating } \\
\text { the EQ3 input files for new } \\
\text { temperatures, but, EQ6 reequilibrates } \\
\text { with the temperature listed in the EQ6 } \\
\text { file, so the difference is so minor that it } \\
\text { will not impact the results as shown for } \\
\text { Case D23C } 90 \text { in Figure A-15. }\end{array}$ \\
\hline $\begin{array}{l}\text { Log fCO } \mathrm{fCO}_{2} \text { and } \mathrm{O}_{2} \\
\text { values }\end{array}$ & -3.0 and -0.7 & $\begin{array}{l}-3.01 \text { and }-0.71 \\
\text { (sensitivities }-1.51 \text { to } \\
-5.01 \text { ) } \\
-0.818 \text { (for } \mathrm{J}-13.3 \text { i files) }\end{array}$ & $\begin{array}{l}\text { The difference is due to the number of } \\
\text { significant figures copied over from } \\
\text { previous input files, but is so minor that } \\
\text { it will not impact the results. }\end{array}$ \\
\hline N Reactor Rate & $\begin{array}{l}10 \times \text { higher rate for } \\
\text { higher temperatures }\end{array}$ & Used base-case rate. & $\begin{array}{l}\text { The base-case rate is already high, so } \\
\text { the difference is so minor, it will not } \\
\text { impact the results. }\end{array}$ \\
\hline
\end{tabular}




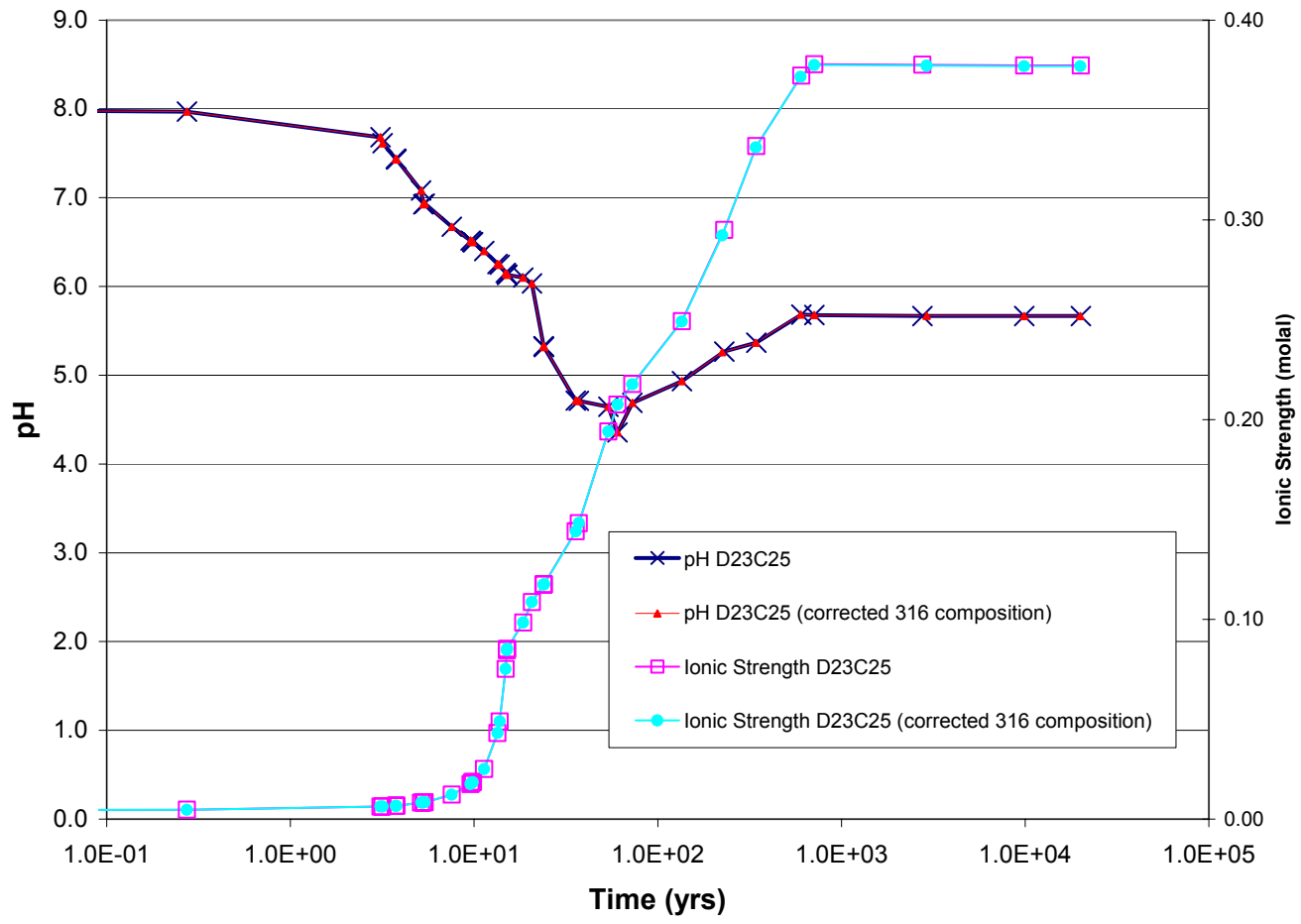

Source: Appendix F, CDSP_Sensitivity.x/s.

Figure A-15. pH and Ionic Strength Comparison for Change in Stainless Steel Type 316 Composition

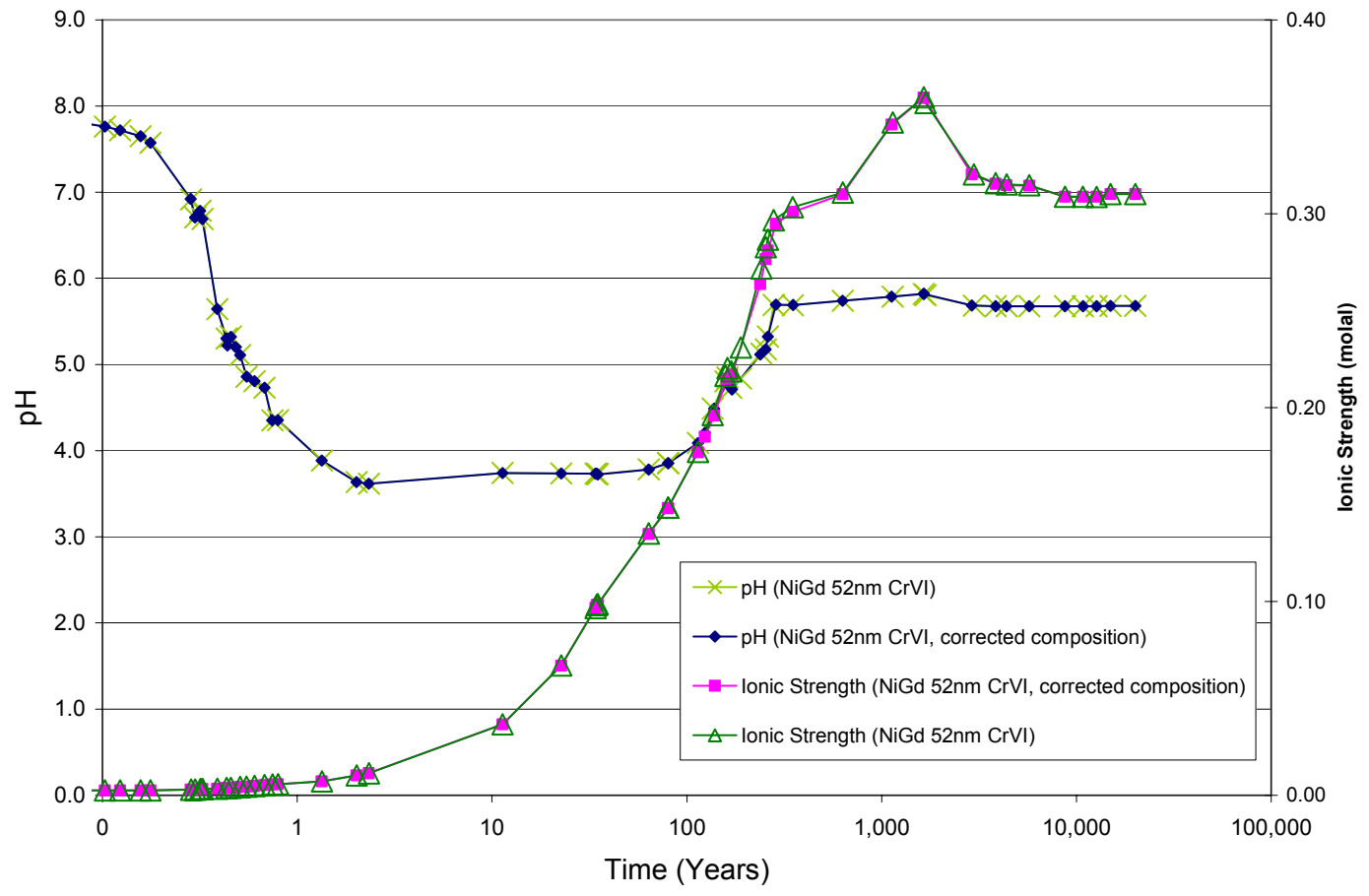

Source: Appendix F, CSNF_NiGd Sensitivity.xls.

Figure A-16. $\mathrm{pH}$ and Ionic Strength Comparison for Change in NiGd Alloy Composition 


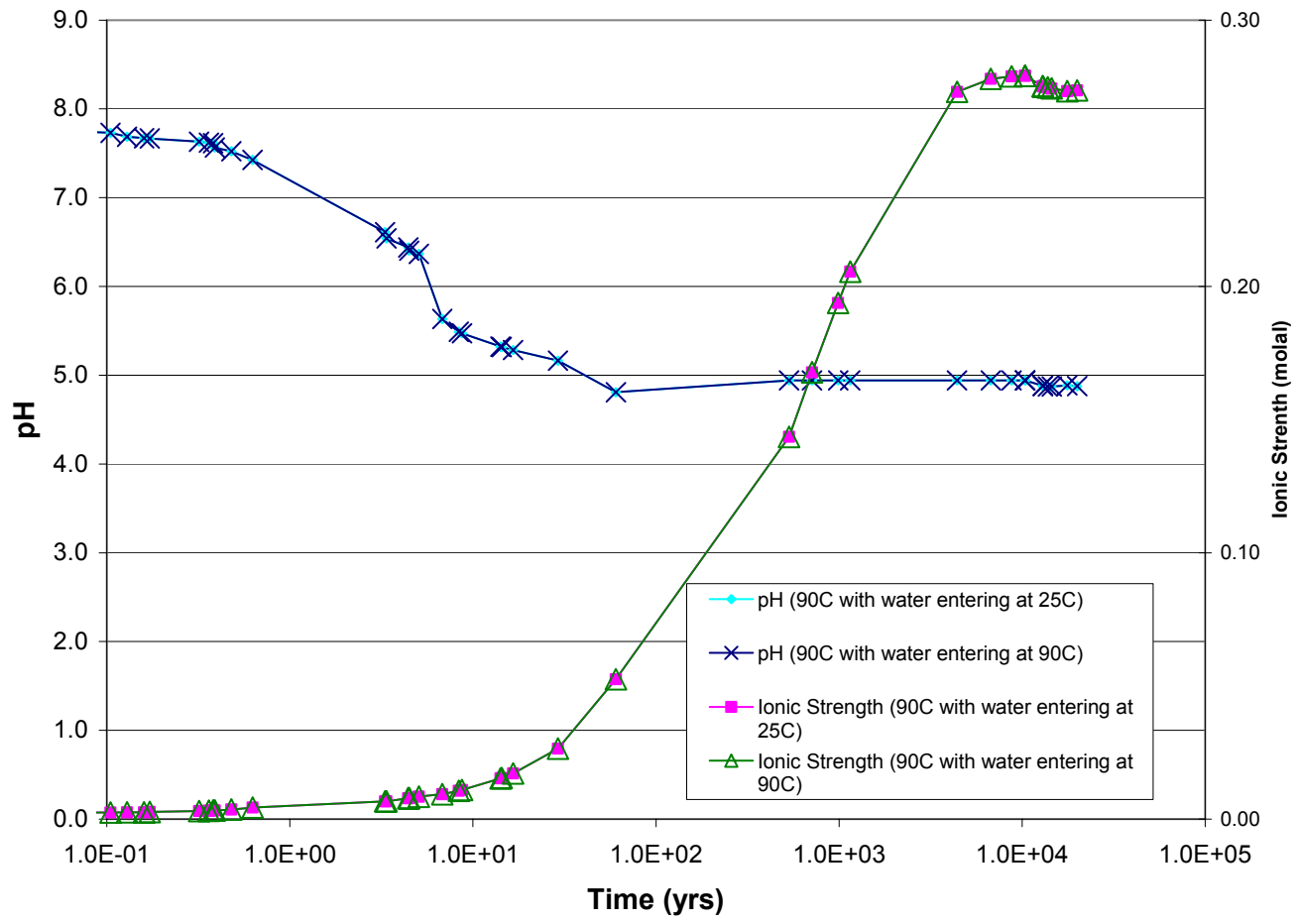

Source: Appendix F, CDSP_Sensitivity.xls.

Figure A-17. $\mathrm{pH}$ and lonic Strength Comparison for Codisposal EQ3 Pickup File at Different Temperature than EQ6 Calculation 


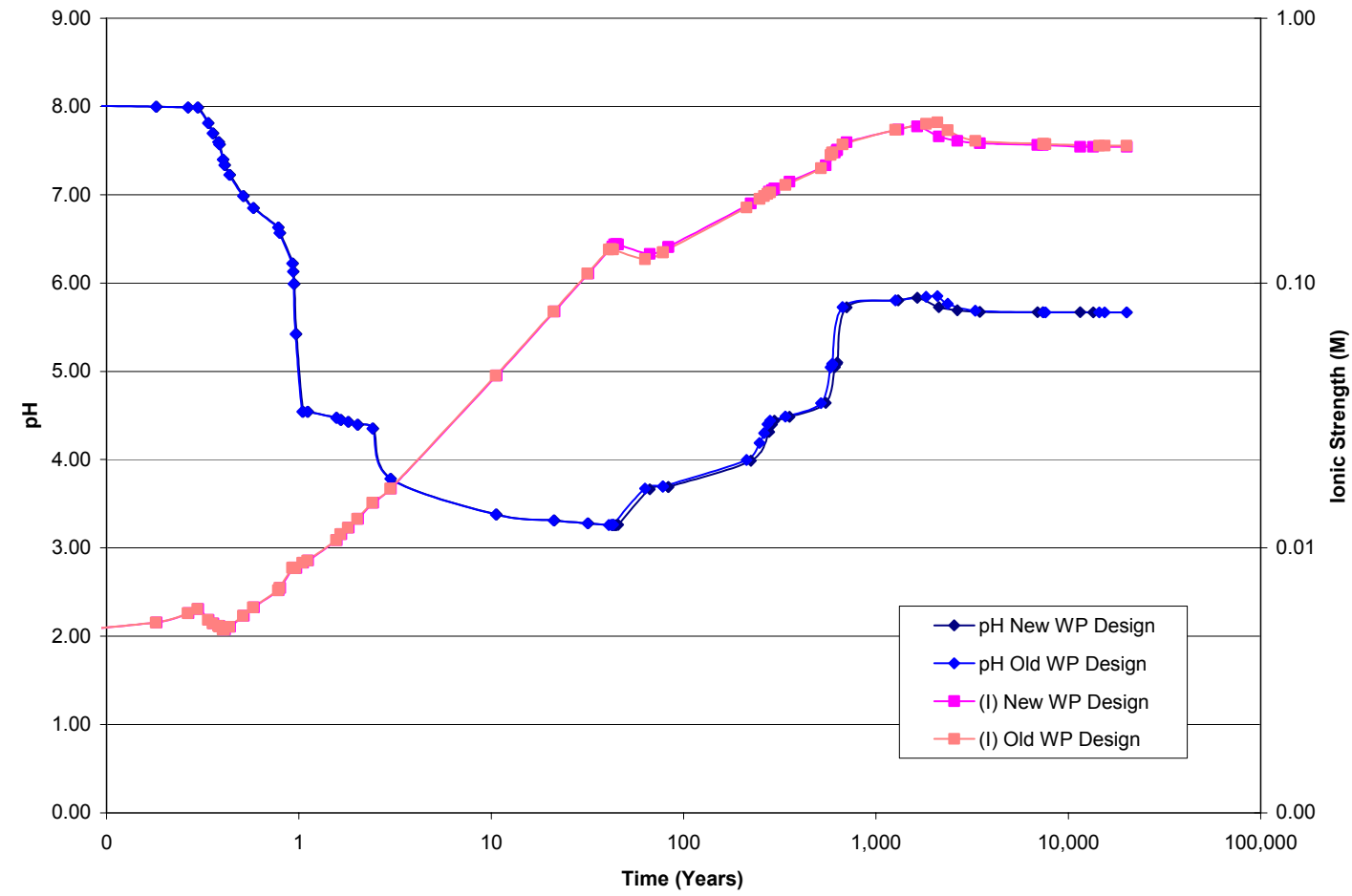

Source: Appendix F, CSNF_NewWP Sensitivity.xIs.

Figure A-18. CSNF: Impact of New Waste Package Design

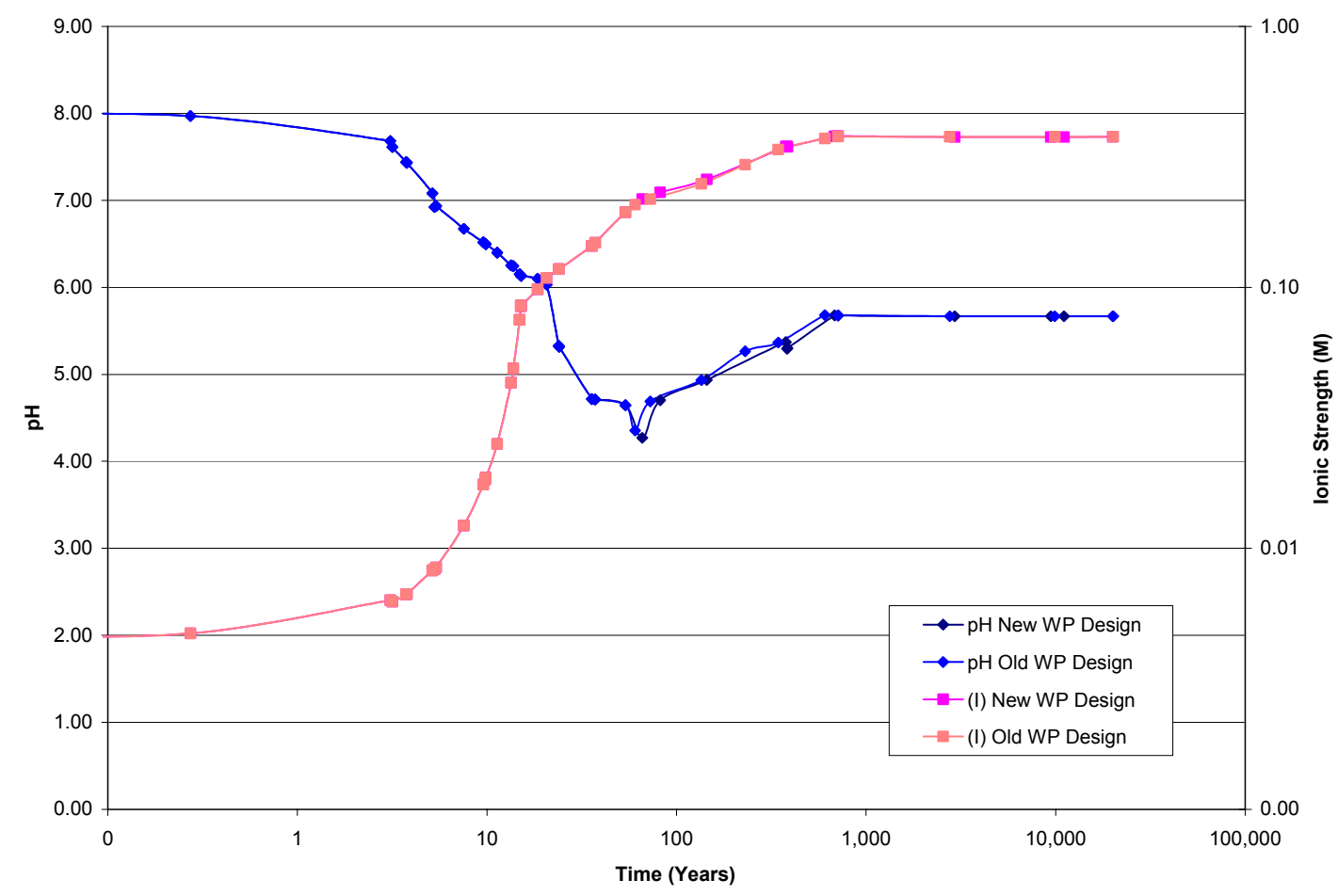

Source: Appendix F, CDSP_NewWP Sensitivity.xls.

Figure A-19. CDSP: Impact of New Waste Package Design 


\section{APPENDIX B}

\section{IN-PACKAGE RADIOLYSIS ANALYSES}




\section{INTENTIONALLY LEFT BLANK}




\section{B. IN-PACKAGE RADIOLYSIS ANALYSES}

\section{B.1 RADIOLYSIS CONTRIBUTION TO IN-PACKAGE CHEMISTRY}

Radiolysis is an important process that could influence the results of the in-package chemistry model. A nonmechanistic treatment in the form of a sensitivity analysis is provided here to examine how radiolysis could affect the $\mathrm{pH}$ and concentration of certain aqueous species. All of the pertinent computer files may be found in Appendix F.

\section{B.2 DATA AND PARAMETERS}

- Gamma and Neutron Radiolysis in the 21-PWR Waste Package from Ten to One Million Years (BSC 2004 [DIRS 172017]). Nitric acid $\left(\mathrm{HNO}_{3}\right)$ production rate at 500 years (assuming waste package breach) is $3.60 \mathrm{E}+13$ molecules $/ \mathrm{yr}-\mathrm{cm}^{3}$ (air) (BSC 2004 [DIRS 172017], Table 21, p. 33). This time was selected because it is the earliest breach, representing juvenile failure of the waste package. Figure 5 of this reference shows that the production is constant after 500 years, so the selection of this time is not critical.

- Geometry of CSNF waste package: Volume $=4,968,751 \mathrm{~cm}^{3}, 10 \%$ fuel exposed surface area $=3,297,160 \mathrm{~cm}^{2}$, void volume with $0.25-\mathrm{cm}$ thick water layer $=4,144,461 \mathrm{~cm}^{3}$, from CSNF.xls, Appendix F.

- Surface area normalization factor for $10 \%$ fuel exposure $=1.213 \mathrm{E}-03$, from CSNF.xls, Appendix F.

- G value for nitric acid production is 1.5 molecules/100 ev energy deposition (BSC 2004 [DIRS 172017], p. 27). The $G$ value represents the number of molecules formed from radiolysis in a material and is linear with energy deposition. This number is used to calculate hydrogen peroxide $\left(\mathrm{H}_{2} \mathrm{O}_{2}\right)$ generation by scaling (first bullet).

- Density of moist air $\left(40 \%\right.$ relative humidity, $\left.30^{\circ} \mathrm{C}\right)$ is $1.16 \mathrm{E}-3 \mathrm{gm} / \mathrm{cm}^{3}$ (MO0312SPAICSCR.002, csnf_radiolysis.xls, Sheet MoistAir, Cell H14). This number is used to calculate hydrogen peroxide generation by scaling the first bullet, above.

- G value for hydrogen peroxide production is 0.72 molecules/100 ev energy deposition. This value is presented in Waterside Corrosion of Zirconium Alloys in Nuclear Power Plants (IAEA 1998 [DIRS 150560], Table 8.2, p. 214) and corroborated by Christensen (1995 [DIRS 161921], p. 375, Table II), Christensen et al. (1994 [DIRS 161919], p. 6, Table 1) and Christensen and Bjergbakke (1982 [DIRS 161918], Table 1, p.16). G value is 0.72 molecules/100 ev energy.

Other accepted engineering numbers:

- Avogadro constant $=6.02 \mathrm{E}+23$ molecules $/$ Mole

- Density of water at $27^{\circ} \mathrm{C}=1 \mathrm{gm} / \mathrm{cm}^{3}$. 


\section{B.3 ASSUMPTIONS}

The following assumptions are made for this report:

- Nitric acid production and hydrogen peroxide production is represented by the production rates at 500 years. This assumption is conservative because 500 years is the earliest waste package breach time because of early failures and radiolysis generally decreases with time. Figure 5 of Gamma and Neutron Radiolysis in the 21-PWR Waste Package from Ten to One Million Years (BSC 2004 [DIRS 172017]) shows that gamma dose and, therefore, most of the radiolysis is nearly constant after 500 years. This assumption needs no further validation.

- Nitric acid produced in the humid air by radiolysis is absorbed into the layers of water on the fuel and does not escape the waste package through the corrosion patches. This assumption is conservative because it is the upper limit of the amount of nitric acid that can be absorbed on the fuel. This assumption is necessary because modeling of chemical diffusion rates on this scale is not available. This assumption is conservative and needs no further validation.

- Radiolysis production in the outer eleven fuel assemblies of the 21-PWR design can be approximated by the radiolysis in the middle nine assemblies. Gamma and Neutron Radiolysis in the 21-PWR Waste Package from Ten to One Million Years (BSC 2004 [DIRS 172017]) provides analysis of the production in the center assembly of the waste package only. Radiation fluxes and, therefore, radiolysis production rates are less in the outer assemblies. This assumption is conservative and needs no further validation.

- Other than the generation of nitric acid and hydrogen peroxide, there are no other collateral chemical effects on the in-package environment. This assumption is justified because $\mathrm{HNO}_{3}$ and $\mathrm{H}_{2} \mathrm{O}_{2}$ have the greatest potential to alter the in-package chemistry.

\section{B.4 MODEL DISCUSSION}

When radiation passes through a material, some energy is deposited in the medium and chemical reactions can occur from the local deposition of energy (radiolysis). The $\mathrm{G}$ value represents the number of molecules of a substance that is formed when $100 \mathrm{ev}$ of energy is deposited in the media. When gamma and fast neutron energy pass through moist air, nitric acid is produced. Gamma and Neutron Radiolysis in the 21-PWR Waste Package from Ten to One Million Years (BSC 2004 [DIRS 172017]) predicts the amount of nitric acid that is produced per $\mathrm{cm}^{3}$ of humid air in the waste package $\left(3.6 \mathrm{E}+13\right.$ molecules $/ y r-\mathrm{cm}^{3}$ at 500 years $)$. The amount of nitric acid formed in the waste package is calculated in EQ6 compatible input units via:

$\mathrm{HNO}_{3}$ production rate $=3.6 \mathrm{E}+13$ molecules $/ y r-\mathrm{cm}^{3} \times($ void volume waste package $)$

$$
\begin{aligned}
& =3.6 \mathrm{E}+13 \text { molecules } / \mathrm{yr}-\mathrm{cm}^{3} \times\left(4,144,461 \mathrm{~cm}^{3}\right) \\
& =1.49 \mathrm{E}+20 \text { molecules } / y r-w a s t e ~ p a c k a g e \times(1 \mathrm{~mole} / 6.02 \mathrm{E}+23 \text { molecules })
\end{aligned}
$$




$$
\begin{aligned}
& =2.48 \mathrm{E}-04 \mathrm{moL} / \mathrm{yr}-\text { waste package } \times(1.213 \mathrm{E}-03) \times(1 \text { year } / 3.16 \mathrm{E}+07 \\
& \text { seconds }) \\
& =9.53 \mathrm{E}-15 \mathrm{moles} / \mathrm{second}
\end{aligned}
$$

where $1.213 \mathrm{E}-03$ is the normalization factor from Table 47.

When gamma and fast neutron energy pass through water, hydrogen peroxide is produced. The production rate for hydrogen peroxide $\left(\mathrm{H}_{2} \mathrm{O}_{2}\right)$ in water is calculated by adjusting the nitric acid production rate by the ratio of $\mathrm{G}$ values and densities and converting to EQ6 compatible input units:

$$
\begin{aligned}
& \mathrm{H}_{2} \mathrm{O}_{2} \text { Production Rate }=\mathrm{PR}_{\mathrm{HNO}_{3}} \times\left(\mathrm{G}_{\mathrm{H} 2 \mathrm{O} 2} / \mathrm{G}_{\mathrm{HNO} 3}\right) \times(\text { density water/density air }) \\
& =3.6 \mathrm{E}+13 \text { molecules } / \mathrm{yr}-\mathrm{cm}^{3} \times(0.72 / 1.5) \times\left(1.0 \mathrm{gm} / \mathrm{cm}^{3} / 1.16 \mathrm{E}-3 \mathrm{gm} / \mathrm{cm}^{3}\right) \\
& =1.5 \mathrm{E}+16 \text { molecules } / \mathrm{yr}-\mathrm{cm}^{3} \times\left(4,144,461 \mathrm{~cm}^{3}\right) \\
& =6.22 \mathrm{E}+22 \text { molecules } / \text { yr-waste package } \times(1 \mathrm{~mol} / 6.02 \mathrm{E}+23 \text { molecules }) \\
& =1.03 \mathrm{E}-01 \mathrm{~mol} / \mathrm{yr}-\text { waste package } \times(1.213 \mathrm{E}-03) \times(1 \text { year } / 3.16 \mathrm{E}+07 \text { seconds }) \\
& =3.97 \mathrm{E}-12 \mathrm{~mol} / \mathrm{second}
\end{aligned}
$$

where 1.213E-03 is the normalization factor from Table 47.

\section{B.5 EQ6 IMPLEMENTATION}

The effect of radiolysis on the in-package chemistry was handled in a nonmechanistic manner (i.e., EQ6 does not have the facility to model the radiolysis process directly; therefore, only the products of radiolysis are included as inputs in EQ6 simulations). However, EQ6 does have the capability to model the effect of $\mathrm{H}_{2} \mathrm{O}_{2}$ and $\mathrm{HNO}_{3}$ on the in-package chemistry.

A series of runs were performed where nitric acid and hydrogen peroxide were included as inputs in EQ6 runs and the results of these simulations were compared to their nonradiolysis counterparts.

Two base-case runs (C12C25 and $\mathrm{C} 22 \mathrm{C} 25$, Section 6.3.1) were used to test the effects of radiolysis. These runs were chosen because they represent the median fuel exposure (clad failure) value and the low and median flux values. It would be expected that the effects of nitric acid and hydrogen peroxide additions would be greater at the low end of the flux range.

Two simulations were performed for each file, the first using the base-case nitric acid and hydrogen peroxide rates listed above, and a second where the $\mathrm{HNO}_{3}$ and $\mathrm{H}_{2} \mathrm{O}_{2}$ rates were multiplied by a factor of ten. An additional run was completed using the $\mathrm{C} 12 \mathrm{C} 25$ input file where the $\mathrm{HNO}_{3}$ and $\mathrm{H}_{2} \mathrm{O}_{2}$ rates were multiplied by a factor of ten and the sulfur content of the Carbon Steel Type A516 waste package components was increased by a factor of 20. The EQ6 inputs are listed in Table B-1. 
Table B-1. EQ6 File Names and Nitric Acid and Hydrogen Peroxide Production Rates

\begin{tabular}{|c|c|c|}
\hline EQ6 Input File & $\mathrm{HNO}_{3}$ Rate (mol/s) & $\mathrm{H}_{2} \mathrm{O}_{2}$ Rate (mol/s) \\
\hline C22C25 & 0.0 & 0.0 \\
\hline C22CBC & $9.53 \mathrm{E}-15$ & $3.97 \mathrm{E}-12$ \\
\hline $\mathrm{C} 22 \mathrm{BC} 10$ & $9.53 \mathrm{E}-14$ & $3.97 \mathrm{E}-11$ \\
\hline $\mathrm{C} 12 \mathrm{C} 25$ & 0.0 & 0.0 \\
\hline C12CBC & $9.53 \mathrm{E}-15$ & $3.97 \mathrm{E}-12$ \\
\hline C12BC10x & $9.53 \mathrm{E}-14$ & $3.97 \mathrm{E}-11$ \\
\hline C12C10x_S20x & $9.53 \mathrm{E}-14$ & $3.97 \mathrm{E}-11$ \\
\hline
\end{tabular}

\section{B.6 RESULTS}

The results of the simulations are displayed in Figure B-1, where the $\mathrm{pH}$ profiles for the various runs are displayed versus time. These results show that neither the base case nor the $10 \times$ basecase generation rates of $\mathrm{HNO}_{3}$ and $\mathrm{H}_{2} \mathrm{O}_{2}$ had an impact on the in-package $\mathrm{pH}$. Therefore, it may be concluded that if radiolysis only effects the chemistry via $\mathrm{HNO}_{3}$ and $\mathrm{H}_{2} \mathrm{O}_{2}$ generation, then it will not be a significant process with regard to influencing the in-package chemistry.

The additional run $\left(\mathrm{C} 12 \mathrm{C} 10 \mathrm{x} \_\mathrm{S} 20 \mathrm{x}\right)$ with twenty times the sulfur in the carbon steel drives the $\mathrm{pH}$ of the system to a low of about $\mathrm{pH}=2.2$ (Figure B-1).

Table B-2 provides the minimum $\mathrm{pH}$, chloride, nitrate, hydrogen peroxide, and ferric iron maximum concentrations for the simulations. Again the runs with $\mathrm{HNO}_{3}$ and $\mathrm{H}_{2} \mathrm{O}_{2}$ input show little deviation compared to the runs without $\mathrm{HNO}_{3}$ and $\mathrm{H}_{2} \mathrm{O}_{2}$.

Table B-2. Chloride, Ferric Iron, and Hydrogen Peroxide Molality

\begin{tabular}{|l|c|c|c|c|c|}
\hline \multicolumn{1}{|c|}{ EQ6 Input File } & $\begin{array}{c}\text { Minimum } \\
\mathbf{p H}\end{array}$ & $\mathbf{C l}$ & $\mathbf{N O}^{-}$ & $\mathbf{H}_{2} \mathbf{O}_{2}(\mathbf{a q})$ & $\mathbf{F e}^{3+}$ \\
\hline $\mathrm{C} 22 \mathrm{C} 25$ & 3.7 & $6.8 \mathrm{E}-04$ & $8.5 \mathrm{E}-04$ & $3.7 \mathrm{E}-19$ & $5.1 \mathrm{E}-11$ \\
\hline $\mathrm{C} 22 \mathrm{CBC}$ & 3.5 & $6.6 \mathrm{E}-04$ & $1.5 \mathrm{E}-03$ & $3.7 \mathrm{E}-19$ & $8.5 \mathrm{E}-11$ \\
\hline $\mathrm{C} 22 \mathrm{BC} 10 \mathrm{x}$ & 3.5 & $6.5 \mathrm{E}-04$ & $3.0 \mathrm{E}-03$ & $3.7 \mathrm{E}-19$ & $8.5 \mathrm{E}-11$ \\
\hline $\mathrm{C} 12 \mathrm{C} 25$ & 3.7 & $9.7 \mathrm{E}-04$ & $5.5 \mathrm{E}-03$ & $3.7 \mathrm{E}-19$ & $5.3 \mathrm{E}-11$ \\
\hline $\mathrm{C} 12 \mathrm{CBC}$ & 3.7 & $9.6 \mathrm{E}-04$ & $7.8 \mathrm{E}-03$ & $3.7 \mathrm{E}-19$ & $5.3 \mathrm{E}-11$ \\
\hline $\mathrm{C} 12 \mathrm{BC} 10 \mathrm{x}$ & 3.7 & $9.2 \mathrm{E}-04$ & $1.9 \mathrm{E}-02$ & $3.7 \mathrm{E}-19$ & $5.4 \mathrm{E}-11$ \\
\hline $\mathrm{C} 12 \mathrm{C} 10 \mathrm{x}$ S20x & 2.2 & $9.7 \mathrm{E}-04$ & $1.6 \mathrm{E}-02$ & $3.7 \mathrm{E}-19$ & $3.8 \mathrm{E}-06$ \\
\hline
\end{tabular}

Output DTN: MO0312SPAICSCR.002.

Based on this nonmechanistic approach to modeling the effects of radiolysis on in-package chemistry it may be stated that radiolysis will not affect the in-package chemistry in a manner that would impact TSPA-LA. The results of these analyses are compiled in DTN: MO0312SPAICSCR.002. Surface complexation, which is not accounted for by this radiolysis analyses, would further moderate the $\mathrm{pH}$ of this system in a manner similar to that discussed in Section 6.8. 


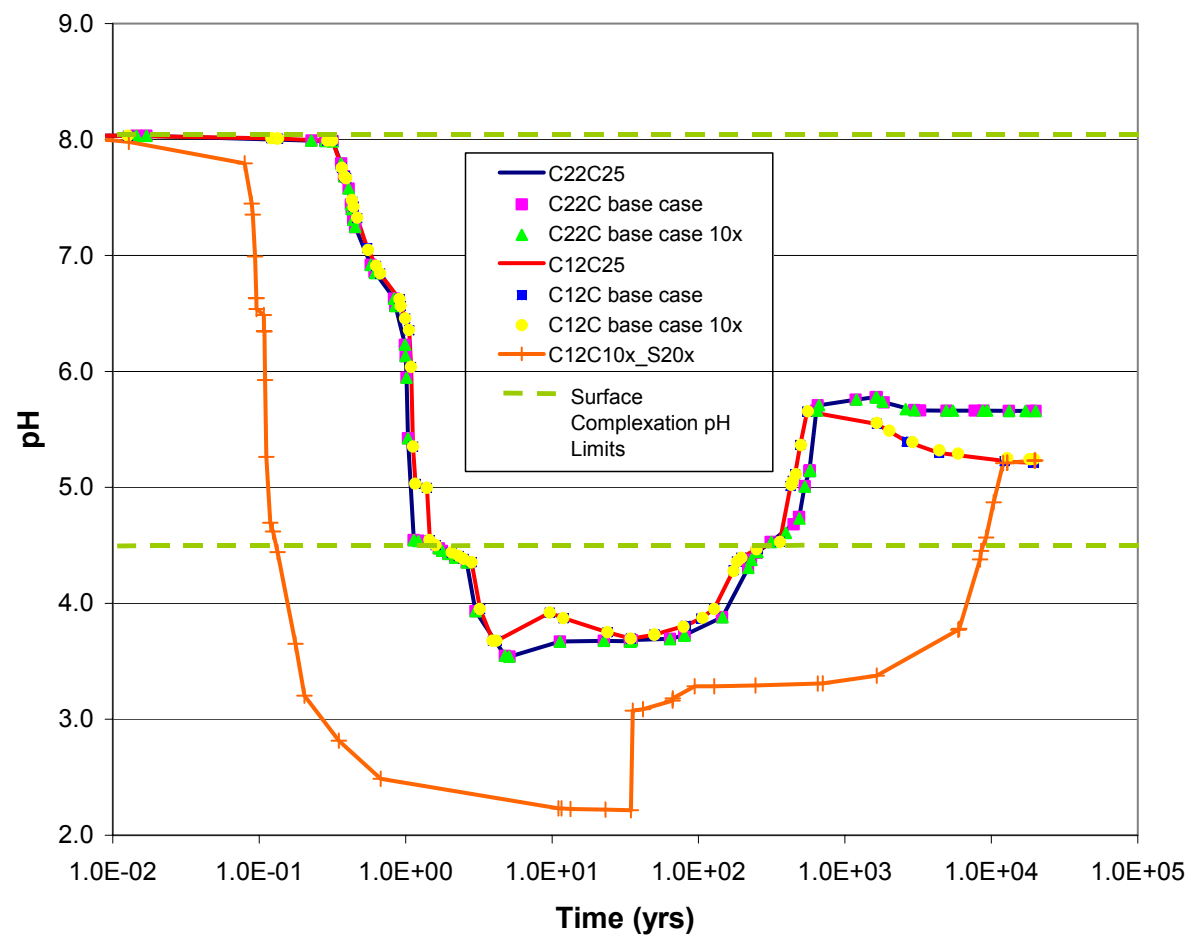

Source: csnf_radiolysis_ICN01.xIs, Output DTN: MO0312SPAICSCR.002.

Figure B-1. pH Profiles Showing Radiolysis Impacts on $\mathrm{pH}$ 


\section{INTENTIONALLY LEFT BLANK}




\section{APPENDIX C}

DATA QUALIFICATION PLAN 


\section{INTENTIONALLY LEFT BLANK}




\section{DATA QUALIFICATION PLAN}

\begin{tabular}{|l|l|l|}
\hline \multirow{2}{*}{ BSC } & DATA QUALIFICATION PLAN & QA:QA \\
\cline { 3 - 3 } & Page 1 of 1 \\
\hline
\end{tabular}

\begin{tabular}{|c|c|c|}
\hline \multicolumn{3}{|l|}{ Section I. Organizational Information } \\
\hline \multicolumn{3}{|l|}{ Qualification Title: } \\
\hline \multicolumn{3}{|c|}{ Qualification of Data that Supports In-Package Chemistry Abstraction (ANL-EBS-MD-000037, Rev. 03) } \\
\hline \multicolumn{3}{|l|}{ Requesting Organization: } \\
\hline \multicolumn{3}{|l|}{ Engineered Systems } \\
\hline \multicolumn{3}{|l|}{ Section II. Process Planning Requirements } \\
\hline \multicolumn{3}{|l|}{ 1. List of Unqualified Data to be evaluated: } \\
\hline \multicolumn{3}{|c|}{$\begin{array}{l}\text { Sources of data that provide direct input to ANL-EBS-MD-000037 and that have not been qualified for all uses will be } \\
\text { evaluated. The Document Input Reference System (DIRS) assigns to these sources the following numbers: } 106164 \text {, } \\
100051,163015,168168 \text {, and } 105483 \text {. Authoritative sources will not be qualified. BSC/OCWRM documents will be } \\
\text { justified within the text of the document. }\end{array}$} \\
\hline \multicolumn{3}{|c|}{$\begin{array}{l}\text { 2. Type of Data Qualification Method(s) [Including rationale for selection of method(s) (Attachment 3) and qualification } \\
\text { attributes (Attachment 4) }\end{array}$} \\
\hline \multicolumn{3}{|c|}{$\begin{array}{l}\text { The method of technical assessment was chosen because documentation or proof of proper information acquisition } \\
\text { in unavailable for review for most data inputs }\end{array}$} \\
\hline \multicolumn{3}{|c|}{$\begin{array}{l}\text { The method of corroborating data was chosen for one of the methods of qualification because corroborating data are } \\
\text { available for comparison and inferences can be clearly identified, justified, and documented }\end{array}$} \\
\hline \multicolumn{3}{|c|}{$\begin{array}{l}\text { The qualification attribute: extent to which the data demonstrate the properties of interest, and one or more of the } \\
\text { following qualification attributes (taken from AP-SIII.2Q, Attachment } 4 \text { ) will be considered: }\end{array}$} \\
\hline $\begin{array}{l}\text { - Qualifications of personnel or c } \\
\text { - Prior peer or other professiona } \\
\text { - Extent and quality of corrobora }\end{array}$ & $\begin{array}{l}\text { ing the information. } \\
\text { nation and their results. } \\
\text { Ise in conjunction with technical asses }\end{array}$ & \\
\hline \multicolumn{3}{|c|}{ 3. Data Qualification Team and Additional Support Staff Required } \\
\hline \multicolumn{3}{|l|}{$\begin{array}{l}\text { Emma Thomas - Chairman } \\
\text { William Downs }\end{array}$} \\
\hline \multicolumn{3}{|l|}{ 4. Data Evaluation Criteria } \\
\hline \multicolumn{3}{|c|}{$\begin{array}{l}\text { The following data evaluation criteria are based on and in this case identical to the attributes in block } 2 \text { : } \\
\text { - The extent to which the data demonstrate the properties of interest. } \\
\text { - Qualifications of personnel or organizations generating the information. } \\
\text { - Prior peer or other professional reviews of the information and their results. } \\
\text { - Extent and quality of corroborating information (for use in conjunction with technical assessment). }\end{array}$} \\
\hline \multicolumn{3}{|l|}{ 5. Identification of Procedures Used } \\
\hline \multicolumn{3}{|l|}{ AP-SIII.2Q, AP-SIII.9Q, and AP-3.15Q } \\
\hline \multicolumn{3}{|l|}{ Section III. Approval } \\
\hline Qualification Chairperson Printed Name & Qualification Chairperson Signature & Date \\
\hline Emma Thomas & & \\
\hline Responsible Manager Printed Name & Qualification Manager Signature & Date \\
\hline Neil Brown & & \\
\hline
\end{tabular}




\section{INTENTIONALLY LEFT BLANK}


APPENDIX D

QUALIFICATION OF DATA THAT SUPPORTS IN-PACKAGE CHEMISTRY ABSTRACTION 


\section{INTENTIONALLY LEFT BLANK}




\section{QUALIFICATION OF DATA THAT SUPPORTS IN-PACKAGE CHEMISTRY ABSTRACTION}

\section{D.1 PURPOSE}

This document relies on data that may not have been collected under an approved quality assurance program that meets the requirements of 10 CFR Part 63, Subpart G [DIRS 156605] or its predecessor, 10 CFR Part 60 (48 FR 28194 [DIRS 100475]). This appendix qualifies the data that this model report uses as direct input. The appendix was prepared according to the AP-SIII.2Q, Qualification of Unqualified Data. This qualification is being performed under the plan presented in Appendix C.

\section{D.2 METHODS AND CRITERIA}

AP-SIII.2Q offers five methods by which data may be qualified. As many of the methods were used as could be justified by the available supporting records. Technical assessment was considered as the strongest argument as documentation or proof of the quality and care of data acquisition is unavailable for review for most data inputs (e.g., laboratory quality plan unavailable for most older data collection activities). According to AP-SIII.2Q (Attachment 3), this confirmation comprises 1) "a discussion and justification that the data collection methodology used was appropriate for the type of data under consideration," 2) "a discussion and justification that the data acquisition and/or subsequent data development discussed in source documentation was appropriate for the type of data under consideration," or 3) "discussion and documentation that the data have been used in applications that are similar to those for which the data will be used." Option 1 was used for the qualification process in this appendix.

In addition to corroborating data and technical assessment, the qualification process considers the extent to which the data demonstrate the properties of interest and at least one of the qualification process attributes of AP-SIII.2Q (Attachment 4).

- Qualifications of personnel or organizations generating the information

- Prior peer or other professional reviews of the information and their results

- Extent and quality of corroborating information (for use in conjunction with technical assessment).

These criteria also serve as the "data evaluation criteria" on which the data qualification team will provide judgements (AP-SIII.2Q, Section 5.1.2 (b)(4)).

The team comprises two members: Emma Thomas, analysis originator, chairs the team and William Downs, Ph.D., who is technically competent in data collection and qualification, assists. As the analysis originator, Emma Thomas is not independent of the information to be qualified (AP-SIII.2Q, Section 5.1.2 (b)(3)). However, the procedure requires that the originator chair the team "... when the qualification is performed within the Analysis or Model Report" (AP-SIII.2Q, Section 5.1.1). William Downs did not participate in the acquisition, but was a reviewer of the analysis. 


\section{D.3 QUALIFICATION OF DATA}

AP-SIII.2Q does not apply to "established fact" or numerical data obtained from an established or authoritative data source. Because some of the data comes from authoritative sources (other than the U.S. Department of Energy, Office of Civilian Radioactive Waste Management), it does not need to be qualified. The remaining data are qualified only for its intended use.

Table D-1 lists the sources of data that are being qualified for their use in this report and designates the attributes or criteria that are used, in conjunction with the corroborating data and technical assessment, to qualify the information.

Table D-1. Sources of Data and Criteria Used to Qualify the Information

\begin{tabular}{|c|c|}
\hline Source & Criteria \\
\hline \multicolumn{2}{|c|}{ Data Sources to be Qualified } \\
\hline $\begin{array}{l}\text { Defense Waste Processing Facility Wasteform and } \\
\text { Canister Description (Baxter } 1988 \text { [DIRS 106164]) }\end{array}$ & $\begin{array}{l}\text { Technical assessment/acceptable methodology } \\
\text { Corroborating Data Personnel/organization qualifications } \\
\text { Demonstrate properties of interest }\end{array}$ \\
\hline $\begin{array}{l}\text { Aqueous Environmental Geochemistry (Langmuir } 1977 \\
\text { [DIRS 100051] }\end{array}$ & $\begin{array}{l}\text { Technical assessment/acceptable methodology } \\
\text { Corroborating Data } \\
\text { Personnel/organization qualifications } \\
\text { Demonstrate properties of interest }\end{array}$ \\
\hline $\begin{array}{l}\text { "Critical Evaluation and Selection of Standard State } \\
\text { Thermodynamic Properties for Chromium Metal and its } \\
\text { Aqueous lons, Hydrolysis Species, Oxides, and } \\
\text { Hydroxides" (Ball and Nordstrom } 1998 \text { [DIRS 163015]) }\end{array}$ & $\begin{array}{l}\text { Technical assessment/acceptable methodology } \\
\text { Corroborating Data } \\
\text { Personnel/organization qualifications } \\
\text { Demonstrate properties of interest }\end{array}$ \\
\hline $\begin{array}{l}\text { "Surface Complexation of Ferrous Iron and Carbonate on } \\
\text { Ferrihydrite and the Mobilization of Arsenic." (Appelo et } \\
\text { al. } 2002 \text { [DIRS 168168] }\end{array}$ & $\begin{array}{l}\text { Technical assessment/acceptable methodology } \\
\text { Personnel/organization qualifications } \\
\text { Demonstrate properties of interest }\end{array}$ \\
\hline $\begin{array}{l}\text { Surface Complexation Modeling, Hydrous Ferric Oxide } \\
\text { (Dzombak and Morel } 1990 \text { [DIRS 105483]) }\end{array}$ & $\begin{array}{l}\text { Technical assessment/acceptable methodology } \\
\text { Personnel/organization qualifications } \\
\text { Demonstrate properties of interest }\end{array}$ \\
\hline
\end{tabular}

The discussions above and in the next section fulfill requirements of AP-SIII.2Q to discuss the data for qualification, the method of qualification, and the evaluation criteria (AP-SIII.2Q, Section 5.3.1, paragraphs (a)(1) through (3)).

A discussion of the remaining requirements follows:

- AP-SIII.2Q, Section 5.3.1 (a)(4) - the team considers the information technically correct because it has undergone a technical assessment and it fulfills at least one of the qualification process attributes of AP-SIII.2Q (Attachment 4).

- AP-SIII.2Q, Section 5.3.1 (a)(5)—no data are generated by this evaluation.

- AP-SIII.2Q, Section 5.3.1 (a)(6) - the team finds that the information is qualified for its use within In-Package Chemistry Model Abstraction ANL-EBS-MD-000037, Rev. 03. 
- AP-SIII.2Q, Section 5.3.1 (a)(7) - the team recommends that the information be given the status of "qualified data"

- AP-SIII.2Q, Section 5.3.1 (a)(8) — the team did not "abandon" any qualification method.

- AP-SIII.2Q, Section 5.3.1 (a)(9) - the data are qualified only for use in this document. It is not qualified for other potential users.

- AP-SIII.2Q, Section 5.3.1 (a)(10)—supporting or corroborating information is identified in Appendix $\mathrm{C}$ when used in the qualification effort.

- AP-SIII.2Q, Section 5.3.1 (a)(11) - the qualification was performed under the data qualification plan presented in Appendix C.

\section{D.3.1 Qualification of Baxter, R.G. 1988 [DIRS 106164]}

Technical Assessment/Acceptable Methodology: This report describes the physical and chemical stability characteristics of the defense high-level waste form borosilicate glass that was developed at the DOE Savannah River National Laboratory, Aiken, South Carolina. The value of interest for this report is the density of the waste glass at $25^{\circ} \mathrm{C}$ is $2.85 \mathrm{~g} / \mathrm{cm}^{3}$. This value is the mean of several calculated densities based on percentages of radionuclide containing sludges and glass constituents.

Personnel/organization qualifications: The author and his organization are nationally recognized as the developers and testors of the borosilicate glass waste form. These data are comparable to "vendor data" for qualification purposes.

Corroborating Data: In order to check the validity of the density of the borosilicate glass waste form, the data were compared to similar data measured on other borosilicate glass samples by scientists at the Oak Ridge National Laboratory, Oak Ridge, Tennessee. The data agreed within $6 \%$ at $25^{\circ} \mathrm{C}$ (Notz et al. 1990 [DIRS 119707]).

Demonstrate properties of interest: The estimates were made for materials selected for use in the repository.

\section{D.3.2 Qualification of Langmuir 1997 [DIRS 100051]}

Technical Assessment/Acceptable Methodology: This publication is a textbook that contains empirical data for numerous thermodynamic and physicochemical parameters. The original source for these data are publications in peer-reviewed journals that have been used in numerous investigations and modeling efforts. These data have been included in virtually all of the equilibrium geochemistry simulation codes (e.g., PHREEQEC, MINTEQA2, etc.) since they were originally published and have been accepted by the scientific community.

Personnel/organization qualifications: The author is a Professor Emeritus at the Colorado School of Mines and has dozens of publications in the area of thermodynamics of dissolved species and mineral phases. 
Corroborating Data: The table, from which the goethite surface data (sites per unit area and surface area per unit mass) were taken, contained data from several sources that demonstrated that the data selected were well within the range of measured data. In addition, similar data in agreement were calculated from basic crystal chemistry models and solvation theory.

Demonstrate properties of interest: The corrosion models for the iron bearing alloys used as either structural elements or waste casks have specified that the corrosion products include goethite $-\gamma$-FeOOH. This selection is considered conservative as the corrosion products include ferrihydrite $\left(\mathrm{Fe}[\mathrm{OH}]_{3}\right)$, goethite $(\gamma-\mathrm{FeOOH})$, and hematite $\left(\alpha-\mathrm{Fe}_{2} \mathrm{O}_{3}\right)$ as aging of the corrosion products proceeds with time. Ferrihydrite has a much larger surface area and would suggest adsorption of more elevated levels of species from solution but will dehydrate to goethite.

\section{D.3.3 Qualification of Ball and Nordstrom 1998 [DIRS 163015]}

Technical Assessment/Acceptable Methodology: This article comes from a peer-reviewed journal, Journal of Chemical \& Engineering Data, that is a major source for thermodynamic data. The authors selected a method to achieve consistency and minimize error that include maintaining thermodynamic relationships, determine the most direct path for derived thermodynamic quantities, and compare derived thermodynamic quantities with empirical data where ever possible. For compounds and species where multiple measurements have been made, statistical analyses were conducted to determine the aleatory dispersion about the mean. The rigor of the methods used to develop these data is compatible with the requirements of the OCRWM quality program.

Personnel/organization qualifications: The authors of this article are nationally recognized specialists in the field of geochemistry and both of them have numerous publications in the field of geochemistry. The junior author, Dr. Kirk Nordstrom, is the coauthor (with J.L. Munoz) of Geochemical Thermodynamics, a text used by numerous Universities for advanced courses in the field.

Corroborating Data: The article contains comparisons of the solubilities of key minerals calculated from the generated thermodynamic data with empirical data. In addition, the thermodynamic data for chromium species and compounds were compared and evaluated with data that had been generated and published by other researchers.

Demonstrate properties of interest: Because the various waste packages contain stainless steel as structural members and hexavalent chromium, $\mathrm{Cr}^{6+}$, represents a risk to human health and the environment, the solubility and sorption characteristics of chromium dissolved species and solids are necessary for assessing the performance of the repository.

\section{D.3.4 Qualification of Appelo et al. 2002 [DIRS 168168]}

Technical Assessment/Acceptable Methodology: This article comes from a peer-reviewed journal, Environmental Science \& Technology, which is a major source for thermodynamic data. The authors selected a method to achieve consistency and minimize error that include maintaining thermodynamic relationships, determine the most direct path for derived thermodynamic quantities, and compare derived thermodynamic quantities with empirical data 
where ever possible. The rigor of the methods used to develop these data is compatible with the requirements of the OCRWM Quality Program.

Personnel/organization qualifications: Dr. C A J Appelo received his $\mathrm{PhD}$ from the Vrije Universiteit, Amsterdam, NL, in 1978. He is a hydrochemical consultant providing consulting and educating for water resources, water quality and water pollution, and has presented short courses in hydrogeochemistry and hydrogeochemical transport modeling in Finland, France, the Netherlands, Portugal, South Africa, and Switzerland. He has over 35 publications in peerreviewed technical journals and is an author of a widely used textbook groundwater geochemistry and pollution and geochemical modeling (Appelo and Postma 1999 [DIRS 172038]). His collaboration with U. S. Geological research scientists led to the development of the geochemical modeling code, PHREEQC, and its database.

Dr. Cristophe Tournassat recently received his $\mathrm{PhD}$ in environmental geochemistry from the University of Grenoble-I, FR. He is now a research scientist with the French Government environment organization BRGM in Orleans.

Dr. Laurent Charlet is a Full Professor in the Earth and Planetary Sciences Department at the University of Grenoble-I, FR. He received his $\mathrm{PhD}$ in 1986 from the University California at Riverside in Soil and Environmental Sciences, was a Postdoctoral Fellow at the Swiss Institute of Aquatic Sciences (EAWAG), and a Research Associate in the Department of Chemistry, University of Bern, Switzerland. His present research interests include mineral-water interface chemistry, atomic-scale environmental chemistry, biogeochemistry and the relationship between contamination and public health. He is author of more than 60 refereed publications in technical journals.

Professor Charlet's professional activity includes service in the Fundamental Environmental Chemistry section of the International Union of Pure and Applied Chemistry (IUPAC); membership in a review panel on nuclear waste confinement for the CNWRA, San Antonio; direction of the European Union (EU) project on "Mercury in French Guyana;" and service as associate editor of Aquatic Chemistry and Advances in Environmental Science, and as guest editor of Geochimica et Cosmochimica Acta.

Demonstrate properties of interest: The value given by Appelo et al. (2002 [DIRS 168168], Table 1, p. 3,097) is the value for the equilibrium constant for reactions given in Table 4-9. These are precisely the data that are required for parameterizing the surface complexation model. The surface complexation model (Section 6.7) is used to calculate the $\mathrm{pH}$ values fixed by surface complexation reactions on ferric (oxy)hydroxides (hydrous ferric oxides) formed within the waste package as a function of $\mathrm{CO}_{2}$ fugacity $\left(\mathrm{fCO}_{2}\right)$. In its development, this model requires values for the equilibrium constants of several chemical reactions. Some of these reactions are between dissolved species or between gases and dissolved species. Equilibrium constants for these reactions are taken from the qualified thermodynamic database Data0.YMP.R2 (DTN: MO0302SPATHDYN.000). Equilibrium constants for surface complexation reactions are also required for the surface complexation model but are not included in the database Data0.YMP.R2. Appelo et al. (2002 [DIRS 168168], Table 1, p. 3,097) provide values for one of the constants needed. 


\section{D.3.5 Qualification of Dzombak and Morel 1990 [DIRS 105483]}

Technical Assessment/Acceptable Methodology: This publication is a textbook that contains data for surface complexation parameters. This textbook is considered the handbook for this type of material by those in the field. The original source for these data are publications in peerreviewed journals that have been used in numerous investigations and modeling efforts. These data have been included in virtually all of the equilibrium geochemistry simulation codes (e.g., PHREEQEC, MINTEQA2, etc.) since they were originally published and have been accepted by the scientific community.

Personnel/organization qualifications: Dr. David A Dzombak is professor in the Department of Civil and Environmental Engineering at Carnegie Mellon University, Pittsburgh, PA and a registered Professional Engineer in Pennsylvania. His research and professional interests include: aquatic chemistry, especially interactions of aqueous chemical species with mineral surfaces; fate and transport of chemicals in surface and subsurface waters; water and wastewater treatment; in situ and ex situ soil treatment; hazardous waste site remediation; abandoned mine drainage remediation; river and watershed restoration; and public communication of environmental science. In addition to this book containing the data to be qualified, he has published more than 50 articles in leading, peer-reviewed, environmental engineering and science journals and numerous book chapters.

Professor Dzombak's professional service activity has included service on the EPA Science Advisory Board (2002 to present); the Committee on Bioavailability of Contaminants in Soils and Sediments, National Research Council (2000 to 2002); editorial board of Water Environment Research (1993 to 1998) and Ground Water (1991 to 1993); Board of Directors and Officer (Treasurer) of the Association of Environmental Engineering and Science Professors (1996 to 1999); chair of committees for the American Academy of Environmental Engineers, American Society of Civil Engineers, and Water Environment Federation; and advisory committees for Allegheny County and the Commonwealth of Pennsylvania.

Dr. François M. M. Morel is the Albert G. Blanke Professor of Geosciences and Princeton University, Director, Princeton Environmental Institute and Director, Center for Environmental BioInorganic Chemistry. His professional activities include teaching, as instructor of undergraduate and graduate subjects in aquatic chemistry element cycles, surface phenomena and biogeochemistry, and research as: Principal Investigator of projects on: (i) coordination chemistry, surface chemistry and photochemistry of trace elements in natural waters; (ii) interactions between the chemistry and microbiota in aquatic systems, (iii) trace metal nutrition and toxicity in phytoplankton; and (iv) environmental bioinorganic chemistry. He is author of four books, 14 book chapters, and more than 135 articles in peer-reviewed engineering and science journals.

Professor Morel's professional service activity has included service on the National Research Council Panel on Marine Mineral Technology (1976 to 1977), Committee on Ocean Waste Transportation (1982 to 1984) and Committee on Irrigation-Induced Water Quality Problems (1985 to 1988). He has also served on the Advisory Board of Environmental Science and Technology (1978 to 1983) and as associate editor (1980), on the Editorial Board of Limnology and Oceanography (1980 to 1983) and as special editor (1990) and is on the editorial board of 
Biogeochemistry, Geobiology, Aquatic Sciences and Environmental Microbiology. He serves Institut National de l'Environnement Industriel et des Risques, as Membre du Conseil Scientifique (1991 to present), and Nancie Centre International De L'eau as membre du Conseil d'Orientation (1995 to present).

Since its publication in 1990, this book by Dzombak and Morel has become a standard source for equilibrium constants surface complexation reactions. Data from it are cited in widely used textbooks on aqueous geochemistry including those by Langmuir (1997 [DIRS 100051]) and Stumm and Morgan (1996 [DIRS 125332]). These data are also included in the databases accompanying the broadly distributed, U. S. Geological Survey geochemical modeling code PHREEQC (BSC 2001. [DIRS 154877]); Parkhurst and Appelo 1999 (1999 [DIRS 159511]) and the widely used U. S. Environmental Protection Agency geochemical assessment model MINTEQA2 (Allison et al. 1991 [DIRS 171707]); HydroGeoLogic; Allison Geoscience Consultants (1999 [DIRS 158974]).

Demonstrate properties of interest: Values provided by Dzombak and Morel (1990 [DIRS 105483], Table 5.7) are for the equilibrium constants for reactions in Table 4-9. These are precisely the data that are required for parameterizing the surface complexation model. The surface complexation model (Section 6.7) is used to calculate the $\mathrm{pH}$ values fixed by surface complexation reactions on ferric (oxy)hydroxides (hydrous ferric oxides) formed within the waste package as a function of $\mathrm{CO}_{2}$ fugacity $\left(f \mathrm{CO}_{2}\right)$. In its development, this model requires values for the equilibrium constants of several chemical reactions. Some of these reactions are between dissolved species or between gases and dissolved species. Equilibrium constants for these reactions are taken from the qualified thermodynamic database Data0.YMP.R2 (DTN: MO0302SPATHDYN.000). Equilibrium constants for surface complexation reactions are also required for the surface complexation model but are not included in database Data0.YMP.R2. Dzombak and Morel (1990 [DIRS 105483], Table 5.7) provide values for two of the needed constants.

\section{D.4 CONCLUSION}

In conclusion, all of the data from the articles or books listed above are qualified for their intended use in this model report. 


\section{INTENTIONALLY LEFT BLANK}


APPENDIX E

EVALUATION OF IN-PACKAGE CHEMISTRY SURFACE COMPLEXATION MODEL 


\section{INTENTIONALLY LEFT BLANK}




\section{E. EVALUATION OF IN-PACKAGE CHEMISTRY SURFACE COMPLEXATION MODEL}

The following evaluation was performed by Yifeng Wang, Principal Member of Technical Staff, Sandia National Laboratories, a recognized expert in the field of geochemistry, with a Ph.D. from the Department of Geological Sciences, Indiana University. This review was conducted on 7/23/2004 in accordance with the requirements of Technical Work Plan for: Regulatory Integration Modeling and Analysis of the Waste Form and Waste Package (BSC 2004 [DIRS 171583]). In his report on his evaluation, Dr. Wang raised several questions. The report and the responses to the raised questions are provided below:

The in-package chemistry model is developed to predict the chemistry (e.g., pH and ionic strength) of inside a breached waste package. The surface complexation model is included as a part of model to provide realistic estimates of in-package $\mathrm{pH}$ values by accounting for the effect of surface protonation and deprotonation on solution $\mathrm{pH}$. This review is focused only on the surface complexation model.

The corrosion of Carbon Steel Type A516 and the oxidation of elemental sulfur contained in the steel will generate a certain quantity of $\mathrm{H}_{2} \mathrm{SO}_{4}$ acid that could potentially lead to a low in-package $\mathrm{pH}$. In reality, this low $\mathrm{pH}$ is likely to be buffered by surface protonation on corrosion products, given the factors that only a trace amount of elemental sulfur (1000 times less than Fe on a molar basis) is contained in Carbon Steel Type A516 and that Fe oxyhydroxides as a corrosion product are practically insoluble and have a high surface adsorption capability with the point of zero charge close to neutral $\mathrm{pH}$. Therefore, the general concept of using a surface complexation mechanism to constrain a more realistic inpackage $\mathrm{pH}$ is scientifically sound.

It is generally recognized that there are a large uncertainties associated with the equilibrium constants of surface complexation reactions, which are usually model-dependent. However, the equilibrium constants used in the in-package chemistry model seem reasonable. First of all, the surface complexation constants are relatively well established for $\mathrm{Fe}$ oxides as compared to other minerals. Second, the actual values used in the model are from a carefully compiled and widely accepted data sources (e.g., Dzombak and Morel 1990 [DIRS 105483]).

A simplified version of surface complexation model, described by an analytic equation, is used in the package chemistry. I have checked the derivation of the equation, and no error has been found. The prediction of the equation has been confirmed by PHREEQC calculations.

In general, the surface complexation model developed for in-package chemistry is adequate for its intended use (i.e., to provide a more realistic prediction of inpackage $\mathrm{pH})$. 
Specific comments:

- In the model abstraction, the in-package chemistry model implies a well-mixed cell for a whole waste package. This assumption is not consistent with the EBS transport model, which assumes two cells in a waste package. Steel corrosion is assumed to be present only in cell 1 . It seems to me that the surface complexation model should be applied only to cell 1 .

Response-Spent fuel will reside inside of a matrix of steel and corrosion products. In the EBS transport model the fuel is referred to as domain 1. Steel and its corrosion products are referred to as domain 2. Water that moves into domain 1 must move first through domain 2 where the corrosion products reside and where the SCM is used to calculate the $\mathrm{pH}$. Water carrying fuel components out of domain 1 must move through domain 2 as well. It is, therefore, reasonable to apply the SCM in domains 2 and 1.

- The technical basis for selection of goethite as a representative corrosion product is not fully justified.

Response-Corrosion product formation is complex and depends upon time, temperature, relative humidity, salt identity and concentrations and so on. It is impossible to fully justify the selection of a single corrosion product such as goethite. For this reason, goethite - a corrosion product that is commonly observed, with mid-range site density and surface areas - was chosen to represent what in all likelihood will be an evolving collection of iron corrosion products. For the purposes of this calculation, the technical basis is believed sufficient.

- Low pH could be also caused by the release of Cr(VII) from Stainless Steel Type 304L. But I am not sure the same surface complexation model can apply to this condition.

Response-Stainless Steel Type 304L can, in theory, cause low pH values. Because the molar dissolution rate of Stainless Steel Type 304L is quite low, the resulting proton production occurs over very long time spans and will tend to be diluted by the steady influx of seepage or condensate.

- There are other uncertainties associated with the surface complexation model. The temperature effect on surface complexation has not been well established in general.

Response-Yes, the temperature effect on surface complexation remains an area of active study. There is no evidence in the evolving subject literature that temperature effects on surface complexation will lead to materially different $\mathrm{pH}$ trajectories though. The competition of other ions on surface protonation and deprotonation could affect on the predicted $\mathrm{pH}$, although the PHREEQC calculations have shown such an effect may be not significant. PVB - Yes, competition could affect the $\mathrm{pH}$, but again the PHREEQC provides sufficient confidence that the large-scale features are captured in the analytical mode. 
APPENDIX F

CD-ROM 


\section{INTENTIONALLY LEFT BLANK}


APPENDIX G

LISTING OF FILES ON COMPACT DISK 


\section{INTENTIONALLY LEFT BLANK}




\section{G. LISTING OF FILES ON COMPACT DISK}

This attachment contains the name and size of the zip file placed on the electronic media (Attachment I). Winzip 7.0 was used to compress the files.

Volume in drive $\mathrm{D}$ is 0411041003

Volume Serial Number is A70 C-D69D

Directory of $d: \backslash$

11/03/2004 09:10a

11/04/2004 09:42a

36,038,099 CDSP.zip

$11 / 04 / 200409: 36 a$

62,058,644 CSNF.zip

$11 / 04 / 2004 \quad 08: 17 \mathrm{a}$

45,487,358 CSNF_Sensitivities.zip

11/03/2004 09:11a

1,643,444 Databases.zip

11/03/2004 09:11a

259,986 EQ3.zip

11/03/2004 09:11a

9,365,630 P\&CE IO Data.zip

11/03/2004 09:12a

2,830,612 SCM_Files.zip

8 File(s) $166,137,347$ bytes

Total Files Listed:

8 File(s) $\quad 166,137,347$ bytes

$0 \operatorname{Dir}(\mathrm{s}) \quad 0$ bytes free

The zip files contain files of various types:

Excel files (extensions $=x l s)$.

EQ3/6 input files $($ extension $=3 \mathbf{i}$ or $6 \mathbf{i})$.

ASCII text file: provides input parameters for EQ3/6.

EQ3/6 output files (extension $=30$ or 60$)$.

ASCII text file: provides detailed information about the system at each print point, which is specified by the user in the input file.

EQ3/6 pickup files (extension $=3$ p or $6 p)$.

ASCII text file: provides a description of the system at the end of that run to be used as an input file for a continuation run.

EQ6 Tab-delimited text files $($ extension $=\mathbf{t x t})$.

*.elem_aqu: total aqueous moles of elements.

*.elem_min: total moles of elements in minerals. 
*.elem_tot: total moles of elements (aqueous + mineral).

*.min_info: moles of each mineral.

EQ6 binary output file (extension = bin).

Binary file: provides detailed information about the system at the full numerical precision for every time step.

EQ3/6 text data files used for the calculations, 'data0.ymd'.

Batch files (extension $=$ bat) used to start EQ6 runs.

Winzip files (extension $=$ zip). 